\title{
ION CHANNEL TRAFFICKING AND CARDIAC ARRHYTHMIAS
}

EDITED BY: Marcel A. G. van der Heyden, Brian P. Delisle, Baoxin Li and Hugues Abriel

PUBLISHED IN: Frontiers in Physiology 


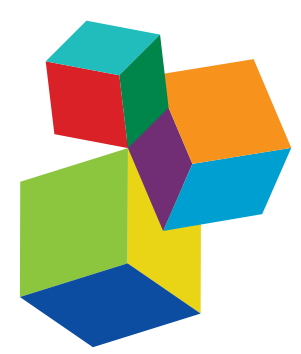

Frontiers Copyright Statement

C Copyright 2007-2018 Frontiers Media SA. All rights reserved.

All content included on this site, such as text, graphics, logos, button

icons, images, video/audio clips, downloads, data compilations and

software, is the property of or is

licensed to Frontiers Media SA

("Frontiers") or its licensees and/or subcontractors. The copyright in the text of individual articles is the property of their respective authors, subject to a license granted to Frontiers.

The compilation of articles constituting this e-book, wherever published, as well as the compilation of all other content on this site, is the exclusive property of Frontiers. For the

conditions for downloading and copying of e-books from Frontiers website, please see the Terms for Website Use. If purchasing Frontiers e-books from other websites or sources, the conditions of the website concerned apply.

Images and graphics not forming part of user-contributed materials may not be downloaded or copied without permission

Individual articles may be downloaded and reproduced in accordance with the principles of the CC-BY

licence subject to any copyright or other notices. They may not be re-sold as an e-book.

As author or other contributor you grant a CC-BY licence to others to reproduce your articles, including any graphics and third-party materials supplied by you, in accordance with the Conditions for Website Use and subject to any copyright notices which you include in connection with your articles and materials.

All copyright, and all rights therein, are protected by national and international copyright laws.

The above represents a summary only.

For the full conditions see the Conditions for Authors and the Conditions for Website Use.

ISSN 1664-8714

ISBN 978-2-88945-643-7

DOI 10.3389/978-2-88945-643-7

\section{About Frontiers}

Frontiers is more than just an open-access publisher of scholarly articles: it is a pioneering approach to the world of academia, radically improving the way scholarly research is managed. The grand vision of Frontiers is a world where all people have an equal opportunity to seek, share and generate knowledge. Frontiers provides immediate and permanent online open access to all its publications, but this alone is not enough to realize our grand goals.

\section{Frontiers Journal Series}

The Frontiers Journal Series is a multi-tier and interdisciplinary set of open-access, online journals, promising a paradigm shift from the current review, selection and dissemination processes in academic publishing. All Frontiers journals are driven by researchers for researchers; therefore, they constitute a service to the scholarly community. At the same time, the Frontiers Journal Series operates on a revolutionary invention, the tiered publishing system, initially addressing specific communities of scholars, and gradually climbing up to broader public understanding, thus serving the interests of the lay society, too.

\section{Dedication to Quality}

Each Frontiers article is a landmark of the highest quality, thanks to genuinely collaborative interactions between authors and review editors, who include some of the world's best academicians. Research must be certified by peers before entering a stream of knowledge that may eventually reach the public - and shape society; therefore, Frontiers only applies the most rigorous and unbiased reviews.

Frontiers revolutionizes research publishing by freely delivering the most outstanding research, evaluated with no bias from both the academic and social point of view. By applying the most advanced information technologies, Frontiers is catapulting scholarly publishing into a new generation.

\section{What are Frontiers Research Topics?}

Frontiers Research Topics are very popular trademarks of the Frontiers Journals Series: they are collections of at least ten articles, all centered on a particular subject. With their unique mix of varied contributions from Original Research to Review Articles, Frontiers Research Topics unify the most influential researchers, the latest key findings and historical advances in a hot research area! Find out more on how to host your own Frontiers Research Topic or contribute to one as an author by contacting the Frontiers Editorial Office: researchtopics@frontiersin.org 


\section{ION CHANNEL TRAFFICKING AND CARDIAC ARRHYTHMIAS}

Topic Editors:

Marcel A. G. van der Heyden, University Medical Center Utrecht, Netherlands

Brian P. Delisle, University of Kentucky, United States

Baoxin Li, Harbin Medical University, China

Hugues Abriel, Swiss National Centre of Competence in Research TransCure, University of Bern, Switzerland

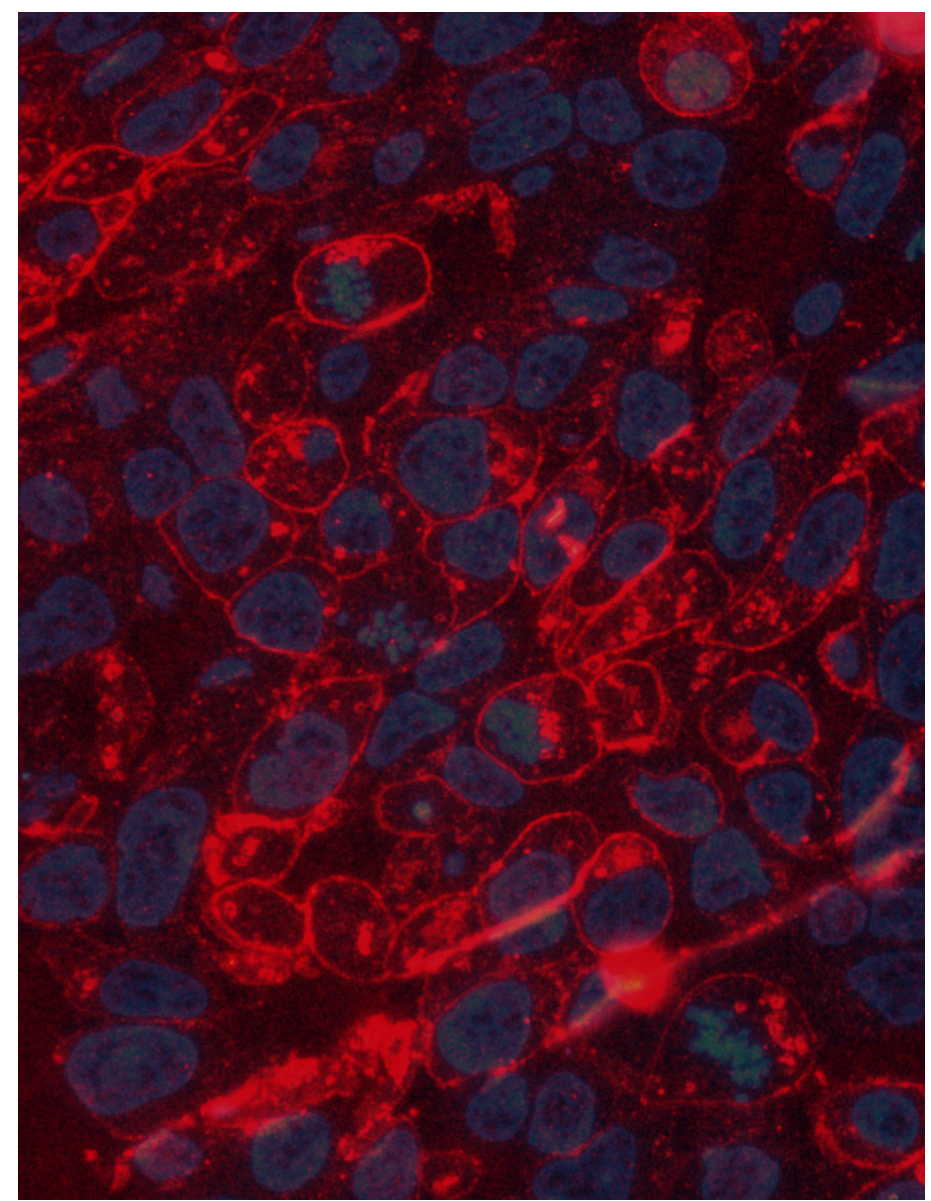

Thick section of pelleted HEK293 cells expressing Kir2.1 (red) following treatment with 10 micromolar Chloroquine for 24 hours. Cell nuclei are stained with DAPI (blue).

Image: Marcel van der Heyden and Wally Müller, licensed under CC-BY

A well-adjusted expression of cardiac ion channels at the sarcolemma is of crucial importance for normal action potential formation and thus cardiac function. The cellular processes that transport channel proteins from the endoplasmic reticulum towards specified regions on the sarcolemmal membrane, and subsequently take them from the plasma membrane to the protein degradation machinery are 
commonly known as trafficking. The research field recognizes that aberrant channel trafficking stands at the basis of many congenital and acquired arrhythmias. The collection of papers in this eBook provides state-of-the-art insight into the world of ion channel trafficking research.

Citation: van der Heyden, M. A. G., Delisle, B. P., Li, B., Abriel, H., eds (2018). Ion Channel Trafficking and Cardiac Arrhythmias. Lausanne: Frontiers Media. doi: 10.3389/978-2-88945-643-7 


\section{Table of Contents}

05 Editorial: Ion Channel Trafficking and Cardiac Arrhythmias

Marcel A. G. van der Heyden, Brian P. Delisle and Hugues Abriel

07 Ion Channel Trafficking: Control of Ion Channel Density as a Target for Arrhythmias?

Elise Balse and Hannah E. Boycott

13 Ankyrins and Spectrins in Cardiovascular Biology and Disease

Mona M. El Refaey and Peter J. Mohler

20 Voltage-Gated Sodium Channel B1/ß1B Subunits Regulate Cardiac Physiology and Pathophysiology

Nnamdi Edokobi and Lori L. Isom

31 Cardiac Arrhythmias and Antiarrhythmic Drugs: An Autophagic Perspective

Joanne J. A. van Bavel, Marc A. Vos and Marcel A. G. van der Heyden

40 Development of a High-Throughput Flow Cytometry Assay to Monitor Defective Trafficking and Rescue of Long QT2 Mutant hERG Channels Scott A. Kanner, Ananya Jain and Henry M. Colecraft

50 Visualizing Mutation-Specific Differences in the Trafficking-Deficient Phenotype of Kv11.1 Proteins Linked to Long QT Syndrome Type 2 Allison R. Hall, Corey L. Anderson, Jennifer L. Smith, Tooraj Mirshahi, Claude S. Elayi, Craig T. January and Brian P. Delisle

61 Kir2.1-Nav1.5 Channel Complexes are Differently Regulated Than Kir2.1 and Nav1.5 Channels Alone

Raquel G. Utrilla, Paloma Nieto-Marín, Silvia Alfayate, David Tinaquero, Marcos Matamoros, Marta Pérez-Hernández, Sandra Sacristán, Lorena Ondo, Raquel de Andrés, F. Javier Díez-Guerra, Juan Tamargo, Eva Delpón and Ricardo Caballero

$77 \quad K_{v} 4.3$ Expression Modulates $\mathrm{Na}_{v} 1.5$ Sodium Current Vincent Portero, Ronald Wilders, Simona Casini, Flavien Charpentier, Arie O. Verkerk and Carol Ann Remme

90 Four TRPM4 Cation Channel Mutations Found in Cardiac Conduction Diseases Lead to Altered Protein Stability

Beatrice Bianchi, Lijo Cherian Ozhathil, Argelia Medeiros-Domingo,

Michael H. Gollob and Hugues Abriel

101 Golgin-97 Targets Ectopically Expressed Inward Rectifying Potassium Channel, Kir2.1, to the Trans-Golgi Network in COS-7 Cells

Tarvinder K. Taneja, Donghui Mat, Bo Y. Kim and Paul A. Welling

110 Cx43 Isoform GJA1-20k Promotes Microtubule Dependent Mitochondrial Transport

Ying Fu, Shan-Shan Zhang, Shaohua Xiao, Wassim A. Basheer, Rachel Baum, Irina Epifantseva, TingTing Hong and Robin M. Shaw 


\section{Editorial: Ion Channel Trafficking and Cardiac Arrhythmias}

\author{
Marcel A. G. van der Heyden ${ }^{1 *}$, Brian P. Delisle ${ }^{2}$ and Hugues Abriel ${ }^{3}$ \\ ${ }^{1}$ Division of Heart and Lungs, Department of Medical Physiology, University Medical Center Utrecht, Utrecht, Netherlands, \\ ${ }^{2}$ Department of Physiology, University of Kentucky, Lexington, KY, United States, ${ }^{3}$ Institute of Biochemistry and Molecular \\ Medicine, Swiss National Centre of Competence in Research TransCure, University of Bern, Bern, Switzerland
}

Keywords: ion channel trafficking, protein complexes, Kv11.1, Nav1.5, Kir2.1, connexin 43, TRPM4, autophagy

\section{Editorial on the Research Topic}

\section{Ion Channel Trafficking and Cardiac Arrhythmias}

The cardiac action potential is one of the most exquisite examples of regulated protein expression that nature presents. The balanced expression of many underlying channel proteins that transport ions with great selectivity at the sarcolemma of cardiomyocytes is crucial to maintain regular cardiac contraction throughout one's lifetime. The coordinated expression must display both robustness and flexibility to sustain stability in action potential generation during homeostasis and rapid adaptation in response to altered physiological demands. Moreover, regional differences in action potential shape within the heart allude to the tuning and fine tuning of functional ion channel expression at the sarcolemma.

The cellular processes that transport channel proteins from the endoplasmic reticulum toward specified regions on the sarcolemma and, subsequently, remove them from the plasma membrane and direct them to the protein degradation machinery are commonly known as trafficking. Recycling and additional intracellular transport mechanisms are contained within this definition. Importantly, several forms of congenital long QT syndrome result from the aberrant trafficking of ion channels. For example, many mutations in the KCNH2 gene, encoding the Kv11.1 (hERG) potassium channel, result in incomplete glycosylation and decreased levels of functional expression at the sarcolemma (Anderson et al., 2014). In addition, drugs that induce arrhythmia also disturb normal trafficking and, hence, alter cardiac electrophysiology (de Git et al., 2013). Finally, cardiac remodeling processes that are associated with cardiac disease also affect the trafficking of ion channels and gap junction proteins (Basheer and Shaw, 2016).

Research on ion channel trafficking is complex as it requires a multidisciplinary approach that combines a plethora of techniques that include molecular biology and cell biology, biochemistry, imaging, and electrophysiology to name a few. Furthermore, the field of cardiac ion channel trafficking is challenged to apply new concepts from basic cell biology that focus on the general structure and basic mechanisms of intracellular transport toward the level of individual ion channels.

It is the purpose of this Frontiers Research Topic on ion channel trafficking and cardiac arrhythmias to reveal some new levels of complexity and to implicitly provide new directions that the field must explore.

Balse and Boycot provide a review on the basic mechanisms of ion channel trafficking, their interdependence on basal cellular (e.g., local lipid composition) and extracellular (e.g., potassium concentration) factors, and some examples of modifying ion channel trafficking in order to counteract arrhythmias. The role of anchoring proteins in steering channel trafficking and membrane localization and their involvement in human cardiac disease is described in the review by El Refaey and Mohler. Thereafter, the role of non-pore-forming Nav- $\beta$-subunits channel proteins in trafficking of sodium and also the potassium channels and their importance in normal channel distribution within the cardiomyocyte are discussed by Edokobi and Isom. In 
their perspective paper, Van Bavel et al. emphasize on the involvement of autophagy pathways in cardiac ion channel trafficking under disease conditions and the impact of drugs, including antiarrhythmics, on autophagy and subsequent arrhythmic outcomes.

The development of a single cell high-throughput system to detect aberrant Kv11.1 trafficking is the aim of the original contribution by Kanner et al. An important implication of their findings is that full glycosylation of the Kv11.1 protein is not, by definition, equal to plasma membrane localization. Hall et al. provide compelling evidence for mutation specific differences in Kv11.1 trafficking defects, that is, variations in intracellular retention, which may have consequences for future treatment options. Importantly, they also demonstrate that the findings obtained in HEK293 cells can be replicated in cardiomyocytes derived from human induced pluripotent stem cells.

Ion channel interdependence with respect to expression and function is the focus of the original contributions by Utrilla et al. and Portero et al. The trafficking properties of the Kir2.1Nav1.5 channel complex are different from those of the individual channels. Utrilla et al. found the dominance of Nav1.5 over Kir2.1 with respect to regulation of internalization, CamKII sensitivity, and degradation. Portero et al. demonstrate the impact of Kv4.3 channel expression on the Nav1.5 current in an ectopic expression system and how this may relate to gain-of-function mutations in the Kv4.3 coding gene in Brugada syndrome. Both studies demonstrate the importance of studying the trafficking of a single channel in the context of other channel types. In view of the balanced channel expression required to generate a cardiac action potential, such channel complex formation and interdependence may not come as a surprise.

Bianchi et al. describe new mutations in TRPM4 channels that are associated with complete heart block or idiopathic ventricular fibrillation and found that the gain- and loss-of-expression is directly related to differences in protein stability in the plasma membrane. Taneja et al. build upon their earlier work on Kir2.1 anterograde transport ( $\mathrm{Li}$ et al., 2016) and provide evidence that the Golgi-tether Golgin-97 is involved in Kir2.1 transport through the Golgi apparatus to reach the trans-Golgi-network.

Finally, $\mathrm{Fu}$ et al. identified an additional function of the connexin 43 isoform GJA1-20k. This connexin 43 isoform increases in expression upon cellular stress, promotes

\section{REFERENCES}

Anderson, C. L., Kuzmicki, C. E., Childs, R. R., Hintz, C. J., Delisle, B. P., and January, C. T. (2014). Large-scale mutational analysis of Kv11.1 reveals molecular insights into type 2 long QT syndrome. Nat. Commun. 5:5535. doi: 10.1038/ncomms6535

Basheer, W. A., and Shaw, R. M. (2016). Connexin 43 and $\mathrm{Ca}_{\mathrm{v}} 1.2$ Ion channel trafficking in healthy and diseased myocardium. Circ. Arrhythm. Electrophysiol. 9:e001357. doi: 10.1161/CIRCEP.115.001357

de Git, K. C., de Boer, T. P., Vos, M. A., and van der Heyden, M. A. (2013). Cardiac ion channel trafficking defects and drugs. Pharmacol. Ther. 139, 24-31. doi: 10.1016/j.pharmthera.2013.03.008

Li, X., Ortega, B., Kim, B., and Welling, P. A. (2016). A common signal patch drives AP-1 protein-dependent golgi export of inwardly rectifying mitochondrial transport along the microtubules, and preserves normal cellular localization of the mitochondria. This study also implicates that ion channel proteins can have additional "noncanonical" cellular functions apart from ion conduction across the plasma membrane. From a physiological point of view, we anticipate that adaptations in action potential features and expression of their underlying ion channels may have direct impact on a number of cellular processes and signaling mechanisms that are initiated by the channel proteins themselves.

Several lessons can be taken from this Frontiers Research Topic. (1) Ion channel trafficking is of great complexity in which each channel protein type follows its own specific path, and even different mutations within the same protein can affect different steps. (2) Ion channel complexes exhibit different trafficking properties when compared to their individual components. (3) Ectopic expression of one channel protein type reveals intrinsic trafficking properties that can be reproduced in cardiac cell types, but full appreciation of trafficking behavior in view of action potential properties may require co-expression of additional channel types. (4) Channel proteins are versatile and have additional cellular functions, apart from conducting ions across the plasma membrane, in intracellular signaling and in regulating subcellular architecture.

Finally, the field of cardiac ion channel trafficking is progressing rapidly. As indicated by several authors in this Frontiers special issue, now the field has to progress from ectopic cell systems toward adult cardiomyocytes. Furthermore, we encourage the study of channel trafficking in vivo to unequivocally determine the direct link between aberrant ion channel trafficking and cardiac arrhythmia.

\section{AUTHOR CONTRIBUTIONS}

$\mathrm{MH}$ drafted and planned the editorial. HA drafted and rewrote the manuscript. BD reread, corrected, and reworded the manuscript.

\section{ACKNOWLEDGMENTS}

HA is supported by Swiss National Science Foundation (310030_165741) and NCCR TransCure grants.

potassium channels. J. Biol. Chem. 291, 14963-14972. doi: 10.1074/jbc.M116. 729822

Conflict of Interest Statement: The authors declare that the research was conducted in the absence of any commercial or financial relationships that could be construed as a potential conflict of interest.

Copyright (c) 2018 van der Heyden, Delisle and Abriel. This is an open-access article distributed under the terms of the Creative Commons Attribution License (CC BY). The use, distribution or reproduction in other forums is permitted, provided the original author(s) and the copyright owner(s) are credited and that the original publication in this journal is cited, in accordance with accepted academic practice. No use, distribution or reproduction is permitted which does not comply with these terms. 


\title{
Ion Channel Trafficking: Control of Ion Channel Density as a Target for Arrhythmias?
}

\author{
Elise Balse ${ }^{1 *}$ and Hannah E. Boycott ${ }^{2}$ \\ 1 Unité de Recherche sur les Maladies Cardiovasculaires, le Métabolisme et la Nutrition, Faculté de Médecine \\ Pitié-Salpêtrière, Sorbonne Universités, UPMC Univ. Paris VI, Inserm, UMRS 1166, Université Pierre et Marie Curie, Paris, \\ France, ${ }^{2}$ Department of Cardiovascular Medicine, John Radcliffe Hospital, University of Oxford, Oxford, United Kingdom
}

OPEN ACCESS

Edited by:

Marcel van der Heyden, University Medical Center Utrecht,

Netherlands

Reviewed by:

Anna Weinzinger

University of Vienna, Austria

Flavien Charpentier,

Institut National de la Santé et de la

Recherche Médicale, France

*Correspondence:

Elise Balse

elise.balse@upmc.fr

Specialty section:

This article was submitted to

Cardiac Electrophysiology,

a section of the journal

Frontiers in Physiology

Received: 23 August 2017 Accepted: 02 October 2017 Published: 17 October 2017

Citation:

Balse E and Boycott HE (2017) Ion Channel Trafficking: Control of Ion Channel Density as a Target for Arrhythmias? Front. Physiol. 8:808. doi: 10.3389/fphys.2017.00808
The shape of the cardiac action potential (AP) is determined by the contributions of numerous ion channels. Any dysfunction in the proper function or expression of these ion channels can result in a change in effective refractory period (ERP) and lead to arrhythmia. The processes underlying the correct targeting of ion channels to the plasma membrane are complex, and have not been fully characterized in cardiac myocytes. Emerging evidence highlights ion channel trafficking as a potential causative factor in certain acquired and inherited arrhythmias, and therapies which target trafficking as opposed to pore block are starting to receive attention. In this review we present the current evidence for the mechanisms which underlie precise control of cardiac ion channel trafficking and targeting.

Keywords: potassium channels, sodium channel, arrhythmias, cardiac, trafficking, accessory proteins

\section{FUNCTIONAL EXPRESSION OF ION CHANNELS IN THE SARCOLEMMA AND CARDIAC EXCITABILITY}

The function of the heart is governed by the electrical and mechanical activity of myocytes. The functional expression of several different types of ion channels in the myocyte sarcolemma determines the shape and duration of the action potential (AP), and therefore controls the effective refractory period (ERP) of the myocardium. The ERP is a protective mechanism that keeps the heart rate in check and thus prevents arrhythmias. Any prolongation or shortening of the ERP is therefore potentially arrhythmogenic. Most genetic arrhythmias are caused by mutations which alter the biophysical properties of ion channels. However, the proper functional expression of ion channels can be disrupted at several points including at the transcriptional, translational, and post-translational levels. In the last two decades, studies have emerged in which mutations carried by ion channels have been shown to be linked to trafficking defects, resulting in retention and/or degradation of the channel early in the trafficking process.

The density of active ion channels in specific membrane domains is a dynamic process resulting from the concomitant and antagonistic action of anterograde (exocytosis, recycling) and retrograde (internalization) pathways. Targeting and stabilization of these channels by anchoring partners in specialized domains of the sarcolemma also dynamically regulate the electrical activity of the cell (Balse et al., 2012; Figure 1).

The majority of mutations related to trafficking defects involve endoplasmic reticulum (ER) exit defects, leading to targeting of misfolded channels to degradation by the ERAD system (endoplasmic reticulum-associated degradation, lysosomal, or proteasomal). Such mutations have been identified for HERG (Furutani et al., 1999), KCNQ1 (Gouas et al., 2004), and SCN5A (Valdivia et al., 2004) and associated with long QT and Brugada syndromes. Sorting signals carried by 
ion channels also are necessary for ER and trans-Golgi network exit (TGN) (Kupershmidt et al., 2002). A mutation involving an endocytotic defect of TRPM4 has also been identified in human progressive familial heart block type I (Kruse et al., 2009). Finally, another crucial factor is the association (early or late) of ion channels with ancillary subunits, chaperones, and anchoring partners that are involved in channel function and localization.

\section{BEYOND CHANNELOPATHIES: TRAFFICKING PROCESSES AS REGULATORS OF CARDIAC ACTION POTENTIAL}

Trafficking and targeting of integral membrane proteins, including ion channels and receptors, have been explored in other cell types such as epithelial cells and neurons. Although these studies have yielded great insights, these mechanisms have not been studied extensively in cardiomyocytes. Such research may provide insight into the regulation of cardiac excitability via ion channel trafficking. Although trafficking defects have been reported for certain ion channel mutations, and are associated with retention in intracellular organelles, the characterization of intracellular trafficking in control and disease conditions are largely lacking in native cardiomyocytes. The fact that these cells are highly structurally and functionally specialized suggests that trafficking and targeting of cardiac ion channels may involve unique and specific pathways. Furthermore, the propagation of electrical activation within the myocardium is a complex process controlled by the spatial/differential distribution of ion channels within single cardiomyocytes that eventually establishes the anisotropic ratio. The underlying mechanisms regulating ion channel targeting to sarcolemmal subdomains, and tethering into macromolecular complexes remains a largely unanswered, yet important question.

In acquired arrhythmias such as heart failure and atrial fibrillation, ion channel dysfunction and electrical remodeling are often associated with tissue remodeling including hypertrophy/dilatation, replacement and interstitial fibrosis, and gap junction disorganization (Rucker-Martin et al., 2006). In this context, abnormal trafficking and targeting of cardiac ion channels emerge as important pathogenic factors of the electrical remodeling (Schotten et al., 2011). Importantly, increased knowledge of the pathways underlying cardiac ion channel trafficking may yield novel drug targets which lack the problems associated with conventional pore block therapies. Such therapies are frequently highly non-selective and have numerous unwanted side effects. The purpose of this mini-review is to provide an overview of the mechanisms of trafficking of ion channels in native cardiomyocytes that could potentially result in the discovery of new targets for antiarrhythmic therapies.

\section{HYPOKALEMIA AND HERG CHANNEL REGULATION}

The $\mathrm{I}_{\mathrm{Kr}}$ current is encoded by the human ether-a-go-go-related gene (HERG, also known as KCNH2) in the heart (Sanguinetti et al., 1995; Trudeau et al., 1995). HERG mutations resulting in reduced $\mathrm{I}_{\mathrm{Kr}}$ cause type 2 long QT syndrome (LQT2), which predisposes individuals to life-threatening arrhythmias. HERG mutations often disrupt the forward trafficking of hERG (thereby reducing sarcolemmal expression of the channel), and subsequently result in decreased $I_{\mathrm{Kr}}$ (Anderson et al., 2006). The hERG channel is also a notorious target for several classes of drugs that engender acquired long QT syndrome (LQTS) (Sanguinetti and Tristani-Firouzi, 2006). For instance, LQTS and Torsades de pointes are exacerbated by hypokalemia, with a moderate increase in serum $\left[\mathrm{K}^{+}\right]$capable of correcting LQTS in some patients (Compton et al., 1996). Hypokalemia is therefore considered a risk factor for LQTS and sudden cardiac death.

Guo and colleagues elegantly revealed how the plasma membrane density of hERG channels is regulated under physiological and pathophysiological (hypokalemia) conditions. They showed that lowering extracellular potassium drastically accelerated hERG internalization and degradation both in overexpression systems and native $I_{\mathrm{Kr}}$ in a hypokalemia rabbit model (Guo et al., 2009). Rabbits fed with low-K ${ }^{+}$diet showed prolonged QTc correlated to significantly prolonged $\mathrm{APD}_{90}$. In vitro, exposure to $0 \mathrm{mM} \mathrm{K}^{+}$medium completely and reversibly eliminated $I_{\mathrm{Kr}}$ without significant effects on other potassium currents. The decrease in $I_{\mathrm{Kr}}$ accompanied reduced expression of hERG, combined with reduced surface expression of the channel. Finally, they showed that $0 \mathrm{mM} \mathrm{K}^{+}$medium induced the internalization of hERG by increasing ubiquitylation and resulted in lysosomal degradation (Guo et al., 2009). These findings provide a potential mechanism for hypokalemiainduced exacerbation of LQTS.

\section{LIPIDIC CONTENT AND $\mathrm{K}_{\mathrm{V}} 1.5$ CHANNEL REGULATION}

Cardiac excitability can be regulated by cellular lipid content. Free cholesterol is a major lipid class shown to regulate membrane fluidity, curvature, and stiffness (Lundbaek et al., 1996). The function of several cardiac ion channels are regulated directly by cholesterol, which modulates channel properties (Oliver et al., 2004; Epshtein et al., 2009).

The $I_{\text {Kur }}$ current, carried by $\mathrm{K}_{\mathrm{V}} 1.5$ channels, is an important component of atrial repolarization (Fedida et al., 1993; Wang et al., 1993) and has been implicated in the pathology of atrial fibrillation (Van Wagoner et al., 1997; Brundel et al., 2001). The groups of D. Fedida and J. Martens contributed substantially to the study of the trafficking of $\mathrm{K}_{\mathrm{V}} 1.5$ channel in expression systems (McEwen et al., 2007; Steele et al., 2007). Trafficking of vesicles is regulated by several Rab GTP-ases, involved at every stage of the process; regulating sorting, tethering and docking of trafficking vesicles. The early endosome (EE), associated with Rab4, mediates fast recycling while the recycling endosome, associated with Rab11, coordinates the slow recycling of proteins back to the cell membrane.

We showed that membrane cholesterol depletion via methyl$\beta$-cyclodextrin $(\mathrm{M} \beta \mathrm{CD})$ increased the number of functional $\mathrm{K}_{\mathrm{V}} 1.5$ channels in the sarcolemma of atrial myocytes, also reducing their mobility as shown by Fluorescence recovery After Photobleaching (Balse et al., 2009). Cholesterol depletion triggers 
exocytosis of ion channels from sub-membrane compartments. Indeed, the overexpression of a dominant negative (DN) form of Rab11 (associated with the recycling endosome), prevented the current increase upon $\mathrm{M} \beta \mathrm{CD}$ treatment whereas overexpression of a DN form of Rab4, associated with the early endosome, did not. The recycling endosome, considered a slow route for ion channel recycling (Steele et al., 2007), is particularly sensitive to cholesterol depletion as rapid dissociation $(<10 \mathrm{~min})$ of the channel from the vesicle was observed (Balse et al., 2009). These results showed that channel turnover can be modified by changes in the lipid environment and that sub-membrane storage compartments can be recruited to modify the electrical properties of cardiomyocytes.

\section{MECHANICAL CHALLENGE AND $K_{\mathrm{v}} 1.5$ CHANNEL REGULATION}

Cardiomyocytes are exposed to mechanical forces when the heart contracts. These forces consist of stretch, shear and strain constraints. Shear forces in the myocardium are primarily generated by the movement of sheets of cardiomyocytes sliding relative to each other when the muscle contracts, as well as by blood flow during the cardiac cycle (LeGrice et al., 1995; Costa et al., 1999). Increased shear stress stimulates intracellular calcium transients (Morad et al., 2005), increases the beating rate of neonatal ventricular myocytes (Lorenzen-Schmidt et al., 2006), and triggers propagating APs in monolayers of ventricular myocytes (Kong et al., 2005).

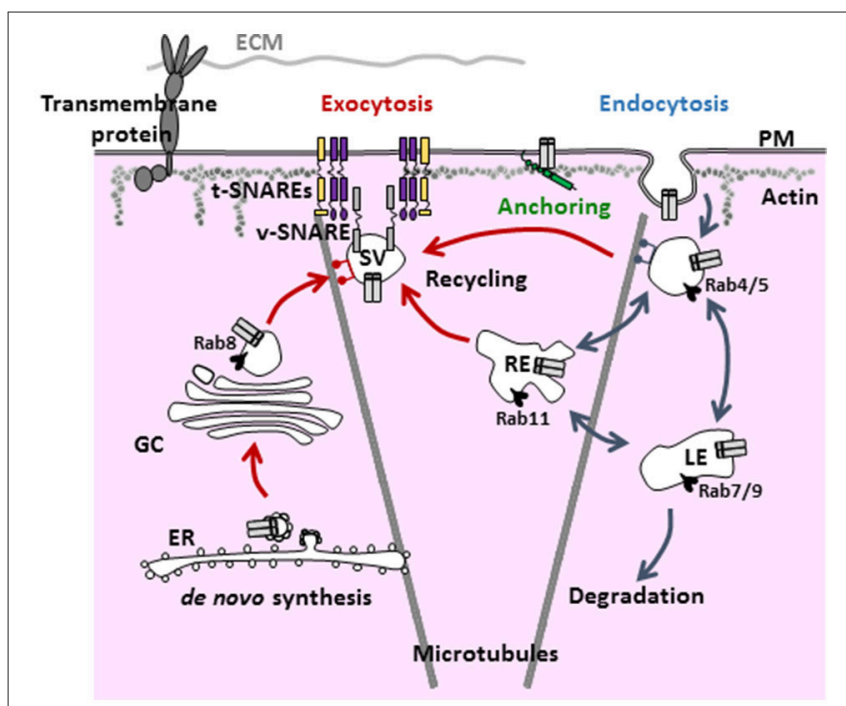

FIGURE 1 | General scheme of the various steps and regulators involved in the trafficking of ion channels. Ion channels are targeted to the plasma membrane via the anterograde and recycling pathways (red arrows). Once targeted to a specialized domain of the membrane, ion channels are stabilized by anchoring partners/associate subunits to be functional (green). Then, signals for internalization (blue arrows) lead to either degradation or recycling. PM, plasma membrane; EE, early endosome; LE, late endosome; ECM, extracellular matrix; RE, recycling endosome; GC, Golgi complex; ER, endoplasmic reticulum; SV, secretory vesicle.
We showed that in rat atrial myocytes shear stress activates a large outward current, mirrored by a decrease in AP duration (Boycott et al., 2013). The main ion channel mediating the increase in current $\mathrm{K}_{\mathrm{V}} 1.5$, which was recruited from subcellular compartments to the sarcolemma, a phenomenon which was directly observed by TIRF microscopy. The donor compartment was again identified as the recycling endosome. $\mathrm{K}_{\mathrm{V}} 1.5$ channel exocytosis requires integrin signaling through focal adhesion kinase (FAK) and relies on an intact microtubule system. We also found that the response was dysregulated in a model of chronic hemodynamic overload. Hypertrophied atrial myocytes had reduced $\mathrm{K}_{\mathrm{v}} 1.5$ expression, despite an increase in basal $I_{K u r}$. The response of these cardiomyocytes to shear stress was reduced, and the kinetics altered. Our results suggested chronically increased mechanical stress over activates the integrin signaling pathway, resulting in an increased $I_{K u r}$, AP shortening and a reduction in the capability of cells to respond to shear stress (Boycott et al., 2013). Thus, pools of $K_{V} 1.5$ from the slow recycling route may comprise an inducible reservoir mediating faster atrial repolarization. The shortening of the AP observed following heart failure in the atria could be partly explained by a shift in the trafficking balance toward increased exocytosis.

\section{MODULATION OF $K_{v} 1.5$ INTERNALIZATION BY ANTIARRHYTHMICS}

Whereas conventional antiarrhythmic drugs generally target ion permeability by binding to the pore of the channel, increasing evidence suggests some compounds can indirectly disrupt protein trafficking. In this context, sustained efforts have been conducted to develop antiarrhythmic agents that affect channel trafficking, notably hERG channels blockers that stabilize misfolded channels and rescue hERG trafficking mutants (Wible et al., 2005).

The group of J. Martens has been at the forefront of investigations into the potential antiarrhythmic properties of drugs which acutely modulate the surface density of functional channels (Schumacher et al., 2009). The class I antiarrhythmic drug quinidine is known to inhibit $I_{\text {Kur }}$ current through open-channel block of $\mathrm{K}_{\mathrm{V}} 1.5$ channel. Using an immunocytochemical approach to quantify surface and internalized channels, Schumacher and colleagues showed that quinidine dose-dependently induced the internalization of $\mathrm{K}_{\mathrm{V}} 1.5$ channel over short-time frames $(10 \mathrm{~min})$ in the HL-1 cell line and in dissociated neonatal mouse myocytes. The effect of quinidine was stereospecific as quinine has no effect on $\mathrm{K}_{\mathrm{V}} 1.5$ channel surface density (despite exerting the pore-block effect of its stereoisomer) and subunit-dependent, as the $\mathrm{K}_{\mathrm{V}} 1.5$ related channels $\mathrm{K}_{\mathrm{V}} 2.1$ or $\mathrm{K}_{\mathrm{V}} 4.2$ did not show internalization at the same time points and doses. In addition, quinidineinduced $\mathrm{K}_{\mathrm{V}} 1.5$ channel internalization followed the same endocytotic pathway as constitutive endocytosis (as previously identified Choi et al., 2005), being microtubule-dependent and dynamin-mediated. Finally, whereas acute treatment allows channel recycling to the surface, chronic treatment with a 
clinical-compatible concentration led to channel degradation through the proteasome. This pharmacological control of $\mathrm{K}_{\mathrm{v}} 1.5$ surface expression and trafficking represents a novel mechanism by which drug stimulated endocytosis of an ion channel may be utilized as an anti-arrhythmic tool.

\section{ORGANIZATION OF ION CHANNEL MACROMOLECULAR COMPLEXES}

It is noteworthy that emerging evidence challenges the assumption that ion channels function as homogeneous complexes. Rather, it seems likely that ion channels form macrocomplexes with other ion channels, and that these complexes contribute to the stabilization of channels at the sarcolemma, and facilitate proper electrical conduction. The MAGUK protein SAP97 contributes to the formation of macromolecular complexes involving different ion channel families: $\mathrm{K}_{\mathrm{V}} 1.5$ (Godreau et al., 2002; Abi-Char et al., 2008), $\mathrm{K}_{\mathrm{V}} 4 . \mathrm{x}$ (El-Haou et al., 2009; Gillet et al., 2015), Kir2.x (Leonoudakis et al., 2001; Milstein et al., 2012; Matamoros et al., 2016), and $\mathrm{Na}_{\mathrm{v}} 1.5$ (Petitprez et al., 2011; Milstein et al., 2012), SAP97 also couples ion channels to signaling pathways, allowing the regulation of $\mathrm{K}_{\mathrm{V}} 4$.x channels by CaMKII (El-Haou et al., 2009). An important recent breakthrough showed that SAP97 regulates the formation of $\mathrm{Na}_{\mathrm{V}} 1.5 / \mathrm{Kir} 2.1$ complexes, the two critical channels underlying $I_{\mathrm{K} 1}$ and $I_{\mathrm{Na}}$, respectively. These currents are responsible for maintenance of the resting membrane potential and rapid depolarization during the upstroke of the AP (Milstein et al., 2012). This multi-channel organization enables reciprocal modulation, contributing to maintenance of normal cardiac excitability. Interestingly, co-expression with $\mathrm{Na}_{\mathrm{v}} 1.5$ seems to reduce internalization of Kir2.1, suggesting that participation in a macromolecular complex reduces anterograde trafficking of Kir2.1 (Milstein et al., 2012). Another example of multi-channel organization for $\mathrm{Na}_{V} 1.5 / \mathrm{Kir} 2 \mathrm{x}$, but mediated by syntrophin, has been recently reported (Matamoros et al., 2016). In addition to $\mathrm{Na}_{\mathrm{v}} 1.5$, other cardiac ion channels have been shown to interact. For example, the KCNQ1/KCNE1 genes that encode $I_{\mathrm{Ks}}$ (Barhanin et al., 1996; Sanguinetti et al., 1996) interact with hERG, and the channels can reciprocally regulate (Ehrlich et al., 2004; Ren et al., 2010; Organ-Darling et al., 2013), with KCNQ1 also functioning as a chaperone for hERG trafficking (Biliczki et al., 2009). In the context of hypokalemia, KCNQ1/hERG coexpression slowed the internalization of mature, i.e. cell-surface expressed, hERG channels whereas KCNQ1 alone is not sensitive to hypokalemia (Guo et al., 2011). As the association between hERG and KCNQ1 only occurs at the plasma membrane, KCNQ1 likely contributes to hERG membrane stability.

\section{MODULATION OF ION CHANNEL ANTEROGRADE TRAFFICKING BY PARTNER PROTEINS}

A fascinating question relates to the nature of the molecular mechanisms which regulate ion channel targeting into distinct subdomains of the sarcolemma and their tethering in large molecular complexes. Cardiac myocytes are structurally and functionally highly polarized cells. While the transmission of the AP between myocytes occurs at the intercalated disc (ID), the AP is conducted along the myocyte at the lateral membrane (LM).

The direct targeting of hemichannels to the ID via the microtubule plus-end-tracking protein EB1 (Shaw et al., 2007) and the targeting of Cav1.2 to T-tubules by BIN1, a protein involved in membrane invagination and endocytotic processes (Hong et al., 2012) have been important major discoveries.

Recently, the spatial distribution of $\mathrm{Na}_{V} 1.5$ has received interest. Whereas $\mathrm{Na}_{V} 1.5$ is highly concentrated at the ID (3 to 8 fold larger current), $\mathrm{Na}_{\mathrm{V}} 1.5$ channels at the LM show a lower density (Verkerk et al., 2007; Lin et al., 2011). This differential distribution of $\mathrm{Na}_{\mathrm{V}} 1.5$ channels favors the anisotropic conduction of the myocardial depolarization wave (Spach, 1999). Several partners of $\mathrm{Na}_{\mathrm{v}} 1.5$ have been identified such as gap junctional (i.e., connexin-43), desmosomal (plakophilin-2), actin cytoskeleton-binding (ankyrin-G), and the MAGUK protein SAP97 at the ID and syntrophin at the LM (for review see Shy et al., 2014). All these partners exert a positive regulatory effect on $I_{\mathrm{Na}}$ since their silencing in vitro, Knock Out in vivo or reduced expression in the Duchenne muscular dystrophy mouse model leads to reduced sodium current and localization. However, whether these proteins are involved anterograde trafficking of $\mathrm{Na}_{V} 1.5$ or associate with the channel once inserted in the plasma membrane to stabilize it is not clear. Recently, we have characterized a new partner of the $\mathrm{Na}_{V} 1.5$ channel in the myocardium, the MAGUK protein CASK. CASK is located at the LM, in association with the syntrophin/dystrophin complex. In contrast with other $\mathrm{Na}_{V} 1.5$ partners, CASK negatively regulates $I_{\mathrm{Na}}$ by impeding $\mathrm{Na}_{\mathrm{V}} 1.5$ anterograde trafficking to the LM (Eichel et al., 2016). In dilated human atria, associated with AF or valve regurgitation, expression of CASK is reduced without affecting its localization. The consequence of this would likely be increased $I_{\mathrm{Na}}$ at the LM and could be considered detrimental for cardiac anisotropy. Keeping with the recent discovery that SAP97 is necessary for the interaction between $\mathrm{Na}_{V} 1.5$ and Kir2.1 (Milstein et al., 2012), MAGUK proteins could be major partners for the organization of multi-channel complexes.

\section{CONCLUSION}

Although only proven in vitro at present, early ER/Golgi trafficking rescue has been shown to be feasible for traffickingdefective mutant channels by temperature decrease, Hsp70 and 91 cytosolic chaperones, and pharmacological chaperones. Pharmacological chaperones include channel blockers, such as anti-histamines (Astemizole), anti-serotoninergic (Cisapride) and antiarrhythmics (e.g., E-4031 for hERG), that are difficult to manipulate as they can also block the channel and worsen the disease. However, certain pore-blocking drugs, such as fexofenadine, have been shown to rescue hERG trafficking of some mutant channels at concentrations far below the IC50 for pore-block (Rajamani et al., 2002). Furthermore, in an iPSC model of LQTS2 in which hERG was not expressed at the sarcolemma, sarcolemmal hERG expression was achieved using the proteasomal inhibitor ALLN, which allowed the re-trafficking and functional expression of the channel (Mehta et al., 2014). These studies highlight the relevance of research into 
pharmacological rescue of trafficking deficient mutant channels. Low molecular weight compounds such as DMSD, TMD and glycerol act as nonspecific chemical chaperones mostly likely by stabilizing proteins during folding and maturation (Kaufman and Ficker, 2003). In acquired cardiopathies, three pathways are worthy of special attention: the recycling endosome/Rab11 pathway, the endocytosis/dynamin/microtubule pathway and, the association of ion channels with specific partners for anterograde trafficking and correct targeting to specialized membrane subdomains of the myocyte. Future studies are necessary to explore the specific roles of ion channel partners on ion channel trafficking/targeting vs. membrane scaffolding to understand the relative contribution of these proteins in dictating cardiac excitability and function under normal and pathological conditions. The highly specialized architecture of the cardiomyocyte dictates that more studies in native

\section{REFERENCES}

Abi-Char, J., El-Haou, S., Balse, E., Neyroud, N., Vranckx, R., Coulombe, A., et al. (2008). The anchoring protein SAP97 retains Kv1.5 channels in the plasma membrane of cardiac myocytes. Am. J. Physiol. Heart Circ. Physiol. 294, H1851-H1861. doi: 10.1152/ajpheart.01045.2007

Anderson, C. L., Delisle, B. P., Anson, B. D., Kilby, J. A., Will, M. L., Tester, D. J., et al. (2006). Most LQT2 mutations reduce Kv11.1 (hERG) current by a class 2 (Trafficking-Deficient) mechanism. Circulation 113, 365-373. doi: 10.1161/CIRCULATIONAHA.105.570200

Balse, E., El-Haou, S., Dillanian, G., Dauphin, A., Eldstrom, J., Fedida, D., et al. (2009). Cholesterol modulates the recruitment of Kv1.5 channels from Rab11associated recycling endosome in native atrial myocytes. Proc. Natl. Acad. Sci. U.S.A. 106, 14681-14686. doi: 10.1073/pnas.0902809106

Balse, E., Steele, D. F., Abriel, H., Coulombe, A., Fedida, D., and Hatem, S. N. (2012). Dynamic of ion channel expression at the plasma membrane of cardiomyocytes. Physiol. Rev. 92, 1317-1358. doi: 10.1152/physrev.00041.2011

Barhanin, J., Lesage, F., Guillemare, E., Fink, M., Lazdunski, M., and Romey, G. (1996). K(V)LQT1 and lsK (minK) proteins associate to form the I(Ks) cardiac potassium current. Nature 384, 78-80. doi: 10.1038/384078a0

Biliczki, P., Girmatsion, Z., Brandes, R. P., Harenkamp, S., Pitard, B., Charpentier, F., et al. (2009). Trafficking-deficient long QT syndrome mutation KCNQ1-T587M confers severe clinical phenotype by impairment of KCNH2 membrane localization: evidence for clinically significant IKr-IKs alpha-subunit interaction. Heart Rhythm 6, 1792-1801. doi: 10.1016/j.hrthm. 2009.08.009

Boycott, H. E., Barbier, C. S., Eichel, C. A., Costa, K. D., Martins, R. P., Louault, F., et al. (2013). Shear stress triggers insertion of voltage-gated potassium channels from intracellular compartments in atrial myocytes. Proc. Natl. Acad. Sci. U.S.A. 110, E3955-E3964. doi: 10.1073/pnas.1309896110

Brundel, B. J., Van Gelder, I. C., Henning, R. H., Tuinenburg, A. E., Wietses, M., Grandjean, J. G., et al. (2001). Alterations in potassium channel gene expression in atria of patients with persistent and paroxysmal atrial fibrillation: differential regulation of protein and mRNA levels for $\mathrm{K}^{+}$channels. J. Am. Coll. Cardiol. 37, 926-932. doi: 10.1016/S0735-1097(00)01195-5

Choi, W. S., Khurana, A., Mathur, R., Viswanathan, V., Steele, D. F., and Fedida, D. (2005). Kv1.5 surface expression is modulated by retrograde trafficking of newly endocytosed channels by the dynein motor. Circ. Res. 97, 363-371. doi: 10.1161/01.RES.0000179535.06458.f8

Compton, S. J., Lux, R. L., Ramsey, M. R., Strelich, K. R., Sanguinetti, M. C., Green, L. S., et al. (1996). Genetically defined therapy of inherited long-QT syndrome: correction of abnormal repolarization by potassium. Circulation 94, 1018-1022. doi: 10.1161/01.CIR.94.5.1018

Costa, K. D., Takayama, Y., McCulloch, A. D., and Covell, J. W. (1999). Laminar fiber architecture and three-dimensional systolic mechanics in canine ventricular myocardium. Am. J. Physiol. 276(2 Pt 2), H595-H607. cells are necessary to improve our understanding of the mechanisms involved, and how they impact upon the pathology of arrhythmia.

\section{AUTHOR CONTRIBUTIONS}

All authors listed have made a substantial, direct and intellectual contribution to the work, and approved it for publication.

\section{FUNDING}

This work was supported by Fondation Leducq "Structural Alterations in the Myocardium and the Substrate for Cardiac Fibrillation" (EB), AFM-Téléthon (EB), and the European Union (EUTRAF-261057; EB and HB).

Ehrlich, J. R., Pourrier, M., Weerapura, M., Ethier, N., Marmabachi, A. M., Hébert, T. E., et al. (2004). KvLQT1 modulates the distribution and biophysical properties of HERG. A novel alpha-subunit interaction between delayed rectifier currents. J. Biol. Chem. 279, 1233-1241. doi: 10.1074/jbc.M309087200

Eichel, C. A., Beuriot, A., Chevalier, M. Y., Rougier, J.S., Louault, F., Dilanian, G., et al. (2016). Lateral membrane-specific MAGUK CASK downregulates NaV1.5 channel in cardiac myocytes. Circ. Res. 119, 544-556. doi: 10.1161/CIRCRESAHA.116.309254

El-Haou, S., Balse, E., Neyroud, N., Dilanian, G., Gavillet, B., Abriel, H., et al. (2009). Kv4 potassium channels form a tripartite complex with the anchoring protein SAP97 and CaMKII in cardiac myocytes. Circ. Res. 104, 758-769. doi: 10.1161/CIRCRESAHA.108.191007

Epshtein, Y., Chopra, A. P., Rosenhouse-Dantsker, A., Kowalsky, G. B., Logothetis, D. E., and Levitan, I. (2009). Identification of a C-terminus domain critical for the sensitivity of Kir2.1 to cholesterol. Proc. Natl. Acad. Sci. U.S.A. 106, 8055-8060. doi: 10.1073/pnas.0809847106

Fedida, D., Wible, B., Wang, Z., Fermini, B., Faust, F., Nattel, S., et al. (1993). Identity of a novel delayed rectifier current from human heart with a Cloned $\mathrm{K}^{+}$channel current. Circ. Res. 73, 210-216. doi: 10.1161/01.RES.73.1.210

Furutani, M., Trudeau, M. C., Hagiwara, N., Seki, A., Gong, Q., Zhou, Z., et al. (1999). Novel mechanism associated with an inherited cardiac arrhythmia: defective protein trafficking by the mutant HERG (G601S) potassium channel. Circulation 99, 2290-2294. doi: 10.1161/01.CIR.99.17.2290

Gillet, L., Rougier, J.-S., Shy, D., Sonntag, S., Mougenot, N., Essers, M., et al. (2015). Cardiac-specific ablation of synapse-associated protein SAP97 in mice decreases potassium currents but not sodium current. Heart Rhythm 12, 181-192. doi: 10.1016/j.hrthm.2014.09.057

Godreau, D., Vranckx, R., Maguy, A., Rücker-Martin, C., Goyenvalle, C., Abdelshafy, S., et al. (2002). Expression, regulation and role of the MAGUK protein SAP-97 in human atrial myocardium. Cardiovasc. Res. 56, 433-442. doi: 10.1016/S0008-6363(02)00602-8

Gouas, L., Bellocq, C., Berthet, M., Potet, F., Demolombe, S., Forhan, A., et al. (2004). New KCNQ1 mutations leading to haploinsufficiency in a general population; defective trafficking of a KvLQT1 mutant. Cardiovasc. Res. 63, 60-68. doi: 10.1016/j.cardiores.2004.02.011

Guo, J., Massaeli, H., Xu, J., Jia, Z., Wigle, J. T., Mesaeli, N., et al. (2009). Extracellular $\mathrm{K}^{+}$concentration controls cell surface density of $\mathrm{IKr}$ in Rabbit Hearts and of the HERG channel in human cell lines. J. Clin. Invest. 119, 2745-2757. doi: 10.1172/JCI39027

Guo, J., Wang, T., Yang, T., Xu, J., Li, W., Fridman, M. D., et al. (2011). Interaction between the cardiac rapidly (IKr) and slowly (IKs) activating delayed rectifier potassium channels revealed by low $\mathrm{K}^{+}$-induced hERG endocytic degradation. J. Biol. Chem. 286, 34664-34674. doi: 10.1074/jbc.M111.253351

Hong, T.T., Smyth, J. W., Chu, K. Y., Vogan, J. M., Fong, T. S., Jensen, B. C., et al. (2012). BIN1 is reduced and Cav1.2 trafficking is impaired in human failing cardiomyocytes. Heart Rhythm 9, 812-820. doi: 10.1016/j.hrthm.2011.11.055 
Kaufman, E. S., and Ficker, E. (2003). Is restoration of intracellular trafficking clinically feasible in the long QT syndrome?: the example of HERG mutations. J. Cardiovasc. Electrophysiol. 14, 320-322. doi: 10.1046/j.1540-8167.2003.02363.x

Kong, C. R., Bursac, N., and Tung, L. (2005). Mechanoelectrical excitation by fluid jets in monolayers of cultured cardiac myocytes. J. Appl. Physiol. 98, 2328-2336; discussion: 2320. doi: 10.1152/japplphysiol.01084.2004

Kruse, M., Schulze-Bahr, E., Corfield, V., Beckmann, A., Stallmeyer, B., Kurtbay, G., et al. (2009). Impaired endocytosis of the ion channel TRPM4 is associated with human progressive familial heart block type, I. J. Clin. Invest. 119, 2737-2744. doi: 10.1172/JCI38292

Kupershmidt, S., Yang, T., Chanthaphaychith, S., Wang, Z., Towbin, J. A., and Roden, D. M. (2002). Defective human ether-à-go-go-related gene trafficking linked to an endoplasmic reticulum retention signal in the C terminus. J. Biol. Chem. 277, 27442-27448. doi: 10.1074/jbc.M1 12375200

LeGrice, I. J., Takayama, Y., and Covell, J. W. (1995). Transverse shear along myocardial cleavage planes provides a mechanism for normal systolic wall thickening. Circ. Res. 77, 182-193. doi: 10.1161/01.RES.77.1.182

Leonoudakis, D., Mailliard, W., Wingerd, K., Clegg, D., and Vandenberg, C. (2001). Inward rectifier potassium channel Kir2.2 is associated with synapse-associated protein SAP97. J. Cell Sci. 114(Pt 5), 987-998.

Lin, X., Liu, N., Lu, J., Zhang, J., Anumonwo, J. M., Isom, L. L., et al. (2011). Subcellular heterogeneity of sodium current properties in adult cardiac ventricular myocytes. Heart Rhythm 8, 1923-1930. doi: 10.1016/j.hrthm.2011.07.016

Lorenzen-Schmidt, I., Schmid-Schönbein, G. W., Giles, W. R., McCulloch, A. D., Chien, S., and Omens, J. H. (2006). Chronotropic response of cultured neonatal Rat ventricular myocytes to short-term fluid shear. Cell Biochem. Biophys. 46, 113-122. doi: 10.1385/CBB:46:2:113

Lundbaek, J. A., Birn, P., Girshman, J., Hansen, A. J., and Andersen, O. S. (1996). Membrane stiffness and channel function. Biochemistry 35, 3825-3830. doi: $10.1021 / \mathrm{bi} 952250 \mathrm{~b}$

Matamoros, M., Pérez-Hernández, M., Guerrero-Serna, G., Amorós, I., Barana, A., Nú-ez, M., et al. (2016). Nav1.5 N-terminal domain binding to $\alpha 1$-syntrophin increases membrane density of human Kir2.1, Kir2.2 and Nav1.5 channels. Cardiovasc. Res. 110, 279-290. doi: 10.1093/cvr/cvw009

McEwen, D. P., Schumacher, S. M., Li, Q., Benson, M. D., I-iguez-Lluhí, J. A., Van Genderen, K. M., et al. (2007). Rab-GTPase-dependent endocytic recycling of Kv1.5 in atrial myocytes. J. Biol. Chem. 282, 29612-29620. doi: 10.1074/jbc.M704402200

Mehta, A., Sequiera, G. L., Ramachandra, C. A., Sudibyo, Y., Chung, Y., Sheng, J., et al. (2014). Re-trafficking of hERG reverses long QT syndrome 2 phenotype in human iPS-derived cardiomyocytes. Cardiovasc. Res. 102, 497-506. doi: 10.1093/cvr/cvu060

Milstein, M. L., Musa, H., Balbuena, D. P., Anumonwo, J. M., Auerbach, D. S., Furspan, P. B., et al. (2012). Dynamic reciprocity of sodium and potassium channel expression in a macromolecular complex controls cardiac excitability and arrhythmia. Proc. Natl. Acad. Sci. U.S.A. 109, E2134-E2143. doi: 10.1073/pnas.1109370109

Morad, M., Javaheri, A., Risius, T., and Belmonte, S. (2005). Multimodality of Ca2+ signaling in Rat atrial myocytes. Ann. N. Y. Acad. Sci. 1047, 112-121. doi: 10.1196/annals.1341.010

Oliver, D., Lien, C.-C., Soom, M., Baukrowitz, T., Jonas, P., and Fakler, B. (2004). Functional conversion between A-type and delayed rectifier $\mathrm{K}^{+}$channels by membrane lipids. Science 304, 265-270. doi: 10.1126/science.1094113

Organ-Darling, L. E., Vernon, A. N., Giovanniello, J. R., Lu, Y., Moshal, K., Roder, K., et al. (2013). Interactions between hERG and KCNQ1 $\alpha$-subunits are mediated by their $\mathrm{COOH}$ termini and modulated by cAMP. Am. J. Physiol. Heart Circ. Physiol. 304, H589-H599. doi: 10.1152/ajpheart.00385.2012

Petitprez, S., Zmoos, A.-F., Ogrodnik, J., Balse, E., Raad, N., El-Haou, S., et al. (2011). SAP97 and dystrophin macromolecular complexes determine two pools of cardiac sodium channels Nav1.5 in cardiomyocytes. Circ. Res. 108, 294-304. doi: 10.1161/CIRCRESAHA.110.228312

Rajamani, S., Anderson, C. L., Anson, B. D., and January, C. T. (2002). Pharmacological rescue of human $\mathrm{K}^{+}$channel long-QT2 mutations: human ether-a-go-go-related gene rescue without block. Circulation 105, 2830-2835. doi: 10.1161/01.CIR.0000019513.50928.74

Ren, X. Q., Liu, G. X., Organ-Darling, L. E., Zheng, R., Roder, K., Jindal, H. K., et al. (2010). Pore mutants of HERG and KvLQT1 downregulate the reciprocal currents in stable cell lines. Am. J. Physiol. Heart Circ. Physiol. 299, H1525-H1534. doi: 10.1152/ajpheart.00479.2009

Rucker-Martin, C., Milliez, P., Tan, S., Decrouy, X., Recouvreur, M., Vranckx, R., et al. (2006). Chronic hemodynamic overload of the Atria is an important factor for gap junction remodeling in human and Rat hearts. Cardiovasc. Res. 72, 69-79. doi: 10.1016/j.cardiores.2006.06.016

Sanguinetti, M. C., Curran, M. E., Zou, A., Shen, J., Spector, P. S., Atkinson, D. L., et al. (1996). Coassembly of K(V)LQT1 and minK (IsK) proteins to form cardiac I(Ks) potassium channel. Nature 384, 80-83. doi: 10.1038/384080a0

Sanguinetti, M. C., Jiang, C., Curran, M. E., and Keating, M. T. (1995). A mechanistic link between an inherited and an acquired cardiac arrthytmia: HERG encodes the IKr potassium channel. Cell 81, 299-307. doi: 10.1016/0092-8674(95)90340-2

Sanguinetti, M. C., and Tristani-Firouzi, M. (2006). hERG potassium channels and cardiac arrhythmia. Nature 440, 463-469. doi: 10.1038/nature04710

Schotten, U., Verheule, S., Kirchhof, P., and Goette, A. (2011). Pathophysiological mechanisms of Atrial fibrillation: a translational appraisal. Physiol. Rev. 91, 265-325. doi: 10.1152/physrev.00031.2009

Schumacher, S. M., McEwen, D. P., Zhang, L., Arendt, K. L., Van Genderen, K. M., and Martens, J. R. (2009). Antiarrhythmic drug-induced internalization of the atrial-specific $\mathrm{k}^{+}$channel kv1.5. Circ. Res. 104, 1390-1398. doi: 10.1161/CIRCRESAHA.108.192773

Shaw, R. M., Fay, A. J., Puthenveedu, M. A., von Zastrow, M., Jan, Y. N., and Jan, L. Y. (2007). Microtubule plus-end-tracking proteins target gap junctions directly from the cell interior to adherens junctions. Cell 128, 547-560. doi: $10.1016 /$ j.cell.2006.12.037

Shy, D., Gillet, L., and Abriel, H. (2014). Targeting the sodium channel NaV1.5 to specific membrane compartments of cardiac cells: not a simple task! Circ. Res. 115, 901-903. doi: 10.1161/CIRCRESAHA.114.305305

Spach, M. S. (1999). Anisotropy of cardiac tissue: a major determinant of conduction? J. Cardiovasc. Electrophysiol. 10, 887-90. doi: 10.1111/j.1540-8167.1999.tb00271.x

Steele, D. F., Eldstrom, J., and Fedida, D. (2007). Mechanisms of cardiac potassium channel trafficking. J. Physiol. 582(Pt 1), 17-26. doi: 10.1113/jphysiol.2007.130245

Trudeau, M. C., Warmke, J. W., Ganetzky, B., and Robertson, G. A. (1995). HERG, a human inward rectifier in the voltage-gated potassium channel family. Science 269, 92-95. doi: 10.1126/science.7604285

Valdivia, C. R., Tester, D. J., Rok, B. A., Porter, C. B., Munger, T. M., Jahangir, A., et al. (2004). A trafficking defective, brugada syndromecausing SCN5A mutation rescued by drugs. Cardiovasc. Res. 62, 53-62. doi: 10.1016/j.cardiores.2004.01.022

Van Wagoner, D. R., Pond, A. L., McCarthy, P. M., Trimmer, J. S., and Nerbonne, J. M. (1997). Outward $\mathrm{K}^{+}$current densities and Kv1.5 expression are reduced in chronic human atrial fibrillation. Circ. Res. 80, 772-781. doi: 10.1161/01.RES.80.6.772

Verkerk, A. O., van Ginneken, A. C., van Veen, T. A., and Tan, H. L. (2007). Effects of heart failure on brain-type $\mathrm{Na}+$ channels in Rabbit ventricular myocytes. Europace 9, 571-577. doi: 10.1093/europace/eum121

Wang, Z., Fermini, B., and Nattel, S. (1993). Sustained depolarization-induced outward current in human atrial myocytes. evidence for a novel delayed rectifier $\mathrm{K}^{+}$current similar to Kv1.5 cloned channel currents. Circ. Res. 73, 1061-1076. doi: 10.1161/01.RES.73.6.1061

Wible, B. A., Hawryluk, P., Ficker, E., Kuryshev, Y. A., Kirsch, G., and Brown, A. M. (2005). HERG-Lite: a novel comprehensive high-throughput screen for drug-induced hERG risk. J. Pharmacol. Toxicol. Methods 52, 136-145. doi: 10.1016/j.vascn.2005.03.008

Conflict of Interest Statement: The authors declare that the research was conducted in the absence of any commercial or financial relationships that could be construed as a potential conflict of interest.

Copyright (C) 2017 Balse and Boycott. This is an open-access article distributed under the terms of the Creative Commons Attribution License (CC BY). The use, distribution or reproduction in other forums is permitted, provided the original author(s) or licensor are credited and that the original publication in this journal is cited, in accordance with accepted academic practice. No use, distribution or reproduction is permitted which does not comply with these terms. 


\section{OPEN ACCESS}

Edited by:

Hugues Abriel,

University of Bern, Switzerland

Reviewed by:

Toon Van Veen

Utrecht University, Netherlands

Wayne Rodney Giles,

University of Calgary, Canada

*Correspondence:

Mona M. El Refaey

mona.elrefaey@osumc.edu

Specialty section: This article was submitted to

Cardiac Electrophysiology, a section of the journal Frontiers in Physiology

Received: 10 September 2017 Accepted: 12 October 2017 Published: 27 October 2017

Citation:

El Refaey MM and Mohler PJ (2017) Ankyrins and Spectrins in

Cardiovascular Biology and Disease.

Front. Physiol. 8:852

doi: 10.3389/fphys.2017.00852

\section{Ankyrins and Spectrins in Cardiovascular Biology and Disease}

\author{
Mona M. El Refaey ${ }^{1,2 *}$ and Peter J. Mohler ${ }^{1,2,3}$ \\ ${ }^{1}$ Dorothy M. Davis Heart and Lung Research Institute, Wexner Medical Center, The Ohio State University, Columbus, OH, \\ United States, ${ }^{2}$ Department of Physiology \& Cell Biology, Wexner Medical Center, The Ohio State University, Columbus, OH, \\ United States, ${ }^{3}$ Department of Internal Medicine, Division of Cardiovascular Medicine, College of Medicine, Wexner Medical \\ Center, The Ohio State University, Columbus, $\mathrm{OH}$, United States
}

Ankyrins are adaptor proteins critical for the expression and targeting of cardiac membrane proteins, signaling molecules, and cytoskeletal elements. Findings in humans and animal models have highlighted the in vivo roles for ankyrins in normal physiology and in cardiovascular disease, most notably in cardiac arrhythmia. For example, human ANK2 loss-of-function variants are associated with a complex array of electrical and structural phenotypes now termed "ankyrin-B syndrome," whereas alterations in the ankyrin-G pathway for $\mathrm{Na}_{v}$ channel targeting are associated with human Brugada syndrome. Further, both ankyrin- $G$ and $-B$ are now linked with acquired forms of cardiovascular disease including myocardial infarction and atrial fibrillation. Spectrins are ankyrin-associated proteins and recent studies support the critical role of ankyrin-spectrin interactions in normal cardiac physiology as well as regulation of key ion channel and signaling complexes. This review will highlight the roles of ankyrins and spectrins in cardiovascular physiology as well as illustrate the link between the dysfunction in ankyrin- and spectrin-based pathways and disease.

Keywords: ankyrin, spectrin, arrhythmia, heart disease, ion channel, signaling

\section{INTRODUCTION}

Cardiovascular disease is the leading cause of death in the United States (Rosamond et al., 2008). In 2013, the overall prevalence of death attributable to cardiovascular diseases (CVD) was 222.9 per 100,000 Americans. On the basis of 2013 data, more than 2,200 Americans die of CVD each day, representing an average of 1 death every $40 \mathrm{~s}$. Arrhythmia is the direct cause of death in many cases. Nearly $80 \%$ of cases of sudden cardiac death are the result of ventricular arrhythmias (Mehra, 2007). Thus, understanding the molecular mechanisms underlying human arrhythmias has been an active area of cardiovascular research (Cunha and Mohler, 2006), with a major focus on ion channels, transporters and receptors that regulate the action potential at baseline and in disease. Ankyrins and spectrins are adaptor proteins now linked with both electrical and structural forms of heart disease. Here, we will review the roles of ankyrin and spectrin polypeptides as critical components of cardiac myocytes using findings from human and animal models.

\section{ANKYRIN GENES}

Ankyrins are a family of intracellular adaptor proteins that organize and anchor integral membrane protein complexes to the spectrin- and actin-based cytoskeleton (Bennett and Baines, 2001). In vertebrates, three genes (ANK1, ANK2, ANK3), encode ankyrin polypeptides. ANK1 is located on 
human chromosome $8 \mathrm{p} 11$ and encodes ankyrin-R polypeptides (Lambert et al., 1990). ANK2 is located on human chromosome 4q25-27 and encodes ankyrin-B polypeptides (Otto et al., 1991). ANK3 is located on human chromosome 10q21 and encodes ankyrin-G polypeptides (Kordeli et al., 1995). Alternative splicing produces a series of ankyrin gene products with unique subcellular distributions and functional properties (Bennett and Baines, 2001; Cunha and Mohler, 2006; Cunha et al., 2008). For example, alternative splicing of ANK2 results in $440 \mathrm{kDa}$ and 220 kDa ankyrin-B (Kunimoto, 1995; Hashemi et al., 2009). Ankyrins $\mathrm{R}, \mathrm{B}$, and $\mathrm{G}$ polypeptides have been identified in ventricular myocytes (Li et al., 1993; Mohler et al., 2002, 2004a,b). However, the full extent of alternative splicing, expression, localization, and function is still under investigation.

\section{ANKYRIN DOMAINS AND BINDING PARTNERS}

Canonical ankyrins have four domains: a membrane-binding domain (MBD), a spectrin-binding domain (SBD), a death domain (DD) and a C-terminal domain (CTD) (Mohler, 2006). Together, DD and CTD encompass the "regulatory domain" (RD). Ankyrin-B and ankyrin-G are closely related in amino acid sequence with $67 \%$ amino acid identity between the MBD, $\mathrm{SBD}$, and DD. Despite this homology and shared expression in cardiac myocytes, ankyrin-B and ankyrin-G maintain differential distributions and non-overlapping functions. For example, while ankyrin- $\mathrm{B}$ is required for the localization of the $\mathrm{Na} / \mathrm{K}$-ATPase and $\mathrm{Na} / \mathrm{Ca}$ exchanger (NCX) (Figure 1) to transverse-tubule membranes, ankyrin- $\mathrm{G}$ is required for targeting $\mathrm{Na}_{\mathrm{v}} 1.5$ to the intercalated disc (Mohler et al., 2004a; Makara et al., 2014; Wu et al., 2015).

The MBD is comprised of 24 consecutive ANK repeats. In heart, this domain is essential for the interaction with ion channels and transporters (Figure 2) including the Na/K-ATPase (Koob et al., 1988), NCX (Li et al., 1993), voltage-gated $\mathrm{Na}_{\mathrm{v}}$ channel (Mohler et al., 2004a), the inward rectifier subunit (Kir6.2) (Li et al., 2010), voltage-gated $\mathrm{Ca}^{2+}$ channels $\left(\mathrm{Ca}_{\mathrm{v}} 1.3\right)$ (Cunha et al., 2011), and inositol trisphosphate receptor ( $\mathrm{InsP}_{3}$ receptor) (Bourguignon et al., 1993; Hortsch et al., 2009). MBD binds to a variety of cell adhesion molecules including members of the L1 family (Davis et al., 1993). The impact of these interactions in the heart is not well studied, but an important area for future research.

The SBD associates with high affinity to $\beta$ spectrin polypeptides (Bennett and Stenbuck, 1979) via the N-terminal ZU5 (Zu5N) domain (Ipsaro and Mondragon, 2010). This interaction is critical for a number of physiological functions including maintenance of normal erythrocyte cell membrane

\footnotetext{
Abbreviations: MBD, Membrane-binding domain; CTD, C-terminal domain; SBD, Spectrin-binding domain; DD, Death domain; LQTS, Long QT syndrome; NCX, Sodium-Calcium exchanger; Na/K ATPase, Sodium-potassium ATPase; IP3R, Inositol trisphosphate receptor; cKO, Conditional knock-out; INa,L, Late component of Nav current; CaMKII, Calcium/calmodulin-dependent kinase; KATP, ATP-sensitive K+ channel; Cav1.3, Voltage gated L-type Ca2+ channel; PP2A, Protein phosphatase 2A; Nav1.5, Voltage-gated sodium channel; TREK-1, TWIK-related potassium channel-1.
}

stability (Bodine et al., 1984). As described later, human ANK2 variants that alter spectrin-binding are now linked with potentially fatal forms of cardiac arrhythmia (Smith et al., 2015). The SBD also interacts with signaling molecules such as $\mathrm{B} 56 \alpha$, the regulatory subunit of protein phosphatase $2 \mathrm{~A}$ (PP2A) (Bhasin et al., 2007; Little et al., 2015).

The ankyrin regulatory domain $(\mathrm{RD})$ interacts with proteins including obscurin. Obscurin is a giant scaffolding protein with key roles in muscle myosin incorporation, A-band formation and lateral alignment of M-lines in adjacent myofibrils (Benian et al., 1996; Borisov et al., 2006; Cunha and Mohler, 2008). Cunha and colleagues demonstrated that ankyrin-B/obscurin interaction recruits PP2A to the cardiac M-line (Cunha and Mohler, 2008) (Figure 1). In addition to the intermolecular interactions, the regulatory domain regulates the intramolecular interactions with the ankyrin MBD (Abdi et al., 2006).

\section{SPECTRIN POLYPEPTIDES IN CARDIAC PHYSIOLOGY}

Spectrins are actin-associated proteins that provide structural support to the plasma membrane and play roles in the localization of membrane and signaling proteins in the heart (Hund and Mohler, 2010). Spectrin alpha $(\alpha)$ and beta ( $\beta$ ) subunits are assembled laterally to form anti-parallel heterodimers, and these heterodimers are assembled to form a flexible hetero-tetramic molecule (Bennett and Baines, 2001). There are two $\alpha$ spectrin genes and five $\beta$ spectrin genes that encode a diverse group of alternatively-spliced spectrin isoforms with specific functions (Bennett and Healy, 2009). In ventricular myocytes, $\alpha \mathrm{II}$ and $\beta \mathrm{II}$ spectrin are found at transverse-tubule and sarcoplasmic reticulum (SR) membranes (Baines and Pinder, 2005), whereas $\beta I V$ spectrin is located at the intercalated disc (Hund et al., 2010).

In heart, $\beta$ II spectrin directly interacts with ankyrin-B at transverse-tubule membranes (Mohler et al., 2004c; Smith et al., 2015). In fact, $\beta$ II spectrin is a critical element of the larger ankyrin-B complex that directly links membrane and signaling proteins including $\mathrm{NCX}, \mathrm{Na} / \mathrm{K}$ ATPase, and $\beta 56 \alpha$ with the underlying actin-based cytoskeleton. Loss of $\beta \mathrm{II}$ spectrin in adult ventricular myocytes directly impacts the expression and localization of ankyrin-B as well as ankyrin-B-associated proteins (Smith et al., 2015). Beyond loss of ankyrin-binding proteins, $\beta$ II spectrin null myocytes unexpectedly showed abnormal localization of the cardiac ryanodine receptor. The relationship of $\beta I I$ spectrin and ryanodine receptor is currently unknown. At the animal level, loss of $\beta$ II spectrin in mice is lethal in mid-gestation due to incomplete development of the heart (Tang et al., 2003). Conditional deletion of $\beta$ II spectrin in ventricular myocytes results in sinus node dysfunction and ventricular arrhythmia. These mice also display cytoskeletal remodeling and accelerated heart failure following transverse aortic constriction. As described later, human ANK2 variants that alter the interaction with $\beta$ II spectrin are linked with congenital arrhythmia (Smith et al., 2015). Further, $\beta$ II spectrin levels are altered in acquired forms of human heart failure and arrhythmia, 


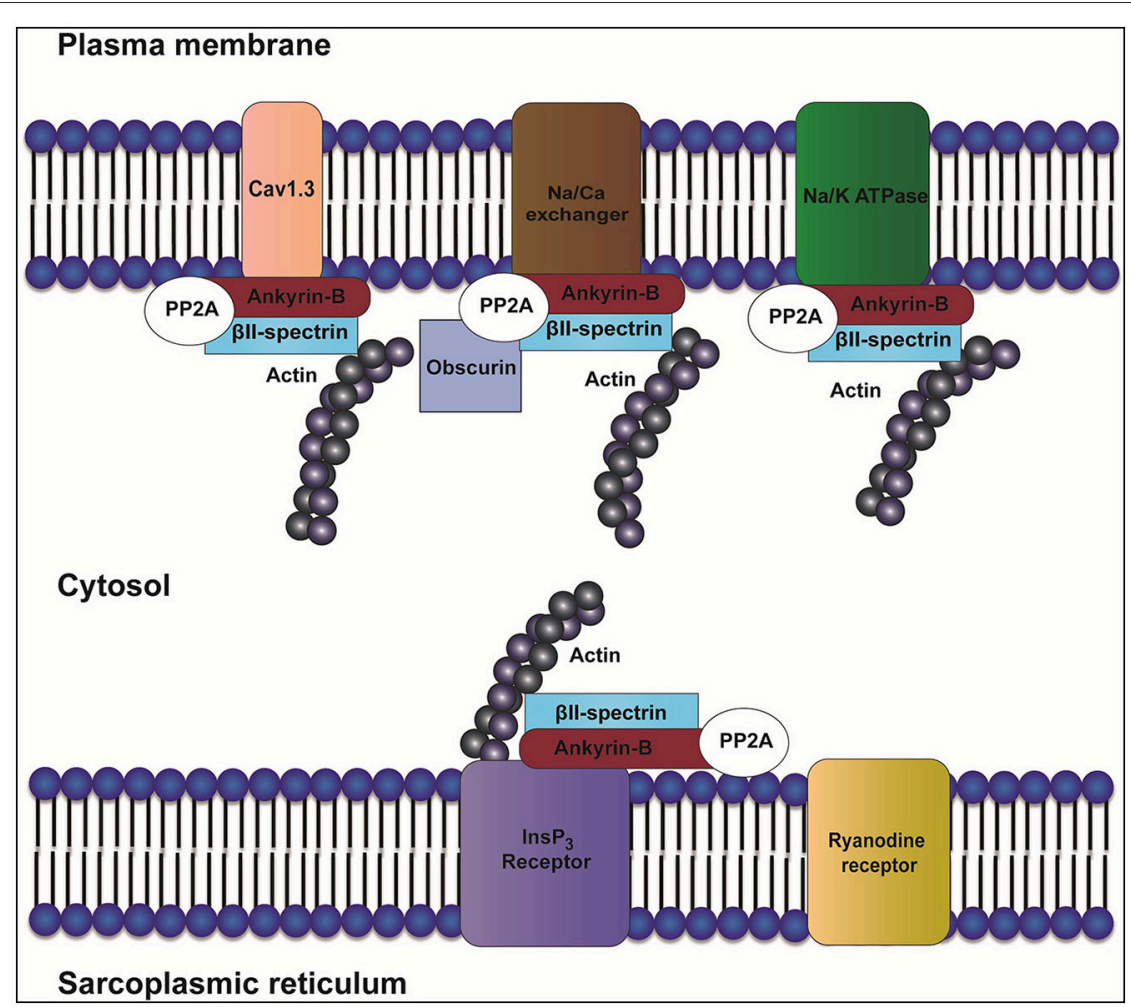

FIGURE 1 | Role of ankyrin-B in localization of the $\operatorname{InsP}_{3}$ receptor, Na/K-ATPase, Cav1.3, and NCX. In heart, ankyrin-B targets and localizes ion channels and transporters such as inositol trisphosphate receptor ( $\left.\operatorname{lnsP}_{3} \mathrm{R}\right)$, sodium/potassium ATPase (Na/K-ATPase), Cav1.3, and Na/Ca exchanger (NCX). Ankyrin-B also targets protein phosphatase type 2A (PP2A) through its regulatory subunit B56 $\alpha$. Interaction between ankyrin-B and $\beta \|$ spectrin forms a complex that is important for the localization and stability of ion channels and transporters such as Na/K-ATPase, $\mathrm{Ca}_{\mathrm{V}} 1.3, \operatorname{lnsP}_{3} \mathrm{R}$, and NCX.

as well as in animal models of cardiovascular disease (Smith et al., 2016). Finally, individuals with Beckwith-Wiedemann syndrome (BWS) with a reduction in $\beta$ II spectrin expression (Yao et al., 2010) show congenital heart failure and ventricular septal defects (Drut et al., 2006).

In heart, $\beta I V$ spectrin directly associates with ankyrin-G and is required for the targeting of calcium/calmodulin-dependent kinase II (CaMKII) to the intercalated disc (Hund et al., 2010). Notably, this interaction is critical for the regulation of $\mathrm{I}_{\mathrm{Na}}$ by modulating CaMKII-dependent phosphorylation of $\mathrm{Na}_{\mathrm{v}} 1.5$ (Hund et al., 2010; Koval et al., 2012). Beyond, ankyrin-G and CaMKII, $\beta$ IV spectrin regulates TREK-1, a mechano-sensitive $\mathrm{K}_{2 \mathrm{P}}$ channel (Heurteaux et al., 2004). More specifically, $\beta I V$ spectrin and TREK-1 associate, and $\beta I V$ spectrin is required for TREK-1 localization and function in ventricular myocytes (Hund et al., 2014). Mice lacking TREK-1 binding display delayed action potential repolarization and arrhythmia. These data support a broader role for $\beta$ IV spectrin in cardiovascular electrophysiology by regulation of TREK-1 membrane localization and function. Like $\beta$ II spectrin, $\beta$ IV spectrin levels are altered in human heart failure as well as in animal models of cardiovascular disease (Hund et al., 2014).

Finally, $\alpha$ II spectrin-deficient embryos are embryonic lethal with abnormal cardiac shape, cardiac dilatation and changes in myocardium (Stankewich et al., 2011). Beyond ankyrins,
Mena and VASP, important regulators of actin dynamics form a complex with $\alpha$ II spectrin in adult cardiomyocytes (Benz et al., 2013). The in vivo role(s) of $\alpha$ II spectrin in adult heart is currently unknown but an important area for future research.

\section{IN VIVO ROLES FOR CARDIAC ANKYRINS}

\section{Ankyrin-G is Required for Targeting $\mathrm{Na}_{\mathrm{v}} \mathbf{1 . 5}$}

In neurons, the link between ankyrin- $\mathrm{G}$ and $\mathrm{Na}_{\mathrm{v}}$ channel targeting is well established (Jenkins and Bennett, 2001; Saifetiarova et al., 2017). In heart, rat ventricular myocytes lacking ankyrin-G display a reduction in $\mathrm{Na}_{\mathrm{v}} 1.5$ expression, localization, and $\mathrm{I}_{\mathrm{Na}}$ (Lowe et al., 2008). In fact, in myocytes with reduced ankyrin-G expression, $\mathrm{Na}_{\mathrm{v}} 1.5$ localization is limited in the perinuclear region of rat ventricular myocytes. Notably, this role is specific for ankyrin-G vs. ankyrin-B as ankyrinB-null neonatal cardiomyocytes show no difference in $\mathrm{Na}_{\mathrm{v}} 1.5$ expression or localization. Further, loss of ankyrin-G is specific for $\mathrm{I}_{\mathrm{Na}}$ vs. other cardiac currents (e.g., $\mathrm{I}_{\mathrm{Ca}, \mathrm{L}}$ ) (Lowe et al., 2008).

In animals, ankyrin-G expression is required for the targeting of $\mathrm{Na}_{\mathrm{v}} 1.5$ and CaMKII to the intercalated disc (Makara et al., 2014). $\mathrm{Na}_{\mathrm{v}} 1.5$ expression and $\mathrm{I}_{\mathrm{Na}}$ is reduced in myocytes derived from mice with selective loss of cardiomyocyte ankyrin-G (cKO) (Makara et al., 2014). Further, $\beta I V$ spectrin 


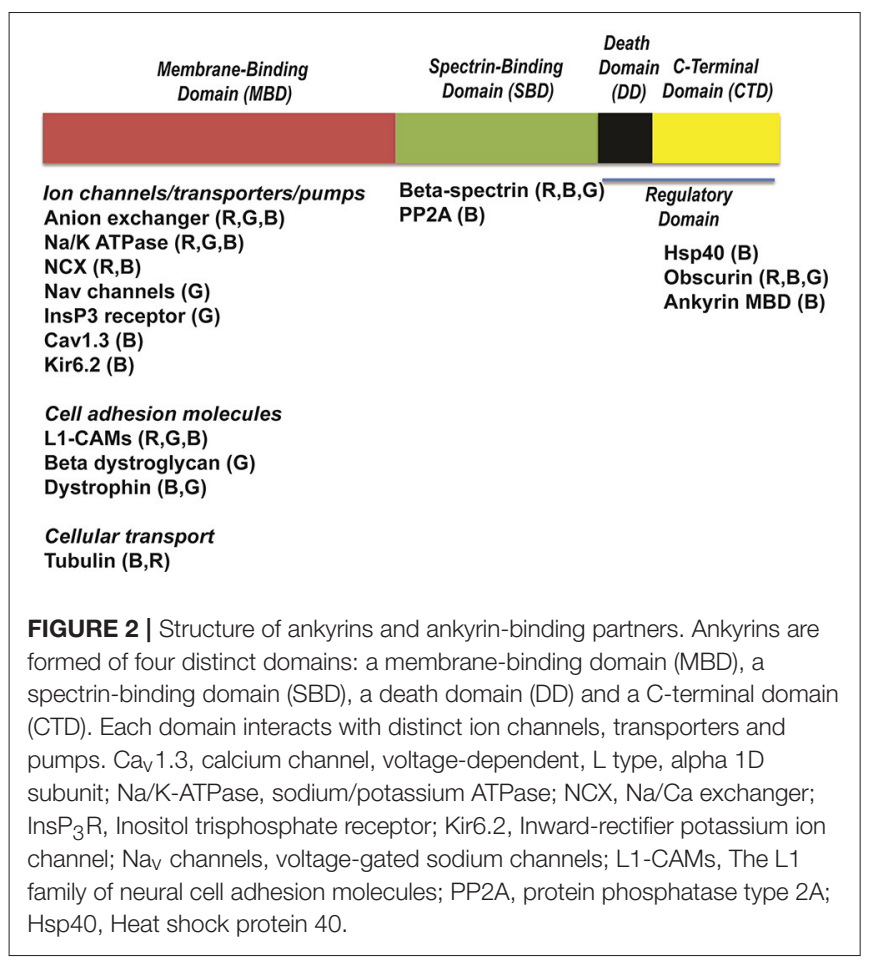

is absent in the intercalated disc of myocytes of ankyrin cKO mice. Electrocardiographic studies of these mice show significant reduction in heart rate, impaired atrioventricular conduction, and an increase in PR interval. Moreover, cKO mice display a significant increase in the QRS interval and delayed intraventricular conduction. Administration of flecainide or catecholamines (elevated adrenergic stimulation) induces arrhythmia in these mice.

Beyond animals, work in humans supports the link between ankyrin-G and $\mathrm{Na}_{\mathrm{v}}$ channel targeting. Priori et al. (2000) identified an individual with Brugada syndrome harboring an $S C N 5 A$ variant in the $\mathrm{Na}_{\mathrm{v}} 1.5$ motif that interacts with ankyrin-G (Mohler et al., 2004a). The group identified the SCN5A variant in a 47-year-old female with a history of palpitations and an unexplained syncope at rest. Using in vitro binding assays, the p.E1053K variant was found to disrupt the interaction between $\mathrm{Na}_{\mathrm{v}} 1.5$ and ankyrin-G resulting in abnormal targeting in myocytes.

A canine myocardial infarction (MI) model was used to study the role of ankyrin-G in acquired arrhythmic disease. At 5 days, there was a $42 \%$ reduction in $\mathrm{Na}_{\mathrm{v}} 1.5$ protein expression and a $50 \%$ increase in ankyrin-G expression in the epicardial border zone. These data suggest that ankyrin-G levels increase to regulate $\mathrm{Na}_{\mathrm{v}} 1.5$ recruitment to sarcolemmal membrane (Dun et al., 2013).

\section{Ankyrin-B}

First identified in brain, ankyrin- $B$ has now been directly linked with a host of functions in the heart. Further, ankyrin-B dysfunction is now well documented in multiple forms of congenital and acquired cardiovascular disease. While ankyrin- $B$ was known to directly associate with critical cardiac ion channels and transporters, an in vivo role for ankyrin-B in cardiac function was first illustrated using mice heterozygous for an ankyrin-B null mutation. While ankyrin-B null mice die shortly after birth, ankyrin- $\mathrm{B}^{+/-}$mice live to adulthood but display bradycardia, heart rate variability, prolonged QT intervals, and sudden cardiac death in response to exercise combined with catecholaminergic stimulation (Mohler et al., 2003). While adult ventricular myocytes from ankyrin- $\mathrm{B}^{+/-}$mice display normal action potential duration, these myocytes display early and delayed after-depolarizations in response to catecholamines. At the molecular level, ankyrin- $\mathrm{B}^{+/-}$ventricular myocytes display reduced expression and abnormal localization of ankyrin-Bbinding partners including $\mathrm{Na} / \mathrm{K}$ ATPase and NCX. As illustrated in computational models (Wolf et al., 2010), loss of $\mathrm{Na} / \mathrm{K}$ ATPase and NCX results in increased SR calcium stores that result in an arrhythmogenic substrate in the ankyrin- $\mathrm{B}^{+/-}$ animals (Mohler et al., 2004b). Subsequent work from Despa and colleagues revealed significant alterations in local $\left[\mathrm{Ca}^{2+}\right]$ as well as hyper-phosphorylation of ryanodine receptors in ankyrin$\mathrm{B}^{+/-}$ventricular myocytes (Camors et al., 2012; Popescu et al., 2016) potentially due to altered PP2A regulation (DeGrande et al., 2012). Further characterization of ankyrin- $B^{+/-}$mice showed premature senescence and reduced longevity with mice showing loss of adiposity starting at 6 months of age (Mohler et al., 2007a).

Ankyrin-B dysfunction is directly linked with human cardiovascular disease. Over two decades ago, Schott and colleagues identified type 4 long QT syndrome in a large French kindred with sinus node dysfunction and episodes of atrial fibrillation (Schott et al., 1995). Prolonged QTc was observed among the 25 affected patients (21 adults and 4 children). Individuals in the family also displayed catecholaminergic polymorphic ventricular arrhythmia and sudden death. Sequencing of the gene encoding ankyrin-B (ANK2) revealed a positional transition (A to G) mutation at position 4,274 in exon 36, leading to the substitution of a glycine for a glutamic acid at amino acid residue 1,425 (p.E1425G) near the regulatory domain of ankyrin-B in forty-five family members (24 carriers and 21 non-carriers). The p.E1425G variant, subsequently identified as a loss-of-function variant in myocytes, showed prevalence in 22 out of 24 individuals with the LQT4 phenotype and was absent in non-affected individuals (Mohler et al., 2003). Since this initial discovery, a number of new ankyrin-B loss-of-function variants have been identified in individuals with ventricular arrhythmias. However, as discussed below, due to the diversity of non-ventricular phenotypes associated with the disease (including many lacking QTc prolongation), the term "ankyrin-B syndrome" has been adopted to describe individuals harboring ANK2 loss-of-function variants (Mohler et al., 2004b, 2007b). As in the case of many cardiovascular disease genes, the penetrance of phenotypes in ANK2 variant carriers is variable. As ankyrin-B polypeptide stability and function is directly impacted by physiological and pathological stress (e.g., inflammation, elevated reactive oxygen species), we predict that a "second hit" may be necessary for full disease penetrance. 
Active areas of research in this field are currently focused on identifying the mechanisms underlying both congenital and acquired ankyrin-B loss in human disease as well as the discovery of new variants. For example, while loss-of-function variants were limited to the $\mathrm{RD}$, new variants in the ankyrin-B MBD have shed light on new phenotypes associated with "ankyrinB syndrome." Recently, a novel MBD variant in the ANK2 gene (p.S646F) was identified in two Gitxan families with LQTS phenotypes by the Swayne and Arbour groups (Swayne et al., 2017). The first person identified was a 28 -year old man with a clinical diagnosis of LQTS and recurrent syncope. Five of this patient's relatives were confirmed to harbor this variant. This variant was also identified in a second family with a clinical diagnosis of LQTS. Within these two families, a total of 13 adults and 5 children have been identified with this novel ANK2 variant. In vitro evaluation illustrated that the expression of ankyrin MBD with p.S646F variant in bacteria was normal and MBD structural properties were intact. However, expression of ankyrin-B p.S646F variant in neonatal cardiomyocytes showed a reduction in ankyrin-B expression and alteration of expression of NCX (Swayne et al., 2017). Finally, beyond LQT and catecholaminergic polymorphic ventricular tachycardia, ANK2 variants have been associated with other forms of ventricular arrhythmia including early repolarization syndrome (Krogh Broendberg et al., 2015).

ANK2 variants are not limited to MBD or RD. Smith et al. identified an ANK2 arrhythmia variant (c.2969G > A) caused by the substitution of Arg to Gln at position 990 (p. R990Q). This variant is rare with a minor allele frequency of $0.007 \%$ and resides near the central ZU5 binding surface for $\beta I I$ spectrin. Using myocytes from ankyrin-B conditional knockout mice (cKO), exogenous expression of WT ankyrin-B, but not ankyrin-B p.R990Q was able to rescue the localization of NCX (Smith et al., 2015).

Ankyrin-B dysfunction is also linked with non-ventricular forms of human arrhythmia. Individuals with select ANK2 lossof-function variants display atrial fibrillation and/or sinus node dysfunction (Le Scouarnec et al., 2008; Cunha et al., 2011). Consistent with these data, ankyrin- $\mathrm{B}^{+/-}$mice also display both atrial and sinus node phenotypes. At the cellular level, primary atrial and sinus node myocytes from ankyrin- $\mathrm{B}^{+/-}$mice display shortened action potentials and loss of L-type $\mathrm{Ca}^{2+}$ current. In ankyrin- $\mathrm{B}^{+/-}$atrial myocytes, voltage-gated $\mathrm{L}$-type $\mathrm{Ca}^{2+}$ channel $\mathrm{Ca}_{\mathrm{v}} 1.3$ (but not $\mathrm{Ca}_{\mathrm{v}} 1.2$ ) expression and function were reduced.

Until recently, ANK2-based disease was linked only to individuals with single "point mutations" (Mohler et al., 2004b, 2007b; Sherman et al., 2005; Krogh Broendberg et al., 2015; Swayne et al., 2017). However, recently a family was identified with an ANK2 transection in chromosome 4 (Huq et al., 2017). The proband had a balanced translocation between the long arms of chromosomes 4 and 9. Five other family members were carriers of the same balanced translocation. The 16-weekold fetus of the proband from a terminated pregnancy was found to have multiple cardiac abnormalities. The proband showed normal echocardiography findings and only Holter monitor recorded few episodes of bradycardia at night. Isolated lymphoblasts from the proband demonstrated a significant reduction in ankyrin- $\mathrm{B}$ and binding partners, confirming a model of ankyrin-B haploinsufficiency. The mother of the proband was also a carrier of the translocation and displayed frequent ventricular ectopy and periods of bigeminy.

Beyond congenital disease, dysfunction in ankyrin-B-based pathways has been linked with acquired forms of cardiovascular disease. In a canine model of myocardial infarction, ankyrin-B mRNA levels were increased and protein levels were decreased in day 5-post infarction in the border zone (Hund et al., 2009). At the myocyte level, abnormal distribution of ankyrin-B was noted. The authors further showed changes in expression and/or distribution of downstream ankyrin-associated proteins $\mathrm{Na} / \mathrm{K}$ ATPase, NCX, InsP 3 receptor and PP2A (Hund et al., 2009). In addition to its role in myocardial infarction, $\mathrm{Li}$ et al. identified the association of ATP-sensitive $\mathrm{K}^{+}$channel ( $\mathrm{K}_{\mathrm{ATP}}$ ) with ankyrin-B as a cardio-protective mechanism against acute ischemia ( $\mathrm{Li}$ et al., 2010). Ankyrin-B levels are now also known to be reduced in patients with atrial fibrillation (Cunha et al., 2011).

\section{Ankyrin-R}

To date, human variants in ANK1 have not been directly linked with cardiac arrhythmia phenotypes. While not the focus on this review, it is of note that variants in $A N K 1$ are a primary cause for hereditary spherocytosis (Eber et al., 1996; Tse and Lux, 1999; Perrotta et al., 2008; Satchwell et al., 2016).

\section{SUMMARY}

Cardiac ankyrins and spectrins are key multifunctional molecules in the heart. In myocytes, ankyrins, and spectrins serve essential roles in targeting ion channels and transporters to critical membrane domains. However, beyond membrane proteins, these molecules serve as crucial cellular nodes to integrate membrane proteins with critical signaling and structural proteins in diverse cardiac cell types. While animals have served as important models to define ankyrin and spectrin function in vivo, more recent findings in patients have both solidified the importance of ankyrins and spectrin in human physiology and disease, and raised important questions related to unexpected roles of these polypeptides. Key future questions in the field remain the impact of environment or "second hit" gene variants on disease susceptibility/penetrance in ANK2 variant carriers, as well as potential non-myocyte/non-cardiac phenotypes in patients with ankyrin gene variants.

\section{AUTHOR CONTRIBUTIONS}

All authors listed, have made substantial, direct and intellectual contribution to the work, and approved it for publication.

\section{ACKNOWLEDGMENTS}

This work was supported by National Heart, Lung and Blood Institute grants HL-135754, HL-134824, and HL-114383 (PM). ME is supported by Dorothy M. Davis Heart and Lung Research Institute Post-doctoral training fellowship in Congenital and Acquired Heart Diseases (5T32HL098039). 


\section{REFERENCES}

Abdi, K. M., Mohler, P. J., Davis, J. Q., and Bennett, V. (2006). Isoform specificity of ankyrin-B: a site in the divergent C-terminal domain is required for intramolecular association. J. Biol. Chem. 281, 5741-5749. doi: 10.1074/jbc.M506697200

Baines, A. J., and Pinder, J. C. (2005). The spectrin-associated cytoskeleton in mammalian heart. Front. Biosci. 10, 3020-3033. doi: 10.2741/1759

Benian, G. M., Tinley, T. L., Tang, X., and Borodovsky, M. (1996). The Caenorhabditis elegans gene unc-89, required fpr muscle M-line assembly, encodes a giant modular protein composed of $\mathrm{Ig}$ and signal transduction domains. J. Cell Biol. 132, 835-848. doi: 10.1083/jcb.132.5.835

Bennett, V., and Baines, A. J. (2001). Spectrin and ankyrin-based pathways: metazoan inventions for integrating cells into tissues. Physiol. Rev. 81, 1353-1392. Available online at: http://physrev.physiology.org/content/81/3/ 1353.full-text.pdf+html

Bennett, V., and Healy, J. (2009). Membrane domains based on ankyrin and spectrin associated with cell-cell interactions. Cold Spring Harb. Perspect. Biol. 1:a003012. doi: 10.1101/cshperspect.a003012

Bennett, V., and Stenbuck, P. J. (1979). The membrane attachment protein for spectrin is associated with band 3 in human erythrocyte membranes. Nature 280, 468-473. doi: 10.1038/280468a0

Benz, P. M., Merkel, C. J., Offner, K., Abeßer, M., Ullrich, M., Fischer, T., et al. (2013). Mena/VASP and alphaII-spectrin complexes regulate cytoplasmic actin networks in cardiomyocytes and protect from conduction abnormalities and dilated cardiomyopathy. Cell Commun. Signal 11:56. doi: 10.1186/1478-811X-11-56

Bhasin, N., Cunha, S. R., Mudannayake, M., Gigena, M. S., Rogers, T. B., and Mohler, P. J. (2007). Molecular basis for PP2A regulatory subunit B56alpha targeting in cardiomyocytes. Am. J. Physiol. Heart Circ. Physiol. 293, H109H119. doi: 10.1152/ajpheart.00059.2007

Bodine, D. M., Birkenmeier, C. S., and Barker, J. E. (1984). Spectrin deficient inherited hemolytic anemias in the mouse: characterization by spectrin synthesis and mRNA activity in reticulocytes. Cell 37, 721-729. doi: 10.1016/0092-8674(84)90408-2

Borisov, A. B., Sutter, S. B., Kontrogianni-Konstantopoulos, A., Bloch, R. J., Westfall, M. V., and Russell, M. W. (2006). Essential role of obscurin in cardiac myofibrillogenesis and hypertrophic response: evidence from small interfering RNA-mediated gene silencing. Histochem. Cell Biol. 125, 227-238. doi: 10.1007/s00418-005-0069-x

Bourguignon, L. Y., Jin, H., Iida, N., Brandt, N. R., and Zhang, S. H. (1993). The involvement of ankyrin in the regulation of inositol 1,4,5-trisphosphate receptor-mediated internal $\mathrm{Ca} 2+$ release from $\mathrm{Ca} 2+$ storage vesicles in mouse T-lymphoma cells. J. Biol. Chem. 268, 7290-7297.

Camors, E., Mohler, P. J., Bers, D. M., and Despa, S. (2012). Ankyrin$\mathrm{B}$ reduction enhances $\mathrm{Ca}$ spark-mediated SR Ca release promoting cardiac myocyte arrhythmic activity. J. Mol. Cell Cardiol. 52, 1240-1248. doi: 10.1016/j.yjmcc.2012.02.010

Cunha, S. R., Hund, T. J., Hashemi, S., Voigt, N., Li, N., Wright, P., et al. (2011). Defects in ankyrin-based membrane protein targeting pathways underlie atrial fibrillation. Circulation 124, 1212-1222. doi: 10.1161/CIRCULATIONAHA.111.023986

Cunha, S. R., Le Scouarnec, S., Schott, J. J., and Mohler, P. J. (2008). Exon organization and novel alternative splicing of the human ANK2 gene: implications for cardiac function and human cardiac disease. J. Mol. Cell Cardiol. 45, 724-734. doi: 10.1016/j.yjmcc.2008.08.005

Cunha, S. R., and Mohler, P. J. (2006). Cardiac ankyrins: Essential components for development and maintenance of excitable membrane domains in heart. Cardiovasc. Res. 71, 22-29. doi: 10.1016/j.cardiores.2006.03.018

Cunha, S. R., and Mohler, P. J. (2008). Obscurin targets ankyrin-B and protein phosphatase 2A to the cardiac M-line. J. Biol. Chem. 283, 31968-31980. doi: 10.1074/jbc.M806050200

Davis, J. Q., McLaughlin, T., and Bennett, V. (1993). Ankyrin-binding proteins related to nervous system cell adhesion molecules: candidates to provide transmembrane and intercellular connections in adult brain. J. Cell Biol. 121, 121-133. doi: $10.1083 /$ jcb.121.1.121

DeGrande, S., Nixon, D., Koval, O., Curran, J. W., Wright, P., Wang, Q., et al. (2012). CaMKII inhibition rescues proarrhythmic phenotypes in the model of human ankyrin-B syndrome. Heart Rhythm 9, 2034-2041. doi: 10.1016/j.hrthm.2012.08.026

Drut, R., Quijano, G., Altamirano, M. E., Jones, M. C., and Maffessoli, O. B. (2006). Vascular malformation and choroid plexus adrenal heterotopia: new findings in Beckwith-Wiedemann syndrome? Fetal Pediatr. Pathol. 25, 191-197. doi: 10.1080/15513810601015704

Dun, W., Lowe, J. S., Wright, P., Hund, T. J., Mohler, P. J., and Boyden, P. A. (2013). Ankyrin-G participates in INa remodeling in myocytes from the border zones of infarcted canine heart. PLOS ONE 8:e78087. doi: 10.1371/journal.pone.0078087

Eber, S. W., Gonzalez, J. M., Lux, M. L., Scarpa, A. L., Tse, W. T., Dornwell, M., et al. (1996). Ankyrin-1 mutations are a major cause of dominant and recessive hereditary spherocytosis. Nat. Genet. 13, 214-218. doi: 10.1038/ng0696-214

Hashemi, S. M., Hund, T. J., and Mohler, P. J. (2009). Cardiac ankyrins in health and disease. J. Mol. Cell Cardiol. 47, 203-209. doi: 10.1016/j.yjmcc.2009.04.010

Heurteaux, C., Guy, N., Laigle, C., Blondeau, N., Duprat, F., Mazzuca, M., et al. (2004). TREK-1, a K+ channel involved in neuroprotection and general anesthesia. EMBO J. 23, 2684-2695. doi: 10.1038/sj.emboj.7600234

Hortsch, M., Nagaraj, K., and Godenschwege, T. A. (2009). The interaction between L1-type proteins and ankyrins-a master switch for L1-type CAM function. Cell Mol. Biol. Lett. 14, 57-69. doi: 10.2478/s11658-0080035-4

Hund, T. J., Koval, O. M., Li, J., Wright, P. J., Qian, L., Snyder, J. S., et al. (2010). A beta(IV)-spectrin/CaMKII signaling complex is essential for membrane excitability in mice. J. Clin. Invest. 120, 3508-3519. doi: 10.1172/JCI43621

Hund, T. J., and Mohler, P. J. (2010). Cardiac spectrins: alternative splicing encodes functional diversity. J. Mol. Cell Cardiol. 48, 1031-1032. doi: 10.1016/j.yjmcc.2010.02.002

Hund, T. J., Snyder, J. S., Wu, X., Glynn, P., Koval, O. M., Onal, B., et al. (2014). beta(IV)-Spectrin regulates TREK-1 membrane targeting in the heart. Cardiovasc. Res. 102, 166-175. doi: 10.1093/cvr/cvu008

Hund, T. J., Wright, P. J., Dun, W., Snyder, J. S., Boyden, P. A., and Mohler, P. J. (2009). Regulation of the ankyrin-B-based targeting pathway following myocardial infarction. Cardiovasc. Res. 81, 742-749.doi: 10.1093/cvr/cvn348

Huq, A. J., Pertile, M. D., Davis, A. M., Landon, H., James, P. A., Kline, C. F., et al. (2017). A novel mechanism for human cardiac Ankyrin-B syndrome due to reciprocal chromosomal translocation. Heart Lung Circ. 26, 612-618. doi: 10.1016/j.hlc.2016.09.013

Ipsaro, J. J., and Mondragón, A. (2010). Structural basis for spectrin recognition by ankyrin. Blood 115, 4093-4101. doi: 10.1182/blood-2009-11-255604

Jenkins, S. M., and Bennett, V. (2001). Ankyrin-G coordinates assembly of the spectrin-based membrane skeleton, voltage-gated sodium channels, and L1 CAMs at Purkinje neuron initial segments. J. Cell Biol. 155, 739-746. doi: $10.1083 /$ jcb. 200109026

Koob, R., Zimmermann, M., Schoner, W., and Drenckhahn, D. (1988). Colocalization and coprecipitation of ankyrin and $\mathrm{Na}+, \mathrm{K}+$-ATPase in kidney epithelial cells. Eur. J. Cell Biol. 45, 230-237.

Kordeli, E., Lambert, S., and Bennett, V. (1995). AnkyrinG. a new ankyrin gene with neural-specific isoforms localized at the axonal initial segment and node of ranvier. J. Biol. Chem. 270, 2352-2359. doi: 10.1074/jbc.270.5.2352

Koval, O. M., Snyder, J. S., Wolf, R. M., Pavlovicz, R. E., Glynn, P., Curran, J., et al. (2012). Ca2+/calmodulin-dependent protein kinase II-based regulation of voltage-gated $\mathrm{Na}+$ channel in cardiac disease. Circulation 126, 2084-2094. doi: 10.1161/CIRCULATIONAHA.112.105320

Krogh Broendberg, A., Pedersen, L. N., Nielsen, J. C., and Jensen, H. K. (2015). Ankyrin-2 variants associated with idiopathic ventricular fibrillation storm in patients with intermittent early repolarization pattern. HeartRhythm Case Rep. 1, 337-341. doi: 10.1016/j.hrcr.2015.05.008

Kunimoto, M. (1995). A neuron-specific isoform of brain ankyrin, 440-kD ankyrinB, is targeted to the axons of rat cerebellar neurons. J. Cell Biol. 131(6 Pt 2), 1821-1829. doi: 10.1083/jcb.131.6.1821

Lambert, S., Yu, H., Prchal, J. T., Lawler, J., Ruff, P., Speicher, D., et al. (1990). cDNA sequence for human erythrocyte ankyrin. Proc. Natl. Acad. Sci. U.S.A. 87, 1730-1734. doi: 10.1073/pnas.87.5.1730

Le Scouarnec, S., Bhasin, N., Vieyres, C., Hund, T. J., Cunha, S. R., Koval, O., et al. (2008). Dysfunction in ankyrin-B-dependent ion channel and transporter targeting causes human sinus node disease. Proc. Natl. Acad. Sci. U. S. A. 105, 15617-15622. doi: 10.1073/pnas.0805500105 
Li, J., Kline, C. F., Hund, T. J., Anderson, M. E., and Mohler, P. J. (2010). AnkyrinB regulates Kir6.2 membrane expression and function in heart. J. Biol. Chem. 285, 28723-28730. doi: 10.1074/jbc.M110.147868

Li, Z. P., Burke, E. P., Frank, J. S., Bennett, V., and Philipson, K. D. (1993). The cardiac $\mathrm{Na}+-\mathrm{Ca} 2+$ exchanger binds to the cytoskeletal protein ankyrin. J. Biol. Chem. 268, 11489-11491.

Little, S. C., Curran, J., Makara, M. A., Kline, C. F., Ho, H. T., Xu, Z., et al. (2015). Protein phosphatase 2A regulatory subunit B56alpha limits phosphatase activity in the heart. Sci Signal 8, ra72. doi: 10.1126/scisignal.aaa5876

Lowe, J. S., Palygin, O., Bhasin, N., Hund, T. J., Boyden, P. A., Shibata, E., et al. (2008). Voltage-gated Nav channel targeting in the heart requires an ankyrin-G dependent cellular pathway. J. Cell Biol. 180, 173-186. doi: $10.1083 /$ jcb. 200710107

Makara, M. A., Curran, J., Little, S. C., Musa, H., Polina, I., Smith, S. A., et al. (2014). Ankyrin-G coordinates intercalated disc signaling platform to regulate cardiac excitability in vivo. Circ. Res. 115, 929-938. doi: 10.1161/CIRCRESAHA.115.305154

Mehra, R. (2007). Global public health problem of sudden cardiac death. J. Electrocardiol. 40, S118-122. doi: 10.1016/j.jelectrocard.2007.06.023

Mohler, P. J. (2006). Ankyrins and human disease: what the electrophysiologist should know. J. Cardiovasc. Electrophysiol. 17, 1153-1159. doi: 10.1111/j.1540-8167.2006.00540.x

Mohler, P. J., Gramolini, A. O., and Bennett, V. (2002). The ankyrin-B Cterminal domain determines activity of ankyrin- $\mathrm{B} / \mathrm{G}$ chimeras in rescue of abnormal inositol 1,4,5-trisphosphate and ryanodine receptor distribution in ankyrin-B (-/-) neonatal cardiomyocytes. J. Biol. Chem. 277, 10599-10607. doi: $10.1074 /$ jbc.M1 10958200

Mohler, P. J., Healy, J. A., Xue, H., Puca, A. A., Kline, C. F., Allingham, R. R., et al. (2007a). Ankyrin-B syndrome: enhanced cardiac function balanced by risk of cardiac death and premature senescence. PLOS ONE 2:e1051. doi: 10.1371/journal.pone.0001051

Mohler, P. J., Le Scouarnec, S., Denjoy, I., Lowe, J. S., Guicheney, P., Caron, L., et al. (2007b). Defining the cellular phenotype of "ankyrin-B syndrome" variants: human ANK2 variants associated with clinical phenotypes display a spectrum of activities in cardiomyocytes. Circulation 115, 432-441. doi: 10.1161/CIRCULATIONAHA.106.656512

Mohler, P. J., Rivolta, I., Napolitano, C., LeMaillet, G., Lambert, S., Priori, S. G., et al. (2004a). Nav1.5 E1053K mutation causing Brugada syndrome blocks binding to ankyrin-G and expression of Nav1.5 on the surface of cardiomyocytes. Proc. Natl. Acad. Sci. U.S.A. 101, 17533-17538. doi: $10.1073 /$ pnas. 0403711101

Mohler, P. J., Schott, J. J., Gramolini, A. O., Dilly, K. W., Guatimosim, S., duBell, W. H., et al. (2003). Ankyrin-B mutation causes type 4 long-QT cardiac arrhythmia and sudden cardiac death. Nature 421, 634-639. doi: 10.1038/nature01335

Mohler, P. J., Splawski, I., Napolitano, C., Bottelli, G., Sharpe, L., Timothy, K., et al. (2004b). A cardiac arrhythmia syndrome caused by loss of ankyrin-B function. Proc. Natl. Acad. Sci. U.S.A. 101, 9137-9142. doi: 10.1073/pnas.0402546101

Mohler, P. J., Yoon, W., and Bennett, V. (2004c). Ankyrin-B targets beta2-spectrin to an intracellular compartment in neonatal cardiomyocytes. J. Biol. Chem. 279, 40185-40193. doi: 10.1074/jbc.M406018200

Otto, E., Kunimoto, M., McLaughlin, T., and Bennett, V. (1991). Isolation and characterization of cDNAs encoding human brain ankyrins reveal a family of alternatively spliced genes. J. Cell Biol. 114, 241-253. doi: 10.1083/jcb. 114.2.241

Perrotta, S., Gallagher, P. G., and Mohandas, N. (2008). Hereditary spherocytosis. Lancet 372, 1411-1426. doi: 10.1016/S0140-6736(08)61588-3

Popescu, I., Galice, S., Mohler, P. J., and Despa, S. (2016). Elevated local [Ca2+] and CaMKII promote spontaneous $\mathrm{Ca} 2+$ release in ankyrin-B-deficient hearts. Cardiovasc. Res. 111, 287-294. doi: 10.1093/cvr/cvw093

Priori, S. G., Napolitano, C., Gasparini, M., Pappone, C., Della Bella, P., Brignole, M., et al. (2000). Clinical and genetic heterogeneity of right bundle branch block and ST-segment elevation syndrome: a prospective evaluation of 52 families. Circulation 102, 2509-2515. doi: 10.1161/01.CIR.102.20.2509
Rosamond, W., Flegal, K., Furie, K., Go, A., Greenlund, K., Haase, N., et al. (2008). Heart disease and stroke statistics-2008 update: a report from the American Heart Association Statistics Committee and Stroke Statistics Subcommittee. Circulation 117, e25-e146. doi: 10.1161/CIRCULATIONAHA.107.187998

Saifetiarova, J., Taylor, A. M., and Bhat, M. A. (2017). Early and late loss of the Cytoskeletal Scaffolding protein, Ankyrin G reveals its role in maturation and maintenance of nodes of Ranvier in Myelinated Axons. J. Neurosci. 37, 2524-2538. doi: 10.1523/JNEUROSCI.2661-16.2017

Satchwell, T. J., Bell, A. J., Hawley, B. R., Pellegrin, S., Mordue, K. E., van Deursen, C. T., et al. (2016). Severe Ankyrin-R deficiency results in impaired surface retention and lysosomal degradation of RhAG in human erythroblasts. Haematologica 101, 1018-1027. doi: 10.3324/haematol.2016.146209

Schott, J. J., Charpentier, F., Peltier, S., Foley, P., Drouin, E., Bouhour, J. B., et al. (1995). Mapping of a gene for long QT syndrome to chromosome 4q25-27. Am. J. Hum. Genet. 57, 1114-1122.

Sherman, J., Tester, D. J., and Ackerman, M. J. (2005). Targeted mutational analysis of ankyrin-B in 541 consecutive, unrelated patients referred for long QT syndrome genetic testing and 200 healthy subjects. Heart Rhythm 2, 1218-1223. doi: 10.1016/j.hrthm.2005.07.026

Smith, S. A., Hughes, L. D., Kline, C. F., Kempton, A. N., Dorn, L. E., Curran, J., et al. (2016). Dysfunction of the beta2-spectrin-based pathway in human heart failure. Am. J. Physiol. Heart Circ. Physiol. 310, H1583-H1591. doi: 10.1152/ajpheart.00875.2015

Smith, S. A., Sturm, A. C., Curran, J., Kline, C. F., Little, S. C., Bonilla, I. M., et al. (2015). Dysfunction in the betaII spectrin-dependent cytoskeleton underlies human arrhythmia. Circulation 131, 695-708. doi: 10.1161/CIRCULATIONAHA.114.013708

Stankewich, M. C., Cianci, C. D., Stabach, P. R., Ji, L., Nath, A., and Morrow, J. S. (2011). Cell organization, growth, and neural and cardiac development require alphaII-spectrin. J. Cell Sci. 124(Pt 23), 3956-3966. doi: 10.1242/jcs.080374

Swayne, L. A., Murphy, N. P., Asuri, S., Chen, L., Xu, X., McIntosh, S., et al. (2017). Novel variant in the ANK2 membrane-binding domain is associated with Ankyrin-B syndrome and structural heart disease in a first nations population with a high rate of long QT syndrome. Circ. Cardiovasc. Genet. 10:e001537. doi: 10.1161/CIRCGENETICS.116.001537

Tang, Y., Katuri, V., Dillner, A., Mishra, B., Deng, C. X., and Mishra, L. (2003). Disruption of transforming growth factor-beta signaling in ELF beta-spectrindeficient mice. Science 299, 574-577. doi: 10.1126/science.1075994

Tse, W. T., and Lux, S. E. (1999). Red blood cell membrane disorders. Br. J. Haematol. 104, 2-13. doi: 10.1111/j.1365-2141.1999.01130.x

Wolf, R. M., Mitchell, C. C., Christensen, M. D., Mohler, P. J., and Hund, T. J. (2010). Defining new insight into atypical arrhythmia: a computational model of ankyrin-B syndrome. Am. J. Physiol. Heart Circ. Physiol. 299, H1505-H1514. doi: 10.1152/ajpheart.00503.2010

Wu, H. C., Yamankurt, G., Luo, J., Subramaniam, J., Hashmi, S. S., Hu, H., et al. (2015). Identification and characterization of two ankyrin-B isoforms in mammalian heart. Cardiovasc. Res. 107, 466-477. doi: 10.1093/cvr/cvv184

Yao, Z. X., Jogunoori, W., Choufani, S., Rashid, A., Blake, T., Yao, W., et al. (2010). Epigenetic silencing of beta-spectrin, a TGF-beta signaling/scaffolding protein in a human cancer stem cell disorder: Beckwith-Wiedemann syndrome. J. Biol. Chem. 285, 36112-36120. doi: 10.1074/jbc.M110. 162347

Conflict of Interest Statement: The authors declares that the research was conducted in the absence of any commercial or financial relationships that could be construed as a potential conflict of interest.

Copyright $\odot 2017$ El Refaey and Mohler. This is an open-access article distributed under the terms of the Creative Commons Attribution License (CC BY). The use, distribution or reproduction in other forums is permitted, provided the original author(s) or licensor are credited and that the original publication in this journal is cited, in accordance with accepted academic practice. No use, distribution or reproduction is permitted which does not comply with these terms. 
OPEN ACCESS

Edited by:

Hugues Abriel,

Universität Bern, Switzerland

Reviewed by:

Thomas Jespersen,

University of Copenhagen, Denmark Steve Poelzing,

Virginia Tech, United States

${ }^{*}$ Correspondence:

Lori L. Isom

lisom@umich.edu

Specialty section:

This article was submitted to

Cardiac Electrophysiology,

a section of the journal

Frontiers in Physiology

Received: 11 January 2018 Accepted: 20 March 2018 Published: 23 April 2018

Citation:

Edokobi N and Isom LL (2018) Voltage-Gated Sodium Channel $\beta 1 / \beta 1 B$ Subunits Regulate Cardiac Physiology and Pathophysiology.

Front. Physiol. 9:351.

doi: 10.3389/fphys.2018.00351

\section{Voltage-Gated Sodium Channel $\beta 1 / \beta 1 B$ Subunits Regulate Cardiac Physiology and Pathophysiology}

\author{
Nnamdi Edokobi and Lori L. Isom* \\ Department of Pharmacology, University of Michigan Medical School, Ann Arbor, MI, United States
}

Cardiac myocyte contraction is initiated by a set of intricately orchestrated electrical impulses, collectively known as action potentials (APs). Voltage-gated sodium channels (Navs) are responsible for the upstroke and propagation of APs in excitable cells, including cardiomyocytes. Navs consist of a single, pore-forming a subunit and two different $\beta$ subunits. The $\beta$ subunits are multifunctional cell adhesion molecules and channel modulators that have cell type and subcellular domain specific functional effects. Variants in $S C N 1 B$, the gene encoding the $\mathrm{Na}_{\mathrm{v}}-\beta 1$ and $-\beta 1 \mathrm{~B}$ subunits, are linked to atrial and ventricular arrhythmias, e.g., Brugada syndrome, as well as to the early infantile epileptic encephalopathy Dravet syndrome, all of which put patients at risk for sudden death. Evidence over the past two decades has demonstrated that $\mathrm{Na}_{v}-\beta 1 / \beta 1 \mathrm{~B}$ subunits play critical roles in cardiac myocyte physiology, in which they regulate tetrodotoxin-resistant and -sensitive sodium currents, potassium currents, and calcium handling, and that $\mathrm{Na}_{\mathrm{v}}-\beta 1 / \beta 1 \mathrm{~B}$ subunit dysfunction generates substrates for arrhythmias. This review will highlight the role of $\mathrm{Na}_{\mathrm{v}}-\beta 1 / \beta 1 \mathrm{~B}$ subunits in cardiac physiology and pathophysiology.

Keywords: sodium channel, B subunit, arrhythmia, epilepsy, cell adhesion, electrophysiology

\section{INTRODUCTION}

The heart contracts to pump blood throughout the body. It consists of specialized cells called cardiac myocytes (CMs), and contraction of $\mathrm{CMs}$ is initiated by electrical impulses called action potentials (APs) (Nerbonne and Kass, 2005). Cardiac APs are generated and propagated through the coordinated signaling of ion channels. Upon membrane depolarization, voltage-gated sodium channels ( $\mathrm{Na}_{\mathrm{V}} \mathrm{s}$ ) activate and inactivate rapidly to allow sodium influx (Hille and Catterall, 2012). This is responsible for the rising phase and propagation of the AP in mammalian CMs (Nerbonne and Kass, 2005). Navs are heterotrimeric transmembrane proteins consisting of one pore-forming $\alpha$ and two $\beta$ subunits (Catterall, 2000). $\mathrm{Na}_{V}-\beta$ subunits are expressed in mammalian heart (Isom et al., 1992; Makita et al., 1994) and their functional loss can result in electrical abnormalities that predispose patients to arrhythmias. Variants in the gene $S C N 1 B$, encoding the splice variants $\mathrm{Na}_{V}-\beta 1$ and $\mathrm{Na}_{V}-\beta 1 \mathrm{~B}$, are implicated in a variety of inherited pathologies including epileptic encephalopathy (O'Malley and Isom, 2015), Brugada syndrome (BrS) (Watanabe et al., 2008; Hu et al., 2012), long-QT syndrome (LQTS) (Riuró et al., 2014), atrial arrhythmias (Watanabe et al., 2009), and sudden infant death syndrome (SIDS) (Hu et al., 2012) (Figure 1, Table 1). Remarkably, regardless of disease etiology, patients with $S C N 1 B$ mutations have an increased risk of sudden death. Classically, the $\mathrm{Na}_{V}-\beta$ subunits were characterized as modulators of the $\mathrm{Na}_{V}$ ion-conducting pore. However, from research over the past two decades, we know that $\mathrm{Na}_{\mathrm{V}}-\beta$ subunits are dynamic, 


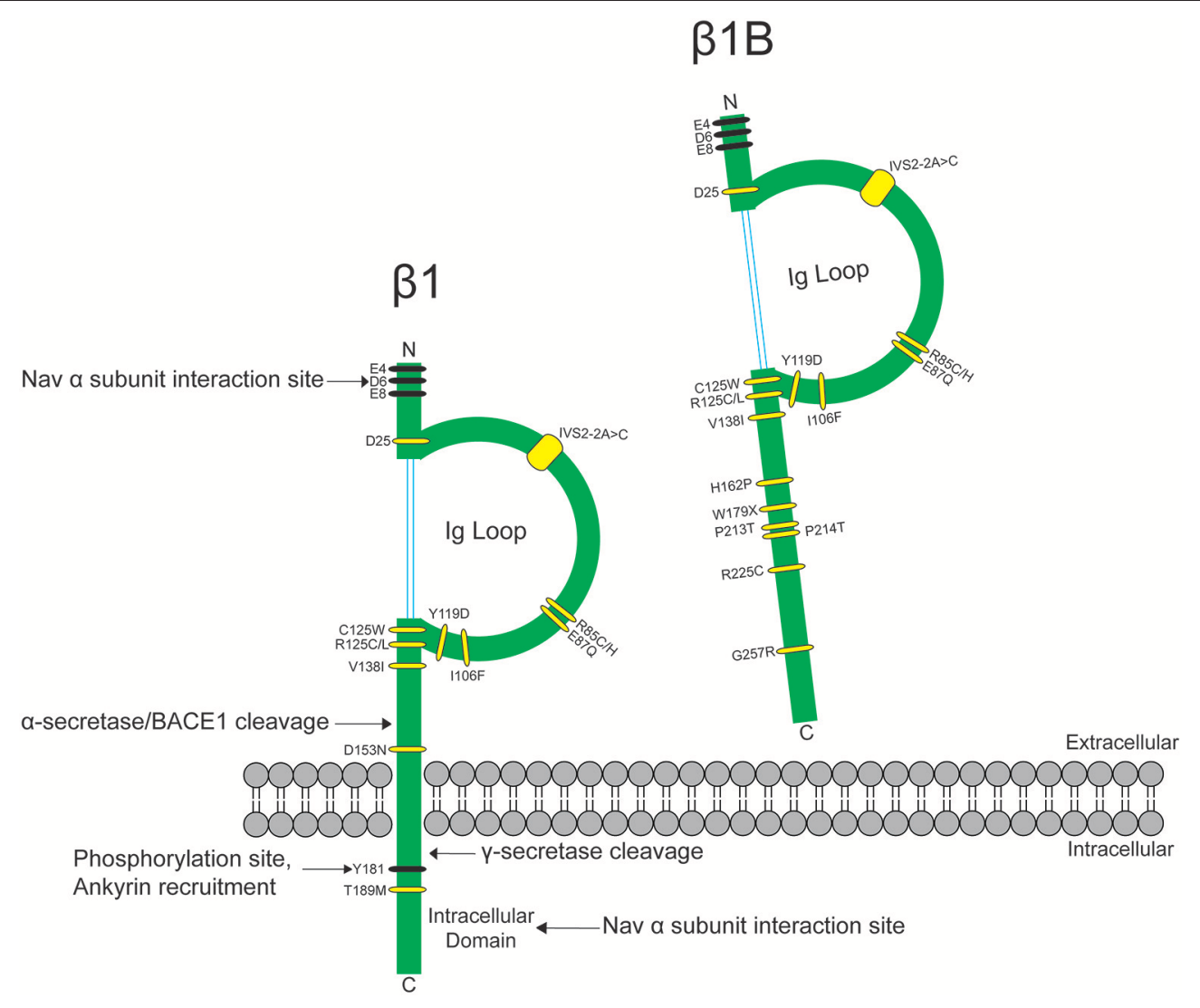

FIGURE 1 | SCN1B variants are linked to epilepsy syndromes and cardiac conduction diseases. SCN1B encodes $\mathrm{Nav}_{\mathrm{v}}-\beta 1$ (left) and its secreted splice variant $\mathrm{Na}-\beta 1 \mathrm{~B}$ (right). Sites for $\beta 1-\alpha$ interaction, ankyrin binding, phosphorylation, and proteolytic cleavage are indicated. Ig: immunoglobulin. Human disease variants in $\beta 1$ or $\beta 1 \mathrm{~B}$ are indicated in yellow and are described in Table 1. Adapted from O'Malley and Isom (2015).

multifunctional proteins that play important roles in cardiac physiology (O'Malley and Isom, 2015). Here, we will focus our review on the current understanding of $\mathrm{Na}_{V}-\beta 1 / \beta 1 \mathrm{~B}$ function in CMs and discuss disease implications.

\section{NAyS ARE DIFFERENTIALLY EXPRESSED IN CARDIAC MYOCYTES}

To understand $\mathrm{Na}_{\mathrm{v}}-\beta$ subunit physiology in heart, one must first consider the associated $\mathrm{Na}_{\mathrm{v}}-\alpha$ subunits. $\mathrm{Na}_{\mathrm{v}} 1.5$ is the predominantly expressed $\mathrm{Na}_{V}-\alpha$ in $\mathrm{CMs}$ and the primary contributor to recorded sodium current $\left(\mathrm{I}_{\mathrm{Na}}\right)$ density (Rogart et al., 1989; Gellens et al., 1992; Catterall, 2000; Maier et al., 2002). $\mathrm{Na}_{\mathrm{v}} 1.5$ is a "tetrodotoxin resistant (TTX-R)" channel (Catterall et al., 2005), in contrast to "TTX-sensitive (TTX-S)" channels, e.g., Navs normally found in brain, for which TTX has nanomolar affinity (Catterall et al., 2005). TTX has micromolar affinity for $\mathrm{Na}_{\mathrm{v}} 1.5$ due to the presence of a cysteine residue in the selectivity filter in a position that is otherwise filled by an aromatic amino acid in TTX-S channels (Satin et al., 1992). TTX-S channels, $\mathrm{Na}_{\mathrm{v}} 1.1, \mathrm{Na}_{\mathrm{v}} 1.3$, and $\mathrm{Na}_{\mathrm{v}} 1.6$, are expressed in heart as well as in brain (Malhotra et al., 2001; Lopez-Santiago et al., 2007). They are preferentially localized in the transverse tubules (T-tubules) (Malhotra et al., 2001, 2002; Lopez-Santiago et al., 2007) where they are postulated to function in excitationcontraction coupling (Maier et al., 2002) (Figure 2).

CMs associate at the intercalated disk (ID), where adherens junctions, gap junctions, and desmosomes participate in intercellular communication (Vermij et al., 2017) (Figure 3A). $\mathrm{Na}_{\mathrm{v}} 1.5$ channels cluster at cell-cell junction sites at the ID, where they co-localize with the cardiac gap junction (GJ) protein, connexin-43 (Cx43) (Maier et al., 2002, 2004) (Figure 3B). $\mathrm{Na}_{\mathrm{v}} 1.5$ clustering may contribute to rapid AP conduction from cell-to-cell, similar to the node-to-node saltatory conducting function of TTX-S Navs in myelinated nerves (Freeman et al., 2016). $\mathrm{Na}_{\mathrm{v}} 1.5$ channels are also expressed at the CM lateral membrane (Figure 2), where they have differing biophysical properties and binding partners from those at the ID (Lin et al., 2011; Petitprez et al., 2011; Shy et al., 2013), suggesting two distinct $\mathrm{Na}_{\mathrm{v}} 1.5$ pools.

\section{CARDIAC NAVS FORM MULTI-PROTEIN COMPLEXES}

$\mathrm{Na}_{V}-\alpha$ subunits interact with multi-protein complexes that are subcellular domain specific in heart. These interactions, 
TABLE 1 | SCN1B variants linked to human disease.

\begin{tabular}{|c|c|c|}
\hline Disease & $\beta 1$ & $\beta 1 B$ \\
\hline Atrial fibrillation & $\begin{array}{l}\text { R85H (Watanabe et al., 2009), D153N (Watanabe et al., } \\
\text { 2009) }\end{array}$ & R85H (Watanabe et al., 2009), D153N (Watanabe et al., 2009) \\
\hline Brugada syndrome & E87Q (Watanabe et al., 2008) & $\begin{array}{l}\text { E87Q (Watanabe et al., 2008), H162P (Holst et al., 2012), } \\
\text { W179X, R214Q (Holst et al., 2012; Hu et al., 2012) }\end{array}$ \\
\hline Dravet syndrome & $\begin{array}{l}\text { I106F (Ogiwara et al., 2012), Y119D (Ramadan et al., } \\
\text { 2017), C121W (Wallace et al., 1998), R125C (Patino et al., } \\
\text { 2009) }\end{array}$ & $\begin{array}{l}\text { I106F (Ogiwara et al., 2012), Y119D (Ramadan et al., } \\
\text { 2017),C121W (Wallace et al., 1998), R125C (Patino et al., } \\
\text { 2009) }\end{array}$ \\
\hline $\begin{array}{l}\text { Generalized Epilepsy with Febrile Seizures } \\
\text { Plus (GEFS+) }\end{array}$ & $\begin{array}{l}\text { D25N (Orrico et al., 2009), R85H (Scheffer et al., 2006), } \\
\text { R85C (Scheffer et al., 2006), R125L (Fendri-Kriaa et al., } \\
\text { 2011), five amino acid deletions (IVS2-2A>C) (Audenaert } \\
\text { et al., 2003) }\end{array}$ & $\begin{array}{l}\text { D25N (Orrico et al., 2009), R85H (Scheffer et al., 2006), R85C } \\
\text { (Scheffer et al., 2006), R125L (Fendri-Kriaa et al., 2011), five } \\
\text { amino acid deletions (IVS2-2A>C) (Audenaert et al., 2003) }\end{array}$ \\
\hline Idiopathic epilepsy & & G257R (Patino et al., 2011) \\
\hline Sudden Infant Death Syndrome (SIDS) & & R214Q (Hu et al., 2012), R225C (Neubauer et al., in press) \\
\hline $\begin{array}{l}\text { Sudden Unexpected Nocturnal Death } \\
\text { Syndrome (SUNDS) }\end{array}$ & V138I (Liu et al., 2014), T189M (Liu et al., 2014) & V138I (Liu et al., 2014) \\
\hline Long QT Syndrome (LQTS) & & P213T (Riuró et al., 2014) \\
\hline
\end{tabular}

which involve $\mathrm{Na}_{\mathrm{v}}-\beta 1$, as discussed throughout this review, are essential for proper cardiac electrical signaling (Figure 3C, Table 2). Ankyrin-G, a cytoskeletal adaptor protein, is necessary for normal expression of $\mathrm{Na}_{\mathrm{v}} 1.5$ and coupling of the channel to the actin cytoskeleton (Mohler et al., 2004). A human SCN5A $\mathrm{BrS}$ variant eliminates $\mathrm{Na}_{\mathrm{v}} 1.5$-ankyrin-G interactions (Mohler et al., 2004). This mutation, located in the $\mathrm{Na}_{\mathrm{v}} 1.5$ DII-III loop, prevents channel cell surface expression in ventricular CMs and alters channel properties. In agreement with this result, rat $\mathrm{CMs}$ with reduced expression of ankyrin-G have reduced levels of $\mathrm{Na}_{\mathrm{v}} 1.5$ expression and $\mathrm{I}_{\mathrm{Na}}$. Abnormal $\mathrm{Na}_{\mathrm{v}} 1.5$ localization can be rescued in ankyrin-G deficient CMs through exogenous over-expression of ankyrin-G (Lowe et al., 2008). Ankyrin$\mathrm{G}$ recruits $\beta \mathrm{IV}$ spectrin, which forms important scaffolding structures and plays a role in the maintenance and integrity of the plasma membrane and cytoskeleton (Yang et al., 2007). $\beta I V$ spectrin associates with and targets a subpopulation of $\mathrm{Ca}^{2+} /$ calmodulin-dependent protein kinase II (CaMKII $\delta$ ) to the ID to phosphorylate a critical serine residue in the $\mathrm{Na}_{\mathrm{v}} 1.5 \mathrm{I}-$ II linker (Hund et al., 2010; Makara et al., 2014). Mouse CMs expressing a mutant form of $\beta I V$ spectrin show a positive shift in $\mathrm{I}_{\mathrm{Na}}$ steady-state inactivation, elimination of late $\mathrm{I}_{\mathrm{Na}}$, shortened APD, and decreased QT intervals (Hund et al., 2010), confirming that formation of the $\mathrm{Na}_{\mathrm{v}} 1.5$-ankyrin-G signaling complex is critical for maintaining normal cardiac excitability.

Cytoskeletal integrity is a pre-requisite for normal electrical coupling. During cardiac development, GJ proteins and $\mathrm{Na}_{\mathrm{v}} 1.5$ appear at the ID after formation of adherens junctions (Vreeker et al., 2014). The perinexus, a newly identified region of the ID, is defined as the area surrounding the plaque of functional GJs (Rhett et al., 2013) (Figure 3B). Here, free connexons appear at the periphery of the GJ, after which they bind to zonula occludens1 (ZO-1). GJs form when ZO-1 free connexons from one cell associate with ZO-1 free connexons of a neighboring cell (Rhett et al., 2011). Disruption of Cx43/ZO-1 interactions increases GJ size (Hunter, 2005), and in a ZO-1 null model, GJ plaques are larger (Palatinus et al., 2010). Cx43 also interacts with $\mathrm{Na}_{\mathrm{v}} 1.5$ in the perinexus (Rhett et al., 2012). The presence of $\mathrm{Na}_{\mathrm{v}} 1.5$ at the perinexus may suggest that, in addition to GJ proteins, Navs may participate in coupling across the extracellular space, with increasing evidence supporting that both $\mathrm{Cx} 43$ and $\mathrm{Na}_{\mathrm{v}} 1.5$ are necessary for cell-to-cell transmission of APs (Gutstein et al., 2001; Lin et al., 2011; Jansen et al., 2012).

$\mathrm{Na}_{\mathrm{v}} 1.5$ contributes to at least two distinct multiprotein complexes in ventricular CMs, one at the lateral membrane containing dystrophin and syntrophin (Figure 2), and the other at the ID involving the membrane-associated guanylate kinase (MAGUK) protein adapter protein, synapse-associated protein 97 (SAP97), and ankyrin-G (Petitprez et al., 2011) (Figure 3C). In heterologous cells, surface expression of $\mathrm{Na}_{\mathrm{v}} 1.5$ is regulated by its interaction with SAP97 via a PDZdomain (post-synaptic density protein-PSD95, disc large tumor suppressor-Dlg1, zonula occludens1-ZO1). Either the truncation of the fourth domain of $\mathrm{Na}_{\mathrm{v}} 1.5$ (Shy et al., 2014) or depletion of SAP97 (Matsumoto et al., 2012) results in reduced channel cell surface expression, with a subsequent decrease of $\mathrm{I}_{\mathrm{Na}}$.

$\mathrm{Na}_{\mathrm{v}} 1.5$ also interacts with fibroblast growth factor homologous factor 1B (FHF1B) (Liu et al., 2003), calmodulin (Kim et al., 2004; Young and Caldwell, 2005), Nedd4like-ubiqutin-protein ligases (Van Bemmelen et al., 2004; Rougier et al., 2005), and is phosphorylated by Fyn (Ahern et al., 2005), a src family tyrosine kinase, all of which are involved in the regulation of channel subcellular localization and activity (Figure 3C). Taken together, these results accentuate the idea that cardiac $\mathrm{Na}_{V} s$ associate with protein complexes that are specific to subcellular domains, and these interactions are critical to cardiac physiology. Undoubtedly, changes in one component of a given complex results in significant consequences to overall cardiac excitability and synchrony. 


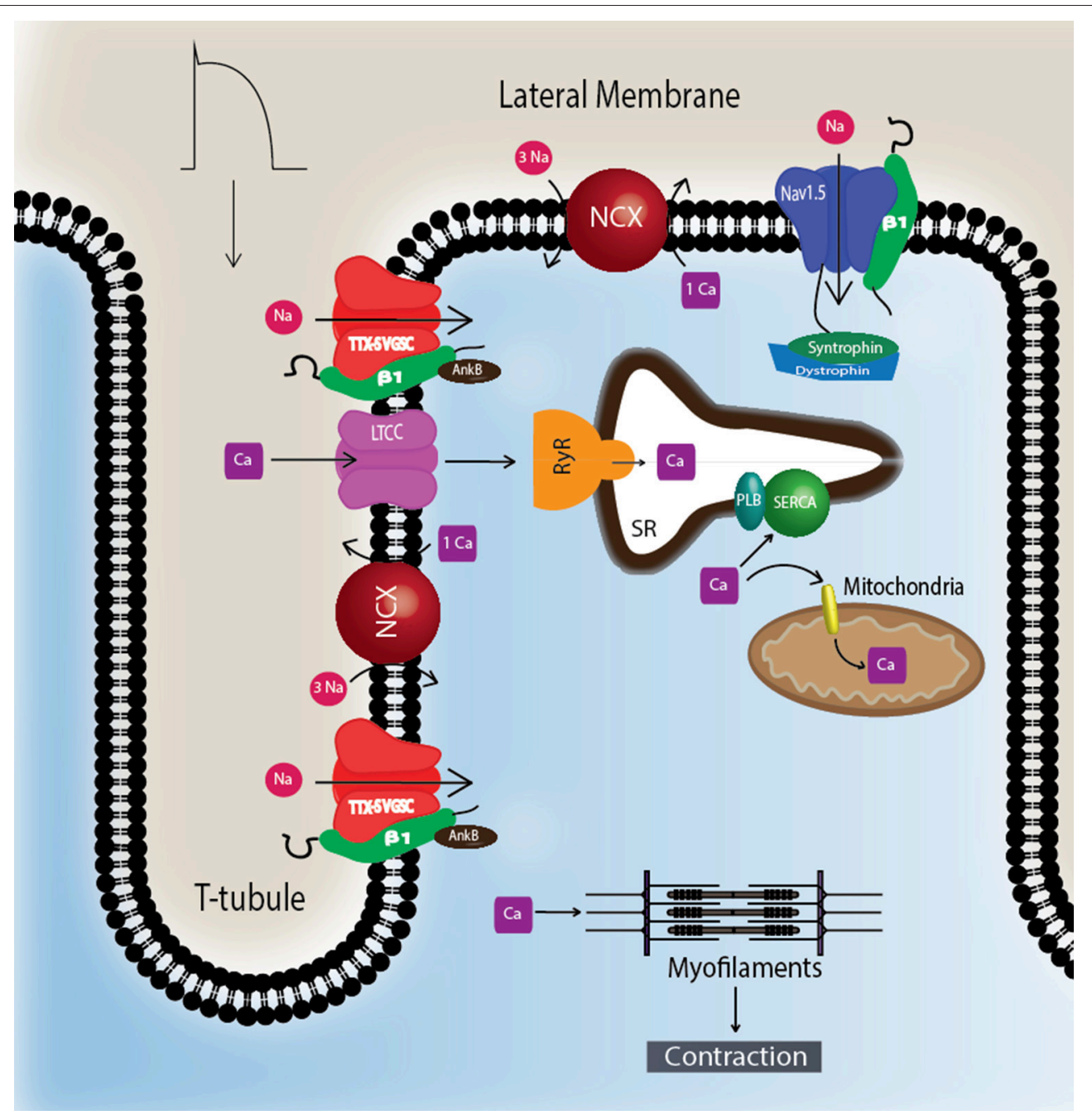

FIGURE 2 | TTX-S Navs are localized to T-tubules. TTX-S Navs, including $\mathrm{Na}_{v} 1.1, \mathrm{Na}_{\mathrm{v}} 1.3$, and $\mathrm{Na}_{\mathrm{v}} 1.6$, are located at the T-tubules of CMs where they are thought to participate in the regulation of excitation-contraction coupling. Non-phosphorylated $\mathrm{Na}_{V}-\beta 1$ subunits are co-localized with TTX-S Nav- $\alpha$ subunits at the T-tubules where they play roles in calcium signaling and homeostasis. Nav1.5 is localized at the lateral membrane as well as the ID (Figure 3). At the lateral membrane, Nav1.5 is complexed with syntrophin and dystrophin. Abbreviations: L-type calcium channel (LTCC), phospholamban (PLB), ryanodine receptor (RyR), sarcoplasmic reticulum $\mathrm{Ca}^{2+}$-ATPase (SERCA), sodium-calcium exchanger (NCX), transverse tubules (T-tubule).

\section{NA $v-\beta$ SUBUNITS MODULATE CARDIAC EXCITABILITY}

In mammalian genomes, five $\mathrm{Na}_{\mathrm{V}}-\beta$ subunits are encoded by four genes, SCN1B-SCN4B (O'Malley and Isom, 2015). Nav- $\beta 1$ $\beta 4$ are transmembrane proteins with type 1 topology consisting of an extracellular $\mathrm{N}$-terminus containing an immunoglobulin (Ig) domain, a transmembrane segment, and an intracellular C-terminus (Brackenbury and Isom, 2011) (Figure 1). Nav- $\beta 1 B$, a splice variant of $S C N 1 B$, contains the $\mathrm{Na}_{\mathrm{V}}-\beta 1 \mathrm{~N}$-terminal and Ig domains, but lacks a transmembrane domain (Kazen-Gillespie et al., 2000), resulting in a secreted protein (Patino et al., 2011) (Figure 1). $\mathrm{Na}_{\mathrm{V}}-\beta$ subunits can interact both covalently and noncovalently with $\mathrm{Na}_{V}-\alpha$ subunits: $\mathrm{Na}_{V}-\beta 1$ and $-\beta 3$ interact noncovalently with $\mathrm{Na}_{\mathrm{V}}-\alpha$ via their $\mathrm{N}$ - and C-termini (McCormick et al., 1998; Meadows et al., 2001), while $\mathrm{Na}_{V}-\beta 2$ and $-\beta 4$ interact covalently with $\mathrm{Na}_{V}-\alpha$ via a single $\mathrm{N}$-terminal cysteine located in the extracellular Ig loop (Chen et al., 2012; Gilchrist et al., 2013).

Canonically, $\mathrm{Na}_{V}-\beta \mathrm{s}$ are known as modulators of $\mathrm{Na}_{V}$ electrophysiological properties and cell surface expression (Brackenbury and Isom, 2011). Heterologous expression systems and mouse models have shown that $\mathrm{Na}_{V}-\beta$ s modulate $\mathrm{Na}_{V}-$ $\alpha$ in cell type specific manners, thus the $\mathrm{Na}_{V} \alpha / \beta$ subunit composition of a given cell confers unique biophysical properties that can be finely tuned (Calhoun and Isom, 2014). Not surprisingly, $\mathrm{Na}_{\mathrm{V}}-\beta 1$ modulation of $\mathrm{Na}_{\mathrm{v}} 1.5$ varies depending on the system studied. In Xenopus oocytes, the amplitude of $\mathrm{Na}_{\mathrm{V}} 1.5$ expressed $\mathrm{I}_{\mathrm{Na}}$ increases with increasing amounts of $\beta 1$ mRNA (Qu et al., 1995). Antisense-mediated post-transcriptional silencing of Scn $1 b$ in H9C2, a CM line, alters TTX-S and TTX-R 


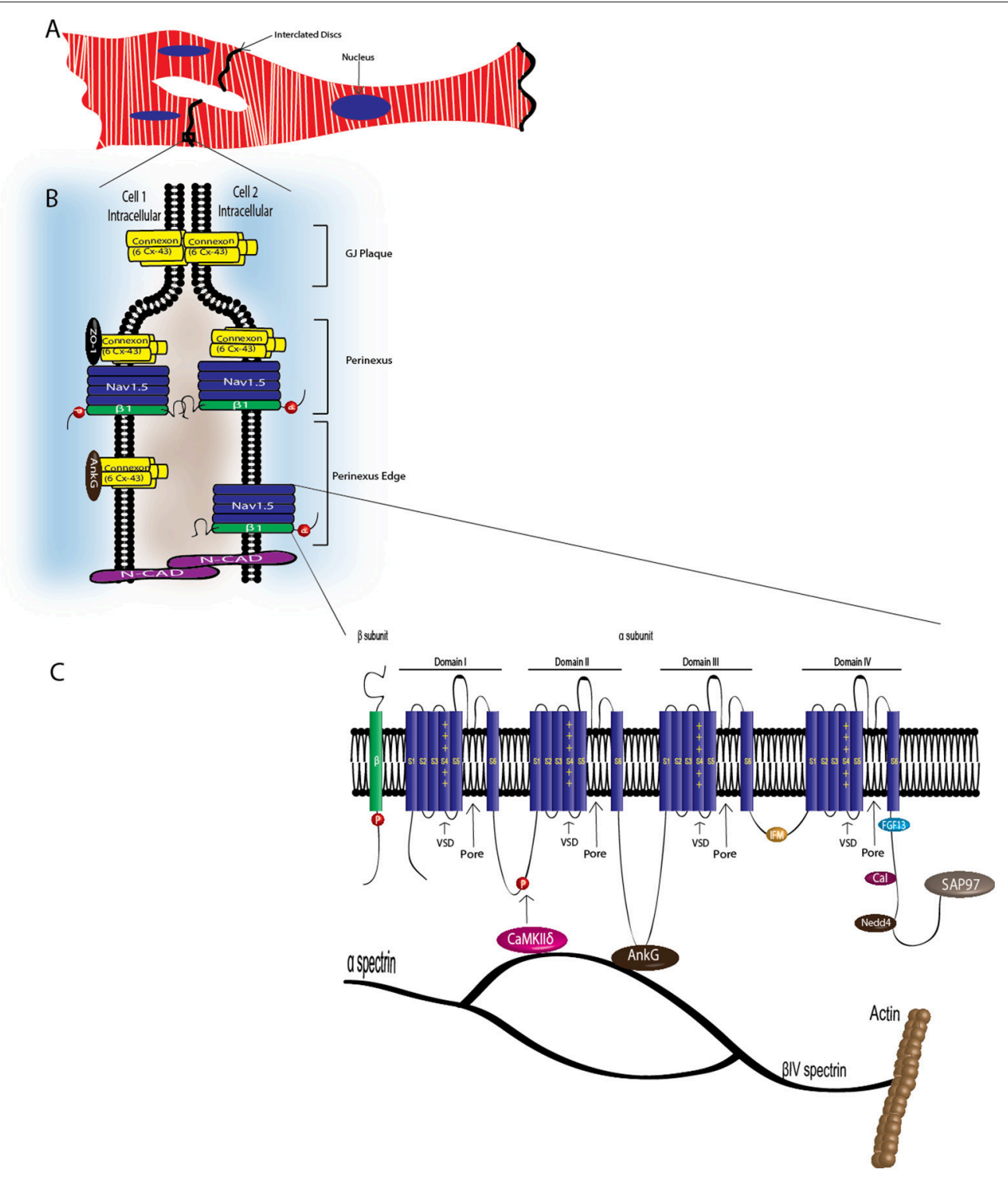

FIGURE 3 | VGSC complexes at the cardiac intercalated disk. CMs associate at the ID, where Nav 1.5 , Nav- $\beta 1$ subunits, adherens junctions, gap junctions, and desmosomes define intercellular communication. (A) Associated CMs. (B) Proposed model of the GJ plaque, perinexus, and perinexus edge. Nav- $\beta 1$ subunits at the ID are tyrosine phosphorylated, possibly through Fyn kinase activation, and may function in cell-cell adhesion in the perinexus and perinexus edge. (C) At the ID, Nav1.5 associates with a multi-protein complex (also see Table 2). The S4 segment of each Nav- $\alpha$ subunit homologous domain forms the voltage sensing domain (VSD) and segments 5 and 6 in each domain create the ion-conducting pore. Three hydrophobic amino acids, IFM, form the inactivation gate. Abbreviations: Ankyrin-G (AnkG), Calmodulin (Cal), Ca ${ }^{2+} /$ calmodulin-dependent protein kinase II (CaMKIII), Fibroblast growth factor homologous factor 1B (FHF1B), N-Cadherin (N-Cad), Nedd4-like-ubiqutin-protein ligases (Nedd4), Synapse-associated protein 97 (SAP97).

$\mathrm{Na}_{\mathrm{v}}-\alpha$ mRNA and protein expression, resulting in decreased $\mathrm{I}_{\mathrm{Na}}$ (Baroni et al., 2014). In contrast, Scn1b null mouse CMs have increased expression of $\operatorname{Scn} 3 a$ and $\operatorname{Scn} 5 a$, along with increased TTX-S and TTX-R I $\mathrm{I}_{\mathrm{Na}}$ (Lopez-Santiago et al., 2007). In heterologous cells, $\mathrm{Na}_{\mathrm{V}}-\beta 1$ expression results in slight changes in $\mathrm{Na}_{\mathrm{v}} 1.5 \mathrm{I}_{\mathrm{Na}}$, but significant effects on voltage-dependence and channel kinetics. In Tsa201 cells transfected with $\mathrm{Na}_{\mathrm{v}} 1.5$, coexpression of $\mathrm{Na}_{\mathrm{V}}-\beta 1$ positively shifts the voltage-dependence of inactivation (Malhotra et al., 2001). Co-expression of $\mathrm{Na}_{V}-\beta 1$ with $\mathrm{Na}_{\mathrm{v}} 1.5$ in Xenopus oocytes causes a depolarizing shift in steady-state inactivation compared with WT alone (Zhu et al., 2017), suggesting that $\beta 1$ may allow the $\alpha$ subunit voltagesensing domains to recover more rapidly to the resting state. Thus, $\mathrm{Na}_{v}-\beta 1$ may initiate fine-tuned acute and chronic feedback mechanisms that differentially control expression and function of $\mathrm{Na}_{V}-\alpha$ in the heart.

$\mathrm{Na}_{\mathrm{v}}-\beta 1 \mathrm{~B}$ is expressed in fetal brain and in heart at all developmental time points. When expressed alone or in the 
TABLE 2 | Nav1.5 ID interacting proteins.

\begin{tabular}{|c|c|c|}
\hline Interacting protein & Effects on $\mathrm{Na}_{\mathrm{V}} 1.5$ & Reference(s) \\
\hline Ankyrin-G (AnkG) & $\begin{array}{l}\text { Proper expression at plasma membrane and coupling to actin } \\
\text { cytoskeleton }\end{array}$ & Mohler et al., 2004 \\
\hline Calmodulin (Cal) & Regulates biophysical properties & $\begin{array}{l}\text { Tan et al., 2002; Kim et al., 2004; Young and Caldwell, 2005; } \\
\text { Gabelli et al., } 2014\end{array}$ \\
\hline $\begin{array}{l}\mathrm{Ca}^{2+} / \text { calmodulin-dependent } \\
\text { protein kinase II (CaMKII } \delta)\end{array}$ & Phosphorylation and modulates excitability & Hund et al., 2010; Makara et al., 2014 \\
\hline $\begin{array}{l}\text { Fibroblast growth factor } \\
\text { homologous factor 1B (FHF1B) }\end{array}$ & Modulate channel gating & Liu et al., 2003 \\
\hline $\begin{array}{l}\text { Nedd4-like-ubiqutin-protein } \\
\text { ligases (Nedd4) }\end{array}$ & $\begin{array}{l}\text { Ubiquitination and regulated internalization. Possible } \\
\text { mechanism in modulation of channel density at the plasma } \\
\text { membrane }\end{array}$ & Van Bemmelen et al., 2004; Rougier et al., 2005 \\
\hline $\begin{array}{l}\text { Synapse-associated protein } 97 \\
\text { (SAP97) }\end{array}$ & Stability and anchoring to the cell membrane & Petitprez et al., 2011; Matsumoto et al., 2012 \\
\hline
\end{tabular}

presence of TTX-S $\mathrm{Na}_{\mathrm{V}}-\alpha$ s in a heterologous expression system, $\mathrm{Na}_{\mathrm{v}}-\beta 1 \mathrm{~B}$ is secreted (Patino et al., 2011). Secreted $\mathrm{Na}_{\mathrm{v}}-\beta 1 \mathrm{~B}$ functions as a CAM ligand to promote signal transduction in cultured neurons (Patino et al., 2011). In contrast, $\mathrm{Na}_{V}$ $\beta 1 \mathrm{~B}$ is retained at the cell surface when co-expressed with $\mathrm{Na}_{\mathrm{v}} 1.5$ (Patino et al., 2011) and $\mathrm{Na}_{\mathrm{v}}-\beta 1 \mathrm{~B}$ co-expression increases $\mathrm{I}_{\mathrm{Na}}$ density compared to $\mathrm{Na}_{\mathrm{V}} 1.5$ alone (Watanabe et al., 2008). The disease variant, $\beta 1 B-G 257 R$ (Figure 1, Table 1), causes $\mathrm{Na}_{\mathrm{V}}-\beta 1 \mathrm{~B}$ to be retained inside the cell, resulting in a functional null phenotype (Patino et al., 2011). The variant, $\beta 1 \mathrm{~B}-\mathrm{W} 179 \mathrm{X}$ (Figure 1, Table 1), fails to increase $\mathrm{Na}_{\mathrm{v}} 1.5 \mathrm{I}_{\mathrm{Na}}$ density, suggesting that it may also be a functional null mutation (Watanabe et al., 2008). A number of $\mathrm{Na}_{\mathrm{v}}-\beta 1 \mathrm{~B}$ variants have now been linked to cardiac arrhythmias (Figure 1, Table 1), thus this subunit is critical to cardiac physiology.

While the $\mathrm{Na}_{\mathrm{v}}-\alpha$ s are known to form and function as monomers, recent evidence suggests that they can also form dimers, and that dimerization is mediated through an interaction site within the first intracellular loop (Clatot et al., 2017). $\mathrm{Na}_{\mathrm{V}}-\alpha$ dimers display coupled gating properties, which are mediated through the action of 14-3-3 proteins (Clatot et al., 2017). The 14-3-3 family of proteins is important for the regulation of cardiac $\mathrm{I}_{\mathrm{Na}}$, and disrupted 14-3-3 expression may exert pro-arrhythmic effects on cardiac electrical properties (Allouis et al., 2006; Sreedhar et al., 2016). The functional importance of cardiac $\mathrm{Na}_{V}-\alpha$ dimerization may be to target and enhance the density of channels at specific subcellular domains. $\mathrm{Na}_{\mathrm{v}} 1.5-\mathrm{R} 1432 \mathrm{G}$, a surface localization defective SCN5A mutant, displays a dominant negative effect on WT $\mathrm{Na}_{\mathrm{V}} 1.5$, but only in the presence of $\mathrm{Na}_{\mathrm{V}}-\beta 1$ (Mercier et al., 2012). Thus, $\mathrm{Na}_{\mathrm{V}}-\beta 1$ may normally mediate physical interactions between $\mathrm{Na}_{\mathrm{v}} 1.5$ dimers, however further research must be performed.

\section{NA $-\beta S$ DO MORE THAN MODULATE INA}

$\mathrm{Na}_{V}-\beta$ subunits are multifunctional (O’Malley and Isom, 2015). In addition to modulating channel gating and cell surface expression/localization, $\mathrm{Na}_{V}-\beta s$ are Ig superfamily cell adhesion molecules (CAMs) that facilitate cell-cell communication and initiate intracellular signaling cascades. $\mathrm{Na}_{V}-\beta 1$ and $-\beta 2$ participate in trans-homophilic cell adhesion, resulting in the recruitment of ankyrin-G to the plasma membrane at sites of cell-cell contact (Malhotra et al., 2000). Importantly, this occurs both in the presence and absence of $\mathrm{Na}_{\mathrm{V}}-\alpha$, at least in vitro. $\mathrm{Na}_{\mathrm{V}}-\beta 1$ and $-\beta 2$ also participate in cell-matrix adhesion, binding tenascin- $\mathrm{R}$ and tenascin- $\mathrm{C}$ to modulate cell migration (Srinivasan et al., 1998; Xiao et al., 1999). The $\mathrm{Na}_{V}-\beta 3$ amino acid sequence is most similar to $\mathrm{Na}_{V}-\beta 1$ compared to the other $\mathrm{Na}_{\mathrm{V}}-\beta$ subunits (Morgan et al., 2000). While $\mathrm{Na}_{\mathrm{V}}-\beta 3$ does not function as a CAM when expressed in Drosophila S2 cells, as shown for $\mathrm{Na}_{V}-\beta 1$ and $-\beta 2$ (Chen et al., 2012), it does so in mammalian cells where trans homophilic adhesion was shown to require an intact Cys2-Cys24 disulfide bond (Yereddi et al., 2013).

$\mathrm{Na}_{V}-\beta$ function, localization, and expression are regulated by multiple post-translational modifications including phosphorylation, glycosylation, and proteolytic cleavage (Calhoun and Isom, 2014). All $\mathrm{Na}_{V}-\beta$ s have highly glycosylated $\mathrm{N}$-terminal domains, containing 3 to $4 \mathrm{~N}$-linked glycosylation sites each (Isom et al., 1992; McCormick et al., 1998; Johnson et al., 2004), and these modifications contribute to cell surface expression and channel modulation (Johnson et al., 2004). Lastly, $\mathrm{Na}_{\mathrm{V}}-\beta \mathrm{s}$ are targets for sequential proteolytic cleavage by $\alpha$-secretase/BACE1 and $\gamma$-secretase, resulting in the release of $\mathrm{N}$-terminal and C-terminal domains (Wong et al., 2005). These cleavage products may have important physiological effects on transcriptional regulation of $\mathrm{Na}_{\mathrm{V}}-\alpha$ subunit genes. For example, $\gamma$-secretase cleavage of $\mathrm{Na}_{\mathrm{V}}-\beta 2$ in neurons in vitro leads to translocation of the intracellular domain to the nucleus, where it increases $S C N 1 A$ mRNA expression and $\mathrm{Na}_{\mathrm{v}} 1.1$ protein (Kim et al., 2007).

Of the five $\mathrm{Na}_{\mathrm{v}}-\beta$ subunits, $\mathrm{Na}_{\mathrm{v}}-\beta 1$ has been the most studied in terms of its CAM function. In the heart, $\mathrm{Na}_{V}-\beta 1$ ID localization suggests a role in cardiac cell-cell contact. Scn $1 b$ and $\operatorname{Scn} 5 a$ have overlapping temporal and spatial expression profiles during heart development (Domínguez et al., 2005). In ventricular CMs, $\mathrm{Na}_{V}-\beta 1$ is co-localized at the ID (Kaufmann 
et al., 2010) with $\mathrm{Na}_{\mathrm{v}} 1.5$ (Maier et al., 2004), as well as at the T-tubules with TTX-S channels (Malhotra et al., 2001; Lopez-Santiago et al., 2007). Recent evidence suggests that $\mathrm{Na}_{V}-\beta 1$-mediated cell-cell adhesion may occur at the perinexal membrane, and this putative interaction can be acutely inhibited by $\beta$ adp1, a novel peptide mimetic of the $\mathrm{Nav}-\beta 1$ CAM domain (Veeraraghavan et al., 2016). Dose-dependent administration of $\beta$ adp 1 decreased cellular adhesion in $\mathrm{Na}_{\mathrm{V}}-\beta 1$-overexpressing fibroblasts. 75\% of $\beta$ adp1-treated hearts exhibited spontaneous ventricular tachycardias, revealing preferential slowing of transverse conduction. These data support a role for trans $\mathrm{Na}_{\mathrm{V}}$ $\beta 1$-mediated cell-cell adhesion at the perinexal membrane and suggest a role for adhesion in conduction (Figure 3B). Because a large proportion of $S C N 1 B$ disease variants affect the Ig domain (Figure 1), it is likely that disruption of $\mathrm{NaV}_{\mathrm{V}}-\beta 1$-mediated cellcell adhesion contributes to disease mechanisms and, if so, that restoring adhesion may be a future therapeutic target.

The $\mathrm{Na}_{V}-\beta 1$ intracellular domain can be phosphorylated at tyrosine (Y) residue 181 (Malhotra et al., 2002, 2004; McEwen et al., 2004), possibly through activation of Fyn kinase (Brackenbury et al., 2008; Nelson et al., 2014) (Figure 1). $\beta 1 \mathrm{Y} 181 \mathrm{E}$, a phosphomimetic, participates in cell adhesion but does not interact with ankyrin or modulate $\mathrm{I}_{\mathrm{Na}}$, suggesting that Y181 is an important regulatory point for cytoskeletal association and channel modulation (Malhotra et al., 2002). In CMs, tyrosine-phosphorylated $\mathrm{Na}_{\mathrm{V}}-\beta 1$ and non-phosphorylated $\mathrm{Na}_{\mathrm{V}}-\beta 1$ are differentially localized to subcellular domains where they interact with specific cytoskeletal and signaling proteins (Malhotra et al., 2004). At the T-tubules, non-phosphorylated $\mathrm{Na}_{V}-\beta 1$ interacts with TTX-S Navs and ankyrin-B (Figure 2) (Malhotra et al., 2004). In contrast, tyrosine-phosphorylated $\mathrm{Na}_{\mathrm{V}}-\beta 1$ is localized to the ID where it interacts with $\mathrm{Na}_{\mathrm{V}} 1.5$ and N-cadherin (Figures 3B,C) (Malhotra et al., 2004). We do not yet know whether phosphorylation targets $\mathrm{Na}_{V}$ $\beta 1$ to specialized subcellular regions or whether $\mathrm{Na}_{\mathrm{V}}-\beta 1$ is differentially phosphorylated upon arrival. Phosphorylation may be a signaling mechanism by which cells regulate the density and localization of $\mathrm{Na}_{\mathrm{V}}-\beta 1$, and by association $\mathrm{Na}_{\mathrm{v}}-\alpha$ s, to specific subcellular domains. In summary, $\mathrm{Na}_{V}-\beta 1$ subunits serve as critical links between the extracellular and intracellular signaling environments of cells through ion channel modulation as well as cell-cell adhesion.

\section{NA $-\beta 1$ MODULATES POTASSIUM CHANNELS}

$\mathrm{Na}_{V}-\beta 1$ can interact with and modulate voltage-gated potassium channels $\left(K_{\mathrm{V}} \mathrm{s}\right)$ in addition to Navs. $\mathrm{K}_{\mathrm{v}}-\alpha$ subunits assemble as tetramers that normally associate with modulatory $\mathrm{Kv}-\beta$ subunits (Snyders, 1999). The $K_{v} 4 . x$ subfamily of channels express rapidly activating, inactivating, and recovering cardiac transient outward currents ( $\mathrm{I}_{\mathrm{to}}$ ) (Snyders, 1999). Co-expression of $\mathrm{NaV}-\beta 1$ with $\mathrm{K}_{\mathrm{v}} 4.3$ results in a $\sim$ four-fold increase in $\mathrm{I}_{\text {to }}$ density (Deschênes and Tomaselli, 2002). Additionally, $\mathrm{Na}_{\mathrm{V}}-\beta 1$ alters the voltagedependence and kinetics of channel gating compared to $\mathrm{K}_{\mathrm{v}} 4.3$ expressed alone (Deschênes and Tomaselli, 2002). Importantly,
$\mathrm{Na}_{\mathrm{V}}-\beta 1$ associates with $\mathrm{K}_{\mathrm{v}} 4.2$ and enhances its surface expression (Marionneau et al., 2012). Whole-cell voltage-clamp recordings obtained from cells expressing $\mathrm{K}_{\mathrm{v}} 4.2$ with $\mathrm{Na}_{\mathrm{V}}-\beta 1$ resulted in higher $\mathrm{I}_{\text {to }}$ densities compared to $\mathrm{K}_{\mathrm{v}} 4.2$ alone (Marionneau et al., 2012). $\mathrm{Na}_{\mathrm{V}}-\beta 1$ can also interact with and modulate $\mathrm{K}_{\mathrm{V}} 1\left(\mathrm{~K}_{\mathrm{V}} 1.1\right.$, $\mathrm{K}_{\mathrm{v}} 1.2, \mathrm{~K}_{\mathrm{v}} 1.3$, or $\left.\mathrm{K}_{\mathrm{v}} 1.6\right)$ and $\mathrm{K}_{\mathrm{v}} 7\left(\mathrm{~K}_{\mathrm{v}} 7.2\right)$ channels (Nguyen et al., 2012). Lastly, $\mathrm{Na}_{\mathrm{V}}-\beta 1 \mathrm{~B}$ can also associate with $\mathrm{K}_{\mathrm{v}} 4.3$, resulting in increased $\mathrm{I}_{\text {to }}\left(\mathrm{Hu}\right.$ et al., 2012). Thus, $\mathrm{K}_{\mathrm{v}}$ currents can be modulated by $\mathrm{Na}_{\mathrm{V}}-\beta$ subunits, at least in heterologous expression systems. Transfection of neonatal rat ventricular myocytes with siRNA targeting $\mathrm{Na}_{V}-\beta 1$ significantly reduced the expression of $\mathrm{K}_{\mathrm{v}} 4$.x protein and reduced both $\mathrm{I}_{\mathrm{Na}}$ and $\mathrm{I}_{\text {to }}$ (Deschênes et al., 2008), suggesting that $\mathrm{Na}_{\mathrm{V}}-\beta 1$ can modulate $\mathrm{K}_{\mathrm{v}}$ currents in the heart in vivo.

The inward rectifier current $\mathrm{I}_{\mathrm{K} 1}$, expressed by Kir2.1, is critical for setting the resting membrane potential and modulating the late-phase of repolarization and AP duration in CMs (Nerbonne and Kass, 2005). Similar to $\mathrm{Na}_{\mathrm{v}} 1.5$, Kir2.x channels contain a C-terminal PDZ-binding domain which mediates interaction with SAP97 and syntrophin (Matamoros et al., 2016). It is thought that Kir2.x channels associate in microdomains that include caveolin $3, \mathrm{Na}_{\mathrm{v}} 1.5$, SAP97, and syntrophin (Vaidyanathan et al., 2013). $\mathrm{Na}_{\mathrm{v}} 1.5$ interacts with $\alpha 1$ syntrophin via an internal N-terminal PDZ-like binding domain in addition to the C-terminal PDZ-binding domains (Matamoros et al., 2016). Importantly, $\mathrm{Na}_{\mathrm{v}} 1.5-\beta 1$ co-expression increases Kir2.1 and Kir2.2, but not Kir2.3, currents, again suggesting that these channels are functionally linked and that $\mathrm{Na}_{\mathrm{v}}-\beta 1$ is critical to the formation of multi-ion channel complexes.

\section{IN VIVO ROLES OF SCN1B}

Animal models have been instrumental in understanding the role of $S c n 1 b$ in cardiac excitability. Scn $1 b$ deletion in mice results in severe seizures, ventricular arrhythmias, and sudden death prior to weaning (Chen, 2004). Scn1b null ventricular CMs exhibit prolonged AP repolarization, increased $\operatorname{Scn} 5 a / \mathrm{Na}_{\mathrm{v}} 1.5$ gene and protein expression, increased $\operatorname{Scn} 3 a$ expression, increased transient and persistent $\mathrm{I}_{\mathrm{Na}}$ density, and prolonged QT and RR intervals (Lopez-Santiago et al., 2007). In agreement with an adhesive role for $\beta 1$, cytoskeletal disruption in CMs also results in increased persistent $\mathrm{I}_{\mathrm{Na}}$ (Undrovinas et al., 1995). Consistent with this, ventricular CMs isolated from cardiac-specific Scn $1 b$ null mice have increased $\mathrm{I}_{\mathrm{Na}}$ density, increased susceptibility to polymorphic ventricular arrhythmias, and altered intracellular calcium handling that is TTX-S (Lin et al., 2015). These data indicate that loss of $S c n 1 b$ expression is arrhythmogenic, mediated by altered ion channel gene and protein expression, $\mathrm{I}_{\mathrm{Na}}, \mathrm{I}_{\mathrm{K}}$, and calcium handling. Cardiac specific Scn1b deletion increases the duration of calcium signaling, resulting in delayed afterdepolarizations (Lin et al., 2015). It will be interesting to determine if expression of disease-associated $S C N 1 B$ variants leads to dysfunctional ryanodine receptor signaling, which can also result in altered levels of intracellular calcium and the generation of arrhythmias (Bers, 2008; Fearnley et al., 2011; Glasscock, 2014). 
The cardiac AP relies on the orchestration of multiple ion channels in concert. $\mathrm{Na}_{\mathrm{V}}-\beta 1$ is an important modulator of $\mathrm{Na}_{\mathrm{V}^{-}}$ $\alpha$ as well as some $\mathrm{K}_{V^{-}}$and Kir- $\alpha$ subunits. $\mathrm{Na}_{\mathrm{V}}$ and $\mathrm{K}$ channels may be functionally linked through $\mathrm{Na}_{\mathrm{V}}-\beta 1 / \beta 1 \mathrm{~B}$, and if so, defects in this mechanism may contribute to cardiac disease. It will be critical to determine the physiological effects of $\mathrm{Na}_{V}-\beta 1$ interaction with other $\mathrm{K}$ channels, calcium channels, or other calcium-handling proteins at the T-tubules. It is intriguing to consider that $\mathrm{Na}_{\mathrm{V}}-\beta 1$ may serve as a central communication hub between sodium, potassium, and calcium channel families to coordinate depolarization, repolarization, and calcium signaling in CMs.

\section{SCN1B AND HUMAN DISEASE}

SCN1B variants are implicated in a variety of inherited pathologies, including epileptic encephalopathy and cardiac arrhythmias (O’Malley and Isom, 2015) (Figure 1, Table 1). The epileptic encephalopathy Dravet syndrome is linked to heterozygous variants in SCN1A leading to haploinsufficiency in most patients, however, a subset of patients has SCN1B homozygous loss-of-function variants (Patino et al., 2009). The leading cause of mortality in Dravet syndrome is Sudden Unexpected Death in Epilepsy (SUDEP) (Nobili et al., 2011; Kalume, 2013; Devinsky et al., 2016). SCN1B variants are also linked to inherited cardiac arrhythmia syndromes that increase the risk of sudden death, including $\mathrm{BrS}$ ( $\mathrm{Hu}$ et al., 2012), LQTS (Riuró et al., 2014), atrial arrhythmias (Watanabe et al., 2009), and SIDS (Hu et al., 2012). Diagnostic overlap between epilepsy and cardiac conduction disease can confound causative links between the two phenotypes (Ravindran et al., 2016). Cardiac conduction abnormalities can be poorly recognized in patients with epilepsy and vice versa (Zaidi et al., 2000). A retrospective electrocardiography study revealed that abnormal ventricular conduction was more common in SUDEP cases than in epileptic controls (Chyou et al., 2016). We propose that

\section{REFERENCES}

Ahern, C. A., Zhang, J. F., Wookalis, M. J., and Horn, R. (2005). Modulation of the cardiac sodium channel Nav1.5 by Fyn, a Src family tyrosine kinase. Circ. Res. 96, 991-998. doi: 10.1161/01.RES.0000166324.00524.dd

Allouis, M., Le Bouffant, F., Wilders, R., Péroz, D., Schott, J. J., Noireaud, J., et al. (2006). 14-3-3 Is a regulator of the cardiac voltage-gated sodium channel Nav1.5. Circ. Res. 98, 1538-1546. doi: 10.1161/01.RES.0000229244.97497.2c

Audenaert, D., Claes, L., Ceulemans, B., Löfgren, a, Van Broeckhoven, C., and De Jonghe, P. (2003). A deletion in SCN1B is associated with febrile seizures and early-onset absence epilepsy. Neurology 61, 854-856. doi: 10.1212/01.WNL.0000080362.55784.1C

Baroni, D., Picco, C., Barbieri, R., and Moran, O. (2014). Antisense-mediated posttranscriptional silencing of $\mathrm{SCN} 1 \mathrm{~B}$ gene modulates sodium channel functional expression. Biol. Cell 106, 13-29. doi: 10.1111/boc.201300040

Bers, D. M. (2008). Calcium cycling and signaling in cardiac myocytes. Annu. Rev. Physiol. 70, 23-49. doi: 10.1146/annurev.physiol.70.113006.100455

Brackenbury, W. J., Davis, T. H., Chen, C., Slat, E., Detrow, M. J., Dickendesher, T. L., et al. (2008). Voltage-gated $\mathrm{Na}+$ channel betal subunit-mediated neurite outgrowth requires Fyn kinase and contributes to postnatal CNS development in vivo. J. Neurosci. 28, 3246-3256. doi: 10.1523/JNEUROSCI.5446-07.2008 variants in $S C N 1 B$, including those linked to epilepsy, predispose patients to compromised cardiac electrical abnormalities. Thus, cardiovascular evaluation may be helpful in treating epileptic encephalopathy patients.

\section{SUMMARY}

$\mathrm{Na}-\beta 1$ and $-\beta 1 \mathrm{~B}$ are multifunctional molecules that associate with $\mathrm{Na}_{\mathrm{v}}$ and $\mathrm{K}$ channels, cytoskeletal proteins, CAMs, and extracellular matrix molecules in the heart and brain. In addition, $\mathrm{Na}_{V}-\beta 1 / \beta 1 \mathrm{~B}$ modulate multiple ionic currents, channel expression levels, and channel subcellular localization. Thus, it is not surprising that variants in $S C N 1 B$ are linked to devastating cardiac and neurological diseases with a high risk of sudden death. In the field of cardiac physiology, important questions remain regarding specific cardiac $\mathrm{Na}_{\mathrm{V}}-\beta 1$ binding partners, potential effects of $\mathrm{Na}_{\mathrm{V}}-\beta 1$ on calcium-handling, the potential role of $\mathrm{Na}_{\mathrm{V}}-\beta 1$ in $\mathrm{Na}_{\mathrm{V}} 1.5$ dimerization, and the mechanism of phosphorylation events that affect $\mathrm{Na}_{\mathrm{V}}-\beta 1$ targeting to and association with subcellular domain specific signaling complexes at the ID, lateral membrane, and T-tubules. Understanding the functions of $\mathrm{Na}_{\mathrm{V}}-\beta 1$ within these protein complexes will help to elucidate underlying mechanisms of cardiac arrhythmias and associated sudden death, as well as lead to the discovery of novel biomarkers and therapeutic targets for human disease.

\section{AUTHOR CONTRIBUTIONS}

All authors listed have made a substantial, direct and intellectual contribution to the work, and approved it for publication.

\section{FUNDING}

This work was funded by NIH R37-NS-076752 to LI and by T32GM00776737 to LI on which NE is a trainee.

Brackenbury, W. J., and Isom, L. L. (2011). Na+ channel $\beta 1$ subunits: overachievers of the ion channel family. Front. Pharmacol. 2:53. doi: 10.3389/fphar.2011.00053

Calhoun, J. D., and Isom, L. L. (2014). The role of non-pore-forming $\beta$ subunits in physiology and pathophysiology of voltage-gated sodium channels. in voltage gated sodium channels. Handb. Exp. Pharmacol. 221, 51-89. doi: 10.1007/978-3-642-41588-3_4

Catterall, W. A. (2000). From ionic currents to molecular mechanisms: the structure and function of voltage-gated sodium channels. Neuron 26, 13-25. doi: 10.1016/S0896-6273(00)81133-2

Catterall, W., Goldin, A. L., and Waxman, S. G. (2005). International Union of Pharmacology. XLVII. Nomenclature and structure-function relationships of voltage-gated sodium channels. Pharmacol. Rev. 57, 397-409. doi: $10.1124 /$ pr.57.4.4

Chen, C. (2004). Mice lacking sodium channel 1 subunits display defects in neuronal excitability, sodium channel expression, and nodal architecture. J. Neurosci. 24, 4030-4042. doi: 10.1523/JNEUROSCI.4139-03.2004

Chen, C., Calhoun, J. D., Zhang, Y., Lopez-Santiago, L., Zhou, N., Davis, T. H., et al. (2012). Identification of the cysteine residue responsible for disulfide linkage of $\mathrm{Na}+$ channel $\alpha$ and $\beta 2$ subunits. J. Biol. Chem. 287, 39061-39069. doi: 10.1074/jbc.M112.397646 
Chyou, J. Y., Friedman, D., Cerrone, M., Slater, W., Guo, Y., Taupin, D., et al. (2016). Electrocardiographic features of sudden unexpected death in epilepsy. Epilepsia 57, e135-e139. doi: 10.1111/epi.13411

Clatot, J., Hoshi, M., Wan, X., Liu, H., Jain, A., Shinlapawittayatorn, K., et al. (2017). Voltage-gated sodium channels assemble and gate as dimers. Nat. Commun. 8:2077. doi: 10.1038/s41467-017-02262-0

Deschênes, I., Armoundas, A., a, Jones, S. P., and Tomaselli, G. F. (2008). Posttranscriptional gene silencing of KChIP2 and Navbeta1 in neonatal rat cardiac myocytes reveals a functional association between $\mathrm{Na}$ and Ito currents. J. Mol. Cell. Cardiol. 45, 336-346. doi: 10.1016/j.yjmcc.2008.05.001

Deschênes, I., and Tomaselli, G. F. (2002). Modulation of Kv4.3 current by accessory subunits. FEBS Lett. 528, 183-188. doi: 10.1016/S0014-5793(02)03296-9

Devinsky, O., Hesdorffer, D. C., Thurman, D. J., Lhatoo, S., and Richerson, G. (2016). Sudden unexpected death in epilepsy: epidemiology, mechanisms, and prevention. Lancet Neurol. 15, 1075-1088. doi: 10.1016/S1474-4422(16)30158-2

Domínguez, J. N., Navarro, F., Franco, D., Thompson, R. P., and Aránega, A. E. (2005). Temporal and spatial expression pattern of betal sodium channel subunit during heart development. Cardiovasc. Res. 65, 842-850. doi: 10.1016/j.cardiores.2004.11.028

Fearnley, C. J., Llewelyn Roderick, H., and Bootman, M. D. (2011). Calcium signaling in cardiac myocytes. Cold Spring Harb. Perspect. Biol. 3:a004242. doi: $10.1101 /$ cshperspect.a004242

Fendri-Kriaa, N., Kammoun, F., Salem, I. H., Kifagi, C., Mkaouar-Rebai, E., Hsairi, I., et al. (2011). New mutation c.374C $>\mathrm{T}$ and a putative disease-associated haplotype within SCN1B gene in Tunisian families with febrile seizures. Eur. J. Neurol. 18, 695-702. doi: 10.1111/j.1468-1331.2010.03216.x

Freeman, S. A., Desmazières, A., Fricker, D., Lubetzki, C., and SolFoulon, N. (2016). Mechanisms of sodium channel clustering and its influence on axonal impulse conduction. Cell. Mol. Life Sci. 73, 723-735. doi: 10.1007/s00018-015-2081-1

Gabelli, S. B., Boto, A., Kuhns, V. H., Bianchet, M. A., Farinelli, F., Aripirala, S., et al. (2014). Regulation of the NaV1.5 cytoplasmic domain by calmodulin. Nat. Commun. 5:5126. doi: 10.1038/ncomms6126

Gellens, M. E., George, A. L., Chen, L. Q., Chahine, M., Horn, R., Barchi, R. L., et al. (1992). Primary structure and functional expression of the human cardiac tetrodotoxin-insensitive voltage-dependent sodium channel. Proc. Natl. Acad. Sci. U.S.A. 89, 554-558. doi: 10.1073/pnas.89.2.554

Gilchrist, J., Das, S., Van Petegem, F., and Bosmans, F. (2013). Crystallographic insights into sodium-channel modulation by the $\beta 4$ subunit. Proc. Natl. Acad. Sci.U.S.A. 110, E5016-E5024. doi: 10.1073/pnas.1314557110

Glasscock, E. (2014). Genomic biomarkers of SUDEP in brain and heart. Epilepsy Behav. 38, 172-179. doi: 10.1016/j.yebeh.2013.09.019

Gutstein, D. E., Morley, G. E., Tamaddon, H., Vaidya, D., Schneider, M. D., Chen, J., et al. (2001). Conduction slowing and sudden Arrhythmic death in mice with cardiac-restricted inactivation of connexin43. Circ. Res. 88, 333-339. doi: 10.1161/01.RES.88.3.333

Hille, B., and Catterall, W. A. (2012). "Chapter 4 - Electrical excitability and ion channels," in Basic Neurochemistry, 8th edn, Principles of Molecular, Cellular, and Medical Neurobiology, eds S. T. Brady, G. J. Siegel, R. W. Albers, and D. L. Price (Amsterdam; Boston, MA; Heidelberg; London; New York, NY; Oxford; Paris; San Diego, CA; San Francisco, CA; Singapore; Sydney; Tokyo: Elsevier; Academic Press), 63-80.

Holst, A. G., Saber, S., Houshmand, M., Zaklyazminskaya, E. V., Wang, Y., Jensen, H. K., et al. (2012). Sodium current and potassium transient outward current genes in Brugada syndrome: screening and bioinformatics. Can. J. Cardiol. 28, 196-200. doi: 10.1016/j.cjca.2011.11.011

Hu, D., Barajas-Martínez, H., Medeiros-Domingo, A., Crotti, L., Veltmann, C., Schimpf, R., et al. (2012). A novel rare variant in SCN1Bb linked to Brugada syndrome and SIDS by combined modulation of Nav1.5 and Kv4.3 channel currents. Heart Rhythm 9, 760-769. doi: 10.1016/j.hrthm.2011. 12.006

Hund, T. J., Koval, O. M., Li, J., Wright, P. J., Qian, L., Snyder, J. S., et al. (2010). A $\beta$ IV -spectrin / CaMKII signaling complex is essential for membrane excitability in mice. J. Clin. Invest. 120, 3508-3519. doi: 10.1172/JCI43621

Hunter, A. W. (2005). Zonula occludens-1 alters connexin43 gap junction size and organization by influencing channel accretion. Mol. Biol. Cell 16, 5686-5698. doi: 10.1091/mbc.E05-08-0737
Isom, L. L., De Jongh, K. S., Patton, D. E., Reber, B. F., Offord, J., Charbonneau, H., et al. (1992). Primary structure and functional expression of the beta 1 subunit of the rat brain sodium channel. Science 256, 839-842. doi: $10.1126 /$ science. 1375395

Jansen, J. A., Noorman, M., Musa, H., Stein, M., De Jong, S., Van Der Nagel, R., et al. (2012). Reduced heterogeneous expression of $\mathrm{Cx} 43$ results in decreased Nav1.5 expression and reduced sodium current that accounts for arrhythmia vulnerability in conditional Cx43 knockout mice. Heart. Rhythm 9, 600-607. doi: 10.1016/j.hrthm.2011.11.025

Johnson, D., Montpetit, M. L., Stocker, P. J., and Bennett, E. S. (2004). The sialic acid component of the betal subunit modulates voltage-gated sodium channel function. J. Biol. Chem. 279, 44303-44310. doi: 10.1074/jbc.M408900200

Kalume, F. (2013). Sudden unexpected death in Dravet syndrome: respiratory and other physiological dysfunctions. Respir Physiol Neurobiol. 189, 324-328. doi: 10.1016/j.resp.2013.06.026

Kaufmann, S. G., Westenbroek, R. E., Zechner, C., Maass, A. H., Bischoff, S., Muck, J., et al. (2010). Functional protein expression of multiple sodium channel alpha- and beta-subunit isoforms in neonatal cardiomyocytes. J. Mol. Cell. Cardiol. 48, 261-269. doi: 10.1016/j.yjmcc.2009.04.017

Kazen-Gillespie, K., a, Ragsdale, D. S., D’Andrea, M. R., Mattei, L. N., Rogers, K. E., and Isom, L. L. (2000). Cloning, localization, and functional expression of sodium channel betalA subunits. J. Biol. Chem. 275, 1079-1088. doi: 10.1074/jbc.275.2.1079

Kim, D. Y., Carey, B. W., Wang, H., Ingano, L. A. M., Binshtok, A. M., Wertz, M. H., et al. (2007). BACE1 regulates voltage-gated sodium channels and neuronal activity. Nat. Cell Biol. 9, 755-764. doi: 10.1038/ncb1602

Kim, J., Ghosh, S., Liu, H., Tateyama, M., Kass, R. S., and Pitt, G. S. (2004). Calmodulin mediates $\mathrm{Ca}^{2+}$ sensitivity of sodium channels. J. Biol. Chem. 279, 45004-45012. doi: 10.1074/jbc.M407286200

Lin, X., Liu, N., Lu, J., Zhang, J., Anumonwo, J. M. B., Isom, L. L., et al. (2011). Subcellular heterogeneity of sodium current properties in adult cardiac ventricular myocytes. Heart. Rhythm 8, 1923-1930. doi: 10.1016/j.hrthm.2011.07.016

Lin, X., O’Malley, H., Chen, C., Auerbach, D., Foster, M., Shekhar, A., et al. (2015). $S c n 1 b$ deletion leads to increased tetrodotoxin-sensitive sodium current, altered intracellular calcium homeostasis and arrhythmias in murine hearts. J. Physiol. 593, 1389-1407. doi: 10.1113/jphysiol.2014.277699

Liu, C., Dib-Hajj, S. D., Renganathan, M., Cummins, T. R., and Waxman, S. G. (2003). Modulation of the cardiac sodium channel Nav1.5 by fibroblast growth factor homologous factor 1B. J. Biol. Chem. 278, 1029-1036. doi: 10.1074/jbc.M207074200

Liu, C., Tester, D. J., Hou, Y., Wang, W., Lv, G., Ackerman, M. J., et al. (2014). Is sudden unexplained nocturnal death syndrome in Southern China a cardiac sodium channel dysfunction disorder? Forensic Sci. Int. 236, 38-45. doi: 10.1016/j.forsciint.2013.12.033

Lopez-Santiago, L. F., Meadows, L. S., Ernst, S. J., Chen, C., Malhotra, J. D., McEwen, D. P., et al. (2007). Sodium channel Scn1b null mice exhibit prolonged QT and RR intervals. J. Mol. Cell. Cardiol. 43, 636-647. doi: 10.1016/j.yjmcc.2007.07.062

Lowe, J. S., Palygin, O., Bhasin, N., Hund, T. J., Boyden, P. A., Shibata, E., et al. (2008). Voltage-gated Nav channel targeting in the heart requires an ankyrin-G-dependent cellular pathway. J. Cell Biol. 180, 173-186. doi: $10.1083 /$ jcb.200710107

Maier, S. K. G., Westenbroek, R. E., McCormick, K. A., Curtis, R., Scheuer, T., and Catterall, W. A. (2004). Distinct subcellular localization of different sodium channel $\alpha$ and $\beta$ subunits in single ventricular myocytes from mouse heart. Circulation 109, 1421-1427. doi: 10.1161/01.CIR.0000121421.61896.24

Maier, S. K. G., Westenbroek, R. E., Schenkman, K. A., Feigl, E. O., Scheuer, T., and Catterall, W. A. (2002). An unexpected role for brain-type sodium channels in coupling of cell surface depolarization to contraction in the heart. Proc. Natl. Acad. Sci. U.S.A. 99, 4073-4078. doi: 10.1073/pnas. 261705699

Makara, M. A., Curran, J., Little, S. C., Musa, H., Polina, I., Smith, S. A., et al. (2014). Ankyrin-G coordinates intercalated disc signaling platform to regulate cardiac excitability in vivo. Circ. Res. 115, 929-938. doi: 10.1161/CIRCRESAHA.115.305154

Makita, N., Bennett, P. B., and George, A. L. (1994). Voltage-gated Na+ channel beta 1 subunit mRNA expressed in adult human skeletal muscle, heart, and brain is encoded by a single gene. J. Biol. Chem. 269, 7571-7578. 
Malhotra, J. D., Chen, C., Rivolta, I., Abriel, H., Malhotra, R., Mattei, L. N., et al. (2001). Characterization of sodium channel alpha- and betasubunits in rat and mouse cardiac myocytes. Circulation 103, 1303-1310. doi: 10.1161/01.CIR.103.9.1303

Malhotra, J. D., Kazen-Gillespie, K., Hortsch, M., and Isom, L. L. (2000). Sodium channel $\beta$ subunits mediate homophilic cell adhesion and recruit ankyrin to points of cell-cell contact. J. Biol. Chem. 275, 11383-11388. doi: $10.1074 /$ jbc.275.15.11383

Malhotra, J. D., Koopmann, M. C., Kazen-Gillespie, K. A., Fettman, N., Hortsch, M., and Isom, L. L. (2002). Structural requirements for interaction of sodium channel beta 1 subunits with ankyrin. J. Biol. Chem. 277, 26681-26688. doi: 10.1074/jbc.M202354200

Malhotra, J. D., Thyagarajan, V., Chen, C., and Isom, L. L. (2004). Tyrosinephosphorylated and nonphosphorylated sodium channel $\beta 1$ subunits are differentially localized in cardiac myocytes. J. Biol. Chem. 279, 40748-40754. doi: 10.1074/jbc.M407243200

Marionneau, C., Carrasquillo, Y., Norris, A. J., Townsend, R. R., Isom, L. L., Link, A. J., et al. (2012). The sodium channel accessory subunit Nav $\beta 1$ regulates neuronal excitability through modulation of repolarizing voltagegated $\mathrm{K}^{+}$channels. J. Neurosci. 32, 5716-5727. doi: 10.1523/JNEUROSCI.645011.2012

Matamoros, M., Perez-Hernández, M., Guerrero-Serna, G., Amorós, I., Barana, A., Núñez, M., et al. (2016). Nav1.5 N-terminal domain binding to $\alpha 1$-syntrophin increases membrane density of human Kir2.1, Kir2.2 and Nav1.5 channels. Cardiovasc. Res. 110, 279-290. doi: 10.1093/cvr/cvw009

Matsumoto, M., Fujikawa, A., Suzuki, R., Shimizu, H., Kuboyama, K., Hiyama, T. Y., et al. (2012). SAP97 promotes the stability of Nax channels at the plasma membrane. FEBS Lett. 586, 3805-3812. doi: 10.1016/j.febslet.2012.09.018

McCormick, K. A., Isom, L. L., Ragsdale, D., Smith, D., Scheuer, T., and Catterall, W. A. (1998). Molecular determinants of $\mathrm{Na}+$ channel function in the extracellular domain of the betal subunit. J. Biol. Chem. 273, 3954-3962. doi: $10.1074 /$ jbc.273.7.3954

McEwen, D. P., Meadows, L. S., Chen, C., Thyagarajan, V., and Isom, L. L. (2004). Sodium channel $\beta 1$ subunit-mediated modulation of Nav1.2 currents and Cell surface density is dependent on interactions with contactin and ankyrin. J. Biol. Chem. 279, 16044-16049. doi: 10.1074/jbc.M400856200

Meadows, L., Malhotra, J. D., Stetzer, a, Isom, L. L., and Ragsdale, D. S. (2001). The intracellular segment of the sodium channel beta 1 subunit is required for its efficient association with the channel alpha subunit. J. Neurochem. 76, 1871-1878. doi: 10.1046/j.1471-4159.2001.00192.x

Mercier, A., Clément, R., Harnois, T., Bourmeyster, N., Faivre, J. F., Findlay, I., et al. (2012). The $\beta 1$-Subunit of Nav1.5 Cardiac Sodium Channel Is Required for a Dominant Negative Effect through $\alpha-\alpha$ Interaction. PLoS ONE 7:e48690. doi: 10.1371/journal.pone.0048690

Mohler, P. J., Rivolta, I., Napolitano, C., LeMaillet, G., Lambert, S., Priori, S. G., et al. (2004). Nav1.5 E1053K mutation causing Brugada syndrome blocks binding to ankyrin-G and expression of Nav1.5 on the surface of cardiomyocytes. Proc. Natl. Acad. Sci.U.S.A. 101, 17533-17538. doi: 10.1073/pnas.0403711101

Morgan, K., Stevens, E. B., Shah, B., Cox, P. J., Dixon, A. K., Lee, K., et al. (2000). Beta 3: an additional auxiliary subunit of the voltagesensitive sodium channel that modulates channel gating with distinct kinetics. Proc. Natl. Acad. Sci. U.S.A. 97, 2308-2313. doi: 10.1073/pnas. 030362197

Nelson, M., Millican-Slater, R., Forrest, L. C., and Brackenbury, W. J. (2014). The sodium channel $\beta 1$ subunit mediates outgrowth of neurite-like processes on breast cancer cells and promotes tumour growth and metastasis. Int. J. Cancer 135, 2338-2351. doi: 10.1002/ijc. 28890

Nerbonne, J. M., and Kass, R. S. (2005). Molecular physiology of cardiac repolarization. Physiol. Rev. 85, 1205-1253. doi: 10.1152/physrev.00002.2005

Neubauer, J., Rougier, J.-S., Abriel, H., and Haas, C. (in press). Functional implications of a rare variant in the sodium channel $\beta 1 \mathrm{~B}$ subunit (SCN1B) in a five-month old male sudden infant death syndrome (SIDS) case. Heart. Case Rep. doi: 10.1016/j.hrcr.2018.01.010

Nguyen, H. M., Miyazaki, H., Hoshi, N., Smith, B. J., Nukina, N., Goldin, A. L., et al. (2012). Modulation of voltage-gated $\mathrm{K}+$ channels by the sodium channel $\beta 1$ subunit. Proc. Natl. Acad. Sci. U.S.A. 109, 18577-18582. doi: $10.1073 /$ pnas. 1209142109
Nobili, L., Proserpio, P., Rubboli, G. B., Montano, N. C., Didato, G., D., and Tassinari, C. (2011). Sudden unexpected death in epilepsy (SUDEP) and sleep. Sleep Med. Rev. 15, 237-246. doi: 10.1016/j.smrv.2010.07.006

O'Malley, H. A., and Isom, L. L. (2015). Sodium channel $\beta$ subunits: emerging targets in channelopathies. Annu. Rev. Physiol. 77, 481-504. doi: 10.1146/annurev-physiol-021014-071846

Ogiwara, I., Nakayama, T., Yamagata, T., Ohtani, H., Mazaki, E., Tsuchiya, S., et al. (2012). A homozygous mutation of voltage-gated sodium channel beta(I) gene SCN1B in a patient with Dravet syndrome. Epilepsia 53, e200-e203. doi: 10.1111/epi.12040

Orrico, A., Galli, L., Grosso, S., Buoni, S., Pianigiani, R., Balestri, P., et al. (2009). Mutational analysis of the SCN1A, SCN1B and GABRG2 genes in 150 Italian patients with idiopathic childhood epilepsies. Clin. Genet. 75, 579-581. doi: 10.1111/j.1399-0004.2009.01155.x

Palatinus, J. A., O’Quinn, M. P., Barker, R. J., Harris, B. S., Jourdan, J., and Gourdie, R. G. (2010). ZO-1 determines adherens and gap junction localization at intercalated disks. Am. J. Physiol. Heart. Circ. Physiol. 300, H583-H594. doi: 10.1152/ajpheart.00999.2010

Patino, G. A., Brackenbury, W. J., Bao, Y., Lopez-Santiago, L. F., O’Malley, H. A., Chen, C., et al. (2011). Voltage-gated $\mathrm{Na}+$ channel beta1B: a secreted cell adhesion molecule involved in human epilepsy. J. Neurosci. 31, 14577-14591. doi: 10.1523/JNEUROSCI.0361-11.2011

Patino, G. A., Claes, L. R. F., Lopez-Santiago, L. F., Slat, E. A., Dondeti, R. S. R., Chen, C., et al. (2009). A functional null mutation of SCN1B in a patient with Dravet Syndrome. J. Neurosci. 29, 10764-10778. doi: 10.1523/JNEUROSCI.2475-09.2009

Petitprez, S., Zmoos, A. F., Ogrodnik, J., Balse, E., Raad, N., El-Haou, S., et al. (2011). SAP97 and dystrophin macromolecular complexes determine two pools of cardiac sodium channels Nav1.5 in cardiomyocytes. Circ. Res. 108, 294-304. doi: 10.1161/CIRCRESAHA.110.228312

Qu, Y., Isom, L. L., Westenbroek, R. E., Rogers, J. C., Tanada, T. N., McCormick, K. A., et al. (1995). Modulation of cardiac $\mathrm{Na}+$ channel expression in Xenopus oocytes by beta 1 subunits. J. Biol. Chem. 270, 25696-25701. doi: $10.1074 /$ jbc.270.43.25696

Ramadan, W., Patel, N., Anazi, S., Kentab, A. Y., Bashiri, F. A., Hamad, M. H., et al. (2017). Confirming the recessive inheritance of SCN1B mutations in developmental epileptic encephalopathy. Clin. Genet. 92, 327-331. doi: $10.1111 /$ cge.12999

Ravindran, K., Powell, K. L., Todaro, M., and O’Brien, T. J. (2016). The pathophysiology of cardiac dysfunction in epilepsy. Epilepsy Res. 127, 19-29. doi: 10.1016/j.eplepsyres.2016.08.007

Rhett, J. M., Jourdan, J., and Gourdie, R. G. (2011). Connexin 43 connexon to gap junction transition is regulated by zonula occludens-1. Mol. Biol. Cell 22, 1516-1528. doi: 10.1091/mbc.E10-06-0548

Rhett, J. M., Ongstad, E. L., Jourdan, J., and Gourdie, R. G. (2012). Cx43 associates with Nav1.5 in the cardiomyocyte perinexus. J. Membr. Biol. 245, 411-422. doi: $10.1007 / \mathrm{s} 00232-012-9465-z$

Rhett, J. M., Veeraraghavan, R., Poelzing, S., and Gourdie, R. G. (2013). The perinexus: Sign-post on the path to a new model of cardiac conduction? Trends Cardiovasc. Med. 23, 222-228. doi: 10.1016/j.tcm.2012.12.005

Riuró, H., Campuzano, O., Arbelo, E., Iglesias, A., Batlle, M., Pérez-Villa, F., et al. (2014). A missense mutation in the sodium channel $\beta 1 \mathrm{~b}$ subunit reveals SCN1B as a susceptibility gene underlying long QT syndrome. Heart Rhythm 11, 1202-1209. doi: 10.1016/j.hrthm.2014.03.044

Rogart, R. B., Cribbs, L. L., Muglia, L. K., Kephart, D. D., and Kaiser, M. W. (1989). molecular cloning of a putative tetrodotoxin-resistant rat heart Na+ channel isoform. Proc. Natl. Acad. Sci. U.S.A. 86, 8170-8174. doi: 10.1073/pnas.86.20.8170

Rougier, J.-S., van Bemmelen, M. X., Bruce, M. C., Jespersen, T., Gavillet, B., Apothéloz, F., et al. (2005). Molecular determinants of voltage-gated sodium channel regulation by the Nedd4/Nedd4-like proteins. Am. J. Physiol. Cell Physiol. 288, C692-C701. doi: 10.1152/ajpcell.00460.2004

Satin, J., Kyle, J. W., Chen, M., Bell, P., Cribbs, L. L., Fozzard, H. A., et al. (1992). A mutant of TTX-resistant cardiac sodium channels with TTX-sensitive properties. Science 256, 1202-1205. doi: 10.1126/science.256.5060.1202

Scheffer, I. E., Harkin, L. A., Grinton, B. E., Dibbens, L. M., Turner, S. J., Zielinski, M. A., et al. (2006). Temporal lobe epilepsy and GEFS+ phenotypes associated with SCN1B mutations. Brain 130, 100-109. doi: 10.1093/brain/awl272 
Shy, D., Gillet, L., and Abriel, H. (2013). Cardiac sodium channel NaV1.5 distribution in myocytes via interacting proteins: the multiple pool model. Biochim. Biophys. Acta 1833, 886-894. doi: 10.1016/j.bbamcr.2012. 10.026

Shy, D., Gillet, L., Ogrodnik, J., Albesa, M., Verkerk, A. O., Wolswinkel, R., et al. (2014). PDZ domain-binding motif regulates cardiomyocyte compartmentspecific nav1.5 channel expression and function. Circulation 130, 147-160. doi: 10.1161/CIRCULATIONAHA.113.007852

Snyders, D. J. (1999). Structure and function of cardiac potassium channels. Cardiovasc. Res. 42, 377-390. doi: 10.1016/S0008-6363(99)00071-1

Sreedhar, R., Arumugam, S., Thandavarayan, R. A., Giridharan, V. V., Karuppagounder, V., Pitchaimani, V., et al. (2016). Depletion of cardiac 14-3-3n protein adversely influences pathologic cardiac remodeling during myocardial infarction after coronary artery ligation in mice. Int. J. Cardiol. 202, 146-153. doi: 10.1016/j.ijcard.2015.08.142

Srinivasan, J., Schachner, M., and Catterall, W., a. (1998). Interaction of voltage-gated sodium channels with the extracellular matrix molecules tenascin-C and tenascin-R. Proc. Natl. Acad. Sci. U.S.A. 95, 15753-15757. doi: $10.1073 /$ pnas. 95.26 .15753

Tan, H. L., Kupershmidt, S., Zhang, R., Stepanovic, S., Roden, D. M., Wilde, A. A. M., et al., (2002). A calcium sensor in the sodium channel modulates cardiac excitability. Nature 415, 442-447. doi: 10.1038/415442a

Undrovinas, A. I., Shander, G. S., and Makielski, J. C. (1995). Cytoskeleton modulates gating of voltage-dependent sodium channel in heart. Am. J. Physiol. 269, H203-H214. doi: 10.1152/ajpheart.1995.269.1.H203

Vaidyanathan, R., Vega, A. L., Song, C., Zhou, Q., Tan, B., Berger, S., et al. (2013). The interaction of caveolin 3 protein with the potassium inward rectifier channel Kir2.1: physiology and pathology related to long QT syndrome 9 (LQT9). J. Biol. Chem. 288, 17472-17480. doi: 10.1074/jbc.M112.435370

Van Bemmelen, M. X., Rougier, J. S., Gavillet, B., Apothéloz, F., Daidié, D., Tateyama, M., et al. (2004). Cardiac voltage-gated sodium channel Nav1.5 is regulated by Nedd4-2 mediated ubiquitination. Circ. Res. 95, 284-291. doi: 10.1161/01.RES.0000136816.05109.89

Veeraraghavan, R., Hoeker, G. S., Poelzing, S., and Gourdie, R. G. (2016). Abstract 13129: Acute Inhibition of Sodium Channel Beta Subunit $(\beta 1)$-mediated Adhesion is Highly Proarrhythmic. Circulation 134, A13129 LP-A13129.

Vermij, S. H., Abriel, H., and van Veen, T. A. B. (2017). Refining the molecular organization of the cardiac intercalated disc. Cardiovasc. Res. 113, 259-275. doi: $10.1093 / \mathrm{cvr} / \mathrm{cvw} 259$

Vreeker, A., van Stuijvenberg, L., Hund, T. J., Mohler, P. J., Nikkels, P. G. J., and van Veen, T. A. B. (2014). Assembly of the cardiac intercalated disk during pre- and postnatal development of the human heart. PLoS ONE 9:e94722. doi: 10.1371/journal.pone.0094722

Wallace, R. H., Wang, D. W., Singh, R., Scheffer, I. E., George, A. L., Phillips, H. et al. (1998). Febrile seizures and generalized epilepsy associated with a mutation in the Na+-channel betal subunit gene SCN1B. Nat. Genet. 19 366-370. doi: 10.1038/1252

Watanabe, H., Darbar, D., Kaiser, D. W., Jiramongkolchai, K., Chopra, S., Donahue, B. S., et al. (2009). Mutations in sodium channel $\beta 1$ - and $\beta 2$-subunits associated with atrial fibrillation. Circ. Arrhythm. Electrophysiol. 2, 268-275. doi: 10.1161/CIRCEP.108.779181

Watanabe, H., Koopmann, T. T., Scouarnec, S., Le, Y. T., Ingram, C. R., Schott, J., et al. (2008). Sodium channel $\beta 1$ subunit mutations associated with Brugada syndrome and cardiac conduction disease in humans. Structure 118, 268-275. doi: 10.1172/JCI33891

Wong, H. K., Sakurai, T., Oyama, F., Kaneko, K., Wada, K., Miyazaki, H., et al. (2005). $\beta$ subunits of voltage-gated sodium channels are novel substrates of $\beta$-site amyloid precursor protein-cleaving enzyme (BACE1) and $\gamma$-secretase. J. Biol. Chem. 280, 23009-23017. doi: 10.1074/jbc.M414648200

Xiao, Z. C., Ragsdale, D. S., Malhotra, J. D., Mattei, L. N., Braun, P. E., Schachner, M., et al. (1999). Tenascin-R is a functional modulator of sodium channel $\beta$ subunits. J. Biol. Chem. 274, 26511-26517. doi: 10.1074/jbc.274.37.26511

Yang, Y., Ogawa, Y., Hedstrom, K. L., and Rasband, M. N. (2007). BIV spectrin is recruited to axon initial segments and nodes of Ranvier by ankyrinG. J. Cell Biol. 176, 509-519. doi: $10.1083 /$ jcb.200610128

Yereddi, N. R., Cusdin, F. S., Namadurai, S., Packman, L. C., Monie, T. P., Slavny, P., et al. (2013). The immunoglobulin domain of the sodium channel $\beta 3$ subunit contains a surface-localized disulfide bond that is required for homophilic binding. FASEB J. 27, 568-580. doi: 10.1096/fj.12-209445

Young, K. A., and Caldwell, J. H. (2005). Modulation of skeletal and cardiac voltage-gated sodium channels by calmodulin. J. Physiol. 565, 349-370. doi: 10.1113/jphysiol.2004.081422

Zaidi, A., Clough, P., Cooper, P., Scheepers, B., and Fitzpatrick, A. P. (2000). Misdiagnosis of epilepsy: many seizure-like attacks have a cardiovascular cause. J. Am. Coll. Cardiol. 36, 181-184. doi: 10.1016/S0735-1097(00) 00700-2

Zhu, W., Voelker, T. L., Varga, Z., Schubert, A. R., Nerbonne, J. M., and Silva, J. R. (2017). Mechanisms of noncovalent $\beta$ subunit regulation of $\mathrm{Na} V$ channel gating. J. Gen. Physiol. 149, 813-831. doi: 10.1085/jgp.201711802

Conflict of Interest Statement: The authors declare that the research was conducted in the absence of any commercial or financial relationships that could be construed as a potential conflict of interest.

Copyright () 2018 Edokobi and Isom. This is an open-access article distributed under the terms of the Creative Commons Attribution License (CC BY). The use, distribution or reproduction in other forums is permitted, provided the original author(s) and the copyright owner are credited and that the original publication in this journal is cited, in accordance with accepted academic practice. No use, distribution or reproduction is permitted which does not comply with these terms. 


\title{
Cardiac Arrhythmias and Antiarrhythmic Drugs: An Autophagic Perspective
}

\author{
Joanne J. A. van Bavel, Marc A. Vos and Marcel A. G. van der Heyden* \\ Department of Medical Physiology, Division of Heart and Lungs, University Medical Center Utrecht, Utrecht, Netherlands
}

\section{OPEN ACCESS}

Edited by:

Carol Ann Remme,

University of Amsterdam, Netherlands

Reviewed by:

Thomas Hund

The Ohio State University,

United States

Craig Doupnik,

Morsani College of Medicine

University of South Florida,

United States

Rob Gourdie,

Medical University of South Carolina,

United States

${ }^{*}$ Correspondence:

Marcel A. G. van der Heyden

m.a.g.vanderheyden@umcutrecht.nl

Specialty section:

This article was submitted to

Cardiac Electrophysiology,

a section of the journal

Frontiers in Physiology

Received: 24 November 2017

Accepted: 07 February 2018

Published: 23 February 2018

Citation:

van Bavel JJA, Vos MA and van der

Heyden MAG (2018) Cardiac

Arrhythmias and Antiarrhythmic

Drugs: An Autophagic Perspective.

Front. Physiol. 9:127.

doi: 10.3389/fphys.2018.00127
Degradation of cellular material by lysosomes is known as autophagy, and its main function is to maintain cellular homeostasis for growth, proliferation and survival of the cell. In recent years, research has focused on the characterization of autophagy pathways. Targeting of autophagy mediators has been described predominantly in cancer treatment, but also in neurological and cardiovascular diseases. Although the number of studies is still limited, there are indications that activity of autophagy pathways increases under arrhythmic conditions. Moreover, an increasing number of antiarrhythmic and non-cardiac drugs are found to affect autophagy pathways. We, therefore, suggest that future work should recognize the largely unaddressed effects of antiarrhythmic agents and other classes of drugs on autophagy pathway activation and inhibition.

Keywords: autophagy, AMPK, antiarrhythmic drugs, arrhythmias, mTOR, heart

\section{INTRODUCTION}

Degradation of cellular material occurs mainly via two pathways: the ubiquitin-proteasome system (UPS) and the autophagy-lysosome pathway. The UPS targets mainly short-lived or misfolded proteins, whereas autophagy includes the degradation, digestion and recycling of autophagy substrates, by lysosomes ( $\mathrm{Li}$ et al., 2012). In healthy conditions, autophagy acts principally as a protective and control mechanism by maintaining cellular growth, proliferation, survival, and clearance of dying cells (Cremonese Filipi-Chiela et al., 2016). Over the last decade, an increasing amount of research has focused on autophagy and attention has been paid to the association between autophagy and cardiac diseases, including ischemia and hypertrophy. Thus far, a potential link between arrhythmic conditions and changes in autophagy activity has gained little attention, although the evidence for such interaction currently expands. There remains a need for increased research focus on the association between pro- and antiarrhythmic drugs and autophagy pathways in the heart. We review the link between cardiac autophagy and arrhythmic conditions, and the limitations regarding the effect of antiarrhythmic drugs on autophagy. Only a few years from now we can determine whether the current niche of arrhythmias and autophagy research will emerge in a mature field of investigation.

\section{AUTOPHAGY TYPES AND TARGETS}

Autophagy substrates (referred to as cellular material) include proteins, proteasomes, lysosomes, endoplasmic reticulum (ER), mitochondria, lipid droplets, polyribosomes, peroxisomes, bacteria, viruses and ruptured phagosomes. These substrates are targeted for degradation as long as they are freely accessible in the cytosol (Galluzzi et al., 2017). Three types of autophagic targeting are recognized (Figure 1A). Microautophagy is the least studied type of autophagy, which involves the direct uptake of soluble cellular substrates from the cytoplasm by invaginations 
in lysosomal membranes (Li et al., 2012). Macroautophagy, the best characterized variant of autophagy, is used synonymous with the term autophagy. It refers to both selective and nonselective capture of cellular components in double-membraned vesicles in the cytosol, and subsequent transport of the content to lysosomes (Feng et al., 2014). Chaperone-mediated autophagy (CMA) is a selective autophagic mechanism, which is mediated by the recognition of a peptide sequence in substrate proteins by chaperones, e.g. hsc70 (Cuervo and Wong, 2014). The substrate binds to lysosome-associated membrane protein 2A (LAMP-2A) and translocates into the lysosome for degradation. The main and most important function of the strictly organized process of autophagy is to maintain cellular homeostasis (Singh and Cuervo, 2011). Autophagy can act selectively, which includes the degradation of specific cargo selected by receptor proteins, and non-selectively by maintenance of intracellular nutrient supply with starvation as its main trigger (Svenning and Johansen, 2013). Besides small cellular components, selective autophagy can target specific cell components, e.g. mitochondria (mitophagy), ER (reticulophagy), ribosomes (ribophagy), lipids (lipophagy), and ion channels (channelophagy, as suggested by Klionsky et al., 2007; Kondratskyi et al., 2017). Autophagic processes are either continuously active (constitutive) or triggered (inducible). The primary stimulus of autophagy in yeast is nutrient withdrawal, whereas in mammals several stimuli can trigger autophagy, of which the most important are nutritional changes (e.g. starvation), organelle damage, hormonal regulation, infectious agents, hypoxia (such as in cardiac ischemia), and intracellular accumulation of toxic products (e.g. some antiarrhythmic drugs; Kudenchuk et al., 1984; Singh and Cuervo, 2011; Reggiori and Klionsky, 2013). The first reports on autophagic processes appeared in 1955. Christian de Duve coined the term "autophagy" in 1963, which was based on the discovery of self-eating lysosomes in rat hepatic cells (De Duve et al., 1955). The following decades, research focused on studying molecular autophagy mechanisms in yeast, which differ from autophagy processes in mammals (Matsuura et al., 1997; Reggiori and Klionsky, 2013). Furthermore, genetic screens revealed the existence of AuTophaGy-related (ATG) genes, of which the role in autophagy is associated to various processes in health and disease (Feng et al., 2014; Schneider and Cuervo, 2014). Recently,

\footnotetext{
Abbreviations: AF, atrial fibrillation; AMPK, AMP-activated protein kinase; AICAR, 5-aminoimidazole-4-carboxamide-1- $\beta$-D-ribofuranoside; Ara-A, adenine 9-beta-D-arabinofuranoside; ATG, AuTophaGy related; CMA, chaperonemediated autophagy; Cx43, connexin43; EPG5, ectopic P-granules autophagy protein 5; ER, endoplasmic reticulum; GABARAP, gamma-aminobutyric acid receptor-associated proteins; GSK3 $\beta$, glycogen synthase kinase $3 \beta$; HAT, histone acetyltransferase; HDAC, histone deacetylase; hERG, human ether-a-go-gorelated gene; hsc70, heat shock-cognate protein of $70 \mathrm{kDa}$; $\mathrm{IP}_{3}$, inositol 1,4,5-triphosphate; I/R, ischemia/reperfusion; LAMP-2A, lysosome-associated membrane protein 2A; LC3-II, microtubule-associated protein $1 \mathrm{~A} / 1 \mathrm{~B}$ chain 3 phosphatidylethanolamine conjugate; LTCC, L-type calcium channel; mTOR, mechanistic target of rapamycin; mTORC1, mTOR complex 1; $\mathrm{NAD}^{+}$, nicotinamide adenine dinucleotide; P-AMPK, phosphorylated AMPK; PI3KCIII, class III phosphatidylinositol 3-kinase; PKA, protein kinase A; RAP, rapid atrial pacing; SNARE, soluble NSF attachment protein receptor; TAC, transverse aortic constriction; TdP, torsade de pointes; TP53, transcription factor 53; ULK1/2, unc-51-like kinase 1 and 2; UPS, ubiquitin proteasome system.
}

the field of autophagy was honored by a Nobel Prize awarded to Yoshinori Ohsumi in 2016 (Levine and Klionsky, 2017).

\section{AUTOPHAGY-RELATED PROTEINS AND THEIR USE AS THERAPEUTICAL TARGETS}

ATG proteins are mainly described in macroautophagy because of its best-known machinery, and are illustrated in Figure 1B. Two important regulators of autophagy initiation are AMPactivated protein kinase (AMPK) and mechanistic target of rapamycin complex 1 (mTORC1). Active AMPK stimulates autophagy initiation, whereas mTORC1 inhibits autophagy (Kim et al., 2011). In autophagy stimulation, the ULK1/2-Atg13FIP200 complex becomes active, ATG proteins are recruited and a phagophore is formed (Xie et al., 2015). The class III phosphatidylinositol 3-kinase (PI3KCIII) complex (beclin1, VPS34, VPS15, and Atg14L) mediates nucleation of the phagophore (Baskaran et al., 2014). Different ubiquitin-like conjugation systems (Atg12-Atg5 and Atg8/LC3) are central in the next autophagic step; elongation of the phagophore, and proteins and lipids involved in autophagosome formation and maturation are recruited by the PI3KCIII complex (Feng et al., 2014; Xie et al., 2015). Beclin-1 is part of the PI3KCIII complex, and plays a key role in autophagosome formation and maturation (Xie et al., 2015). Mature autophagosomes move along microtubules and fuse with lysosomes in a process that involves gamma-aminobutyric acid receptorassociated proteins (GABARAP) and soluble NSF attachment protein receptor (SNARE) family proteins (Nair et al., 2011; Itakura et al., 2012). Autophagy's final step is degradation of the autophagolysosome cargo by different types of proteases (Kaminskyy and Zhivotovsky, 2012). Detailed overviews of the macroautophagy machinery are given by Feng et al. (2014) and Xie et al. (2015).

Inability to maintain cellular homeostasis due to defective autophagy associates with a variety of systemic diseases, such as cancer, neurodegeneration, liver disease and (cardio-) myopathies (Schneider and Cuervo, 2014). Distinct ATG proteins are considered as interesting targets for autophagy modulation (Figure 1B, Table 1), in which the field of cancer therapy progressed furthest (Mulcahy Levy et al., 2017). Rapamycin and its analogs (rapalogs) inhibit mTORC1 resulting in autophagy activation, and are used in certain cancer treatments (Li J. et al., 2014). Other recognized mTORC1 inhibitors are perhexiline (antianginal agent), niclosamide (used in treating worm infections), and rottlerin (natural product, known to open potassium channels) (Balgi et al., 2009). Activation of autophagy can also result from AMPK activators, such as commonly used antidiabetic agents metformin and phenformin, and AMP analog 5-aminoimidazole-4-carboxamide-1- $\beta$-D-ribofuranoside (AICAR) (Zhou et al., 2001; Yang et al., 2013; Ducommon et al., 2014). Common inhibitors of AMPK include adenine 9-betaD-arabinofuranoside (Ara-A, or vidarabine) and compound C (Zhou et al., 2001; Pelletier et al., 2005). Antitumor drug wogonin can affect the next step in the autophagy pathway (phagophore nucleation) by targeting the beclin-1/PI3K complex, and thereby 
A

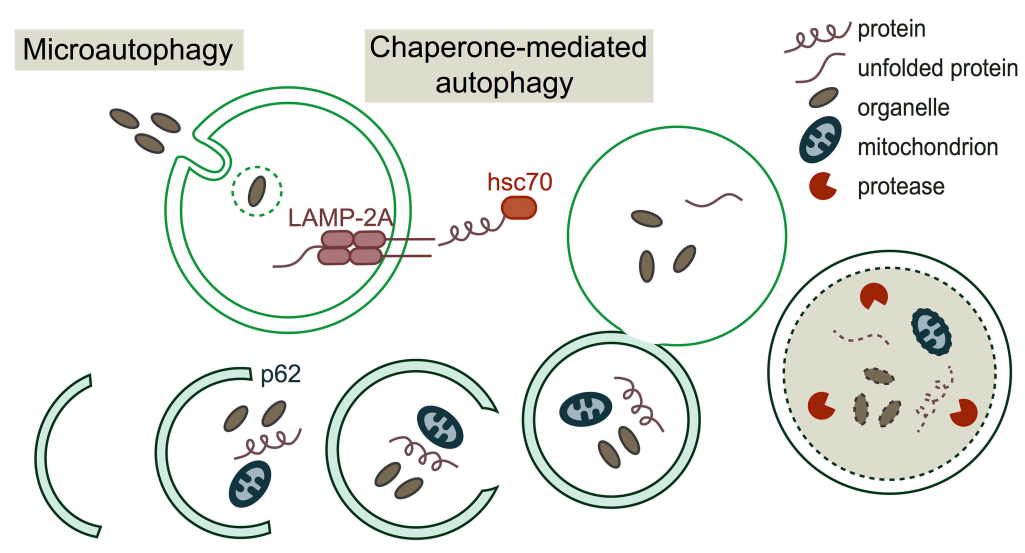

\section{Macroautophagy}

B

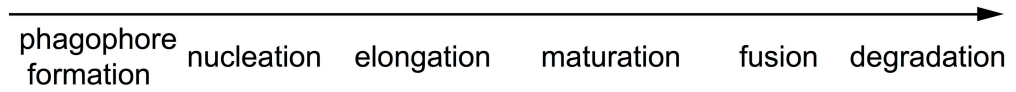

metformin

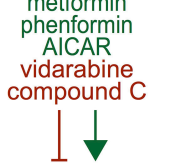
formation

class III

PI3K complex

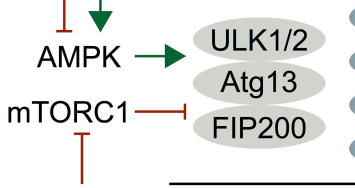

beclin-1

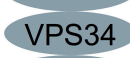

VPS15

Atg14L
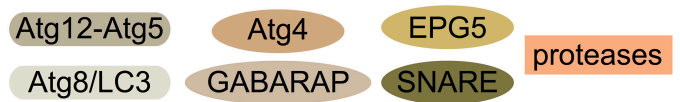

rapamycin
perhexiline
niclosamide
rottlerin
amiodarone

phagophore

formation

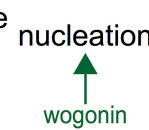

elongation

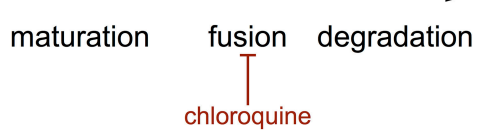

FIGURE 1 | Autophagy types, processes, molecular players and pharmacological regulators. (A) Schematic presentation of the three autophagy types.

Microautophagy refers to the direct uptake of soluble cellular substrates from the cytoplasm by invaginations in lysosomal membranes. Chaperone-mediated autophagy includes targeting of a specific motif in a substrate protein, translocation of the substrate to the lysosome by heat shock-cognate protein of $70 \mathrm{kDa}$ (hsc70), and translocation into the lysosome by lysosome-associated membrane protein 2A (LAMP-2A) on the lysosomal membrane. Macroautophagy starts with formation of a double-membraned phagophore, at which proteins and lipids are recruited by, among others, p62 (nucleation). Then, the phagophore elongates, matures, and the autophagosome fuses with a lysosome. (B) Overview of the mediators involved in macroautophagy and some of their stimulators/inhibitors (green and red respectively). Autophagy initiation occurs by activated AMPK, which phosphorylates the ULK1/2-Atg13-FIP200 complex. mTORC1 inhibits this complex. Once the autophagy pathway is activated, a phagophore is formed and the class III PI3K complex is responsible for nucleation. Two different conjugation systems are important for elongation of the phagophore (Atg12-Atg5 and Atg8/LC3). GABARAP and Atg4 are involved in autophagosome maturation, and fusion of the autophagosome with a lysosome is mediated by EPG5 and SNARE proteins. Finally, the cargo is degraded by proteases.

inducing autophagy in human pancreatic cancer cells ( $\mathrm{Li}$ et al., 2016). The antimalarial and anti-inflammatory agent chloroquine targets the last step in the autophagy pathway by inhibiting fusion of autophagosomes and lysosomes (Yoon et al., 2010). Although certain compounds seem to target autophagy pathways effectively, former mentioned compounds can act directly with a positive effect (e.g., tumor regression), as well as indirectly causing side effects.

\section{AUTOPHAGY IN THE HEART: SOME LESSONS FROM GENE DEFECTS}

Autophagy is important for maintenance of the highly organized cardiac structure, function and homeostasis. Nutrient insufficient conditions lead to the inactivation of mTORC1: rapamycin interacts with and inhibits mTORC1 activating unc-51-like kinase 1 and 2 (ULK1 and ULK2), leading to autophagy induction (Lavandero et al., 2013). Activation of sensitive nutrient sensor AMPK occurs when ATP/AMP levels decrease due to exercise, ischemia or lack of glucose, resulting in autophagy initiation (Hardie et al., 2012). Other important autophagy mediators in the cardiovascular system include inositol 1,4,5-triphosphate $\left(\mathrm{IP}_{3}\right)$, transcription factor 53 (TP53), cyclic AMP-dependent protein kinase A (PKA), histone acetyltransferases (HATs) and histone deacetylases (HDACs), glycogen synthase kinase $3 \beta$ (GSK3 $\beta$ ), nicotinamide adenine dinucleotide $\left(\mathrm{NAD}^{+}\right)$and microRNAs, which can initiate and inhibit autophagy, as reviewed by Lavandero et al. (2013). Impaired autophagy pathway signaling, due to ATG protein deficiency, may cause cardiac pathologies. 
Mice with Atg5 and Atg7 deficiency, ATG proteins involved in phagophore elongation, displayed dilated cardiomyopathy and contractile dysfunction, and accumulation of defective proteins and organelles, respectively (Komatsu et al., 2005; Nakai et al., 2007). Ectopic P-granules autophagy protein 5 (EPG5), important in translocation of autophagosomes to lysosomes, deficient individuals suffer from the Vici syndrome; a multisystem disorder with autophagy malfunction (Cullup et al., 2013). Cardiac symptoms, predominantly hypertrophy and left ventricular dilatation, are present in $90 \%$ of the Vici syndrome patients (Byrne et al., 2016). Deficiency of LAMP2 , required for the fusion of autophagosomes with endosomes and lysosomes (Endo et al., 2015), leads to Danon disease causing intellectual disability, skeletal myopathy and severe cardiomyopathy (D'souza et al., 2014). LAMP-2 deficient mice have a high mortality rate, show autophagosome accumulation in the pancreas, liver, kidney, skeletal muscle and heart, and possess cardiomyocytes filled with large vacuoles. The latter might be the cause of a reduced heart muscle contractility observed in these mice (Tanaka et al., 2000). Apart from the reductive, but instructive, ATG deficient models, most studies however focus on ischemia/reperfusion (I/R) and hypertrophy models to examine the role of cardiac autophagy (Lavandero et al., 2013).

\section{AUTOPHAGY IN CARDIAC ISCHEMIA/REPERFUSION AND HYPERTROPHY MODELS}

Both protective (clearance and removal of misfolded proteins and roles in energy homeostasis) and detrimental (massive digestion of cellular components and cross-talk to other forms of cell death) functions of autophagy have been presented in ischemic and hypertrophy models (Sciarretta et al., 2011). In the ischemic heart, upregulation of autophagy associates with a reduction in infarct size and apoptosis, and vice versa, suggested to work cardioprotective by maintaining energy levels (Sciarretta et al., 2014). In this situation, the drop in ATP levels during ischemia activates AMPK leading to an upregulation of autophagy activation (Takagi et al., 2007). In mice hearts however that underwent $I / R$, when oxygen and nutrient supply is impaired and subsequently restored, AMPK is inactivated, mTOR is upregulated, and beclin-1 is highly upregulated, suggesting an inhibition of autophagy (Matsui et al., 2007). Remarkably, these mice showed an increase in autophagosome levels and a decrease in apoptosis.

Cardiac hypertrophy is associated with an upregulation of autophagy. Weng et al. (2014) presented an increase in autophagic gene (Atg5 and Atg16) expression, and increased beclin-1 and microtubule-associated protein $1 \mathrm{~A} / 1 \mathrm{~B}$ chain 3 phosphatidylethanolamine conjugate (LC3-II) levels in transverse aortic constriction (TAC), to induce pressure overload, operated mice. Furthermore, AMPK induces autophagy in TAC operated hearts by regulating the mTORC1 pathway, leading to inhibition of cardiac hypertrophy and improved cardiac function (Li Y. et al., 2014). Cardiac-specific knockout of mTOR showed an impaired hypertrophic response and enhanced heart failure progression after TAC mediated pressure-overload in mice, suggesting detrimental effects when mTOR is lacking (Zhang et al., 2010). However, pharmacologic inhibition of mTOR indicates a cardiac protective effect: rapamycin treatment in TAC operated mice showed an inhibitory effect on cardiac hypertrophy development (McMullen et al., 2004). Moreover, treatment of rapamycin in cardiac transplant recipients resulted in reduced left ventricular mass and improved diastolic function (Raichlin et al., 2008). Altogether, current evidence states that regulation of autophagy levels is crucial in protecting cardiomyocytes under ischemic and hypertrophic conditions.

\section{INCREASED AUTOPHAGY ACTIVATION IN ARRHYTHMIC CONDITIONS}

Connexin43 ( $\mathrm{Cx} 43)$ proteins form gap junctions, which are responsible for the propagation of cardiac action potentials between cardiomyocytes. In the recent years, literature has been growing regarding the role of autophagy in degradation of $\mathrm{Cx} 43$ (Falk et al., 2014). A lowered expression of Cx43 was also linked to arrhythmias: among others, (Shu et al., 2017) showed a lowered $\mathrm{Cx} 43$ protein expression in a canine model with atrial fibrillation (AF) induced by rapid atrial pacing (RAP). It remains to be identified if a lowered $\mathrm{Cx} 43$ expression in arrhythmic conditions was mediated by autophagic degradation. As an indication of autophagy activation, levels of autophagy mediators have been examined in several arrhythmic conditions. A RAP canine model, vulnerable to AF, showed an increase in LC3B-II (LC3 family member) and phosphorylated AMPK (p-AMPK) protein levels (Yuan et al., 2014). Moreover, in the same study, it was presented that these autophagy mediators were increased in human patients suffering from AF. Furthermore, beclin-1 and LC3B-II expression levels were increased in I/R-injured fibrillated mouse hearts (Meyer et al., 2013). The increased levels of these autophagy mediators suggest increased autophagy activation in response to arrhythmias. Although the number of autophagic vacuoles was elevated in patients who underwent coronary artery bypass grafting with postoperative AF, decreased levels of LC3B-II levels were found in these patients (Garcia et al., 2012). A decrease in vesicle degradation and an impaired autophagic flow can clarify the elevated vesicle levels and the decreased LC3B-II levels, respectively (Garcia et al., 2012). These exciting findings, albeit just a few, appear to outpoint that autophagy pathways are becoming activated in arrhythmic conditions, and are therefore of interest as potential therapeutic targets. Nonetheless, the exact mechanistic relationship between autophagy and cardiac arrhythmias clearly remains to be elucidated.

\section{ANTIARRHYTHMIC DRUGS AFFECT AUTOPHAGY PATHWAYS}

Along with limited research into autophagy occurrence and regulation in arrhythmic conditions, only a few studies have thus far focused on the effect of antiarrhythmic drugs on autophagy activation and the results are interesting. Table 1 demonstrates the effect on autophagic regulation, the effective concentrations 
TABLE 1 | The effect of the discussed compounds on autophagy activation, their effective concentration on autophagy regulation, their therapeutic plasma concentrations, and their potential link to arrhythmic conditions.

\begin{tabular}{|c|c|c|c|c|c|}
\hline Compound & $\begin{array}{l}\text { Autophagic } \\
\text { activation }\end{array}$ & \multicolumn{2}{|c|}{ Concentrations } & \multirow{2}{*}{$\begin{array}{l}\text { Associated with } \\
\text { arrhythmias }^{\text {a }}\end{array}$} & \multirow{2}{*}{$\begin{array}{l}\text { References } \\
\begin{array}{l}\text { Zhou et al., 2001; Almilaji et al., } \\
2013\end{array}\end{array}$} \\
\hline AICAR & $\uparrow$ & $\begin{array}{l}\text { AMPK activation } \\
\text { Plasma levels }\end{array}$ & $\begin{array}{l}500 \mu \mathrm{M} \\
\text { not reported }\end{array}$ & & \\
\hline Amiodarone & $\uparrow$ & $\begin{array}{l}\text { mTORC1 inhibition } \\
\text { Plasma levels }\end{array}$ & $\begin{array}{l}>10 \mu \mathrm{M} \\
0.8-3.9 \mu \mathrm{M}\end{array}$ & $\begin{array}{l}+ \\
\text { QT prolongation }\end{array}$ & $\begin{array}{l}\text { Balgi et al., 2009; Tarapués } \\
\text { et al., 2014; Hrudikova } \\
\text { Vyskocilova et al., } 2017 .\end{array}$ \\
\hline Chloroquine & $\downarrow$ & $\begin{array}{l}\text { Autolysosome fusion } \downarrow \\
\text { Mean peak plasma level }\end{array}$ & $\begin{array}{l}120 \mu \mathrm{M} \\
0.4 \mu \mathrm{M}\end{array}$ & $\begin{array}{l}+ \\
\text { at high dose }\end{array}$ & $\begin{array}{l}\text { Walker et al., 1983; White, 2007; } \\
\text { Yoon et al., } 2010\end{array}$ \\
\hline Compound C & $\downarrow$ & $\begin{array}{l}\text { AMPK inhibition } \\
\text { Plasma levels }\end{array}$ & $\begin{array}{l}20 \mu \mathrm{M} \\
\text { not reported }\end{array}$ & $\begin{array}{l}\downarrow \text { (potentially) by } \\
\text { hERG activation }\end{array}$ & $\begin{array}{l}\text { Zhou et al., 2001; Almilaji et al., } \\
2013\end{array}$ \\
\hline Dronedarone & $\uparrow$ & $\begin{array}{l}\text { Autophagy activation } \\
\text { Steady-state plasma } \\
\text { levels }\end{array}$ & $\begin{array}{l}2 \mu \mathrm{M} \\
0.15-0.3 \mu \mathrm{M}\end{array}$ & $\begin{array}{l}+ \\
\text { QT prolongation }\end{array}$ & $\begin{array}{l}\text { Wadhani et al., 2006; Patel et al., } \\
\text { 2009; Piccoli et al., } 2011\end{array}$ \\
\hline Metformin & $\uparrow$ & $\begin{array}{l}\text { AMPK activation } \\
\text { Steady-state plasma } \\
\text { levels }\end{array}$ & $\begin{array}{l}>2 \mu \mathrm{M} \\
10-40 \mu \mathrm{M}\end{array}$ & $\begin{array}{l}\downarrow A F \text { in } \\
\text { DM patients }\end{array}$ & $\begin{array}{l}\text { Zhou et al., 2001; Chang et al., } \\
2014\end{array}$ \\
\hline Niclosamide & $\uparrow$ & $\begin{array}{l}\text { mTORC1 inhibition } \\
\text { Serum concentration } \\
\text { range }\end{array}$ & $\begin{array}{l}1 \mu \mathrm{M} \\
0.76- \\
18.32 \mu \mathrm{M}\end{array}$ & Not reported & $\begin{array}{l}\text { Andrews et al., 1982; Balgi et al., } \\
2009\end{array}$ \\
\hline Nifedipine & $\uparrow$ & $\begin{array}{l}\text { Autophagy activation } \\
\text { Mean peak plasma level }\end{array}$ & $\begin{array}{l}10 \mu \mathrm{M} \\
0.35 \mu \mathrm{M}\end{array}$ & $\begin{array}{l}\downarrow \\
\text { LTCC blocker }\end{array}$ & $\begin{array}{l}\text { Van Bortel et al., 1989; Redfern } \\
\text { et al., 2003; Pushparaj et al., } \\
2015\end{array}$ \\
\hline Paliperidone & $\uparrow$ & $\begin{array}{l}\text { Downstream effector } \\
\text { mTOR } \\
\text { Mean plasma level }\end{array}$ & $\begin{array}{l}\text { not reported } \\
84.4 \mathrm{nM}\end{array}$ & $\begin{array}{l}+ \\
\text { hERG inhibition }\end{array}$ & $\begin{array}{l}\text { Nazirizadeh et al., 2010; } \\
\text { Vigneault et al., 2011; Mas et al., } \\
2015\end{array}$ \\
\hline Pentamidine & $\uparrow$ & $\begin{array}{l}\text { Kir2.1 degradation } \\
\text { Plasma levels }\end{array}$ & $\begin{array}{l}5-10 \mu \mathrm{M} \\
0.5-2.4 \mu \mathrm{M}\end{array}$ & $\begin{array}{l}+ \\
\text { Risk for TdP }\end{array}$ & $\begin{array}{l}\text { Waalkes et al., 1970; Antoniou } \\
\text { and Gough, 2005; Nalos et al., } \\
2011\end{array}$ \\
\hline Perhexiline & $\uparrow$ & $\begin{array}{l}\text { mTORC1 inhibition } \\
\text { Serum concentration } \\
\text { range }\end{array}$ & $\begin{array}{l}1-10 \mu \mathrm{M} \\
0.8-3.8 \mu \mathrm{M}\end{array}$ & $\begin{array}{l}+ \\
\text { hERG inhibition }\end{array}$ & $\begin{array}{l}\text { Plicher et al., 1985; Walker et al., } \\
\text { 1999; Balgi et al., } 2009\end{array}$ \\
\hline Phenformin & $\uparrow$ & $\begin{array}{l}\text { AMPK activation } \\
\text { Plasma level }\end{array}$ & $\begin{array}{l}>0.3 \mathrm{mM} \\
0.27 \mu \mathrm{M}\end{array}$ & $\begin{array}{l}+ \\
\text { hERG inhibition }\end{array}$ & $\begin{array}{l}\text { Marchetti et al., 1987; Almilaji } \\
\text { et al., 2013; Vincent et al., } 2015\end{array}$ \\
\hline PI3K inhibitors ${ }^{b}$ & $\uparrow$ & $\begin{array}{l}\text { AMPK activation }{ }^{\mathrm{C}} \\
\text { Mean peak plasma level }\end{array}$ & $\begin{array}{l}5 \mu \mathrm{M} \\
3.6 \mu \mathrm{M}\end{array}$ & $\begin{array}{l}+ \\
\text { APD prolongation }\end{array}$ & $\begin{array}{l}\text { Fava et al., 2008; Yu et al., 2013; } \\
\text { Cohen et al., } 2017\end{array}$ \\
\hline Propranolol & $\downarrow$ & $\begin{array}{l}\text { Late block in autophagy } \\
\text { Plasma levels }\end{array}$ & $\begin{array}{l}10 \mu \mathrm{M} \\
20-428 \mu \mathrm{M}\end{array}$ & $\begin{array}{l}\downarrow \text { shorter QT } \\
\text { in LQT1 }\end{array}$ & $\begin{array}{l}\text { Castleden et al., 1975; Farah } \\
\text { et al., 2014; Ahn et al., } 2017\end{array}$ \\
\hline Ranolazine & $\uparrow$ & $\begin{array}{l}\text { Autophagy activation } \\
\text { Mean steady-state level }\end{array}$ & $\begin{array}{l}1 \mu \mathrm{M} \\
6 \mu \mathrm{M}\end{array}$ & $\begin{array}{l}\downarrow \\
\text { AF episodes }\end{array}$ & $\begin{array}{l}\text { CV Therapeutics Inc., 2007; } \\
\text { Huang et al., 2010; Guerra et al., } \\
2017\end{array}$ \\
\hline Rapamycin & $\uparrow$ & $\begin{array}{l}\text { mTORC1 inhibition } \\
\text { Target concentration } \\
\text { range }\end{array}$ & $\begin{array}{l}0.5-100 \mathrm{nM} \\
4-22 \mathrm{nM}\end{array}$ & $\begin{array}{l}+ \\
>28 n M\end{array}$ & $\begin{array}{l}\text { Stenton et al., 2005; Foster and } \\
\text { Toschi, 2009; Karakas et al., } \\
2016\end{array}$ \\
\hline Rottlerin & $\uparrow$ & $\begin{array}{l}\text { mTORC1 inhibition } \\
\text { Plasma levels }\end{array}$ & $\begin{array}{l}1-3 \mu \mathrm{M} \\
\text { not reported }\end{array}$ & $\begin{array}{l}+ \\
\text { APD shortening }\end{array}$ & Lu et al., 2008; Balgi et al., 2009 \\
\hline Verapamil & $\uparrow$ & $\begin{array}{l}\text { Autophagy activation } \\
\text { Mean peak plasma level }\end{array}$ & $\begin{array}{l}1 \mu \mathrm{M} \\
0.8 \mu \mathrm{M}\end{array}$ & $\begin{array}{l}\text { + LTCC and } \\
\text { hERG inhibition }\end{array}$ & $\begin{array}{l}\text { Frishman et al., 1982; Redfern } \\
\text { et al., 2003; Williams et al., } 2008\end{array}$ \\
\hline Vidarabine & $\downarrow$ & $\begin{array}{l}\text { AMPK inhibition } \\
\text { Mean peak plasma level }\end{array}$ & $\begin{array}{l}>0.5 \mathrm{mM} \\
3.7 \mu \mathrm{M}\end{array}$ & - & $\begin{array}{l}\text { Whitley et al., 1980; Pelletier } \\
\text { et al., 2005; Wada et al., } 2016\end{array}$ \\
\hline Wogonin & $\uparrow$ & $\begin{array}{l}\text { Beclin-1/PI3K activation } \\
\text { Plasma levels }\end{array}$ & $\begin{array}{l}40 \mu \mathrm{M} \\
\text { not reported }\end{array}$ & $\begin{array}{l}\downarrow \\
\text { in ischemic model }\end{array}$ & Lee et al., 2011; Li et al., 2016 \\
\hline
\end{tabular}

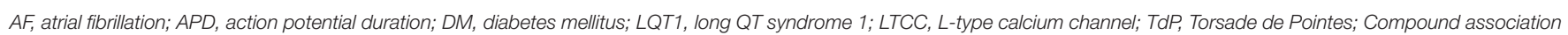
with arrhythmias (+), no association (-), preventive effect ( $\downarrow$ ) or "not reported."

${ }^{a}$ Arrhythmic associations tested in human, animal, or in vitro models.

${ }^{b}$ PI3K inhibitor examples are, as mentioned in the text, nilotinib, dasatinib, and sunitinib.

${ }^{c}$ Nilotinib concentration. 
affecting autophagy, the clinical effective concentrations, and a possible association with arrhythmias of the compounds discussed in this perspective. The effective concentrations of the compounds on autophagy regulation, although tested in vitro with limited concentration ranges, can be compared to drug plasma levels in patients. Overlapping concentrations indicate that a number of clinically used compounds are likely to influence authophagy regulation. Antiarrhythmic drugs are classified by the effect on the targets whose actions form the cardiac action potential. Class I drugs block $\mathrm{Na}^{+}$channels, class II drugs are adrenergic receptor antagonists, class III drugs are $\mathrm{K}^{+}$channel blockers, and the AV-node conduction is slowed down by class IV drugs usually by blockage of L-type calcium channels (LTCCs). The antiarrhythmic effects of $\mathrm{Na}^{+}$channel blocker ranolazine, initially developed as antianginal agent, are convincing (Gupta et al., 2015). Huang et al. (2010) showed induced autophagy activation after ranolazine treatment in HL1 cells and isolated rat cardiomyocytes. Commonly used betablocker propranolol is reported as autophagy inhibitor: increased LC3-II levels, autophagosome formation, and p62 (which degrades during autophagy stimulation) levels were measured in HepG2 cells, suggesting an inhibition of hepatic autophagy by propranolol at a later stage due to reduced degradation (Farah et al., 2014). Class III antiarrhythmic drug amiodarone inhibits mTORC1 leading to stimulation of the autophagy pathway, which was explored in vitro (Balgi et al., 2009). In another in vitro study, we indicated lysosomal impairment by amiodarone and its synthetic analog dronedarone, which resulted in increased inward rectifier potassium channel $\mathrm{K}_{\mathrm{ir}} 2.1$ expression and intracellular accumulation (Ji et al., 2017a). The well-known drawback of amiodarone is its high incidence of side effects, including thyroid toxicity, pulmonary toxicity, hepatic toxicity, neurological toxicity, which seem to be related to the lifetime cumulative dose of the drug (Santangeli et al., 2012). However, pharmacological activation of autophagy by amiodarone has been shown to improve liver regeneration after partial hepatectomy in mice (Lin et al., 2015). LTCC blocker nifedipine, used as arterial vasodilator, increases autophagic flow, as shown by increased presence of autophagosomes and LC3-II levels, and lower p62 levels in isolated rat cardiomyocytes (Pushparaj et al., 2015). LTCC blocker verapamil, used in treating angina and arrhythmias, increases autophagic flux, which was shown by elevated LC3-II levels in PC12 cells and in a series of human cell lines, in which the latter also included increased development of autophagic vacuoles (Williams et al., 2008; Kania et al., 2017). These studies, although limited in number, clearly represent the existing link between antiarrhythmic drugs and autophagy, and the direct outcomes can be both activation and inhibition of autophagy.

\section{NON-CARDIAC DRUGS CAN ACT PROARRHYTHMIC AND AFFECT AUTOPHAGY}

As well as antiarrhythmic compounds, non-cardiac drugs can have the tendency to act proarrhythmic, e.g. by prolonging the QT interval with an increased risk for Torsade de Pointes
(TdP) arrhythmias (Bossu et al., 2016), and they can affect the autophagic pathway. Many compounds with increased proarrhythmic risk are clinically used, or only reached phase I of clinical trials, to treat various disease areas. The former discussed drug chloroquine, which increases the lysosomal $\mathrm{pH}$ and thereby prevents the degradation of certain autophagy substrates, is reported as proarrhythmic. Accumulated levels of $\mathrm{K}_{\mathrm{ir}} 2.1$ were found intracellularly and $\mathrm{I}_{\mathrm{K} 1}$ densities increased due to chloroquine treatment (Jansen et al., 2008). From an autophagic perspective these results can be linked to the chloroquine-induced QT prolongation, conduction disturbances and cardiomyopathy at high doses, as reviewed by White (2007). The proarrhythmic effect of antiprotozoal drug pentamidine has been firstly reported in 1987 by the description of two case reports with occurrence of TdP arrhythmias after administration of pentamidine, which results have been confirmed later on (Wharton et al., 1987; Antoniou and Gough, 2005). We suggested a link between pentamidine and autophagy, in which pentamidine may induce lysosomal degradation of potassium channel $\mathrm{K}_{\mathrm{ir}} 2.1$ (Nalos et al., 2011). Pentamidine analogs have been, and still are, tested to finally develop efficient and specific $\mathrm{K}_{\mathrm{ir}} 2$.x ion-channel-carried inward rectifier current $\left(\mathrm{I}_{\mathrm{k} 1}\right)$ inhibitors for treating atrial fibrillation and short QT syndrome type 3 (Takanari et al., 2013; Ji et al., 2017b). Antipsychotic drug paliperidone, which inhibits human ether-a-go-go-related gene (hERG) $\mathrm{K}^{+}$channel, has also been characterized to increase the QT interval and increase the risk for TdP arrhythmia (Vigneault et al., 2011; Hagiwara et al., 2016). It may be assumed that it also affects autophagy, since mTOR was identified as a downstream effector of paliperidone-induced extrapyramidal symptoms (side effect of antipsychotics), as observed in a network analysis of gene expression (Mas et al., 2015). The role of autophagy in cancer has been characterized as paradoxical because of its pro-survival and pro-death outcomes (Helgason et al., 2013). A frequently altered pathway in cancer includes PI3K and its inhibitors seem to treat solid tumors and hematologic malignancies (Mayer and Arteaga, 2016). Nilotinib, dasatinib and sunitinib are examples of PI3K inhibitors, which are approved by the FDA to treat certain cancer types, and are shown to induce autophagy pathways in cancer cell models (Le et al., 2010; Yu et al., 2013; Wang et al., 2017). However, a recent study by Cohen et al. (2017), presented a prolongation of the action potential by former named PI3K inhibitors, and thereby clearly suggests that drug safety testing should be improved. The compounds discussed in this paragraph, either approved by the FDA or currently in clinical trials, seem to affect the autophagy pathway and cardiac action potential, while their original purpose is not to affect those. Causality however, needs to be demonstrated.

\section{CONCLUSION AND FUTURE PERSPECTIVES}

Autophagy regulation is crucial in basal and diseased conditions, and has been shown to act both protective and detrimental in cardiac disease models. Up to now, evidence has brought forward that autophagy activation changes in arrhythmic conditions of the heart. In addition, some antiarrhythmic drugs have been 
shown to affect autophagy pathways and this may associate with adverse effects. The direct effects and deciphering of the complex underlying mechanisms of antiarrhythmic drugs on autophagy mediation in the heart remain to be determined. Ion channels are crucial in maintaining a regular cardiac rhythm and some are also involved in autophagy regulation, as reviewed by Kondratskyi et al. (2017), indicating a possible direction of future research. Another research aim should be to understand the dependent role of remodeling on autophagy in cardiac arrhythmic conditions. Gene defect models and arrhythmia-induced models are promising in understanding the mechanistic relationship between autophagy and arrhythmias. We also suggest that future work should include the examination of autophagy effects in

\section{REFERENCES}

Ahn, J., Kim, H. J., Choi, J. I., Lee, K. N., Shim, J., Ahn, H. S., et al. (2017). Effectiveness of beta-blockers depending on the genotype of congenital long-QT syndrome: a meta-analysis. PLoS ONE 12:e0185680. doi: 10.1371/journal.pone.0185680

Almilaji, A., Munoz, C., Elvira, B., Fajol, A., Pakladok, T., Honisch, S., et al. (2013). AMP-activated protein kinase regulates hERG potassium channel. Eur. J. Physiol. 465, 1573-1582. doi: 10.1007/s00424-013-1299-8

Andrews, P., Thyssen, J., and Lorke, D. (1982). The biology and toxicology of molluscicides, bayluscide. Pharmacol. Ther. 19, 245-295. doi: 10.1016/0163-7258(82)90064-X

Antoniou, T., and Gough, K. A. (2005). Early-onset pentamidine-associated second-degree heart block and sinus bradycardia: case report and review of the literature. Pharmacotherapy 25, 899-903. doi: 10.1592/phco.2005.25.6.899

Balgi, A. D., Fonseca, B. D., Donohue, E., Tsang, T. C. F., Lajoie, P., Proud, C. G., et al. (2009). Screen for chemical modulators of autophagy reveals novel therapeutic inhibitors of mTORC1 signaling. PLoS ONE 4:e7124. doi: 10.1371/journal.pone.0007124

Baskaran, S., Carlson, L., Stjepanovic, G., Young, L. N., Kim, D. J., Grob, P., et al. (2014). Architecture and dynamics of the autophagic phosphatidylinositol 3-kinase complex. Elife 3:e05115. doi: 10.7554/eLife.05115

Bossu, A., Van der Heyden, M. A. G., De Boer, T. P., and Vos, M. A. (2016). A 2015 focus on preventing drug-induced arrhythmias. Expert Rev. Cardiovasc. Ther. 14, 245-253. doi: 10.1586/14779072.2016.1116940

Byrne, S., Dionisi-Vici, C., Smith, L., Gautel, M., and Jungbluth, H. (2016). Vici syndrome: a review. Orphanet J. Rare Dis. 11:21. doi: 10.1186/s13023-016-0399-x

Castleden, C. M., Kaye, C. M., and Parsons, R. L. (1975). The effect of age on plasma levels of propranolol and practolol in man. Br. J. Clin. Pharmacol. 2, 303-306.

Chang, S., Wu, L., Chiou, M., Liu, J., Yu, K., Kuo, C., et al. (2014). Association of metformin with lower atrial fibrillation risk among patients with type 2 diabetes mellitus: a population-based dynamic cohort and in vitro studies. Cardiovasc. Diabetol. 13:123. doi: 10.1186/014-0123-x

Cohen, I. S., Lin, R. Z., and Ballou, L. M. (2017). Acquired long QT syndrome and phosphoinositide 3-kinase. Trends Cardiovasc. Med. 27, 451-459. doi: 10.1016/j.tcm.2017.05.005

Cremonese Filipi-Chiela, E., Viegas, M. S., Paulo Thome, M., Buffon, A., Wink, M. R., and Lenz, G. (2016). Modulation of autophagy by calcium signalosome in human disease. Mol. Pharmacol. 90, 371-384. doi: 10.1124/mol.116.105171

Cuervo, A. M., and Wong, E. (2014). Chaperone-mediated autophagy: roles in disease and aging. Cell Res. 24, 92-104. doi: 10.1038/cr.2013.153

Cullup, T., Kho, A. L., Dionisi-Vici, C., Brandmeier, B., Smith, F., Urry, Z., et al. (2013). Recessive mutations in EPG5 cause Vici syndrome, a multisystem disorder with defective autophagy. Nat. Genet. 45, 83-87. doi: 10.1038/ng.2497

CV Therapeutics Inc. (2007). Data from: Ranexa (Ranolazine) Tablet, Film Coated, Extended Release. Available online at: https://dailymed.nlm.nih.gov/dailymed/ archives/fdaDrugInfo.cfm? archiveid $=5376$

De Duve, C., Pressman, B. C., Gianetto, R., Wattiaux, R., and Appelmans, F. (1955). Tissue fractionation studies. 6. Intracellular exploring the effectiveness of antiarrhythmic drugs. This may improve drug development to provide safer antiarrhythmic drugs by removal of autophagy pathway disturbances. Antiarrhythmic drugs may then not further worsen autophagy dysregulation in arrhythmic conditions. Beyond doubt, from an autophagic perspective; focus should increase on its regulation under arrhythmic conditions, and on the effects of its unknown targeting by antiarrhythmic compounds and other drugs.

\section{AUTHOR CONTRIBUTIONS}

All authors listed, have made substantial, direct and intellectual contribution to the work, and approved it for publication.

distribution patterns of enzymes in rat-liver tissue. Biochem. J. 60, 604-717.

D’souza, R. S., Levandowski, C., Slavov, D., Graw, S. L., Allen, L. A., Adler, E., et al. (2014). Danon disease: clinical features, evaluation, and management. Circ. Heart Fail. 7, 843-849. doi:10.1161/CIRCHEARTFAILURE.114. 001105

Ducommon, S., Ford, R. J., Bultot, L., Deak, M., Bertrand, L., Kemp, B. E., et al. (2014). Enhanced activation of cellular AMPK by dual-small molecule treatment: AICAR and A769662. Am. J. Physiol. Endocrinol. Metab. 306, 688-696. doi: 10.1152/ajpendo.00672.2013

Endo, Y., Furuta, A., and Nishino, I. (2015). Danon disease: a phenotypic expression of LAMP-2 deficiency. Acta Neurophatol. 129, 391-398. doi: 10.1007/s00401-015-1385-4

Falk, N. M., Kells, R. M., and Berthoud, V. M. (2014). Degradation of connexins and gap junctions. FEBS Lett. 588, 1221-1229. doi: 10.1016/j.febslet.2014.01.031

Farah, B. L., Sinha, R. A., Wu, Y., Singh, B. K., Zhou, J., Bay, B. H., et al. (2014). B-adrenergic agonist and antagonist regulation of autopahgy in HepG2 cells, primary mouse hepatocytes and mouse liver. PLoS ONE 9:e98155. doi: 10.1371/journal.pone.0098155

Fava, C., Kantarjian, H., Cortes, J., and Jabbour, E. (2008). Development and targeted use of nilotinib in chronic myeloid leukemia. Drug Des. Devel. Ther. 2, 233-243.

Feng, Y., He, D., Yao, Z., and Klionsky, D. J. (2014). The machinery of macroautophagy. Cell Res. 24, 24-41. doi: 10.1038/cr.2013.168

Foster, D. A., and Toschi, A. (2009). Targeting mTOR with rapamycin: one dose does not fit all. Cell Cycle 8, 1026-1029. doi: 10.4161/cc.8.7.8044

Frishman, W., Kirsten, E., Klein, M., Pine, M., Johnson, S. M., Hillis, L. D., et al. (1982). Clinical relevance of verapamil plasma levels in stable angina pectoris. Am. J. Cardiol. 50, 1180-1184. doi: 10.1016/0002-9149(82)90440-4

Galluzzi, L., Baehrecke, E. H., Ballabio, A., Boya, P., Bravo-San Pedro, J. M., Cecconi, F., et al. (2017). Molecular definitions of autophagy and related processes. EMBO J. 36, 1811-1836. doi: 10.15252/embj.201796697

Garcia, L., Verdejo, H. E., Kuzmicic, J., Zalaquett, R., Gonzalez, S., Lavandero, S., et al. (2012). Impaired cardiac autophagy in patients developing postoperative atrial fibrillation. J. Thorac. Cardiovasc. Surg. 143, 451-459. doi: 10.1016/j.jtcvs.2011.07.056

Guerra, F., Romandini, A., Barbarossa, A., Belardinelli, L., and Capucci, A. (2017). Ranolazine for rhythm control in atrial fibrillation: a systemic review and meta-analysis. Int. J. Cardiol. 15, 284-291. doi: 10.1016/j.ijcard.2016.11.103.

Gupta, T., Khera, S., Kolte, D., Aronow, W. S., and Iwai, S. (2015). Antiarrhythmic properties of ranolazine: a review of the current evidence. Int. J. Cardiol. 187, 66-74. doi: 10.1016/j.ijcard.2015.03.324

Hagiwara, M., Kambayashi, R., Aimoto, M., Nagasawam, Y., and Takahara, A. (2016). In vivo analysis of torsadogenic potential of an antipsychotic drug paliperidone using the acute atrioventricular block rabbit as a proarrhythmia model. J. Pharmacol. Sci. 132, 48-54. doi: 10.1016/j.jphs.2016.05.001

Hardie, D. G., Ross, F. A., and Hawly, S. A. (2012). AMPK: a nutrient and energy sensor that maintains energy homeostasis. Nat. Rev. Mol. Cell Biol. 13, 251-262. doi: $10.1038 / \mathrm{nrm} 3311$ 
Helgason, G. V., Holyoake, T. L., and Ryan, K. M. (2013). Role of autophagy in cancer prevention, development and therapy. Essays Biochem. 55, 133-151. doi: $10.1042 /$ bse 0550133

Hrudikova Vyskocilova, E., Grundmann, M., Duricova, J., and Kacirova, I. (2017). Therapeutic monitoring of amiodarone: pharmacokinetics and evaluation of the relationship between effect and dose/concentration. Biomed. Pap. Med. Fac. Univ. Palacky. Olomouc. Czech. Repub. 161, 134-143. doi: 10.5507/pb.2017.016

Huang, C., Yitzhaki, S., Perry, C. N., Liu, W., Giricz, Z., Mentzer, R. M., et al. (2010). Autophagy induced by ischemic preconditioning is essential for cardioprotection. J. Cardiacvasc. Transl. Res. 3, 365-373. doi: 10.1007/s12265-010-9189-3

Itakura, E., Kishi-Itakura, C., and Mizushima, N. (2012). The hairpin-type tailanchored SNARE syntaxin 17 targets to autophagosomes for fusion with endosomes/lysosomes. Cell 151, 1256-1269. doi: 10.1016/j.cell.2012.11.001

Jansen, J. A., De Boer, T. P., Wolswinkel, R., van Veen, T. A. B., Vos, M. A., van Rijen, H. V. M., et al. (2008). Lysosome mediated Kir2.1 breakdown directly influences inward rectifier current density. Biochem. Biophys. Res. Commun. 367, 686-692. doi: 10.1016/j.bbrc.2007.12.168

Ji, Y., Takanari, H., Qile, M., Nalos, L., Houtman, M. J. C., Romunde, F. L., et al. (2017a). Class III antiarhythmic drugs amiodarone and dronedarone impair Kir2.1 backward trafficking. J. Cell. Mol. Med. 21, 2514-2523. doi: $10.1111 /$ jcmm.13172

Ji, Y., Veldhuis, M. G., Zandvoort, J., Romunde, F. L., Houtman, M. J. C., Duran, K., et al. (2017b). PA-6 inhibits inward rectifier currents carried by V93I and D172N gain-of-function Kir2.1 channels, but increases channel protein expression. J. Biomed. Sci. 24:44. doi: 10.1186/s12929-017-0352-x

Kaminskyy, V., and Zhivotovsky, B. (2012). Proteases in autophagy. Biochim. Biophys. Acta 1824, 44-50. doi: 10.1016/j.bbapap.2011.05.013

Kania, E., Pajak, B., O’Prey, J., Sierra Gonzalez, P., Litwiniuk, A., Urbanska, K., et al. (2017). Verapamil treatment induces cytoprotective autophagy by modulating cellular metabolism. FEBS J. 284, 1370-1387. doi: 10.1111/febs.14064

Karakas, N. M., Erdogan, I., Ozdemir, B., and Sezgin, A. (2016). Pain syndrome and ventricular arrhythmia induced by sirolimus and resolved by dosage adjustment in a child after heart transplant: a case report. Exp. Clin. Transplant. doi: 10.6002/ect.2015.0320. [Epub ahead of print].

Kim, J., Kundu, M., Viollet, B., and Guan, K. (2011). AMPK and mTOR regulate autophagy through direct phorphorylation of Ulk1. Nat. Cell Biol. 13, 132-141. doi: $10.1038 / \mathrm{ncb} 2152$

Klionsky, D. J., Cuervo, A. M., Dunn, W. A. Jr., Levine, B., Van der Klei, I. J., and Seglen, P. O. (2007). How shall I eat thee? Autophagy 3, 413-416. doi: 10.4161/auto.4377

Komatsu, M., Waguri, S., Ueno, T., Iwata, J., Murata, S., Tanida, I., et al. (2005). Impairment of starvation-induced and consitutive autophagy in Atg7-deficient mice. J. Cell Biol. 169, 425-434. doi: 10.1083/jcb.200412022

Kondratskyi, A., Kondratska, K., Skryma, R., Klionsky, D. J., and Prevarskaya, N. (2017). Ion channels in the regulation of autophagy. Autophagy 5,1-19. doi: $10.1080 / 15548627.2017 .1384887$

Kudenchuk, P. J., Pierson, D. J., Greene, H. L., Graham, E. L., Sears, G. K., and Trobaugh, G. B. (1984). Prospective evaluation of amiodarone pulmonary toxicity. Chest 86, 541-548. doi: 10.1378/chest.86.4.541

Lavandero, S., Tronscoso, R., Rothermel, B. A., Martinet, W., Sadoshima, J., and Hill, J. A. (2013). Cardiovascular autophagy: concepts, controversies, and perspectives. Autophagy 9, 1455-1466. doi: 10.4161/auto.25969

Le, X., Mao, W., Lu, Z., Carter, B., and Bast, R. C. (2010). Dasatinib induces autophagic cell death in human ovarian cancer. Cancer 116, 4980-4990. doi: $10.1002 / \mathrm{cncr} .25426$

Lee, Y. M., Cheng, P. Y., Chen, S. Y., Chung, M. T., and Sheu, J. R. (2011). Wogonin suppresses arrhythmias, inflammatory responses, and apoptosis induced by myocardial ischemia/reperfusion in rats. J. Cardiovasc. Pharmacol. 58, 133-142. doi: 10.1097/FJC.0b013e31821a5078

Levine, B., and Klionsky, D. J. (2017). Autophagy wins the 2016 nobel prize in physiology or medicine: breakthroughs in baker's yeast fuel advances in biomedical research. Proc. Natl. Acad. Sci. U.S.A. 114, 201-205. doi: $10.1073 /$ pnas.1619876114

Li, J., Kim, S. G., and Blenis, J. (2014). Rapamycin: one drug, many effects. Cell Metab. 19, 373-379. doi: 10.1016/j.cmet.2014.01.001

Li, S., Sun, S., Gao, J., and Sun, F. (2016). Wogonin induces Beclin$1 / \mathrm{PI} 3 \mathrm{~K}$ and reactive oxygen species-mediated autophagy in human pancreatic cancer cells. Oncol. Lett. 12, 5059-5067. doi: 10.3892/ol.201 6.5367

Li, W., Li, J., and Bao, J. (2012). Microautophagy: lesser-known self-eating. Cell. Mol. Life Sci. 69, 1125-1136. doi: 10.1007/s00018-011-0865-5

Li, Y., Chen, C., Yao, F., Su, Q., Liu, D., Xue, R., et al. (2014). AMPK inhibits cardiac hypertrophy by promoting autophagy via mTORC1. Arch. Biochem. Biophys. 558, 79-86. doi: 10.1016/j.abb.2014.06.023

Lin, C., Chen, Y., Lin, C., Chen, Y., Lo, G., Lee, P., et al. (2015). Amiodarone as an autophagy promotor reduces liver injury and enhances liver regeneration and survival in mice after partial hepatectomy. Sci. Rep. 5:15807. doi: $10.1038 /$ srep 15807

Lu, H. R., Vlaminckx, E., Hermans, A. N., Rohrbacher, J., Van Ammel, K., Towart, R., et al. (2008). Predicting drug-induced changes in QT interval and arrhythmias: QT-shortening drugs point to gaps in the ICHS7B guidelines. $\mathrm{Br}$. J. Pharmacol. 154, 1427-1438. doi: 10.1038/bjp.2008.191

Marchetti, P., Benci, L., Cecchetti, P., Giannarelli, R., Boni, C., Ciociaro, D., et al. (1987). Plasma biguanide levels are correlated with metabolic effects in diabetic patients. Clin. Pharmacol. Ther. 41, 450-454. doi: 10.1038/clpt.1987.55

Mas, S., Gasso, P., Parellada, E., Bernardo, M., and Lafuente, A. (2015). Network analysis of gene expression in peripheral blood identifies mTOR and NF$\mathrm{kB}$ pathways involved in antipsychotic-induced extrapyramidal symptoms. Pharmacogenomics J. 15, 452-460. doi: 10.1038/tpj.2014.84

Matsui, Y., Takagi, H., Qu, X., Abdellatif, M., Sakoda, H., Asano, T., et al. (2007). Distinct roles of autophagy in the heart during ischemia and reperfusion: roles of AMP-activated protein kinase and Beclin 1 in mediating autophagy. Circ. Res. 100, 914-922. doi: 10.1161/01.RES.0000261924. 76669.36

Matsuura, A., Tsukada, M., Wada, Y., and Ohsumi, Y. (1997). Apglp, a novel protein kinase required for the autophagic process in Saccharomyces cerevisiae. Gene 192, 245-250. doi: 10.1016/S0378-1119(97)00084-X

Mayer, I. A., and Arteaga, C. L. (2016). The PI3K/AKT pathway as a target for cancer treatment. Annu. Rev. Med. 67, 11-28 doi: 10.1146/annurev-med-062913-051343

McMullen, J. R., Sherwood, M. C., Tarnavski, O., Zhang, L., Dorfman, A. L., Shioi, T., et al. (2004). Inhibition of mTOR signaling with rapamycin regresses established cardiac hypertrophy induced pressure overload. Circulation 109, 3050-3055. doi: 10.1161/01

Meyer, G., Czompa, A., Reboul, C., Csepanyi, E., Czegledi, A., Bak, I., et al. (2013). The cellular autophagy markers beclin-1 and LC3B-II are increased during reperfusion in fibrillated mouse hearts. Curr. Pharm. Des. 19, 6912-6918. doi: $10.2174 / 138161281939131127122510$

Mulcahy Levy, J. M., Towers, C. G., and Thorburn, A. (2017). Targeting autophagy in cancer. Nat. Rev. Cancer 17, 528-542. doi: 10.1038/nrc.2017.53

Nair, U., Jotwani, A., Geng, J., Gammoh, N., Richerson, D., Yen, W., et al. (2011). SNARE proteins are required for macroautophagy. Cell 146, 290-302. doi: 10.1016/j.cell.2011.06.022

Nakai, A., Yamaguchi, O., Takeda, T., Higuchi, Y., Hikoso, S., Taniike, M., et al. (2007). The role of autophagy in the basal state and in response to hemodynamic stress. Nat. Med. 13, 619-624. doi: 10.1038/nm1574

Nalos, L., De Boer, T. P., Houtman, M. J. C., Rook, M. B., Vos, M. A., and Van der Heyden, M. A. G. (2011). Inhibition of lysosomal degradation rescues pentamidine-mediated decreases of K(ir)2.1 ion channel expression but not of K(v)11.1. Eur. J. Pharmacol. 652, 96-103. doi: 10.1016/j.ejphar.2010.10.093

Nazirizadeh, Y., Vogel, F., Bader, W., Haen, E., Pfuhlmann, B., Gründer, G., et al. (2010). Serum concentrations of paliperidone versus risperidone and clinical effects. Eur. J. Pharmacol. 66, 797-803. doi: 10.1007/s00228-010-0812-7

Patel, C., Yan, G. X., and Kowey, P. R. (2009). Dronedarone. Circulation 120, 636-644. doi: 10.1161/CIRCULATIONNAHA.109.858027

Pelletier, A., Joly, E., Prentki, M., and Coderre, L. (2005). Adenosine 5'monophosphate-activated protein kinase and p38 mitogen-activated protein kinase participate in the stimulation of glucose uptake by dinitrophenol in adult cardiomyocytes. Endocrinology 146, 2285-2294. doi: 10.1210/en.2004-1565

Piccoli, E., Nadai, M., Caretta, C. M., Bergonzini, V., Del Vecchio, C., Ha, H. R., et al. (2011). Amiodarone impairs trafficking through late endosomes inducing a Niemann-Pick C-like phenotype. Biochem. Pharmacol. 82, 1234-1249. doi: 10.1016/j.bcp.2011.07.090

Plicher, J., Cooper, J. D., Turnell, D. C., Matenga, J., Paul, R., and Lockhart, J. D. (1985). Investigations of long-term treatment with perhexiline maleate 
using therapeutic monitoring and electromyography. Ther. Drug. Monit. 7, 54-60.doi: 10.1097/00007691-198503000-00009

Pushparaj, C., Das, A., Purroy, R., Nager, M., Herreros, J., Pamplona, R., et al. (2015). Voltage-gated calcium channel blockers deregulate macroautophagy in cardiomyocytes. Int. J. Biochem. Cell Biol. 68, 166-175. doi: 10.1016/j.biocel.2015.09.010

Raichlin, E., Chandrasekaran, K., Kremers, W. K., Frantz, R. O., Clavelli, A. L., Pereira, N. L., et al. (2008). Sirolimus as primary immunosuppressant reduces left ventricular mass and improves diastolic function of the cardiac allograft. Transplantation 86, 1395-1400. doi: 10.1097/TP.0b013e318189049a

Redfern, W. S., Carlsson, L., Davis, A. S., Lynch, W. G., Machkenzie, I., Palethorpe, S., et al. (2003). Relationships between preclinical cardiac electrophysiology, clinical QT interval prolongation and torsade de pointes for a broad range of drugs: evidence for a provisional safety margin in drug development. Cardiovasc. Res. 58, 32-45. doi: 10.1016/S0008-6363(02)00846-5

Reggiori, F., and Klionsky, D. J. (2013). Autophagic processes in yeast: mechanism, machinery and regulation. Genetics 194, 341-361. doi: 10.1534/genetics.112.149013

Santangeli, P., Di Biase, L., Burkhardt, J. D., Bai, R., Mohanty, P., Pump, A., et al. (2012). Examining the safety of amiodarone. Expert Opin. Drug Saf. 11, 191-214. doi: 10.1517/14740338.2012.660915

Schneider, J. L., and Cuervo, A. M. (2014). Autophagy and human disease: emerging themes. Curr. Opin. Genet. Dev. 26, 16-23. doi: 10.1016/j.gde.2014.04.003

Sciarretta, S., Hariharan, N., Monden, Y., Zablocki, D., and Sadoshima, J. (2011). Is autophagy in response to ischemia and reperfusion protective or detrimental for the heart? Pediatr. Cardiol. 32, 275-281. doi: 10.1007/s00246-010-9855-x

Sciarretta, S., Yee, D., Shenoy, V., Nagarajan, N., and Sadoshima, J. (2014). The importance of autophagy in cardioprotection. High Blood Press. Cardiovasc. Prev. 21, 21-28. doi: 10.1007/s40292-013-0029-9

Shu, C., Huang, W., Zeng, Z., He, Y., Luo, B., Liu, H., et al. (2017). Connexin 43 is involved in the sympathetic atrial fibrillation in canine and canine atrial myocytes. Anatol. J. Cardiol. 18, 3-9. doi: 10.14744/AnatolJCardiol.2017.7602

Singh, R., and Cuervo, A. M. (2011). Autophagy in the cellular energetic balance. Cell Metab. 13, 495-504. doi: 10.1016/j.cmet.2011.04.004

Stenton, S. B., Partovi, N., and Ensom, M. H. H. (2005). Sirolimus. Clin. Pharmacokinet. 44, 769-786. doi: 10.2165/00003088-200544080-00001

Svenning, S., and Johansen, T. (2013). Selective autophagy. Essays Biochem. 55, 79-92. doi: 10.1042/bse 0550079

Takagi, H., Matsui, Y., Hirotani, S., Sakoda, H., Asano, T., and Sadoshima, J. (2007). AMPK mediates autophagy during myocardial ischemia in vivo. Autophagy 3 , 405-407. doi: 10.4161/auto.4281

Takanari, H., Nalos, L., Stary-Weinzinger, A., De Git, K. C. G., Varkevisser, R., Linder, T., et al. (2013). Efficient and specific cardiac Ik1 inhibition by a new pentamidine analogue. Cardiovasc. Res. 99, 203-214. doi: 10.1093/cvr/cvt103

Tanaka, Y., Guhde, G., Suter, A., Eskelinen, E., Hartmann, D., Lullmann-Rauch, R., et al. (2000). Accumulation of autophagic vacuoles and cardiomyopathy in LAMP-2-deficient mice. Nature 406, 902-906. doi: 10.1038/35022595

Tarapués, M., Cereza, G., Arellano, A. L., Montané, E., and Figueras, A. (2014). Serious QT interval prolongation with ranolazine and amiodarone. Int. J. Cardiol. 172, e60-e61. doi: 10.1016/j.ijcard.2013.12.061

Van Bortel, L., Böhm, R., Mooij, J., Schiffers, P., and Rahn, K. H. (1989). Total and free steady-state plasma levels and pharmacokinetics of nifedipine in patients with terminal renal failure. Eur. J. Clin. Pharmacol. 37, 185-189.

Vigneault, P., Kaddar, N., Bourgault, S., Caillier, B., Pilote, S., Patoine, D., et al. (2011). Prolongation of cardiac ventricular repolarization under paliperidone: how and how much? J. Cardiovasc. Pharmacol. 57, 690-695. doi: 10.1097/FJC.0b013e318217d941

Vincent, E. E., Coelho, P. P., Blagih, J., Griss, T., Viollet, B., and Jones, R. G. (2015). Differential effects of AMPK agonists on cell growth and metabolism. Oncogene 34, 3627-3639. doi: 10.1038/onc.2014.301

Waalkes, T. P., Denham, C., and DeVita, V. T. (1970). Pentamidine: clinical pharmacologic correlations in man and mice. Clin. Pharmacol. Ther. 11, 505-512. doi: $10.1002 / \mathrm{cpt} 1970114505$

Wada, T., Nakamura, Y., Cao, X., Ohara, H., Izumi-Nakaseko, H., Nakazato, Y., et al. (2016). Antiviral drug vidarabine possessing cardiac type 5 adenylyl cyclase inhibitory property did not affect cardiohemodynamic or electrophysiological variables in the halothane-anesthetized dogs. J. Toxicol. Sci. 41, 115-122. doi: 10.2131/jts.41.115

Wadhani, N., Sarma, J. S. M., Singh, B. N., Radzik, D., and Gaud, C. (2006). Dosedependent effects of oral dronedarone on the circadian variation of RR and QT intervals in healthy subjects: implications for antiarrhythmic actions. J. Cardiovasc. Pharmacol. Ther. 11, 184-190. doi: 10.1177/1074248406290678

Walker, B. D., Valenzuela, S. M., Singleton, C. B., Tie, H., Bursill, J. A., Wyse, K. R., et al. (1999). Inhibition of HERG channels stably expressed in a mammalian cell line by the antianginal agent perhexiline maleate. Br. J. Pharmacol. 127, 243-251. doi: 10.1038/sj.bjp.0702502

Walker, O., Dawodu, A. H., Adeyokunnu, A. A., Salako, L. A., and Alvan, G. (1983). Plasma chloroquine and desethylchloroquine concentrations in children during and after chloroquine treatment for malaria. Br. J. Clin. Pharmac. 16, 701-705.

Wang, B., Lu, D., Xuan, M., and Hu, W. (2017). Antitumor effect of sunitinib in human prostate cancer cells functions via autophagy. Exp. Ther. Med. 13, 1285-1294. doi: 10.3892/etm.2017.4134

Weng, L., Zhang, W., Ye, Y., Yin, P., Yuan, J., Wang, X., et al. (2014). Aliskerin ameliorates pressure overload-induced heart hypertrophy and fibrosis in mice. Acta Pharmacol. Sin. 35, 1005-1014. doi: 10.1038/aps.2014.45

Wharton, J. M., Demopulos, P. A., and Goldschlager, N. (1987). Torsade de pointes during administration of pentamidine isethionate. Am. J. Med. 83, 571-576. doi: 10.1016/0002-9343(87)90774-1

White, N. J. (2007). Cardiotoxicity of antimalarial drugs. Lancet Infect. Dis. 7, 549-558. doi: 10.1016/S1473-3099(07)70187-1

Whitley, R. J., Tucker, B. C., Kinkel, A. W., Barton, N. H., Pass, R. F., Whelchel, J. D., et al. (1980). Pharmacology, tolerance, and antiviral activity of vidarabine monophosphate in humans. Antimicrob. Agents Chemother. 18, 709-715.

Williams, A., Sarkar, S., Cuddon, P., Ttofi, E. K., Saiki, S., Siddiqi, F. H., et al. (2008). Novel targets for Huntington's disease in an mTOR-independent autophagy pathway. Nat. Chem. Biol. 4, 295-305. doi: 10.1038/nchembio.79

Xie, Y., Kang, R., Sun, X., Zhong, M., Huang, J., Klionsky, D. J., et al. (2015). Posttranslational modification of autophagy-related proteins in macroautophagy. Autophagy 11, 28-45. doi: 10.4161/15548627.2014.984267

Yang, L., Sha, H., Davisson, R. L., and Qi, L. (2013). Phenformin activates the unfolded protein response in an AMP-activated protein kinase (AMPK)-dependent manner. J. Biol. Chem. 288, 13631-13638. doi: 10.1074/jbc.M113.462762

Yoon, Y. H., Cho, K. S., Hwang, J. J., Lee, S., Choi, J. A., and Koh, J. (2010). Induction of lysosomal degradation, arrested autophagy, and cell death by chloroquine in cultured ARPE-19 cells. Invest. Ophthalmol. Vis. Sci. 51, 6030-6037. doi: 10.1167/iovs.10-5278

Yu, H., Lin, C., Tai, W., Liu, C., Shiau, C., and Chen, K. (2013). Nilotinib induces autophagy in hepatocellular carcinoma through AMPK activation. J. Biol. Chem. 288, 18249-18259. doi: 10.1074/jbc.M112.446385

Yuan, Y., Zhao, J., Yan, S., Wang, D., Zhang, S., Yun, F., et al. (2014). Autophagy: a potential novel mechanistic contributor to atrial fibrillation. Int. J. Cardiol. 172, 492-494. doi: 10.1016/j.ijcard.2014.01.027

Zhang, D., Contu, R., Latronico, M. V. G., Zhang, J. L., Rizzi, R., Catalucci, D., et al. (2010). MTORC1 regulates cardiac function and myocyte survival through $4 \mathrm{E}$ BP1 inhibition in mice. J. Clin. Invest. 120, 2805-2816. doi: 10.1172/JCI43008

Zhou, G., Myers, R., Li, Y., Chen, Y., Shen, X., Fenyk-Melody, J., et al. (2001). Role of AMP-activated protein kinase in mechanism of metformin action. J. Clin. Invest. 108, 1167-1174. doi: 10.1172/JCI 13505

Conflict of Interest Statement: The authors declare that the research was conducted in the absence of any commercial or financial relationships that could be construed as a potential conflict of interest.

Copyright $\odot 2018$ van Bavel, Vos and van der Heyden. This is an open-access article distributed under the terms of the Creative Commons Attribution License (CC $B Y)$. The use, distribution or reproduction in other forums is permitted, provided the original author(s) and the copyright owner are credited and that the original publication in this journal is cited, in accordance with accepted academic practice. No use, distribution or reproduction is permitted which does not comply with these terms. 


\section{Development of a High-Throughput Flow Cytometry Assay to Monitor Defective Trafficking and Rescue of Long QT2 Mutant hERG Channels}

OPEN ACCESS

Edited by:

Brian P. Delisle,

University of Kentucky, United States

Reviewed by:

Geoff Abbott,

University of California, Irvine,

United States

Alexey V. Glukhov,

University of Wisconsin System,

United States

*Correspondence:

Henry M. Colecraft

hc2405@cumc.columbia.edu

Specialty section:

This article was submitted to

Cardiac Electrophysiology,

a section of the journal

Frontiers in Physiology

Received: 25 January 2018 Accepted: 04 April 2018

Published: 19 April 2018

Citation:

Kanner SA, Jain $A$ and Colecraft HM (2018) Development of a High-Throughnut Flow Cytometry Assay to Monitor Defective Trafficking and Rescue of Long QT2 Mutant hERG Channels.

Front. Physiol. 9:397. doi: 10.3389/fphys.2018.00397

\section{Scott A. Kanner ${ }^{1}$, Ananya Jain ${ }^{2}$ and Henry M. Colecraft ${ }^{1,2,3 *}$}

${ }^{1}$ Doctoral Program in Neurobiology and Behavior, Columbia University College of Physicians and Surgeons, New York, NY, United States, ${ }^{2}$ Department of Physiology and Cellular Biophysics, Columbia University College of Physicians and Surgeons, New York, NY, United States, ${ }^{3}$ Department of Pharmacology, Columbia University College of Physicians and Surgeons, New York, NY, United States

Long QT Syndrome (LQTS) is an acquired or inherited disorder characterized by prolonged QT interval, exertion-triggered arrhythmias, and sudden cardiac death. One of the most prevalent hereditary LQTS subtypes, LQT2, results from loss-of-function mutations in the $\mathrm{hERG}$ channel, which conducts $I_{K r}$, the rapid component of the delayed rectifier $\mathrm{K}^{+}$current, critical for cardiac repolarization. The majority of LQT2 mutations result in Class 2 deficits characterized by impaired maturation and trafficking of hERG channels. Here, we have developed a high-throughput flow cytometric assay to analyze the surface and total expression of wild-type (WT) and mutant hERG channels with single-cell resolution. To test our method, we focused on 16 LQT2 mutations in the hERG Per-Arnt-Sim (PAS) domain that were previously studied via a widely used biochemical approach that compares levels of $135-\mathrm{kDa}$ immature and $155-\mathrm{kDa}$ fully glycosylated hERG protein to infer surface expression. We confirmed that LQT2 mutants expressed in HEK293 cells displayed a decreased surface density compared to WT hERG, and were differentially rescued by low temperature. However, we also uncovered some notable differences from the findings obtained via the biochemical approach. In particular, three mutations (N33T, R56Q, and A57P) with apparent WT-like hERG glycosylation patterns displayed up to $50 \%$ decreased surface expression. Furthermore, despite WT-like levels of complex glycosylation, these mutants have impaired forward trafficking, and exhibit varying half-lives at the cell surface. The results highlight utility of the surface labeling/flow cytometry approach to quantitatively assess trafficking deficiencies associated with LQT2 mutations, to discern underlying mechanisms, and to report on interventions that rescue deficits in hERG surface expression.

Keywords: long QT syndrome type 2, HERG channels (Kv11), ion channel trafficking, flow cytometry, cardiac arrhythmias

\section{INTRODUCTION}

Long QT Syndrome (LQTS) is an inherited or acquired disorder characterized by delayed cardiac action potential repolarization, which predisposes to polymorphic ventricular tachycardias (torsade de pointes), syncope, and sudden cardiac death (SCD) (Moss and Kass, 2005; Bohnen et al., 2016). Congenital LQTS occurs in approximately 1 in 2000 live births (Schwartz et al., 2009), and 
accounts for a significant portion of $\sim 400,000$ cases of SCD in the United States each year (Tester and Ackerman, 2009; George, 2013). Loss-of-function mutations in several genes have been linked to LQTS (LQT1-LQT13), with around 70\% occurring in genes encoding pore-forming subunits for the primary repolarizing $\mathrm{K}^{+}$currents in ventricular cardiomyocytes KCNQ1 (LQT1) and hERG (LQT2) (Bohnen et al., 2016).

The hERG potassium channels assemble as a tetramer of four Kv11.1 $\alpha_{1}$ pore-forming subunits, and conduct $I_{K r}$, the rapid component of the delayed rectifier $\mathrm{K}^{+}$current (Trudeau et al., 1995). $I_{K r}$ is critical for proper cardiac repolarization, as well as the suppression of arrhythmic events caused by premature stimuli (Sanguinetti et al., 1995; Vandenberg et al., 2012). Over 500 LQT2 mutations in hERG have been described to date, with $\sim 40 \%$ consisting of non-sense mutations and $\sim 60 \%$ being missense mutations (Schwartz et al., 2009; Smith et al., 2016). Four classes of mutations have been described: Class 1 mutations affect channel synthesis or translation; Class 2 mutations affect channel trafficking and intracellular transportation; Class 3 mutations alter channel gating; and Class 4 affect ion permeability (Smith et al., 2016). It has become apparent that the vast majority ( $\sim 88 \%)$ of LQT2 mutations are Class 2 type, featuring compromised channel trafficking to the plasma membrane (Anderson et al., 2006, 2014; Smith et al., 2016). Understanding the mechanisms regulating hERG trafficking and how these may be dysregulated in disease is important for molecular insights into the pathophysiology of LQT2.

The hERG channels undergo several levels of posttranslational processing and maturation before the functional channel reaches the cell surface (Figure 1). They are synthesized in the endoplasmic reticulum (ER), which provides an environment for optimum folding and assembly. In the ER, the $132-\mathrm{kDa}$ protein undergoes $\mathrm{N}$-linked core glycosylation of the protein, generating a $135-\mathrm{kDa}$ immature protein (Zhou et al., 1998b; Petrecca et al., 1999; Gong et al., 2002) (Figure 1, left - step 1). From the ER, hERG that is properly folded and assembled is exported via COPII vesicles (Delisle et al., 2009) to the Golgi where it is matured through N-linked complex glycosylation to generate a $155-\mathrm{kDa}$ protein that is biochemically distinguishable from the immature form (Figure 1, left - step 2). Most studies investigating hERG trafficking defects in inherited or acquired LQT2 have taken advantage of these biochemical signatures, utilizing immunoblot assays to distinguish relative expression of $135-\mathrm{kDa}$ immature and $155-\mathrm{kDa}$ mature bands and, thereby, infer surface expression (Figure 1, left - step 3) (Zhou et al., 1998b, 1999; Gong et al., 2002, 2005; Guo et al., 2009; Dennis et al., 2011; Apaja et al., 2013; Ke et al., 2013).

The conclusion that a majority of LQT2 mutations are of the Class 2 type (i.e., trafficking-deficient) come from observations that there is either a relative or a complete loss of the 155$\mathrm{kDa}$ mature hERG protein in most of these instances (Anderson et al., 2006, 2014; Ke et al., 2013). An important feature of many trafficking-deficient LQT2 mutants is that they are not irretrievably lost, but can be rescued by incubation at low temperature or with chemical chaperones such as the Kv11.1 channel blocker, E-4031 (Zhou et al., 1999; Ficker et al., 2002; Anderson et al., 2006). Such correction typically results in the re-emergence of the mature $155-\mathrm{kDa}$ band, thereby providing a signature that can be monitored to evaluate rescue efficacy (Figure 1, right).

Despite the evident efficacy of the biochemical assay to probe hERG protein trafficking, there are some potential limitations to this approach. First, it does not provide a direct measure of surface channels. This is pertinent giving findings that glycosylation may not be absolutely required for surface trafficking (Gong et al., 2002), and the possibility that some fully glycosylated channels may still be compromised in their ability to reach the cell surface (Dennis et al., 2011; Smith et al., 2011). Second, the method may lack subcellular discrimination since glycosylated channels could potentially reside in the Golgi as well as post-Golgi compartments including the cell surface and endosomes. Finally, the biochemical approach is relatively laborintensive which limits opportunities for rapid high throughput screening strategies to identify novel trafficking correctors as potential therapeutics. Here, we sought to develop an optical high-throughput assay to monitor surface and total hERG protein expression that would be useful to discern mechanisms underlying LQT2 trafficking deficiencies and also amenable as an assay for identifying new hERG protein trafficking correctors.

\section{RESULTS}

\section{Design and Implementation of a Flow Cytometric Assay to Analyze WT and Mutant hERG Surface Expression}

Previous studies from our laboratory and others have shown the utility of a 13-residue high-affinity bungarotoxin binding site (BBS) introduced as an extracellular epitope tag to faithfully label surface population of distinct ion channels and membrane proteins (Sekine-Aizawa and Huganir, 2004; Wilkins et al., 2008; Yang et al., 2010; Aromolaran et al., 2014; Cassidy et al., 2014). Building on previous work that utilized an extracellular HA epitope for surface detection of hERG (Ficker et al., 2003; Wible et al., 2005), we introduced the BBS tag into the extracellular S1-S2 loop of hERG to enable efficient detection of surface channels in non-permeabilized cells with Alexa Fluor 647-conjugated bungarotoxin $\left(\right.$ BTX $\left._{647}\right)$ (Figure 2A). We also fused YFP to the C-terminus of hERG to enable simultaneous fluorescence detection of total hERG expression (Figure 2A). Human embryonic kidney (HEK293) cells transiently transfected with wild-type (WT) BBS-hERG-YFP displayed robust fluorescence signals for total (yellow; YFP) and surface (red; BTX 647 ) channel pools when imaged by confocal microscopy (Figure 2B). We used flow cytometry to quantify total and surface BBS-hERGYFP channel pools in an unbiased and high-throughput manner, all with single cell resolution (Figure 2C). Consistent with the confocal microscopy results, cells expressing WT BBShERG-YFP (i.e., YFP-positive cells) displayed robust surface expression, with red fluorescence signals up to a 100-fold higher than a threshold level established with single color controls (Figures 2C,D). 


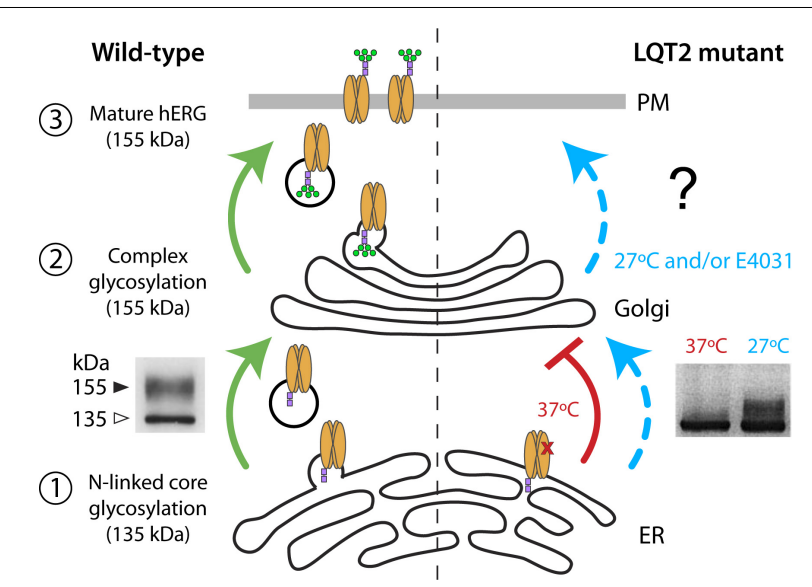

FIGURE 1 | hERG maturation, glycosylation, and surface trafficking. (Left) Forward trafficking of WT hERG (green) is represented. WT hERG undergoes assembly and post-translational $\mathrm{N}$-linked core glycosylation (purple squares) in the endoplasmic reticulum (step 1) and complex glycosylation (green circles) in the Golgi (step 2). Functional channels on the cell surface contain the fully glycosylated 155-kDa mature form of hERG (step 3). Immunoblot (inset, Left) adapted from Gong et al. (2002) represents core glycosylated (135-kDa) and complex glycosylated (155-kDa) hERG bands. (Right) Correctable LQT2 mutant (i.e., Class 2 trafficking defect) is represented at $37^{\circ} \mathrm{C} \mathrm{(red)} \mathrm{and}$ incubation with low temperature/chemical chaperone (blue). Immunoblot (inset, Right) adapted from Zhou et al. (1999) demonstrates temperature-dependent rescue of complex glycosylation.

As an initial test of the robustness of this assay to report on trafficking-deficient LQT2 mutants, we examined the impact of introducing an LQT2-causing point mutation in hERG,
C44F, which is known to be trafficking-deficient as it is not post-translationally processed to the $155-\mathrm{kDa}$ mature form of the protein (Lupoglazoff et al., 2001; Anderson et al., 2014). Consistent with this view, mutant BBS-hERG $\mathrm{C}_{44 F}$-YFP displayed no surface $\mathrm{BTX}_{647}$ red fluorescence in YFP-positive cells (Figures 2E-G).

\section{Surface Labeling Assay Reveals Distinct Subtypes of LQT2-Causing Mutations in the PAS Domain}

The hERG1a protein contains two major intracellular domains the N-terminal Per-Arnt-Sim (PAS) domain and C-terminal cyclic nucleotide binding domain (CNBD) - which interact and require proper folding for effective channel trafficking and gating (Muskett et al., 2011; Gianulis et al., 2013; Ng et al., 2014; Wang and MacKinnon, 2017) (Figure 3A). In a recent comprehensive study, Anderson et al. (2014) conducted a large-scale analyses of hERG channel mutations to better understand and characterize trafficking properties of the channel resulting from mutations in distinct domains. They expressed mutant hERG channels in a heterologous expression system, under two corrective conditions incubation at decreased temperature $\left(27^{\circ} \mathrm{C}\right)$ or with the drug E-4031, a potassium channel blocker and pharmacological chaperone. Utilizing the immunoblot assay, they confirmed the predominance of impaired trafficking as the mechanism underlying loss-of-function of LQT2 mutant channels, and further demonstrated five distinct subclasses of mutations: (1) WT-like, (2) correctable by low temperature alone, (3) corrected by E4031 alone, (4) corrected by both low temperature and
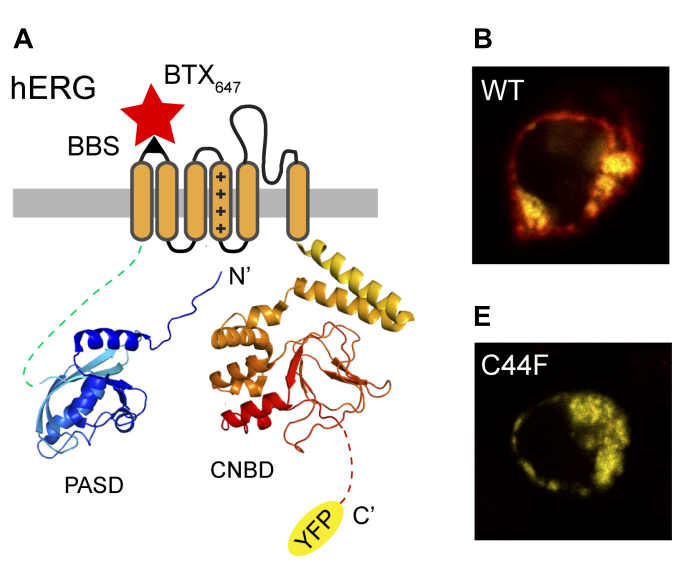

C
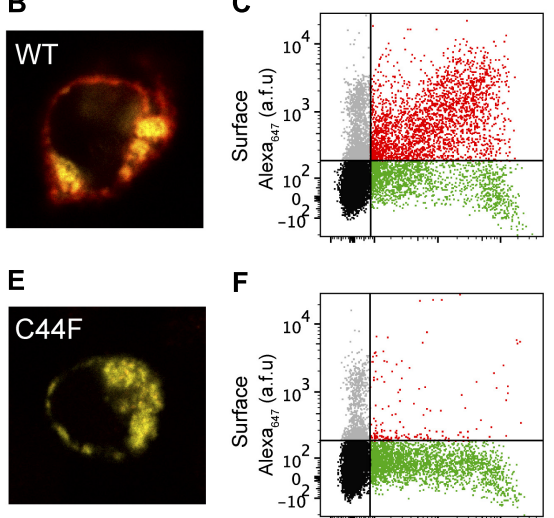

$\mathbf{F}$

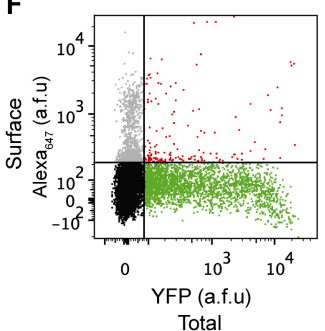

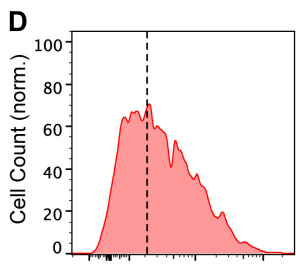

G

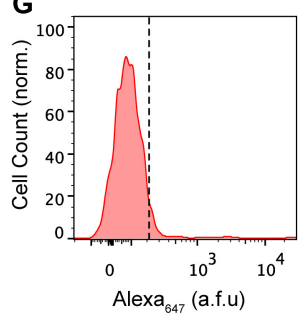

FIGURE 2 | Surface labeling of hERG channels. (A) Cartoon of BBS-hERG-YFP subunit. PASD (blue) and CNBD (red) structures adapted from Wang and MacKinnon (2017) (PDB: 5VA2). The bungarotoxin binding site (BBS) epitope (S1-S2) allows for selective labeling of surface hERG channels while YFP signal represents total $\mathrm{hERG}$ protein expression. (B) Confocal image of a live cell expressing BBS-hERG-YFP and stained with BTX 647 . (C) Flow cytometry dot plot showing surface $\left(B_{64 X_{647}}\right.$ fluorescence) and total (YFP fluorescence) $h E R G$ expression in cells expressing BBS-hERG-YFP. Vertical and horizontal lines represent thresholds for YFP and BTX 647 -positive cells, respectively, based on the analyses of single color controls. Represented are YFP-positive cells with BTX 647 signal above (red dots) or below threshold (green dots); BTX 647 -positive cells with YFP signal below threshold (gray dots); and untransfected cells (black dots).

(D) Histogram of BTX 647 fluorescence in cells expressing WT BBS-hERG-YFP, generated from population of YFP-positive cells. Dotted line is threshold value for

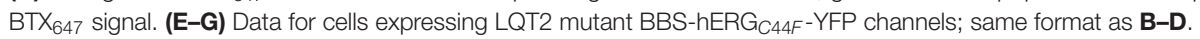



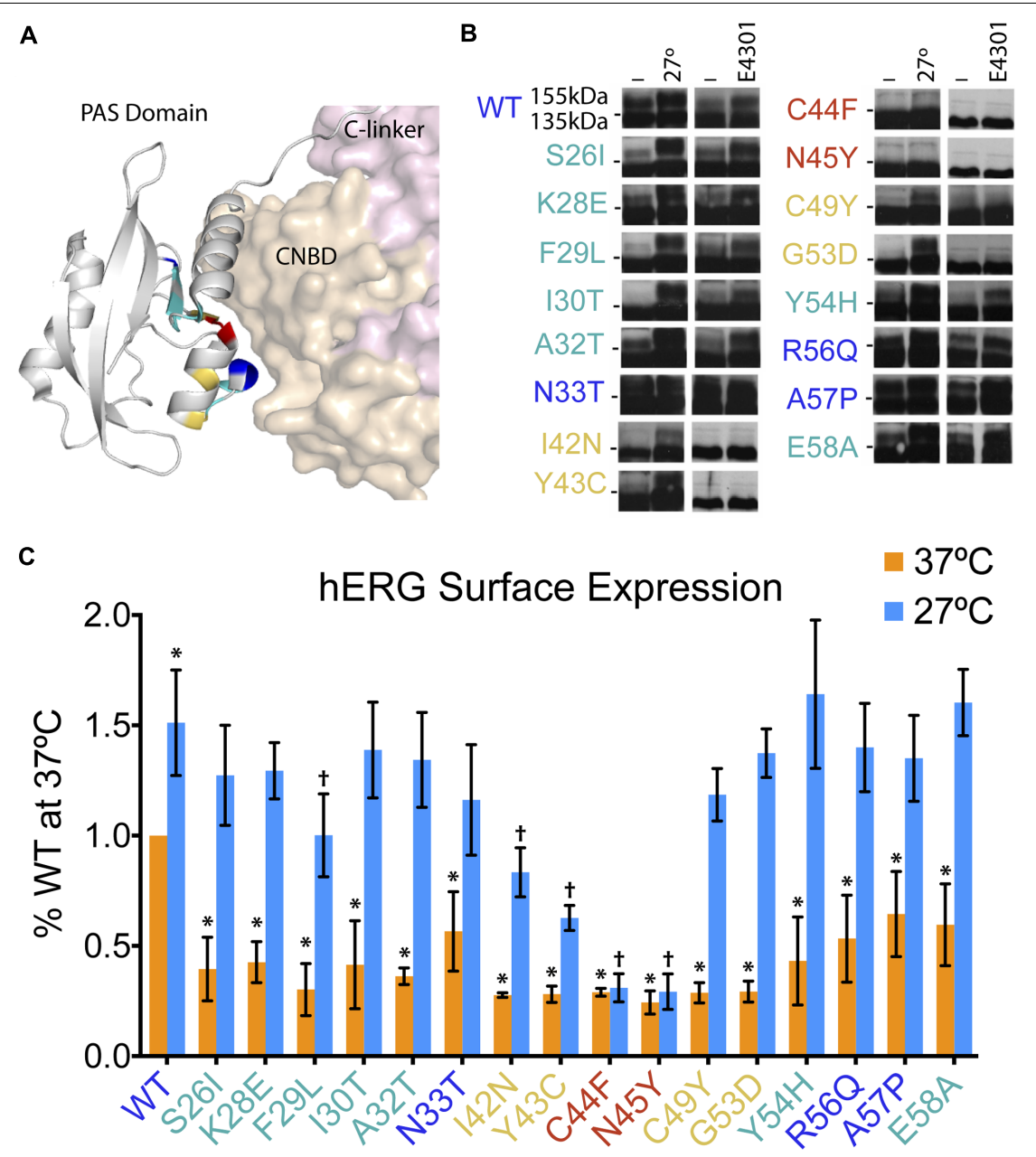

FIGURE 3 | Low temperature rescue of defective surface trafficking in 16 LQT2 hERG channels with mutations in the PAS domain. (A) Structure of the hERG PAS domain in complex with CNBD, adapted from Wang and MacKinnon (2017) (PDB: 5VA2). Positions of 16 LQT2 mutations highlighted according to their reported impact on hERG trafficking as assessed by the prevalence of the 155-kDa mature protein and the rescue of this band by low temperature and/or E4031-WT glycosylation (blue), uncorrectable (red), temperature correctable only (yellow), and temperature and E4031 correctable (teal). (B) Western blot analyses of PAS domain LQT2 mutants reproduced from Anderson et al. (2014) (with permission from Nature Communications). Horizontal dashes at the sides of the blots represent $140 \mathrm{kDa}$. (C) Quantification of surface hERG channels (Alexa647 fluorescence) from flow cytometry experiments $(n=8878-30497$ cells; $N=4$ ) for WT and LQT2 mutant $h E R G$ channels at 37 and $27^{\circ} \mathrm{C}$. Data are normalized to $W T$ hERG surface expression at $37^{\circ} \mathrm{C} .{ }^{*} p<0.02$ versus $W T 37^{\circ} \mathrm{C}, \dagger p<0.02$ versus $W T 27^{\circ} \mathrm{C}$, two-way ANOVA followed by Dunnett's test.

E4031, and (5) uncorrectable by either low temperature or E4031.

The comprehensive study by Anderson et al. (2014), in combination with previous studies looking at PAS domain mutations (Gianulis and Trudeau, 2011; Harley et al., 2012; Ke et al., 2013; Perry et al., 2016), provided a valuable resource and opportunity to test the robustness of the flow cytometry approach and its potential utility in providing mechanistic information beyond that provided by the biochemical method. To accomplish this, we focused on 16 mutations clustered in the PAS domain that based on the relative prevalence of $155-\mathrm{kDa}$ fully glycosylated band were previously classified as: (1) WTlike (N33T, R56Q, A57P; blue), (2) uncorrectable (C44F, N45Y; red), (3) temperature correctable only (I42N, Y43C, C49Y, G53D; yellow), and (4) both low temperature and E4031 correctable
(S26I, K28E, F29L, I30T, A32T, Y54H, E58A; teal) (Figure 3B; Western blots reproduced from Anderson et al., 2014).

We expressed WT and mutant BBS- and YFP-tagged hERG channels in HEK293 cells, under both $37^{\circ} \mathrm{C}$ and low temperature $\left(27^{\circ} \mathrm{C}\right)$ conditions. Quantification of surface intensity from four independent experiments are shown, normalized to WT surface expression at $37^{\circ} \mathrm{C}$ (Figure 3C). Reassuringly, comparison of the surface density data to the immunoblotting study shows areas of concordance. First, we observed that all the LQT2 mutant channels displayed significant deficits in surface density compared to WT when cells were incubated at $37^{\circ} \mathrm{C}$. Second, incubation at $27^{\circ} \mathrm{C}$ resulted in rescued surface density for all mutants except $\mathrm{C} 44 \mathrm{~F}$ and $\mathrm{N} 45 \mathrm{Y}$. However, there were some notable differences from the previous study. We observed a significant reduction in surface density of N33T, R56Q, and A57P 
channels that were previously classified as WT-like based on their glycosylation pattern at $37^{\circ} \mathrm{C}$ (Figure 3C). Moreover, the low temperature rescue of I42N and Y43C channels was only partial, which was not evident by the biochemical assay (Figures 3B,C) (Anderson et al., 2014).

Overall, these results validate the utility of the flow cytometry approach to quantify surface expression of WT and LQT2 hERG channels in a robust and sensitive manner, and to quantitatively evaluate correction of trafficking deficiencies.

\section{LQT2 Mutations With WT-Like Glycosylation Patterns Demonstrate Reduced Surface Expression, Impaired Forward Trafficking, and Distinct Half-Lives at the Cell Surface}

The discrepancy between the biochemical and flow cytometry approaches in the assignment of WT-like properties to N33T, R56Q, and A57P channels was interesting as it suggested that the presence of a WT-like abundance of the $155-\mathrm{kDa}$ mature protein does not necessarily translate to normal channel surface density. On the basis of the flow cytometry approach, these mutants would be more appropriately characterized as temperature correctable, rather than WT-like (Figures 4A-D).

It was instructive to consider the potential mechanisms contributing to the deficits in surface expression of these mutant channels despite their WT glycosylation patterns. In principle, these could be mediated by impaired forward trafficking, decreased stability of the channel at the surface, or a combination of both mechanisms. An advantage of the flow cytometry approach is it can be adapted to probe these possibilities utilizing two complementary, optical pulse-chase assays (Kanner et al., 2017). To test differences in forward trafficking, we utilized a livecell assay to analyze the delivery of new channels to the surface over time (Figure 4E). Live, non-permeabilized cells expressing WT or mutant BBS-hERG-YFP channels at $37^{\circ} \mathrm{C}$ for $24 \mathrm{~h}$ were moved to $4^{\circ} \mathrm{C}$ to halt all trafficking processes and subsequently exposed to unconjugated BTX to block all extracellular BBS epitopes initially present at the plasma membrane (pulse). Cells were then incubated at $37^{\circ} \mathrm{C}$ for varying time periods (chase), after which cells were returned to $4^{\circ} \mathrm{C}$ and the newly delivered surface channels labeled with BTX $_{647}$ and quantified by flow cytometry. Control cells expressing WT BBS-hERGYFP demonstrated a steady delivery of new channels to the surface (Figure 4F). In contrast, all three mutants demonstrated impaired delivery of new channels to the surface as evident by a significantly reduced plateau in BTX $_{647}$ fluorescence (Figure 4F).

To determine the residence time of channels at the cell surface, we utilized a second optical, pulse-chase assay to measure removal of channels from the plasma membrane (Figure 4G). Live, non-permeabilized cells expressing WT and mutant BBShERG-YFP channels incubated at $27^{\circ} \mathrm{C}$ for $24 \mathrm{~h}$ (to ensure a comparable number of channels initially at the cell surface) were moved to $4^{\circ} \mathrm{C}$ and labeled with biotinylated bungarotoxin (BTX-biotin) at $4^{\circ} \mathrm{C}$ (pulse). Cells were then incubated at $37^{\circ} \mathrm{C}$ for varying time periods to resume trafficking (chase), and subsequently labeled with streptavidin-conjugated Alexa
Fluor 647 (SA-647) at $4^{\circ} \mathrm{C}$. In this paradigm, SA-647 labeling would only occur on channels that were initially present at the surface and labeled with BTX-biotin during the pulse period. As expected, WT hERG channels demonstrated an exponential decrease in surface labeling over time (Figure $4 \mathbf{H}$ ). Interestingly, the three mutants demonstrated different rates of decline in surface labeling (Figure 4H), implying different rates of internalization, with R56Q displaying the most rapid removal from the cell surface.

\section{DISCUSSION}

In this study, we sought to develop a high-throughput optical flow cytometric assay that enables quantitative assessment of WT and LQT2 hERG channel trafficking, and rescue of traffickingdeficient mutants by low temperature or pharmacological chaperones. The method is complementary to other previously described approaches to monitor hERG channel trafficking, including a biochemical assay that assesses relative abundance of immature $135-\mathrm{kDa}$ and fully glycosylated $155-\mathrm{kDa}$ forms of the protein. By comparing results from the flow cytometric analyses of 16 PAS domain mutant hERG channels to published data of the same mutations assessed by the biochemical approach, we find not only areas of concordance that validates the assay, but also some discrepancies that highlight advantages of the flow cytometry method. We discuss the flow cytometry assay and our results in the context of established methods to monitor hERG channel trafficking and some of the results obtained with these approaches.

\section{Complex Glycosylation as a Marker for hERG Maturation and Surface Trafficking}

The first studies elucidating glycosylation as a critical player in the maturation of WT hERG channels were reported almost two decades ago (Zhou et al., 1998b, 1999; Petrecca et al., 1999). It was further shown that while certain LQT2 mutations displayed post-translational processing similar to WT, others exhibited an impaired maturation evident as an absence of the $155-\mathrm{kDa}$ fully processed protein band (Zhou et al., 1998a; Anderson et al., 2006, 2014). Moreover, treatment of cells with protease led to the digestion and disappearance of the mature $155-\mathrm{kDa}$ band, with no effect on the immature $135-\mathrm{kDa}$ band, consistent with the mature protein being predominantly at the cell surface (Zhou et al., 1998b; Rajamani et al., 2006). Consequently, biochemical analyses of the relative abundance of 135- and 155$\mathrm{kDa}$ hERG bands has been a standard widely adopted tool to analyze trafficking of WT and mutant hERG channels under different conditions. Nevertheless, it is noteworthy that Gong et al. (2002) demonstrated that while N-linked glycosylation of hERG occurs at residue N598, mutating this site did not abolish hERG channel surface expression despite the disappearance of the $155-\mathrm{kDa}$ form of the protein. Hence, while glycosylation is important for hERG maturation, it is not absolutely required for assembly and expression of functional hERG channels at the cell surface. This suggests the possibility that a sole reliance on the biochemical assay to categorize mechanisms underlying LQT2 


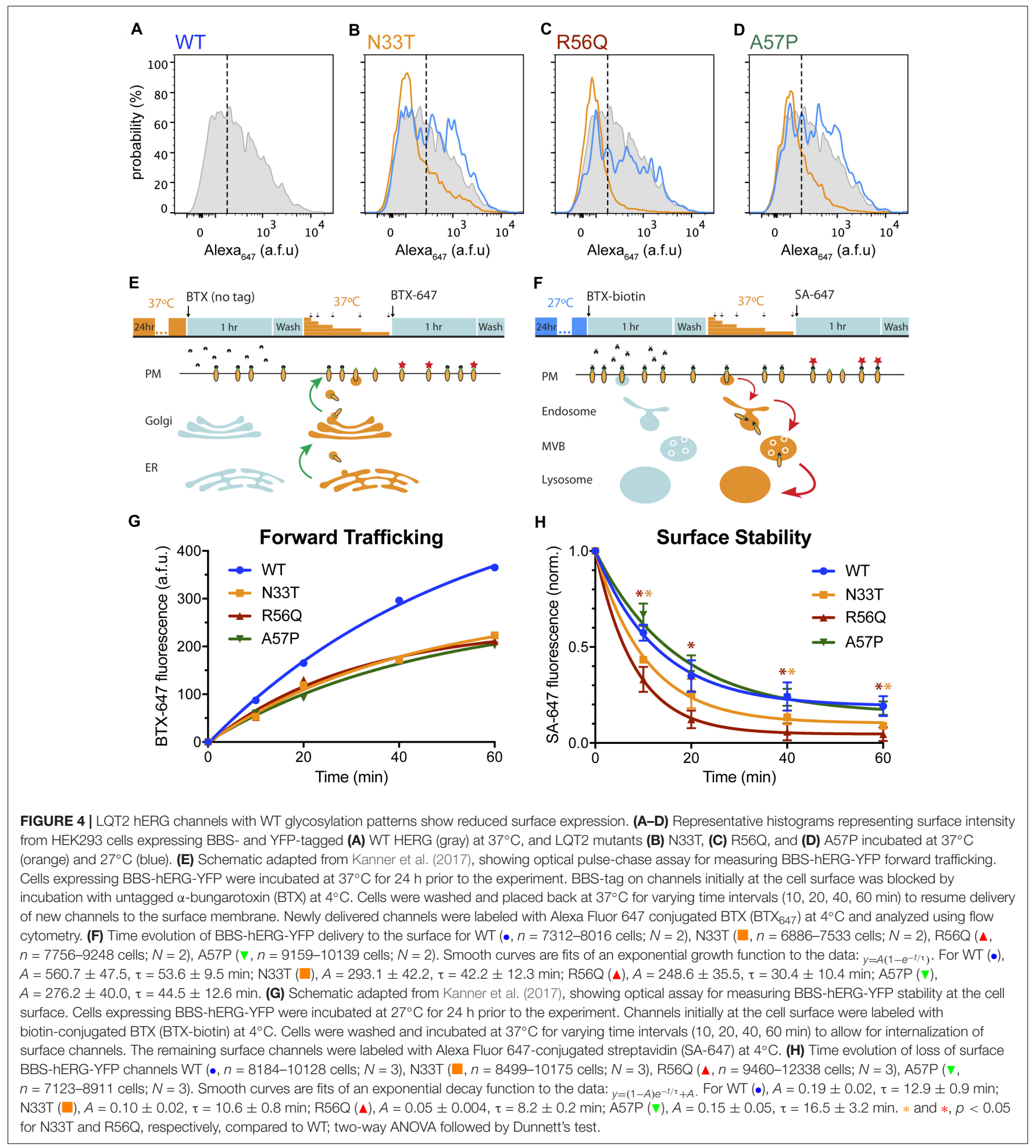

mutations could potentially misclassify some as being in the Class 2 trafficking-deficient category.

There has been relatively scant research on the prevalence of the opposite phenomenon: Does a WT-like glycosylation pattern guarantee channel surface density similar to WT hERG? Previous studies found that despite rescue of the mature $155-\mathrm{kDa}$ band in antidepressant-induced and inherited G601S LQT2 by lysosomal inhibitors and microtubule depolymerization, respectively, there was no subsequent rescue in functional hERG expression at the surface membrane (Dennis et al., 2011; Smith et al., 2011). Of the 16 PAS domain LQT2 mutations we studied, three had been previously classified as WT-like on the basis of their 
glycosylation patterns (Anderson et al., 2014). Remarkably, we found that all three exhibited significantly reduced surface expression compared to WT hERG, demonstrating lack of an absolute correlation between relative abundance of the 155$\mathrm{kDa}$ mature protein form and its level of expression at the cell surface. We further found that the putative WT-like LQT2 mutant channels displayed impaired forward trafficking. Given that these mutants have WT glycosylation patterns, they have presumably reached or passed through the Golgi compartment. We cannot distinguish from our results whether the impaired forward trafficking arises from deficits in transport from the Golgi to the cell surface, or whether it mostly reflects shortfalls in some post-Golgi recycling compartments. This is pertinent as robust Rab11-mediated recycling of hERG channels has been observed (Lamothe and Zhang, 2013; Chen et al., 2015).

\section{Differential Plasma Membrane Stability of LQT2-Causing Mutants}

Our flow cytometry method indicated that the residence time of WT hERG channels at the cell surface was short, with an apparent half-life of $\sim 9 \mathrm{~min}$. The measured half-life was even shorter with the LQT2 mutations R56Q ( $5.7 \mathrm{~min})$, and to a lesser extent N33T (7.3 $\mathrm{min})$, but not A57P ( 11.7 min). Overall, the flow cytometry approach suggests a more rapid removal of surface hERG channels than has been previously reported. There have been several approaches applied to analyze the turnover or stability of hERG channels at the cell surface. One method uses the biochemical approach to follow the loss of the fully glycosylated hERG protein band in cells treated with brefeldin $\mathrm{A}$. The half-life for the disappearance of the fully glycosylated hERG protein from this approach is on the order of $\sim 10 \mathrm{~h}$. This biochemical method measures the turnover of mature hERG proteins, and is distinguished from our approach which directly measures the removal of surface channels. Notably, it has been demonstrated using the biochemical approach that some LQT2 mutations, including $\mathrm{R} 56 \mathrm{Q}$, display a decreased protein stability compared to WT hERG (Ke et al., 2013). Our finding that R56Q is more rapidly removed from the cell surface is in broad agreement with this previous report.

Another approach similar in principle to the method described here utilizes a hemagglutinin (HA) tag engineered into the extracellular S1-S2 loop of hERG. The labeling and fate of surface channels are then detected either by confocal microscopy in single cells, or cell surface ELISA in a population of cells (Wible et al., 2005; Apaja et al., 2013; Karnik et al., 2013). Apaja et al. (2013) utilized the cell surface ELISA approach to measure the plasma membrane residence time of WT and LQT2 hERG proteins. They measured a plasma membrane half-life of the WT protein of $\sim 9$ and $3 \mathrm{~h}$ in HeLa and H9C2i cells, respectively. It is not clear why the two methods, which seem similar in principle, give rise to such disparate values for the residence time of hERG channels in the plasma membrane. One possibility is that the different cell types used in the studies could have an impact. To this point, Apaja et al. (2013) observe a threefold difference in the hERG plasma membrane residence time between HeLa and $\mathrm{H} 9 \mathrm{C} 2 \mathrm{i}$ cells. Another factor could be the stable versus transient expression of hERG channels in heterologous systems. As demonstrated in several studies with cystic fibrosis transmembrane conductance regulator (CFTR) trafficking, differences among absolute half-lives of channels at the cell surface may appear in heterologous systems and primary cells (albeit with similar relative changes of mutant relative to WT) (Sharma et al., 2004; Swiatecka-Urban et al., 2005; Cholon et al., 2010). Thus, future studies applying the BTX $_{647}$ labeling method in the native cellular context of primary adult rodent cardiomyocytes will be important for distinguishing among these different possibilities.

A caveat for approaches that utilize epitope and fluorescent protein tags is the potential for unanticipated effects on hERG channel trafficking. This concern is mitigated by our findings that: (1) the tagged WT hERG trafficks robustly to the cell surface, and (2) the impact of PAS domain mutations on hERG surface density is largely consistent with expectations based on previous analyses of glycosylation patterns and low temperature rescue.

\section{Flow Cytometry as a Versatile Assay to Classify Trafficking-Deficient hERG Mutants and Elucidate New Therapeutic Strategies}

Beyond the enhanced sensitivity and capacity to increase mechanistic insights, an important advantage of the flow cytometry method is its versatility compared to existing approaches. Existing ELISA-based assays rely on total fluorescence/chemiluminescence from cell populations. The lack of single cell resolution limits comparisons to homogeneous populations and potentially overlooks critical points in quality control (i.e., punctate/apoptotic cells, variable protein expression). Confocal studies allow for cellular/subcellular visualization, but do not provide the ability to easily quantify a large number of cells in an unbiased fashion. The flow cytometry method combines benefits of both approaches, enabling rapid analyses of a large population of cells with single-cell resolution, accounting for variations in transfection efficiency, and permitting normalization of channel surface expression to total protein expression levels. As such, there is no need to make stable cell lines for different mutations, and the capability to simultaneously analyze many colors at a time allows for potential applications that require multiplexing. Lastly, recent development and availability of 96-well flow cytometry protocols allow this approach to be adapted for medium- to high-throughput formats to identify novel correctors of hERG channel trafficking in a mutation-specific manner (Krutzik and Nolan, 2006; Duensing and Watson, 2018).

Although we have not conducted functional studies on these LQT2 mutants, it is important to note that previous studies observed changes in gating kinetics in certain PAS domain mutations (Chen et al., 1999; Gianulis and Trudeau, 2011). As such, the mere rescue of trafficking deficiencies may not be sufficient for therapeutic rescue of hERG function in the complex electrical milieu of the cardiac action potential (Perry et al., 2016). This highlights the need for combinatorial approaches for treating LQT2 pathology at both the cell biological 
(i.e., impaired forward trafficking, reduced residency time at the cell surface), and biophysical (i.e. conductance, gating kinetics) level. As there is no single mutation that is dominant in LQTS (with more variants being continually discovered), the use of new methods, such as flow cytometry, to further hone existing classifications of mutations and elucidate therapeutic subclasses will be critical in the pursuit of precision medicine for inherited arrhythmias and other ion channelopathies.

\section{MATERIALS AND METHODS}

\section{Molecular Biology and Cloning of Plasmid Vectors}

The BBS-hERG-YFP constructs were engineered on the previously described hERGla-YFP template (Puckerin et al., 2016), which utilized overlap extension PCR to fuse enhanced yellow fluorescent protein (EYFP) in frame to the C-terminus of hERG1a. A 13-residue bungarotoxin-binding site (BBS; TGGCGGTACTACGAGAGCAGCCTGGAGCCCTACC CCGAC) (Sekine-Aizawa and Huganir, 2004; Yang et al., 2010) was then introduced between residues T436/E437 in the extracellular S1-S2 loop of hERG using the QuikChange Lightning Site-Directed Mutagenesis Kit (Stratagene) according to the manufacturer's instructions. 16 LQT2 mutations were introduced in the PAS domain of BBS-hERG-YFP via site-directed mutagenesis.

\section{Cell Culture and Transfections}

Low passage human embryonic kidney (HEK293) cells were cultured at $37^{\circ} \mathrm{C}$ in Dulbecco's Modified Eagle's Medium (DMEM) supplemented with $8 \%$ fetal bovine serum (FBS) and $100 \mathrm{mg} / \mathrm{mL}$ of penicillin-streptomycin. HEK293 cell transfection was accomplished using the calcium phosphate precipitation method. Briefly, plasmid DNA was mixed with $7.75 \mu \mathrm{L}$ of $2 \mathrm{M}$ $\mathrm{CaCl}_{2}$ and sterile deionized water (to a final volume of $62.5 \mu \mathrm{L}$ ). The mixture was added dropwise, with constant tapping to $62.5 \mu \mathrm{L}$ of $2 \mathrm{x}$ Hepes buffered saline containing (in $\mathrm{mM}$ ): HEPES 50, $\mathrm{NaCl} 280, \mathrm{Na}_{2} \mathrm{HPO}_{4}$ 1.5, pH 7.09. The resulting DNAcalcium phosphate mixture was incubated for $20 \mathrm{~min}$ at room temperature and then added dropwise to HEK293 cells (60$80 \%$ confluent). Cells were washed with $\mathrm{Ca}^{2+}$-free phosphate buffered saline after $4-6 \mathrm{~h}$ and maintained in supplemented DMEM.

\section{Flow Cytometry Assay of Total and Surface Q1 Channels}

Cell surface and total ion channel pools were assayed by flow cytometry in live, transfected HEK293 cells as previously described (Yang et al., 2010; Aromolaran et al., 2014). Briefly, $48 \mathrm{~h}$ post-transfection, cells cultured in 12-well plates gently washed with ice cold PBS containing $\mathrm{Ca}^{2+}$ and $\mathrm{Mg}^{2+}$ (in $\mathrm{mM}: 0.9 \mathrm{CaCl}_{2}$, $0.49 \mathrm{MgCl}_{2}, \mathrm{pH} 7.4$ ), and then incubated for $30 \mathrm{~min}$ in blocking medium (DMEM with $3 \% \mathrm{BSA}$ ) at $4^{\circ} \mathrm{C}$. HEK293 cells were then incubated with $1 \mu \mathrm{M}$ Alexa Fluor 647 conjugated $\alpha$-bungarotoxin (BTX-647; Life Technologies) in DMEM/3\% BSA on a rocker at $4^{\circ} \mathrm{C}$ for $1 \mathrm{~h}$, followed by washing three times with PBS (containing $\mathrm{Ca}^{2+}$ and $\mathrm{Mg}^{2+}$ ). Cells were gently harvested in $\mathrm{Ca}^{2+}$-free PBS, and assayed by flow cytometry using a BD LSRII Cell Analyzer (BD Biosciences, San Jose, CA, United States). CFP- and YFPtagged proteins were excited at 407 and $488 \mathrm{~nm}$, respectively, and Alexa Fluor 647 was excited at $633 \mathrm{~nm}$.

Optical pulse chase assays to monitor rates of channel forward trafficking and internalization were conducted on live, transfected HEK293 cells as previously described (Kanner et al., 2017). For the forward trafficking studies, cells were incubated at $37^{\circ} \mathrm{C}$ for $24 \mathrm{~h}$ prior to the experiments. Cells were placed on $4^{\circ} \mathrm{C}$ to halt trafficking processes and washed twice with PBS containing $\mathrm{Ca}^{2+}$ and $\mathrm{Mg}^{2+}$. For forward trafficking experiments, cells were incubated with $3 \mu \mathrm{M}$ untagged BTX in $\mathrm{DMEM} / 3 \% \mathrm{BSA}$ at $4^{\circ} \mathrm{C}$ for $1 \mathrm{~h}$ to block surface channels, and then washed three times with PBS containing $\mathrm{Ca}^{2+}$ and $\mathrm{Mg}^{2+}$. Cells were incubated with DMEM/3\% BSA and placed at $37^{\circ} \mathrm{C}$ to resume trafficking for different time intervals $(0$, $10,20,40,60 \mathrm{~min})$. Cells were then returned to $4^{\circ} \mathrm{C}$ and newly delivered channels were labeled with $1 \mu \mathrm{M}$ BTX-647 in DMEM/3\% BSA for $1 \mathrm{~h}$. Finally, cells were washed three times with PBS containing $\mathrm{Ca}^{2+}$ and $\mathrm{Mg}^{2+}$, gently harvested in $\mathrm{Ca}^{2+}$-free PBS, and assayed by flow cytometry. For surface stability/internalization experiments, cells were incubated at $27^{\circ} \mathrm{C}$ for $24 \mathrm{~h}$ prior to the experiments. Cells were placed on ice $\left(4^{\circ} \mathrm{C}\right)$ to halt trafficking processes and washed twice with PBS containing $\mathrm{Ca}^{2+}$ and $\mathrm{Mg}^{2+}$. Cells were then incubated in $\mathrm{DMEM} / 3 \% \mathrm{BSA}$ blocking medium for $30 \mathrm{~min}$ at $4^{\circ} \mathrm{C}$ followed by a $1 \mathrm{~h}$ incubation at $4^{\circ} \mathrm{C}$ (pulse) with $1 \mu \mathrm{M}$ biotinylated $\alpha$-bungarotoxin (BTX-biotin; Life Technologies), with gentle rocking. Cells were washed three times in PBS containing $\mathrm{Ca}^{2+}$ and $\mathrm{Mg}^{2+}$ and placed in $\mathrm{DMEM} / 3 \% \mathrm{BSA}$ at $37^{\circ} \mathrm{C}$ for different time intervals $(0,10,20,40,60 \mathrm{~min})$ to resume trafficking (chase). Cells were returned to $4^{\circ} \mathrm{C}$, washed once with PBS, and channels remaining at the surface were labeled with streptavidin-conjugated Alexa Fluor 647 (Life Technologies). Finally, cells were washed three more times with PBS with $\mathrm{Ca}^{2+}$ and $\mathrm{Mg}^{2+}$, harvested in $\mathrm{Ca}^{2+}$-free PBS, and assayed by flow cytometry.

\section{Data and Statistical Analyses}

Data were analyzed off-line using FlowJo, Microsoft Excel, Origin and GraphPad Prism software. Statistical analyses were performed in Origin or GraphPad Prism using built-in functions. Statistically significant differences between means $(p<0.05)$ were determined using two-way ANOVA, followed by Dunnett's correction for multiple comparisons. Data are presented as means \pm SD.

\section{AUTHOR CONTRIBUTIONS}

SK designed and conducted the experiments, analyzed and interpreted the data, and wrote the manuscript. AJ conducted the experiments and analyzed the data. HC designed the experiments, analyzed and interpreted the data, and wrote the manuscript. 


\section{FUNDING}

This work was supported by Grant Nos. RO1-HL121253 and 1RO1-HL122421 from the NIH (to HC). SK was supported by a Medical Scientist Training Program (Grant No.T32 GM007367). AJ was supported by a Summer Undergraduate Research Fellowship (SURF) from Columbia University. Flow cytometry experiments were performed in the CCTI Flow Cytometry Core, supported in part by the NIH (S10RR027050). Confocal images were collected in the HICCC Confocal and

\section{REFERENCES}

Anderson, C. L., Delisle, B. P., Anson, B. D., Kilby, J. A., Will, M. L., Tester, D. J., et al. (2006). Most LQT2 mutations reduce Kv11.1 (hERG) current by a class 2 (trafficking-deficient) mechanism. Circulation 113, 365-373. doi: 10.1161/ CIRCULATIONAHA.105.570200

Anderson, C. L., Kuzmicki, C. E., Childs, R. R., Hintz, C. J., Delisle, B. P., and January, C. T. (2014). Large-scale mutational analysis of Kv11.1 reveals molecular insights into type 2 long QT syndrome. Nat. Commun. 5:5535. doi: $10.1038 /$ ncomms6535

Apaja, P. M., Foo, B., Okiyoneda, T., Valinsky, W. C., Barriere, H., Atanasiu, R., et al. (2013). Ubiquitination-dependent quality control of hERG K+ channel with acquired and inherited conformational defect at the plasma membrane. Mol. Biol. Cell 24, 3787-3804. doi: 10.1091/mbc.E13-07-0417

Aromolaran, A. S., Subramanyam, P., Chang, D. D., Kobertz, W. R., and Colecraft, H. M. (2014). LQT1 mutations in KCNQ1 C-terminus assembly domain suppress IKs using different mechanisms. Cardiovasc. Res. 104, 501-511. doi: $10.1093 / \mathrm{cvr} / \mathrm{cvu} 231$

Bohnen, M. S., Peng, G., Robey, S. H., Terrenoire, C., Iyer, V., Sampson, K. J., et al. (2016). Molecular pathophysiology of congenital long QT syndrome. Physiol. Rev. 97, 89-134. doi: 10.1152/physrev.00008.2016

Cassidy, J. S., Ferron, L., Kadurin, I., Pratt, W. S., and Dolphin, A. C. (2014). Functional exofacially tagged $\mathrm{N}$-type calcium channels elucidate the interaction with auxiliary alpha2delta-1 subunits. Proc. Natl. Acad. Sci. U.S.A. 111, 8979-8984. doi: 10.1073/pnas.1403731111

Chen, J., Guo, J., Yang, T., Li, W., Lamothe, S. M., Kang, Y., et al. (2015). Rab11dependent recycling of the human ether-a-go-go-related gene (hERG) channel. J. Biol. Chem. 290, 21101-21113. doi: 10.1074/jbc.M115.636324

Chen, J., Zou, A., Splawski, I., Keating, M. T., and Sanguinetti, M. C. (1999). Long QT syndrome-associated mutations in the Per-Arnt-Sim (PAS) domain of HERG potassium channels accelerate channel deactivation. J. Biol. Chem. 274, 10113-10118. doi: 10.1074/jbc.274.15.10113

Cholon, D. M., O’Neal, W. K., Randell, S. H., Riordan, J. R., and Gentzsch, M. (2010). Modulation of endocytic trafficking and apical stability of CFTR in primary human airway epithelial cultures. Am. J. Physiol. Lung Cell. Mol. Physiol. 298, L304-L314. doi: 10.1152/ajplung.00016.2009

Delisle, B. P., Underkofler, H. A., Moungey, B. M., Slind, J. K., Kilby, J. A., Best, J. M., et al. (2009). Small GTPase determinants for the Golgi processing and plasmalemmal expression of human ether-a-go-go related (hERG) K+ channels. J. Biol. Chem. 284, 2844-2853. doi: 10.1074/jbc.M807289200

Dennis, A. T., Nassal, D., Deschenes, I., Thomas, D., and Ficker, E. (2011). Antidepressant-induced ubiquitination and degradation of the cardiac potassium channel hERG. J. Biol. Chem. 286, 34413-34425. doi: 10.1074/jbc. M111.254367

Duensing, T. D., and Watson, S. R. (2018). Antibody screening using highthroughput flow cytometry. Cold Spring Harb. Protoc. 2018:dbto093773. doi: $10.1101 /$ pdb.top093773

Ficker, E., Dennis, A. T., Wang, L., and Brown, A. M. (2003). Role of the cytosolic chaperones Hsp70 and Hsp90 in maturation of the cardiac potassium channel HERG. Circ. Res. 92, e87-e100. doi: 10.1161/01.RES.0000079028.31393.15

Ficker, E., Obejero-Paz, C. A., Zhao, S., and Brown, A. M. (2002). The binding site for channel blockers that rescue misprocessed human long QT syndrome type 2 ether-a-gogo-related gene (HERG) mutations. J. Biol. Chem. 277, 4989-4998. doi: $10.1074 /$ jbc.M107345200
Specialized Microscopy Shared Resource, supported by NIH (P30 CA013696).

\section{ACKNOWLEDGMENTS}

We thank Dr. Gail Robertson (University of Wisconsin) for providing hERG cDNA; Dr. Ademuyiwa Armolaran for constructing BBS-hERG-YFP; and Ming Chen for the excellent technical support.

George, A. L. Jr. (2013). Molecular and genetic basis of sudden cardiac death. J. Clin. Invest. 123, 75-83. doi: 10.1172/JCI62928

Gianulis, E. C., Liu, Q., and Trudeau, M. C. (2013). Direct interaction of eag domains and cyclic nucleotide-binding homology domains regulate deactivation gating in hERG channels. J. Gen. Physiol. 142, 351-366. doi: 10. 1085/jgp.201310995

Gianulis, E. C., and Trudeau, M. C. (2011). Rescue of aberrant gating by a genetically encoded PAS (Per-Arnt-Sim) domain in several long QT syndrome mutant human ether-á-go-go-related gene potassium channels. J. Biol. Chem. 286, 22160-22169. doi: 10.1074/jbc.M110.205948

Gong, Q., Anderson, C. L., January, C. T., and Zhou, Z. (2002). Role of glycosylation in cell surface expression and stability of HERG potassium channels. Am. J. Physiol. Heart Circ. Physiol. 283, H77-H84. doi: 10.1152/ajpheart.000 08.2002

Gong, Q., Keeney, D. R., Molinari, M., and Zhou, Z. (2005). Degradation of trafficking-defective long QT syndrome type II mutant channels by the ubiquitin-proteasome pathway. J. Biol. Chem. 280, 19419-19425. doi: 10.1074/ jbc.M502327200

Guo, J., Massaeli, H., Xu, J., Jia, Z., Wigle, J. T., Mesaeli, N., et al. (2009). Extracellular $\mathrm{K}+$ concentration controls cell surface density of $\mathrm{IKr}$ in rabbit hearts and of the HERG channel in human cell lines. J. Clin. Invest. 119, 2745-2757. doi: 10.1172/JCI39027

Harley, C. A., Jesus, C. S., Carvalho, R., Brito, R. M., and Morais-Cabral, J. H. (2012). Changes in channel trafficking and protein stability caused by LQT2 mutations in the PAS domain of the HERG channel. PLoS One 7:e32654. doi: 10.1371/journal.pone.0032654

Kanner, S. A., Morgenstern, T., and Colecraft, H. M. (2017). Sculpting ion channel functional expression with engineered ubiquitin ligases. eLife 6:e29744. doi: 10.7554/eLife.29744

Karnik, R., Ludlow, M. J., Abuarab, N., Smith, A. J., Hardy, M. E., Elliott, D. J., et al. (2013). Endocytosis of HERG is clathrin-independent and involves arf6. PLoS One 8:e85630. doi: 10.1371/journal.pone.0085630

Ke, Y., Ng, C., Hunter, M. J., Mann, S. A., Heide, J., Hill, A. P., et al. (2013). Trafficking defects in PAS domain mutant Kv11. 1 channels: roles of reduced domain stability and altered domain-domain interactions. Biochem. J. 454, 69-77. doi: 10.1042/BJ20130328

Krutzik, P. O., and Nolan, G. P. (2006). Fluorescent cell barcoding in flow cytometry allows high-throughput drug screening and signaling profiling. Nat. Methods 3, 361-368. doi: 10.1038/nmeth872

Lamothe, S. M., and Zhang, S. (2013). The serum- and glucocorticoid-inducible kinases SGK1 and SGK3 regulate hERG channel expression via ubiquitin ligase Nedd4-2 and GTPase Rab11. J. Biol. Chem. 288, 15075-15084. doi: 10.1074/jbc. M113.453670

Lupoglazoff, J. M., Denjoy, I., Berthet, M., Neyroud, N., Demay, L., Richard, P., et al. (2001). Notched $\mathrm{T}$ waves on Holter recordings enhance detection of patients with LQt2 (HERG) mutations. Circulation 103, 1095-1101. doi: 10. 1161/01.CIR.103.8.1095

Moss, A. J., and Kass, R. S. (2005). Long QT syndrome: from channels to cardiac arrhythmias. J. Clin. Invest. 115, 2018-2024. doi: 10.1172/JCI25537

Muskett, F. W., Thouta, S., Thomson, S. J., Bowen, A., Stansfeld, P. J., and Mitcheson, J. S. (2011). Mechanistic insight into human ether-a-go-go-related gene (hERG) $\mathrm{K}+$ channel deactivation gating from the solution structure of the EAG domain. J. Biol. Chem. 286, 6184-6191. doi: 10.1074/jbc.M110. 199364 
Ng, C. A., Phan, K., Hill, A. P., Vandenberg, J. I., and Perry, M. D. (2014). Multiple interactions between cytoplasmic domains regulate slow deactivation of Kv11.1 channels. J. Biol. Chem. 289, 25822-25832. doi: 10.1074/jbc.M114. 558379

Perry, M. D., Ng, C. A., Phan, K., David, E., Steer, K., Hunter, M. J., et al. (2016). Rescue of protein expression defects may not be enough to abolish the proarrhythmic phenotype of long QT type 2 mutations. J. Physiol. 594, 4031-4049. doi: 10.1113/JP271805

Petrecca, K., Atanasiu, R., Akhavan, A., and Shrier, A. (1999). N-linked glycosylation sites determine HERG channel surface membrane expression. J. Physiol. 515, 41-48. doi: 10.1111/j.1469-7793.1999.041ad.x

Puckerin, A., Aromolaran, K. A., Chang, D. D., Zukin, R. S., Colecraft, H. M., Boutjdir, M., et al. (2016). hERG 1a LQT2 C-terminus truncation mutants display hERG 1b-dependent dominant negative mechanisms. Heart Rhythm 13, 1121-1130. doi: 10.1016/j.hrthm.2016.01.012

Rajamani, S., Anderson, C. L., Valdivia, C. R., Eckhardt, L. L., Foell, J. D., Robertson, G. A., et al. (2006). Specific serine proteases selectively damage KCNH2 (hERG1) potassium channels and I(Kr). Am. J. Physiol. Heart Circ. Physiol. 290, H1278-H1288. doi: 10.1152/ajpheart.00777.2005

Sanguinetti, M. C., Jiang, C., Curran, M. E., and Keating, M. T. (1995). A mechanistic link between an inherited and an acquired cardiac arrhythmia: HERG encodes the IKr potassium channel. Cell 81, 299-307. doi: 10.1016/00928674(95)90340-2

Schwartz, P. J., Stramba-Badiale, M., Crotti, L., Pedrazzini, M., Besana, A., Bosi, G., et al. (2009). Prevalence of the congenital long-QT syndrome. Circulation 120, 1761-1767. doi: 10.1161/CIRCULATIONAHA.109.863209

Sekine-Aizawa, Y., and Huganir, R. L. (2004). Imaging of receptor trafficking by using alpha-bungarotoxin-binding-site-tagged receptors. Proc. Natl. Acad. Sci. U.S.A. 101, 17114-17119. doi: 10.1073/pnas.0407563101

Sharma, M., Pampinella, F., Nemes, C., Benharouga, M., So, J., Du, K., et al. (2004). Misfolding diverts CFTR from recycling to degradation: quality control at early endosomes. J. Cell Biol. 164, 923-933. doi: 10.1083/jcb.200312018

Smith, J. L., Anderson, C. L., Burgess, D. E., Elayi, C. S., January, C. T., and Delisle, B. P. (2016). Molecular pathogenesis of long QT syndrome type 2. J. Arrhythm. 32, 373-380. doi: 10.1016/j.joa.2015.11.009

Smith, J. L., McBride, C. M., Nataraj, P. S., Bartos, D. C., January, C. T., and Delisle, B. P. (2011). Trafficking-deficient hERG $\mathrm{K}(+)$ channels linked to long QT syndrome are regulated by a microtubule-dependent quality control compartment in the ER. Am. J. Physiol. Cell Physiol. 301, C75-C85. doi: 10. 1152/ajpcell.00494.2010

Swiatecka-Urban, A., Brown, A., Moreau-Marquis, S., Renuka, J., Coutermarsh, B., Barnaby, R., et al. (2005). The short apical membrane half-life of rescued \{Delta\}F508-cystic fibrosis transmembrane conductance regulator (CFTR) results from accelerated endocytosis of $\{$ Delta\}F508-CFTR in polarized human airway epithelial cells. J. Biol. Chem. 280, 36762-36772. doi: 10.1074/jbc. M508944200
Tester, D. J., and Ackerman, M. J. (2009). Cardiomyopathic and channelopathic causes of sudden unexplained death in infants and children. Annu. Rev. Med. 60, 69-84. doi: 10.1146/annurev.med.60.052907.103838

Trudeau, M. C., Warmke, J. W., Ganetzky, B., and Robertson, G. A. (1995). HERG, a human inward rectifier in the voltage-gated potassium channel family. Science 269, 92-95. doi: 10.1126/science.7604285

Vandenberg, J. I., Perry, M. D., Perrin, M. J., Mann, S. A., Ke, Y., and Hill, A. P. (2012). hERG $\mathrm{K}(+)$ channels: structure, function, and clinical significance. Physiol. Rev. 92, 1393-1478. doi: 10.1152/physrev.00036.2011

Wang, W., and MacKinnon, R. (2017). Cryo-EM structure of the open human Ether-a-go-go-Related K(+) channel hERG. Cell 169, 422.e10-430.e10. doi: 10.1016/j.cell.2017.03.048

Wible, B. A., Hawryluk, P., Ficker, E., Kuryshev, Y. A., Kirsch, G., and Brown, A. M. (2005). HERG-Lite: a novel comprehensive high-throughput screen for drug-induced hERG risk. J. Pharmacol. Toxicol. Methods 52, 136-145. doi: 10.1016/j.vascn.2005.03.008

Wilkins, M. E., Li, X., and Smart, T. G. (2008). Tracking cell surface GABAB receptors using an alpha-bungarotoxin tag. J. Biol. Chem. 283, 34745-34752. doi: 10.1074/jbc.M803197200

Yang, T., Xu, X., Kernan, T., Wu, V., and Colecraft, H. M. (2010). Rem, a member of the RGK GTPases, inhibits recombinant CaV1.2 channels using multiple mechanisms that require distinct conformations of the GTPase. J. Physiol. 588, 1665-1681. doi: 10.1113/jphysiol.2010.187203

Zhou, Z., Gong, Q., Epstein, M. L., and January, C. T. (1998a). HERG channel dysfunction in human long QT syndrome. Intracellular transport and functional defects. J. Biol. Chem. 273, 21061-21066.

Zhou, Z., Gong, Q., and January, C. T. (1999). Correction of defective protein trafficking of a mutant HERG potassium channel in human long QT syndrome. Pharmacological and temperature effects. J. Biol. Chem. 274, 31123-31126. doi: $10.1074 /$ jbc. 274.44 .31123

Zhou, Z., Gong, Q. M., Ye, B., Fan, Z., Makielski, J. C., Robertson, G. A., et al. (1998b). Properties of HERG channels stably expressed in HEK 293 cells studied at physiological temperature. Biophys. J. 74, 230-241. doi: 10.1016/S00063495(98)77782-3

Conflict of Interest Statement: The authors declare that the research was conducted in the absence of any commercial or financial relationships that could be construed as a potential conflict of interest.

Copyright (C) 2018 Kanner, Jain and Colecraft. This is an open-access article distributed under the terms of the Creative Commons Attribution License (CC BY). The use, distribution or reproduction in other forums is permitted, provided the original author(s) and the copyright owner are credited and that the original publication in this journal is cited, in accordance with accepted academic practice. No use, distribution or reproduction is permitted which does not comply with these terms. 
OPEN ACCESS

Edited by:

Zhilin Qu,

University of California, Los Angeles,

United States

Reviewed by:

Ademuyiwa S. Aromolaran, VA NY Harbor Health Care System,

United States

Flavien Charpentier, UMR6291 L'unité de Recherche de l'Institut du Thorax, France

${ }^{*}$ Correspondence: Brian P. Delisle brian.delisle@uky.edu

Specialty section:

This article was submitted to Cardiac Electrophysiology, a section of the journal Frontiers in Physiology

Received: 23 January 2018 Accepted: 02 May 2018 Published: 23 May 2018

Citation:

Hall AR, Anderson CL, Smith JL, Mirshahi T, Elayi CS, January CT and Delisle BP (2018) Visualizing

Mutation-Specific Differences in the Trafficking-Deficient Phenotype of KV11.1 Proteins Linked to Long QT Syndrome Type 2.

Front. Physiol. 9:584. doi: 10.3389/fphys.2018.00584

\section{Visualizing Mutation-Specific Differences in the Trafficking-Deficient Phenotype of Kv11.1 Proteins Linked to Long QT Syndrome Type 2}

\author{
Allison R. Hall1 ${ }^{\text {, Corey L. Anderson }}{ }^{2}$, Jennifer L. Smith ${ }^{1}$, Tooraj Mirshahi ${ }^{3}$, \\ Claude S. Elayi ${ }^{4}$, Craig T. January ${ }^{2}$ and Brian P. Delisle ${ }^{1 *}$
}

'Department of Physiology, University of Kentucky, Lexington, KY, United States, ${ }^{2}$ Cellular and Molecular Arrhythmia Research Program, University of Wisconsin-Madison, Madison, WI, United States, ${ }^{3}$ Department of Molecular and Functional Genomics, Genomic Medicine Institute, Geisinger Clinic, Danville, PA, United States, ${ }^{4}$ Department of Cardiology, Gill Heart Institute, University of Kentucky, Lexington, KY, United States

$\mathrm{KCNH} 2$ encodes the Kv11.1 $\alpha$-subunit that underlies the rapidly activating delayedrectifier $\mathrm{K}^{+}$current in the heart. Loss-of-function $\mathrm{KCNH2}$ mutations cause long QT syndrome type 2 (LQT2), and most LQT2-linked missense mutations inhibit the trafficking of Kv11.1 channel protein to the cell surface membrane. Several trafficking-deficient LQT2 mutations (e.g., G601S) generate Kv11.1 proteins that are sequestered in a microtubule-dependent quality control (QC) compartment in the transitional endoplasmic reticulum (ER). We tested the hypothesis that the QC mechanisms that regulate LQT2-linked Kv11.1 protein trafficking are mutation-specific. Confocal imaging analyses of HEK293 cells stably expressing the trafficking-deficient LQT2 mutation F805C showed that, unlike G601S-Kv11.1 protein, F805C-Kv11.1 protein was concentrated in several transitional ER subcompartments. The microtubule depolymerizing drug nocodazole differentially affected G601S- and F805C-Kv11.1 protein immunostaining. Nocodazole caused G601S-Kv11.1 protein to distribute into peripheral reticular structures, and it increased the diffuse immunostaining of F805CKv11.1 protein around the transitional ER subcompartments. Proteasome inhibition also affected the immunostaining of G601S- and F805C-Kv11.1 protein differently. Incubating cells in MG132 minimally impacted G601S-Kv11.1 immunostaining, but it dramatically increased the diffuse immunostaining of F805C-Kv11.1 protein in the transitional ER. Similar results were seen after incubating cells in the proteasome inhibitor lactacystin. Differences in the cellular distribution of G601S-Kv11.1 and F805CKv11.1 protein persisted in transfected human inducible pluripotent stem cell derived cardiomyocytes. These are the first data to visually demonstrate mutation-specific differences in the trafficking-deficient LQT2 phenotype, and this study has identified a novel way to categorize trafficking-deficient LQT2 mutations based on differences in intracellular retention.

Keywords: $\mathrm{K}^{+}$channel, trafficking, long QT syndrome, arrhythmia, Kv11.1, hERG 


\section{INTRODUCTION}

Long QT syndrome (LQTS) is a disorder characterized by delayed ventricular repolarization, prolongation of the QT interval on an electrocardiogram (ECG), and an increased risk for the ventricular arrhythmia Torsades de Pointes (Crotti et al., 2008). LQT2 is a major form of LQTS, which is caused by lossof-function (LOF) mutations in the KCNH2 gene (a.k.a the human ether-a-go-go related gene or hERG) (Curran et al., 1995; Sanguinetti et al., 1996; Smith et al., 2016). KCNH2 encodes the pore-forming Kv11.1 $\alpha$-subunits that conduct the rapidly activating delayed-rectifier $\mathrm{K}^{+}$current $\left(I_{\mathrm{Kr}}\right)$ in the heart (Trudeau et al., 1995).

The majority of LQT2-linked mutations are missense, and heterologous expression studies demonstrate that $\sim 90 \%$ of LQT2 missense mutations decrease the intracellular transport (trafficking) of Kv11.1 channels to the cell surface membrane (Zhou et al., 1998a; Ficker et al., 2000a; Anderson et al., 2006, 2014). Trafficking-deficient LQT2 mutations are postulated to disrupt Kv11.1 $\alpha$-subunit protein folding/assembly and cellular quality control (QC) mechanisms in endoplasmic reticulum (ER) prevent their trafficking early in the secretory pathway (Zhou et al., 1998a, 1999; Ficker et al., 2003; Delisle et al., 2005; Gong et al., 2005; Walker et al., 2007, 2010; Foo et al., 2016). A key finding is several drugs that bind to Kv11.1 channels and block $I_{\mathrm{Kr}}$ (e.g., E-4031) can act as "pharmacological chaperones" to improve the trafficking and functional expression for many LQT2 channels (pharmacological correction) (Zhou et al., 1999; Ficker et al., 2002; Anderson et al., 2006, 2014). This is an important finding because it indicates that some trafficking-deficient LQT2 channels are promising targets for therapeutic intervention to improve delivery of channels to the surface membrane. Data suggest that pharmacological chaperones bind to the high affinity drug-binding site in the Kv11.1 pore to stabilize Kv11.1 channel conformations suitable for ER export into the secretory pathway (Zhou et al., 1999; Ficker et al., 2002; Ellgaard and Helenius, 2003; Delisle et al., 2005; Gong et al., 2006).

We previously studied the cellular QC mechanisms that prevent the trafficking of the LQT2-linked missense mutations Gly601Ser (G601S) early in the secretory pathway. In control conditions, most of the G601S-Kv11.1 protein is excluded from ER exit sites (ERES) and sequestered in a microtubule-sensitive ER compartment that contains the transitional ER protein BAP31 (Furutani et al., 1999; Ficker et al., 2002; Wakana et al., 2008; Smith et al., 2011, 2013). This transitional ER compartment did not contain other ER or ER Golgi Intermediate proteins, including calnexin, proteins with the ER retention KDEL sequence, the ER-associated degradation (ERAD) protein derlin-1, the ERES protein Sec31, or the ER-Golgi intermediate compartment $53 \mathrm{kDa}$ protein (ERGIC-53). Importantly, we found that incubating cells in the pharmacological chaperone E4031 directly increased the trafficking of the sequestered G601SKv11.1 channels to the cell surface membrane (Smith et al,, 2013). In this study we investigate the cellular QC control mechanisms that prevent the trafficking of the LQT2-linked missense mutation F805C (Ficker et al., 2002). Unlike G601S (which is located on the extracellular side of the Kv11.1 $\alpha$-subunit in the pore domain), $\mathrm{F} 805 \mathrm{C}$ is located on the intracellular portion of the Kv11.1 $\alpha$-subunit in the cyclic nucleotide-binding domain (CNBD) and does not undergo pharmacological correction with E-4031 because it likely impairs Kv11.1 tetramer assembly (Ficker et al., 2002; Delisle et al., 2003). We tested the hypothesis that the ER QC control mechanisms that prevent the trafficking of G601Sand $\mathrm{F} 805 \mathrm{C}-\mathrm{Kv} 11.1$ proteins are different.

\section{MATERIALS AND METHODS}

\section{Cell Lines and Drug Exposure}

The Human Embryonic Kidney 293 (HEK293) cells used in this study stably express Kv11.1 channel proteins (wild type or WT, G601S, R752W, or F805C) and they have been previously described (Zhou et al., 1998b; Delisle et al., 2003; Anderson et al., 2006). Cells are cultured at $37^{\circ} \mathrm{C}$ $\left(5 \% \mathrm{CO}_{2}\right)$ in MEM supplemented with $10 \%$ Fetal Bovine Serum (FBS, Invitrogen, Carlsbad, CA, United States) and geneticin. The data shown in Figures 1-4, 5B are obtained from stably expressing cell lines. For some experiments we transiently transfected G601S- or F805C-Kv11.1 plasmid cDNA in HEK293 cells. Transfections were performed similar to that previously described (Anson et al., 2004), $3 \mu \mathrm{g}$ of Kv11.1 plasmid cDNA was transfected with the Superfect Transfection Reagent (Qiagen, Germantown, MD, United States). The data for Figure 5A are from transiently expressing HEK293 cells. We also used transiently transfected iCell Cardiomyocytes (Cellular Dynamics International, Madison, WI, United States). iCell Cardiomyocytes were transiently transfected with green fluorescent protein (GFP) tagged Kv11.1 cDNA plasmids ( $3 \mu \mathrm{g}$ ) using the Viafect (Promega, Madison, WI, United States) transfection reagent and the protocol for iCell Cardiomyocytes. The GFP cDNA is located in-frame and upstream of the Kv11.1 protein start site. For pharmacological studies, we incubated cells in nocodazole $(20 \mu \mathrm{M})$ (Millipore, Sigma, St. Louis, MO, United States), bortezomib, lactacystin, and MG132 (Millipore, Sigma, St. Louis, MO, United States), or E-4031 $(10 \mu \mathrm{M})$ (Alomone Laboratories, Jerusalem, Israel). Nocodazole, bortezomib, lactacystin or MG132 were dissolved in DMSO and added to the MEM (final DMSO concentration was $<0.1 \%$ ). E-4031 was dissolved in water. Control studies were done in parallel with equivalent amounts of vehicle (DMSO or water) only.

\section{Immunocytochemistry and Confocal Imaging}

Immunocytochemistry and confocal imaging experiments were done similar to those previously described (Smith et al., 2011, 2013). HEK293 cells or iCell Cardiomyocytes were plated in $35 \mathrm{~mm}$ tissue culture plates containing collagen-coated coverslips. Cells were fixed with $4 \%$ buffered paraformaldehyde for $10 \mathrm{~min}$, permeabilized with triton X-100 $(0.1 \%)$ for $10 \mathrm{~min}$, and rinsed in $0.75 \%$ glycine buffer for $10 \mathrm{~min}$ to quench background fluorescence. The cells were incubated with $2 \mathrm{~mL}$ blocking solution (10\% goat serum in PBS) for $1 \mathrm{~h}$ to block non-specific binding sites, and 


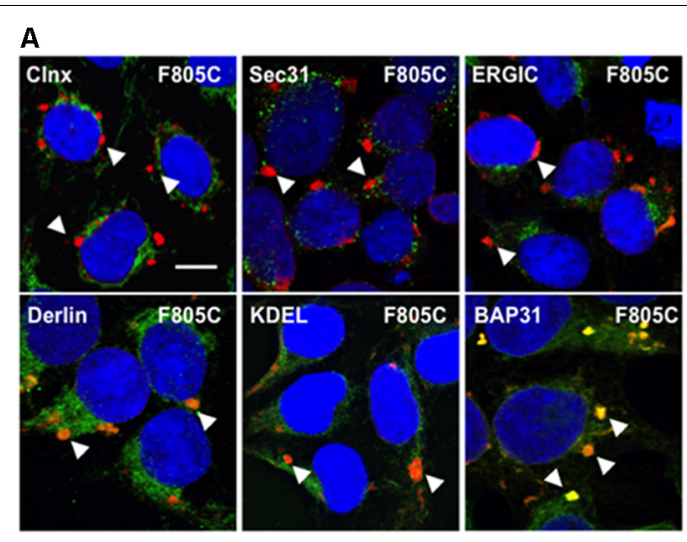

B

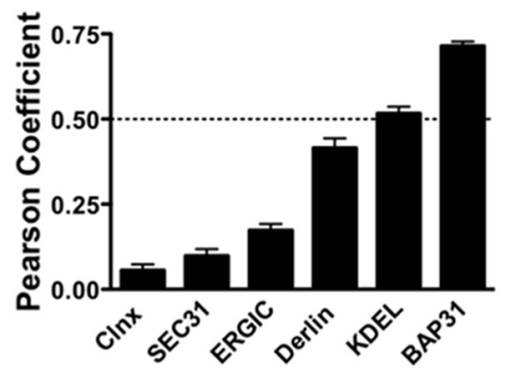

FIGURE 1 | F805C selectively co-localizes with BAP31. (A) Representative confocal images of HEK293 cells expressing F805C-Kv11.1 protein showing the overlap between anti-Kv11.1 and anti-ER/ERGIC protein immunostaining. Anti-Kv11.1 immunostaining is shown in red; anti-calnexin ( $n=12$ images), anti-Sec31 ( $n=19$ images), anti-ERGIC-53 ( $n=19$ images), anti-derlin-1 ( $n=18$ images), anti-KDEL ( $n=15$ images), or anti-BAP31 ( $n=17$ images) is shown as green; overlapping immunostaining of red and green signals of similar intensities is shown as yellow; and the cell nuclei are labeled blue. The arrowheads highlight the distinct immunostaining pattern of F805C-Kv11.1 protein, and the scale bar represents $10 \mu \mathrm{m}$. (B) The mean Costes' Pearson Coefficient $(\mathrm{PC})$ for the image data sets are shown. $\mathrm{PC}$ values at or below the dashed line are $(P C=0.5)$ indicative of weak or no co-localization. Two independent cultures were tested for each condition.

the cells were subsequently incubated with the appropriate primary antibodies: anti-Kv11.1 (1:1000, Alomone Laboratories, Jerusalem, Israel), anti-calnexin (1:1000, Abcam, Cambridge, MA, United States), anti-KDEL (1:1000, Abcam, Cambridge, MA, United States), anti-Sec31a (1:100, BD Labs, Franklin Lakes, NJ, United States), anti-Bap31 (1:500, Abcam, Cambridge, MA, United States), and anti-ERGIC-53 (1:1000, Alexis Biochemicals, Plymouth Meeting, PA, United States) mixed with blocking solution at room temperature. Excess antibody was washed off with three $10 \mathrm{~min}$ long rinses of blocking solution. The cells were then incubated for $1 \mathrm{~h}$ with the appropriate Highly Cross-absorbed Alexa Fluor antibodies (1:500, Invitrogen Inc., Carlsbad, CA, United States). The cells were washed four times for $10 \mathrm{~min}$ with blocking solution alone. After the final wash, the coverslips were mounted onto a slide using ProLong Gold with DAPI mounting medium (Invitrogen, Carlsbad, CA, United States). For iCell Cardiomyocytes experiments, we prepared the cells as described above but utilized the fluorescence signal from GFP for imaging analyses. Imaging was performed at the University of Kentucky Imaging Facility using a Leica TSP SP5 confocal microscope (Leica, Wetzler, Germany). HEK293 cells or iCell Cardiomyocytes did not show any labeling with any of the secondary antibodies when used alone (data not shown). Data are shown as representative single $\mathrm{z}$-scan images for each fluorescence signal (fluorescent images). Overlapping signals of similar intensities colored as red and green are shown as yellow and green and purple are shown as white.

Co-localization analyses were performed using Image ${ }^{1}$. We calculated the Pearson Coefficient (PC) and the Manders Colocalization Coefficients (MCC) for some experiments. The $\mathrm{PC}$ is the goodness of fit for the linear regression describing the relation between overlapping signal intensities. We calculated the coefficients using the intensity thresholds defined by the Costes' approach to minimize the contribution of noise. Using the Costes PC approach, the values range between 0 (no co-localization) to 1 (100\% co-localization). Weak co-localization is defined as having PC values $<0.5$ (Bolte and Cordelieres, 2006). The MCC calculates the fraction of overlap between the signals even if the intensities of the signals are very different from one another. The MCC also vary from 0 (no overlap) to 1 (complete overlap) and are calculated for both signals (M1 and M2). We use the MCC to describe the fraction of Kv11.1 signal in compartments containing the BAP31 signal (M1), or to describe the fraction of BAP31 signal in compartments containing Kv11.1 signal (M2).

\section{Statistics}

A one-way ANOVA was performed on data sets. In order to identify which experimental groups differed from control, post hoc Bonferroni's tests on selected data sets were performed (Prism, La Jolla, CA, United States). Significance was reported at $p<0.05$.

\section{RESULTS}

\section{F805C-Kv11.1 Protein Selectivity Co-localizes With BAP31}

We initially tested whether the trafficking-deficient F805CKv11.1 protein co-localized with different ER/ERGIC proteins (Figure 1A) in HEK293 cells by calculating the Costes PC. Confocal data showed that F805C-Kv11.1 protein immunostaining localized into several discrete compartments throughout the cell. Based on the PC analysis, the F805C-Kv11.1 protein did not (or only weakly) co-localize with the ER lectin chaperone calnexin (Hammond et al., 1994), the ER Golgi Intermediate Complex (ERGIC) protein ERGIC-53 (Schweizer et al., 1993), the ERES protein Sec31 (Salama et al., 1997), the ERAD protein derlin-1 (Lilley and Ploegh, 2004), or ER proteins that contain the KDEL ER retention signal sequence (Munro and Pelham, 1987) (Figure 1B). However, F805C-Kv11.1 protein co-localized with the transitional ER protein BAP31. These data suggest that F805C-Kv11.1 protein is concentrated in the transitional ER.

\footnotetext{
${ }^{1}$ https://imagej.nih.gov
} 

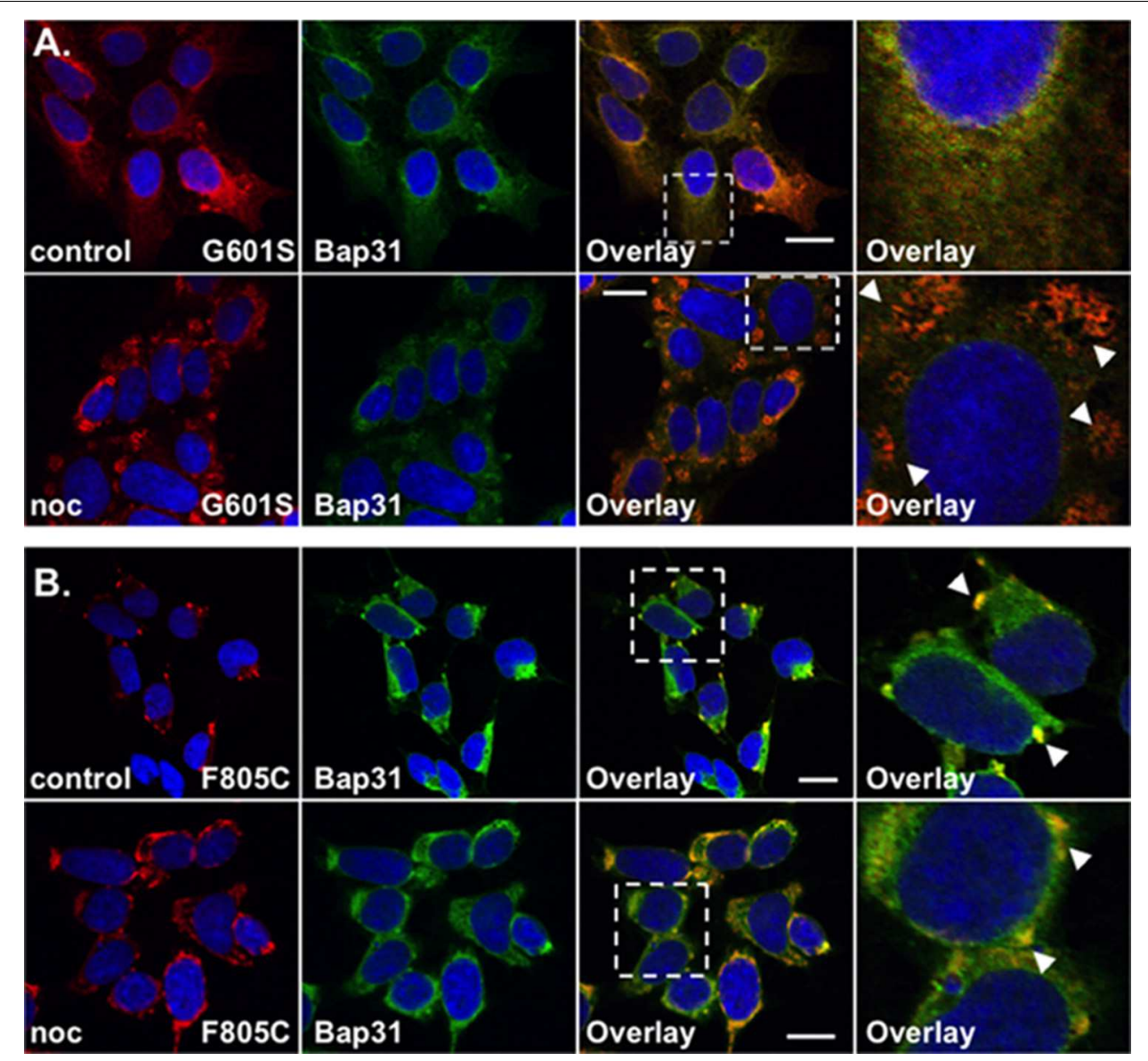

FIGURE 2 | G601S- and F805C-Kv11.1 proteins show distinct immunostaining patterns. Shown are representative confocal images of HEK293 cells expressing (A) G601S- or (B) F805C-Kv11.1 protein immunostained with anti-Kv11.1 (red, first column), anti-Bap31 (green, second column) in control conditions (top row; $n=13$ images for G601S and $n=17$ images for F805C) or after incubation in nocodazole (bottom row; $n=15$ images for G601S and $n=16$ images for F805C). The overlay images are also shown (overlapping immunostaining is yellow, third column), and the white dashed box portion of the overlay image is shown in larger detail (fourth column). The nuclei are labeled blue. The arrowheads in (A) highlight the reticular immunostaining pattern of G601S-Kv11.1 protein after nocodazole treatment, the arrowheads in (B) highlight the unique immunostaining pattern of F805C-Kv11.1 protein, and the scale bar represents $10 \mu \mathrm{m}$. Two independent cultures were tested for each condition.

\section{G601S- and F805C-Kv11.1 Proteins Show Differences in Protein Immunostaining}

We previously showed that G601S-Kv11.1 protein is sequestered in microtubule-dependent ER QC compartment with BAP31 (Smith et al., 2011, 2013). We directly compared the antiKv11.1 protein immunostaining pattern of HEK293 cells expressing G601S-Kv11.1 or F805C-Kv11.1 protein in control conditions or after treatment in the microtubule depolymerizing agent nocodazole $(20 \mu \mathrm{M})$ for $2 \mathrm{~h}$. Similar to what was previously reported, cells expressing G601S-Kv11.1 protein showed a peri-nuclear immunostaining pattern that diffused into the cell periphery and co-localized with BAP31 in control conditions (Figure 2A; $\mathrm{PC}=0.62 \pm 0.02$ in control $n=13$ images) (Smith et al., 2011, 2013). Incubating cells in nocodazole caused G601S-Kv11.1 and BAP31 protein to redistribute together into several peripheral reticulated membrane compartments $(\mathrm{PC}=0.72 \pm 0.02$ after nocodazole, $n=15$ images). In control conditions, the $\mathrm{F} 805 \mathrm{C}-\mathrm{Kv} 11.1$ protein immunostaining pattern was qualitatively different than the G601S-Kv11.1 protein immunostaining pattern (Figure 2B). Similar to Figure 1A, the F805C-Kv11.1 protein immunostaining was concentrated in several compartments that co-localized with BAP31 protein $(\mathrm{PC}=0.71 \pm 0.01$ in control $n=17$ images). Nocodazole treatment did not cause F805C-Kv11.1 protein to redistribute to reticulated membrane compartments, but it modestly increased the amount of diffuse F805CKv11.1 protein immunostaining, still co-localizing with BAP31 $(\mathrm{PC}=0.77 \pm 0.02$ after nocodazole, $n=16$ images $)$. We conclude that unlike G601S-Kv11.1 protein, F805C-Kv11.1 protein likely concentrates to distinct sub-compartments in the transitional ER.

\section{F805C-Kv11.1 Protein Immunostaining Is Disrupted by Proteasome Inhibition}

The WT Kv11.1 $\alpha$-subunit is synthesized in the ER as a $\sim 135$ $\mathrm{kDa}$ N-linked glycoprotein, and once the WT-Kv11.1 $\alpha$-subunit 


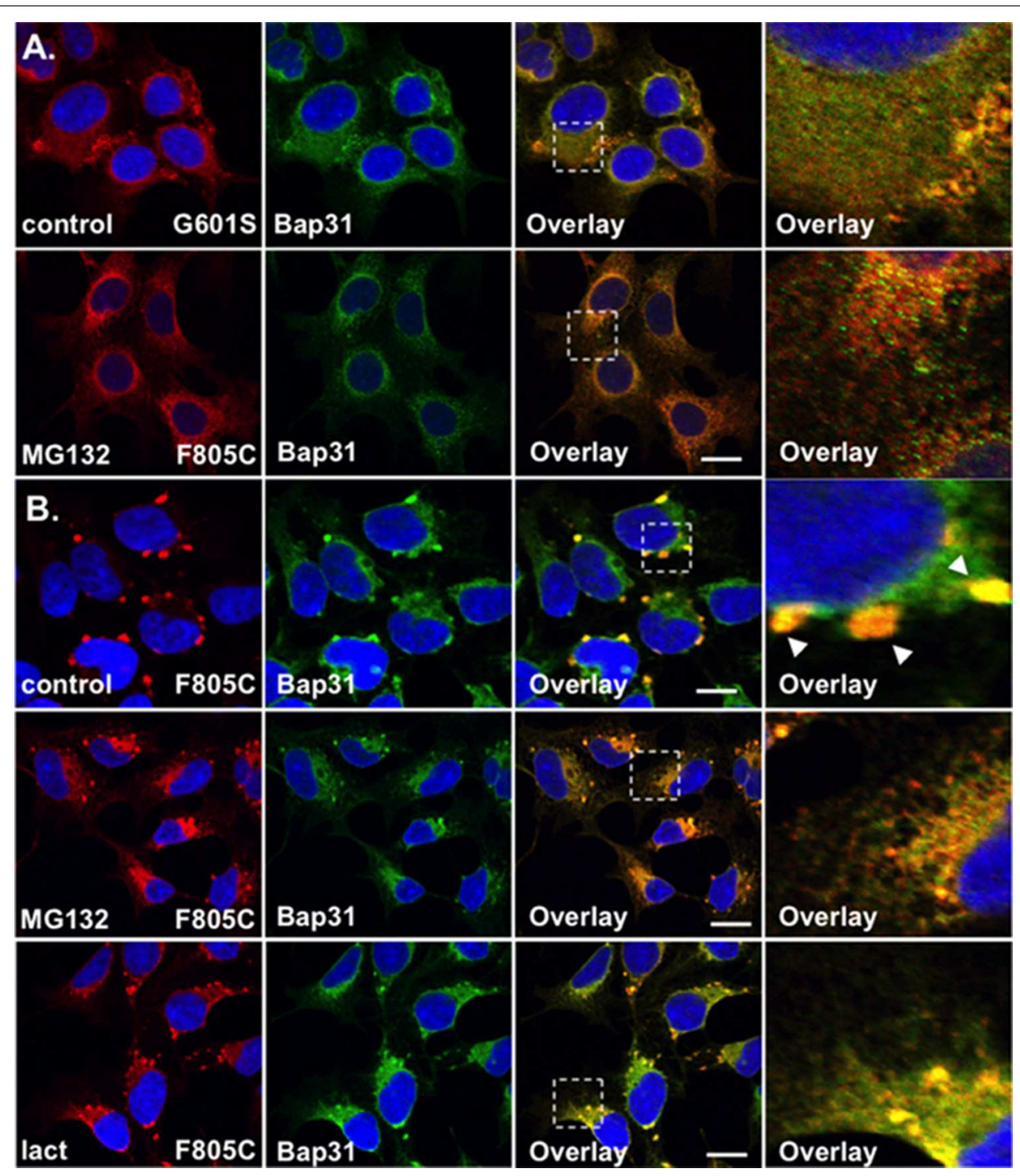

FIGURE 3 | F805C-Kv11.1 protein immunostaining is sensitive to proteasome inhibition. Shown are representative images of HEK293 cells expressing (A) G601Sor (B) F805C-Kv11.1 protein immunostained with anti-Kv11.1 (red, first column), anti-Bap31 (green, second column), the overlay (co-localization is shown as yellow, third column), and the white dashed box portion of the overlay in more detail (fourth column). The nuclei are shown in blue and the scale bars represent $10 \mu \mathrm{m}$. The top row of images in (A,B) show control conditions ( $n=13$ images for G601S and $n=17$ images for F805C) and the second row of images in (A,B) show cells after incubation in $5 \mu \mathrm{M}$ MG132 for $5 \mathrm{~h}$ ( $n=15$ images for G601S and $n=17$ images for F805C). The arrowheads in (B) highlight the immunostaining pattern of F805C-Kv11.1 protein in control conditions. The bottom row of images show F805C-Kv11.1 protein immunostaining after incubation in $5 \mu \mathrm{M}$ lactacystin $(n=17$ images) for $5 \mathrm{~h}$. Two independent cultures were tested for each condition.

traffics to the Golgi apparatus, it is terminally glycosylated to a $\sim 155 \mathrm{kDa}$ glycoprotein (Zhou et al., 1998b; Petrecca et al., 1999). Studies show that only $60 \%$ of the $135 \mathrm{kDa}$ WT-Kv11.1 protein is processed to the terminally glycosylated $155 \mathrm{kDa}$ form. The fraction of WT-Kv11.1 protein that fails to mature is degraded via the ERAD (ubiquitin-proteasome) pathway (Gong et al., 2005). In the presence of proteasome inhibitors, there is an increase in the immature form of WTKv11.1 protein, and a decrease in the efficiency in the ER dislocation of WT-Kv11.1 protein in ERAD pathway (Gong et al., 2005). Therefore, we tested whether the proteasome inhibitor MG132 impacted G601S- or F805C-Kv11.1 protein immunostaining. We incubated HEK293 cells expressing G601Sor F805C-Kv11.1 protein in the proteasome inhibitor MG132 $(5 \mu \mathrm{M})$ for $5 \mathrm{~h}$ (Figures $\mathbf{3 A}, \mathbf{B})$. This incubation time is based on previous reports that investigated the impact that proteasome inhibitors had on the ER retention of proteins in other studies (Kamhi-Nesher et al., 2001; Spiliotis et al., 2002; Wakana et al., 2008). Compared to control cells, incubating cells in MG132 did not appear to alter G601SKv11.1 protein immunostaining or its co-localization with BAP31 $(\mathrm{PC}=0.57 \pm 0.02$ after MG132, $n=15$ images $)$. In contrast, 

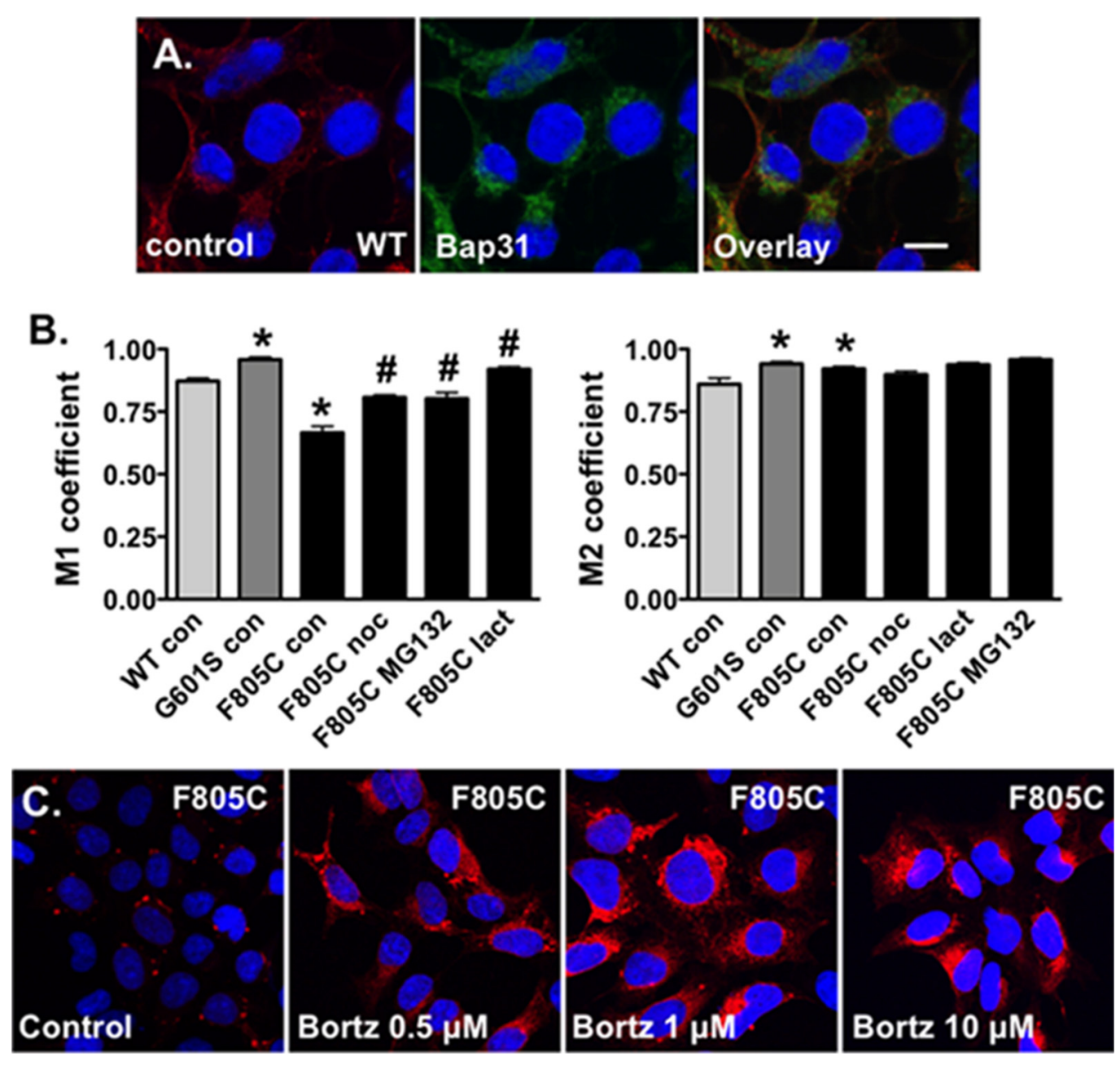

FIGURE 4 | Proteasome inhibition increases the fraction of Kv11.1 signal overlapping with BAP31 signal. (A) Shown are representative confocal images of HEK293 cells expressing WT-Kv11.1 protein immunostained with anti-Kv11.1 (red, first column), anti-Bap31 (green, second column) in control conditions. The nuclei are labeled blue, and the scale bar represents $10 \mu \mathrm{m}$. (B) Shown is the graph for the MCC that describes the fraction of Kv11.1 signal in compartments containing the BAP31 signal (M1, left graph), as well as the fraction of BAP31 signal in compartments containing Kv11.1 signal (M2, right graph). We compared M1 and M2 for cells stably expressing WT-, G601S-, or F805C-Kv11.1 protein in control conditions $\left(n=19,13\right.$, and 17 images, respectively, ${ }^{*} p<0.05$ compared to cells expressing WT-Kv11.1 in control conditions). We also compared the M1 or M2 in cells expressing F805C-Kv11.1 in control conditions to cells incubated in nocodazole (F805C noc, $n=16$ images), MG132 (F805C MG132, $n=17$ images), or lactacystin (F805C lact, $n=17$ images). At least two independent cultures were tested for each condition $(\# p<0.05)$ compared to cells expressing F805C-Kv11.1 protein in control conditions. (C) Shown are representative images of cells expressing F805C-Kv11.1 protein immunostained with anti-Kv11.1 (red) in control conditions or in different concentrations of bortezomib for $5 \mathrm{~h}$. The nuclei are labeled blue. The effect of bortezomib on F805C-Kv11.1 immunostaining was confirmed in two independent test cultures ( $n=5-11$ images per condition).

treating cells expressing F805C-Kv11.1 protein dramatically transformed the protein immunostaining pattern from several compartments to a peri-nuclear pattern that diffused into the cell periphery (Figure 3B). Although incubating cells in MG132 dramatically altered the distribution of F805C-Kv11.1 protein, the $\mathrm{F} 805 \mathrm{C}-\mathrm{Kv} 11.1$ protein still co-localized with BAP31 ( $\mathrm{PC}=0.78 \pm 0.02$ after MG132, $n=17$ images). We next determined if another proteasome inhibitor similarly affected the immunostaining pattern of cells expressing F805C-Kv11.1 protein. Incubating cells expressing $\mathrm{F} 805 \mathrm{C}-\mathrm{Kv} 11.1$ protein in the proteasome inhibitor lactacystin for $5 \mathrm{~h}$ also altered the F805C-Kv11.1 protein immunostaining pattern similar to cells incubated with MG132 (Figure 3B). Moreover, incubating cells in lactacystin did not alter $\mathrm{F} 805 \mathrm{C}-\mathrm{Kv} 11.1$ protein co-localization with $\mathrm{BAP} 31$ ( $\mathrm{PC}=0.72 \pm 0.03$ after lactacystin, $n=17$ images). These data indicate that $\mathrm{F} 805 \mathrm{C}-\mathrm{Kv} 11.1$ protein concentrates in sub-compartments of the transitional ER that are sensitive to proteasome inhibition.

\section{Nocodazole, Lactacystin, and MG132}

Increase the Fractional Overlap of F805C-Kv11.1 Protein With BAP31 and Immunostaining

The Costes' PC quantifies the co-localization between Kv11.1 and BAP31 protein immunostaining by measuring the goodness of 


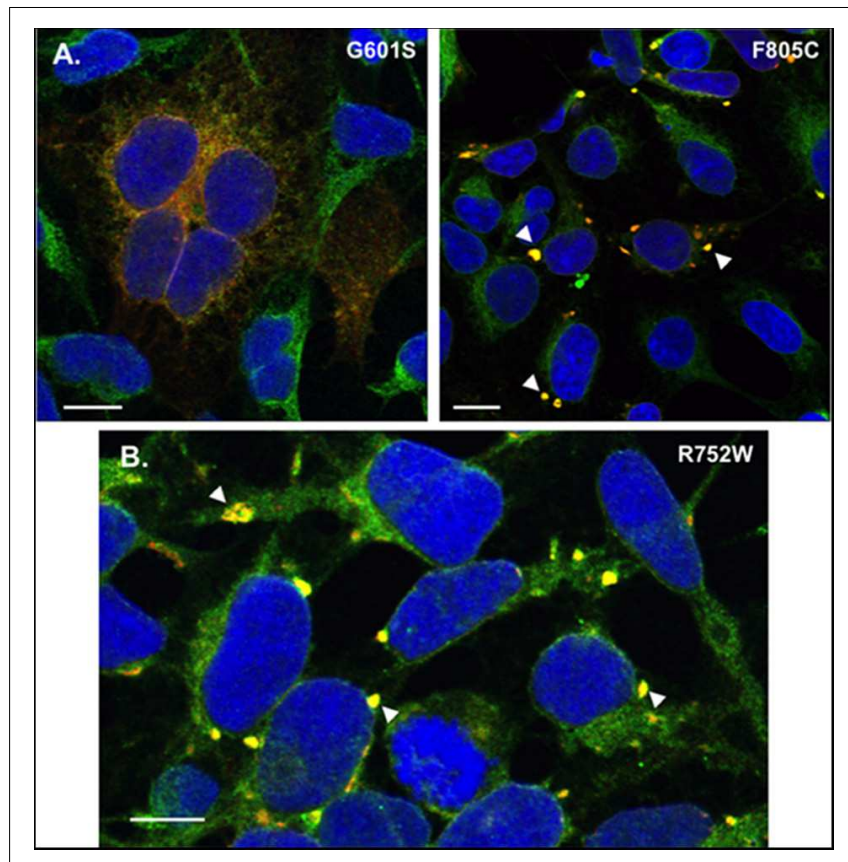

FIGURE 5 | Transient transfection of G601S- or F805C-Kv11.1 does not alter mutation-specific differences in immunostaining pattern, and cells stably expressing R752W-Kv11.1 protein show similar immunostaining patterns as cells expressing F805C-Kv11.1 protein. (A) Representative confocal images of HEK293 cells transiently expressing G601S-Kv11.1 (left) or F805C-Kv11.1 (right) protein showing the overlapped anti-Kv11.1 (red) and anti-BAP31 immunostaining (green) ( $n=12$ images for each, from 2 independent cultures). Overlapping immunostaining of red and green signal of similar intensities is shown as yellow and the cell nuclei are labeled blue. The transfection efficiency is $<100 \%$, so not all cells were expressing Kv11.1 protein. (B) Representative confocal images of HEK293 cells stably expressing R752W-Kv11.1 protein showing the overlap between anti-Kv11.1 (red) and anti-BAP31 immunostaining (green). Overlapping immunostaining of red and green signal of similar intensities is shown as yellow and the cell nuclei are labeled blue. The arrowheads highlight the immunostaining pattern of R752W-Kv11.1 protein, and the scale bar represents $10 \mu \mathrm{m}$. The mean Costes' Pearson Coefficient (PC) for the image data is $0.65 \pm 0.01$ ( $n=11$ images from 2 independent cultures).

fit for the relation between overlapping signal intensities. An additional approach for confocal image analysis is to calculate the MCC, which provides a measure of how much one signal overlaps with a second signal. Qualitatively, the major effect of incubating cells expressing F805C-Kv11.1 protein in nocodazole (Figure 2B), MG132, or lactacystin (Figure 3B) was to increase the overlap of Kv11.1 protein with BAP31 immunostaining, therefore we quantified the MCC between Kv11.1 protein and BAP31.

Manders Colocalization Coefficients analyses have not been done for cells expressing Kv11.1 proteins. Therefore we imaged cells stably expressing WT-Kv11.1 protein (Figure 4A) and compared the M1 and M2 with cells expressing G601Sor F805C-Kv11.1 protein. The data show the M1 for cells expressing WT-Kv11.1 protein is smaller than that of cells expressing G601S-Kv11.1 protein (Figure 4B). In other words, cells expressing WT-Kv11.1 protein show less overlap of Kv11.1 protein with BAP31 compared to cells expressing G601SKv11.1 protein. These data are consistent with more G601SKv11.1 protein retained in the transitional ER compartment. In contrast, the M1 for cells expressing WT-Kv11.1 protein is greater than F805C-Kv11.1 protein. This is because F805CKv11.1 protein concentrates in several small transitional ER subcompartments. We conclude that mutation-specific differences in the trafficking-deficient LQT2 phenotype can be quantified by differences in the fraction of Kv11.1 protein overlapping with BAP31.

In contrast the M2 for cells expressing WT-Kv11.1 protein is smaller than cells expressing G601S- or F805C-Kv11.1 protein (Figure 4B). This means that more BAP31 overlapped with Kv11.1 protein in cells expressing G601S- or F805C-Kv11.1 protein. This is because cells expressing WT-Kv11.1 protein appear to have more Kv11.1 protein in the cell surface membrane (Figure 4A).

We next determined how incubating cells expressing F805C-Kv11.1 protein in nocodazole or the proteasome inhibitors affected the M1 and M2 (Figure 4B). Compared to control cells expressing F805C-Kv11.1, incubating cells expressing F805C-Kv11.1 protein in the proteasome inhibitors increased M1. These data demonstrate that nocodazole and the proteasome inhibition increased the amount of F805CKv11.1 protein in the larger transitional ER compartment. We did not see any significant changes in M2, indicating that incubating cells in nocodazole or proteasome inhibitors did affect the high amount of BAP31 overlap with F805C-Kv11.1 protein.

The effect of proteasome inhibitors on the immunostaining patterns of F805C-Kv11.1 protein was striking. Inhibiting the proteasome pathway is an approach in the treatment of certain cancers, including myeloma and mantle cell lymphoma (Chen et al., 2011). Bortezomib is the first FDA approved proteasome inhibitor to be implemented in cancer treatment. Therefore, we also determined the impact that different concentrations of bortezomib had on the immunostaining pattern of F805C-Kv11.1 protein (Figure 4C). We found that, similar to MG132 and lactacystin, incubating cells in different concentrations of bortezomib for $5 \mathrm{~h}$ transformed the F805CKv11.1 protein immunostaining pattern to a diffuse peri-nuclear pattern.

\section{G601S- and F805C-Kv11.1 Proteins Show Differences in Protein Immunostaining in Transiently Transfected Cells}

One possible reason for the immunostaining difference between the cell lines expressing G601S- and F805C-Kv11.1 could be due to differences in protein expression. The unique immunostaining pattern of F805C-Kv11.1 protein might be because the mutant protein levels are too high for a normal functioning of the cellular QC system. Therefore we immunostained HEK293 cells transiently transfected with equal amounts of G601S- or F805C-Kv11.1 plasmid DNA. Importantly, the mutation-specific immunostaining pattern of G601S- and F805C-Kv11.1 proteins were similar 
to what was seen in stably expressing cells (Figure 5A). These data suggest that the mutation-specific difference in immunostaining was not due to differences in mutant Kv11.1 cDNA levels.

We previously showed that cells stably expressing different LQT2-linked mutations in the Kv11.1 pore region (A614V- or N629D-Kv11.1) exhibit a diffuse immunostaining pattern that co-localizes with BAP31 similar to G601S-Kv11.1 protein (Smith et al., 2013). We determined whether R752WKv11.1 (another LQT2-linked mutation that is located intracellular CNBD, impairs Kv11.1 tetramer assembly, and does not undergo pharmacological correction with E-4031) exhibited a similar immunostaining pattern as cells expressing F805C-Kv11.1 protein. Imaging cells stably expressing R752W-Kv11.1 protein showed that it also concentrated in transitional ER subcompartments (Figure 5B). Together, the data demonstrate that the immunostaining pattern seen in cells expressing of F805C-Kv11.1 protein is also seen in cells expressing other LQT2-linked mutant proteins in the CNBD.

\section{G601S and F805C Show Distinct Immunostaining Patterns in iPSC-CMs}

We next determined whether the mutation-specific immunostaining patterns of G601S- or F805C-Kv11.1 proteins persisted in human inducible pluripotent stem cell derived cardiomyocytes (iPSC-CMs). This will help to determine if mutation-specific differences occurs in a more native-like cell that expresses endogenous WT-Kv11.1 protein (including the shorter Kv11.1b subunit) (Jones et al., 2004, 2014). iPSC-CMs were transfected with WT-, G601S- or F805C-Kv11.1 proteins tagged with GFP on the Kv11.1 amino-terminus to distinguish between heterologously expressed and endogenous WT-Kv11.1 or WT-Kv11.1b protein. We immunostained the cells for BAP31. Similar to what we previously showed in HEK293 cells, WT-Kv11.1-GFP protein expressed in iPSC-CMs did not co-localize with BAP31 (Figures 6A,D) (Smith et al., 2013). G601S-Kv11.1-GFP expressed in iPSC-CMs co-localized with BAP31, and importantly, this co-localization was decreased in iPSC-CMs treated with the pharmacological chaperone E-4031 for 24-48 h (Figures 6B,D). In most iPSC-CMs, F805C-Kv11.1GFP protein concentrated in discrete compartments (although the co-localization with BAP31 was not as strong as it was in HEK293 cells) (Figures 6C,D). These data confirm that the differences in subcellular localization of WT-, G601S-, and F805C-Kv11.1 proteins persisted in a cell model of human cardiomyocytes.

\section{DISCUSSION}

In this study we demonstrate that the trafficking-deficient LQT2 missense mutation F805C generated Kv11.1 protein that accumulates in discrete ER subcompartments. In HEK293 cells F805C-Kv11.1 protein did not co-localize with several ER/ERGIC marker proteins, but it did co-localize with the transitional ER protein BAP31. The immunostaining pattern of F805C-Kv11.1 protein was sensitive to the microtubule depolymerizing drug nocodazole, as well as the proteasome inhibitors MG132 or lactacystin. Interestingly, these drugs did not alter F805C-Kv11.1 protein co-localization with BAP31, but they all caused the F805C-Kv11.1 protein to become more diffuse and increased the overlapping immunostaining between F805CKv11.1 and BAP31. In contrast, G601S-Kv11.1 protein did not accumulate in distinct subcompartments and its immunostaining pattern was insensitive to proteasome inhibition. Importantly, the mutation-specific differences in the subcellular patterns of G601S- and Kv11.1-Kv11.1 protein were also present in human iPSC-CMs. We conclude that distinct QC mechanisms in the ER regulate the retention of G601S- and F805C-Kv11.1 protein.

Mutation-specific differences in trafficking-deficient phenotype for LQT2 mutations have long been recognized (Ficker et al., 2000b; Anderson et al., 2006, 2014; Smith et al., 2016). For example, there are mutation-specific differences in pharmacological correction, intragenic suppression, and dominant negative effects on the trafficking of WTKv11.1 protein, suggesting that different mutations likely disrupt different steps in the native Kv11.1 protein folding pathway (e.g., co-assembly of $\alpha$-subunits, formation of the voltage-sensor/pore domains, increasing the proximity of the $\mathrm{NH}_{2}$ and $\mathrm{COOH}$ termini, etc.) (Ficker et al., 2000a; Delisle et al., 2005; Anderson et al., 2006; Smith et al., 2016). However, this is the first study to investigate mutation specific differences in cellular mechanisms associated with ER retention. Although we focus only on two different mutations, we found that other trafficking-deficient LQT2-linked proteins have immunostaining/co-localization patterns similar to cells expressing G601S-Kv11.1 (A614V and N629D) (Smith et al., 2013) or F805C-Kv11.1 protein (R752W, Figure 5B). Therefore, this study has identified a novel way to categorize subgroups of trafficking-deficient LQT2 mutations. We expect these findings will help identify new drugs that improve LQT2 protein trafficking by targeting mutation-specific ER QC mechanisms.

The exact mechanism by which proteasome inhibitors alter F805C-Kv11.1 protein immunostaining remains unclear. Previous studies show that retrotranslocation of misfolded proteins into the cytosol likely occurs concurrently with their degradation by the proteasome, and that upon inhibition of proteasomal activity, misfolded proteins remain intact in the secretory pathway (Hirsch and Ploegh, 2000). Consistent with this concept, studies show that inhibition of the proteasome decreases the efficiency of WT-Kv11.1 protein dislocation from the ER (Gong et al., 2005). However, F805C-Kv11.1 protein did not co-localize with the ERAD protein derlin-1, and surprisingly, we found that longer-term proteasome inhibition did not improve Kv11.1 protein trafficking but actually appeared to inhibit it (data not shown).

An intriguing implication to the findings in this study is that, because different immunostaining patterns of different LQT2-linked mutant proteins can be easily visualized with microtubule depolymerizing agents or proteasome inhibitors, cell lines expressing these trafficking-deficient Kv11.1 

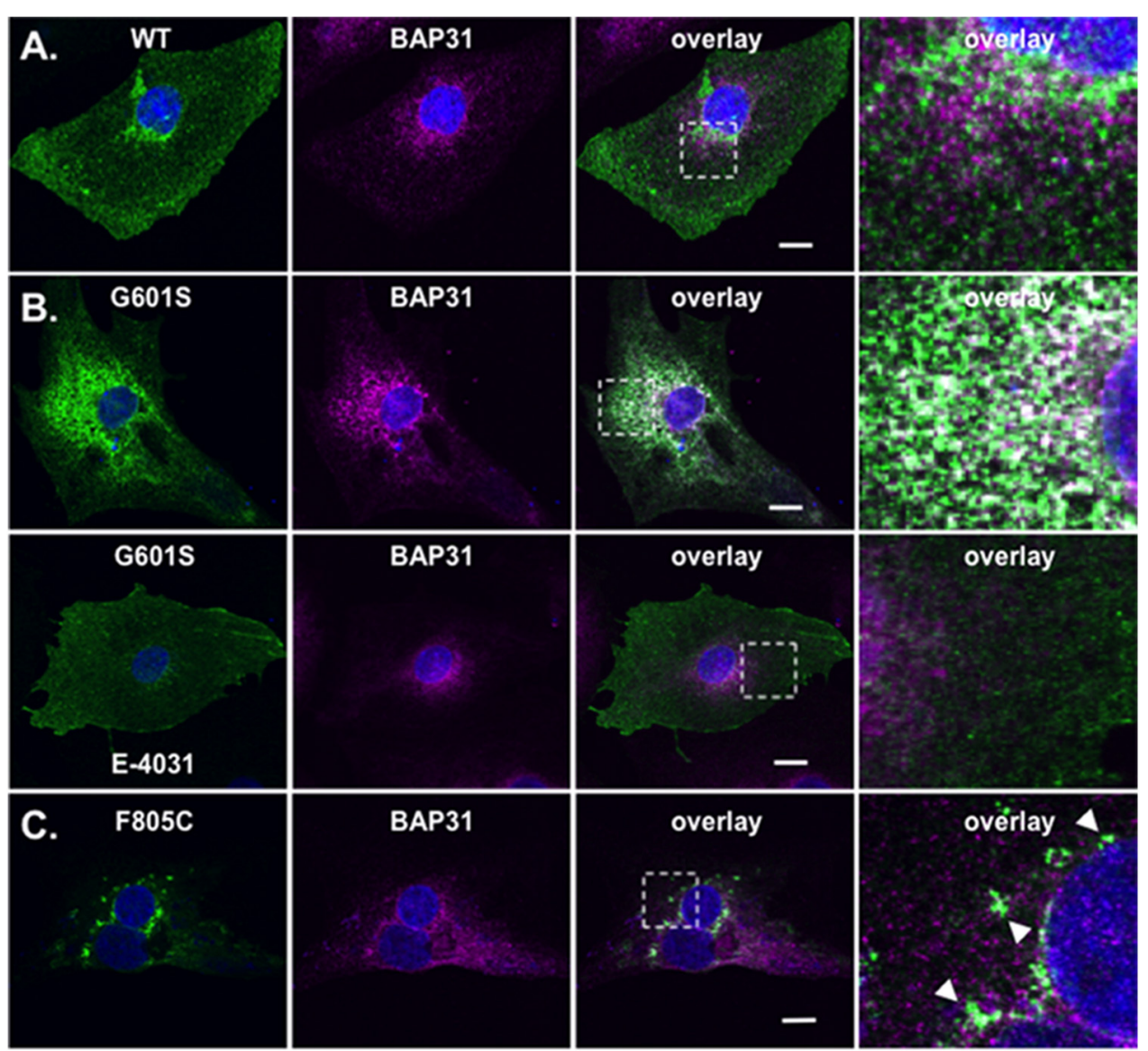

D.

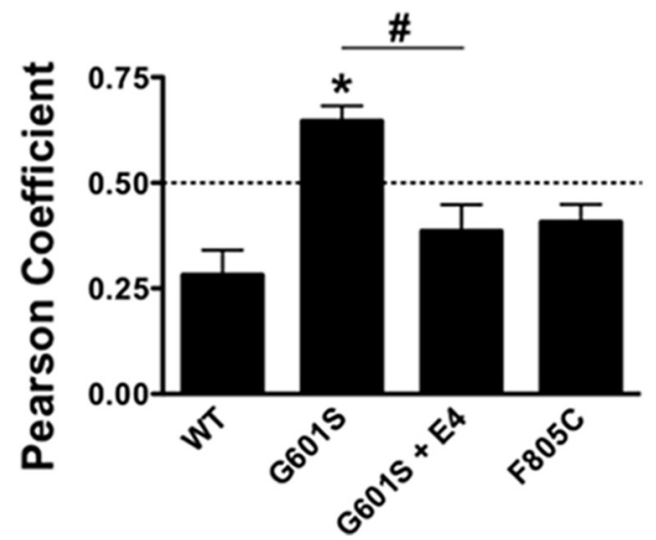

FIGURE 6 | G601S- and F805C-Kv11.1 proteins show distinct immunostaining patterns in iPSC-CMs. Shown are representative images of iPSC-CMs expressing (A) WT-Kv11.1-GFP, (B) G601S-Kv11.1-GFP, or (C) F805C-Kv11.1-GFP (green, first column), immunostained with anti-BAP31 (purple, second column). Also shown are the overlays (co-localization is shown as white, third column) and the white dashed box portion of the overlay in more detail (fourth column). The nuclei are stained in blue and the scale bar represents $10 \mu \mathrm{m}$. The row in (A), top row in (B), and row in (C) show iPSC-CMs in control conditions. The arrowheads in (C) highlight the unique fluorescence pattern of cells expressing F805C-Kv11.1-GFP. The bottom row in (B) shows images from iPSC-CMs expressing G601S-Kv11.1-GFP after incubation in $10 \mu \mathrm{M}$ E-4031 (E4) for $\sim 24 \mathrm{~h}$. (D) The mean Costes' Pearson Coefficient (PC) for the iPSC-CMs expressing WT-GFP ( $n=16$ images), G601S-GFP ( $n=20$ images), G601S-GFP after incubation in $10 \mu \mathrm{M} \mathrm{E-4031} \mathrm{(} n=19$ images), or F805C-GFP ( $n=14$ images) (* $p<0.05$ compared to WT, \#p $<0.05$ compared to G601S con). Two independent cultures were tested for each condition.

proteins might be used as a novel drug-screening platform to identify new anti-neoplastic agents that have microtubule depolymerization properties or inhibit the proteasome activity.
There are several limitations to this study. We primarily used HEK293 cells for most of the experiments in the study, however, we confirmed similar mutation-specific differences in the subcellular localization of G601S- and F805C-Kv11.1 proteins 
in iPSC-CMs. Interestingly the co-localization of F805C-Kv11.1 and BAP31 protein was decreased in iPSC-CM. We suspect that this difference might be due to cell type specific differences. For example, the subcellular localization of mutant F805C-Kv11.1 protein may be altered by endogenous WT-Kv11.1 proteins (including the Kv11.1b protein). However, F805C-Kv11.1 is not expected to co-assemble with other Kv11.1 subunits (Ficker et al., 2002). Another possibility is that the larger size of iPSCCMs might help to better resolve the spatial differences between F805C-Kv11.1 protein and BAP31. Regardless, the data clearly show that both G601S- and F805C-Kv11.1 proteins have unique localization patterns in both cell types, suggesting they are regulated by different QC pathway interactions.

\section{REFERENCES}

Anderson, C. L., Delisle, B. P., Anson, B. D., Kilby, J. A., Will, M. L., Tester, D. J., et al. (2006). Most LQT2 mutations reduce Kv11.1 (hERG) current by a class 2 (trafficking-deficient) mechanism. Circulation 113, 365-373. doi: 10.1161/ CIRCULATIONAHA.105.570200

Anderson, C. L., Kuzmicki, C. E., Childs, R. R., Hintz, C. J., Delisle, B. P., and January, C. T. (2014). Large-scale mutational analysis of Kv11.1 reveals molecular insights into type 2 long QT syndrome. Nat. Commun. 5:5535. doi: 10.1038/ncomms6535

Anson, B. D., Ackerman, M. J., Tester, D. J., Will, M. L., Delisle, B. P., Anderson, C. L., et al. (2004). Molecular and functional characterization of common polymorphisms in HERG (KCNH2) potassium channels. Am. J. Physiol. Heart Circ. Physiol. 286, H2434-H2441. doi: 10.1152/ajpheart.00891.2003

Bolte, S., and Cordelieres, F. P. (2006). A guided tour into subcellular colocalization analysis in light microscopy. J. Microsc. 224, 213-232. doi: 10.1111/j.1365-2818. 2006.01706.x

Chen, D., Frezza, M., Schmitt, S., Kanwar, J., and Dou, Q. P. (2011). Bortezomib as the first proteasome inhibitor anticancer drug: current status and future perspectives. Curr. Cancer Drug Targets 11, 239-253. doi: 10.2174/ 156800911794519752

Crotti, L., Celano, G., Dagradi, F., and Schwartz, P. J. (2008). Congenital long QT syndrome. Orphanet J. Rare Dis. 3:18. doi: 10.1186/1750-1172-3-18

Curran, M. E., Splawski, I., Timothy, K. W., Vincent, G. M., Green, E. D., and Keating, M. T. (1995). A molecular basis for cardiac arrhythmia: HERG mutations cause long QT syndrome. Cell 80, 795-803. doi: 10.1016/00928674(95)90358-5

Delisle, B. P., Anderson, C. L., Balijepalli, R. C., Anson, B. D., Kamp, T. J., and January, C. T. (2003). Thapsigargin selectively rescues the trafficking defective LQT2 channels G601S and F805C. J. Biol. Chem. 278, 35749-35754. doi: 10. 1074/jbc.M305787200

Delisle, B. P., Slind, J. K., Kilby, J. A., Anderson, C. L., Anson, B. D., Balijepalli, R. C., et al. (2005). Intragenic suppression of trafficking-defective KCNH2 channels associated with long QT syndrome. Mol. Pharmacol. 68, 233-240. doi: 10.1124/mol.105.012914

Ellgaard, L., and Helenius, A. (2003). Quality control in the endoplasmic reticulum. Nat. Rev. Mol. Cell Biol. 4, 181-191. doi: 10.1038/nrm1052

Ficker, E., Dennis, A. T., Obejero-Paz, C. A., Castaldo, P., Taglialatela, M., and Brown, A. M. (2000a). Retention in the endoplasmic reticulum as a mechanism of dominant-negative current suppression in human long QT syndrome. J. Mol. Cell Cardiol. 32, 2327-2337. doi: 10.1006/jmcc.2000.1263

Ficker, E., Dennis, A. T., Wang, L., and Brown, A. M. (2003). Role of the cytosolic chaperones Hsp70 and Hsp90 in maturation of the cardiac potassium channel HERG. Circ. Res. 92, e87-e100. doi: 10.1161/01.RES.0000079028.31393.15

Ficker, E., Obejero-Paz, C. A., Zhao, S., and Brown, A. M. (2002). The binding site for channel blockers that rescue misprocessed human long QT syndrome type 2 ether-a-gogo-related gene (HERG) mutations. J. Biol. Chem. 277, 4989-4998. doi: 10.1074/jbc.M107345200

Ficker, E., Thomas, D., Viswanathan, P. C., Dennis, A. T., Priori, S. G., Napolitano, C., et al. (2000b). Novel characteristics of a misprocessed mutant

\section{AUTHOR CONTRIBUTIONS}

$\mathrm{AH}$, JS, and BD performed the experiments and data analysis. CA, $\mathrm{CE}, \mathrm{TM}, \mathrm{CJ}$, and $\mathrm{BD}$ contributed to the writing, interpretation, editing, and presentation of the manuscript.

\section{FUNDING}

This work was supported by a grant from the American Heart Association Cardiovascular Genome Phenome Discovery Grant (BD) [15CVGPSD27580000] and the Competitive Catalyst Renewal Grant [17CCRG33700289] (BD).

HERG channel linked to hereditary long QT syndrome. Am. J. Physiol. Heart Circ. Physiol. 279, H1748-H1756.

Foo, B., Williamson, B., Young, J. C., Lukacs, G., and Shrier, A. (2016). hERG quality control and the long QT syndrome. J. Physiol. 594, 2469-2481. doi: 10.1113/JP270531

Furutani, M., Trudeau, M. C., Hagiwara, N., Seki, A., Gong, Q., Zhou, Z., et al. (1999). Novel mechanism associated with an inherited cardiac arrhythmia: defective protein trafficking by the mutant HERG (G601S) potassium channel. Circulation 99, 2290-2294. doi: 10.1161/01.CIR.99.17.2290

Gong, Q., Jones, M. A., and Zhou, Z. (2006). Mechanisms of pharmacological rescue of trafficking-defective hERG mutant channels in human long QT syndrome. J. Biol. Chem. 281, 4069-4074. doi: 10.1074/jbc.M511765200

Gong, Q., Keeney, D. R., Molinari, M., and Zhou, Z. (2005). Degradation of trafficking-defective long QT syndrome type II mutant channels by the ubiquitin-proteasome pathway. J. Biol. Chem. 280, 19419-19425. doi: 10.1074/ jbc.M502327200

Hammond, C., Braakman, I., and Helenius, A. (1994). Role of N-linked oligosaccharide recognition, glucose trimming, and calnexin in glycoprotein folding and quality control. Proc. Natl. Acad. Sci. U.S.A. 91, 913-917. doi: 10.1073/pnas.91.3.913

Hirsch, C., and Ploegh, H. L. (2000). Intracellular targeting of the proteasome. Trends Cell Biol. 10, 268-272. doi: 10.1016/S0962-8924(00)01768-2

Jones, D. K., Liu, F., Vaidyanathan, R., Eckhardt, L. L., Trudeau, M. C., and Robertson, G. A. (2014). hERG 1 b is critical for human cardiac repolarization. Proc. Natl. Acad. Sci. U.S.A. 111, 18073-18077. doi: 10.1073/pnas.14149 45111

Jones, E. M., Roti Roti, E. C., Wang, J., Delfosse, S. A., and Robertson, G. A. (2004). Cardiac IKr channels minimally comprise hERG 1a and 1 b subunits. J. Biol. Chem. 279, 44690-44694. doi: 10.1074/jbc.M408344200

Kamhi-Nesher, S., Shenkman, M., Tolchinsky, S., Fromm, S. V., Ehrlich, R., and Lederkremer, G. Z. (2001). A novel quality control compartment derived from the endoplasmic reticulum. Mol. Biol. Cell 12, 1711-1723. doi: 10.1091/mbc.12. 6.1711

Lilley, B. N., and Ploegh, H. L. (2004). A membrane protein required for dislocation of misfolded proteins from the ER. Nature 429, 834-840. doi: 10. 1038/nature02592

Munro, S., and Pelham, H. R. (1987). A C-terminal signal prevents secretion of luminal ER proteins. Cell 48, 899-907. doi: 10.1016/0092-8674(87)90 086-9

Petrecca, K., Atanasiu, R., Akhavan, A., and Shrier, A. (1999). N-linked glycosylation sites determine HERG channel surface membrane expression. J. Physiol. 515(Pt 1), 41-48. doi: 10.1111/j.1469-7793.1999.041ad.x

Salama, N. R., Chuang, J. S., and Schekman, R. W. (1997). Sec31 encodes an essential component of the COPII coat required for transport vesicle budding from the endoplasmic reticulum. Mol. Biol. Cell 8, 205-217. doi: 10.1091/mbc. 8.2.205

Sanguinetti, M. C., Curran, M. E., Spector, P. S., and Keating, M. T. (1996). Spectrum of HERG K+-channel dysfunction in an inherited cardiac arrhythmia. Proc. Natl. Acad. Sci. U.S.A. 93, 2208-2212. doi: 10.1073/pnas.93. 5.2208 
Schweizer, A., Ericsson, M., Bachi, T., Griffiths, G., and Hauri, H. P. (1993). Characterization of a novel $63 \mathrm{kDa}$ membrane protein. Implications for the organization of the ER-to-Golgi pathway. J. Cell Sci. 104(Pt 3), 671-683.

Smith, J. L., Anderson, C. L., Burgess, D. E., Elayi, C. S., January, C. T., and Delisle, B. P. (2016). Molecular pathogenesis of long QT syndrome type 2. J. Arrhythm. 32, 373-380. doi: 10.1016/j.joa.2015.11.009

Smith, J. L., Mcbride, C. M., Nataraj, P. S., Bartos, D. C., January, C. T., and Delisle, B. P. (2011). Trafficking-deficient hERG K channels linked to long QT syndrome are regulated by a microtubule-dependent quality control compartment in the ER. Am. J. Physiol. Cell Physiol. 301, C75-C85. doi: 10. 1152/ajpcell.00494.2010

Smith, J. L., Reloj, A. R., Nataraj, P. S., Bartos, D. C., Schroder, E. A., Moss, A. J., et al. (2013). Pharmacological correction of long QT-linked mutations in KCNH2 (hERG) increases the trafficking of Kv11.1 channels stored in the transitional endoplasmic reticulum. Am. J. Physiol. Cell Physiol. 305, C919C930. doi: 10.1152/ajpcell.00406.2012

Spiliotis, E. T., Pentcheva, T., and Edidin, M. (2002). Probing for membrane domains in the endoplasmic reticulum: retention and degradation of unassembled MHC class I molecules. Mol. Biol. Cell 13, 1566-1581. doi: 10. 1091/mbc.01-07-0322

Trudeau, M. C., Warmke, J. W., Ganetzky, B., and Robertson, G. A. (1995). HERG, a human inward rectifier in the voltage-gated potassium channel family. Science 269, 92-95. doi: 10.1126/science.7604285

Wakana, Y., Takai, S., Nakajima, K., Tani, K., Yamamoto, A., Watson, P., et al. (2008). Bap31 is an itinerant protein that moves between the peripheral endoplasmic reticulum (ER) and a juxtanuclear compartment related to ERassociated Degradation. Mol. Biol. Cell 19, 1825-1836. doi: 10.1091/mbc.E0708-0781
Walker, V. E., Atanasiu, R., Lam, H., and Shrier, A. (2007). Co-chaperone FKBP38 promotes HERG trafficking. J. Biol. Chem. 282, 23509-23516. doi: 10.1074/jbc. M701006200

Walker, V. E., Wong, M. J., Atanasiu, R., Hantouche, C., Young, J. C., and Shrier, A. (2010). Hsp40 chaperones promote degradation of the HERG potassium channel. J. Biol. Chem. 285, 3319-3329. doi: 10.1074/jbc.M109.024000

Zhou, Z., Gong, Q., Epstein, M. L., and January, C. T. (1998a). HERG channel dysfunction in human long QT syndrome. Intracellular transport and functional defects. J. Biol. Chem. 273, 21061-21066.

Zhou, Z., Gong, Q., and January, C. T. (1999). Correction of defective protein trafficking of a mutant HERG potassium channel in human long QT syndrome. Pharmacological and temperature effects. J. Biol. Chem. 274, 31123-31126. doi: 10.1074/jbc.274.44.31123

Zhou, Z., Gong, Q., Ye, B., Fan, Z., Makielski, J. C., Robertson, G. A., et al. (1998b). Properties of HERG channels stably expressed in HEK 293 cells studied at physiological temperature. Biophys. J. 74, 230-241.

Conflict of Interest Statement: The authors declare that the research was conducted in the absence of any commercial or financial relationships that could be construed as a potential conflict of interest.

Copyright (c) 2018 Hall, Anderson, Smith, Mirshahi, Elayi, January and Delisle. This is an open-access article distributed under the terms of the Creative Commons Attribution License (CC BY). The use, distribution or reproduction in other forums is permitted, provided the original author(s) and the copyright owner are credited and that the original publication in this journal is cited, in accordance with accepted academic practice. No use, distribution or reproduction is permitted which does not comply with these terms. 


\section{OPEN ACCESS}

Edited by:

Hugues Abriel,

University of Bern, Switzerland

Reviewed by:

Jean-Sebastien Rougier,

University of Bern, Switzerland

Vincent Portero,

Academic Medical Center (AMC),

Netherlands

Thomas Hund,

The Ohio State University Columbus,

United States

*Correspondence: Eva Delpón

edelpon@med.ucm.es

${ }^{\dagger}$ These authors have contributed equally to this work.

${ }^{\ddagger}$ Co-senior authors.

Specialty section:

This article was submitted to

Cardiac Electrophysiology,

a section of the journal

Frontiers in Physiology

Received: 26 July 2017 Accepted: 25 October 2017 Published: 14 November 2017

Citation:

Utrilla RG, Nieto-Marín P, Alfayate S,

Tinaquero $D$, Matamoros $M$

Pérez-Hernández M, Sacristán S, Ondo $L$, de Andrés R, Diez-Guerra FJ, Tamargo J, Delpón E and Caballero $R$

(2017) Kir2.1-Nav1.5 Channel Complexes Are Differently Regulated than Kir2.1 and Nav1.5 Channels

Alone. Front. Physiol. 8:903. doi: 10.3389/fphys.2017.00903

\section{Kir2.1-Nav1.5 Channel Complexes Are Differently Regulated than Kir2.1 and Nav1.5 Channels Alone}

\author{
Raquel G. Utrilla ${ }^{1,2 \dagger}$, Paloma Nieto-Marín ${ }^{1,2 \dagger}$, Silvia Alfayate ${ }^{1,2}$, David Tinaquero ${ }^{1,2}$, \\ Marcos Matamoros ${ }^{1,2}$, Marta Pérez-Hernández ${ }^{1,2}$, Sandra Sacristán ${ }^{2}$, Lorena Ondo ${ }^{1,2}$, \\ Raquel de Andrés ${ }^{3}$, F. Javier Díez-Guerra ${ }^{3}$, Juan Tamargo ${ }^{1,2}$, Eva Delpón ${ }^{1,2 * \pm}$ and \\ Ricardo Caballero ${ }^{1,2 f}$ \\ 1 Department of Pharmacology, School of Medicine, Instituto de Investigación Sanitaria Gregorio Marañón, Universidad \\ Complutense, Madrid, Spain, ${ }^{2}$ CIBERCV, Madrid, Spain, ${ }^{3}$ Departamento de Biología Molecular and Centro de Biología \\ Molecular "Severo Ochoa" (UAM-CSIC), Universidad Autónoma de Madrid, Madrid, Spain
}

Cardiac Kir2.1 and Nav1.5 channels generate the inward rectifier $\mathrm{K}^{+}\left(\mathrm{I}_{\mathrm{K} 1}\right)$ and the $\mathrm{Na}^{+}$ $\left(I_{\mathrm{Na}}\right)$ currents, respectively. There is a mutual interplay between the ventricular $I_{\mathrm{Na}}$ and $I_{\mathrm{K} 1}$ densities, because Nav1.5 and Kir2.1 channels exhibit positive reciprocal modulation. Here we compared some of the biological properties of Nav1.5 and Kir2.1 channels when they are expressed together or separately to get further insights regarding their putative interaction. First we demonstrated by proximity ligation assays (PLAs) that in the membrane of ventricular myocytes Nav1.5 and Kir2.1 proteins are in close proximity to each other ( $<40 \mathrm{~nm}$ apart). Furthermore, intracellular dialysis with anti-Nav1.5 and anti-Kir2.1 antibodies suggested that these channels form complexes. Patch-clamp experiments in heterologous transfection systems demonstrated that the inhibition of the $\mathrm{Ca}^{2+}$ /calmodulin-dependent protein kinase II (CaMKII) decreased the $I_{\mathrm{Na}}$ and the $\mathrm{I}_{\mathrm{K} 1}$ generated by Nav1.5 and Kir2.1 channels when they were coexpressed, but not the $\mathrm{I}_{\mathrm{K} 1}$ generated by Kir2.1 channels alone, suggesting that complexes, but not Kir2.1 channels, are a substrate of CaMKIl. Furthermore, inhibition of CaMKII precluded the interaction between Nav1.5 and Kir2.1 channels. Inhibition of 14-3-3 proteins did not modify the $I_{\mathrm{Na}}$ and $I_{K 1}$ densities generated by each channel separately, whereas it decreased the $I_{\mathrm{Na}}$ and $\mathrm{I}_{\mathrm{K} 1}$ generated when they were coexpressed. However, inhibition of 14-3-3 proteins did not abolish the Nav1.5-Kir2.1 interaction. Inhibition of dynamin-dependent endocytosis reduced the internalization of Kir2.1 but not of Nav1.5 or Kir2.1-Nav1.5 complexes. Inhibition of cytoskeleton-dependent vesicular trafficking via the dynein/dynactin motor increased the $\mathrm{I}_{\mathrm{K} 1}$, but reduced the $\mathrm{I}_{\mathrm{Na}}$, thus suggesting that the dynein/dynactin motor is preferentially involved in the backward and forward traffic of Kir2.1 and Nav1.5, respectively. Conversely, the dynein/dynactin motor participated in the forward movement of Kir2.1-Nav1.5 complexes. Ubiquitination by Nedd4-2 ubiquitin-protein ligase promoted the Nav1.5 degradation by the proteasome, but not that of Kir2.1 channels. Importantly, the Kir2.1-Nav1.5 complexes were degraded following this route 
as demonstrated by the overexpression of Nedd4-2 and the inhibition of the proteasome with MG132. These results suggested that Kir2.1 and Nav1.5 channels closely interact with each other leading to the formation of a pool of complexed channels whose biology is similar to that of the Nav1.5 channels.

Keywords: Nav1.5, Kir2.1, heart, ion channel biology, patch-clamp

\section{INTRODUCTION}

Kir2.1 channels generate the inward rectifier $\mathrm{K}^{+}$current $\left(\mathrm{I}_{\mathrm{K} 1}\right)$ that plays a key role in the control of the resting membrane potential and the duration of the late-phase of repolarization in human cardiac cells (Anumonwo and Lopatin, 2010; de Boer et al., 2010). On the other hand, Nav1.5 channels carry the inward $\mathrm{Na}^{+}$current $\left(\mathrm{I}_{\mathrm{Na}}\right)$, which determines the $\mathrm{Na}^{+}$influx that depolarizes the membrane potential during the upstroke of the action potential (Abriel, 2010; Wilde and Brugada, 2011). It has been recently demonstrated that there is a positive reciprocal modulation between Kir2.1 and Nav1.5 channels, in such a way that an increase in Kir2.1 channels expression leads to the increase of the $\mathrm{I}_{\mathrm{Na}}$ density in cardiac ventricular myocytes and vice versa (Milstein et al., 2012; Matamoros et al., 2016). The reciprocal modulation is mediated by the binding of both channel types to $\alpha 1$-syntrophin, a scaffolding protein containing a PDZ domain (Matamoros et al., 2016). Indeed Nav1.5 channels interact with $\alpha 1$-syntrophin via two different PDZ-binding domains, one the canonical, constituted by the three last C-terminal residues (SIV) and another "PDZ-like" domain, determined by the presence of Ser20 and located "internally" at the N-terminus of the channel (Matamoros et al., 2016). Conversely, Kir2.1 channels exhibit a unique a1-syntrophin binding site within its C-terminal PDZ-binding domain (Matamoros et al., 2016), suggesting that Nav1.5, but not Kir2.1, could bind two molecules of $\alpha 1$-syntrophin at a time (Matamoros et al., 2016). These results suggested that at least some Nav1.5 and Kir2.1 channels form a multiprotein complex in which they interact directly or indirectly. The aims of the present work are to explore whether these complexes, if any, are formed just at the plasma membrane or at early stages of the protein assembly, as well as to characterize some of their biological properties (such as their anterograde or retrograde trafficking routes). The existence of such complexes would allow a dynamic and delicate control of the expression of these cardiac ion channels whose balanced function is critical for an adequate control of the excitability and cardiac impulse propagation. The results obtained demonstrate that at least a pool of Kir2.1 and Nav1.5 channels are in close proximity and interact at the membrane of cardiac cells forming complexes with anterograde and retrograde trafficking routes similar to those of the Nav1.5 channels alone.

\footnotetext{
Abbreviations: AIP, autocamtide-2-related inhibitory peptide; BFA, BrefeldinA; CAF, chronic atrial fibrillation; CaMKII, $\mathrm{Ca}^{2+} /$ calmodulin-dependent protein kinase II; CHO, Chinese Hamster Ovary; COPI, coat-associated protein I; DAPI, 4,6-diamidino-2-phenylindole; ER, Endoplasmic reticulum; HEK-293, Human Embryonic Kidney-293; $\mathrm{I}_{\mathrm{K} 1}$, Inward rectifier potassium current; $\mathrm{I}_{\mathrm{Kir} 2.1}$, Current generated by Kir2.1 channels; $\mathrm{I}_{\mathrm{Na}}$, Inward sodium current; $\mathrm{I}_{\mathrm{NaL}}$, late sodium
}

\section{METHODS}

\section{Kir2.x and Nav1.5 Constructs and Chinese Hamster Ovary (CHO) Cell Transfection}

Human Kir2.1 (kindly provided by Dr. José Jalife; University of Michigan, USA) was subcloned into pcDNA3.1 plasmid (Invitrogen, USA). Human cardiac Nav1.5 (hH1) and Nav $\beta 1$ cDNA subcloned in pCGI vector were kindly gifted by Dr. Connie R. Bezzina (University of Amsterdam, The Netherlands). $\mathrm{CHO}$ cells were cultured as previously described (Caballero et al., 2010b, 2017; Núñez et al., 2013; Matamoros et al., 2016) and transiently transfected with the cDNA encoding Nav1.5 channels $(1.6 \mu \mathrm{g})$ and $\mathrm{hNav} \beta 1(1.6 \mu \mathrm{g}$; Nav1.5- $\beta)$ alone or together with Kir2.1 $(1.6 \mu \mathrm{g})$ plus the cDNA encoding the CD8 antigen $(0.5 \mu \mathrm{g})$ by using FUGENE XtremeGENE (Roche Diagnostics, Switzerland) following manufacturer instructions. Forty-eight hours after transfection, cells were incubated with polystyrene microbeads precoated with anti-CD8 antibody (Dynabeads M450; Life Technologies, USA). Most of the cells that were beaded also had channel expression. Coexpression of Nav1.5 and Kir2.1 channels was always tested electrophysiologically and only cells coexpressing both channels were patched.

Human Nedd4-2 (KIAA0439), p.K44A dynamin-2 mutant, and p.R56,60A 14-3-3 (14-3-3DN) mutant cDNAs subcloned in pcDNA3.1 were kindly gifted by Prof. Dr. Hugues Abriel (University of Bern, Switzerland), Dr. Federico Sesti (Rutgers University, USA), and Dr. Isabelle Baro (INSERM, France), respectively. In some experiments, Kir2.1 and Nav1.5 channels were cotransfected with the p50 subunit of the dynein/dynactin complex (1.6 $\mu \mathrm{g}$, Origene, USA), p.K44A dynamin-2 (1.6 $\mu \mathrm{g})$, 14-3-3DN $(1.6 \mu \mathrm{g})$, or Nedd4-2 $(1.6 \mu \mathrm{g})$.

\section{Patch-Clamping}

Kir2.1 ( $\mathrm{I}_{\text {Kir2.1 }}$ ) and Nav1.5 ( $\mathrm{I}_{\text {Nav1.5}}$ ) currents were recorded at room temperature $\left(21-23^{\circ} \mathrm{C}\right)$ using the whole-cell patchclamp technique using an Axopatch-200B amplifier (Molecular Devices, USA) (Caballero et al., 2010a,b, 2017; Núñez et al., 2013; Matamoros et al., 2016). Recording pipettes were pulled from $1.0 \mathrm{~mm}$ o.d. borosilicate capillary tubes (GD1, Narishige Co., Ltd, Japan) using a programmable patch micropipette puller (Model P-2000 Brown-Flaming, Sutter Instruments Co., USA) and were heat-polished with a microforge (Model MF83, Narishige). Micropipette resistance was kept below 3.5 and $1.5 \mathrm{M} \Omega$ for $\mathrm{I}_{\mathrm{Kir} 2.1}$ and $\mathrm{I}_{\mathrm{Nav1.5}}$ recordings, respectively, when filled with the internal solution and immersed in the external solution. In all experiments, series resistance was compensated

current; $\mathrm{I}_{\mathrm{Nav1.5}}$, Current generated by Nav1.5 channels; I-V, current-voltage; LJP, Liquid junction potential; PBS, Phosphate buffered saline; PKA, protein kinase A; PLA, proximity ligand assay; TRITC, Tetramethylrhodamine. 
manually by using the series resistance compensation unit of the Axopatch amplifier, and $\geq 80 \%$ compensation was achieved. Uncompensated access resistance and $\mathrm{CHO}$ cell capacitance were $1.6 \pm 0.3 \mathrm{M} \Omega$ and $12.8 \pm 0.2 \mathrm{pF}(n=663)$, respectively. Peak $\mathrm{I}_{\text {Kir2.1 }}$ and $\mathrm{I}_{\mathrm{Nav1.5}}$ amplitudes were $-2.3 \pm 0.1$ and $-2.9 \pm 0.2 \mathrm{nA}$, respectively. Therefore, under our experimental conditions no significant voltage errors $(<5 \mathrm{mV})$ due to series resistance were expected with the micropipettes used.

To record $\mathrm{I}_{\mathrm{Kir} 2.1}$ and $\mathrm{I}_{\mathrm{Nav1.5}}$, CHO cells were perfused with an external solution containing (mM): $\mathrm{NaCl} 136, \mathrm{KCl} 4$, $\mathrm{CaCl}_{2}$ 1.8, $\mathrm{MgCl}_{2}$ 1, HEPES 10, and glucose 10 ( $\mathrm{pH} 7.4$ with $\mathrm{NaOH}$ ). Recording pipettes were filled with an internal solution containing (mM): K-aspartate $80, \mathrm{KCl} 42, \mathrm{KH}_{2} \mathrm{PO}_{4}$ 10, MgATP 5 , phosphocreatine 3, HEPES 5, and EGTA 5 ( $\mathrm{pH} 7.2$ with $\mathrm{KOH}$ ) to record $\mathrm{I}_{\text {Kir2.1 }}$ (liquid junction potential-LJP $=-13.2 \mathrm{mV}$ ) or $\mathrm{NaF}$ 10, CsF 110, CsCl 20, HEPES 10, and EGTA 10 (pH 7.35 with $\mathrm{CsOH}$ ) to record $\mathrm{I}_{\mathrm{Nav1.5}}$. $\mathrm{I}_{\mathrm{Kir} 2.1}$ current-voltage (I-V) curves were corrected according to the calculated LJP between the pipette and external solution (Caballero et al., 2010b, 2017; Matamoros et al., 2016). To minimize the contribution of time-dependent shifts of channel availability during sodium current recordings, all data were collected $20 \mathrm{~min}$ after establishing the whole-cell configuration. Under these conditions current amplitudes and voltage dependence of activation and inactivation were stable during the time of recordings (Matamoros et al., 2016; Caballero et al., 2017).

In some experiments, $\mathrm{I}_{\mathrm{Kir} 2.1}$ and $\mathrm{I}_{\mathrm{Nav1.5}}$ were recorded in transiently transfected $\mathrm{CHO}$ cells dialyzed with anti-Kir2.1 or anti-Nav1.5 antibodies added to the internal solution (Archer et al., 1998). For the experiments conducted to determine the effect of the presence of both Nav1.5 and Kir2.1 on channel internalization kinetics, $\mathrm{I}_{\mathrm{Nav} 1.5}$ and $\mathrm{I}_{\mathrm{Kir} 2.1}$ were recorded at different time points after addition of $50 \mathrm{ng} / \mathrm{mL}$ brefeldin-A (BFA) to the culture medium (Rougier et al., 2005). In some experiments, cells were incubated with the $\mathrm{Ca}^{2+} /$ calmodulindependent protein kinase II (CaMKII) inhibitor KN93 (1 $\mu \mathrm{M}$, $24 \mathrm{~h}$; Wagner et al., 2006) or with the proteasome inhibitor MG132 (20 MM, 2 h; Shy et al., 2014). In another group of patchclamp experiments the CaMKII inhibitor autocamtide-2-related inhibitory peptide (AIP) was added to the internal solution $(1 \mathrm{nM})$ that dialyzes the cells.

\section{Pulse Protocols and Analysis}

The protocol to record $\mathrm{I}_{\mathrm{Nav1.5}}$ consisted of 50 -ms pulses in $5 \mathrm{mV}$ increments from $-120 \mathrm{mV}$ to potentials between -80 and $+50 \mathrm{mV}$. $\mathrm{I}_{\mathrm{Nav} 1.5}$ amplitude was measured at the peak of the current traces. For $\mathrm{I}_{\mathrm{Kir} 2.1}$, the protocol to obtain I-V curves consisted of $250-\mathrm{ms}$ pulses in $10 \mathrm{mV}$ increments from $-60 \mathrm{mV}$ to potentials between -120 and $+20 \mathrm{mV}$ (Caballero et al., 2010b, 2017; Matamoros et al., 2016). I $I_{\text {Kir2.1 }}$ amplitude was measured at the end of the pulse. $\mathrm{I}_{\mathrm{Kir} 2.1}$ and $\mathrm{I}_{\mathrm{Nav1.5}}$ recordings were sampled at 4 and $50 \mathrm{kHz}$, respectively, filtered at half the sampling frequency, and stored on the hard disk of a computer for subsequent analysis. Data were analyzed using pCLAMP software (Molecular Devices). In each experiment, current amplitudes were normalized to membrane capacitance to obtain current densities.

\section{Rat Ventricular Myocyte Isolation}

Single ventricular myocytes were isolated from hearts of male Sprague-Dawley rats (225-250 g) by enzymatic dissociation with collagenase type II (Worthington) following previously described methods (Matamoros et al., 2016; Caballero et al., 2017). Rats were heparinized (1.000 U/kg i.p.) and anesthetized with sodium pentobarbital (50 mg/kg i.p.). Animal studies were approved by the University Committee on the Use and Care of animals at the Complutense University and conformed to the Guidelines from Directive 2010/63/EU of the European Parliament on the protection of animals used for scientific purposes.

\section{Proximity Ligation Assay}

The Duolink $^{\circledR}$ (Sigma, USA) proximity ligation assay (PLA) was conducted by using previously described methods (Söderberg et al., 2006; Shy et al., 2014) in non-permeabilized rat ventricular myocytes. This assay allows for the in situ detection of proteins that are located in close proximity to each other ( $<40 \mathrm{~nm}$ apart). Experiments were performed according to the manufacturer's recommendations and using all incubation buffers without detergents in order to avoid cell membrane permeabilization. Isolated ventricular myocytes were fixed and incubated in blocking solution and then, incubated with primary antibodies as specified in previously described methods (Núñez et al., 2013). Subsequent incubation steps were performed at $37^{\circ} \mathrm{C}$ and the appropriate washing buffers were used after each incubation, as specified in the manufacturer's protocol. After washing three times in phosphate buffered saline (PBS) to remove the primary antibody, Duolink secondary antibodies, conjugated to PLA probes, were added to the myocytes for a $1 \mathrm{~h}$ incubation. These PLA probes consist of oligonucleotides which were subsequently joined together in a circle after addition of ligation solution (containing ligase enzyme) and incubation for $30 \mathrm{~min}$. Next, rolling circle amplification of this circular template was achieved by addition of amplification solution, containing polymerase and fluorescently labeled oligonucleotides which hybridized to the circular template during $100 \mathrm{~min}$ of incubation. Samples were then mounted with Duolink in situ mounting medium with 4',6-diamidino-2-phenylindole (DAPI) and viewed with a confocal microscope. Cell images and fluorescent signals were acquired on a Leica TCS-SP5 AOBS confocal microscope (Mannheim, Germany) with a 40x and 63x oil objectives, using a tetramethylrhodamine (TRITC) filter to visualize fluorescently labeled oligonucleotides $\left(\lambda_{\text {ex }}=554 \mathrm{~nm} ; \lambda_{\text {em }}=579 \mathrm{~nm}\right)$. Laser lines at 561 and $358 \mathrm{~nm}$ for excitation of fluorescently labeled oligonucleotides and DAPI were provided by a diode-pumped solid-state laser and a UV laser, respectively. Samples without primary antibodies were used as negative controls. Images were analyzed with ImageJ software (National Institutes of Health, USA) assigning green color to images taken under TRITC channel.

\section{Cell Imaging}

Cell surface labeling of Kir2.1 channels cotransfected or not with Nav1.5 in Human Embryonic Kidney-293 (HEK-293) cells was performed by confocal microscopy (Núñez et al., 2013; 
Confocal Microscope Zeiss LSM710 with objective 63X/1.4 PlanApochromat Oil DIC M27). Kir2.1 channels were fused to the circularly permuted Venus 173 (Kir2.1-CpVenus) fluorescent protein and images were acquired by exciting Venus at $500 \mathrm{~nm}$ and monitoring its emission at 535/22 $\mathrm{nm}$. The capture conditions of the confocal microscope were optimized to obtain very thin optical sections $(<300 \mathrm{~nm},<1$ Airy unit) as stated by the Nyquist sampling criterium (Pawley, 2006). ImageJ software was used to process the images and measure signal intensity (Núñez et al., 2013).

\section{Co-immunoprecipitation and Western Blot Analysis}

Co-immunoprecipitation was performed in $\mathrm{CHO}$ cells as previously described (Matamoros et al., 2016). Forty-eight hours after transfection with the plasmids encoding Kir2.1CpVenus and/or Nav1.5 channel, CHO cells were washed with cold PBS and lysed in RIPA buffer to extract proteins and, thereafter, incubated for $30 \mathrm{~min}$ at $4^{\circ} \mathrm{C}$. Precleared supernatant was incubated with $2 \mu \mathrm{g}$ anti-Kir2.1 (N112B/14; Neuromab), 4 $\mu \mathrm{g}$ anti-CaMKII $\delta$ (A010-56AP; Badrilla) or $3.2 \mu \mathrm{g}$ anti-Nav1.5 (S0819, Sigma) antibodies for $3 \mathrm{~h}$ at $4^{\circ} \mathrm{C}$, after which $20 \mu \mathrm{l}$ of protein A/G-Sepharose beads (Santa Cruz Biotechnology Inc, USA) were added overnight at $4{ }^{\circ} \mathrm{C}$ in rotation. Proteinantibody complexes were centrifuged and washed four times with cold PBS buffer. After the last centrifugation, $30 \mu \mathrm{l}$ of loading dye with $\beta$-mercaptoethanol were added to the protein-antibody complexes and lysates and supernatants were prepared adding $20 \mu \mathrm{l}$ of protein plus $30 \mu \mathrm{l}$ of loading dye with $\beta$-mercaptoethanol. Thereafter, all samples were heated at $95^{\circ} \mathrm{C}$ for $5 \mathrm{~min}$ and then separated by SDS/PAGE and immunoblotted following described methods (Matamoros et al., 2016; Caballero et al., 2017). Briefly, samples were run on $10 \%$ Mini-PROTEAN ${ }^{\circledR}$ TGX $^{\mathrm{TM}}$ gels (Bio-Rad, USA) and transferred to nitrocellulose membranes (Bio-Rad). Non-specific binding sites were blocked with $5 \%$ non-fat dry milk in PBS with Tween-20 (0.5\%) for $1 \mathrm{~h}$ at room temperature. Membranes were then incubated with anti-GFP or anti-CaMKII $\delta$ specific primary antibodies diluted in $5 \%$ non-fat dry milk overnight at $4^{\circ} \mathrm{C}$. After washing, membranes were incubated with peroxidase-conjugated secondary antibodies or HRP-protein A. Antigen complexes were detected using enhanced chemiluminescence (Supersignal West Femto, Thermofisher, UK) and visualized using the Chemidoc MP System and Image Lab 5.2.1. software (Bio-Rad). Original blots are shown in Supplemental Figures 3-5.

\section{Antibodies}

In the PLA, mouse monoclonal anti-Nav1.5 (1:50; ab62388, Abcam, UK) and rabbit monoclonal anti-Kir2.1 (1:100, ab109750, Abcam) primary antibodies were used. These antibodies bind to extracellular domains of Nav1.5 (residues 59-72 of human Nav1.5) and Kir2.1 (residues 107-122 of human Kir2.1 channels), respectively. Duolink secondary antibodies conjugated to PLA probes were also used. For electrophysiological experiments, rabbit anti-Nav1.5 $(1.2 \mu \mathrm{g} / \mathrm{mL}$, S0819, Sigma) and rabbit anti-Kir2.1 (1:1,000, ab65796, Abcam) were used. Both Nav1.5 (residues 493-511 located at the cytoplasmic loop between Domain I and II) and Kir2.1 (residues 1-81) antibodies bind to intracellular domains of the channels. For co-immunoprecipitation and western blot analysis rabbit polyclonal anti-CAMKII $\delta$ (1:5,000 A010-56AP, Badrilla, UK) and rabbit polyclonal anti-GFP (1:1,000 ab290; Abcam) primary antibodies were used for detection of the C-terminal domain of CAMKII $\delta$ and Kir2.1-CpVenus, respectively. Peroxidaseconjugated secondary antibodies (Jackson ImmunoResearch, USA) were used for detection of the proteins in lysates and HRP-protein A (Life Technologies) was used for detection of the immunoprecipitated proteins. Non-immune antibodies (IgG from rabbit or mouse serum) used as negative controls for co-immunoprecipitation experiments were obtained from Sigma-Aldrich.

\section{Statistical Analysis}

Results are expressed as mean \pm SEM. Unpaired t-test or one-way ANOVA followed by Newman-Keuls test were used where appropriate. In small-size samples $(n<15)$, statistical significance was confirmed by using non-parametric tests. To take into account repeated sample assessments, data were analyzed with multilevel mixed-effects models. A value of $P<$ 0.05 was considered significant.

\section{RESULTS}

The positive reciprocal modulation between Kir2.1 and Nav1.5 channels is not due to a change of the biophysical properties, such as single channel conductance or open probability of the channels (Milstein et al., 2012). These results led to propose that it is due to an increase of their expression at the cell membrane. To test this hypothesis, we conducted immunofluorescence analyses in HEK293 cells transfected with Kir2.1 alone or together with Nav1.5 channels. Figure 1A left shows representative z-stack confocal images obtained in a cell expressing Kir2.1-CpVenus alone. The intensity of the signal emitted by CpVenus throughout the cell region selected (yellow line) has been represented as an inset (top left). The maximum signal, which corresponds to the cell membrane, is represented by the two discrete peaks. As can be observed in the right panel of Figure 1A and Figure 1B, coexpression with Nav1.5 channels significantly increased the intensity of the maximum signal emitted by CpVenus. Even though considering the limitations of the experimental approach, these results suggested that the amount of Kir2.1 channels at the cell membrane increases $(P<0.05)$.

Next, we measured the putative association between Nav1.5 and Kir2.1 channels using PLA in rat ventricular myocytes by means of the Duolink ${ }^{\circledR}$ technology. In PLA, a fluorescent signal is only generated when the plus and minus probes attached to each antibody are bound together, allowing for the in situ detection of proteins that are located in close proximity to each other (<40 nm apart; Söderberg et al., 2006; Shy et al., 2014). Importantly, to conduct these experiments myocytes were not permeabilized and, thus, the antibodies, which bind to extracellular domains of Nav1.5 and Kir2.1 channels (see section Methods), only detected the Nav1.5 and Kir2.1 channels present at the cell membrane. Figure 1C (bottom middle) shows 
A

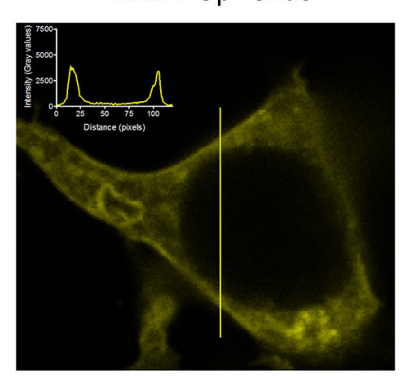$$
\text { C }
$$

C Brightfield

\section{过}

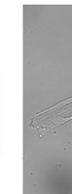

\section{Kir2.1-CpVenus+Nav1.5}

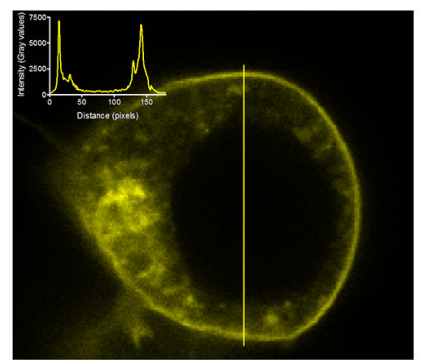

Z-Series projection

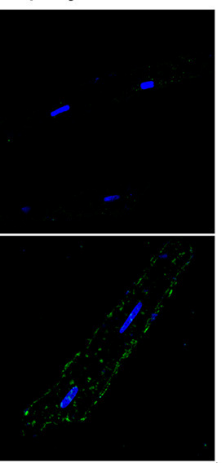

B

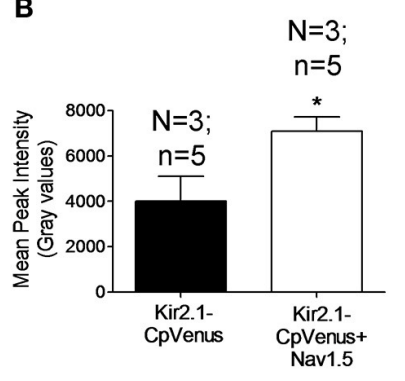

D

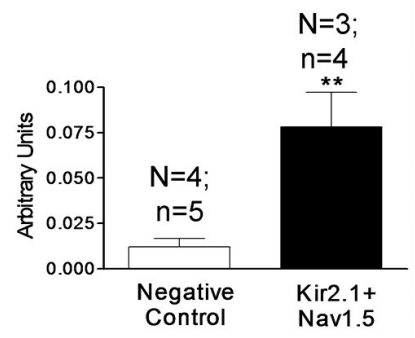

FIGURE 1 | Kir2.1 and Nav1.5 channels are in close proximity at the membrane of cardiac myocytes. (A) Confocal microscopy images of HEK293 cells expressing Kir2.1-CpVenus alone (left) or in the presence of Nav1.5 (right). The insets show the intensity of the signal emitted by CpVenus throughout the cell region selected (yellow line). (B) Peak mean signal corresponding to the cell membrane in cells expressing Kir2.1-CpVenus with or without Nav1.5 channels. (C) Confocal microscopy images of rat ventricular myocytes processed using Duolink ${ }^{\circledR}$ PLA. The green signal demonstrates a physical interaction between Nav1.5 and Kir2.1. Cell nuclei were visible by DAPI staining (blue). (D) Mean intensity of the green signal in the negative control and in the presence of Nav1.5+Kir2.1 antibodies. In (B,D), each bar represents the mean \pm SEM of " $n$ " cells of " $N$ " preparations. ${ }^{\star} P<0.05$ vs. Kir2.1-CpVenus alone. ${ }^{\star \star} P<0.01$ vs. negative control.

a single section image from the center of a rat ventricular myocyte showing a sparse fluorescent signal distributed along the cell membrane. The Z-series projection (bottom right) shows more abundant fluorescent spots corresponding to the top of the membrane. Comparison of the mean intensity data demonstrated a $\approx 6.5$-fold increase in the fluorescence signal (Figure 1D) compared to the negative controls (Figure 1C top panels) consisting of myocytes assayed with Duolink ${ }^{\circledR}$ technology but without incubating with the primary Nav1.5 and Kir2.1 antibodies $(P<0.01)$. Further negative controls were developed in human atrial myocytes in which PLA was developed after extracellular treatment with either anti-Kir2.1 or anti-Nav1.5 antibodies alone. Supplemental Figure 1 confirms that in the absence of one of the antibodies the Duolink assay did not produce any fluorescent signal. These data demonstrated that at the cardiomyocyte membrane at least a pool of Nav1.5 and Kir2.1 channels physically interacts with each other.

To further elucidate the degree of proximity of Kir2.1 and Nav1.5 channels at the cell membrane, the $I_{\text {Kir2.1 }}$ and $\mathrm{I}_{\text {Nav1.5 }}$ were recorded in $\mathrm{CHO}$ cells transfected with Kir2.1, Nav1.5 channels or both and dialyzed with an internal solution supplemented with either anti-Kir2.1 or anti-Nav1.5 antibodies. In these experiments, the tip of the pipette was filled with antibody-free internal solution, in order to obtain "control" current records. Importantly, the epitope of the antiNav1.5 and anti-Kir2.1 antibodies used in these experiments (see section Methods) were intracellular domains of Nav1.5 and Kir2.1 channels, respectively. Figures 2E,F show the normalized density of $\mathrm{I}_{\mathrm{Kir} 2.1}$ recorded at $-120 \mathrm{mV}$ and of peak $\mathrm{I}_{\mathrm{Nav1.5}}$ as a function of time elapsed after seal breaking and, thus of time in the presence of their corresponding antibodies. As expected, neither $\mathrm{I}_{\mathrm{Kir} 2.1}$ (Figures 2A,E) nor $\mathrm{I}_{\mathrm{Nav} 1.5}$ (Figures 2B,F) decreased in cells dialyzed with anti-Nav1.5 or anti-Kir2.1 antibodies (squares), respectively (Figure $2 \mathbf{H}$ ). Conversely, and also as expected, both $\mathrm{I}_{\text {Kir2.1 }}$ (Figure 2E) and $\mathrm{I}_{\mathrm{Nav1.5}}$ (Figure 2F) progressively decreased in cells dialyzed with anti-Kir2.1 and anti-Nav1.5 antibodies (circles), respectively $(P<0.05$; Figure 2H). Figures 2C,D show superimposed $\mathrm{I}_{\text {Kir2.1 }}$ (Figure 2C) and $\mathrm{I}_{\text {Nav1.5 }}$ (Figure 2D) traces recorded in cells cotransfected with Kir2.1+Nav1.5 channels and dialyzed with anti-Nav1.5 and anti-Kir2.1 antibodies, respectively, while Figure 2G shows the normalized density of $\mathrm{I}_{\mathrm{Kir2} .1}$ and of peak $\mathrm{I}_{\mathrm{Nav1.5}}$ as a function of dialyzing time. Surprisingly, $\mathrm{I}_{\mathrm{Kir} 2.1}$ density decreased in cells dialyzed with anti-Nav1.5 antibodies and $\mathrm{I}_{\mathrm{Nav} 1.5}$ also diminished in cells dialyzed with anti-Kir2.1 antibodies (Figures 2C,D,G,H; $P<0.05$ ). These results would suggest that 
A

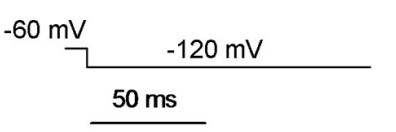

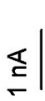

Kir2.1

Anti-Nav1.5

C

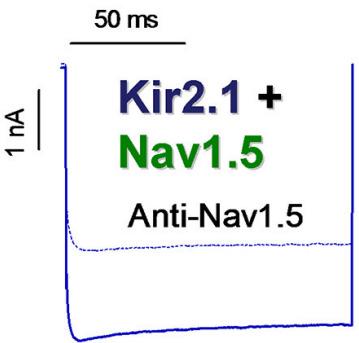

E

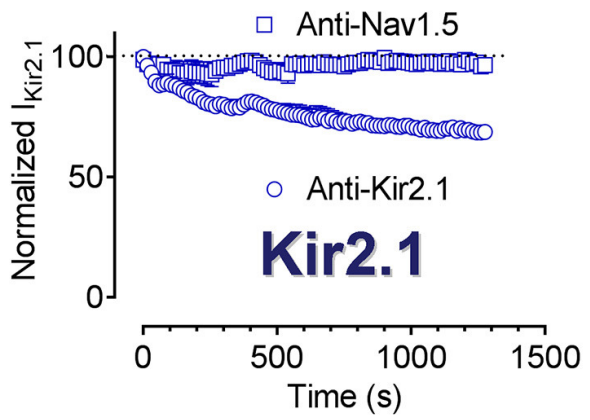

G

$\square \mathrm{I}_{\text {Nav1.5 }}$ (Anti-Kir2.1)

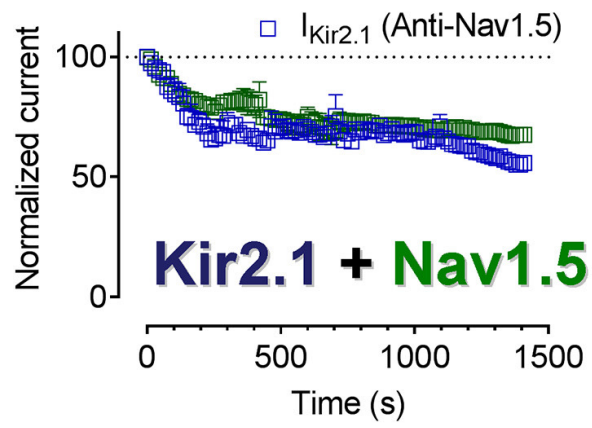

B

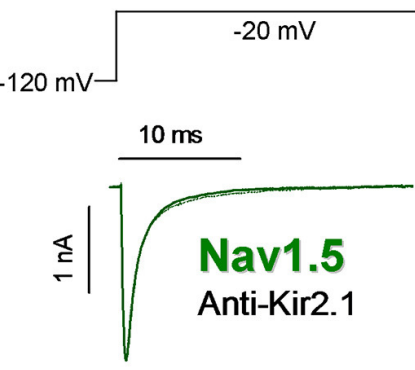

D

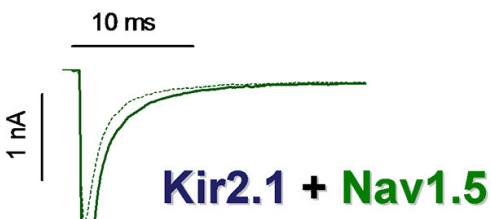

Anti-Kir2.1

$\mathbf{F}$

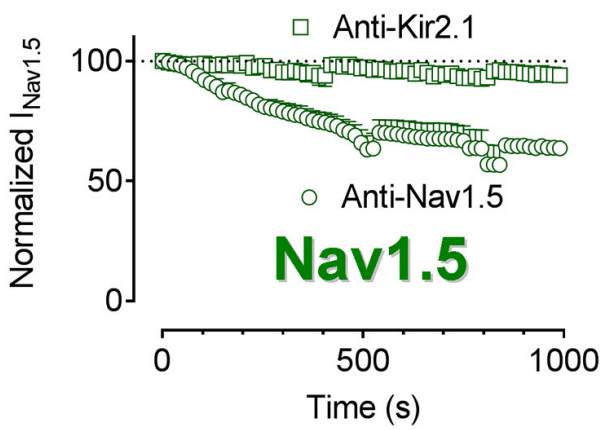

H $\quad \mathrm{I}_{\text {Kir2.1 }} \quad \mathrm{I}_{\mathrm{Nav1.5}}$

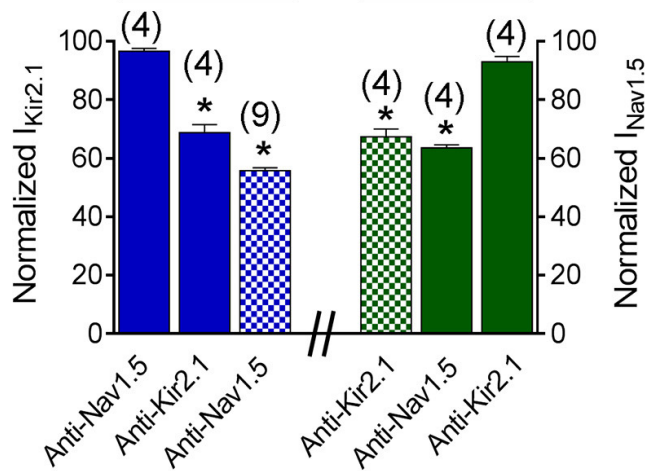

FIGURE 2 | Kir2.1 and Nav1.5 channels closely interact at the cell membrane. (A-D) $I_{\text {Kir2.1 }}$ (A,C) and $I_{\text {Nav1.5 }}$ (B,D) traces recorded by applying the protocols shown at the top in $\mathrm{CHO}$ cells expressing Kir2.1 or Nav1.5 channels alone $\mathbf{( A , B )}$ or together $\mathbf{( C , D )}$ in control conditions (solid lines) or after dialyzing the cell with the antibodies indicated (dashed lines). (E-G) Normalized $I_{\text {Kir2.1. }}$ (measured at $-120 \mathrm{mV}$ ) (E,G) and peak $I_{\text {Nav1.5 }} \mathbf{( F , G ) ~ m e a s u r e d ~ i n ~ t h e ~ a b s e n c e ~ a n d ~ p r e s e n c e ~ o f ~}$ anti-Kir2.1 or anti-Nav1.5 antibodies in cells transfected with Kir2.1 or Nav1.5 channels alone (E,F) or cotransfected with both (G) plotted as a function of time. (H) Bar graphs showing the mean normalized current density values measured in each experimental group at the end of the recordings. Each point/bar represents the mean \pm SEM of $(n)$ cells of $\geq 3$ preparations. In $(\mathbf{H})$, ${ }^{\star} P<0.05$ vs. IKir2.1 or I Nav1.5 generated by Kir2.1 or Nav1.5 channels alone in the presence of anti-Nav1.5 or anti-Kir2.1 antibodies. For clarity the results of other statistical comparisons were not shown.

the distance between both channels is narrow enough to allow Kir2.1 channels to be "silenced" when the Nav1.5 antibody interacts with the Nav1.5 channels present in the Kir2.1-Nav1.5 complexes and vice versa and further supported the hypothesis that at least a pool of Kir2.1 and Nav1.5 channels interact at the cell membrane forming complexes. 


\section{Effects of CaMKII on Kir2.1 and Nav1.5 Channels and Kir2.1-Nav1.5 Complexes}

It is well-established that Nav1.5 channels are one of the most important targets of CaMKII in cardiac myocytes (Wagner et al., 2006; Ashpole et al., 2012; Herren et al., 2015). Electrophysiological studies in HEK-293 cells have demonstrated that the kinase phosphorylates residues located in the cytoplasmic loop between domains I and II of the channel leading to an increase of the late $\mathrm{I}_{\mathrm{Na}}\left(\mathrm{I}_{\mathrm{NaL}}\right)$ and to a shift of the voltage-dependence of Nav1.5 channel inactivation to hyperpolarized potentials (Ashpole et al., 2012). To analyze the modulatory role of CaMKII on the channels expressed separately or together, we recorded the $\mathrm{I}_{\mathrm{Kir} 2.1}$ and $\mathrm{I}_{\mathrm{Nav1.5}}$ in cells transfected with the channels and incubated or not with the CaMKII inhibitor KN93 $(1 \mu \mathrm{M})$ for $24 \mathrm{~h}$. Under our experimental conditions, inhibition of CaMKII did not modify $\mathrm{I}_{\text {Kir2.1 }}$ in cells transfected with Kir2.1 alone $(n \geq 10 ; P>$
0.05; Figure 3A) whereas it significantly decreased the $\mathrm{I}_{\mathrm{Nav1.5}}$ in cells transfected with Nav1.5 channels alone $(P<0.05$; Figure 3B). Furthermore, inhibition of the CaMKII-dependent phosphorylation significantly decreased the $\mathrm{I}_{\mathrm{NaL}}$ recorded at the end of $500 \mathrm{~ms}$ pulses and shifted the inactivation curve to depolarized potentials (Supplemental Figure 2). Coexpression of Nav1.5 and Kir2.1 channels markedly and significantly increased both $\mathrm{I}_{\mathrm{Kir} 2.1}$ (Figure 3A) and $\mathrm{I}_{\mathrm{Nav1} 1.5}$ (Figure 3B) (gray bars) as a consequence of the reciprocal positive modulation (Milstein et al., 2012; Matamoros et al., 2016), and the $\mathrm{I}_{\mathrm{NaL}}$ (Supplemental Figure 2). Interestingly, in cells cotransfected with Kir2.1 and Nav1.5 channels simultaneously, incubation with KN93 significantly reduced the $\mathrm{I}_{\mathrm{Nav1}}$ (Figure 3B) and $\mathrm{I}_{\mathrm{NaL}}$ as expected (Supplemental Figure 2), and, unexpectedly, it also reduced the $\mathrm{I}_{\mathrm{Kir} 2.1}$ compared to that generated in cotransfected cells in which CaMKII was not inhibited (Figure 3A). In another group of experiments CaMKII was

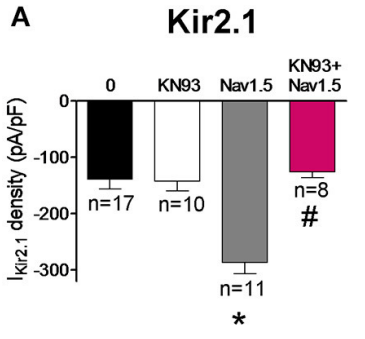

E

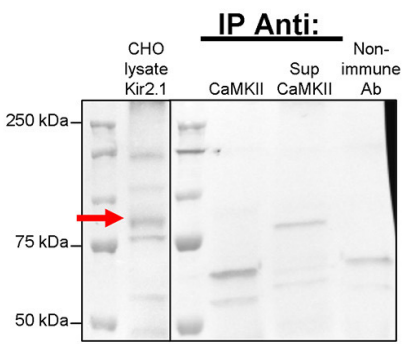

IB: GFP

H

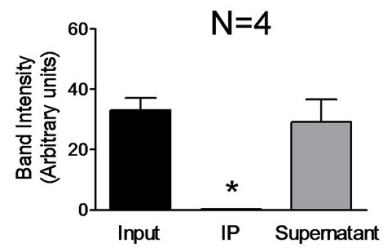

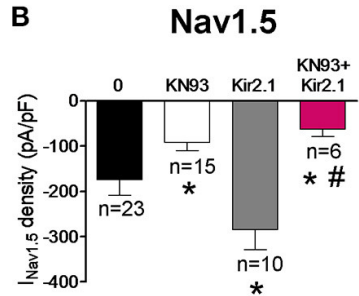

C

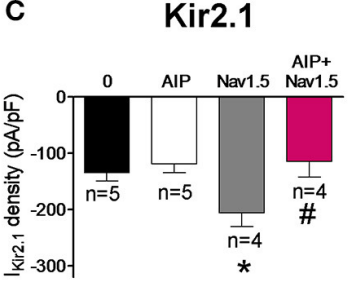

D Nav1.5

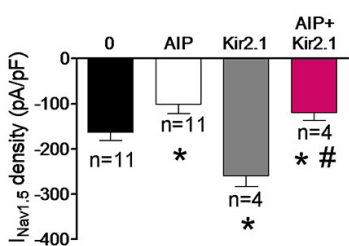

$\mathbf{F}$

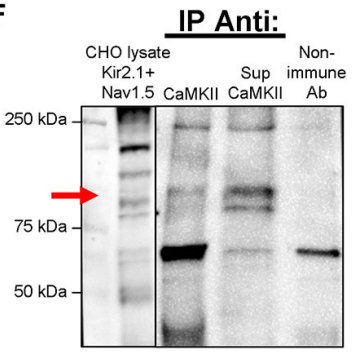

IB: GFP

Kir2.1+Nav1.5

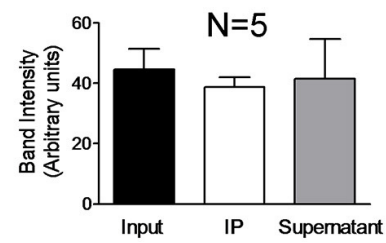

G

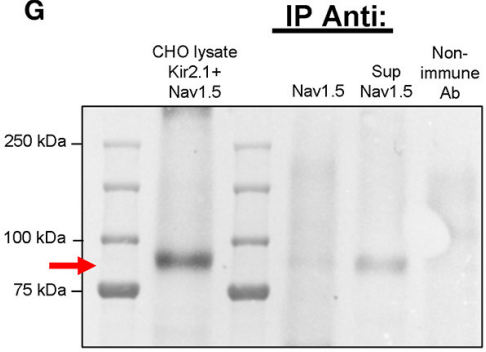

IB: GFP

$\mathbf{J}$

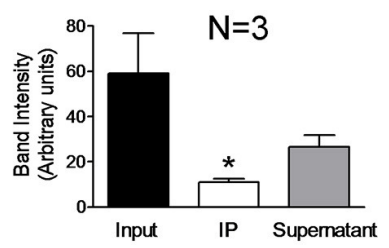

FIGURE 3 | Effects of CaMKII inhibition on Kir2.1 and Nav1.5 channel complexes. (A,B) $I_{\text {Kir2.1 }}$ density at $-120 \mathrm{mV}$ (A) and peak $I_{\text {Nav1.5 }}$ (B) recorded in CHO cells expressing the constructs indicated, incubated or not with KN93 (1 $\mu$ M-24h). (C,D) $\left.\right|_{\text {Kir2.1 }}$ density at $-120 \mathrm{mV}$ (C) and peak $I_{\text {Nav1.5 }}$ (D) recorded in CHO cells expressing the constructs indicated, dialyzed or not with AIP (1 nM). (E-G) Kir2.1 did not immunoprecipitate with CaMKII in the lysates obtained from CHO cells transfected with Kir2.1-CpVenus alone (E), while partially immunoprecipitated in cells cotransfected with Nav1.5 channels (F). In the presence of KN93 (1 $\mu$ M-24 $\mathrm{h}$ incubation), Kir2.1 did not immunoprecipitate with Nav1.5 (G). CpVenus was detected by western blot in the lysates by using an anti-GFP antibody. Also shown is the supernatant (Sup) recovered after centrifugation of the immunoprecipitant (IP). All immunoprecipitation reactions used membrane-enriched preparations. As a negative control, lysate treated with non-specific IgG (and Protein A/G) was used ("Non-immune Ab" lane). IB, antibody used for immunoblotting; IP Anti, antibody used for immunoprecipitation. (H-J) Densitometric analysis of the co-immunoprecipitation experiments depicted in (E-G) showing the mean intensity of the bands of the inputs, immunoprecipitants (IP) and supernatants. In (A-D) and (H-J), each bar represents the mean \pm SEM of " $n$ " cells of $\geq 2$ preparations (A-D) or " $N$ " preparations (H-J). In (A-D), ${ }^{*} P<0.05$ vs. cells transfected with Kir2.1 or Nav1.5 channels alone; $\# P<0.05$ vs. cells transfected with Kir2.1+Nav1.5. For clarity the results of other statistical comparisons were not shown. In $(\mathbf{H}, \mathbf{J}),{ }^{*} P<0.05$ vs. input and supernatant. 
inhibited with autocamtide-2-related inhibitory peptide (AIP) which was added to the "internal" solution that dialyzes the cells after the patch rupture $(1 \mathrm{nM})$. Data presented in Figures 3C,D and Supplemental Figure 2 confirmed that CaMKII inhibition significantly decreased the $\mathrm{I}_{\mathrm{Nav1.5}}$ and the $\mathrm{I}_{\mathrm{NaL}}$ in cells expressing Nav1.5 channels either alone or in the presence of Kir2.1 channels. Conversely, CaMKII inhibition only decreased the $\mathrm{I}_{\text {Kir2.1 }}$ generated in cells cotransfected with Kir2.1 and Nav1.5 channels. Overall the results suggest that when both Kir2.1 and Nav1.5 channels are expressed together, a pool of Kir2.1 channels, probably those that are interacting with Nav1.5 channels, becomes a target for CaMKII (Figures 3B,D). To test this hypothesis co-immunoprecipitation experiments with Kir2.1-CpVenus channels cotransfected or not with Nav1.5 were conducted. As can be observed in Figures 3E,H, and consistently with the electrophysiological results, in cells expressing Kir2.1-CpVenus alone CaMKII did not co-immunoprecipitate with Kir2.1 channels, that were detected in the supernatant fraction by means of anti-GFP antibody which recognizes $\mathrm{CpVenus.} \mathrm{Conversely,} \mathrm{CaMKII} \mathrm{partially} \mathrm{co-}$ immunoprecipitated with Kir2.1 in cells cotransfected with both Kir2.1 and Nav1.5 channels (Figures 3F,I). The results pointed to a relevant role of CaMKII in the reciprocal positive modulation between Kir2.1 and Nav1.5 channels. Thus, we conducted co-immunoprecipitation experiments in cells cotransfected with Nav1.5 and Kir2.1 and incubated with KN93. Under these conditions Kir2.1-CpVenus channels did not coimmunoprecipitate with Nav1.5 channels (Figures 3G,J).

\section{Regulation of Kir2.1-Nav1.5 Complexes by 14-3-3 Proteins}

$14-3-3$ is a family of $30-\mathrm{kDa}$ cytosolic acidic proteins with multiple effects including regulation of ion channel trafficking (Obsil and Obsilova, 2011). Furthermore, it has been demonstrated that 14-3-3 could prevent phosphatase action on phosphorylated residues (Tutor et al., 2006; Obsil and Obsilova, 2011). It has been shown that $14-3-3 \eta$ can interact with Nav1.5 channels at the intercalated discs of cardiac myocytes. Moreover, 14-3-3 in COS7 cells modify the voltage dependence of inactivation and recovery from inactivation kinetics, but not the $\mathrm{I}_{\mathrm{Nav1.5}}$ density (Allouis et al., 2006). To test whether 14-3-3 regulate somehow Kir2.1, Nav1.5, and Kir2.1-Nav1.5 complexes we used a double mutant (p.R56A,60A) of 14-3-3 which acts as a dominant negative (14-3-3DN; Allouis et al., 2006). Cotransfection of 14-3-3DN in cells expressing Kir2.1 or Nav1.5 alone did not significantly modify either $\mathrm{I}_{\text {Kir2.1 }}$ or $\mathrm{I}_{\mathrm{Nav1}} .5$ densities (Figures 4A,B; $\mathrm{P}>0.05$ ). Interestingly, 14-3-3DN abolished the positive reciprocal modulation thus inhibiting both the $\mathrm{I}_{\mathrm{Kir} 2.1}$ and $\mathrm{I}_{\mathrm{Nav1.5}}$ in cells cotransfected with both channels (Figures 4A,B; $P<0.05$ ). These results would suggest that 14-3-3 proteins may target Kir2.1 and Nav1.5 channel complexes in a different way that each channel separately. However, these results could also be explained considering that 14-3-3 proteins are responsible for the positive reciprocal modulation. Therefore, we analyzed whether the inhibition of the 14-3-3 proteins precludes the interaction between Nav1.5 and Kir2.1 channels. To this end, we recorded the $\mathrm{I}_{\text {Kir2.1 }}$ and $\mathrm{I}_{\mathrm{Nav1.5}}$ in cells expressing both channels, cotransfected with 14-3-3DN, and dialyzed with an internal solution containing anti-Nav1.5 or anti-Kir2.1 antibodies, respectively. As can be observed in Figures 4C,D, when 14-3-3 proteins are inhibited, intracellular dialysis with anti-Nav1.5 and anti-Kir2.1 antibodies significantly decreased the $\mathrm{I}_{\mathrm{Kir} 2.1}$ and $\mathrm{I}_{\mathrm{Nav} 1.5}$, respectively. These results strongly suggested that inhibition of 14-3-3 proteins did not preclude the formation of Nav1.5-Kir2.1 complexes.

\section{Trafficking of Nav1.5 and Kir2.1 Complexes}

In the next groups of experiments we further analyzed the biological properties of the Kir2.1-Nav1.5 complexes by comparing the trafficking of Kir2.1 and Nav1.5 channels when they are expressed alone or together in CHO cells. It has been proposed that the dynein/dynactin complex plays a role in normal vesicular traffic of ion channels toward and from the sarcolemma (Balse et al., 2012). Overexpression of dynamitin (the p50 subunit of dynactin) has been routinely used to block the dynein function since it dissociates the dynactin complex, decoupling the dynein motor from its cargo (Figure 5A; Burkhardt et al., 1997; Balse et al., 2012). Figures 5B,C show the current-density voltage curves for $\mathrm{I}_{\mathrm{Kir} 2.1}$ and $\mathrm{I}_{\mathrm{Nav1.5}}$ recorded in cells cotransfected or not with p50. Cotransfection of p50 increased the $\mathrm{I}_{\mathrm{Kir} 2.1}$ at potentials between -120 and $-90 \mathrm{mV}$ and between -70 and $-50 \mathrm{mV}$ (Figures 5B,D; $P<0.05$ ), suggesting that the dynein/dynactin complex is involved in the retrograde trafficking of Kir2.1 channels. Conversely, p50 reduced the $\mathrm{I}_{\mathrm{Nav} 1.5}$ at potentials ranging -40 and $+30 \mathrm{mV}$ in cells expressing Nav1.5 channels alone (Figures 5C,E; $P<0.05$ ), thus confirming previous results that demonstrate the role of the dynein/dynactin complex in the anterograde trafficking of Nav1.5 channels (Chatin et al., 2014). When Kir2.1 and Nav1.5 channels were expressed together, both $\mathrm{I}_{\mathrm{Kir} 2.1}$ and $\mathrm{I}_{\mathrm{Nav1.5}}$ were significantly increased as expected (Figures 5B-E). Conversely, overexpression of p50 abolished the reciprocal modulation between Kir2.1 and Nav1.5 (Figures 5B-E). In fact, in cells expressing Kir2.1+Nav1.5 channels in which the dynein function was blocked the $\mathrm{I}_{\mathrm{Kir2} .1}$ was not increased (Figures 5B,D; $P>$ 0.05). On the other hand, the density of the $I_{\text {Nav1.5 }}$ recorded in cells expressing Nav1.5, Kir2.1, and p50 was smaller than that recorded in cells expressing either Nav1.5 channels alone or Kir2.1+Nav1.5 (Figures 5C,E; $P>0.05$ ). These results indicate that Kir2.1 channels are affected differently by the blockade of the dynein/dynactin complex when they are expressed alone or in combination with Nav1.5 channels and suggest that the dynein/dynactin complex is involved in the anterograde trafficking of Nav1.5 channels alone and of the Kir2.1-Nav1.5 channel complexes.

\section{Internalization and Retrograde Trafficking of Nav1.5 and Kir2.1 Complexes}

BFA is a fungal metabolite commonly used to block protein trafficking to cell membrane through the classical secretory pathway involving the endoplasmic reticulum (ER) and the Golgi apparatus (Rougier et al., 2005; Mercier et al., 2015). To test whether the Nav1.5 and Kir2.1 internalization kinetics are 

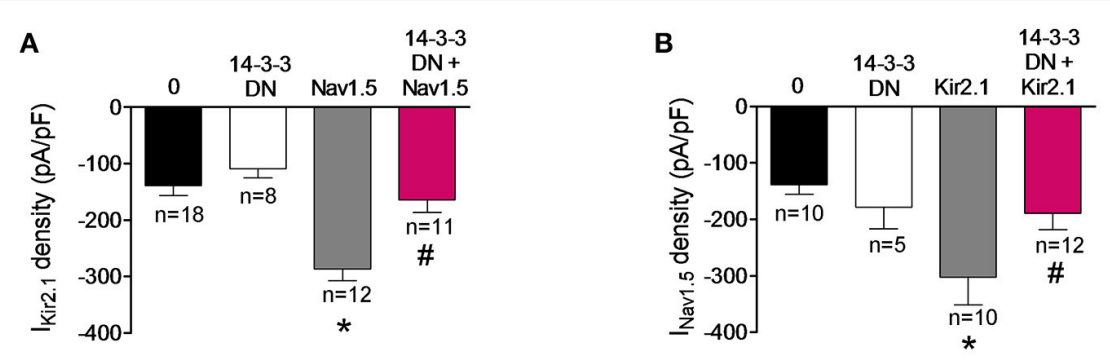

Kir2.1+Nav1.5+14-3-3DN
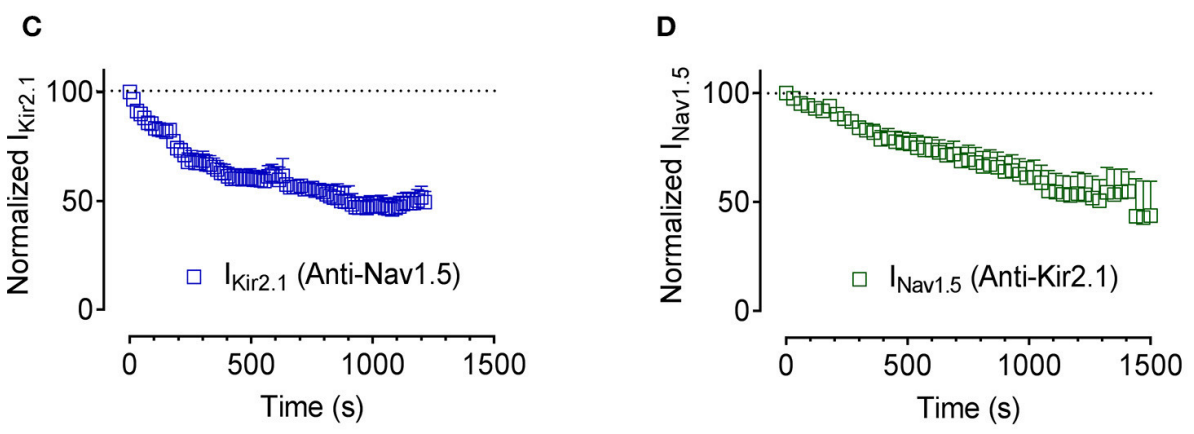

FIGURE 4 | Effects of 14-3-3 inhibition on Kir2.1-Nav1.5 channel complexes. (A,B) $\left.\right|_{\text {Kir2.1 }}$ density at $-120 \mathrm{mV}$ (A) and peak $\left.\right|_{\mathrm{Nav1.5}}$ (B) recorded in CHO cells expressing the constructs indicated, cotransfected or not with 14-3-3DN. Each bar represents the mean \pm SEM of " $n$ " cells of $\geq 4$ preparations. * $P<0.05$ vs. cells transfected with Kir2.1 or Nav1.5 channels alone; \#P<0.05 vs. cells transfected with Kir2.1+Nav1.5. For clarity the results of other statistical comparisons were not shown. (C,D) Normalized I Kir2.1 measured at -120 mV (C) and peak I Nav1.5 (D) measured in the absence and presence of anti-Nav1.5 and anti-Kir2.1 antibodies, respectively, in cells cotransfected with Kir2.1, Nav1.5, and 14-3-3DN plotted as a function of time. Each point represents the mean \pm SEM of 4 experiments of $\geq 3$ preparations in each group.

affected by the presence of both channels together, $\mathrm{I}_{\mathrm{Nav1}} .5$ and $\mathrm{I}_{\text {Kir2.1 }}$ were recorded after incubation with BFA $(50 \mathrm{ng} / \mathrm{mL})$ for progressively increasing periods of time. Using this approach, it would be expected that most of the trafficking of newly synthesized channels to the cell membrane is blocked, and thus, the time course of internalization of the channels located in the membrane can be assessed. Figures 6A-D show the normalized mean density of $\mathrm{I}_{\mathrm{Kir} 2.1}$ and $\mathrm{I}_{\mathrm{Nav1} 1.5}$ recorded in $\mathrm{CHO}$ cells as a function of the duration of the incubation with BFA and, as can be observed, both $\mathrm{I}_{\text {Kir2.1 }}$ and $\mathrm{I}_{\mathrm{Nav1.5}}$ densities gradually decreased to a residual value upon incubation with BFA. In contrast, $\mathrm{I}_{\mathrm{Kir} 2.1}$ and $\mathrm{I}_{\mathrm{Nav1.5}}$ densities did not change when cells were incubated with $1 \%$ ethanol, the BFA vehicle, for 6 or $24 \mathrm{~h}$ (Figures 6A-D). The fit of a monoexponential function to the data obtained in the presence of BFA yielded the half-time constants $(\tau)$ which for Kir2.1 and Nav1.5 channel internalization averaged 5.1 and 4.9 h, respectively (Figures 6A,B). In cells cotransfected with Kir2.1 and Nav1.5 channels the time course of Kir2.1 and Nav1.5 channel internalization was not significantly modified (Figures 6C,D; $n \geq 4 ; P>0.05$ ).

It has been demonstrated that dynamin-2 has an important role in the endocytosis of different ion channels including Kir2.1 (Tong et al., 2001; Boyer et al., 2009). To test whether the Kir2.1 channel internalization is modified in the presence of Nav1.5 channels we took advantage of a dynamin-2 mutant (p.K44A;
Figure 7A), which functions as a dominant negative and inhibits the activity of the endogenous dynamin-2 (Hinshaw and Schmid, 1995). In Figures 7B,C $\mathrm{I}_{\mathrm{Kir} 2.1}$ and $\mathrm{I}_{\mathrm{Nav1.5}}$ traces recorded in $\mathrm{CHO}$ cells transfected with Kir2.1, Nav1.5 alone or together and cotransfected with p.K44A dynamin-2 are presented. In cells expressing Kir2.1 (Figures 7B,D) or Nav1.5 (Figures 7C,E) channels separately, overexpression of p.K44A dynamin-2 significantly increased the $\mathrm{I}_{\mathrm{Kir} 2.1}$ but did not modify the $\mathrm{I}_{\mathrm{Nav1.5}}$ density, confirming that internalization of Kir2.1, but not that of Nav1.5, channels is dynamin-dependent. Again, coexpression of Nav1.5 and Kir2.1 channels reciprocally and positively modulated the $\mathrm{I}_{\mathrm{Kir} 2.1}$ and the $\mathrm{I}_{\mathrm{Nav} 1.5}$ densities (Figures 7D,E). Interestingly, in cells expressing Kir2.1 and Nav1.5 channels, p.K44A dynamin-2 expression did not further increase either the $\mathrm{I}_{\mathrm{Kir} 2.1}$ or the $\mathrm{I}_{\mathrm{Nav1.5}}$ densities $(P>0.05)$, suggesting that, as Nav1.5 channels alone, the Kir2.1-Nav1.5 complexes are resistant to the dynamin-2 inhibition (Figures 7D,E).

It has been extensively demonstrated that the ubiquitinprotein ligase Nedd4-2 ubiquitinates Nav1.5 by binding to the PY motif located at the C-terminus of the channel and promotes its degradation by the proteasome (van Bemmelen et al., 2004; Rougier et al., 2005; Xu et al., 2009). On the other hand, it was demonstrated that Nedd4-2 reduces the $\mathrm{I}_{\mathrm{Kir} 2.1}$ density in Xenopus oocytes, although the molecular determinants were not identified (Alesutan et al., 2011). The degradation route of 
A

Kir2.1

B
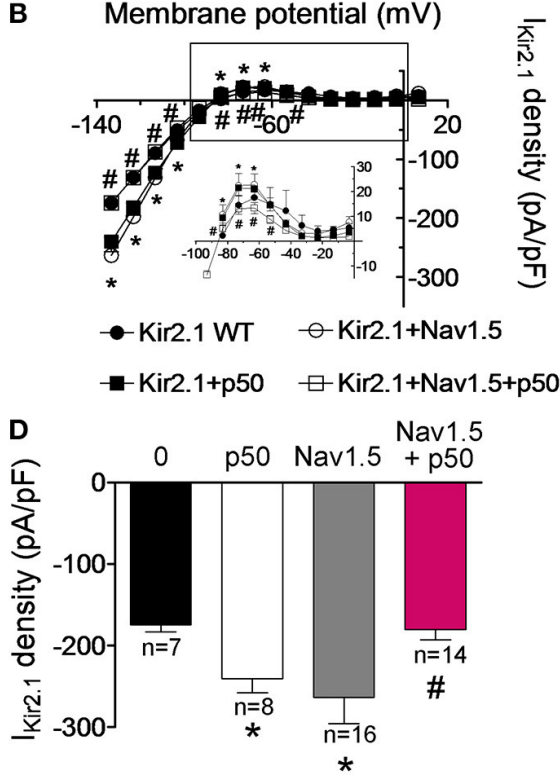

Nav1.5

C

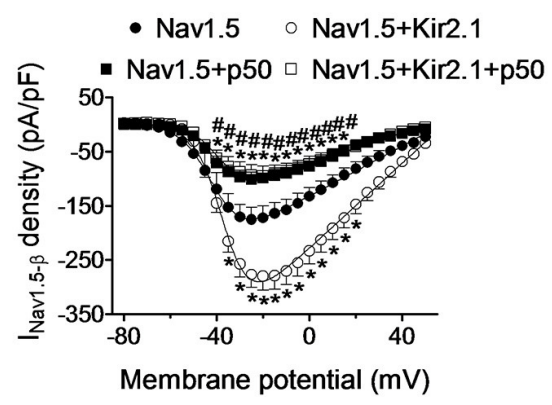

E

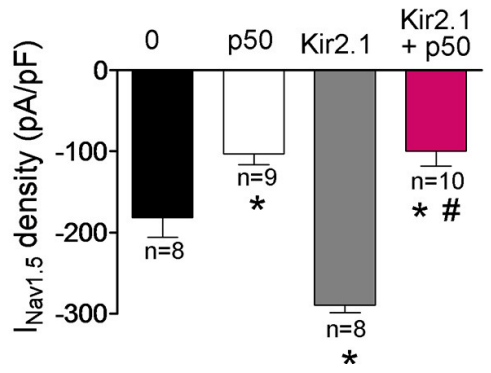

FIGURE 5 | Effects of the dynein/dynactin complex inhibition on Kir2.1 and Nav1.5 channels trafficking. (A) Schematic representation of a cell highlighting the role of the dynein/dynactin complex on ion channel trafficking. (B,C) Current-density voltage relationships for $I_{\text {Kir2.1 }}$ (B) and $I_{\text {Nav1.5 }}$ (C) recorded in $\mathrm{CHO}$ cells expressing the constructs indicated together or not with dynamitin (the p50 subunit of dynactin) to inhibit the dynein/dynactin complex. (D,E) $\left.\right|_{\text {Kir2.1 }}$ density at $-120 \mathrm{mV}$ (D) and peak I Nav1.5 (E) recorded in cells expressing the constructs indicated alone or together with p50. Each point/bar represents the mean \pm SEM of " $n$ " cells of $\geq 4$ preparations. ${ }^{*} P<0.05$ vs. cells transfected with Kir2.1 or Nav1.5 channels alone; $\# P<0.05$ vs. cells transfected with Kir2.1+Nav1.5 without p50. For clarity the results of other statistical comparisons were not shown.

the putative Kir2.1-Nav1.5 complexes was further analyzed by cotransfecting the cells with Nedd4-2. Under our conditions, Nedd4-2 did not significantly modify the $\mathrm{I}_{\text {Kir2.1 }}$ in cells expressing Kir2.1 alone (Figure 8A; $P>0.05$ ) but, as expected (van Bemmelen et al., 2004), it significantly decreased the $\mathrm{I}_{\mathrm{Nav1} .5}$ in cells expressing Nav1.5 channels alone $(P<0.05$; Figure 8B), confirming that Nav1.5, but not Kir2.1 channels, are targeted by Nedd4-2. Importantly, both $\mathrm{I}_{\mathrm{Kir} 2.1}$ and $\mathrm{I}_{\mathrm{Nav1.5}}$ densities recorded in cells coexpressing Kir2.1, Nav1.5, and Nedd4-2 were significantly reduced $(P<0.05)$. These results indicated that Kir2.1-Nav1.5 complexes were targeted by Nedd4- 2 as Nav1.5 channels were and suggested that these complexes are degraded by the proteasome. To test this hypothesis, $\mathrm{I}_{\text {Kir2.1 }}$ (Figure $8 \mathrm{C}$ ) and $\mathrm{I}_{\mathrm{Nav1.5}}$ (Figure 8D) were recorded in cells incubated with the proteasome inhibitor MG132 $(20 \mu \mathrm{M})$ for $2 \mathrm{~h}$ (Shy et al., 2014). MG132 treatment increased the $I_{\text {Nav1.5 }}$ in cells expressing Nav1.5 channels alone (Figure 8D; $P<0.05$ ) without modifying the $\mathrm{I}_{\mathrm{Kir} 2.1}$ in cells expressing Kir2.1 channels alone (Figure 8C; $P>0.05)$. It could be possible that the absence of effects of MG132 on $\mathrm{I}_{\text {Kir2.1 }}$ is due to the fact that degradation of Kir2.1 channels by the proteasome takes more time than that of Nav1.5 channels. To analyze this possibility, $\mathrm{I}_{\mathrm{Kir} 2.1}$ was recorded in cells incubated with MG132 for a longer period of time ( $4 \mathrm{~h}$ ). Under these conditions, $\mathrm{I}_{\mathrm{Kir} 2.1}$ density was not significantly modified either $(-159 \pm 14$ vs. $-155 \pm 18 \mathrm{pA} / \mathrm{pF}$ at $-120 \mathrm{mV} ; P>$ $0.05)$. All these results are in agreement with the selective role of the proteosome in the degradation of Nav1.5 channels but not of Kir2.1 channels. In cells coexpressing Kir2.1 and Nav1.5 channels, incubation with MG132 produced a further increase of $\mathrm{I}_{\mathrm{Kir} 2.1}$ and $\mathrm{I}_{\mathrm{Nav1.5}}$ densities compared to those generated by the positive reciprocal modulation (Figures 8C,D; $n \geq 6 ; P<$ $0.05)$. These results would confirm that Nav1.5 channels and Kir2.1-Nav1.5 complexes are degraded by the proteasome.

\section{DISCUSSION}

The present results suggest that there is a pool of Nav1.5 and Kir2.1 channels that form complexes that exhibit biological properties similar to those of Nav1.5 channels.

Previous data have shown that in ventricular myocytes there is a positive reciprocal modulation between Kir2.1 and Nav1.5 channels (Milstein et al., 2012; Matamoros et al., 2016) which is due to their interaction with $\alpha 1$-syntrophin (Matamoros et al., 2016). The results here obtained with immunofluorescence 


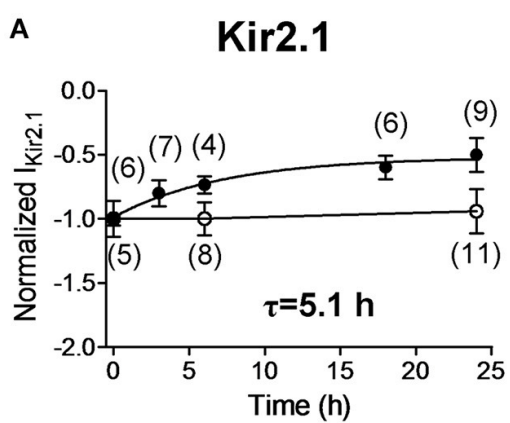

C Kir2.1+Nav1.5

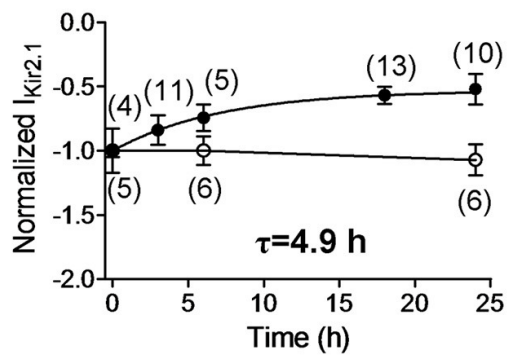

B

Nav1.5

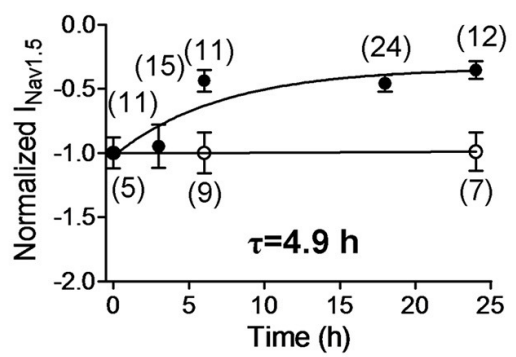

D Nav1.5+Kir2.1

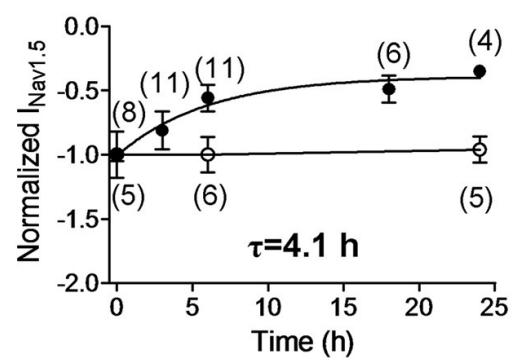

FIGURE 6 | Time course of internalization of Kir2.1 and Nav1.5 channels. (A-D) Mean normalized density of the currents recorded in CHO cells expressing the constructs indicated and incubated with BFA (50 ng/mL) (solid circles) for 0 (Control), 3, 6, 18, and $24 \mathrm{~h}$ or with $1 \%$ ethanol (open circles) for 0,6 , and $24 \mathrm{~h}$. Half-time constants $(\tau)$ yielded by the monoexponential fit to the BFA data are also shown. Each point represents the mean \pm SEM of $(n)$ cells of $\geq 4$ preparations.

experiments in heterologous expression systems suggested that cotransfection with Nav1.5 channels markedly increased the expression of Kir2.1. Therefore, these results seem to add further support to the hypothesis that the Kir2.1-Nav1.5 reciprocal modulation relies on the increase in the expression of the channels in the cell membrane. On the other hand, the PLA here conducted demonstrated that Kir2.1 and Nav1.5 channels are in close proximity to each other at the membrane of cardiac cells $(<40 \mathrm{~nm})$. Moreover, when both channels are expressed together, intracellular targeting Kir2.1 with a specific antibody reduces the $\mathrm{I}_{\mathrm{Nav1.5}}$ and vice versa. Therefore, we propose that there is a pool of Kir2.1 and Nav1.5 channels that form complexes (Milstein et al., 2012; Matamoros et al., 2016). Similarly, it has been shown that two voltage-dependent $\mathrm{K}^{+}$channels, Kv11.1 (hERG) and Kv7.1 (KvLQT1), may interact in such a way that expression of Kv7.1 increases Kv11.1 currents without major biophysical changes (Ehrlich et al., 2004). Recently it has been shown that this modulation is not due to the formation of heterotetrameric Kv11.1-Kv7.1 channels, suggesting that the positive modulation was due to the interaction between both subunits (Biliczki et al., 2015) in a similar way as we propose for Nav1.5 and Kir2.1.

It has been demonstrated that CaMKII coimmunoprecipitates with and phosphorylates Nav1.5 (Wagner et al., 2006; Herren et al., 2015). This modulation acutely affects the channel gating increasing the $\mathrm{I}_{\mathrm{NaL}}$ without a noticeable effect over the peak current in HEK-293 cells (Ashpole et al., 2012). In our hands inhibition of CaMKII decreased the $I_{\mathrm{NaL}}$ and shifted the voltage dependence of $\mathrm{I}_{\mathrm{Nav1.5}}$ inactivation toward more positive potentials, results that are in agreement with those observed previously (Wagner et al., 2006). Additionally, here we demonstrated that long lasting CaMKII inhibition with KN93 or intracellular dialysis with AIP (two CaMKII inhibitors) decreased somehow the peak $\mathrm{I}_{\mathrm{Nav1} 1.5}$. On the other hand, Wagner et al. (2009) demonstrated that CaMKII can produce dual effects on Kir2.1 channels, downregulating the mRNA and protein expression, but acutely increasing the $\mathrm{I}_{\mathrm{K} 1}$ density in rabbit and mouse myocytes. Our co-immunoprecipitation experiments showed that Kir2.1 channels alone did not co-immunoprecipitate with CaMKII, conversely, in cells expressing both Kir2.1+Nav1.5 channels they did. In agreement with these results, KN93 significantly reduced the $\mathrm{I}_{\text {Kir2.1 }}$ when Kir2.1 and Nav1.5 channels are expressed together. Of note, in cardiac myocytes Nav1.5 and Kir2.1 channels are always expressed simultaneously, thus our results in transfection systems are in agreement with those obtained in native cells, i.e., CaMKII acutely increases $I_{\text {Kir2.1 }}$ and its inhibition diminishes the current density. It can be speculated that the presence of Nav1.5 together with Kir2.1 promotes a conformation of Kir2.1 channels that allows their interaction with the kinase (Wagner et al., 2006, 2009). Alternatively, it is possible that CaMKII-induced phosphorylation of Nav1.5 affects Kir2.1 when both channels form complexes. Furthermore, the coexpression with Kir2.1 channels significantly increased the $\mathrm{I}_{\mathrm{NaL}}$ which, in turn, was diminished by the inhibition of CamKII. Moreover, when the CaMKII is inhibited, Kir2.1 channels did not co-immunoprecipitate with Nav1.5 channels anymore. Therefore, we propose that formation of Nav1.5-Kir2.1 


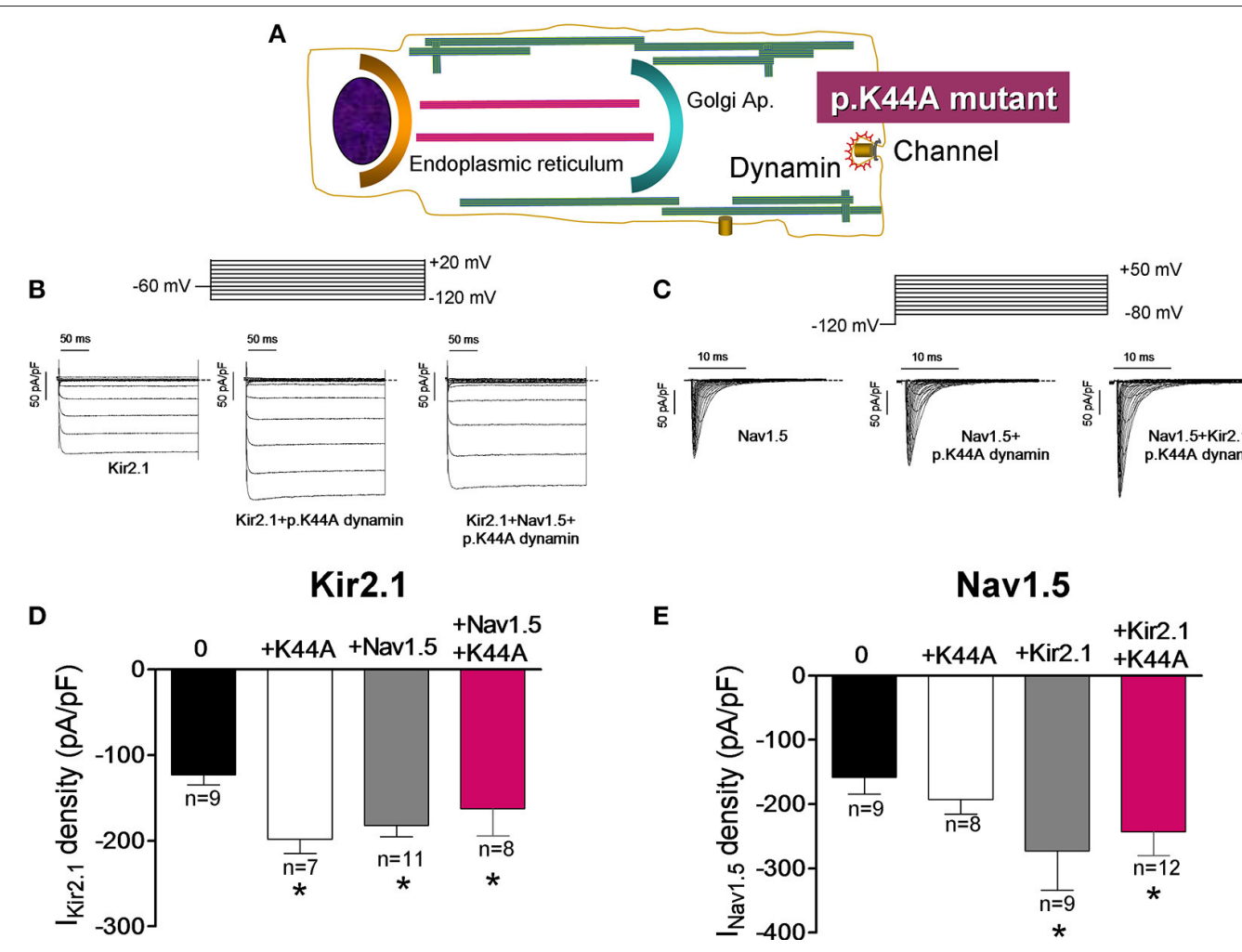

FIGURE 7 | Effects of the dynamin-2 inhibition on Kir2.1 and Nav1.5 channels internalization. (A) Schematic representation of a cell highlighting the role of dynamin-2 in ion channel endocytosis. (B,C) $\left.\right|_{\text {Kir2.1 }}$ (B) and $I_{\text {Nav1.5 }}$ (C) traces recorded by applying the protocols shown at the top in $\mathrm{CHO}$ cells transfected with the constructs indicated. The dashed lines represent the zero current level. (D,E) Bar graphs depicting $I_{\text {Kir2.1 }}$ density at $-120 \mathrm{mV}$ (D) and peak $I_{\text {Nav1.5 }}$ (E) in cells expressing Kir2.1 and Nav1.5 channels, respectively in the absence or presence of the constructs indicated cotransfected or not with p.K44A dynamin-2. Each bar represents the mean \pm SEM of " $n$ " experiments of $\geq 3$ preparations. ${ }^{\star} P<0.01$ vs. cells transfected with Kir 2.1 or Nav1.5 channels alone. For clarity the results of other statistical comparisons were not shown.

complexes strengthens the interaction of CaMKII with both Kir2.1 and Nav1.5 channels, and, importantly, that CaMKII plays a role in the positive reciprocal modulation between Nav1.5 and Kir2.1 channels that merits to be elucidated.

It has been proposed that binding of 14-3-3 to ER retention motifs (RXR) decreases channel affinity for coat-associated protein I (COPI), an essential component for the recycling of membrane proteins from the Golgi to the ER, promoting surface expression of properly folded channels (Balse et al., 2012). In our hands, 14-3-3DN did not modify $\mathrm{I}_{\mathrm{Kir} 2.1}$ and $\mathrm{I}_{\mathrm{Nav1.5}}$ densities in cells expressing the individual channels but inhibited both currents in cells expressing Kir2.1+Nav1.5 channels. These results would mean that the presence of both channels together promotes the existence of a structural conformation that allows the ER retention motifs (RXR) of the channel proteins to be accessible for 14-3-3 preventing their binding to COPI (Figure 9). It is also possible that the effects observed upon 143-3 inhibition could be the consequence of the disruption of the interaction between Kir2.1 and Nav1.5 channels, avoiding the formation of the complexes. However, the results obtained with the intracellular application of anti-Kir2.1 and anti-Nav1.5 antibodies suggested that 14-3-3 inhibition did not preclude the formation of Nav1.5-Kir2.1 complexes. It has been demonstrated that protein kinase A (PKA)-dependent phosphorylation of Nav1.5 channels enhances Nav1.5-trafficking from the ER toward the membrane in rat cardiomyocytes (Zhou et al., 2002). This effect seems to be mediated by the PKA phosphorylation of sites (S525 and S528) that are proximally-located to an ER retention signal (Zhou et al., 2002). On the other hand, 14-3-3 proteins preferentially bind to phosphorylated proteins and protect them from dephosphorylation, thus enhancing the effects derived from phosphorylation (Kagan et al., 2002; Tutor et al., 2006). Allouis and co-workers demonstrated that 14-3-3 proteins bind to the intracellular I to II linker of Nav1.5 channels, i.e., close to the PKA phosphorylation site (Allouis et al., 2006) and, thus, also probably protect Nav1.5 channels from dephosphorylation. Should this occur, binding of 14-3-3 proteins to Nav1.5 channels would increase the $\mathrm{I}_{\mathrm{Na}}$ by enhancing the Nav1.5 trafficking from the ER toward the plasma membrane. Conversely, 14-33 binding to Nav1.5 channels does not increase the $\mathrm{I}_{\mathrm{Na}}$ density (Allouis et al., 2006) as demonstrated in experiments conducted in hetereologous expression systems in which only Nav1.5 channels were transfected (Allouis et al., 2006 and the present results). It can be hypothesized that 14-3-3 proteins enhance the anterograde traffic of Nav1.5-Kir2.1 channel complexes, but not that of Nav1.5 channels alone. This would explain why 

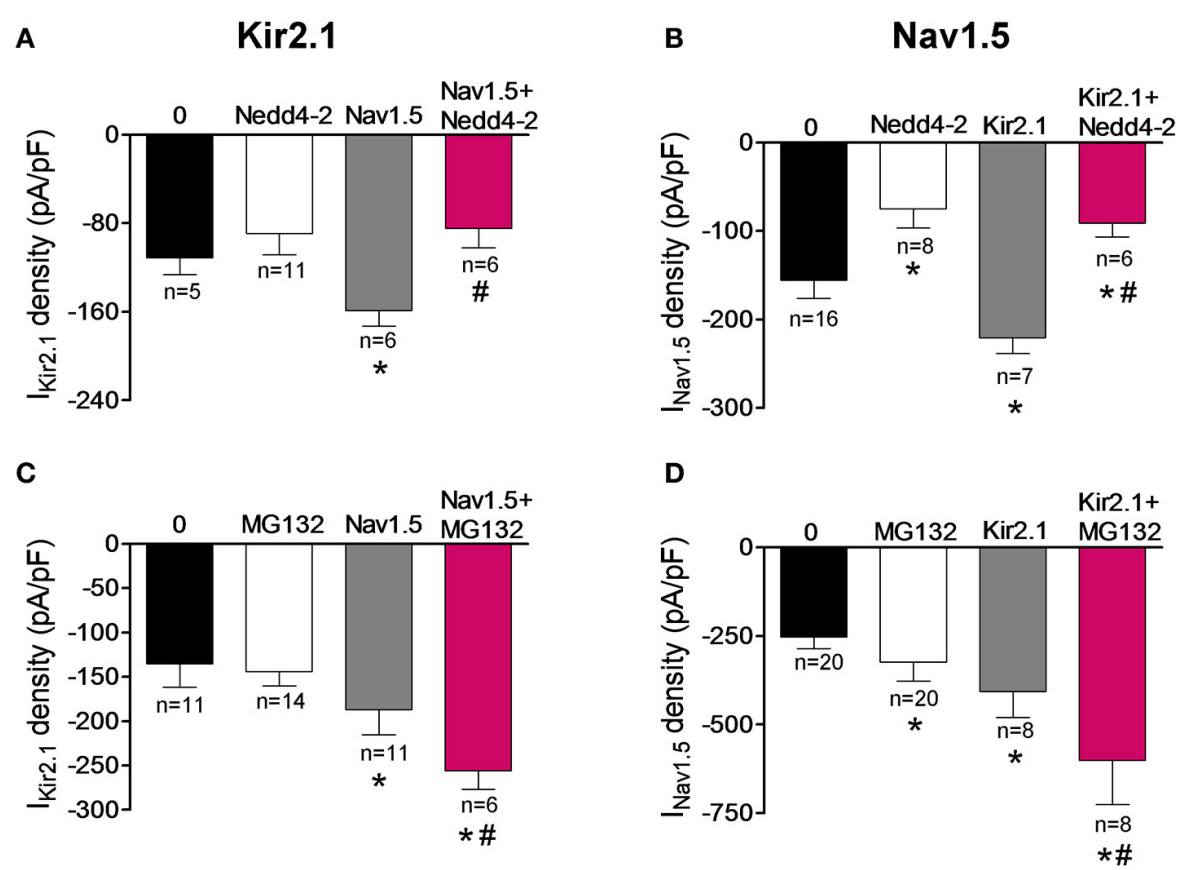

FIGURE 8 | Kir2.1 and Nav1.5 channel complexes are ubyquitinated and degraded by the proteasome. (A,B) $\left.\right|_{\text {Kir2.1 }}$ density at -120 mV (A) and peak $I_{\text {Nav1.5 }}$ (B) recorded in cells expressing Kir2.1 and Nav1.5 channels cotransfected or not with the ubiquitin ligase Nedd4-2. (C,D) $I_{\text {Kir2.1 }}$ density at -120 mV (C) and peak $I_{\text {Nav1 } 1.5}$ (D) recorded in cells expressing Kir2.1 and Nav1.5 channels incubated or not with the proteasome inhibitor MG132 (2 $\mu$ M for $2 \mathrm{~h}$ ). Each bar represents the mean \pm SEM of "n" experiments of $\geq 4$ preparations. ${ }^{\star} P<0.05$ vs. cells transfected with Kir2.1 or Nav1.5 channels alone; \# $P<0.05$ vs. cells transfected with Kir2.1+Nav1.5. For clarity the results of other statistical comparisons were not shown.

inhibition of 14-3-3 proteins decreased the $\mathrm{I}_{\text {Nav1.5 }}$ density in cells cotransfected with Nav1.5+Kir2.1 channels but not in cells transfected with Nav1.5 channels alone. Similarly, this would explain the $\mathrm{I}_{\mathrm{Kir} 2.1}$ increase observed in cells cotransfected with Nav1.5 and Kir2.1 channels. Further experiments are needed to test this hypothesis.

Overall, data here presented support the contention that at least a pool of Nav1.5 and Kir2.1 channels form complexes whose behavior is not identical to each channel separately (Figure 9). It has been described that in the brain Kir2.1 can form complexes with several anchoring and regulatory proteins such as SAP97 and Veli (Leonoudakis et al., 2004). However, the existence of such complexes in the heart has not been described thus far. Therefore, to further characterize the biology of the complexes, we analyzed how some of the mechanisms involved in anterograde and retrograde trafficking of the individual channels are affected when they are expressed together. Microtubule cytoskeleton is involved in ion channel trafficking by means of the dynein and kinesin motors that track along microtubules (Balse et al., 2012). The experiments conducted in cells overexpressing the p50 subunit to inhibit the dynein/dynamitin motor complex showed that it is involved in the retrograde and anterograde trafficking of Kir2.1 and Nav1.5 channels, respectively. Our results confirm previous data showing that p50 interacts with Nav1.5 channels reducing their expression at the cell surface and the $\mathrm{I}_{\mathrm{Nav1.5}}$ density (Chatin et al., 2014). Importantly, our results also suggested that the dynein/dynamitin motor complex is critical for the anterograde trafficking of the pool of Kir2.1 and Nav1.5 channels that form the complexes, supporting the hypothesis that their biology may be similar to that of Nav1.5 channels (Figure 9).

The experiments conducted in cells incubated with BFA, demonstrated that internalization kinetics of Kir2.1-Nav1.5 complexes is similar to that of Kir2.1 and Nav1.5 channels alone. However, our results suggest that the internalization process of Kir2.1 channels is qualitatively different to that of the Kir2.1-Nav1.5 complexes. We demonstrated that dynamin2 inhibition by overexpression of the p.K44A mutant increased the $\mathrm{I}_{\text {Kir2.1 }}$, but not the $\mathrm{I}_{\mathrm{Nav1.5}}$, confirming that Kir2.1 channel endocytosis is dynamin-dependent (Tong et al., 2001; Boyer et al., 2009), whereas that of Nav1.5 is not (Laedermann et al., 2014). Interestingly, p.K44A did not modify $\mathrm{I}_{\mathrm{Kir} 2.1}$ and $\mathrm{I}_{\mathrm{Nav1.5}}$ generated in cells expressing both channels, suggesting that the internalization of Kir2.1-Nav1.5 complexes is not dynamindependent either (Figure 9). It has been shown that Nav1.5 channels internalization relies on ubiquitination by Nedd4-2 (van Bemmelen et al., 2004; Rougier et al., 2005; Laedermann et al., 2014). Data on Kir2.1 ubiquitination are scarce, although it was proposed that Nedd4-2 may reduce $\mathrm{I}_{\mathrm{Kir} 2.1}$ density in Xenopus oocytes (Alesutan et al., 2011). Our results confirmed that overexpression of Nedd4-2 reduces the $\mathrm{I}_{\mathrm{Nav1.5}}$ but not the $\mathrm{I}_{\mathrm{Kir} 2.1}$ in cells expressing Nav1.5 and Kir2.1 channels alone, respectively. Interestingly, both $\mathrm{I}_{\mathrm{Kir} 2.1}$ and $\mathrm{I}_{\mathrm{Nav1.5}}$ were reduced in cells expressing both Kir2.1 and Nav1.5 channels suggesting that the putative Kir2.1-Nav1.5 complexes are ubiquitinated by Nedd4-2 (Figure 9). It has been proposed that the fate of the ubiquitinated 


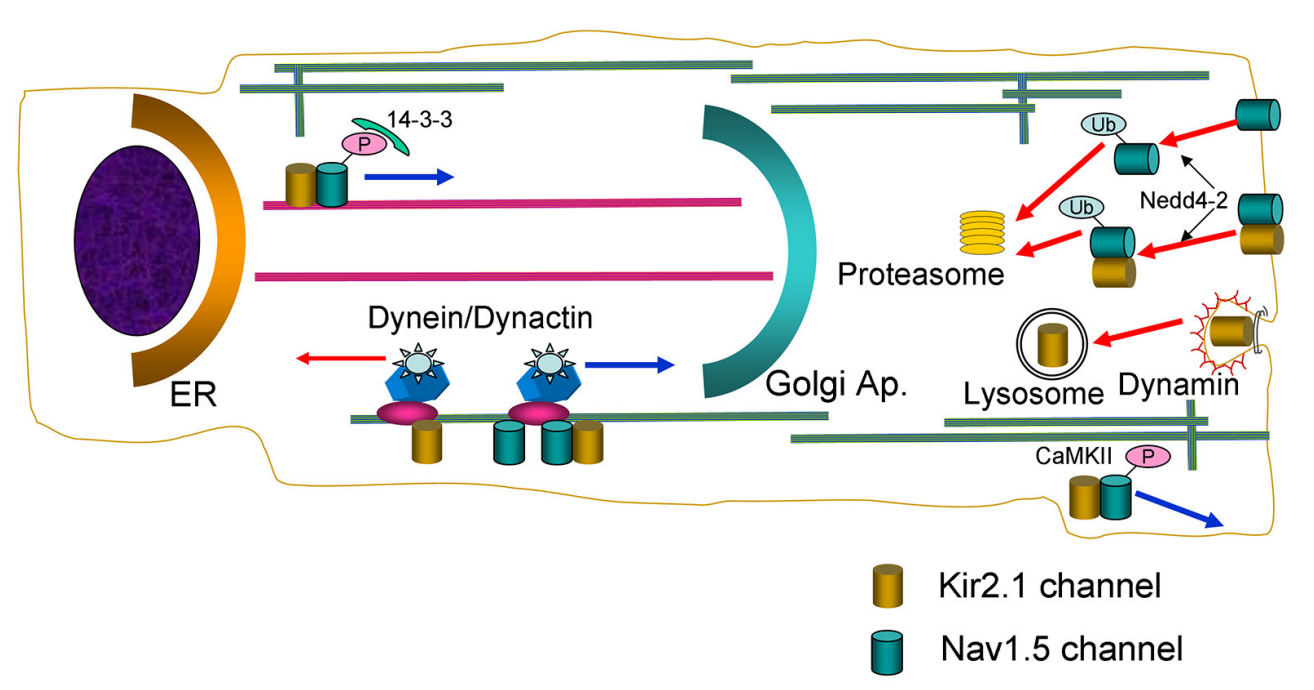

FIGURE 9 | Schematic diagram summarizing the main findings of the present study. Nav1.5 and Kir2.1 channels are represented by green and golden cylinders, respectively. ER, endoplasmic reticulum; $\mathrm{P}$, phosphate; Ub, ubiquitin chains.

channels is different depending on whether they are mono- or polyubiquitinated. Monoubiquitinated proteins are more prone to enter a recycling pathway, whereas polyubiquitinated ones are preferentially degraded by the proteasome (Laedermann et al., 2014). Rougier et al. (2005) demonstrated that in HEK293 cells Nav1.5 channels are polyubiquitinated suggesting that they are subject to proteasomal degradation. Other studies, however, suggested that in vivo Nav1.5 could be mono- or polyubiquitinated (Laedermann et al., 2014). Our results suggested that Nav1.5 and Kir2.1-Nav1.5 complexes are polyubiquitinated and degraded by the proteasome (Figure 9).

\section{Physiological Relevance}

$\mathrm{I}_{\mathrm{K} 1}$ and $\mathrm{I}_{\mathrm{Na}}$ play a key role in regulating cardiac excitability under physiological conditions and in the control of the frequency of the rotors that are responsible for fibrillating arrhythmias (Jalife, 2016). The classical paradigm considered that these currents were functionally coupled. Our results provide new evidences demonstrating that there is also a physical interaction between a pool of Nav1.5 and Kir2.1 channels that allows the formation of complexes, which probably are formed at early stages of protein assembly. By means of such a mechanism, the membrane expression of these ion channels in the ventricles can be strictly and simultaneously regulated, allowing a tighter control of the resting membrane potential and excitability and thus, preventing the ocurrence of fibrillating arrhythmias. Therefore, it can be speculated that changes in the expression of one of the channels, such as those produced by diseaseassociated remodeling or mutations, could concomitantly alter the expression of the other channel. We recently demonstrated that in human atrial myocytes obtained from patients in sinus rhythm and chronic atrial fibrillation (CAF) the CAF-induced $\mathrm{I}_{\mathrm{K} 1}$ increase was not accompanied by an $\mathrm{I}_{\mathrm{Na}}$ increase. This result was explained considering that the presence of Kir2.3 subunits precludes the reciprocal positive modulation between Nav1.5 and Kir2.x channels (Matamoros et al., 2016) and that in the human atria Kir2.3 channels are preferentially expressed (Gaborit et al., 2007). Further studies are needed to analyze whether changes in the expression of Kir2.1 or Nav1.5 produced by disease-associated remodeling process (for instance the Kir2.1 decrease produced by heart failure) might be accompanied by reciprocal decreases of either the $\mathrm{I}_{\mathrm{Na}}$ or the $\mathrm{I}_{\mathrm{K} 1}$ in the human ventricle. On the other hand, the consequences of the presence of mutated Nav1.5 or Kir2.1 channels on the ventricular $I_{K 1}$ and the $I_{\mathrm{Na}}$, respectively, must also be elucidated.

\section{Limitations of the Study}

Most of the results were obtained in heterologous expression systems and not in cardiac myocytes. This allowed us to compare separately the effects of each experimental maneuver on Nav1.5 and Kir2.1 channels as well as on the Kir2.1-Nav1.5 complexes. It is important to note that the vast majority of the information on cardiac ion channel biology has been obtained in expression systems (Balse et al., 2012). This could be accounted for considering the limited survival of cultured cardiac myocytes, since for the analysis of the channel biology the transfection with the cDNA encoding several proteins or the incubation with some reagents with high toxicity is needed. Our results stress the fact that results obtained in heterologous expression systems with isolated channels could be different to what actually occurs in cardiac myocytes where the rest of the channels are also present.

\section{CONCLUSION}

Overall our results suggest that there is a pool of Nav1.5 and Kir2.1 channels that form complexes with anterograde and retrograde trafficking routes similar to those of Nav1.5 channels 
alone. These complexes allow a tight control of the current densities that determine cardiac excitability and action potential propagation. Therefore, the formation of the complexes would have an important physiological and/or pathological relevance that merits further investigation.

\section{AUTHOR CONTRIBUTIONS}

Conducting experiments, acquiring and analyzing data, RGU, PN-M, SA, DT, MM, MP-H, SS, LO, RdA, and FJD-G. Designing research, analyzing data, and writing MS: JT, ED, and RC.

\section{FUNDING}

This work was supported by Fondos Europeos de Desarrollo Regional; Ministerio de Economía y Competitividad

\section{REFERENCES}

Abriel, H. (2010). Cardiac sodium channel $\mathrm{Na}(\mathrm{v}) 1.5$ and interacting proteins: physiology and pathophysiology. J. Mol. Cell. Cardiol. 48, 2-11. doi: 10.1016/j.yjmcc.2009.08.025

Alesutan, I., Munoz, C., Sopjani, M., Dërmaku-Sopjani, M., Michael, D., Fraser, S., et al. (2011). Inhibition of Kir2.1 (KCNJ2) by the AMP-activated protein kinase. Biochem. Biophys. Res. Commun. 408, 505-510. doi: 10.1016/j.bbrc.2011.04.015

Allouis, M., Le Bouffant, F., Wilders, R., Péroz, D., Schott, J. J., Noireaud, J., et al. (2006). 14-3-3 is a regulator of the cardiac voltage-gated sodium channel Nav1.5. Circ. Res. 98, 1538-1546. doi: 10.1161/01.RES.0000229244.97497.2c

Anumonwo, J. M., and Lopatin, A. N. (2010). Cardiac strong inward rectifier potassium channels. J. Mol. Cell. Cardiol. 48, 45-54. doi: 10.1016/j.yjmcc.2009.08.013

Archer, S. L., Souil, E., Dinh-Xuan, A. T., Schremmer, B., Mercier, J. C., El Yaagoubi, A., et al. (1998). Molecular identification of the role of voltage-gated $\mathrm{K}^{+}$ channels, Kv1.5 and Kv2.1, in hypoxic pulmonary vasoconstriction and control of resting membrane potential in rat pulmonary artery myocytes. J. Clin. Invest. 101, 2319-2330. doi: 10.1172/JCI333

Ashpole, N. M., Herren, A. W., Ginsburg, K. S., Brogan, J. D., Johnson, D. E., Cummins, T. R., et al. (2012). $\mathrm{Ca}^{2+} /$ calmodulin-dependent protein kinase II (CaMKII) regulates cardiac sodium channel Nav1.5 gating by multiple phosphorylation sites. J. Biol. Chem. 287, 19856-19869. doi: 10.1074/jbc.M111.322537

Balse, E., Steele, D. F., Abriel, H., Coulombe, A., Fedida, D., and Hatem, S. N. (2012). Dynamic of ion channel expression at the plasma membrane of cardiomyocytes. Physiol. Rev. 92, 1317-1358. doi: 10.1152/physrev.00041.2011

Biliczki, P., Rüdiger, A., Girmatsion, Z., Pourrier, M., Mamarbachi, A. M., Hébert, T. E., et al. (2015). The interaction between delayed rectifier channel alphasubunits does not involve hetero-tetramer formation. Naunyn Schmiedebergs Arch. Pharmacol. 388, 973-981. doi: 10.1007/s00210-015-1108-3

Boyer, S. B., Slesinger, P. A., and Jones, S. V. (2009). Regulation of Kir2.1 channels by the Rho-GTPase, Rac1. J. Cell Physiol. 218, 385-393. doi: 10.1002/jcp.21610

Burkhardt, J. K., Echeverri, C. J., Nilsson, T., and Vallee, R. B. (1997). Overexpression of the dynamitin (p50) subunit of the dynactin complex disrupts dynein-dependent maintenance of membrane organelle distribution. J. Cell Biol. 139, 469-484. doi: 10.1083/jcb.139.2.469

Caballero, R., de la Fuente, M. G., Gómez, R., Barana, A., Amorós, I., DolzGaitón, P., et al. (2010a). In humans, chronic atrial fibrillation decreases the transient outward current and ultrarapid component of the delayed rectifier current differentially on each atria and increases the slow component of the delayed rectifier current in both. J. Am. Coll. Cardiol. 55, 2346-2354. doi: 10.1016/j.jacc.2010.02.028

Caballero, R., Dolz-Gaitón, P., Gómez, R., Amorós, I., Barana, A., González de la Fuente, M., et al. (2010b). Flecainide increases Kir2.1 currents by interacting
[SAF2014-58769-P and SAF2014-55686-R (FJD-G)]; Instituto de Salud Carlos III [PI16/00398]; Comunidad Autónoma de Madrid (S2010/BMD-2374), The ERA-Net for Research on Rare Diseases (AC14/00029), Mutua Madrileña and Banco Bilbao Vizcaya Argentaria Foundations, and the Spanish Society of Cardiology Grants.

\section{ACKNOWLEDGMENTS}

We thank Paloma Vaquero for her invaluable technical assistance.

\section{SUPPLEMENTARY MATERIAL}

The Supplementary Material for this article can be found online at: https://www.frontiersin.org/articles/10.3389/fphys. 2017.00903/full\#supplementary-material with cysteine 311, decreasing the polyamine-induced rectification. Proc. Natl. Acad. Sci. U.S.A. 107, 15631-15636. doi: 10.1073/pnas.1004021107

Caballero, R., Utrilla, R. G., Amorós, I., Matamoros, M., Pérez-Hernández, M., Tinaquero, D., et al. (2017). Tbx20 controls the expression of the KCNH2 gene and of hERG channels. Proc. Natl. Acad. Sci. U.S.A. 114, E416-E425. doi: 10.1073/pnas.1612383114

Chatin, B., Colombier, P., Gamblin, A. L., Allouis, M., and Le Bouffant, F. (2014). Dynamitin affects cell-surface expression of voltage-gated sodium channel Nav1.5. Biochem. J. 463, 339-349. doi: 10.1042/BJ20140604

de Boer, T. P., Houtman, M. J., Compier, M., and van der Heyden, M. A. (2010). The mammalian $\mathrm{K}(\mathrm{IR}) 2 . \mathrm{x}$ inward rectifier ion channel family: expression pattern and pathophysiology. Acta Physiol. 199, 243-256. doi: 10.1111/j.1748-1716.2010.02108.x

Ehrlich, J. R., Pourrier, M., Weerapura, M., Ethier, N., Marmabachi, A. M., Hébert, T. E., et al. (2004). KvLQT1 modulates the distribution and biophysical properties of HERG. A novel alpha-subunit interaction between delayed rectifier currents. J. Biol. Chem. 279, 1233-1241. doi: 10.1074/jbc.M3090 87200

Gaborit, N., Le Bouter, S., Szuts, V., Varro, A., Escande, D., Nattel, S. et al. (2007). Regional and tissue specific transcript signatures of ion channel genes in the non-diseased human heart. J. Physiol. 582, 675-693. doi: 10.1113/jphysiol.2006.126714

Herren, A. W., Weber, D. M., Rigor, R. R., Margulies, K. B., Phinney, B. S., and Bers, D. M. (2015). CaMKII phosphorylation of $\mathrm{Na}(\mathrm{v}) 1.5$ : novel in vitro sites identified by mass spectrometry and reduced S516 phosphorylation in human heart failure. J. Proteome Res. 14, 2298-2311. doi: 10.1021/acs.jproteome.5b00107

Hinshaw, J. E., and Schmid, S. L. (1995). Dynamin self-assembles into rings suggesting a mechanism for coated vesicle budding. Nature 374, 190-192. doi: $10.1038 / 374190 \mathrm{a} 0$

Jalife, J. (2016). Dynamics and molecular mechanisms of ventricular fibrillation in structurally normal hearts. Card. Electrophysiol. Clin. 8, 601-612. doi: 10.1016/j.ccep.2016.04.009

Kagan, A., Melman, Y. F., Krumerman, A., and McDonald, T. V. (2002). 14-3-3 amplifies and prolongs adrenergic stimulation of HERG $\mathrm{K}^{+}$channel activity. EMBO J. 21, 1889-1898. doi: 10.1093/emboj/21.8.1889

Laedermann, C. J., Decosterd, I., and Abriel, H. (2014). Ubiquitylation of voltage-gated sodium channels. Handb. Exp. Pharmacol. 221, 231-250. doi: 10.1007/978-3-642-41588-3_11

Leonoudakis, D., Conti, L. R., Radeke, C. M., McGuire, L. M., and Vandenberg, C. A. (2004). A multiprotein trafficking complex composed of SAP97, CASK, Veli, and Mint1 is associated with inward rectifier Kir2 potassium channels. J. Biol. Chem. 279, 19051-19063. doi: 10.1074/jbc.M400284200

Matamoros, M., Pérez-Hernández, M., Guerrero-Serna, G., Amorós, I., Barana, A., Núñez, M., et al. (2016). Nav1.5 N-terminal domain binding to $\alpha 1$-syntrophin 
increases membrane density of human Kir2.1, Kir2.2 and Nav1.5 channels. Cardiovasc. Res. 110, 279-290. doi: 10.1093/cvr/cvw009

Mercier, A., Clément, R., Harnois, T., Bourmeyster, N., Bois, P., and Chatelier, A. (2015). Nav1.5 channels can reach the plasma membrane through distinct N-glycosylation states. Biochim. Biophys. Acta 1850, 1215-1223. doi: 10.1016/j.bbagen.2015.02.009

Milstein, M. L., Musa, H., Balbuena, D. P., Anumonwo, J. M., Auerbach, D. S., Furspan, P. B., et al. (2012). Dynamic reciprocity of sodium and potassium channel expression in a macromolecular complex controls cardiac excitability and arrhythmia. Proc. Natl. Acad. Sci. U.S.A. 109, E2134-E2143. doi: 10.1073/pnas.1109370109

Núñez, L., Barana, A., Amorós, I., de la Fuente, M. G., Dolz-Gaitón, P., Gómez, R., et al. (2013). p.D1690N Nav1.5 rescues p.G1748D mutation gating defects in a compound heterozygous Brugada syndrome patient. Heart Rhythm 10, 264-272. doi: 10.1016/j.hrthm.2012.10.025

Obsil, T., and Obsilova, V. (2011). Structural basis of 14-3-3 protein functions. Semin. Cell Dev. Biol. 22, 663-672. doi: 10.1016/j.semcdb.2011.09.001

Pawley, J. B. (2006). "Points, pixels, and gray levels: digitizing image data, in Handbook of Biological Confocal Microscopy, 3rd Edn., ed B. J. Pawley (New York, NY: Springer Science+Business Media, LLC), 64-68.

Rougier, J. S., van Bemmelen, M. X., Bruce, M. C., Jespersen, T., Gavillet, B., Apothéloz, F., et al. (2005). Molecular determinants of voltage-gated sodium channel regulation by the Nedd4/Nedd4-like proteins. Am. J. Physiol. Cell Physiol. 288, C692-C701. doi: 10.1152/ajpcell.00460.2004

Shy, D., Gillet, L., Ogrodnik, J., Albesa, M., Verkerk, A. O., Wolswinkel, R., et al. (2014). PDZ domain-binding motif regulates cardiomyocyte compartmentspecific Nav1.5 channel expression and function. Circulation 130, 147-160. doi: 10.1161/CIRCULATIONAHA.113.007852

Söderberg, O., Gullberg, M., Jarvius, M., Ridderstråle, K., Leuchowius, K. J., Jarvius, J., et al. (2006). Direct observation of individual endogenous protein complexes in situ by proximity ligation. Nat. Methods 3, 995-1000. doi: 10.1038/nmeth947

Tong, Y., Brandt, G. S., Li, M., Shapovalov, G., Slimko, E., Karschin, A., et al. (2001). Tyrosine decaging leads to substantial membrane trafficking during modulation of an inward rectifier potassium channel. J. Gen. Physiol. 117, 103-118. doi: 10.1085/jgp.117.2.103

Tutor, A. S., Delpón, E., Caballero, R., Gómez, R., Núñez, L., Vaquero, M., et al. (2006). Association of 14-3-3 proteins to $\beta 1$-adrenergic receptors modulates Kv11.1 $\mathrm{K}^{+}$channel activity in recombinant systems. Mol. Biol. Cell 17, 4666-4674. doi: 10.1091/mbc.E06-05-0422 van Bemmelen, M. X., Rougier, J. S., Gavillet, B., Apothéloz, F., Daidié, D., Tateyama, M., et al. (2004). Cardiac voltage-gated sodium channel Nav1.5 is regulated by Nedd4-2 mediated ubiquitination. Circ. Res. 95, 284-291. doi: 10.1161/01.RES.0000136816.05109.89

Wagner, S., Dybkova, N., Rasenack, E. C., Jacobshagen, C., Fabritz, L., Kirchhof, P., et al. (2006). $\mathrm{Ca}^{2+} /$ calmodulin-dependent protein kinase II regulates cardiac $\mathrm{Na}^{+}$channels. J. Clin. Invest. 116, 3127-3138. doi: 10.1172/JCI26620

Wagner, S., Hacker, E., Grandi, E., Weber, S. L., Dybkova, N., Sossalla, S., et al. (2009). Ca/calmodulin kinase II differentially modulates potassium currents. Circ. Arrhythm. Electrophysiol. 2, 285-294. doi: 10.1161/CIRCEP.108.842799

Wilde, A. A., and Brugada, R. (2011). Phenotypical manifestations of mutations in the genes encoding subunits of the cardiac sodium channel. Circ. Res. 108, 884-897. doi: 10.1161/CIRCRESAHA.110.238469

Xu, P., Duong, D. M., Seyfried, N. T., Cheng, D., Xie, Y., Robert, J., et al. (2009). Quantitative proteomics reveals the function of unconventional ubiquitin chains in proteasomal degradation. Cell 137, 133-145. doi: 10.1016/j.cell.2009.01.041

Zhou, J., Shin, H. G., Yi, J., Shen, W., Williams, C. P., and Murray, K. T. (2002). Phosphorylation and putative ER retention signals are required for protein kinase A-mediated potentiation of cardiac sodium current. Circ. Res. 91, 540-546. doi: 10.1161/01.RES.0000033598.00903.27

Conflict of Interest Statement: The authors declare that the research was conducted in the absence of any commercial or financial relationships that could be construed as a potential conflict of interest.

The reviewer JR and handling Editor declared their shared affiliation.

The handling editor declared a past collaboration with the authors MM and MP-H.

Copyright (c) 2017 Utrilla, Nieto-Marín, Alfayate, Tinaquero, Matamoros, PérezHernández, Sacristán, Ondo, de Andrés, Díez-Guerra, Tamargo, Delpón and Caballero. This is an open-access article distributed under the terms of the Creative Commons Attribution License (CC BY). The use, distribution or reproduction in other forums is permitted, provided the original author(s) or licensor are credited and that the original publication in this journal is cited, in accordance with accepted academic practice. No use, distribution or reproduction is permitted which does not comply with these terms. 


\section{OPEN ACCESS}

Edited by:

Marcel van der Heyden,

University Medical Center Utrecht,

Netherlands

Reviewed by:

Anthony Varghese,

University of Wisconsin-River Falls,

United States

Ricardo Caballero,

Complutense University of Madrid,

Spain

Susanne Kämmerer,

Institut für Pharmakologie und

Toxikologie, Technische Universität

Dresden, Germany

${ }^{*}$ Correspondence:

Carol Ann Remme

c.a.remme@amc.uva.nl

${ }^{\dagger}$ These authors have contributed equally to this work.

Specialty section: This article was submitted to Cardiac Electrophysiology, a section of the journal

Frontiers in Physiology

Received: 06 December 2017

Accepted: 20 February 2018

Published: 12 March 2018

Citation:

Portero V, Wilders R, Casini S,

Charpentier $F$, Verkerk $A O$ and Remme CA (2018) KV 4.3 Expression Modulates Nav1.5 Sodium Current.

Front. Physiol. 9:178

doi: 10.3389/fphys.2018.00178

\section{Kv4.3 Expression Modulates Nav1.5 Sodium Current}

\author{
Vincent Portero ${ }^{1}$, Ronald Wilders ${ }^{2}$, Simona Casini ${ }^{1}$, Flavien Charpentier ${ }^{3}$, \\ Arie O. Verkerk ${ }^{1,2 \dagger}$ and Carol Ann Remme ${ }^{1 * t}$
}

${ }^{1}$ Department of Experimental Cardiology, Academic Medical Center, Amsterdam, Netherlands, ${ }^{2}$ Department of Medical Biology, Academic Medical Center, Amsterdam, Netherlands, ${ }^{3}$ L'Institut du Thorax, INSERM, CNRS, Université de Nantes, Nantes, France

In cardiomyocytes, the voltage-gated transient outward potassium current ( to $\left._{\text {o }}\right)$ is responsible for the phase-1 repolarization of the action potential (AP). Gain-of-function mutations in KCND3, the gene encoding the I $_{\text {to }}$ carrying $\mathrm{K}_{\mathrm{V}} 4.3$ channel, have been associated with Brugada syndrome (BrS). While the role of $I_{\text {to }}$ in the pro-arrhythmic mechanism of BrS has been debated, recent studies have suggested that an increased Ito may directly affect cardiac conduction. However, the effects of an increased Ito on AP upstroke velocity or sodium current at the cellular level remain unknown. We here investigated the consequences of $K_{v} 4.3$ overexpression on Nav1.5 current and consequent sodium channel availability. We found that overexpression of $K_{V} 4.3$ protein in HEK293 cells stably expressing Nav1.5 (HEK293-Nav1.5 cells) significantly reduced Nav 1.5 current density without affecting its kinetic properties. In addition, $K_{v} 4.3$ overexpression decreased AP upstroke velocity in HEK293-Nav1.5 cells, as measured with the alternating voltage/current clamp technique. These effects of $K_{V} 4.3$ could not be explained by alterations in total Nav1.5 protein expression. Using computer simulations employing a multicellular in silico model, we furthermore demonstrate that the experimentally observed increase in $\mathrm{K}_{\mathrm{V}} 4.3$ current and concurrent decrease in Nav1.5 current may result in a loss of conduction, underlining the potential functional relevance of our findings. This study gives the first proof of concept that $K_{V} 4.3$ directly impacts on Nav1.5 current. Future studies employing appropriate disease models should explore the potential electrophysiological implications in (patho)physiological conditions, including BrS associated with KCND3 gain-of-function mutations.

Keywords: transient outward current, sodium current, channels, action potential, myocyte, arrhythmias, computer simulation

\section{INTRODUCTION}

The cardiac sodium current $\left(\mathrm{I}_{\mathrm{Na}}\right)$, generated by the $S C N 5 A$-encoded voltage-gated $\mathrm{Na}^{+}$channel (Nav1.5) (Gellens et al., 1992), is responsible for the initial fast upstroke of the cardiac action potential (AP). It determines excitability of myocardial cells and ensures proper conduction of the electrical impulse within the heart. Consequently, $\mathrm{Na}_{V} 1.5$ channel dysfunction may lead to conduction slowing, ventricular arrhythmias, and sudden cardiac death. In particular, SCN5A mutations leading to loss of sodium channel function are associated with isolated (progressive) conduction slowing or block (Schott et al., 1999), sick sinus syndrome (Benson et al., 2003), and Brugada syndrome (BrS) (Chen et al., 1998; Crotti et al., 2012; Le Scouarnec et al., 2015). 
In cardiomyocytes, the voltage-gated transient outward $\mathrm{K}^{+}$ current $\left(\mathrm{I}_{\mathrm{to}}\right)$ is responsible for the phase-1 repolarization of the cardiac AP and thereby contributes to the refractory period and inotropic state of the myocardium. In human, $\mathrm{I}_{\text {to }}$ is generated by the $\mathrm{K}_{\mathrm{V}} 4.3$ channel, which is encoded by the gene KCND3 (Niwa and Nerbonne, 2010). Gain-of-function mutations in $K C N D 3$, or its regulatory subunits, have also been associated with BrS (Delpón et al., 2008; You et al., 2015; Portero et al., 2016), giving rise to an ongoing discussion on the apparent role of $\mathrm{I}_{\text {to }}$ in the pro-arrhythmic mechanism of BrS (Wilde et al., 2010). Previous studies have suggested that an increased $I_{\text {to }}$ may directly affect cardiac conduction due to a current-to-load mismatch during the depolarization process (Hoogendijk et al., $2010 a, b)$. However, the effects of a gain-of-function of $I_{t o}$ on the AP upstroke velocity at the cellular level remain unknown. The characterization of various knock-out mouse models of $\alpha$ subunits generating the fast component of $\mathrm{I}_{\text {to }}$ (Kcnd3, Kcnd2) confirmed the involvement of $\mathrm{I}_{\text {to }}$ in phase- 1 repolarization, but its impact on AP upstroke velocity or $\mathrm{I}_{\mathrm{Na}}$ density were not investigated (Niwa et al., 2008; Liu et al., 2015). We recently evaluated the effects of an in silico $\mathrm{I}_{\text {to }}$ injection on AP upstroke and repolarization velocity using the dynamic clamp technique (Verkerk et al., 2016). In that study, we observed a minimal effect $(\approx 2 \%)$ of in-silico $\mathrm{I}_{\mathrm{to}}$ injection on upstroke velocity but only when the injected current was large and rapidly activated at very negative potentials (around $-50 \mathrm{mV}$ ). However, while

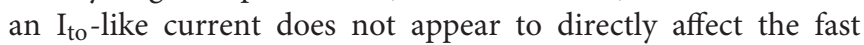
depolarization, evidence is increasing that various ion channel proteins may interact and thus modulate each other's expression, function, or membrane trafficking (Balse and Boycott, 2017). For example, studies highlighted an interaction and co-regulation of the Kir2.1 and $\mathrm{Na}_{\mathrm{V}} 1.5$ proteins with a direct effect on their electrophysiological properties and thus important for cardiac excitability (Milstein et al., 2012). Moreover, a recent study demonstrated a direct interaction between the $\mathrm{K}_{\mathrm{V}} 4.3$ and hERG proteins, resulting in an increase in hERG current density upon co-expression of hERG with $\mathrm{K}_{\mathrm{V}} 4.3$ (Zhao et al., 2017). Considering these novel studies and the involvement of both $\mathrm{I}_{\mathrm{Na}}$ and $\mathrm{I}_{\text {to }}$ in BrS, we hypothesized that the level of expression of $\mathrm{K}_{\mathrm{V}} 4.3$ may impact on $\mathrm{I}_{\mathrm{Na}}$.

We addressed this hypothesis by evaluating the impact of $\mathrm{K}_{\mathrm{V}} 4.3$ protein overexpression on $\mathrm{Na}_{\mathrm{V}} 1.5$-based current and sodium channel availability in HEK293 cells stably expressing $\mathrm{Na}_{V} 1.5$ (HEK293-Na 1.5 ). We show that an overexpression of $\mathrm{K}_{\mathrm{V}} 4.3$ channels leads to a reduction of $\mathrm{Na}_{\mathrm{V}} 1.5$ current density and lower AP upstroke velocity, as measured with the alternating voltage/current clamp (VC/CC) technique. These effects of $\mathrm{K}_{\mathrm{V}} 4.3$ overexpression could not be explained by alterations in total $\mathrm{Na}_{V} 1.5$ protein expression. Computer simulations furthermore indicate that the experimentally observed decreased upstroke velocity is not directly due to an increase in the $\mathrm{K}_{\mathrm{V}}$ 4.3-based $\mathrm{I}_{\mathrm{to}}$, but instead a consequence of the $\mathrm{K}_{\mathrm{V}} 4.3$ protein itself. We also demonstrate that an increase in $\mathrm{I}_{\text {to }}$ as well as a decrease in $\mathrm{I}_{\mathrm{Na}}$ can affect cardiac conduction and that a combination of both can lead to dramatic consequences, underlining the potential functional relevance of our findings.

\section{MATERIALS AND METHODS HEK293-Nav1.5 Cell Culture and Transfection}

To avoid artifacts due to co-transfections, we evaluated the effect of the overexpression of $\mathrm{K}_{\mathrm{V}} 4.3$ protein on $\mathrm{Na}_{\mathrm{V}} 1.5$ currents using a genetically modified cell line constitutively overexpressing the human Nav1.5 channel (van Bemmelen et al., 2004). HEK293 cells stably expressing hNav1.5 (HEK293-Nav 1.5 , kindly provided by Drs. Hugues Abriel and Jean-Sébastien Rougier) were cultured in DMEM (Gibco) supplemented with 10\% FBS (Biowest), L-glutamine (Gibco), penicillin-streptomycin (Gibco), and Zeomycin (Invitrogen) in a $5 \% \mathrm{CO}_{2}$ incubator at $37^{\circ} \mathrm{C}$. Cells were transfected at $70 \%$ confluency in $36.8 \mathrm{~mm}$ culture wells with $1 \mu \mathrm{g}$ IRES-GFP or $1 \mu \mathrm{g}$ KCND3-IRES-GFP cDNA using lipofectamine (Invitrogen, Carlsbad, USA). Both IRES-GFP and KCND3-IRES-GFP (human KCND3 transcript reference: NM_004980.4) constructs contained the same M61 vector plasmid backbone (Addgene). Gene-transfer was monitored by means of green fluorescence from the IRES-GFP or KCND3IRES-GFP bicistronic vector. Patch clamp experiments were performed on single fluorescent cells 2 days after transfection.

\section{Ventricular Cell Preparation}

Animal procedures were performed in accordance with governmental and institutional guidelines for animal use in research and were approved by the Animal Experimental Committee of the Academic Medical Center, Amsterdam, The Netherlands. Single left ventricular myocytes were isolated from 3 to 5 months old $\mathrm{FVB} / \mathrm{N}$ mice by enzymatic dissociation (Remme et al., 2006). Therefore, mice were anesthetized by an intraperitoneal injection of pentobarbital prior to cervical dislocation, after which the heart was excised, cannulated, and mounted on a Langendorff perfusion set-up. The hearts were perfused for $5 \mathrm{~min}$ with Tyrode's solution containing (in $\mathrm{mM}$ ): $140 \mathrm{NaCl}, 5.4 \mathrm{KCl}, 1.8 \mathrm{CaCl}_{2}, 1 \mathrm{MgCl}_{2}$, 5.5 glucose, 5 HEPES; $\mathrm{pH} 7.4(\mathrm{NaOH})$. Subsequently, the heart was perfused for $8 \mathrm{~min}$ with a similar solution in which the calcium concentration was lowered to $1 \mu \mathrm{M}$, after which the enzyme Liberase Blendzyme type 4 (Roche; $0.05 \mathrm{mg} / \mathrm{ml}$ ) and trypsin (Boehringer, $1 \mu \mathrm{l} / \mathrm{ml}$ of $2.5 \%$ solution) were added for 10 minutes. Single myocytes were obtained by gently triturating the digested tissue in the low calcium enzyme solution supplemented with bovine serum albumin (BSA, $50 \mathrm{mg} / \mathrm{ml}$ ). Myocytes were washed twice in normal calcium Tyrode's solution and quiescent, rod-shaped cross-striated cells with smooth surface were selected for measurements.

\section{Western Blot Experiment for Total Nav1.5 Quantification}

Forty-eight hours after transfection $(1 \mu \mathrm{g}$ IRES-GFP or $1 \mu \mathrm{g}$ KCND3-IRES-GFP plasmid), HEK293-Nav 1.5 cells were washed twice with PBS and lysed in PBS containing 0.1\% Triton and complete mini EDTA-free protease inhibitor mixture tablet (Roche). Cell lysates were then sonicated twice for $10 \mathrm{~s}$ and centrifuged for $10 \mathrm{~min}$ at $8.000 \mathrm{rpm}$. The supernatant was quantified using the BCA kit and $40 \mu \mathrm{g}$ of each separated 
cell lysate was loaded on a $4-20 \%$ gradient gel (Bio-Rad) after $5 \mathrm{~min}$ of denaturation at $60^{\circ} \mathrm{C}$ in Laemmli buffer. The Rb $\alpha$ GFP antibody used for Western blotting was purchased from Santa Cruz Biotechnology, Rb $\alpha$ Calnexin from Calbiochem, and $\mathrm{Rb} \alpha \mathrm{Na}_{\mathrm{V}} 1.5$ from Sigma-Aldrich. Goat anti-rabbit horseradish peroxidase-conjugated secondary antibodies were purchased from GE Healthcare Life Science. Chemo luminescence signal was acquired with the ImageQuant LAS 4000 instrument. Band intensities were quantified using the public domain ImageJ software (USA National Institutes of Health). Total $\mathrm{Na}_{V} 1.5$ protein expression protein was normalized to the calnexin signal.

\section{Electrophysiology}

\section{Data Acquisition}

$\mathrm{Na}_{\mathrm{V}} 1.5$ and $\mathrm{K}_{\mathrm{V}} 4.3$ currents and upstroke velocities $(\mathrm{dV} / \mathrm{dt})$ were measured in the whole-cell configuration of the patchclamp technique using an Axopatch 200B amplifier (Molecular Devices Corporation, Sunnyvale, CA, USA) or a custom-made amplifier, capable of fast switching between voltage clamp (VC) and current clamp (CC) modes (Berecki et al., 2010). Voltage control, data acquisition, and analysis were accomplished using custom software. Potentials were corrected for the calculated liquid junction potentials (Barry and Lynch, 1991). Signals were low-pass filtered with a cut-off frequency of $5 \mathrm{kHz}$ and digitized at 20,4 , and $40 \mathrm{kHz}$ for $\mathrm{Na}_{\mathrm{V}} 1.5, \mathrm{~K}_{\mathrm{V}} 4.3$, and upstroke velocities, respectively. Patch pipettes were pulled from borosilicate glass (Harvard Apparatus) and had resistances of $\approx 2.0 \mathrm{M} \Omega$ after filling with the solutions as indicated below. Series resistance was compensated by $\geq 80 \%$. Cell membrane capacitance $\left(C_{m}\right)$ was calculated by dividing the time constant of the decay of the capacitive transient upon $5 \mathrm{mV}$ hyperpolarizing voltage step from $-40 \mathrm{mV}$ by the series resistance. The average $C_{m}$ was not significantly different between the IRES-GFP and $\mathrm{K}_{\mathrm{V}} 4$.3-IRESGFP cells [IRES-GFP: $12.27 \pm 0.76 \mathrm{pF}(n=36)$; $\mathrm{K}_{\mathrm{V}} 4.3$-IRESGFP: $12.00 \pm 0.99 \mathrm{pF}(n=37)$; mean \pm standard error of the mean (SEM)].

\section{$\mathrm{K}_{\mathrm{V}} 4.3$ and Nav1.5 Current Measurements With Conventional VC}

$\mathrm{Na}_{V} 1.5$ current was measured at room temperature $\left(21^{\circ} \mathrm{C}\right)$ with patch pipettes containing (in $\mathrm{mM}$ ): $60 \mathrm{CsCl}, 50$ aspartic acid, 11 EGTA, $1.0 \mathrm{CaCl}_{2}, 1.0 \mathrm{MgCl}_{2}, 5.0 \mathrm{Na}_{2}$ ATP, 10 HEPES, pH $7.2(\mathrm{CsOH})$. Bath solution for $\mathrm{Na}_{\mathrm{V}} 1.5$ current measurements contained (in $\mathrm{mM}$ ): $20 \mathrm{NaCl}, 130 \mathrm{CsCl}, 2 \mathrm{CaCl}_{2}, 1 \mathrm{MgCl}_{2}$, 5 glucose, 10 HEPES, pH $7.4(\mathrm{CsOH}) . \mathrm{K}_{\mathrm{V}} 4.3$ current was measured at $37^{\circ} \mathrm{C}$ in Tyrode's solution with the aforementioned composition. Patch pipettes for $\mathrm{K}_{\mathrm{V}} 4.3$ current measurements were filled with solution containing (in $\mathrm{mM}$ ): $125 \mathrm{~K}$-gluc, 20 $\mathrm{KCl}, 5 \mathrm{NaCl}, 1 \mathrm{MgCl}_{2}$, 10 BAPTA, 5 MgATP, 10 HEPES, pH 7.2 (NMDG-OH).

Current density and gating properties were determined by means of custom voltage-clamp protocols as indicated in figure insets. Cycle lengths were 5 and $10 \mathrm{~s}$ for $\mathrm{Na}_{V} 1.5$ and $\mathrm{K}_{\mathrm{V}} 4.3$ current, respectively. Both $\mathrm{Na}_{\mathrm{V}} 1.5$ and $\mathrm{K}_{\mathrm{V}} 4.3$ current densities were defined as the difference between peak and steady-state current, divided by $\mathrm{C}_{\mathrm{m}}$. To determine the activation characteristics of $\mathrm{Na}_{V} 1.5$ current, currentvoltage (I-V) curves were corrected for driving force and normalized to maximum peak current. Steady-state activation and inactivation curves were fitted using the Boltzmann equation $\mathrm{I} / \mathrm{I}_{\max }=\mathrm{A} /\left\{1.0+\exp \left[\left(\mathrm{V}_{1 / 2}-\mathrm{V}\right) / \mathrm{k}\right]\right\}$ to determine $\mathrm{V}_{1 / 2}$ (membrane potential for the half-maximal (in)activation) and the slope factor $\mathrm{k}$.

\section{Upstroke Velocity Measurements Using Alternating $\mathrm{VC} / \mathrm{CC}$}

The alternating VC/CC technique was used to measure $\mathrm{Na}_{\mathrm{V}} 1.5$ current-driven upstrokes at physiological temperature and $\mathrm{Na}^{+}$ concentrations, as described previously (Berecki et al., 2010). Patch pipette and bath solutions were similar to those used for $\mathrm{K}_{V} 4.3$ current measurements (see above). HEK293-Na 1.5 cells and freshly isolated myocytes were voltage clamped at a holding potential of $-85 \mathrm{mV}$, a value close to the resting membrane potential of working cardiomyocytes. Next, upstroke and repolarization were elucidated by switching for $20 \mathrm{~ms}$ to the CC mode of the patch clamp amplifier. Upstrokes were elicited by $1.2 \times$ threshold current pulses through the patch pipette at $0.5 \mathrm{~Hz}$ and the stimulus current was present during the entire $20 \mathrm{~ms}$ in CC mode. Maximal upstroke velocity $\left(\mathrm{dV} / \mathrm{dt}_{\max }\right)$ during VC/CC, offline corrected for the contribution of stimulus current $\left(\mathrm{I}_{\mathrm{stim}}\right)$, served as an indicator of $\mathrm{Na}_{\mathrm{V}} 1.5$ current availability.

\section{Computer Simulations}

\section{Numerical Reconstruction of $\mathrm{Na}_{\mathrm{V}} 1.5$ and $\mathrm{K}_{\mathrm{V}} 4.3$ Currents in HEK293 Cells}

Alternating VC/CC experiments in HEK293 cells expressing $\mathrm{Na}_{V} 1.5$ and $\mathrm{K}_{\mathrm{V}} 4.3$ channels were simulated in a standard cell model with intracellular and extracellular sodium and potassium concentrations similar to those of the patch-clamp experiments. The cell model contained equations for $\mathrm{I}_{\mathrm{Na}}, \mathrm{I}_{\text {to }}$, and $\mathrm{I}_{\text {stim. The }}$ $\mathrm{I}_{\mathrm{Na}}$ and $\mathrm{I}_{\text {to }}$ equations were taken from the human ventricular cell model by Ten Tusscher and Panfilov (2006) with the $\mathrm{I}_{\mathrm{Na}}$ and $\mathrm{I}_{\text {to }}$ densities scaled by a factor of 1.8 and 6.0, respectively, to arrive at the experimentally observed values for the maximum upstroke velocity and repolarization velocity. $\mathrm{I}_{\text {stim }}$ was set to $6.5 \mathrm{pA} / \mathrm{pF}$ to ensure that the maximum upstroke velocity was reached at $\approx 4 \mathrm{~ms}$ after the stimulus onset as in the experiments. For numerical integration of the differential equations we applied a simple and efficient Euler-type integration scheme (Rush and Larsen, 1978) with a 1 - $\mu$ s time step.

\section{Maximum Upstroke Velocity and Repolarization Velocity in Murine Left Ventricular Myocytes}

The alternating VC/CC protocol of the experiments on single left ventricular myocytes was implemented in the CellML code (Cuellar et al., 2003) of the apical version of the mouse ventricular AP model by Bondarenko et al. (2004). The amplitude of the $20 \mathrm{~ms}$ stimulus current was set to $10 \mathrm{pA} / \mathrm{pF}$, which made the AP upstroke occur at $\approx 4 \mathrm{~ms}$ after the stimulus onset. The maximum upstroke velocity and repolarization velocity were determined from the time derivative of the action potential trace. The CellML code was edited and run in version 0.9.31.1409 of the Windows based Cellular Open Resource (COR) environment (Garny et al., 2003) with its standard CVODE integrator. 


\section{Action Potential Transfer in Human Left Ventricular Myocytes}

AP transfer was studied in a one-dimensional strand of human left ventricular myocytes. The strand consisted of 80 longitudinally coupled cells, each described by the Ten Tusscher and Panfilov model of a single human ventricular myocyte (Ten Tusscher and Panfilov, 2006). The intercellular coupling conductance was set to $6 \mathrm{nS}$ and the myoplasmic resistivity was set to $150 \Omega \cdot \mathrm{cm}$. The first cell of the strand was stimulated at a rate of $1 \mathrm{~Hz}$ with a 2 -ms, $\approx 20 \%$ supra-threshold stimulus current with an amplitude of $3.2 \mathrm{nA}$. As in other studies (Shaw and Rudy, 1997; Thomas et al., 2003; Wilders, 2012), the entire cell length (of $74 \mu \mathrm{m}$ ) was used as the spatial discretization element, with elements connected by the lumped myoplasmic resistance (calculated from the myocyte dimensions and the myoplasmic resistivity of $150 \Omega \cdot \mathrm{cm}$ ) and gap junctional resistance. At the selected gap junctional conductance of $6 \mathrm{nS}$, this lumped resistance was almost completely determined by the gap junctional resistance (Wilders, 2012). The aforementioned Eulertype integration scheme was used for numerical integration.

\section{Statistics}

Data are expressed as mean \pm SEM. Mann-Whitney Rank Sum test, Student $t$-test, or Two-Way Repeated Measures ANOVA followed by pairwise comparison using the Student-NewmanKeuls test were used when appropriate. The level of statistical significance was set to $p<0.05$.

\section{RESULTS}

\section{Characterization of $\mathrm{K}_{\mathrm{v}} 4.3$ Current in HEK293 Cells Stably Expressing Nav1.5}

First, we characterized the $\mathrm{K}_{\mathrm{V}} 4.3$-driven current resulting from transfection of the KCND3-IRES-GFP plasmid in HEK293 cells stably expressing $\mathrm{Na}_{V} 1.5$ (HEK293-Nav 1.5). Figure $1 \mathrm{~A}$ shows representative currents measured between -100 to $40 \mathrm{mV}$ (with $10 \mathrm{mV}$ increment) during 1-s voltage clamp steps from a holding potential of $-80 \mathrm{mV}$ in a HEK293-Nav1.5 cell transfected with either IRES-GFP (top) or KCND3-IRES-GFP (bottom). A prepulse of $5 \mathrm{~ms}$ to $-40 \mathrm{mV}$ was applied to activate and inactivate the $\mathrm{Na}_{V} 1.5$-based sodium current present in these HEK293$\mathrm{Na}_{V} 1.5$ cells (Figure 1A, inset). Similar to previous reports, cells transfected with IRES-GFP showed a small endogenous current upon depolarization (Figure 1A, top) (Niwa et al., 2008). In contrast, cells transfected with KCND3-IRES-GFP displayed a large $\mathrm{K}_{\mathrm{V}} 4.3$ current which started to activate around $-40 \mathrm{mV}$ and increased in amplitude upon further depolarization due to enhanced activation and increased $\mathrm{K}^{+}$driving force (Figure 1A, bottom) (Giles and van Ginneken, 1985). Figure 1B shows the average I-V relationships of the $\mathrm{K}_{\mathrm{V}} 4.3$ current, which was defined as the difference between the peak and steady-state current. Its density was defined as the current amplitude divided by the membrane capacitance $\left(\mathrm{C}_{\mathrm{m}}\right)$, amounting to $\approx 450 \mathrm{pA} / \mathrm{pF}$ at $40 \mathrm{mV}$ in the KCND3-IRES-GFP transfected HEK293-Nav 1.5 cells, and $>20$ times smaller in the IRES-GFP transfected cells. Figure 1C shows the voltage-dependency of inactivation for the $\mathrm{K}_{\mathrm{V}} 4.3$ current in the cells transfected with KCND3-IRES-GFP, measured using a two-pulse protocol with a 1-s prepulse to a potential between -100 and $40 \mathrm{mV}$ followed by a $500-\mathrm{ms}$ test pulse to $40 \mathrm{mV}$, demonstrating that the $\mathrm{K}_{\mathrm{V}} 4.3$ current is fully available at $-70 \mathrm{mV}$ and more negative potentials. The $\mathrm{V}_{1 / 2}$ and $\mathrm{k}$ of the voltage-dependency of inactivation were $-45.9 \pm 2.6$ and $-5.6 \pm 0.4 \mathrm{mV}$, respectively. Figure 1D shows the recovery from inactivation in KCND3-IRES-GFP transfected HEK293-Na 1.5 cells analyzed with 200 -ms pulses to $40 \mathrm{mV}$ with variable interpulse intervals. The time constant of recovery from inactivation, analyzed with a mono-exponential fit (Figure 1D, dashed line) was $160 \pm 29 \mathrm{~ms}$, demonstrating that recovery from inactivation was completed with an inter-pulse interval of $1 \mathrm{~s}$ and longer. The $\mathrm{K}_{\mathrm{V}} 4.3$ current biophysical properties are summarized in Table S1. These data indicate that overexpression of KCND3-IRES-GFP in HEK293-Nav1.5 cells results in a large $\mathrm{I}_{\text {to }}$, confirming the functional expression of $\mathrm{K}_{\mathrm{V}} 4.3$ channels at the cell membrane.

\section{Kv4.3 Expression Reduces Nav1.5 Current in HEK293-Nav1.5 Cells}

Secondly, we characterized the effects of $\mathrm{K}_{\mathrm{V}} 4.3$ overexpression on $\mathrm{Na}_{V} 1.5$-based current in HEK293-Nav1.5 cells. Figure 2A shows representative $\mathrm{Na}_{\mathrm{V}} 1.5$ current activated by $500-\mathrm{ms}$ depolarizing voltage clamp steps of $5 \mathrm{mV}$ increment from a holding potential of $-120 \mathrm{mV}$ in a IRES-GFP or KCND3IRES-GFP transfected HEK293-Nav 1.5 cell. In both conditions, $\mathrm{Na}_{\mathrm{V}} 1.5$ current started to activate around $-60 \mathrm{mV}$, peaked around $-30 \mathrm{mV}$, and subsequently decreased in amplitude due to the reduction in $\mathrm{Na}^{+}$driving force. As shown in the average I-V relationships in Figure 2 B, Na 1.5 current density was significantly smaller in the KCND3-IRES-GFP transfected cells compared to IRES-GFP transfected cells. For example, at $-40 \mathrm{mV} \mathrm{Na} 1.5$ current density was $-609 \pm 62$ and $-447 \pm 61$ $\mathrm{pA} / \mathrm{pF}$ ( $p<0.05$; pairwise comparison using a Student-NewmanKeuls test following two-way repeated measures ANOVA) in IRES-GFP and KCND3-IRES-GFP transfected HEK293-Nav 1.5 cells, respectively, indicating a decrease in $\mathrm{Na}_{V} 1.5$ current density by $\approx 25 \%$ due to $\mathrm{K}_{\mathrm{V}} 4.3$ overexpression. Next, we determined whether the $\mathrm{Na}_{V} 1.5$ current density decrease was accompanied by gating property changes. Because the current decay could not be reliably fit to a 2-exponential function, the time course of inactivation was instead determined by analyzing the time required for $50 \%$ of current decay to occur $\left(t_{50 \%}\right)$ at $-30 \mathrm{mV}$ (Remme et al., 2006). $t_{50 \%}$ did not differ significantly between IRES-GFP and KCND3-IRES-GFP transfected cells [0.88 \pm $0.06 \mathrm{~ms}(n=15)$ vs. $0.84 \pm 0.03 \mathrm{~ms}(n=19)$, respectively, $p=$ 0.41 ; Student's $t$-test $]$. For determining the voltage-dependency of activation for IRES-GFP and KCND3-IRES-GFP transfected cells, $\mathrm{I}-\mathrm{V}$ relationships, as shown in Figure 2B, were first corrected for the $\mathrm{Na}^{+}$driving force. Of note, the reversal potential of $\mathrm{Na}_{V} 1.5$ current calculated using the Nernst equation is evaluated at $+17.58 \mathrm{mV}$, which is in line with the sodium current recordings represented in Figure 2A. Next, currents were normalized to their maximal amplitude and the curves were fitted to a Boltzmann distribution curve. Figure 2C shows overlapping curves of voltage-dependency of inactivation. The latter curves were constructed by normalizing currents to their maximal 

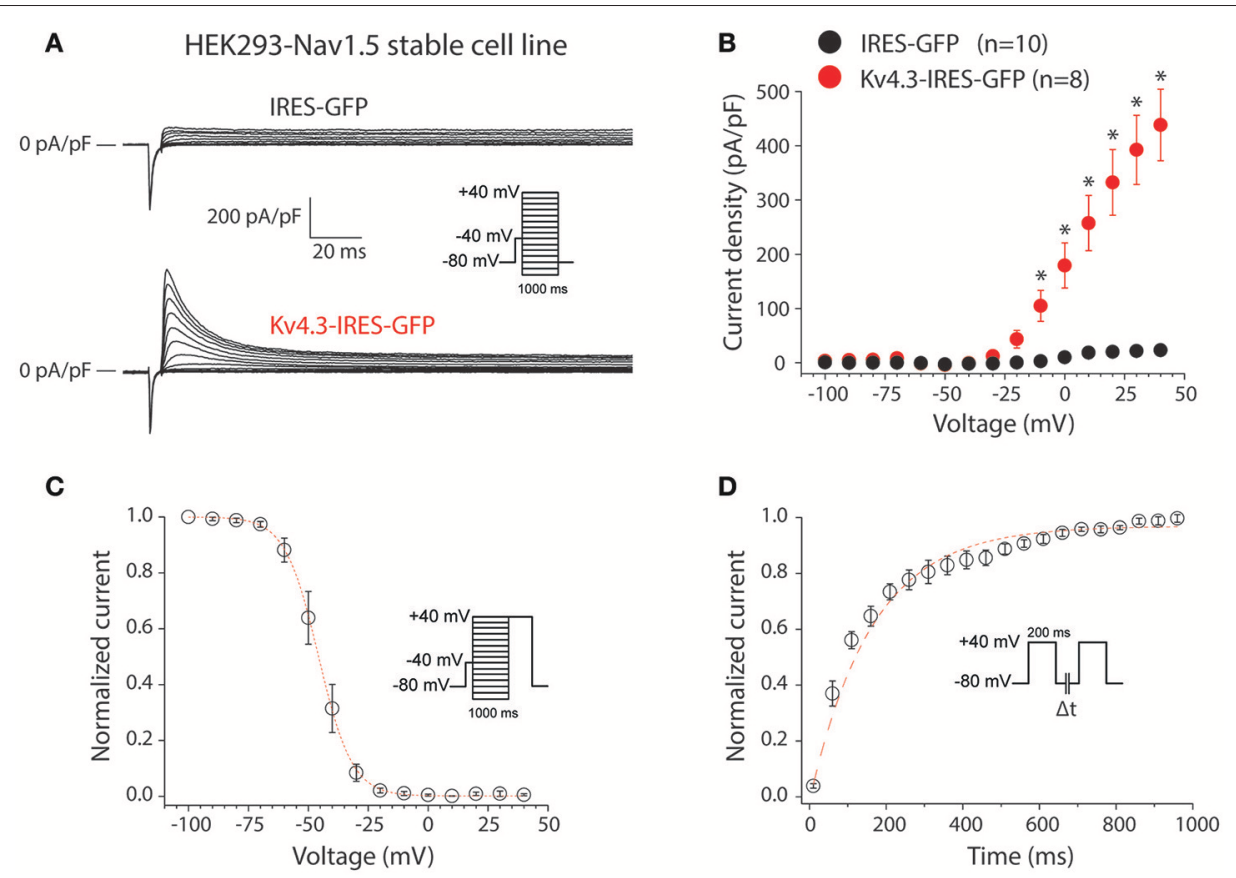

FIGURE 1 | KV4.3 currents in HEK293-Nav1.5 cells transfected with KCND3. (A) Typical current traces in response to voltage clamp steps to test potentials ranging from -100 to $40 \mathrm{mV}$ recorded from HEK293 cells stably expressing Nav1.5 (HEK293-Nav1.5) and transfected with IRES-GFP (top) or KCND3-IRES-GFP (bottom). Inset: voltage clamp protocol used. (B) Current-voltage (I-V) relationships of the peak outward current in KCND3-IRES-GFP and IRES-GFP transfected cells. Asterisks denote $p<0.05$. (C) Voltage-dependency of $K_{V} 4.3$ inactivation in $K_{V} 4.3-I R E S-G F P$ cells $(n=8)$. The dotted line is the Boltzmann fit to the average data. Inset: voltage clamp protocol used. (D) Average recovery from inactivation curve measured with two subsequent $200-\mathrm{ms}$ pulses from -80 to $+40 \mathrm{mV}$ with variable inter-pulse durations $(\Delta t)$ of $1-1,000-\mathrm{ms}(n=4)$. Inset: voltage clamp protocol used. The red dashed line is a mono-exponential fit of the average data.

current during the voltage clamp step to $-20 \mathrm{mV}$. Similarly, Figure 2D shows overlapping curves of voltage-dependency of activation for IRES-GFP and KCND3-IRES-GFP transfected cells. These data demonstrate that neither the voltage-dependency of activation nor the voltage-dependency of inactivation of $\mathrm{Na}_{V} 1.5$ current were affected by $\mathrm{K}_{\mathrm{V}} 4.3$ expression. The $\mathrm{Na}_{\mathrm{V}} 1.5$ current biophysical properties are summarized in Table S1. Western blot analysis showed no differences in Nav1.5 protein expression levels between HEK293-Nav1.5 cells with overexpression of KCND3-IRES-GFP or GFP (Figure 3; original images provided in the Supplementary Material, Figure S1). Thus, our data demonstrate that $\mathrm{K}_{\mathrm{V}} 4.3$ expression reduces $\mathrm{Na}_{\mathrm{V}} 1.5$ current without affecting its gating properties or the $\mathrm{Na}_{V} 1.5$ expression level.

\section{Kv4.3 Expression Reduces Action Potential Upstroke Velocity}

Thirdly, we assessed upstroke velocities in the HEK293-Nav1.5 cells, transfected with either IRES-GFP or KCND3-IRES-GFP plasmids. Noteworthy, HEK293 cells expressing Na 1.5 display fast depolarizations upon switching from voltage clamp (VC) to current clamp (CC) due to $\mathrm{Na}^{+}$channel activation as previously shown (Berecki et al., 2010; Verkerk et al., 2016; Lieve et al., 2017). Thus, the alternating VC/CC technique allows for a more dynamic assessment of $\mathrm{Na}_{V} 1.5$ current as compared to measurements in VC configuration, in the setting of more physiological temperature and $\mathrm{Na}^{+}$gradients across the membrane. Figure $\mathbf{4 A}$ shows typical upstrokes (top) and their time derivatives (bottom) measured upon switching from a holding potential of $-85 \mathrm{mV}$ in VC to CC for $20-$ ms. Upstrokes were evoked at $0.5 \mathrm{~Hz}$, a stimulus frequency at which $\mathrm{K}_{\mathrm{V}} 4.3$ current is fully available (cf. Figure 1D). Figure 4B summarizes the maximum upstroke velocities (top) and maximum repolarization velocities (bottom). On average, the maximum upstroke velocity of KCND3-IRES-GFP transfected cells was $21 \%$ lower than that of IRES-GFP transfected cells (441 \pm 17 vs. $556 \pm 24 \mathrm{~V} / \mathrm{s} ; p<0.05)$. Both cell types displayed a repolarization phase following the upstroke (Figure 4A) with a significantly larger maximum velocity (73 \pm 13 vs. $22 \pm 3 \mathrm{~V} / \mathrm{s}$ ) in KCND3-IRES-GFP as compared to IRESGFP transfected cells (Figure 4B, bottom). In Figure 4C, we plotted for each cell its maximum repolarization velocity vs. its maximum upstroke velocity, further demonstrating an inverse relationship between $\mathrm{Na}_{V} 1$.5-induced depolarization and $\mathrm{K}_{V} 4$.3induced repolarization velocities: $\mathrm{K}_{\mathrm{V}} 4.3$ expression increases repolarization velocity, but reduces upstroke velocity.

\section{Relation Between Repolarization and Depolarization in Ventricular Myocytes of Mice}

The above presented data indicate that $\mathrm{K}_{\mathrm{V}} 4.3$ (over)expression decreases $\mathrm{Na}_{V} 1.5$ current (Figure 2B) and upstroke velocity 

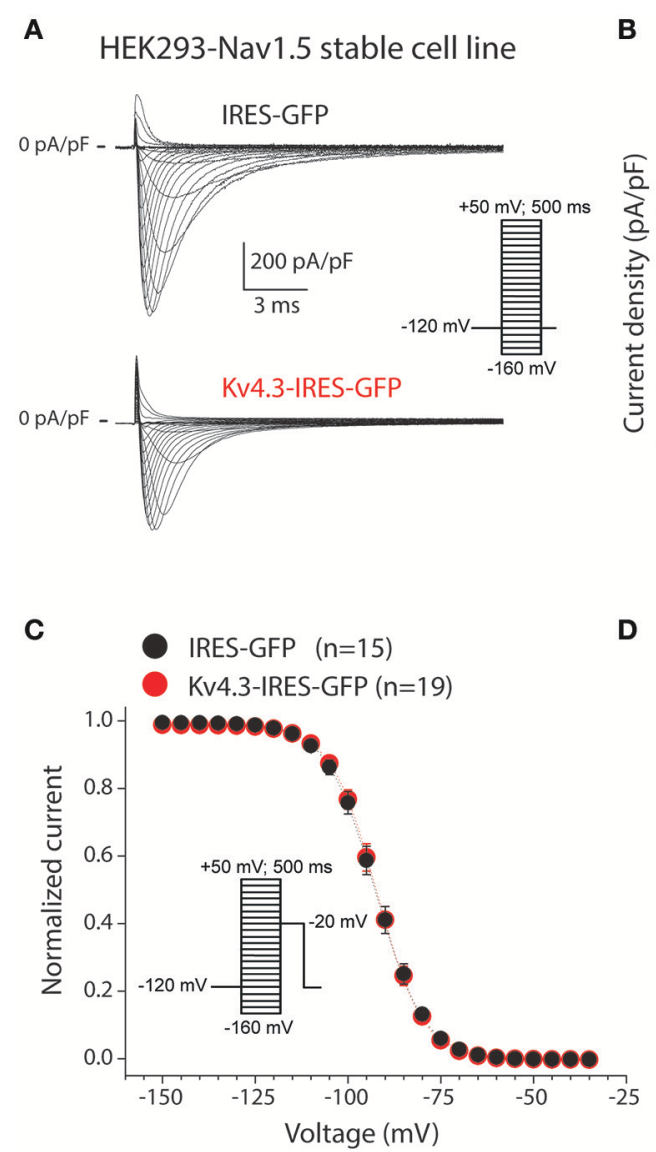
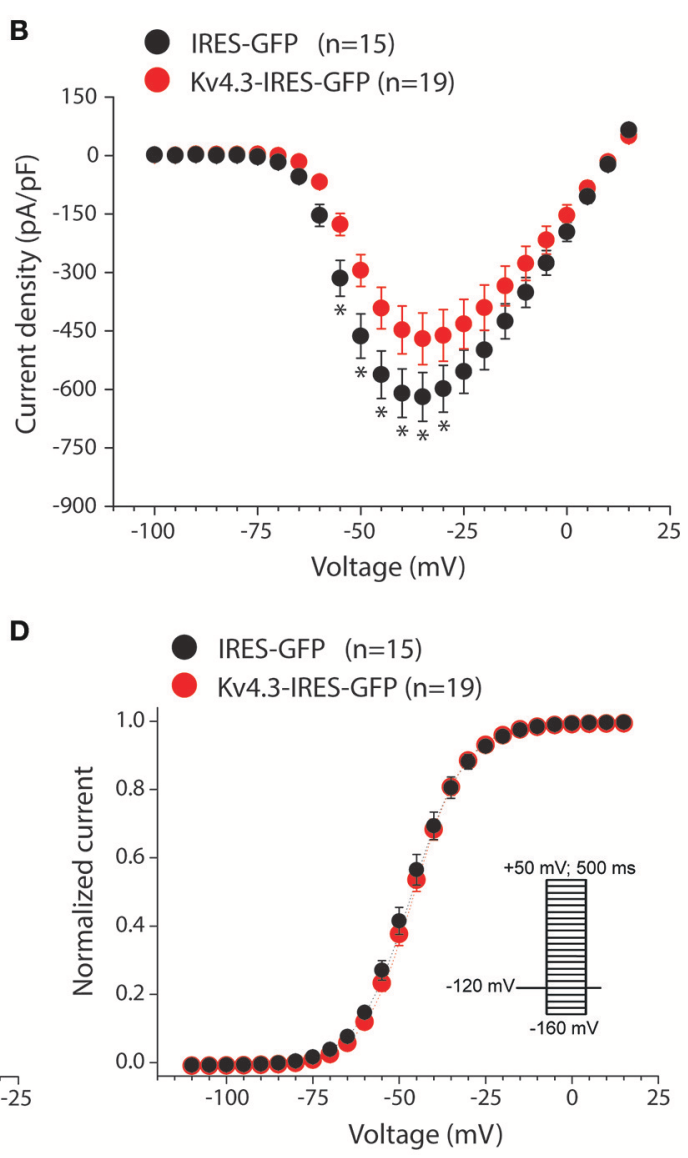

FIGURE 2 | KV 4.3 overexpression reduces Nav1.5 currents. (A) Typical Nav1.5 current traces in response to 500 -ms depolarizing voltage steps from a holding potential of $-120 \mathrm{mV}$ to test potentials ranging from -160 to $50 \mathrm{mV}$ in IRES-GFP (top) and KCND3-IRES-GFP (bottom) transfected HEK293-Nav1.5 cells. Inset: voltage clamp protocol used. (B) Average I-V relationships of the Nav1.5 peak current in IRES-GFP and KCND3-IRES-GFP transfected cells. Asterisks denote $p<$ 0.05. (C,D) Average steady-state inactivation (C) and activation (D) curves. Insets: voltage clamp protocol used. Voltage-dependency of inactivation was measured using a two-pulse protocol where a 500-ms conditioning prepulse to membrane potentials between -160 and $50 \mathrm{mV}$ (to induce steady-state inactivation), was followed by a 50 -ms test pulse to $-20 \mathrm{mV}$. Voltage-dependency of activation was measured using the same protocol described as described in (A).

\section{A}

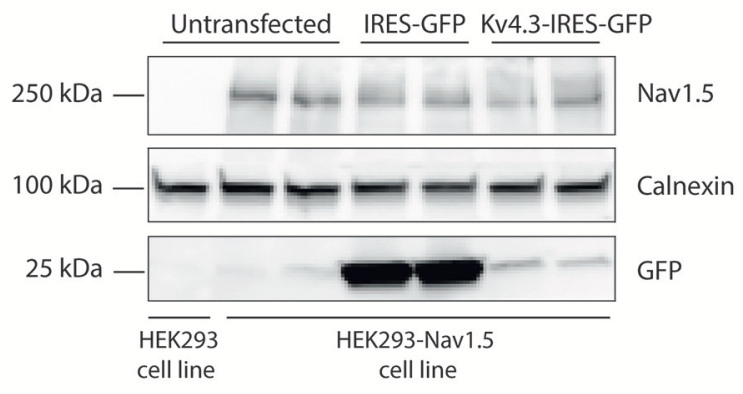

\section{B}

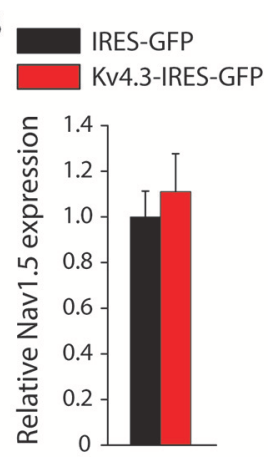

FIGURE 3 | Nav1.5 total expression is not affected by $K_{V} 4.3$ overexpression. (A) Representative Western blots of Nav1.5, calnexin and GFP protein expression in HEK293-Nav1.5 cells. Data from IRES-GFP and KCND3-IRES-GFP transfected cells as well as untransfected cells. Total lysate of HEK293 cells lacking the Nay 1.5 overexpression cassette (leftmost lane) was used as negative control for Nav1.5 antibody specificity. (B) Average total Nav1.5 expression normalized to calnexin protein expression in KCND3-IRES-GFP transfected HEK293-Nav1.5 cells, compared to IRES-GFP transfected HEK293-Nav1.5 cells ( $n=6$, 3 different blots). 


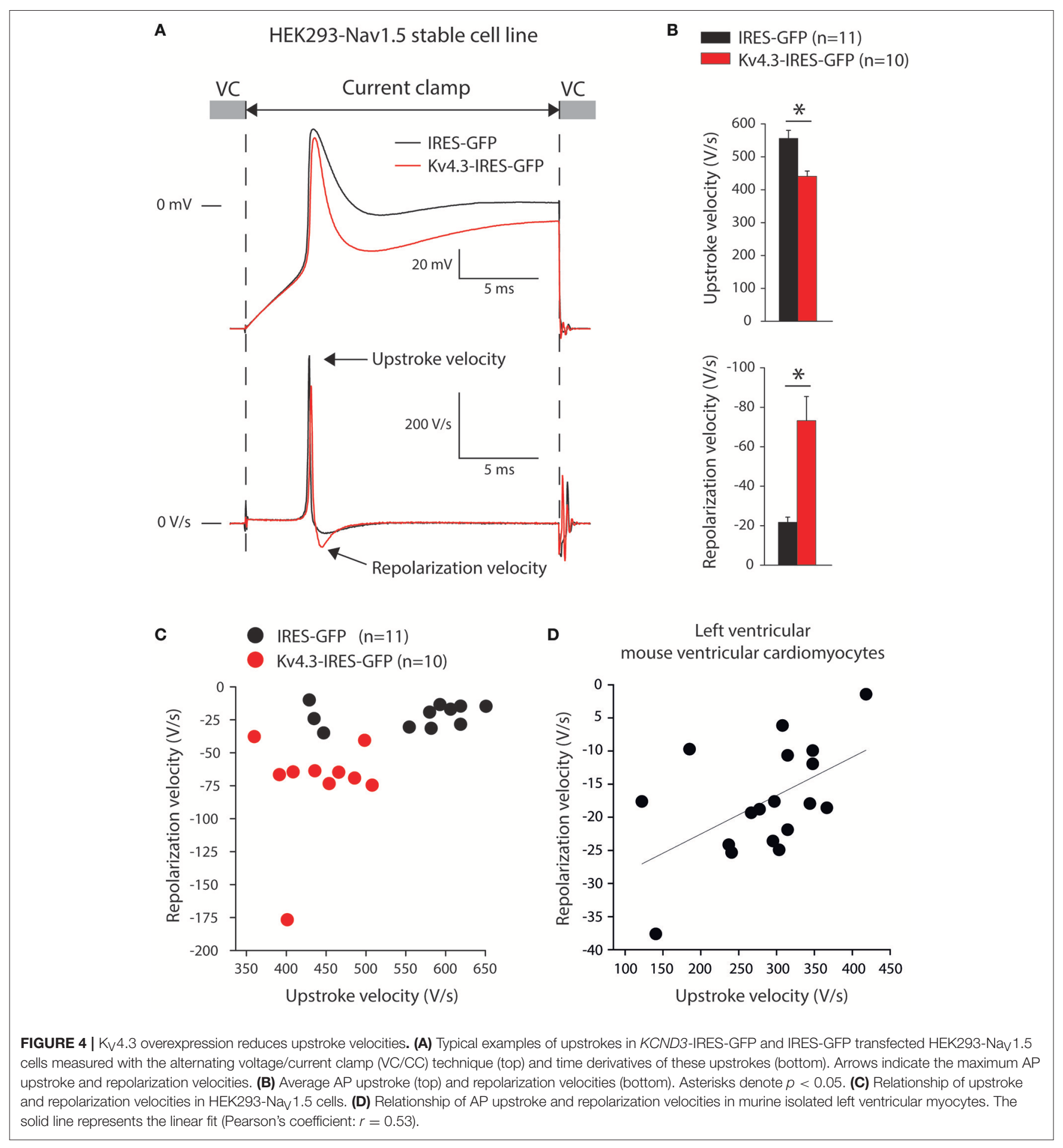

(Figure 4B), resulting in an inverse relationship between the maximum velocities of depolarization and repolarization (Figure 4C). Next, we determined whether a relationship between repolarization and depolarization also exists in cardiomyocytes. Therefore, we re-analyzed data of alternating VC/CC measurements in murine isolated left ventricular myocytes performed for a previous study (Remme et al., 2006).
In mouse ventricular myocytes, the maximum upstroke and repolarization velocities were $285 \pm 19$ and $-18 \pm$ $2 \mathrm{~V} / \mathrm{s} \quad(n=18)$, respectively. In Figure 4D, we plotted for each cell its maximum repolarization velocity vs. its maximum upstroke velocity, demonstrating an inverse relationship, similar to our experiments on HEK293 cells (Figure 4C). 


\section{Computer Simulations}

To assess the functional relevance of the aforementioned findings, we first carried out computer simulations to explore whether the presence of a $\mathrm{K}_{\mathrm{V}} 4.3$-based $\mathrm{I}_{\text {to }}$ per se may affect the maximum upstroke velocity of the HEK293-Nav1.5 cells. To this end, we constructed a model of a HEK293 cell expressing both $\mathrm{I}_{\mathrm{Na}}$ and $\mathrm{I}_{\text {to }}$ channels to further explore the findings of the alternating VC/CC experiment of Figures 4A,B. The $\mathrm{I}_{\mathrm{Na}}$ and $\mathrm{I}_{\text {to }}$ equations were taken from the human ventricular cell model by Ten Tusscher and Panfilov (2006). The characteristics of the simulated $\mathrm{I}_{\mathrm{Na}}$ and $\mathrm{I}_{\text {to }}$ are shown in Figures $5 \mathrm{~A}-\mathbf{D}$ (and also in Figures S2, S3). As illustrated in Figures 5E-G, $\mathrm{I}_{\text {to }}$ is effectively zero at the moment of maximum upstroke velocity, indicating that this maximum upstroke velocity is fully determined by $\mathrm{I}_{\mathrm{Na}}$. Conversely, $\mathrm{I}_{\mathrm{Na}}$ is almost zero at the moment of maximum repolarization velocity. Accordingly, there is no direct contribution of $\mathrm{I}_{\mathrm{Na}}$ to the maximum repolarization velocity, although it must be noted that $\mathrm{I}_{\mathrm{Na}}$ may still affect repolarization velocity through its effect on AP shape. If the voltage-dependency of the $\mathrm{I}_{\text {to }}$ channels is shifted by $-30 \mathrm{mV}$, thus letting them start to activate near $-40 \mathrm{mV}, \mathrm{I}_{\text {to }}$ is still effectively zero at the moment of maximum upstroke velocity (data not shown).

Next, we established to which extent the $\mathrm{K}_{\mathrm{V}} 4.3$-based $\mathrm{I}_{\text {to }}$ and the $\mathrm{Na}_{V} 1.5$-based $\mathrm{I}_{\mathrm{Na}}$ per se modulate the maximum upstroke velocity and repolarization velocity of murine left
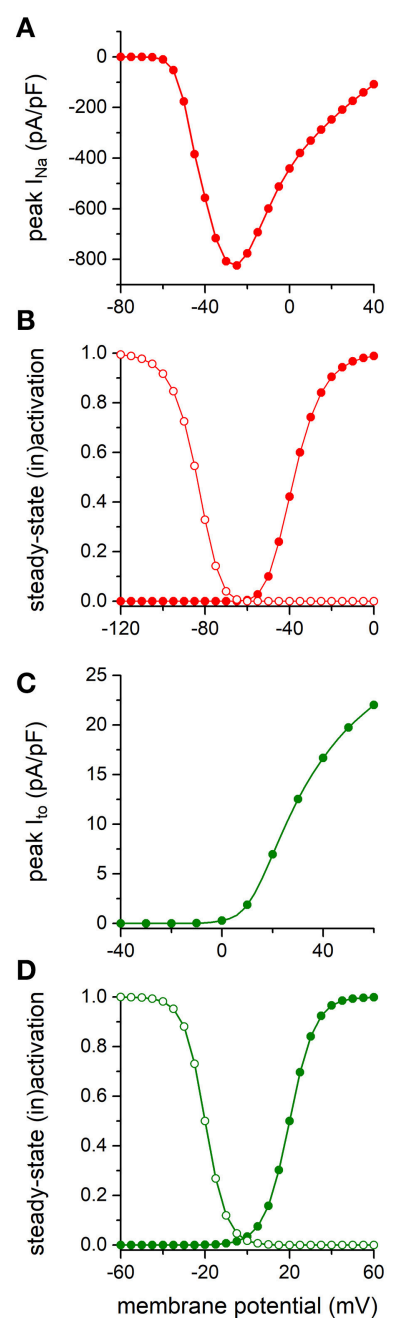
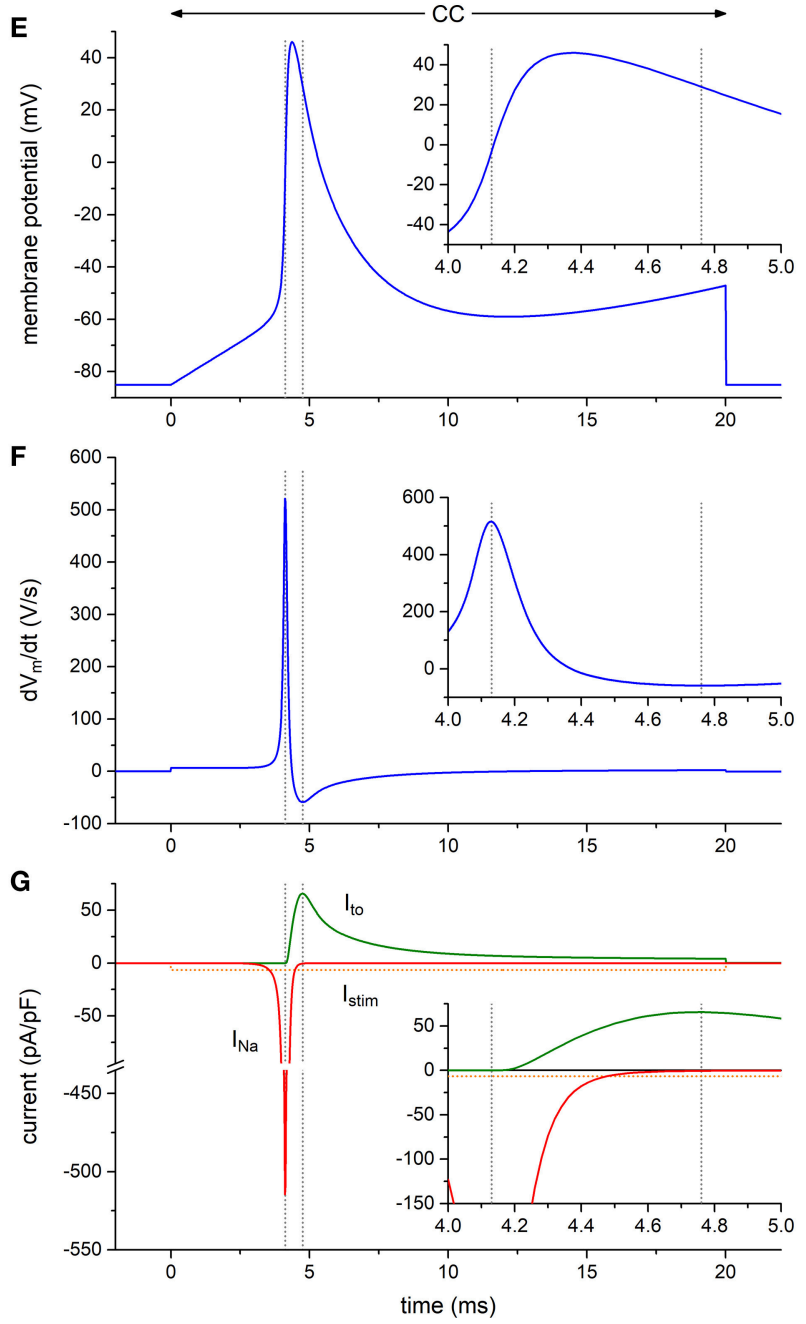

FIGURE 5 | Numerical reconstruction of Nav1.5 and $\mathrm{K}_{\mathrm{V}} 4.3$ currents in alternating VC/CC experiments. (A-D) Characteristics of the simulated hNav1.5 driven fast sodium current $\left(l_{\mathrm{Na}}\right)$ and $\mathrm{hK}_{\mathrm{V}} 4.3$ driven transient outward current $\left(\mathrm{l}_{\mathrm{to}}\right)$. (A) $\mathrm{I}_{\mathrm{Na}}$ peak current as obtained with the voltage clamp protocol of Figure 2. (B) $I_{\mathrm{Na}}$ steady-state activation and inactivation curves (closed and open symbols, respectively) as obtained with the voltage clamp protocol of Figure 2. (C) $I_{\text {to }}$ peak current as obtained with the voltage clamp protocol of Figure 1. (D) $\left.\right|_{\text {to }}$ steady-state activation and inactivation curves (closed and open symbols, respectively). (E-G) Reconstruction of the alternating VC/CC experiment. (E) Membrane potential $\left(V_{m}\right)$ during the 20-ms current clamp (CC) phase. Inset: $V_{m}$ on an expanded time scale. (F) Time derivative of the membrane potential trace of (E). Inset: $\mathrm{dV} / \mathrm{m} / \mathrm{dt}$ on an expanded time scale. (G) Individual time courses of $I_{\mathrm{Na}}$, I $\mathrm{I}_{\mathrm{to}}$, and the 20 - $\mathrm{ms}$ inward stimulus current $\left(\mathrm{I}_{\text {stim }}\right)$. Note the axis break. Inset: $I_{\mathrm{Na}}, I_{\text {to }}$, and $\mathrm{I}_{\text {stim }}$ on an expanded time scale. The vertical dashed lines in (E-G) indicate the time of the maximum upstroke velocity (left lines) and the time of the maximum repolarization velocity (right lines). Alternating VC/CC protocol as in the patch-clamp experiments on HEK293-Nav1.5 cells. 
ventricular myocytes. To this end, we ran computer simulations of the alternating $\mathrm{VC} / \mathrm{CC}$ experiment on mouse ventricular myocytes of Figure 4D using the apical version of the mouse ventricular AP model by Bondarenko et al. (2004), in which we increased or decreased the density of either $\mathrm{I}_{\text {to }}$ or $\mathrm{I}_{\mathrm{Na}}$. The characteristics of $\mathrm{I}_{\mathrm{Na}}$ and $\mathrm{I}_{\text {to }}$ of the Bondarenko et al. (2004) model are shown in Figures 6A-C (and also in Figures S2, S3). As shown in Figure 6D, and as expected from Figure 5, the maximum upstroke velocity is independent of $\mathrm{I}_{\text {to }}$ conductance $\left(G_{\text {to }}\right)$, whereas $G_{\text {to }}$ is an important determinant of repolarization velocity. The maximum repolarization velocity increases almost linearly with $\mathrm{G}_{\text {to }}$ (Figure 6D, open squares), albeit not in a
1:1 fashion-a four times increase in $G_{\text {to }}$ (from 40 to $160 \%$ of its control value) results in a 2.3 times increase in maximum repolarization velocity, which can be explained by accompanying changes in AP shape (and thus in channel activation and inactivation) as well as the presence of other membrane currents. As shown in Figure 6E, the maximum upstroke velocity is strongly dependent on $\mathrm{I}_{\mathrm{Na}}$ conductance $\left(\mathrm{G}_{\mathrm{Na}}\right)$, whereas repolarization velocity is only substantially affected by $G_{\mathrm{Na}}$ at lower values of $\mathrm{G}_{\mathrm{Na}}$. At these lower values, the AP reaches a considerably lower peak (data not shown), which in turn results in less activation of $I_{\text {to }}$ channels as well as a lower driving force for these channels. At control or higher values
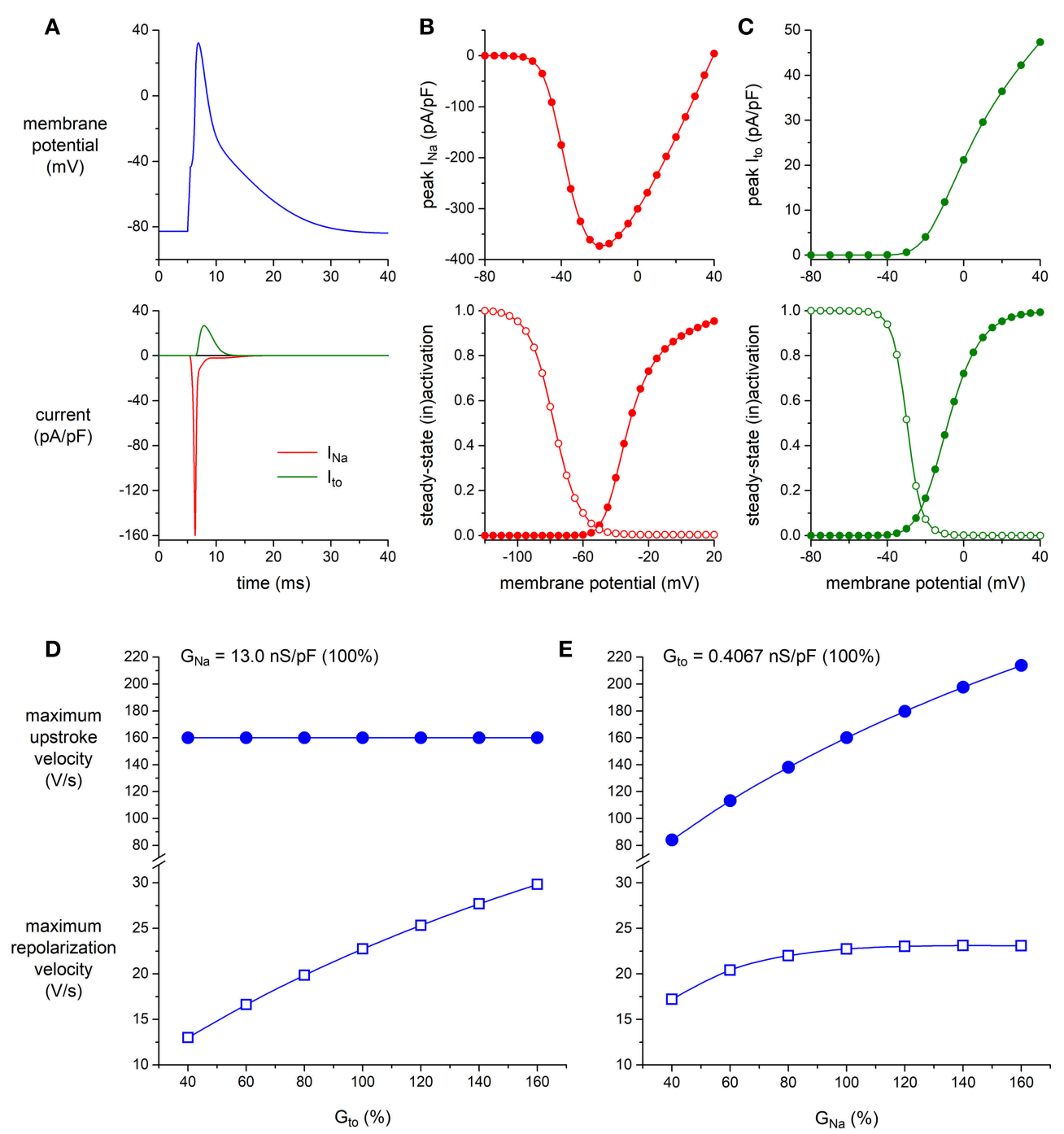

FIGURE 6 | Effect of $I_{\mathrm{Na}}$ and $\mathrm{I}_{\text {to }}$ density on maximum upstroke and repolarization velocity in simulated murine left ventricular myocytes. (A-C) Characteristics of the computer model of apical mouse ventricular myocytes (Bondarenko et al., 2004) used in the simulations. (A) Action potential (top) and associated $I_{N a}$ and $I_{\text {to }}$ (bottom). (B) $I_{\mathrm{Na}}$ peak current (top) and steady-state activation and inactivation curves (bottom; closed and open symbols, respectively), as obtained with the voltage clamp protocol of Figure 2. (C) I to peak current (top) and steady-state activation and inactivation curves (bottom; closed and open symbols, respectively), as obtained with the voltage clamp protocol of Figure 1. (D,E) Maximum upstroke velocity and maximum repolarization velocity as obtained in a reconstruction of the alternating VC/CC experiment. (D) Maximum upstroke velocity (filled symbols) and maximum repolarization velocity (open symbols) as a function of $I_{\text {to }}$ conductance ( $G_{t o}$ ) at a constant value of $I_{\mathrm{Na}}$ conductance $\left(\mathrm{G}_{\mathrm{Na}}\right.$ ). (E) Maximum upstroke velocity and maximum repolarization velocity as a function of $\mathrm{G}_{\mathrm{Na}}$ at a constant value of $\mathrm{G}_{\mathrm{to}}$. Alternating VC/CC protocol as in the patch-clamp experiments on murine left ventricular myocytes. 
of $\mathrm{G}_{\mathrm{Na}}$, repolarization velocity is not notably dependent on $\mathrm{G}_{\mathrm{Na}}$.

Finally, we tested whether a decrease in $\mathrm{G}_{\mathrm{Na}}$ can result in a loss of conduction in the presence of a concomitant increase in $\mathrm{G}_{\text {to }}$. This was studied in a one-dimensional strand of poorly coupled human left ventricular myocytes, as illustrated in Figure 7A. Under control conditions $\left(100 \% \mathrm{G}_{\mathrm{Na}}\right.$ and $100 \%$ $\mathrm{G}_{\mathrm{to}}$ ), the stimulated leftmost cell of the strand was able to drive its neighboring cells (Figure 7B). This was also observed upon a $20 \%$ increase in $\mathrm{G}_{\text {to }}$ or a $50 \%$ decrease in $\mathrm{G}_{\mathrm{Na}}$ (Figures 7 C, D, respectively). The main effect of the decrease in $\mathrm{G}_{\mathrm{Na}}$ was a slowing of conduction (cf. Table 1). However, the introduction of a concomitant $20 \%$ increase in $\mathrm{G}_{\text {to }}$ led to loss of conduction: an action potential was elicited in the first cell of the strand, but this cell was unable to transfer this action potential to its neighboring cells (Figure 7E). Thus, a simultaneous increase in $\mathrm{I}_{\text {to }}$ and decrease in $\mathrm{I}_{\mathrm{Na}}$ in the setting of a compromised cellular coupling, as may occur on a microscopic scale in BrS patients, may result in severe conduction alteration.

\section{DISCUSSION}

In the present study, we report for the first time a direct effect of $\mathrm{K}_{\mathrm{V}} 4.3$ expression on $\mathrm{Na}_{\mathrm{V}} 1.5$ current and consequent sodium channel availability. We found that overexpression of $\mathrm{K}_{\mathrm{V}} 4.3$ protein reduces $\mathrm{Na}_{\mathrm{V}} 1.5$ current density (Figure 2) without affecting total $\mathrm{Na}_{\mathrm{V}} 1.5$ protein expression. Moreover, $\mathrm{K}_{\mathrm{V}} 4.3$ overexpression decreased the upstroke velocity, which was not due to a direct effect of the current generated by $\mathrm{K}_{\mathrm{V}} 4.3$. These findings suggest that the observed effects of $\mathrm{K}_{\mathrm{V}} 4.3$ on $\mathrm{Na}_{\mathrm{V}} 1.5$ are due to a functional interaction between the two channel proteins rather than an electrophysiological interference. The physiological relevance of our findings was demonstrated in a multicellular in silico model where we found that an $\mathrm{I}_{\text {to }}$ increase and concomitant $\mathrm{I}_{\mathrm{Na}}$ decrease is capable of impairing conduction (Figure 7).

\section{Decreased AP Upstroke Velocity Secondary to $\mathrm{K}_{\mathrm{v}} 4.3$ Overexpression}

Using the alternating $\mathrm{VC} / \mathrm{CC}$ technique, we observed in HEK293 cells stably expressing $\mathrm{Na}_{\mathrm{V}} 1.5$ a decrease in upstroke velocity secondary to overexpression of $\mathrm{K}_{\mathrm{V}} 4.3$. Upstroke velocity decreased to a similar extent as $\mathrm{Na}_{\mathrm{V}} 1.5$ sodium current density $(\approx 25 \%)$ in cells overexpressing $\mathrm{K}_{\mathrm{V}} 4.3$ compared to cells overexpressing only GFP. Although the alternating VC/CC technique is not commonly used in cardiac electrophysiology, it allows detailed $\mathrm{I}_{\mathrm{Na}}$ studies in a dynamic fashion under closeto-physiological conditions as occurring during cardiac action potentials (Berecki et al., 2010). Previously it has been used to demonstrate changes in $\mathrm{I}_{\mathrm{Na}}$ during heart failure (Berecki et al., 2010), changes in intracellular $\mathrm{Ca}^{2+}$ concentration (Casini et al., 2009), and in the setting of SCN5A mutations (Remme et al., 2006; Lieve et al., 2017). Using dynamic clamp, we have recently assessed the effect of an $\mathrm{I}_{\text {to }}$-like current on the upstroke velocity in HEK293 cells transiently overexpressing $\mathrm{Na}_{V} 1.5$ channels. That study revealed only a minor influence of $\mathrm{I}_{\text {to }}$, if any, on
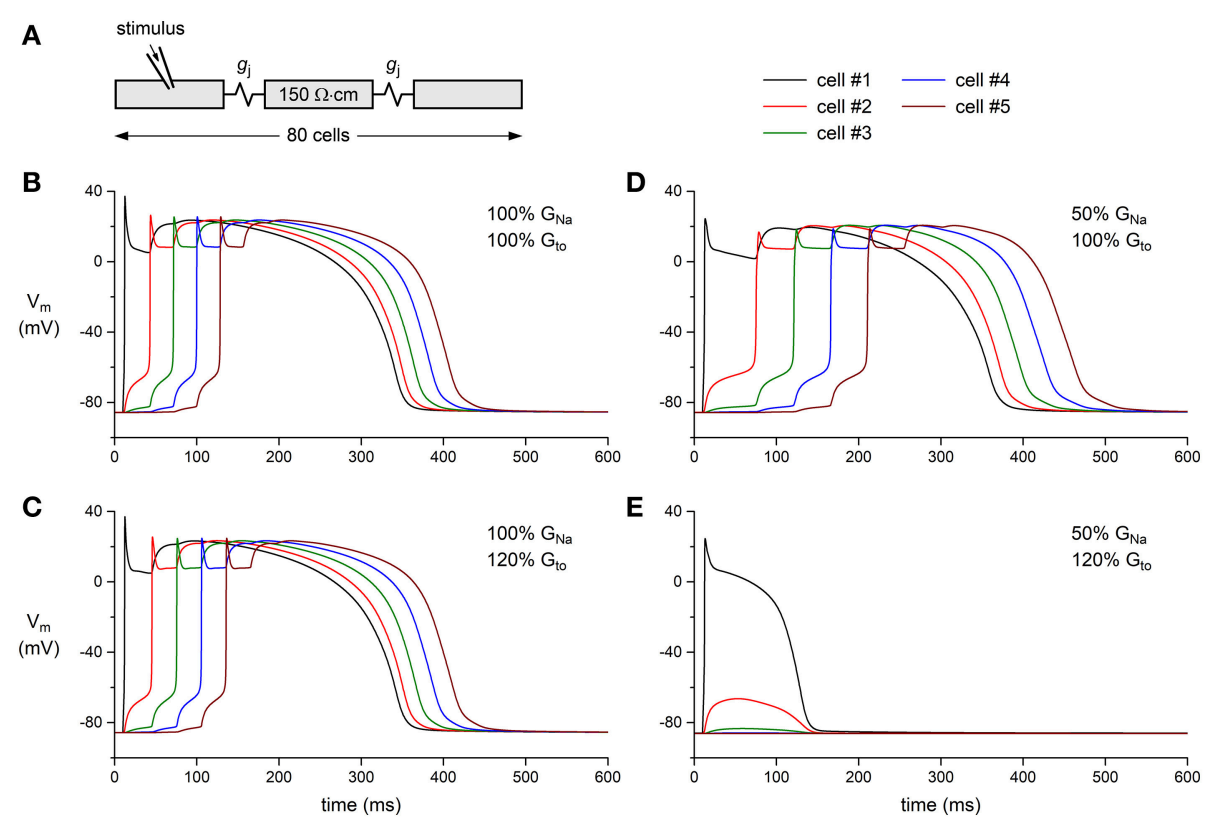

FIGURE 7 | Effect of $\mathrm{I}_{\mathrm{Na}}$ and $\mathrm{I}_{\text {to }}$ density on action potential propagation in a simulated strand of human left ventricular myocytes. (A) Geometry of the strand. The intercellular coupling conductance $\left(\mathrm{g}_{\mathrm{j}}\right)$ was set to $6 \mathrm{nS}$ and the myoplasmic resistivity was set to $150 \Omega \cdot \mathrm{cm}$. (B-E) Action potential propagation in the strand as a function of $I_{\mathrm{Na}}$ conductance $\left(\mathrm{G}_{\mathrm{Na}}\right)$ and $\mathrm{I}_{\text {to }}$ conductance $\left(\mathrm{G}_{\mathrm{to}}\right)$. (B) Control conditions: $\mathrm{G}_{\mathrm{Na}}$ and $\mathrm{G}_{\mathrm{to}}$ both set to $100 \%$ of their control value. (C) Slight slowing of action potential propagation upon an increase in $\mathrm{G}_{\text {to }}$ to $120 \%$ of its control value. (D) Slowing of action potential propagation upon a decrease in $\mathbf{G}_{\mathrm{Na}}$ to $50 \%$ of its control value. (E) Failure of action potential propagation upon a concomitant decrease in $\mathrm{G}_{\mathrm{Na}}$ and increase in $\mathrm{G}_{\mathrm{to}}$. 
TABLE 1 | Action potential parameters and propagation in a strand of human left ventricular myocytes.

\begin{tabular}{lcccc}
\hline Settings & $\begin{array}{c}\text { APA } \\
(\mathbf{m V})\end{array}$ & $\begin{array}{c}\left.\mathbf{( d V}_{\mathbf{m}} / \mathbf{d t}\right)_{\mathbf{m a x}} \\
\mathbf{( V / s})\end{array}$ & $\begin{array}{c}\mathbf{A P D}_{\mathbf{9 0}} \\
\mathbf{( m s )}\end{array}$ & $\begin{array}{c}\mathbf{C V} \\
(\mathbf{c m} / \mathbf{s})\end{array}$ \\
\hline $100 \% \mathrm{G}_{\mathrm{Na}}, 100 \% \mathrm{G}_{\mathrm{to}}$ & 111.3 & 223.5 & 275.6 & 0.260 \\
$100 \% \mathrm{G}_{\mathrm{Na}}, 120 \% \mathrm{G}_{\mathrm{to}}$ & 110.5 & 217.1 & 272.1 & 0.245 \\
$50 \% \mathrm{G}_{\mathrm{Na}}, 100 \% \mathrm{G}_{\text {to }}$ & 104.6 & 79.0 & 248.1 & 0.163 \\
\hline
\end{tabular}

Data obtained from computer simulations with an intercellular coupling conductance of 6 $n S$. APA, action potential amplitude; $\left(d V_{m} / d t\right)_{\text {max }}$, maximum upstroke velocity; $A P D_{90}$, action potential duration at $90 \%$ repolarization; $\mathrm{CV}$, conduction velocity in the strand. Action potential parameters for cells in the middle of the strand.

upstroke velocity (Verkerk et al., 2016). Here, we confirmed these results using computer simulations based on the current densities recorded (Figure 5). The $\mathrm{I}_{\text {to }}$ current is not yet present at the time of the maximum upstroke velocity confirming that $\mathrm{I}_{\text {to }}$ does not affect the upstroke velocity in single cells. Moreover, no correlation between $I_{\text {to }}$ density and AP upstroke velocity was observed during simulations of the electrical activity of cardiomyocytes (Figure 6). Thus, the observed $\mathrm{K}_{\mathrm{V}} 4.3$-induced decrease in upstroke velocity is not a consequence of an increased $\mathrm{K}_{\mathrm{V}} 4.3$ current.

In freshly isolated left ventricular myocytes of mice, we found an inverse relationship between the maximum upstroke velocity and repolarization velocity (Figure 4D). It is tempting to speculate that such a relationship is due to effects of $\mathrm{K}_{\mathrm{V}} 4.3$ expression, but this observation might also be due to different currents or transcription gradient of both Kcnd3 and Scn $5 a$ through the myocardial wall. Nevertheless, it indicates that depolarization and repolarization are not independent factors. Future overexpression or knock-down experiments in myocytes are needed to provide further insight into the potential relevance of our observation.

\section{Modulation of Nav1.5 Current by $\mathrm{K}_{\mathrm{v}} 4.3$ Expression}

We found that $\mathrm{K}_{\mathrm{V}} 4.3$ overexpression resulted in a significantly decreased $\mathrm{Na}_{V} 1.5$ current density, while neither current kinetics nor total $\mathrm{Na}_{V} 1.5$ protein expression were affected. Several studies have previously reported interactions and consequent inter-relationships between sodium and potassium channels, or their associated subunits, leading to electrophysiological modifications of either current (Hu et al., 2012; Milstein et al., 2012; Matamoros et al., 2016; Utrilla et al., 2017). For instance, Kir2.1 and Nav1.5 channels when co-expressed exert a synergic effect on current density due to a distinct trafficking process as compared to when these channels are expressed separately (Utrilla et al., 2017). Concerning the direct interaction of $\mathrm{K}_{\mathrm{V}} 4.3$ and $\mathrm{Na}_{\mathrm{V}} 1.5$, a mutation in the $S C N 1 B$ gene encoding the cardiac sodium channel $\beta 1$ subunit has been found in $\mathrm{BrS}$ and sudden infant death syndrome patients (Hu et al., 2012). This specific SCN1B mutation led to a decreased $\mathrm{I}_{\mathrm{Na}}$ together with an increased $\mathrm{I}_{\text {to }}$, suggesting that $\mathrm{Na}_{\mathrm{v}} 1.5$ may physically interact with $\mathrm{K}_{\mathrm{V}} 4.3$ via $\beta 1$ to form a macromolecular complex. In neurons, both sodium and potassium channels mainly localize at the axon initial segment (AIS), a subcellular region involved in AP genesis. Ion channel recruitment to the AIS is highly dependent on the cytoskeleton and associated proteins which densely populate this region (Brachet et al., 2010; Leterrier et al., 2011; Vacher et al., 2011). A comparable structure is observed at the intercalated discs in adult cardiomyocytes, a subcellular region also characterized by a high density of sodium channels (AgulloPascual et al., 2014; Marsman et al., 2014; El Refaey et al., 2017). Our findings, together with existing knowledge, may suggest a potential subcellular co-localization of $\mathrm{K}_{\mathrm{V}} 4.3$ and $\mathrm{Na}_{\mathrm{V}} 1.5$ in cardiomyocytes and a possible explanation for the co-regulation of channel function. Further studies should aim at unraveling the molecular mechanism involved in our observation. A recent work also highlighted the synergic impact of $\mathrm{K}_{\mathrm{V}} 4.3$ expression on hERG channels in HEK293 cells (Zhao et al., 2017). This study together with our findings strongly suggest that the overexpression or knock-down of $\mathrm{K}_{\mathrm{V}} 4.3$ in cardiomyocytes may lead to a complex modulation of ion channels initially seen as unrelated including $\mathrm{Na}_{V} 1.5, \mathrm{hERG}$, and Kir2.1 channels.

\section{Potential (Patho)Physiological Implications}

Our computer simulations show that a concomitant increase in $\mathrm{I}_{\text {to }}$ and decrease in $\mathrm{I}_{\mathrm{Na}}$ are capable of significantly affecting cardiac conduction. Our current observations may thus be particularly relevant in the phenotypical explanation of $\mathrm{BrS}$ patients presenting with mutations in the KCND3 gene or in genes encoding $\mathrm{K}_{\mathrm{V}} 4.3$ associated subunits leading to gain-offunction through an increased protein stability or membrane trafficking of $\mathrm{K}_{\mathrm{V}} 4.3$ channels. In this context, an increased $\mathrm{I}_{\text {to }}$ current could be associated with a simultaneous decrease in $\mathrm{I}_{\mathrm{Na}}$ and consequent conduction slowing (Kucera et al., 2017). Such an effect is likely even more prominent within the subepicardium, a region with relatively low $\mathrm{I}_{\mathrm{Na}}$ and high $\mathrm{I}_{\text {to }}$. This may be of particular relevance in the right ventricular subepicardium and right ventricular outflow tract, where fractionated signals indicative of slowed conduction are often observed in BrS patients (Nademanee et al., 2011). Importantly, concomitant cardiac structural abnormalities, for example age-dependent development of fibrosis (Coronel et al., 2005), may further compromise conduction and hence unmask the impact of increased $\mathrm{I}_{\text {to }}$ (Hoogendijk et al., 2010a). Moreover, one may speculate that the known gender differences in $\mathrm{I}_{\text {to }}$ magnitude may also contribute to the male preponderance for $\mathrm{BrS}$ via an indirect effect on $\mathrm{I}_{\mathrm{Na}}$ (Di Diego et al., 2002).

\section{Limitations}

While we clearly demonstrated that $\mathrm{K}_{\mathrm{V}} 4.3$ is capable of decreasing $\mathrm{Na}_{V} 1.5$ current density, extrapolation to physiological cardiomyocyte conditions must be done with some caution. The upstroke velocities measured in our experiments are in the same range of values as recorded in cardiomyocytes (Berecki et al., 2010; Veerman et al., 2017). However, KCND3 overexpression resulted in $\mathrm{K}_{\mathrm{V}} 4.3$ currents larger than the $\mathrm{I}_{\text {to }}$ previously reported in various animal species and human ventricular cardiomyocytes (Niwa and Nerbonne, 2010). 
Consequently, the $\mathrm{K}_{V} 4.3$-induced $\approx 25 \%$ reduction of $\mathrm{Na}_{V} 1.5$ current density and upstroke velocity reported in this study is likely smaller in animal species and human. Moreover, our experiments in HEK293 cells were performed without $\beta$ subunits of either $\mathrm{Na}_{\mathrm{V}} 1.5$ or $\mathrm{K}_{\mathrm{V}} 4.3$. We therefore cannot exclude a supplementary complexity of Nav 1.5 macromolecular complexes in cardiomyocytes. Nevertheless, our myocyte data at least demonstrate that depolarization is not independent of repolarization.

\section{CONCLUSION}

Overall, this study gives the first proof of concept that the $\mathrm{K}_{\mathrm{V}} 4.3$ protein directly impacts on $\mathrm{Na}_{\mathrm{V}} 1.5$ current. Future studies employing appropriate disease models should explore the potential electrophysiological implications in (patho)physiological conditions, including BrS associated with gain-of-function mutations in KCND3.

\section{AUTHOR CONTRIBUTIONS}

Experimental design: VP, RW, FC, AV, and CR; Data acquisition: VP, RW, and AV; Analysis and interpretation of data: VP, RW, SC, AV, and CR; Drafting manuscript: VP, RW, AV, and CR;

\section{REFERENCES}

Agullo-Pascual, E., Lin, X., Leo-Macias, A., Zhang, M., Liang, F.-X., Li, Z., et al. (2014). Super-resolution imaging reveals that loss of the C-terminus of connexin43 limits microtubule plus-end capture and $\mathrm{Na}_{\mathrm{V}} 1.5$ localization at the intercalated disc. Cardiovasc. Res. 104, 371-381. doi: 10.1093/cvr/ crul 195

Balse, E., and Boycott, H. E. (2017). Ion channel trafficking: control of ion channel density as a target for arrhythmias? Front. Physiol. 8:808. doi: 10.3389/fphys.2017.00808

Barry, P. H., and Lynch, J. W. (1991). Liquid junction potentials and small cell effects in patch-clamp analysis. J. Membr. Biol. 121, 101-117. doi: 10.1007/BF01870526

Benson, D. W., Wang, D. W., Dyment, M., Knilans, T. K., Fish, F. A., Strieper, M. J., et al. (2003). Congenital sick sinus syndrome caused by recessive mutations in the cardiac sodium channel gene (SCN5A). J. Clin. Invest. 112, 1019-1028. doi: 10.1172/JCI18062

Berecki, G., Wilders, R., de Jonge, B., van Ginneken, A. C. G., and Verkerk, A. O. (2010). Re-evaluation of the action potential upstroke velocity as a measure of the $\mathrm{Na}^{+}$current in cardiac myocytes at physiological conditions. PLoS ONE 5:e15772. doi: 10.1371/journal.pone.0015772

Bondarenko, V. E., Szigeti, G. P., Bett, G. C. L., Kim, S.-J., and Rasmusson, R. L. (2004). Computer model of action potential of mouse ventricular myocytes. Am. J. Physiol. Heart Circ. Physiol. 287, H1378-H1403. doi: 10.1152/ajpheart.00185.2003

Brachet, A., Leterrier, C., Irondelle, M., Fache, M.-P., Racine, V., Sibarita, J.-B., et al. (2010). Ankyrin G restricts ion channel diffusion at the axonal initial segment before the establishment of the diffusion barrier. J. Cell. Biol. 191, 383-395. doi: $10.1083 /$ jcb. 201003042

Casini, S., Verkerk, A. O., van Borren, M. M. G. J., van Ginneken, A. C. G., Veldkamp, M. W., de Bakker, J. M. T., et al. (2009). Intracellular calcium modulation of voltage-gated sodium channels in ventricular myocytes. Cardiovasc. Res. 81, 72-81. doi: 10.1093/cvr/cvn274

Chen, Q., Kirsch, G. E., Zhang, D., Brugada, R., Brugada, J., Brugada, P., et al. (1998). Genetic basis and molecular mechanism for idiopathic ventricular fibrillation. Nature 392, 293-296. doi: 10.1038/32675
Editing manuscript, and approval: VP, RW, SC, FC, AV, and CR; Funding: CR.

\section{FUNDING}

This study was supported by an Innovational Research Incentives Scheme Vidi grant from ZonMw (grant no. 91714371 to CR).

\section{ACKNOWLEDGMENTS}

We thank Drs. Hugues Abriel and Jean-Sebastien Rougier (Institute of Biochemistry and Molecular Medicine, Bern, Switzerland) for kindly providing the HEK293-Nav 1.5 cell line, Dr. Ruben Coronel (Academic Medical Center, Amsterdam, The Netherlands) for inspiring discussions, and Jan G. Zegers and Dr. Antoni C.G van Ginneken (Academic Medical Center, Amsterdam, The Netherlands) for developing and providing technical assistance with the soft- and hardware.

\section{SUPPLEMENTARY MATERIAL}

The Supplementary Material for this article can be found online at: https://www.frontiersin.org/articles/10.3389/fphys. 2018.00178/full\#supplementary-material

Coronel, R., Casini, S., Koopmann, T. T., Wilms-Schopman, F. J. G., Verkerk, A. O., de Groot, J. R., et al. (2005). Right ventricular fibrosis and conduction delay in a patient with clinical signs of Brugada syndrome: a combined electrophysiological, genetic, histopathologic, and computational study. Circulation 112, 2769-2777. doi: 10.1161/CIRCULATIONAHA.105.532614

Crotti, L., Marcou, C. A., Tester, D. J., Castelletti, S., Giudicessi, J. R., Torchio, M., et al. (2012). Spectrum and prevalence of mutations involving BrS1- through BrS12-susceptibility genes in a cohort of unrelated patients referred for Brugada syndrome genetic testing: implications for genetic testing. J. Am. Coll. Cardiol. 60, 1410-1418. doi: 10.1016/j.jacc.2012.04.037

Cuellar, A. A., Lloyd, C. M., Nielsen, P. F., Bullivant, D. P., Nickerson, D. P., and Hunter, P. J. (2003). An overview of CellML 1.1, a biological model description language. Simulation 79, 740-747. doi: 10.1177/0037549703040939

Delpón, E., Cordeiro, J. M., Núñez, L., Thomsen, P. E. B., Guerchicoff, A., Pollevick, G. D., et al. (2008). Functional effects of KCNE3 mutation and its role in the development of Brugada syndrome. Circ. Arrhythm. Electrophysiol. 1, 209-218. doi: 10.1161/CIRCEP.107.748103

Di Diego, J. M., Cordeiro, J. M., Goodrow, R. J., Fish, J. M., Zygmunt, A. C., Pérez, G. J., et al. (2002). Ionic and cellular basis for the predominance of the Brugada syndrome phenotype in males. Circulation 106, 2004-2011. doi: 10.1161/01.CIR.0000032002.22105.7A

El Refaey, M. M., and Mohler, P. J. (2017). Ankyrins and spectrins in cardiovascular biology and disease. Front. Physiol. 8:852. doi: 10.3389/fphys.2017.00852

Garny, A., Kohl, P., and Noble, D. (2003). Cellular open resource (COR): a public CellML based environment for modelling biological function. Int. J. Bifurcat. Chaos 13, 3579-3590. doi: 10.1142/S021812740300882X

Gellens, M. E., George, A. L., Chen, L. Q., Chahine, M., Horn, R., Barchi, R. L., et al. (1992). Primary structure and functional expression of the human cardiac tetrodotoxin-insensitive voltage-dependent sodium channel. Proc. Natl. Acad. Sci. U.S.A. 89, 554-558. doi: 10.1073/pnas.89.2.554

Giles, W. R., and van Ginneken, A. C. G. (1985). A transient outward current in isolated cells from the crista terminalis of rabbit heart. J. Physiol. 368, 243-264. doi: 10.1113/jphysiol.1985.sp015856

Hoogendijk, M. G., Opthof, T., Postema, P. G., Wilde, A. A. M., de Bakker, J. M. T., and Coronel, R. (2010a). The Brugada ECG pattern: a marker of channelopathy, structural heart disease, or neither? Toward a unifying 
mechanism of the Brugada syndrome. Circ. Arrhythm. Electrophysiol. 3, 283-290. doi: 10.1161/CIRCEP.110.937029

Hoogendijk, M. G., Potse, M., Linnenbank, A. C., Verkerk, A. O., den Ruijter, H. M., van Amersfoorth, S. C. M., et al. (2010b). Mechanism of right precordial ST-segment elevation in structural heart disease: excitation failure by currentto-load mismatch. Heart Rhythm 7, 238-248. doi: 10.1016/j.hrthm.2009.10.007

Hu, D., Barajas-Martínez, H., Medeiros-Domingo, A., Crotti, L., Veltmann, C., Schimpf, R., et al. (2012). A novel rare variant in $S C N 1 B b$ linked to Brugada syndrome and SIDS by combined modulation of Nav 1.5 and $\mathrm{K}_{\mathrm{V}} 4.3$ channel currents. Heart Rhythm 9, 760-769. doi: 10.1016/j.hrthm.2011.12.006

Kucera, J. P., Rohr, S., and Kleber, A. G. (2017). Microstructure, cell-tocell coupling, and ion currents as determinants of electrical propagation and arrhythmogenesis. Circ. Arrhythm. Electrophysiol. 10:e004665. doi: 10.1161/CIRCEP.117.004665

Le Scouarnec, S., Karakachoff, M., Gourraud, J.-B., Lindenbaum, P., Bonnaud, S., Portero, V., et al. (2015). Testing the burden of rare variation in arrhythmiasusceptibility genes provides new insights into molecular diagnosis for Brugada syndrome. Hum. Mol. Genet. 24, 2757-2763. doi: 10.1093/hmg/ddv036

Leterrier, C., Vacher, H., Fache, M.-P., d'Ortoli, S. A., Castets, F., Autillo-Touati, A., et al. (2011). End-binding proteins EB3 and EB1 link microtubules to ankyrin $\mathrm{G}$ in the axon initial segment. Proc. Natl. Acad. Sci. U.S.A. 108, 8826-8831. doi: 10.1073/pnas.1018671108

Lieve, K. V., Verkerk, A. O., Podliesna, S., van der Werf, C., Tanck, M. W., Hofman, N., et al. (2017). Gain-of-function mutation in SCN5A causes ventricular arrhythmias and early onset atrial fibrillation. Int. J. Cardiol. 236, 187-193. doi: 10.1016/j.ijcard.2017.01.113

Liu, J., Kim, K.-H., Morales, M. J., Heximer, S. P., Hui, C.-C., and Backx, P. H. (2015). Kv4.3-encoded fast transient outward current is presented in Kv4.2 knockout mouse cardiomyocytes. PLoS ONE 10:e133274. doi: 10.1371/journal.pone.0133274

Marsman, R. F. J., Bezzina, C. R., Freiberg, F., Verkerk, A. O., Adriaens, M. E., Podliesna, S., et al. (2014). Coxsackie and adenovirus receptor is a modifier of cardiac conduction and arrhythmia vulnerability in the setting of myocardial ischemia. J. Am. Coll. Cardiol. 63, 549-559. doi: 10.1016/j.jacc.2013.10.062

Matamoros, M., Pérez-Hernández, M., Guerrero-Serna, G., Amorós, I., Barana, A., Núñez, M., et al. (2016). Nav1.5 N-terminal domain binding to $\alpha 1$-syntrophin increases membrane density of human Kir2.1, Kir2.2 and Nav1.5 channels. Cardiovasc. Res. 110, 279-290. doi: 10.1093/cvr/cvw009

Milstein, M. L., Musa, H., Balbuena, D. P., Anumonwo, J. M. B., Auerbach, D. S., Furspan, P. B., et al. (2012). Dynamic reciprocity of sodium and potassium channel expression in a macromolecular complex controls cardiac excitability and arrhythmia. Proc. Natl. Acad. Sci. U.S.A. 109, E2134-E2143. doi: 10.1073/pnas.1109370109

Nademanee, K., Veerakul, G., Chandanamattha, P., Chaothawee, L., Ariyachaipanich, A., Jirasirirojanakorn, K., et al. (2011). Prevention of ventricular fibrillation episodes in Brugada syndrome by catheter ablation over the anterior right ventricular outflow tract epicardium. Circulation 123, 1270-1279. doi: 10.1161/CIRCULATIONAHA.110.972612

Niwa, N., and Nerbonne, J. M. (2010). Molecular determinants of cardiac transient outward potassium current $\left(\mathrm{I}_{\mathrm{to}}\right)$ expression and regulation. J. Mol. Cell. Cardiol. 48, 12-25. doi: 10.1016/j.yjmcc.2009.07.013

Niwa, N., Wang, W., Sha, Q., Marionneau, C., and Nerbonne, J. M. (2008). Kv4.3 is not required for the generation of functional $\mathrm{I}_{\mathrm{to}, \mathrm{f}}$ channels in adult mouse ventricles. J. Mol. Cell. Cardiol. 44, 95-104. doi: 10.1016/j.yjmcc.2007.10.007

Portero, V., Le Scouarnec, S., Es-Salah-Lamoureux, Z., Burel, S., Gourraud, J.-B., Bonnaud, S., et al. (2016). Dysfunction of the voltage-gated $\mathrm{K}^{+}$channel $\beta 2$ subunit in a familial case of Brugada syndrome. J. Am. Heart. Assoc. 5:e003122. doi: 10.1161/JAHA.115.003122

Remme, C. A., Verkerk, A. O., Nuyens, D., van Ginneken, A. C. G., van Brunschot, S., Belterman, C. N. W., et al. (2006). Overlap syndrome of cardiac sodium channel disease in mice carrying the equivalent mutation of human SCN5A-1795insD. Circulation 114, 2584-2594. doi: 10.1161/CIRCULATIONAHA.106.653949
Rush, S., and Larsen, H. (1978). A practical algorithm for solving dynamic membrane equations. IEEE Trans. Biomed. Eng. 25, 389-392. doi: 10.1109/TBME.1978.326270

Schott, J. J., Alshinawi, C., Kyndt, F., Probst, V., Hoorntje, T. M., Hulsbeek, M., et al. (1999). Cardiac conduction defects associate with mutations in SCN5A. Nat. Genet. 23, 20-21. doi: 10.1038/12618

Shaw, R. M., and Rudy, Y. (1997). Ionic mechanisms of propagation in cardiac tissue: roles of the sodium and L-type calcium currents during reduced excitability and decreased gap junction coupling. Circ. Res. 81, 727-741. doi: 10.1161/01.RES.81.5.727

Ten Tusscher, K. H. W. J., and Panfilov, A. V. (2006). Cell model for efficient simulation of wave propagation in human ventricular tissue under normal and pathological conditions. Phys. Med. Biol. 51, 6141-6156. doi: 10.1088/0031-9155/51/23/014

Thomas, S. P., Kucera, J. P., Bircher-Lehmann, L., Rudy, Y., Saffitz, J. E., and Kléber, A. G. (2003). Impulse propagation in synthetic strands of neonatal cardiac myocytes with genetically reduced levels of connexin43. Circ. Res. 92, 1209-1216. doi: 10.1161/01.RES.0000074916.41221.EA

Utrilla, R. G., Nieto-Marín, P., Alfayate, S., Tinaquero, D., Matamoros, M., Pérez-Hernández, M., et al. (2017). Kir2.1-Nav1.5 channel complexes are differently regulated than Kir2.1 and Nav1.5 channels alone. Front. Physiol. 8:903. doi: 10.3389/fphys.2017.00903

Vacher, H., Yang, J.-W., Cerda, O., Autillo-Touati, A., Dargent, B., and Trimmer, J. S. (2011). Cdk-mediated phosphorylation of the Kv $\beta 2$ auxiliary subunit regulates Kv1 channel axonal targeting. J. Cell. Biol. 192, 813-824. doi: $10.1083 /$ jcb. 201007113

van Bemmelen, M. X., van, Rougier, J.-S., Gavillet, B., Apothéloz, F., Daidié, D., Tateyama, M., et al. (2004). Cardiac voltage-gated sodium channel Nav 1.5 is regulated by Nedd4-2 mediated ubiquitination. Circ. Res. 95, 284-291. doi: 10.1161/01.RES.0000136816.05109.89

Veerman, C. C., Podliesna, S., Tadros, R., Lodder, E. M., Mengarelli, I., de Jonge, B., et al. (2017). The Brugada syndrome susceptibility gene HEY2 modulates cardiac transmural ion channel patterning and electrical heterogeneity. Circ. Res. 121, 537-548. doi: 10.1161/CIRCRESAHA.117.310959

Verkerk, A. O., Veerman, C. C., Zegers, J. G., and Wilders, R. (2016). Effects of the transient outward potassium current on action potential upstroke velocities tested using the dynamic clamp technique. Comput. Cardiol. 43, 257-260. doi: 10.22489/CinC.2016.076-143

Wilde, A. A. M., Postema, P. G., Di Diego, J. M., Viskin, S., Morita, H., Fish, J. M., et al. (2010). The pathophysiological mechanism underlying Brugada syndrome: depolarization versus repolarization. J. Mol. Cell. Cardiol. 49, 543-553. doi: 10.1016/j.yjmcc.2010.07.012

Wilders, R. (2012). Arrhythmogenic right ventricular cardiomyopathy: considerations from in silico experiments. Front. Physiol. 3:168. doi: $10.3389 /$ fphys.2012.00168

You, T., Mao, W., Cai, B., Li, F., and Xu, H. (2015). Two novel Brugada syndromeassociated mutations increase $\mathrm{K}_{\mathrm{V}} 4.3$ membrane expression and function. Int. J. Mol. Med. 36, 309-315. doi: 10.3892/ijmm.2015.2223

Zhao, X.-J., Zhu, C., Tian, L.-Y., Fu, Y.-C., Zhang, Y., Chen, X., et al. (2017). Kv4.3 modulates the distribution of hERG. Sci. Rep. 7:17757. doi: 10.1038/s41598-017-17837-6

Conflict of Interest Statement: The authors declare that the research was conducted in the absence of any commercial or financial relationships that could be construed as a potential conflict of interest.

Copyright (c) 2018 Portero, Wilders, Casini, Charpentier, Verkerk and Remme. This is an open-access article distributed under the terms of the Creative Commons Attribution License (CC BY). The use, distribution or reproduction in other forums is permitted, provided the original author(s) and the copyright owner are credited and that the original publication in this journal is cited, in accordance with accepted academic practice. No use, distribution or reproduction is permitted which does not comply with these terms. 


\section{OPEN ACCESS}

Edited by:

Bas Boukens,

University of Amsterdam, Netherlands

Reviewed by:

Davor Pavlovic,

University of Birmingham,

United Kingdom

David R. Van Wagoner,

Cleveland Clinic Lerner College of

Medicine, United States

*Correspondence:

Hugues Abrie

hugues.abrie/@ibmm.unibe.ch

Specialty section:

This article was submitted to

Cardiac Electrophysiology,

a section of the journal

Frontiers in Physiology

Received: 29 November 2017

Accepted: 20 February 2018

Published: 08 March 2018

Citation:

Bianchi B, Ozhathil LC,

Medeiros-Domingo A, Gollob MH and Abriel H (2018) Four TRPM4 Cation Channel Mutations Found in Cardiac Conduction Diseases Lead to Altered Protein Stability. Front. Physiol. 9:177. doi: 10.3389/fphys.2018.00177
Four TRPM4 Cation Channel Mutations Found in Cardiac Conduction Diseases Lead to Altered Protein Stability

\author{
Beatrice Bianchi ${ }^{1}$, Lijo Cherian Ozhathil ${ }^{1}$, Argelia Medeiros-Domingo ${ }^{2}$, Michael H. Gollob ${ }^{3}$ \\ and Hugues Abriel ${ }^{\text {* }}$
}

${ }^{1}$ Swiss National Centre of Competence in Research (NCCR) TransCure, Institute of Biochemistry and Molecular Medicine, University of Bern, Bern, Switzerland, ${ }^{2}$ Department of Cardiology, Inselspital, University Hospital Bern, Bern, Switzerland,

${ }^{3}$ Department of Medicine, Peter Munk Cardiac Centre, Toronto General Hospital, University of Toronto, Toronto, ON, Canada

Transient receptor potential melastatin member 4 (TRPM4), a non-selective cation channel, mediates cell membrane depolarization in immune response, insulin secretion, neurological disorders, and cancer. Pathological variants in TRPM4 gene have been linked to several cardiac phenotypes such as complete heart block $(\mathrm{CHB})$, ventricular tachycardia, and Brugada syndrome (BrS). Despite recent findings regarding the functional implications of TRPM4 in cardiac diseases, the molecular and cellular mechanisms leading to altered conduction are poorly understood. In the present study, we identify and characterize four novel TRPM4 variants found in patients with CHB or ventricular fibrillation. Three of them, p.A101T, p.S1044C and a double variant p.A101T/P1204L, led to a decreased expression and function of the channel. On the contrary, the variant p.Q854R showed an increase in TRPM4 current. Recent evidence indicates that altered degradation rate of mutant proteins represents a pathogenic mechanism underlying genetic diseases. In consequence, protein turnover of WT-TRPM4 and TRPM4 variants overexpressed in HEK293 cells was analyzed using cycloheximide, an inhibitor of protein biosynthesis. Upon addition of cycloheximide, WT-TRPM4 decayed with a half-life of $\sim 20 \mathrm{~h}$, while loss-of-expression variants showed a $\sim 30 \%$ increase in degradation rate, with a half-life close to $12 \mathrm{~h}$. Together, the gain-of-expression variant showed a higher stability and a doubled half-life compared to WT-TRPM4. In conclusion, decreased or increased protein expression of several TRPM4 variants linked to cardiac conduction disorders or ventricular arrhythmias were found to be caused by altered TRPM4 half-life compared to the WT form.

Keywords: TRPM4, protein trafficking, cycloheximide, cardiac disorders, protein stability, ion channels, mutations

\section{INTRODUCTION}

The transient receptor potential melastatin 4 (TRPM4) protein is an intracellular $\mathrm{Ca}^{2+}$. activated non-selective cation channel, which is impermeable to $\mathrm{Ca}^{2+}$. TRPM4 exhibits a voltage dependence, which has not been previously described for any TRP channel, indicating that TRPM4 is both a Ca ${ }^{2+}$-activated and voltage-modulated cation channel (Nilius et al., 2005). At negative membrane potentials, TRPM4 allows $\mathrm{Na}^{+}$entry into the cell, leading to cellular membrane 
depolarization. At positive membrane potentials, TRPM4 channels permit cellular $\mathrm{K}^{+}$efflux, leading to membrane repolarization (Launay et al., 2002; Ramsey et al., 2006). TRPM4 is widely expressed in several tissues and is involved in a variety of physiological processes, including modulation of immune cells activity, such as T-cells (Launay et al., 2004), mast cells (Shimizu et al., 2009) and dendritic cells (Barbet et al., 2010), insulin secretion by pancreatic $\beta$ cells (Cheng et al., 2007), mechanotransduction in cerebral arteries (Vennekens and Nilius, 2007), and $\mathrm{Ca}^{2+}$ signaling in cancer (Sozucan et al., 2015; Ceylan et al., 2016; Sagredo et al., 2017). In addition, TRPM4 has been linked to several neurological disorders such as experimental autoimmune encephalomyelitis and multiple sclerosis (Schattling et al., 2012), spinal cord injuries (Gerzanich et al., 2009), and traumatic brain injuries (Simard et al., 2010). TRPM4 was reported to participate in electrical perturbations following cardiac ischemia and reperfusion episodes because of its sensitivity to $\mathrm{Ca}^{2+}$ and ATP (Kalogeris et al., 2012). It has been shown that in a model of hypoxia-reoxygenation using isolated mouse interventricular septum, TRPM4 inhibitors 9-phenantrol and flufenamic acid reduced $\left[\mathrm{Ca}^{2+}\right]_{i}$ overload, thus reducing the so called early afterdepolarization (EAD) (Simard et al., 2012). However, the physiological role for this channel in cardiac function remains unclear. Recent studies have linked genetic variants of TRPM4 gene to progressive familial heart block type 1 (PFHB1) (Kruse et al., 2009; Daumy et al., 2016), isolated cardiac conduction disease (ICCD) (Liu et al., 2010), atrio-ventricular block (AVB) (Stallmeyer et al., 2012; Syam et al., 2016), right bundle branch block (RBBB) (Stallmeyer et al., 2012) and Brugada syndrome (BrS) (Liu et al., 2013; Gualandi et al., 2017). Several TRPM4 variants linked to inherited cardiac diseases were shown to cause either gain- or loss-of-function of the channel activity. However, the molecular details of these alterations, and how both gain- and loss-of-function variants may lead to conduction defects remains poorly understood.

In the present study, we identified four novel TRPM4 genetic variants found in patients with either complete heart block (CHB) or idiopathic ventricular fibrillation (IVF). Biochemical and functional characterizations of these variants identified three with loss-of-function and one with gain-of-function. We further examined the possible mechanisms leading to altered protein stability using cycloheximide, an inhibitor of protein synthesis. Our results revealed an altered protein turnover in loss- and gain-of-expression mutant compared to the WT form of TRPM4, showing that altered half-life of TRPM4 is one of the mechanisms leading to several cardiac conduction disorders.

\section{MATERIALS AND METHODS}

\section{Patient Genetic Screening}

The study was conducted according to the Swiss and Canadian guidelines for genetic research and approved by the ethics committees of University Hospital Bern and the University of Ottawa Heart Institute respectively. All subjects gave written informed consent in accordance with the Declaration of Helsinki. Genomic DNA was isolated from peripheral macrophages by standard procedures using Gentra Puregene Blood kit (Qiagen, Hilden, Germany). A targeted exome panel sequencing was performed by Next Generation Sequencing using the TrueSight One Sequencing Panel (Illumina, San Diego, CA, USA). Sequence data were compared with the reference sequence of the human TRPM4 gene (MIM\# 606936; RefSeq NM_017636.3; Ensembl gene reference: ENSG00000130529, referring to isoform TRPM4b).

\section{Generation of TRPM4 Mutants}

The complete human wild-type HA-tagged TRPM4 cDNA was cloned in a pcDNA4/TO vector. Mutants were obtained by in vitro mutagenesis using Q5 Site-Directed Mutagenesis kit (New England Biolabs, Ipswich, MA, USA). Mutant cDNA clones were then sequenced before using them in experiments.

\section{Cell Culture and Transfection}

Human embryonic kidney (HEK293) cells were cultured with Dulbecco's modified Eagle's culture medium supplemented with $4 \mathrm{mM}$ Glutamine, $10 \%$ FBS and a cocktail of streptomycinpenicillin antibiotics. For the electrophysiological studies, the cells were transiently transfected with $240 \mathrm{ng}$ of HA-TRPM4 WT or HA-TRPM4 p.A101T, HA-TRPM4 p.Q854R, HA-TRPM4 p.S1044C, HA-TRPM4 p.P1204L, and double variant HATRPM4 p.A101T/P1204L in a $35 \mathrm{~mm}$ dish (BD Falcon, Durham, North Carolina, USA) mixed with $4 \mu \mathrm{L}$ of JetPEI (Polyplus transfection, Illkirch, France) and $46 \mu \mathrm{L}$ of $150 \mathrm{mM} \mathrm{NaCl}$. The cells were incubated for $24 \mathrm{~h}$ at $37^{\circ} \mathrm{C}$ with $5 \% \mathrm{CO}_{2}$. All transfections included $100 \mathrm{ng}$ of eGFP as a reporter gene. Expression of GFP was used to identify transfected cells, for patch clamp experiments.

For the biochemical experiments, HEK293 cells were transiently transfected with $240 \mathrm{ng}$ of either HA-TRPM4 WT, or HA-TRPM4 p.A101T, HA-TRPM4 p.Q854R, HA-TRPM4 p.S1044C, HA-TRPM4 p.P1204L, and double variant HATRPM4 p.A101T/P1204L, or empty vector (pcDNA4TO) in a P100 dish (BD Falcon, Durham, North Carolina, USA) mixed with $30 \mu \mathrm{L}$ of JetPEI (Polyplus transfection, Illkirch, France) and $250 \mu \mathrm{L}$ of $150 \mathrm{mM} \mathrm{NaCl}$. The cells were incubated for $48 \mathrm{~h}$ at $37^{\circ} \mathrm{C}$ with $5 \% \mathrm{CO}_{2}$.

\section{Cell Surface Biotinylation Assay}

Following $48 \mathrm{~h}$ of incubation, transiently transfected HEK293 cells, previously washed twice with cold 1X PBS, were treated with EZlinkTM Sulfo-NHS-SS-Biotin (Thermo Scientific, Waltham, MA, USA) $0.5 \mathrm{mg} / \mathrm{mL}$ in cold $1 \mathrm{X}$ PBS for $15 \mathrm{~min}$ at $4^{\circ} \mathrm{C}$. Subsequently, the cells were washed twice with $200 \mathrm{mM}$ Glycine in cold 1X PBS and twice with cold 1X PBS to inactivate and remove the excess biotin, respectively. The cells were then lysed with $1 \mathrm{X}$ lysis buffer [50 mM HEPES pH 7.4; $150 \mathrm{mM}$ $\mathrm{NaCl} ; 1.5 \mathrm{mM} \mathrm{MgCl} 2 ; 1 \mathrm{mM}$ EGTA pH 8.0; 10\% Glycerol; $1 \%$ Triton X-100; $1 \mathrm{X}$ Complete Protease Inhibitor Cocktail (Roche, Mannheim, Germany)] for $1 \mathrm{~h}$ at $4^{\circ} \mathrm{C}$. Cell lysates were centrifuged at $16,000 \mathrm{~g}$ at $4^{\circ} \mathrm{C}$ for $15 \mathrm{~min}$. Two milligrams of the supernatant were incubated with $50 \mu \mathrm{L}$ Streptavidin Sepharose High Performance beads (GE Healthcare, Uppsala, Sweden) for $2 \mathrm{~h}$ at $4{ }^{\circ} \mathrm{C}$, and the remaining supernatant was kept as the input. The beads were subsequently washed five times with $1 \mathrm{X}$ lysis buffer before elution with $50 \mu \mathrm{L}$ of $2 \mathrm{X}$ NuPAGE sample buffer (Invitrogen, Carlsbad, CA, USA) plus $100 \mathrm{mM} \mathrm{DTT}$ at $37^{\circ} \mathrm{C}$ for 
$30 \mathrm{~min}$. These biotinylated fractions were analyzed as TRPM4 expressed at the cell surface. The input fractions, analyzed as total expression of TRPM4, were resuspended with 4X NuPAGE Sample Buffer plus $100 \mathrm{mM}$ DTT to give a concentration of 1 $\mathrm{mg} / \mathrm{mL}$ and incubated at $37^{\circ} \mathrm{C}$ for $30 \mathrm{~min}$.

\section{Western Blot Experiments}

Protein samples were analyzed on $9 \%$ polyacrylamide gels, transferred with the TurboBlot dry blot system (Biorad, Hercules, CA, USA) and detected with anti-TRPM4 (generated by Pineda, Berlin, Germany), anti $\alpha$-actin A2066 (SigmaAldrich, St. Louis, MO, USA), anti-alpha $\mathrm{Na}^{+} / \mathrm{K}^{+}$ATPase $\alpha 1$ ab7671 (Abcam, Cambridge, UK) antibodies using SNAP i.d. (Millipore, Billerica, MA, USA). The anti-TRPM4 antibody was generated by Pineda (Berlin, Germany) using the following peptide sequence: NH2-CRDKRESDSERLKRTSQKV-CONH2. A fraction of the antisera, which was subsequently used in this study, was affinity purified. Actin and alpha- $\mathrm{Na}^{+} / \mathrm{K}^{+}$ATPase were used to normalize TRPM4 protein band intensity in total fraction and surface fraction respectively. Original Western blot pictures of the three replicates for total and surface fractions were shown in Supplementary Figures 1, 9, and $\mathbf{1 1}$ for total expression, and Supplementary Figures 2, 10 and 12 for surface expression. A summary of raw WB picture was also submitted as Supplementary Figure 13. All the Western Blots have been quantified using Image Studio Lite software from LI-COR Biosciences (Lincoln, NE, USA).

\section{Immunoprecipitation and Protein Half-Life Determination Experiments}

For half-life experiments, HEK 293 transiently transfected cells were treated with $100 \mu \mathrm{g} / \mathrm{mL}$ cycloheximide (Millipore, Billerica, MA, USA) or $0,3 \%$ DMSO as control and lysed at various time points using 1X UBI buffer [50 mM HEPES pH 7.4, $150 \mathrm{mM}$ $\mathrm{NaCl}, 1 \mathrm{mM}$ EGTA pH 8.0, 10\% Glycerol, 1\% Triton X-100, $1 \mathrm{X}$ Complete Protease Inhibitor Cocktail EDTA-free (Roche, Mannheim, Germany)]. Two milligrams of protein lysate were incubated overnight with $20 \mu \mathrm{g}$ of anti-TRPM4 antibody in a final volume of $1 \mathrm{~mL}$. The lysate-antibody was then transferred on Protein G Sepharose 4 Fast Flow beads (GE Healthcare, Uppsala, Sweden) and rotated overnight at $4^{\circ} \mathrm{C}$. Beads were washed 5 times with $1 \mathrm{X}$ UBI buffer with $0.5 \%$ Triton before elution with $50 \mu \mathrm{L}$ of $2 \mathrm{X}$ NuPAGE sample buffer (Invitrogen, Carlsbad, CA, USA) plus $100 \mathrm{mM} \mathrm{DTT}$ at $37^{\circ} \mathrm{C}$ for $30 \mathrm{~min}$. Samples were loaded on a 9\% polyacrylamide gel and TRPM4 expression was revealed using anti-HA antibody (Enzo Life Sciences, Lausen, Switzerland). Original Western blot pictures are shown in Supplementary data (Supplementary Figures 3-8). To extrapolate the half-life of WT-TRPM4 and TRPM4 variants, the relative protein band intensity was fitted with monoexponential function, and time for $50 \%$ decay of intensity was estimated.

\section{Quantitative Real Time PCR}

Total RNA isolation was performed using TRIzol Reagent (Applied Biosystems, Foster City, CA, USA) as described by the manufacturer. Concentration and purity of total RNA was determined by optical density measurement using a NanoDrop
2000 spectrophotometer (Thermo Scientific, Waltham, MA, USA). cDNA was synthesized using High Capacity cDNA Reverse Transcription kit (Applied Biosystems, Foster City, CA, USA) and quantitative expression analysis was performed with 7500 Fast Real-Time PCR System (Applied Biosystems, Foster City, CA, USA). Quantification of mRNA expression levels was investigated with TaqMan gene expression assay Hs00214167_m1 for human TRPM4, using GAPDH TaqMan gene expression assay Hs02758991_g1 as a control. Relative expression of the studied gene was calculated with the $2^{-\Delta \Delta \mathrm{Ct}}$ method.

\section{Cellular Electrophysiology}

Electrophysiological recordings were performed in the insideout patch clamp configuration with patch pipettes $(1-2 \mu \mathrm{m}$ tip opening) pulled from $1.5 \mathrm{~mm}$ borosilicate glass capillaries (ZeitzInstruments, $\mathrm{GmbH}$, München, Germany) using micropipette puller P 97 (Sutter Instruments, Novato, CA, USA). The tips were polished to have a pipette resistance of 2-4 M $\Omega$ in the bath solution. The pipette solution contained (in $\mathrm{mM}$ ) 150 $\mathrm{NaCl}, 10 \mathrm{HEPES}$, and $2 \mathrm{CaCl}_{2}(\mathrm{pH} 7.4$ with $\mathrm{NaOH})$. The bath solution contained (in mM) $150 \mathrm{NaCl} 10$ HEPES, 2 HEDTA ( $\mathrm{pH} 7.4$ with $\mathrm{NaOH}$ ) as $0 \mathrm{Ca}^{2+}$ solution. Solutions containing $300 \mu \mathrm{M} \mathrm{Ca}^{2+}$ were made by adding the appropriate concentration of $\mathrm{CaCl}_{2}$ without buffer to a solution containing (in mM) $150 \mathrm{NaCl}, 10$ HEPES ( $\mathrm{pH} 7.4$ with $\mathrm{NaOH}$ ) as reported previously (Zhang et al., 2005). Bath solution with 0 and $300 \mu \mathrm{M} \mathrm{Ca}^{2+}$ concentrations were applied to cells by a modified rapid solution exchanger (Perfusion Fast-Step SF77B; Warner Instruments Corp., CT, USA). Membrane currents were recorded with a Multiclamp 700B amplifier (Molecular Devices, Sunnyvale CA, USA) controlled by Clampex 10 via a Digidata 1332A (Molecular Devices, Sunnyvale, CA, USA). Data were low-pass filtered at $5 \mathrm{kHz}$ and sampled at $10 \mathrm{kHz}$. Experiments were performed at room temperature $\left(20-25^{\circ} \mathrm{C}\right)$. For measuring steady state currents, stimulation protocol consisted of a single $200 \mathrm{~ms}$ voltage step to -100 and then to $+100 \mathrm{mV}$.

\section{Statistical Analysis}

Data are represented as the mean \pm s.e.m. One-way ANOVA followed by Sidak's multiple comparison test was used to compare the samples, with a $p<0.05$ considered as significant. Electrophysiology data were exported and analyzed using IGOR PRO 6 (Wavematrix, London, UK).

\section{RESULTS}

\section{Patients Information}

In the present study, we performed genetic analysis of the TRPM4 gene in patients to elucidate its role in various types of cardiac conduction disorders or ventricular arrhythmias. The clinical details of the variant carriers are presented in Table $\mathbf{1}$ and the electrocardiogram (ECG) recordings are shown in Figure 1. In Ottawa Heart Institute, 26 patients with premature heart block (age $<60$ years) were screened. Together, 100 patients from an elderly (age $>70$ years) control population were screened for the identified rare variants. In Bern, the TRPM4 gene is 
TABLE 1 | Patients characteristics.

\begin{tabular}{|c|c|c|c|c|c|c|}
\hline Patient ID & Protein & Sex & Age at diagnosis (years) & Circumstances of discovery & Family history & Phenotype \\
\hline 1 & p.A101T & Male & 54 & Dizziness & No & $\mathrm{CHB}$ \\
\hline $1 \mathrm{~A}$ & p.A101T & Male & 71 & Asymptomatic & No & cRBBB \\
\hline 2 & p.Q854R & Female & 53 & Syncope & Unknown & $\mathrm{CHB}$ \\
\hline 3 & p.S1044C & Female & 48 & Syncope & Mother had PM (deceased) & $\mathrm{CHB}$ \\
\hline 4 & p.A101T/P1204L & Female & 17 & Resuscitated SCD & Yes & IVF \\
\hline
\end{tabular}

CHB, complete heart block; CRBBB, complete right bundle branch block; PM, pacemaker; SCD, sudden cardiac death; IVF, idiopathic ventricular fibrillation.

screened routinely in cases with suspected channelopathies. In these cohorts, four novel TRPM4 variants leading to cardiac disorders were identified (Figure 1A). The p.A101T variant was found in a 54 years old male with dizziness, who was diagnosed with $\mathrm{CHB}$ (Figure 1B). The same variant was also found in an asymptomatic control patient who was subsequently identified to have a complete RBBB on ECG. Other variants in the control patient were absent (Table 1). The p.Q854R and p.S1044C variants were found in two female patients with syncope and an ECG presentation of $\mathrm{CHB}$ at 53 and 48 years of age respectively. The mother of the 48 years old patient also had a pacemaker (Table 1). The missense p.A101T mutation was also found, together with a p.P1204L mutation, in a 17 years old patient from the University Hospital Bern who had sudden cardiac death. This patient had exhibited frequent monomorphic premature ventricular beats during exercise prior to her sudden cardiac death (SCD) event (Figures 1C,D). She had history of recurrent syncope since she was 14 years old. ECG and magnetic resonance imaging (MRI) were normal. This patient had also a novel homozygous mutation in ryanodine receptor 2 (RYR2) in position c.365G >A (p.R122H), but no clear Catecholaminergic Polymorphic Ventricular Tachycardia (CPVT) was observed. Relatives have been tested for the three mutations: both parents are heterozygous for RYR2-R122H, and the mother is carrier of both TRPM4 mutations. Both parents are asymptomatic and exhibit no obvious cardiac pathological phenotype. Given the uncertainty of the causative genotype, p.P1204L has been also investigated as a single variant, but was already reported to be implicated in cardiac conduction disturbances and/or BrS (Stallmeyer et al., 2012; Liu et al., 2013). To predict the impact of the amino acid substitution, exome variant server (http://evs.gs. washington.edu/EVS/), as well as Polyphen2, SIFT and Mutation Taster were used (Table 2). For data interpretation, human gene mutation database (HGMD, Biobase), 1000 genoms and ExAC browser were used.

\section{TRPM4 Variants Expression Pattern}

To understand the consequences of the four novel mutations on the TRPM4 channel, we analyzed total expression of TRPM4 after transient transfection of HEK293 cells and its expression at the cell surface by Western Blot and cell surface biotinylation experiments. As previously reported (Syam et al., 2014), we observed that the TRPM4 channel is expressed in fully and core glycosylated forms. As shown in Figure 2, we observed a $50 \%$ reduction in the total expression of p.A101T and p.S1044C, when compared to the WT TRPM4, both in fully and in core glycosylated bands (Figures 2A-C). p.P1204L and the double variant p.A101T/P1204L showed a more severe reduction in the total expression, in both fully and core glycosylated bands (70 and $75 \%$ respectively), when compared to WT TRPM4 (Figures 2A-C). The decrease in TRPM4 expression was more pronounced at the cell surface for all the loss-of-expression variants $(70 \%$ loss for p.A101T and p.A101T/P1204L, 60\% loss for p.S1044C, 80\% loss for p.P1204L), for both fully and core glycosylated bands (Figures 2B-D). On the other hand, p.Q854R showed an increased protein expression in both fully and core glycosylated bands of total and surface expression (130 and 110\% respectively) (Figures 2B-D). However, these increases were not statistically significant. We then performed quantitative RealTime PCR experiments to determine whether these differences in protein expression may have been due to variable mRNA levels after transient transfection. No significant differences were observed in mRNA expression among the variants when compared to WT TRPM4 gene (Figure 3).

\section{Functional Analysis}

To determine possible functional alterations caused by these variants, macro-patch current recordings were performed using inside-out patch clamp on HEK293 cells expressing WT TRPM4 or p.A101T, p.Q854R, p.S1044C, p.P1204L, and p.A101T/P1204L. Figure 4 shows that a $200 \mathrm{~ms}$ voltage step from -100 to $+100 \mathrm{mV}$ from a holding voltage of $0 \mathrm{mV}$ elicited small outward $\mathrm{Na}^{+}$currents when exposed to nominally $0 \mathrm{Ca}^{2+}$ bath solution $(39.6 \pm 9.5 \mathrm{pA})$, whereas it induced large outward currents in presence of $300 \mu \mathrm{M} \mathrm{Ca}^{2+}(4768.7 \pm 574.6 \mathrm{pA})$. The amplitude of outward current measured at the end of voltage step to $+100 \mathrm{mV}$ varied among the variants. In line with the western blot data (Figure 2), variants p.A101T (249.7 $\pm 44.5 \mathrm{pA}, n=7)$, p.S1044C (314 $\pm 95.4 \mathrm{pA}, n=6), \mathrm{p} . \mathrm{P} 1204 \mathrm{~L}(248.7 \pm 82.9 \mathrm{pA}, n$ $=7)$, and double variant p.A101T/P1204L (142.6 $\pm 27.7 \mathrm{pA}, n$ $=11$ ) showed reduced current while the variant p.Q854R (8735 $\pm 637.7 \mathrm{pA}, n=7$ ) showed increased outward current when compared to WT (4768.7 $\pm 574.6 \mathrm{pA}, n=13$; Figure 4B).

\section{Half-Life of WT-TRPM4 and TRPM4 Variants}

To understand the cellular mechanism leading to loss- or gain-of-expression in TRPM4 variants, the half-life of WT and mutated TRPM4 was analyzed using the protein synthesis blocker cycloheximide. Approximately $24 \mathrm{~h}$ after transfection, transiently transfected HEK293 cells were incubated with $100 \mu \mathrm{g} / \mathrm{mL}$ cycloheximide and harvested prior to inhibition $(0 \mathrm{~h})$ 
A

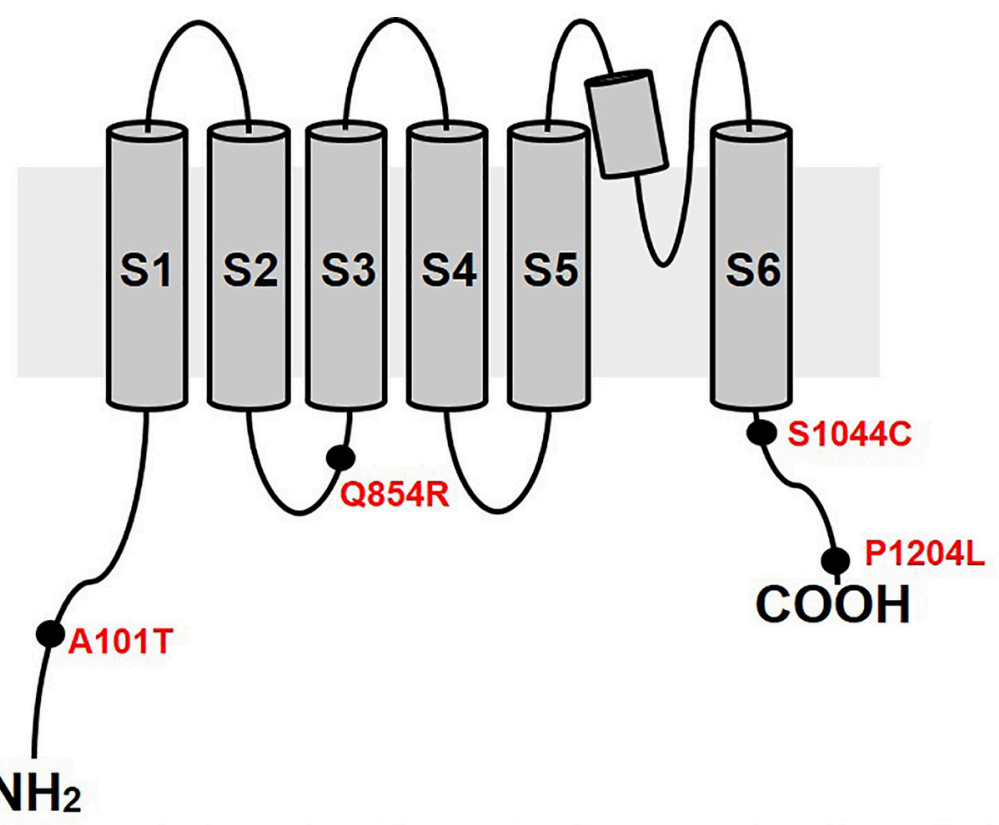

B

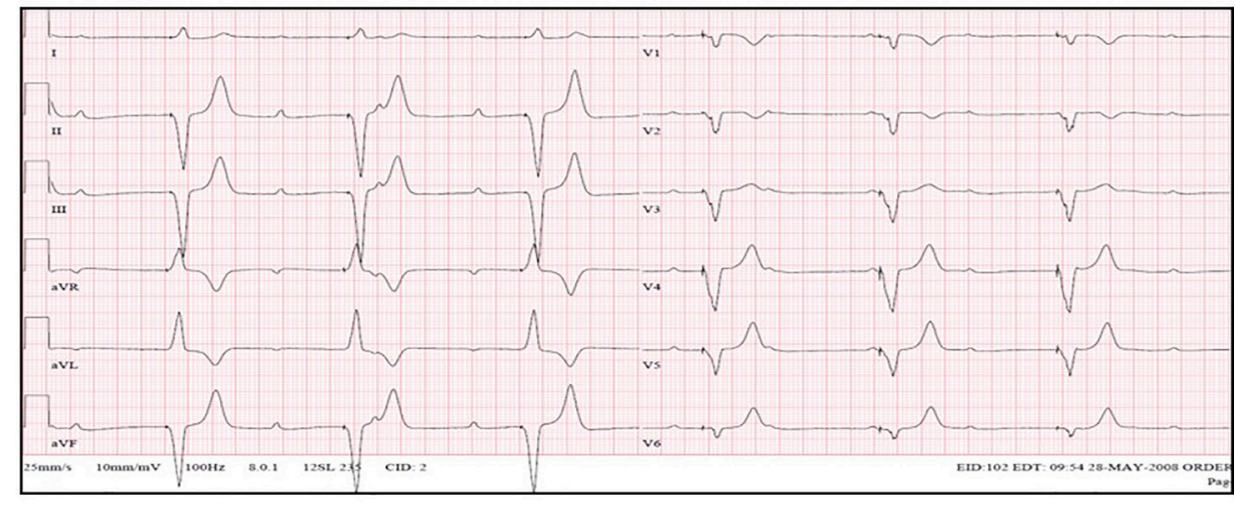

C

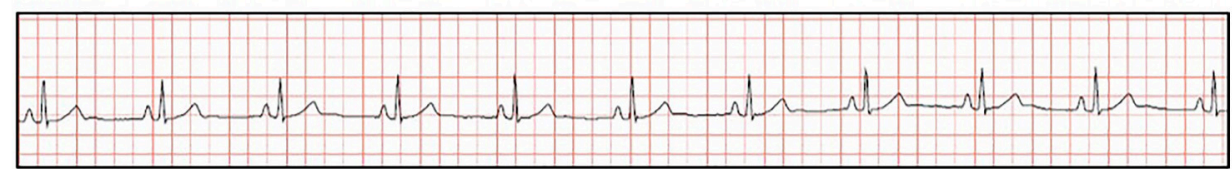

D

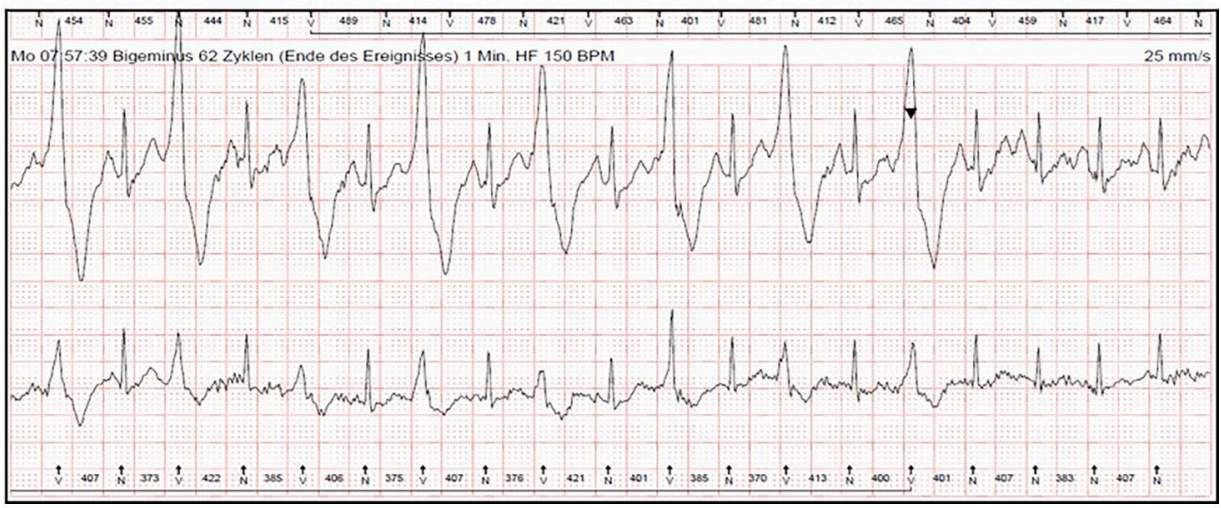

FIGURE 1 | ECG recordings and variants information. (A) Variants location in the TRPM4 protein. (B) ECG from patient 1 carrying p.A101T variant and showing a complete heart block phenotype. (C,D) ECG from patient 5 carrying p.A101T/P1204L variant at rest (C) and under physical exercise showing IVF phenotype (D). The arrowhead shows the administration of beta-blockers. 
TABLE 2 | Variants characteristics.

\begin{tabular}{|c|c|c|c|c|c|c|c|}
\hline $\begin{array}{l}\text { Patient } \\
\text { ID }\end{array}$ & cDNA & Exon & Protein & Predicted protein localization & GVS function & EVS Eur-Am & PolyPhen-2 analysis \\
\hline 1 & c. $301 \mathrm{G}>\mathrm{A}$ & 3 & p.A101T & $\mathrm{N}$-terminal, cytoplasmic & Missense & $A=161 / G=8439$ & Benign (Score:0.000) \\
\hline 3 & c. $3130 \mathrm{~A}>\mathrm{T}$ & 20 & p.S1044C & Helical & n.d. & N.P & n.d. \\
\hline 4 & c. $3611 \mathrm{C}>\mathrm{T}$ & 23 & p.P1204L & C-terminal, cytoplasmic & Missense & $\mathrm{T}=28 / \mathrm{C}=8542$ & $\begin{array}{l}\text { Possibly damaging } \\
\text { (Score:0.008) }\end{array}$ \\
\hline
\end{tabular}

EVS Eur-Am, Exome Variant Server European-American Population; GVS, Genome Variation Server; N.P., not present in Exome Variant Server; n.d., not determined.

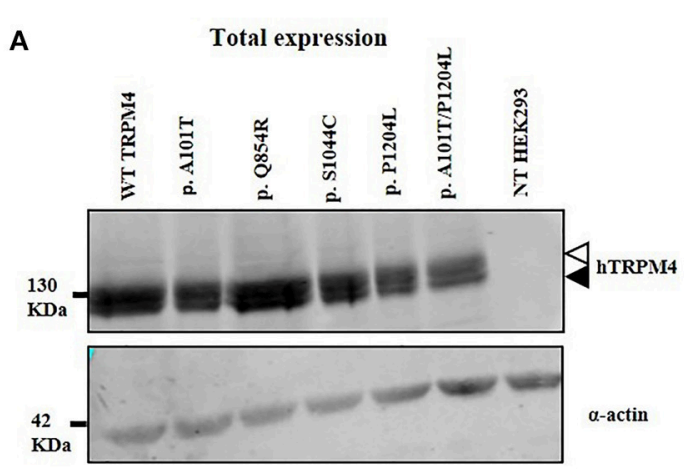

\section{C}
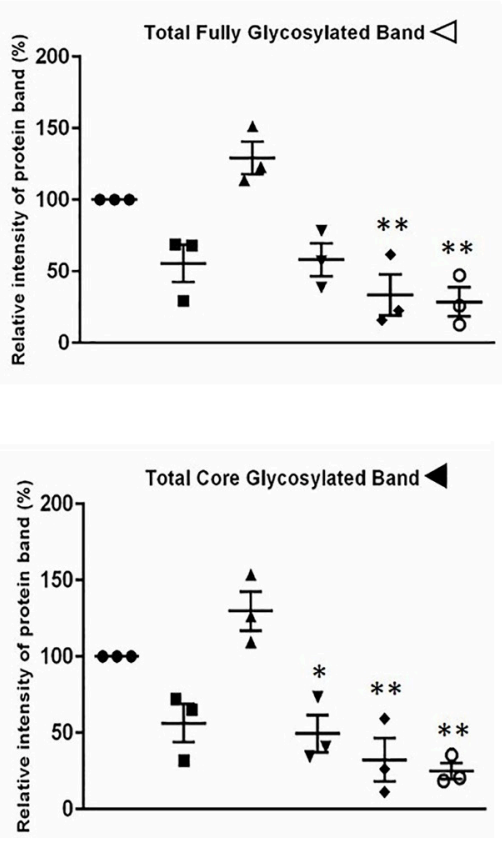

B Surface expression

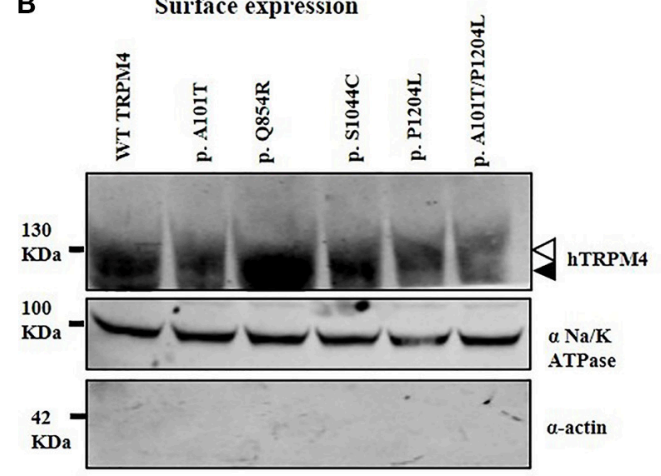

D

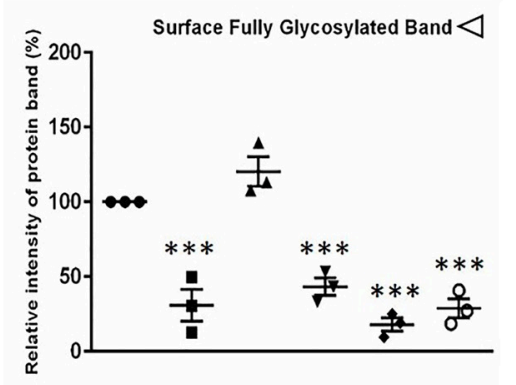

- WT TRPM4

- p.A101T

- p.Q854R

$\checkmark$ p.S1044C

- p.P1204L

- p.A101T/P1204L

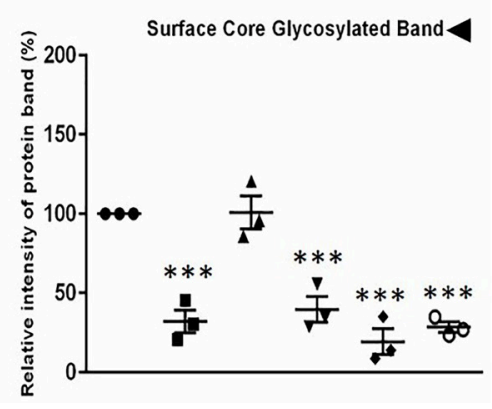

FIGURE 2 | Western Blot analysis of HEK293 cells transiently expressing WT-TRPM4 and TRPM4 variants. Representative immunoblots of human TRPM4 expression at the total (A) and surface expression (B). Actin and alpha $\mathrm{Na}^{+} / \mathrm{K}^{+}$ATPase were used for normalization of the total and the surface expression respectively. White and black arrowheads represent fully and core glycosylated band respectively. Quantification of the total expression (C) and surface expression (D) is shown as relative intensity of protein band for both full and core glycosylated forms of TRPM4 in each fraction. Data are represented as mean \pm s.e.m. of $n=3$; ${ }^{\star} P<0.05$; ${ }^{\star \star} P<0.005 ;{ }^{\star \star \star} P<0.001$

and at $4,16,24$, and $36 \mathrm{~h}$ post-treatment using a TRPM4 immunoprecipitation protocol. For each time point, a $0.3 \%$ DMSO control was used to normalize TRPM4 expression.
The observed pattern of WT-TRPM4 protein expressed over time following cycloheximide treatment (Figure 5) provided a half-life of $\sim 18 \mathrm{~h}$ for the fully glycosylated form, and 


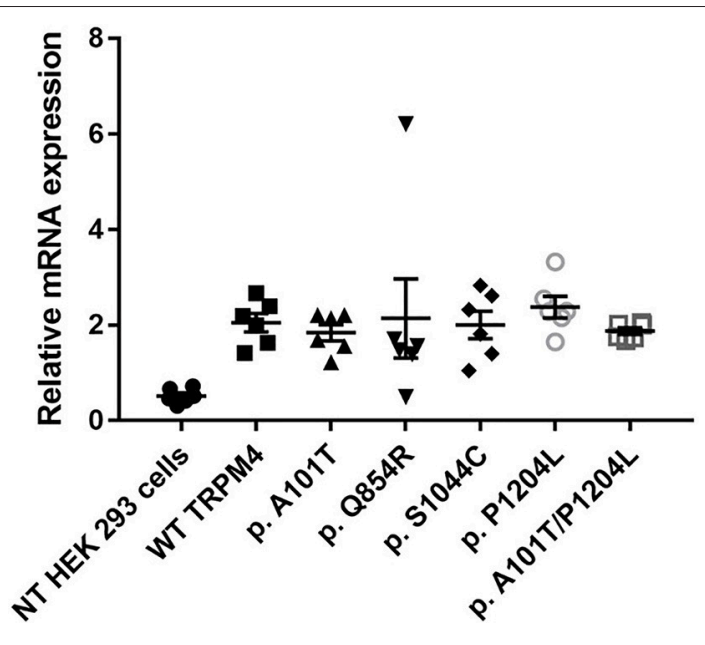

FIGURE 3 | mRNA TRPM4 expression of WT and variants. qPCR analysis on TRPM4 gene expression in HEK 293 cells transiently transfected with WT-TRPM4 and TRPM4 variants. Data are represented as relative mRNA expression. The expression of GAPDH is used as reference (mean \pm s.e.m. of $n=6$ ). No significant differences are observed between WT and variants.

$30 \mathrm{~h}$ for the core glycosylated form (Figure 6 and Table 3). Interestingly, in presence of cycloheximide we observed a more rapid decay in TRPM4 expression of all loss-ofexpression variants, with a half-life of $\sim 12 \mathrm{~h}$ for p.A101T, p.S1044C and the double variant p.A101T/P1204L, for both fully and core glycosylated fractions (Figures 5, 6 and Table 3). p.P1204L was even more rapidly degraded, and the signal was only partially detectable after $10 \mathrm{~h}$ incubation, leading to a half-life of both fully and core glycosylated band of $\sim 8 \mathrm{~h}$ (Figure 6 and Table 3). Under the same conditions, gainof-expression p.Q854R variant half-life has been estimated, resulting to exceed $24 \mathrm{~h}$, and reaching $50 \mathrm{~h}$ in both fully and core glycosylated band (Figure 6 and Table 3). Taken together, these experiments indicate that the difference in plasma membrane expression of WT-TRPM4 and TRPM4 variants reflects different degradation kinetics, which causes variations in protein expression.

\section{DISCUSSION}

In the present study, four novel TRPM4 variants have been identified in patients with $\mathrm{CHB}$ and IVF. Biochemical and electrophysiological studies revealed a reduced protein expression and function for p.A101T, p.S1044C, and p.A101T/P1204L compared to WT, while p.Q854R showed an increased TRPM4-mediated current. Furthermore, we observed that, when expressed in HEK293 cells, these variant TRPM4 proteins had either increased or decreased degradation rates when compared to WT protein.

The underlying mechanisms leading to conduction defects caused by TRPM4 mutations are not yet understood. Moreover, in this work, both gain and loss of function variants led to the same pathology. A similar observation was made in a series
A
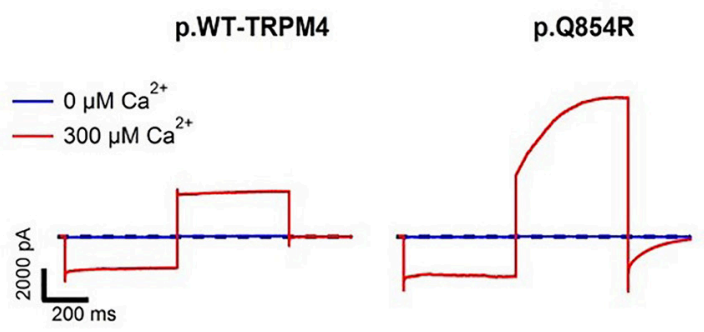

p.A101T

p.P1204L
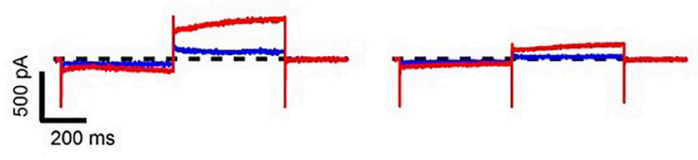

p.A101T / P1240L

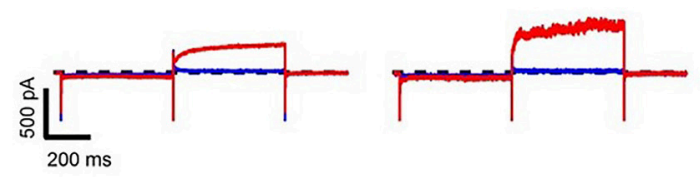

B

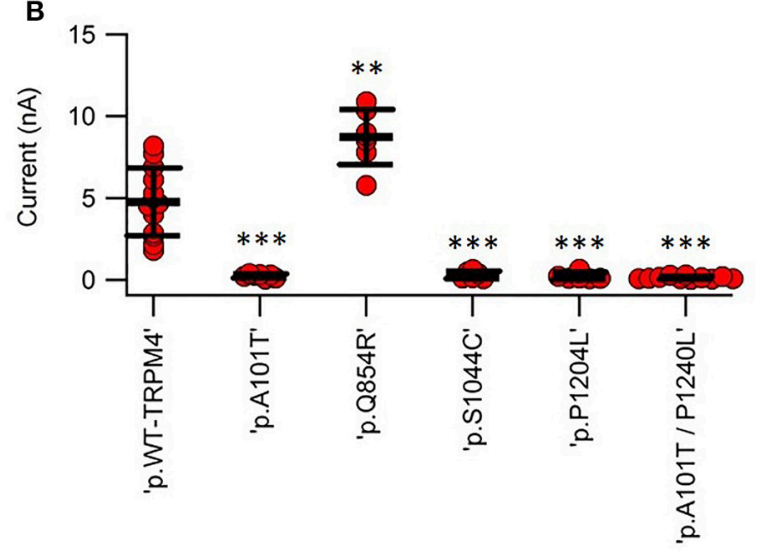

FIGURE 4 | Inside-out patch clamp recordings of WT and TRPM4 variants. (A) Individual current traces of WT TRPM4 and TRPM4 variants after applying $300 \mu \mathrm{M} \mathrm{Ca}^{2+}$. (B) Quantification of currents of WT and cardiac conduction disorders variants. ${ }^{* *} P<0.005 ;{ }^{* * *} P<0.001$ (WT, $n=13$; A101T, $n=7$; Q854R, $n=7$; S1044C, $n=6$; P1204L, $n=7$; A101T/P1204L, $n=11$ ).

of Brugada cases with mutations in the TRPM4 channel (Liu et al., 2013) and in another series of patients with congenital or childhood atrioventricular block (Syam et al., 2016). While it may seem paradoxical that both gain- and loss-of-function can lead to similar phenotype, one may propose that, if TRPM4 is influencing the resting membrane potential of conduction system cells, both membrane hyperpolarization and depolarization will cause conduction slowing (Abriel et al., 2012), in analogy to 


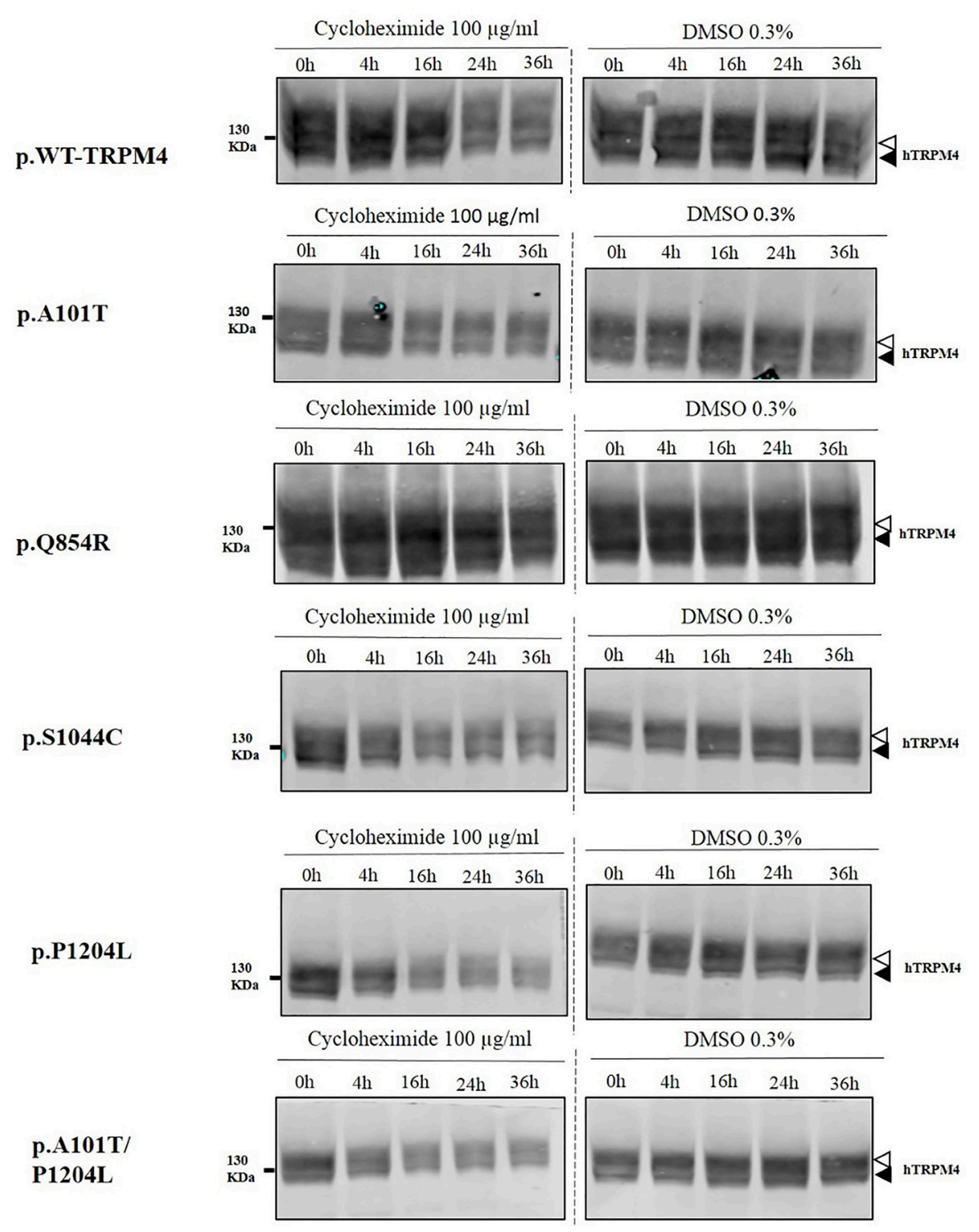

FIGURE 5 | Half-life of WT and TRPM4 variants. Immunoblots showing immunoprecipitation with anti-TRPM4 antibody. Cells were harvested prior to treatment (0 h) and 4, 16, 24, and $36 \mathrm{~h}$ after treatment with $100 \mu \mathrm{g} / \mathrm{ml}$ cycloheximide. TRPM4 is detected using anti-HA antibody in presence of $100 \mu \mathrm{g} / \mathrm{ml}$ cycloheximide (left panel), or $0.3 \%$ DMSO (right panel). White and black arrowheads represent fully and core glycosylated band respectively. Data are representative of three independent experiments.

the supernormal conduction phenomenon which has been described in atrioventricular conduction (Moore et al., 1993). However, to date, there is no report demonstrating a direct role of TRPM4 in this phenomenon, hence motivating further investigation on the role of TRPM4 in the conduction pathway (Mathar et al., 2014). The presence of a TRPM4 loss-of-function variant in a case with IVF is intriguing and we can thus far only speculate that its possible consequences on impulse propagation may exacerbate the arrhythmogenic potential of the observed RYR2 mutation. It is however impossible to exclude that this presents a variant with no direct functional consequences in vivo. A recent report investigated the involvement of TRPM4 in conduction block and arrhythmic phenomena associated with cardiac remodeling and injury, showing that TRPM4 channel is activated by a physiological range of $\mathrm{Ca}^{2+}$ concentrations and that its excessive activity can cause arrhythmic changes ( $\mathrm{Hu}$ et al., 2017). In mouse ventricles, a negative impact of TRPM4 channel activity on cardiac contractility despite action potential prolongation has been proposed, and this mechanism was found to be suppressed in TRPM4 KO mice (Mathar et al., 2014). Further improvement of action potential models may help to understand more complex mechanisms underlying arrhythmias and conduction failures associated with TRPM4 genetic mutations. 


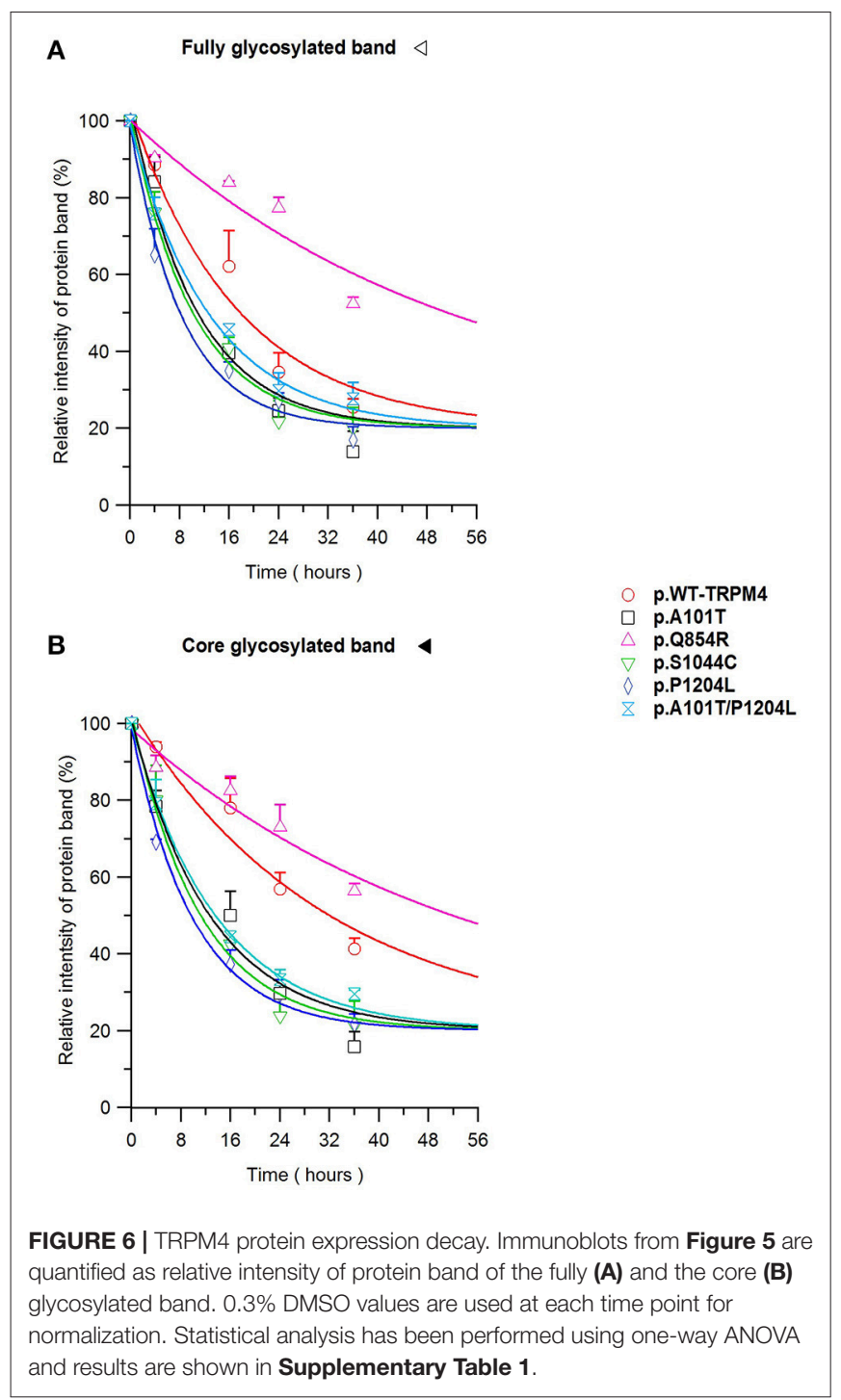

Using cycloheximide, we investigated whether the variantinduced altered expression of TRPM4 in HEK293 cells may result from modified protein stability. TRPM4 half-lives of the core and fully glycosylated fractions have been determined for the WT and variant proteins causing conduction defects. Our findings revealed that the fully and the core glycosylated fractions of WT channels had half-lives of $\sim 20$ and $\sim 30 \mathrm{~h}$, respectively. These values are in line with Woo and colleagues' study, where they observed a half-life of $\sim 24 \mathrm{~h}$ for WT mouse TRPM4 (Woo et al., 2013). Together, loss-of-expression mutants undergo a more rapid degradation rate, resulting in reduced half-life compared to WT. Interestingly, the mutation leading to gainof-expression significantly decreased the degradation rate of the fully and core glycosylated fractions, with a half-life of $\sim 50 \mathrm{~h}$. In contrast, the loss-of-expression variant half-life alterations were mainly seen in the core glycosylated fractions. These observation are consistent with a model where the decrease and increase of TRPM4 currents are due to changes in TRPM4 channel
TABLE 3 | Variants half-life values.

\begin{tabular}{lcc}
\hline Variant & $\begin{array}{c}\text { Fully glycosylated band } \\
\text { half-life values (hours } \pm \\
\text { s.e.m.) }\end{array}$ & $\begin{array}{c}\text { Core glycosylated band } \\
\text { half-life values (hours } \pm \\
\text { s.e.m.) }\end{array}$ \\
\hline WT-TRPM4 & $17.4 \pm 1.6$ & $31.4 \pm 2.6$ \\
p.A101T & $10.5 \pm 1.1$ & $12.7 \pm 1.2$ \\
p.Q854R & $52.3 \pm 6.8$ & $53.8 \pm 4.7$ \\
p.S1044C & $10.1 \pm 0.7$ & $11.0 \pm 0.6$ \\
p.P1204L & $8.3 \pm 0.6$ & $9.9 \pm 0.4$ \\
p.A101T/P1204L & $13.0 \pm 0.6$ & $13.8 \pm 0.4$ \\
\hline
\end{tabular}

densities at the plasma membrane caused by variant-induced trafficking alterations. However, it is likely that the mechanisms leading to the loss of expression are not the same as the one underlying the gain of expression. It can be hypothesized that the increased degradation rates of the core-glycosylated fractions reflect misfolding of the nascent proteins and subsequent ERassociated protein degradation (ERAD) (Meusser et al., 2005). In a recent study (Syam et al., 2016), two loss-of-expression TRPM4 variants found in patients with congenital AVB were rescued upon decreased incubation temperature for $24 \mathrm{~h}$ suggesting that variant-induced misfolding of TRPM4 may be a common molecular mechanism similar to the case of human ethera-go-go-related gene voltage-gated potassium channel Kv11.1 (Zhou et al., 1999). On the other hand, assuming that the fully glycosylated TRPM4 fraction is predominant at the plasma membrane, it can be speculated that the reduced degradation of the p.Q854R variant reflects a decreased internalization rate as proposed for other gain of function variants (Kruse et al., 2009). Future experiments will have to be performed to assess this hypothesis.

Ion channels, including many TRP channels, are subjected to post-translational modifications which regulate their trafficking and stability at the cell membrane. It has been reported that human and mouse TRPM4 are N-linked glycosylated at a unique residue, $\mathrm{Asn}^{992}$ and $\mathrm{Asn}^{988}$ respectively (Woo et al., 2013; Syam et al., 2014). N-glycosylation has been found to be crucial for surface expression of several TRP channels, but most studies have been performed on heterologous systems, with induced ion channels overexpression; therefore, native and recombinant proteins may act differently due to differences in in vivo glycosylation. Recent reports suggested the role of SUMOylation as a possible post-translational modification implicated in TRPM4 trafficking. Kruse and colleagues proposed that the p.E7K TRPM4 mutation leading to a gain-of-function and expression was subjected to an increased SUMOylation which augments its membrane expression (Kruse et al., 2009). In contrast, Syam et al. showed immunoprecipitation experiments with WT TRPM4 and the gain-of-expression variant p.G582S, where no direct SUMOylation of TRPM4 seemed to be observed (Syam et al., 2016). Ubiquitination is another frequent post-translational modification of ion channels. In our previous work (Syam et al., 2016), we performed GSTS5a pull down experiments to address whether ubiquitination 
was involved in differences in expression and degradation between WT and variants. Our findings revealed that the difference in degradation rate of WT and mutants does not depend on a different rate of ubiquitination. Based on these contrasting results, the involvement of SUMOylation and/or ubiquitination leading to increased TRPM4 expression in patients with cardiac conduction disorders still remains to be elucidated.

Recently, the electron cryo-microscopy structure of the human TRPM4 has been reported (Winkler et al., 2017). It is shown there that TRPM4 is composed by four cytosolic Cterminal domains which form an umbrella-like structure, with a coil domain for the "pole" and four N-terminal helical "ribs." p.A101T and p.P1204L are found in well conserved N-terminal and C-terminal residues respectively, while p.Q854R is located in the S2-S3 linker and does not seem to play a crucial role in TRPM4 structure. Interestingly, p.S1044C has been identified to be located in the intracellular gate and might play a role in TRPM4 permeability to $\mathrm{Na}^{+}$(Winkler et al., 2017). Further studies would be required to assess S1044 specific role in the channel function.

\section{LIMITATIONS OF THE STUDY}

The novel TRPM4 variants described in this work were not assessed in terms of their intrinsic biophysical properties. Further studies using cardiac cells instead of HEK 293 cells may give additional information regarding their relevance in action potential conduction and could lead to a better understanding of the role of TRPM4 in cardiac conduction disorders. In conclusion, although the molecular mechanism underlying protein degradation dysfunctions and their role in cardiac diseases are only beginning to be revealed, it has become clear that altered protein degradation affecting protein half-life may play an important role in a variety of genetic cardiac disorders, including cardiac conduction defects in presence of TRPM4 mutations. Further studies, using knock-in mice or CRISPR/Cas9-dependent editing of human iPS-derived cardiomyocytes, may help to develop clinically relevant strategies to correct protein trafficking abnormalities, including misfolded TRPM4 mutants in cardiac conduction phenotypes.

\section{REFERENCES}

Abriel, H., Syam, N., Sottas, V., Amarouch, M. Y., and Rougier, J. S. (2012). TRPM4 channels in the cardiovascular system: physiology, pathophysiology, and pharmacology. Biochem. Pharmacol. 84, 873-881. doi: 10.1016/j.bcp.2012.06.021

Barbet, G., Demion, M., Moura, I. C., Serafini, N., Vrtovsnik, F., Monteiro, R. C., et al. (2010). Nature Immunol. 9, 1148-1156. doi: 10.1038/ni.1648.

Ceylan, G. G., Önalan, E. E., Kuloglu, T., Aydog, G., Keleş, I., Tonyali, S., et al. (2016). Potential role of melastatin-related transient receptor potential cation channel subfamily $\mathrm{M}$ gene expression in the pathogenesis of urinary bladder cancer. Oncol. Lett. 12, 5235-5239. doi: 10.3892/ol.2016.5359

Cheng, H., Beck, A., Launay, P., Gross, S. A., Stokes, A. J., Kinet, J. P., et al. (2007). TRPM4 controls insulin secretion in pancreatic beta-cells. Cell Calcium 41, 51-61. doi: 10.1016/j.ceca.2006.04.032

\section{AUTHOR CONTRIBUTIONS}

$\mathrm{BB}$ and HA: conceived the study and wrote the manuscript; LO and $\mathrm{BB}$ : contributed to the biochemical and functional analyses; MG and AM-D: recruited the patients and provided expert clinical advice. All authors interpreted the data, contributed and commented on drafts of the article, and approved the final version.

\section{FUNDING}

This work was supported by NCCR Transcure 51NF40-160620 and a grant by the Swiss Heart Foundation to HA.

\section{ACKNOWLEDGMENTS}

We thank Dr. Jean-Sébastien Rougier for his help and useful comments on the manuscript.

\section{SUPPLEMENTARY MATERIAL}

The Supplementary Material for this article can be found online at: https://www.frontiersin.org/articles/10.3389/fphys. 2018.00177/full\#supplementary-material

Supplementary Figure 1 | Raw WB picture 1 of total expression.

Supplementary Figure 2 | Raw WB picture 1 of surface expression.

Supplementary Figure 3 | Raw WB picture of WT-TRPM4 half-life.

Supplementary Figure 4 | Raw WB picture of p.A101T half-life.

Supplementary Figure 5 | Raw WB picture of p.Q854R half-life.

Supplementary Figure 6 | Raw WB picture of p.S1044C half-life.

Supplementary Figure 7 | Raw WB picture of p.P1204L half-life.

Supplementary Figure 8 | Raw WB picture of p.A101T/P1204L half-life

Supplementary Figure 9 | Raw WB picture 2 of total expression.

Supplementary Figure 10 | Raw WB picture 2 of surface expression.

Supplementary Figure 11 | Raw WB picture 3 of total expression.

Supplementary Figure 12 | Raw WB picture 3 of surface expression.

Supplementary Figure 13 | Summary of raw WB used for Figures 2A,B.

Supplementary Table 1 | Half-lives statistical values.

Daumy, X., Amarouch, M. Y., Lindenbaum, P., Bonnaud, S., Charpentier, E., Bianchi, B., et al. (2016). Targeted resequencing identifies TRPM4 as a major gene predisposing to progressive familial heart block type i. Int. J. Cardiol. 207, 349-358. doi: 10.1016/j.ijcard.2016.01.052

Gerzanich, V., Woo, S. K., Vennekens, R., Tsymbalyuk, O., Ivanova, S., Ivanov, A., et al. (2009). De novo expression of Trpm4 initiates secondary hemorrhage in spinal cord injury. Nat. Med. 15, 185-191. doi: 10.1038/nm.1899

Gualandi, F., Zaraket, F., Malagù, M., Parmeggiani, G., Trabanelli, C., Fini, S., et al. (2017). Mutation load of multiple ion channel gene mutations in brugada syndrome. Cardiology 137, 256-260. doi: 10.1159/0004 71792

Hu, Y., Duan, Y., Takeuchi, A., Hai-Kurahara, L., Ichikawa, J., Hiraishi, K., et al. (2017). Uncovering the arrhythmogenic potential of TRPM4 activation in atrial-derived HL-1 cells using novel recording and numerical approaches. Cardiovasc. Res. 113, 1243-1255. doi: 10.1093/cvr/cvx117 
Kalogeris, T., Baines, C. P., Krenz, M., and Korthuis, R. J. (2012). Cell biology of ischemia/reperfusion injury. Int. Rev. Cell Mol. Biol. 298, 229-317. doi: 10.1016/B978-0-12-394309-5.00006-7

Kruse, M., Schulze-Bahr, E., Corfield, V., Beckmann, A., Stallmeyer, B., Kurtbay, G., et al. (2009). Impaired endocytosis of the ion channel TRPM4 is associated with human progressive familial heart block type I. J. Clin. Invest. 119, 2737-2744. doi: 10.1172/JCI38292

Launay, P., Cheng, H., Srivatsan, S., Penner, R., Fleig, A., and Kinet, J. P. (2004). TRPM4 regulates calcium oscillations after T cell activation. Science 306, 1374-1377. doi: 10.1126/science. 1098845

Launay, P., Fleig, A., Perraud, A. L., Scharenberg, A. M., Penner, R., and Kinet, J. P. (2002). TRPM4 is a $\mathrm{Ca}^{2+}$-activated nonselective cation channel mediating cell membrane depolarization. Cell 109, 397-407. doi: 10.1016/S0092-8674(02)00719-5

Liu, H., Chatel, S., Simard, C., Syam, N., Salle, L., Probst, V., et al. (2013). Molecular genetics and functional anomalies in a series of 248 brugada cases with 11 mutations in the TRPM4 channel. PLoS ONE 8:e54131. doi: 10.1371/journal.pone.0054131

Liu, H., El Zein, L., Kruse, M., Guinamard, R., Beckmann, A., Bozio, A., et al. (2010). Gain-of-function mutations in TRPM4 cause autosomal dominant isolated cardiac conduction disease. Circ. Cardiovasc. Genet. 3, 374-385. doi: 10.1161/CIRCGENETICS.109.930867

Mathar, I., Kecskes, M., Van der Mieren, G., Jacobs, G., Camacho Londoño, J. E., Uhl, S., et al. (2014). Increased $\beta$-adrenergic inotropy in ventricular myocardium from Trpm4-/- mice. Circ. Res. 114, 283-294. doi: 10.1161/CIRCRESAHA.114.302835

Meusser, B., Hirsch, C., Jarosch, E., and Sommer, T. (2005). ERAD: the long road to destruction. Nat. Cell Biol. 7, 766-772. doi: 10.1038/ncb0805-766

Moore, E. N., Spear, J. F., and Fisch, C. (1993). "Supernormal" conduction and excitability. J. Cardiovasc. Electrophysiol. 4, 320-337. doi: 10.1111/j.1540-8167.1993.tb01234.x

Nilius, B., Prenen, J., Tang, J., Wang, C., Owsianik, G., Jannssens, A., et al. (2005). Regulation of the $\mathrm{Ca} 2+$ sensitivity of the nonselective cation channel TRPM4. J. Biol. Chem. 280, 6423-6433. doi: 10.1074/jbc.M4110 89200

Ramsey, I. S., Delling, M., and Clapham, D. E. (2006). An introduction to TRP channels. Annu. Rev. Physiol. 68, 619-647. doi: 10.1146/annurev.physiol.68. 040204.100431

Sagredo, A. I., Sagredo, E. A., Cappelli, C., Báez, P., Rodrigo, A. M., Blanco, C., et al. (2017). TRPM4 regulates Akt/GSK3- $\beta$ activity and enhances $\beta$-catenin signaling and cell proliferation in prostate cancer cells. Mol. Oncol. 12, 151-165. doi: $10.1002 / 1878-0261.12100$

Schattling, B., Steinbach, K., Thies, E., Kruse, M., Menigoz, A., Ufer, F., et al. (2012). TRPM4 cation channel mediates axonal and neuronal degeneration in experimental autoimmune encephalomyelitis and multiple sclerosis. Nat. Med. 18, 1805-1811. doi: 10.1038/nm.3015

Shimizu, T., Owsianik, G., Freichel, M., Flockerzi, V., Nilius, B., and Vennekens, R. (2009). TRPM4 regulates migration of mast cells in mice. Cell Calcium 45, 226-232. doi: 10.1016/j.ceca.2008.10.005
Simard, C., Sallè, L., Rouet, R., and Guinamard, R. (2012). Transient receptor potential melastatin 4 inhibitor 9-phenanthrol abolishes arrhythmias indiced by hypoxia and reoxigenation in mouse ventricle. Br. J. Pharmacol. 165, 2354-2364. doi: 10.1111/j.1476-5381.2011.01715.x

Simard, J. M., Kahle, K. T., and Gerzanich, V. (2010). Molecular mechanisms of microvascular failure in central nervous system injury-synergistic roles of NKCC1 and SUR1/TRPM4. J. Neurosurg. 113, 622-629. doi: 10.3171/2009.11.JNS081052

Sozucan, Y., Kalender, M. E., Sari, I., Suner, A., Oztuzcu, S., Arman, K., et al. (2015). TRP genes family expression in colorectal cancer. Exp. Oncol. 37, 208-212.

Stallmeyer, B., Zumhagen, S., Denjoy, I., Duthoit, G., Hébert, J.-L., Ferrer, X., et al. (2012). Mutational spectrum in the $\mathrm{Ca}^{2+}$-activated cation channel gene TRPM4 in patients with cardiac conductance disturbances. Hum. Mutat. 33, 109-117. doi: 10.1002/humu.21599

Syam, N., Chatel, S., Ozhathil, L. C., Sottas, V., Baruteau, A., Rougier, J. S., Amarouch, M., et al. (2016). Variants of transient receptor potential melastatin member 4 in childhood atrioventricular block. J. Am. Heart Assoc. 5:e001625. doi: 10.1161/JAHA.114.001625

Syam, N., Rougier, J. S., and Abriel, H. (2014). Glycosylation of TRPM4 and TRPM5 channels: molecular determinants and functional aspects. Front. Cell. Neurosci. 8:52. doi: 10.3389/fncel.2014.00052

Vennekens, R., and Nilius, B. (2007). Insights into TRPM4 function, regulation and physiological role. Handb. Exp. Pharmacol. 179, 269-285. doi: 10.1007/978-3-540-34891-7_16

Winkler, P. A., Huang, Y., Sun, W., Du, J., and Lü, W. (2017). Electron cryomicroscopy structure of a human TRPM4 channel. Nature 552, 200-204. doi: $10.1038 /$ nature 24674

Woo, S. K., Kwon, M. S., Ivanov, A., Geng, Z., Gerzanich, V., and Simard, J. M. (2013). Complex n-Glycosylation stabilizes surface expression of transient receptor potential melastatin $4 \mathrm{~b}$ protein. J. Biol. Chem. 288, 36409-36417. doi: 10.1074/jbc.M113.530584

Zhang, Z., Okawa, H., Wang, Y., and Liman, E. R. (2005). Phosphatidylinositol 4, 5-Bisphosphate rescues TRPM4 channels from desensitization. J. Biol. Chem. 280, 39185-39192. doi: 10.1074/jbc.M506965200

Zhou, Z., Gong, Q., and January, C. T. (1999). Correction of defective protein trafficking of a mutant HERG potassium channel in human long QT syndrome. J. Biol. Chem. 274, 31123-31126. doi: 10.1074/jbc.274.44.31123

Conflict of Interest Statement: The authors declare that the research was conducted in the absence of any commercial or financial relationships that could be construed as a potential conflict of interest.

Copyright (c) 2018 Bianchi, Ozhathil, Medeiros-Domingo, Gollob and Abriel. This is an open-access article distributed under the terms of the Creative Commons Attribution License (CC BY). The use, distribution or reproduction in other forums is permitted, provided the original author(s) and the copyright owner are credited and that the original publication in this journal is cited, in accordance with accepted academic practice. No use, distribution or reproduction is permitted which does not comply with these terms. 
OPEN ACCESS

Edited by:

Marcel van der Heyden, University Medical Center Utrecht, Netherlands

Reviewed by:

Lee L. Eckhardt,

University of Wisconsin-Madison, United States Irena Levitan,

University of Illinois at Chicago, United States

*Correspondence: Paul A. Welling pwelling@umaryland.edu

tThese authors have contributed equally to this work.

Specialty section: This article was submitted to Cardiac Electrophysiology, a section of the journal

Frontiers in Physiology

Received: 12 February 2018

Accepted: 17 July 2018

Published: 03 August 2018

Citation:

Taneja TK, Ma D, Kim BY and Welling PA (2018) Golgin-97 Targets

Ectopically Expressed Inward Rectifying Potassium Channel, Kir2.1, to the trans-Golgi Network in COS-7

Cells. Front. Physiol. 9:1070. doi: 10.3389/fphys.2018.01070

\section{Golgin-97 Targets Ectopically Expressed Inward Rectifying Potassium Channel, Kir2.1, to the trans-Golgi Network in COS-7 Cells}

\author{
Tarvinder K. Taneja ${ }^{\dagger}$, Donghui Ma ${ }^{\dagger}$, Bo Y. Kim and Paul A. Welling*
}

Department of Physiology, Maryland Center for Kidney Discovery, School of Medicine, University of Maryland, Baltimore, Baltimore, MD, United States

The inward rectifying potassium channel, Kir2.1, is selected as cargo at the transGolgi network (TGN) for export to the cell surface through a unique signal-dependent interaction with the AP1 clathrin-adaptor, but it is unknown how the channel is targeted at earlier stages in the secretory pathway for traffic to the TGN. Here we explore a mechanism. A systematic screen of Golgi tethers identified Golgin-97 as a Kir2.1 binding partner. In vitro protein-interaction studies revealed the interaction is direct, occurring between the GRIP domain of Golgin-97 and the cytoplasmic domain of Kir2.1. Imaging and interaction studies in COS-7 cells suggest that Golgi-97 binds to the channel en route through the Golgi. RNA interference-mediated knockdown of Golgin-97 prevented exit of Kir2.1 from the Golgi. These observations identify Golgin-97 as a Kir2.1 binding partner that is required for targeting the channel to the TGN. Based on our studies in COS-7 cells, we propose Golgi-97 facilitates formation of AP1-dependent export carriers for Kir2.1 by coupling anterograde delivery of Kir2.1 with retrograde recycling of AP-1 containing endosomes to the TGN.

Keywords: potassium channel, golgi apparatus, clathrin, inward rectifying $\mathrm{K}$ channel, membrane trafficking

\section{INTRODUCTION}

Highly orchestrated trafficking processes ensure that cardiac ion channels are expressed on appropriate membrane domains at suitable densities to maintain the electrical rhythm of the heart. Targeting of the inward rectifying potassium channel, Kir2.1, to the t-tubule and sarcolemma in ventricular myocytes (Ma et al., 2011), for example, is made possible by a series of sequential processes that deliver newly synthesized channels from the endoplasmic reticulum to the Golgi (Ma et al., 2001), control trans-Golgi network (TGN) to the cell surface (Ma et al., 2011), and drive association with appropriate lipid domains (Vaidyanathan et al., 2013, 2018; Han et al., 2014) and scaffolding complexes (Leonoudakis et al., 2004a,b; Rubi et al., 2017). The importance of membrane trafficking is underscored by human disease; mutations in Kir2.1 that disrupt proper trafficking (Bendahhou et al., 2003; Ballester et al., 2006; Ma et al., 2011) cause Andersen-Tawil syndrome (Plaster et al., 2001), which predisposes affected patients to cardiac arrhythmias.

Although great progress has been made in unraveling many of the mechanisms that control the transport of Kir2.1 in the secretory pathway, it still remains poorly understood how the channel is sorted in the Golgi from resident Golgi-proteins for transport to the TGN. Differences in transmembrane spans and lipid partitioning (Patterson et al., 2008) are generally believed to provide a universal mechanism. In the present study, we consider a new Golgi segregation process, involving Golgin molecules. 
Members of the Golgin protein family are well appreciated to act as specific tethers that selectively capture transport vesicles for SNARE-mediated fusion with distinct membrane compartments of the Golgi (Munro, 2011; Witkos and Lowe, 2015; Gillingham and Munro, 2016). Different Golgins associate with different Golgi regions and have distinct capture activities toward vesicles of different origins (Wong and Munro, 2014). Additionally, anterograde trafficking of several proteins through the Golgi, including the HERG cardiac potassium channel (Bundis et al., 2006), require specific Golgin molecules.

In the course of defining the TGN export mechanism in Kir2.1 (Ma et al., 2011) and related channels (Li et al., 2016), we made a serendipitous observation that implicated Golgin-97 in intra Golgi trafficking. We found mutations in the TGN export signal caused marked accumulation of the channel throughout the entire Golgi apparatus, suggesting export from the TGN might be closely coupled to anterograde transport through the Golgi. Remarkably, the Golgi-export mutants in the cis-Golgi tightly co-localized with Golgi-97, a golgin molecule that is usually confined to the TGN, making us wonder if a Golgin-97 interaction mechanism might explain how channels are selected in the Golgi for delivery to the TGN. Here, we test this idea.

\section{MATERIALS AND METHODS}

\section{Antibodies}

Antibodies used in this study were: anti-HA mouse monoclonal antibody (Covance Inc., Princeton, NJ, United States), anti-HA rabbit monoclonal (Upstate Cell Signaling Solutions, Waltham, MA, United States), anti-myc rabbit polyclonal, (Santa Cruz Biotechnology, Inc., Santa Cruz, CA, United States), antiGolgin-97 (Invitrogen, \#A21270), anti-p230 (BD Transduction Laboratories, Lexington, KY, United States \#611230), antiGM130 (BD Transduction Laboratories, \#51-9001978), horseradish peroxidase (HRP)-conjugated goat anti-mouse or anti-rabbit (Jackson Laboratory, Bar Harbor, ME, United States), Goat anti-GST-HRP (Amersham Biosciences, Piscataway, N), United States), Alexa Fluor-conjugated secondary antibodies (Invitrogen Molecular Probes, Eugene, OR, United States).

\section{Molecular Biology}

All Kir2.1 constructs are derived from the mouse Kir2.1 channel cDNA (NM_008425). As described before (Ma et al., 2001), an external hemagglutinin (HA) epitope tag was engineered into the channel at a location that does not affect that the physiological function or biochemical properties of the channel (Ma et al., 2007). For some interaction studies, a myc-tag was incorporated in frame on to the N-terminus of Kir2.1 cytoplasmic C-terminal domain fragments. cDNAs for human Golgin-97 (MGC 22154), ARL1 (MGC 12286), and Golgi Matrix Protein 130 (Golga2, MGC 78452) were acquired from distributors of the IMAGE collection, and mouse p230/Golgin 245 was purchased from ATCC (10089301), and tagged in frame to the ORFs at the $\mathrm{N}$ or C-termini with HA or myc-epitopes. Site-directed mutagenesis was carried out using a PCR based strategy with PfuTurbo DNA polymerase (QuikChange, Stratagene). The pcDNA3.1 mammalian expression vector (Invitrogene, Inc.) was used to express the cloned channel genes in COS7 cells. For GST pulldown analyses, recombinant DNA fragments were subcloned into pGEX-5X-2. All sequences were confirmed by dye termination DNA sequencing analysis (University of Maryland School of Medicine Biopolymer Core).

\section{Cell Culture and Transfection}

COS7 cells were cultured in high glucose DMEM medium (Invitrogene, Inc., Carlsbad, CA, United States) supplemented with $10 \%$ Fetal Bovine Serum, $100 \mathrm{U} / \mathrm{ml}$ penicillin and $100 \mu \mathrm{g} / \mathrm{ml}$ streptomycin in a humidified atmosphere at $37^{\circ} \mathrm{C}$ in $5 \% \mathrm{CO} 2$. Cells were transfected using Fugene 6 or X-tremeGENE 9 transfection reagent (Roche Ltd., Basel, Switzerland).

\section{RNA Interference}

The double-stranded siRNA to target human form of Golgin-97 and non-targeting siRNA were purchased from Thermo/Dharmacon Inc. (Lafayette, CO, United States). The Golgi-97 probe corresponded to sense sequence 5'GAUCACAGCCCUGGAACAAUU-3'. Cells were transfected with $\sim 160$ pmole of either probe, and transfected on the subsequent day with Kir2.1 and/or non-targeting Golgin cDNAs, and then assayed after an additional $\sim 36 \mathrm{~h}$.

\section{Immunoprecipitation}

COS-7 cells were lysed in ice-cold detergent buffer (1\% Triton $\mathrm{X}-100,1 \times \mathrm{PBS}$, with protease inhibitors) and the clarified supernatant $(15,000 \mathrm{~g}$ spin, $15 \mathrm{~min})$ was incubated with Protein A $+\mathrm{G}$ beads (Cal Biochem, cat IP05), and $1 \mu \mathrm{g}$ of immunoprecipitating antibody for $4 \mathrm{~h}$ rotating at $4^{\circ} \mathrm{C}$. Beads were washed for $5 \mathrm{~min}$ with $1 \times$ PBS for three times; bound proteins were eluted with $2 \times$ Laemmli sample buffer for $30 \mathrm{~min}$ at room temperature; and the entire immunoprecipitate was run on a SDS-gel, and transferred to nitrocellulose for immunoblot analysis.

\section{Quantitative Chemiluminescence Detection of Surface Proteins}

To quantify cell surface expression of Kir2.1 in mammalian cells, $36 \mathrm{~h}$ after transfection COS7 were fixed with 3\% paraformaldehyde (PFA) for $15 \mathrm{~min}$ on ice, blocked on ice with blocking buffer (5\% Fetal Bovine Serum in $1 \times$ PBS, $30 \mathrm{~min}$ ), incubated with mouse monoclonal anti-HA (Covance Inc; 1:300 dilution in blocking buffer, $1 \mathrm{~h}$ at room temperature), washed (with $1 \times \mathrm{PBS}$, three times for $5 \mathrm{~min}$ ), incubated with goat anti-mouse IgG HRP-conjugated secondary antibody (1:1000 dilution, Jackson) (in blocking buffer, $30 \mathrm{~min}$ ), and then extensively washed $(1 \times \mathrm{PBS}, 5 \mathrm{~min} /$ time for four times in total). After washing, the cells were scraped off from the plates and resuspended well into $500 \mu \mathrm{l} 1 \times \mathrm{PBS}$. From the cell suspension, $10 \mu \mathrm{l}$ of cell suspension was withdrawn and incubated with $100 \mu \mathrm{l}$ of mixed SuperSignal ELISA Pico solution (Pierce Biotechnology, Inc., Rockford, IL, United States), and subsequently chemiluminescence signal was measured as previously described (Ma et al., 2007). To normalize the data for 
total protein expression level, western-blot analyses were carried out in parallel with anti-HA, or anti-Kir2.1 (Chemicon Inc.), and then quantified by densitometry analysis. Reported values are the average of triplicate transfections from three different experiments.

\section{Production of Recombinant GST Fusion Proteins and Pull-Down Analysis}

The GST fusion proteins were purified on glutathione-agarose beads according to the standard protocol supplied from Amersham Biosciences, except using two times more lysis buffer than the original volume suggested in the protocol to maximize the yield. To purify the recombinant protein to high homogeneity, the GST beads were further washed with high salt buffer $(0.5 \mathrm{M} \mathrm{NaCl}, 25 \mathrm{mM}$ HEPES, and $2.5 \mathrm{mM} \mathrm{MgCl}$, pH7.0) twice before balancing with $1 \times$ KOAc buffer $(115 \mathrm{mM}$ KOAc, $25 \mathrm{mM}$ HEPES, and $2.5 \mathrm{mM} \mathrm{MgCl}_{2}$, pH7.0) for pull-down analysis. The relative amount of fusion protein was quantitated by SDS-PAGE electrophoresis and then stained with coomassie blue in parallel with serial diluted BSA standard. For pull-down assays, $10 \mu \mathrm{g}$ of purified GST beads were incubated with $100 \mu \mathrm{g}$ of cellular lysates. After overnight incubation at $4^{\circ} \mathrm{C}$, the GST beads were extensively washed with $1 \times$ PBS buffer containing $0.1 \%$ Triton $\mathrm{X}-100$ to remove any non-specific binding (4 times for 10 min each time). Proteins bound on the beads were eluted by SDS-loading dye, fractionated by SDS-PAGE gel electrophoresis, blotted onto nitrocellulose membrane, and then probed with the relevant antibody.

\section{RESULTS}

\section{Kir2.1 Interacts Specifically With Golgin-97}

We considered the possibility that Kir2.1 might be pre-selected as secretory cargo in the Golgi for export at the TGN by interaction with specific Golgin tethering molecules. To explore this hypothesis, we first surveyed members of the two main classes of Golgi tethers (GM130 and the GRIP domain containing Golgins, Golgin-245/p230, and Golgin-97) for interaction with Kir2.1. As measured by co-immunoprecipitation from COS7 cells that were transfected with Kir2.1, we found that the wildtype channel Kir2.1 (WT) and the TGN-export mutant $(\Delta 314-$ 315) channel but not the ER-export mutant ( $\triangle \mathrm{FCY}$ ) interact with Golgin-97, as expected for an interaction that is initiated within the Golgi (Figure 1A). Consistent with this idea, we found more of the TGN-export mutant $(\Delta 314-15)$ channel co-immunoprecipitated with Golgin-97 than the WT channel

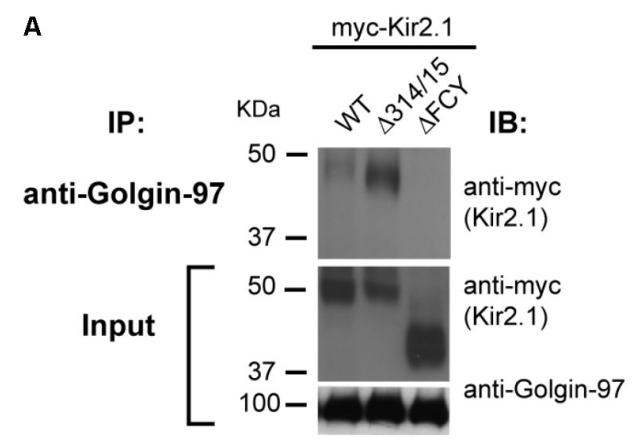

B

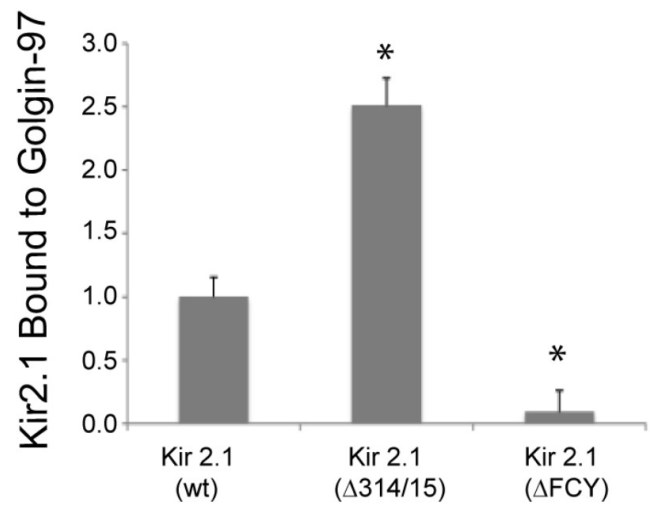

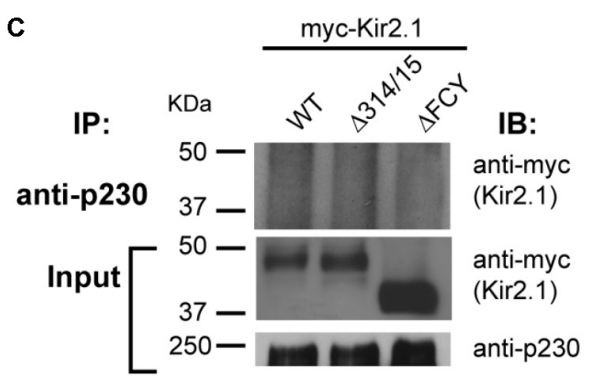

D

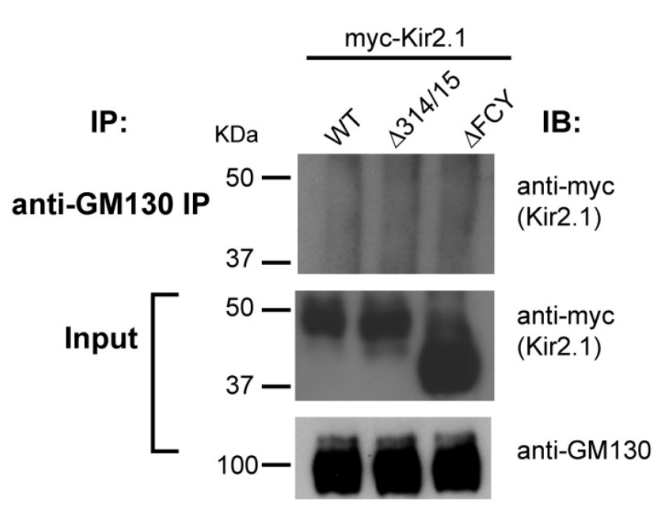

FIGURE 1 | Kir2.1 specifically binds to Golgin-97. Immunoprecipitation (IP) performed with (A) anti-Golgin-97; (C) anti-p230; (D) anti-GM130 antibodies from COS cells transfected with myc-Kir2.1 wild type $(\mathrm{WT})$, the TGN-export mutant ( $\triangle 314-315)$, and the ER-export mutant $(\Delta \mathrm{FCY})$ and then immunoblotted (IB) with myc-antibodies to detect Kir2.1 in the Golgin immunoprecipitates. 5\% input is shown below; (B) Quantification of the relative amounts of Kir2.1 immunoprecipatated with Golgin-97. * $P<0.05$. 

A
$\mathrm{N}$
Coiled-coil domain
GRIP domain C

Golgin-97

B

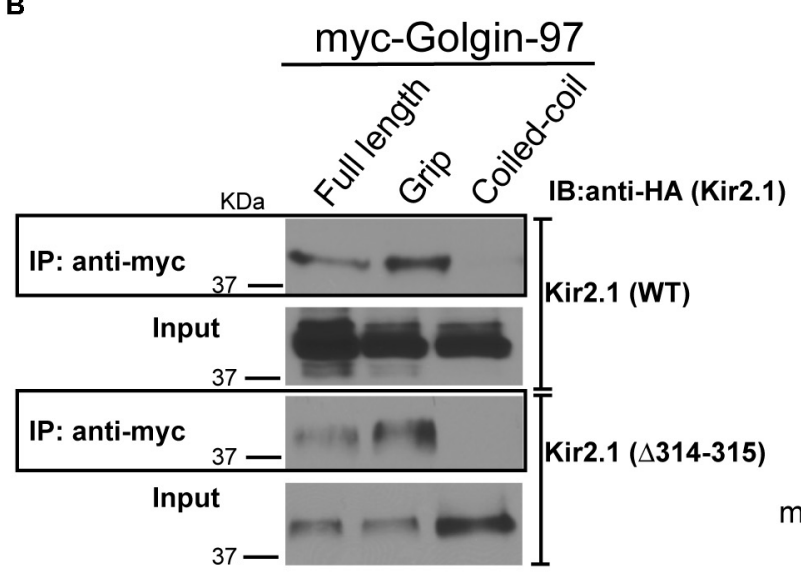

D

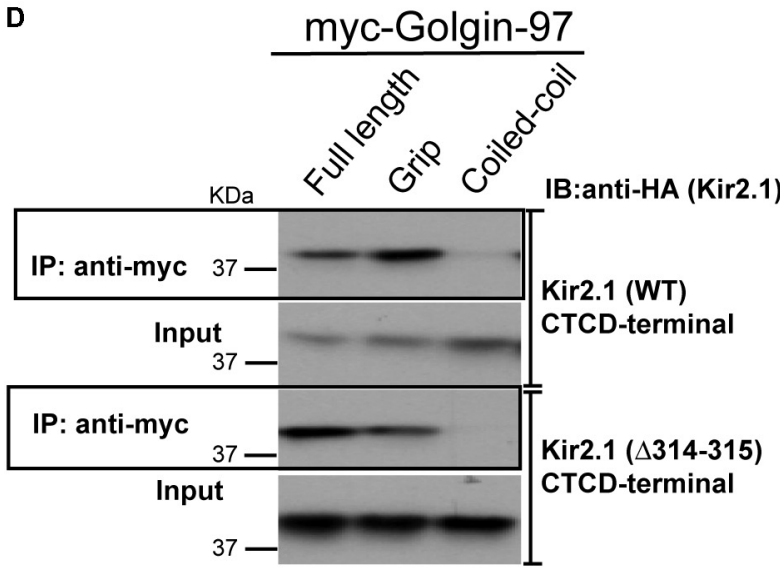

C

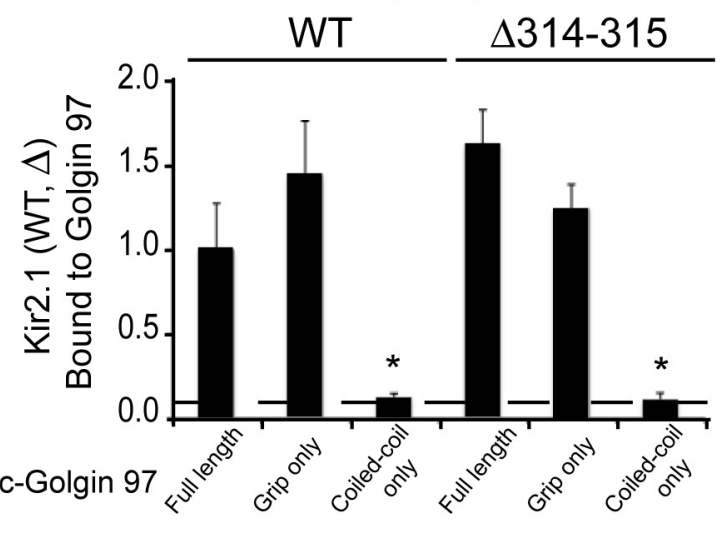

E

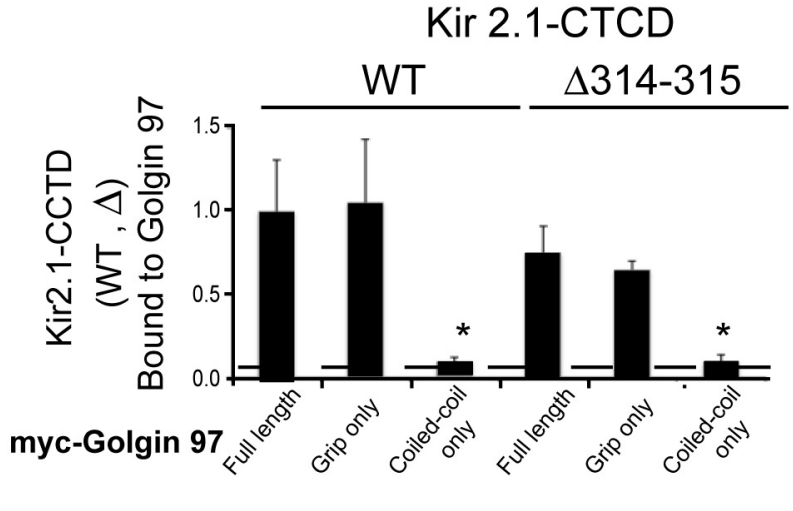

$\mathbf{F}$

GST-

Kir2.1 CTCD

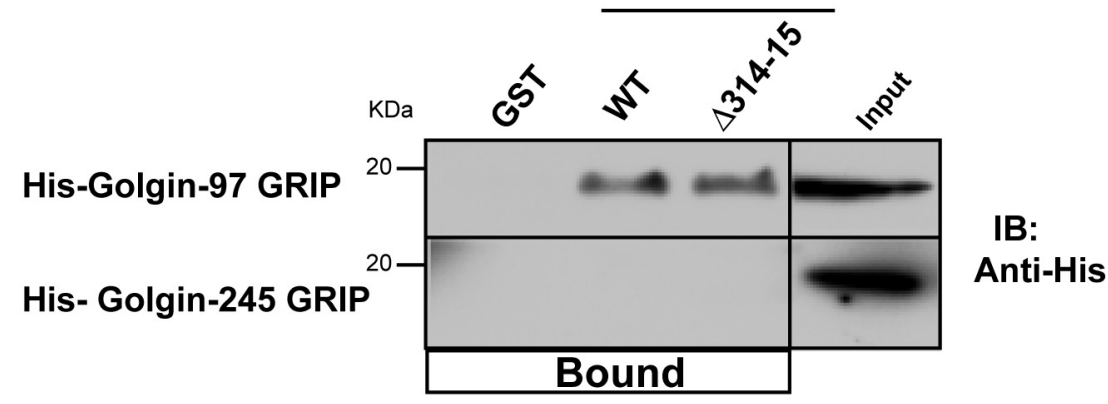

FIGURE 2 | Golgin-97 GRIP domain directly interacts with Kir2.1. (A) Domain structure of Golgin-97, showing the GRIP domain and the coiled-coil domain. (B) Anti-myc immunoprecipitation (IP) followed by anti-HA immunoblotting (IB) from COS cells co-transfected with myc-Golgi 97 (Full length, Grip domain only, or coiled-coiled domain only) and HA-Kir2.1 wild type, WT, or the TGN-export mutant ( $\triangle 314-315)$ or (D) the HA-tagged Kir2.1 COOH-terminal cytoplasmic domain (CTCD). (C,E) Quantitative summaries comparing relative amounts of Kir2.1 (WT or $\Delta 314-315)$ immunoprecipitated with full-length Golgin-97, or GRIP or Coiled-Coil domain, ${ }^{*} P<0.05$. (F) GST pulldowns: GST alone or GST fusion proteins of the Kir2.1 CTCD were used to test for direct interaction with His-tagged GRIP domains of Golgin-97 or Golgin-245 purified from bacteria. Protein bound is shown relative to $5 \%$ input. 
(Figure 1B). By contrast, we were unable co-immunoprecipitate Kir2.1 with antibodies to Golgin-245/p230 (Figure 1C), another TGN-localized, GRIP-containing Golgin (Cowan et al., 2002), or GM130 (Figure 1D), a member of the Golgin family of coiled-coil proteins that controls membrane tethering between the cis-Golgi intermediate compartment and endoplasmic reticulum and that has been implicated in HERG-channel trafficking (Newton-Cheh et al., 2009). Thus, Kir2.1/Golgin-97 interaction appears to be specific, at least amongst the Golgin molecules that were studied.

\section{Golgin-97 GRIP Domain Associates With the Cytoplasmic Domain of Kir2.1}

We next sought to determine the protein binding domains that govern the interaction between Kir2.1 and Golgi-97. Golgin-97 contains two major domains, the $\sim 45$ residue GRIP domain, which binds to Arl1 to drive Golgi localization (Lu and Hong, 2003; Panic et al., 2003; Derby et al., 2004; Lu et al., 2004; Wu et al., 2004), and a long coiled domain, which provides a tethering function (Wong and Munro, 2014; Figure 2A). To test which Golgin-97 domain(s) interact with Kir2.1, COS7 were cotransfected different myc-tagged Golgin-97 constructs and HAtagged Kir2.1, and anti-myc immunoprecipitations were followed by anti-HA immunoblotting. As shown in Figure 2 (Figure 2B representative gel, Figure $\mathbf{2 C}$, summary data, $n=3$ ), the isolated GRIP domain of Golgin-97 but not the coiled-coil domain is sufficient for binding to Kir2.1. Both WT Kir2.1 and the TGNexport mutant (Kir2.1 $\Delta 314-315$ ) are able to interact with the GRIP domain.

We considered that the large C-terminal cytoplasmic domain (CTCD) to be the most likely structure in the channel to interact with Golgin-97, and, therefore tested if it was sufficient to interact with Golgin-97. For these studies, the HA-tagged C-terminal domain (WT or the $\Delta 314-315$ mutant) was coexpressed in COS7 cells with myc-tagged Golgin-97 (full length or isolated) and myc-antibody immunoprecipitations were performed (Figure 2D, summarized in Figure 2E). As detected in anti-HA Western blots of the myc-antibody immunoprecipitates, we found the Kir2.1 CTCD is able to interact with full length Golgin-97 through the GRIP domain. The $\Delta 314-315$ mutant, which lacks part of the Golgi-export signal (Ma et al., 2011), also supports interaction with the Golgin-97 grip domain. Thus, Kir2.1 cytoplasmic C-terminus has the capacity to orchestrate Golgi-97 binding, independently of TGN-export.

To test if the interaction is direct, His-tagged Golgin GRIP domains of Golgin-97 and Golgin-245 were produced in E. coli, purified and tested for binding in GST-affinity

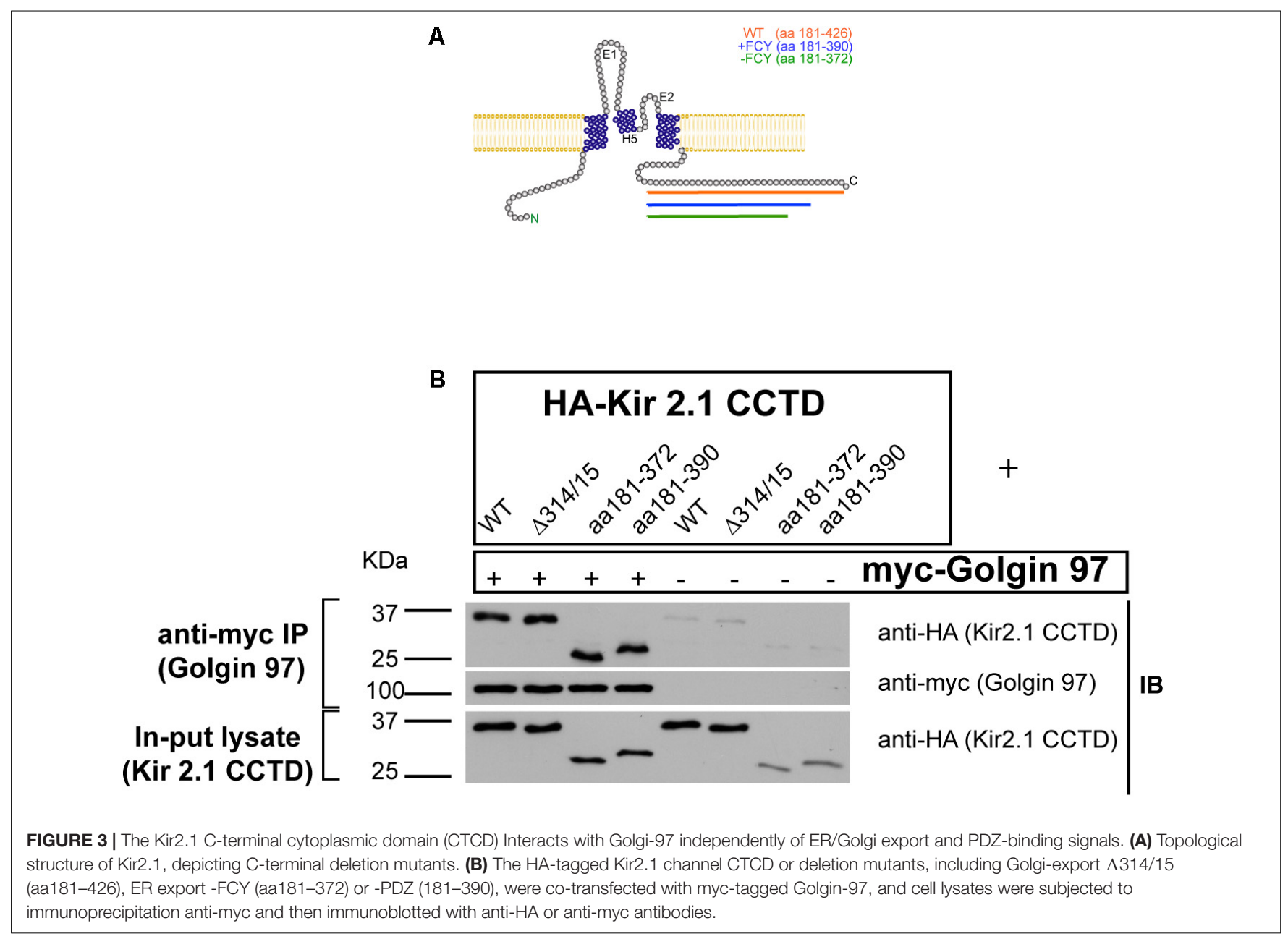




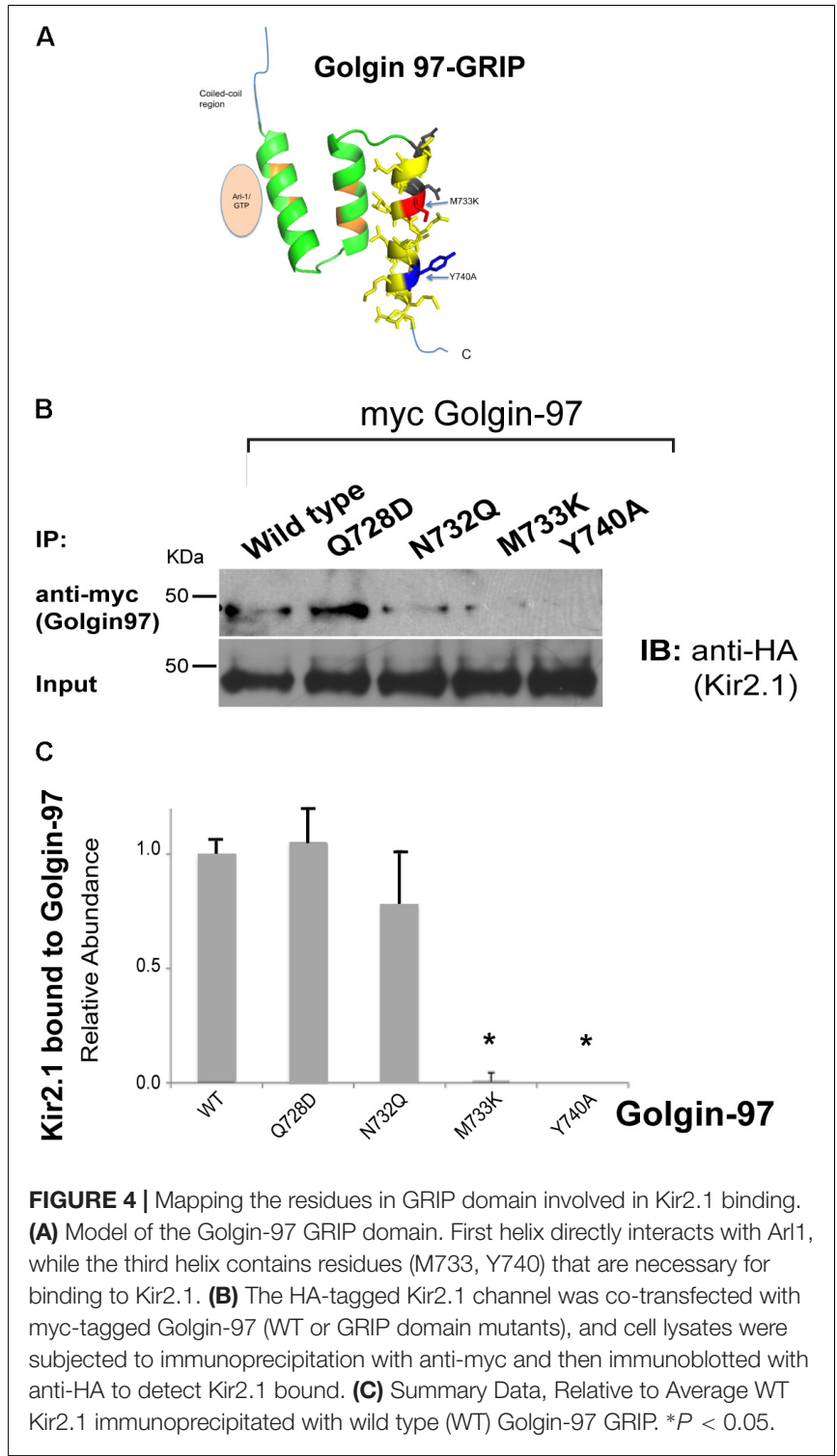

chromatography studies with purified GST-fusion proteins of the Kir2.1 C-terminal domain (WT and $\Delta 314-315$ mutant). As shown in Figure 2F, GST-Kir2.1C (WT and $\Delta 314-315$ mutant), but not GST alone, pulled down the Golgin-97 GRIP domain. The interaction appeared to be highly specific because the Golgin-245 grip domain was unable to interact with GSTKir2.1CTCD; no detectable binding was observed even after prolonged exposure.

We wondered if Golgi-97 might interact with the "FCY" ER-export signal (Ma et al., 2001) or the PDZ binding site (Leonoudakis et al., 2004a) at the extreme C-terminus of Kir2.1. To test this, we transfected COS cells with myc-tagged Golgin-97 and HA-tagged fragments of the Kir2.1 C-terminus (Figure 3A), and performed anti-myc immunoprecipitation, anti-HA immunoblots (Figure 3B). CTCD fragments, included the full length polypeptide (aa 181-426); a CTCD deletion mutant, lacking the PDZ binding motif (aa 181-390); and another CTCD domain, lacking the FCY ER export signal (181337). As shown in Figure 3, each of the CTCD fragments co-immunoprecipitated with Golgin-97. Because Golgin-97 interacts with Kir2.1, independently of the ER-export signal it unlikely that Golgin-97 controls ER- to-Golgi transport of Kir2.1.

\section{Residues in GRIP Domain Essential for the Interaction With Kir2.1}

We hypothesized that Kir2.1 might interact with the Golgin-97 GRIP domain at a site that is distinct from the Arl1-binding domain, and structural homology modeling with Golgin-245 (Figure 4A), suggested that the third helix as the most likely channel interaction site. Sequence analysis identified several residues in the third helix of the Golgi-97 GRIP domain that are different from the GRIP domain of Golgin-245. We replaced these residues with the corresponding amino acids found Golgin245. As evaluated by co-immunoprecipitation, M733K and Y740A point mutations abrogated the binding of the GRIP domain to Kir2.1 (Figures 4B,C). Thus, M733 and Y740 are necessary for the interaction, presumably by acting as a direct docking site for Kir2.1.

\section{Interaction of Golgin-97 and Kir2.1 Occurs at the Golgi}

We next determined whether the Golgin-97-Kir2.1 interaction is initiated in the Golgi. For these studies, COS7 cells were transfected with two different Kir2.1 trafficking mutants, the ERexport deficient, $\triangle \mathrm{FCY}$, (Ma et al., 2001) or the Golgi-export deficient, $\Delta 314-315$ (Ma et al., 2011), and the channels were co-localized (Figure 5A) or co-immunoprecipitated (Figure 5B) with Golgi 97, before and after treatment with brefeldin A (Ward et al., 2001). As shown in Figure 5, the $\triangle$ FCY mutant channel largely resided in subcellular compartment, typical of the endoplasmic reticulum as shown previously (Ma et al., 2001), and did not appreciably co-localize (Figure 5A) or coimmunoprecipitate with Golgin-97 (Figure 5B), regardless of BFA treatment. By contrast, a large fraction of the Golgi-export mutant, Kir2.1 $\Delta 314-315$, interacted with and co-localized with Golgin-97 in a perinuclear compartment, typical of the Golgi as shown previously (Ma et al., 2011). Treatment with BFA stimulated the absorption of Kir2.1 $\Delta 314-315$ and Golgi97 to the ER, where the two proteins remained co-localized (Figure 5A), and co-immunoprecipitated (Figure 5B). These observations are consistent with the idea that Golgin-97 channel binds to Golgin-97 in the cis- or medial Golgi en route to the TGN, and the proteins remain tightly associated even after BFA treatment.

\section{Knockdown of Golgin-97 Inhibits the Cell Surface Delivery of Kir2.1}

To evaluate the functional consequence of the interaction between Kir2.1 and Golgin-97, we assessed the impact of knocking down Golgi-97 on the subcellular localization and expression of Kir2.1 at the plasmalemma. Significant reduction in Golgin-97 protein abundance was achieved upon transfection with Golgin-97 specific siRNA, compared to the scramble 


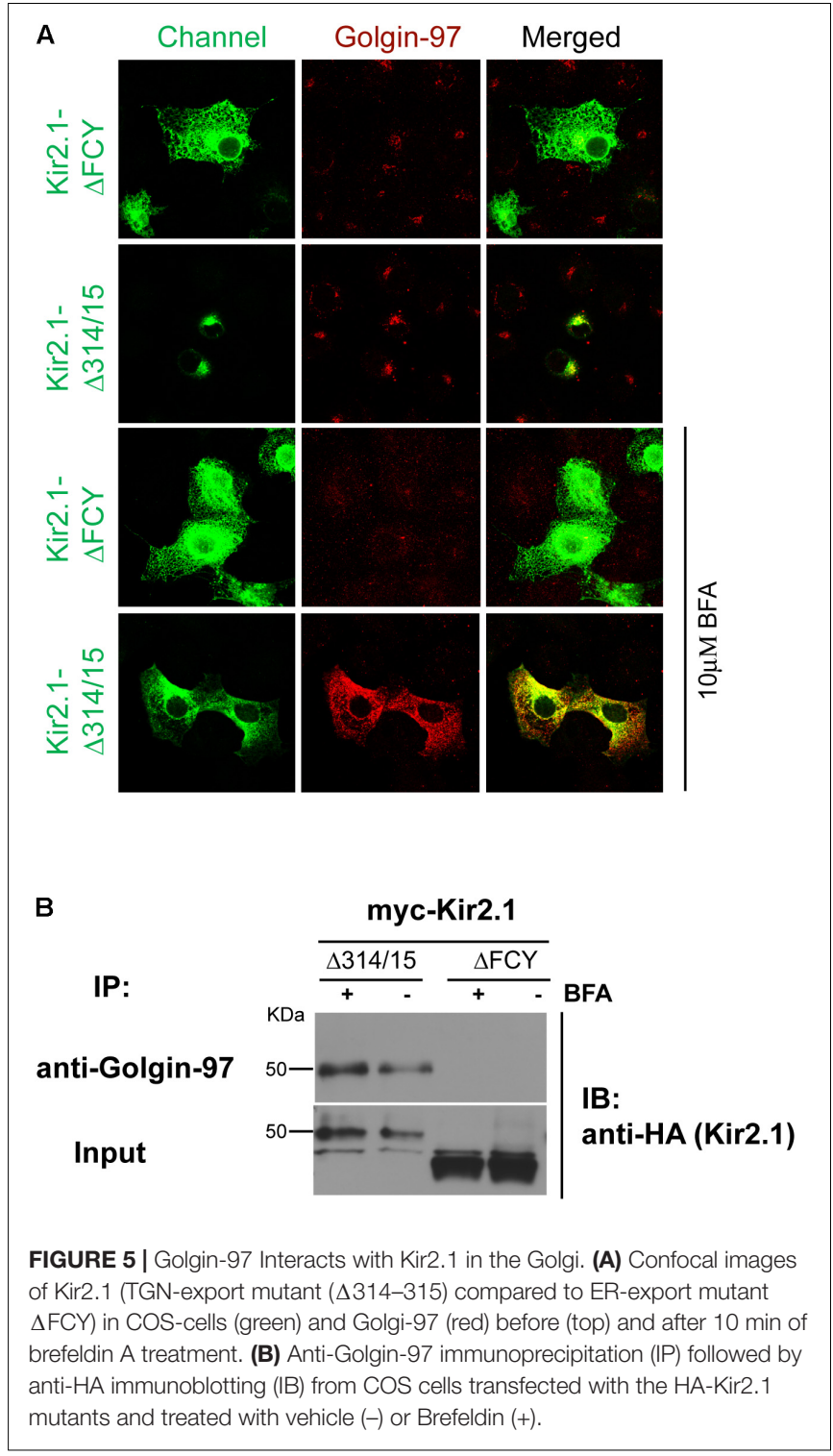

probe (Figure 6A) in COS cells. As measured by surface antiHA antibody binding and analytical luminometry, Golgin-97 depletion significantly reduced Kir2.1 expression on the surface membrane (Figure 6B). Immunocytochemistry and confocal microscopy revealed that Kir2.1 largely accumulated in the Golgi following Golgin-97 knockdown, while the scramble siRNA probe had no effect on the Kir2.1 distribution at the cell surface membrane (Figure 6C). We conclude from these studies that Golgin-97 is necessary for Kir2.1 export from the Golgi.

To test whether Golgin-97 drives Kir2.1 channel trafficking in a manner that is dependent on channel interaction, we performed rescue experiments with siRNA-resistant Golgi-97 constructs, and compared the rescue response of WT Golgi-97 to binding deficient (M733K and Y740A) mutants (Figure 6D). For these studies, COS-7 cells were co-transfected with the Golgin-97 constructs, Golgin-97 siRNA and the external epitope tagged Kir2.1. As measured by surface anti-HA antibody
A

SiRNA:

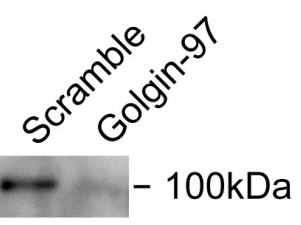

B

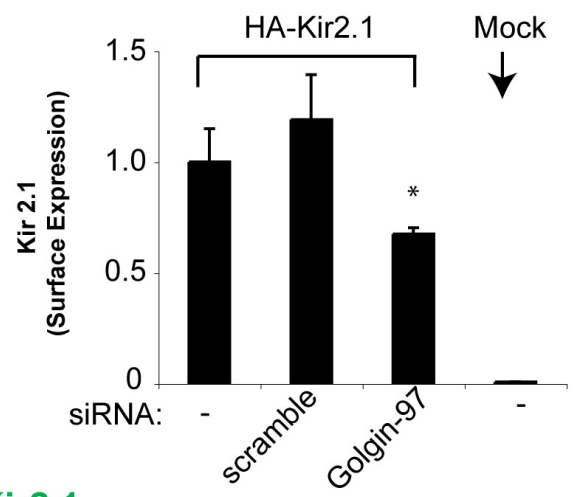

C

Kir2.1
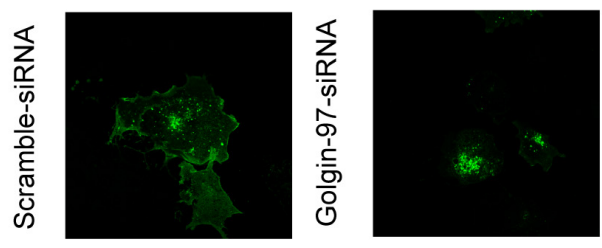

D
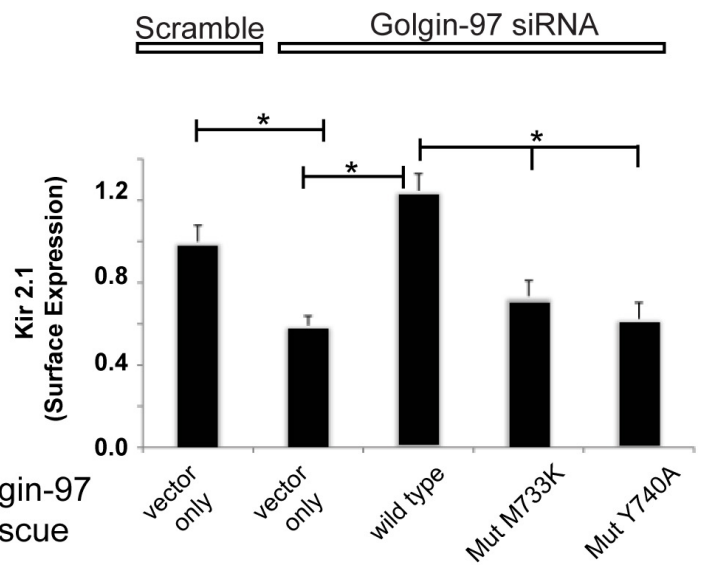

FIGURE 6 | Golgin-97 is required for efficient delivery of Kir2.1 to the cell surface membrane from the Golgi. (A) Immunoblot of Golgin-97 from COS cells transfected with scramble or Golgi-97 siRNA. (B) Surface Expression of external HA-epitope tagged Kir2.1 in COS cells co-transfected with scramble or Golgi-97 siRNA or nothing. Mock are cells transfected with vector alone. (C) Representative confocal microscopy of Kir2.1 in COS cells transfected with scrample, or Golgin-97 siRNA. (D) Rescue Studies, Surface Expression of external HA-epitope tagged Kir2.1 in COS cells co-transfected with scramble or Golgi-97 siRNA and Golgin-97 rescue cDNA (WT vs mutant), $* P<0.05$

binding, expression of wild type Golgi-97, but not the binding deficient mutants, rescued the trafficking of Kir2.1 to the surface membrane in Golgin-97 knockdown cells. Thus, trafficking of 
Kir2.1 to the cell surface is dependent on Kir2.1 interaction with Golgin-97.

\section{DISCUSSION}

This study reveals a previously unappreciated trafficking process that directs potassium channels in the Golgi for delivery to the plasma membrane. It has been generally believed that secretory proteins are sorted in Golgi from resident Golgi proteins and proteins traveling to the ER by virtue of differences in transmembrane spans and lipid partitioning (Patterson et al., 2008). Similar processes have recently have been shown to segregate endolysosomal proteins from plasma membrane-destined proteins in the cis-Golgi for transport to distinct exit sites at the TGN (Chen et al., 2017). Our data suggest signal-dependent protein-protein interactions can also drive Golgi sorting processes. Indeed, we identified Golgin97 as an interacting partner of Kir2.1, and found Gogin-97 is essential for Golgi-trafficking and delivery of Kir2.1 to the cell surface membrane. Because the interaction is initiated in the Golgi, we propose Golgin-97 marks the channel for inclusion in specialized exit sites at the TGN, where the Kir2.1 and related channels are incorporated into clathrin-coated vesicles through AP1 clathrin adaptor interactions (Ma et al., 2011).

The discovery of Golgin-97-dependent Kir2.1 trafficking extends our understanding of the Golgin molecules. Golgin97 and Golgin p230 belong to a subset of the Golgin family members that interact with TGN membranes (Munro, 2011). Although both Golgins depend on Arl1 for TGN localization (Lu and Hong, 2003; Panic et al., 2003; Derby et al., 2004; Shin et al., 2005), they associate with distinct sets of vesicular carriers (Wong and Munro, 2014) and appear to orchestrate different trafficking processes. For instance, Golgin-p230 is required for TNF secretion (Lieu et al., 2008), whereas Golgi-97 is required for controlling exit of E-cadherin from the TGN (Lock et al., 2005). Golgin specificity is achieved, in part, by differences in vesiclebinding sequences found in the coiled-coil domains (Wong and Munro, 2014; Gillingham and Munro, 2016). In fact, the coiledcoil domain of Golgin-97 contains a specialized binding site for adaptor molecules that associate with donor vesicles (Wong and Munro, 2014). Our observations reveal an additional mechanism. By specifically interacting with Kir2.1 through the GRIP domain, Golgin-97 specifies trafficking at the acceptor membrane. It will be important to learn if other Golgin-97 dependent forward trafficking processes, such as Golgi export of E-cadherin (Lock et al., 2005), are also orchestrated by direct binding interactions at the acceptor membrane.

Although Golgin-97 is required for efficient anterograde trafficking of Kir2.1 and E-cadherin from the TGN (Lock et al., 2005), it also mediates the retrograde transport of endosomes to the TGN (Shin et al., 2017; Wong et al., 2017). We speculate that these seemingly opposite functions are interrelated. Similar to other Golgins, which facilitate endosome-to-Golgi transport to maintain Golgi structure (Derby et al., 2007), Golgin-97 may facilitate retrograde transport of specific endosomes to recycle trafficking machineries and, thereby maintain TGN subdomains that are competent for the export of Kir2.1 and E-cadherin. Because Kir2.1 (Ma et al., 2011) and E-cadherin (Hase et al., 2013) share a common AP1 clathrin-adaptor dependent Golgi export mechanism, we speculate Golgin97 mediated endosome-to-TGN transport allows recycling of the appropriate compliment of proteins that are required to nucleate AP1-dependent export carriers, reminiscent of the way that GCC185 recycles AP1 (Derby et al., 2007; Brown et al., 2011).

We found binding site for Golgin-97 is embedded within the large cytoplasmic region of the Kir2.1 C-terminus. Significantly, the binding site is distinct from other known trafficking motifs in the channel, including the Golgi-export signal (Ma et al., 2011), the ER-export signal (Ma et al., 2001), and the PDZ binding motif (Leonoudakis et al., 2004a). The region harbors several residues that are mutated in Andersen-Tawil syndrome (Plaster et al., 2001), and that are known to be required for efficient surface expression (Bendahhou et al., 2003). It will be interesting to learn if these residues form the interaction site for Golgin-97.

There are several limitations of this study that deserve discussion. First, this study focused on membrane trafficking of Kir2.1 in a heterologous expression system. It presently remains to be determined if Golgin-97 controls Kir2.1 in a similar way in tissues where the channel is endogenously expressed, including the heart, skeletal muscle, smooth muscle, and endothelium. Studying endogenous Kir 2.1 trafficking in native tissue is currently not practical, however. Native expression levels are much lower than in experimental expression systems and antibodies are lacking sufficient efficacy to detect the native channel protein with sufficient specificity. Development of new tools will be required to test the Golgi-97 dependent trafficking mechanism in native tissues, such as by engineering an epitope tag on the channel gene, and then studying endogenous tagged-channel in cells isolated from the genetically modified model. Second, these studies were designed to study membrane trafficking of Kir2.1, not necessarily channel activity. It will be interesting for future studies to determine whether Golgi-97 as any direct effects on channel activity.

In summary, Golgin-97 directly interacts with Kir2.1 to control anterograde transport at the Golgi. Signal-dependent interactions with Golgi tethering proteins provide a mechanism to target interacting proteins to specialized TGN sub-domains to facilitate trafficking to appropriate subcellular membrane domains.

\section{AUTHOR CONTRIBUTIONS}

TT and DM designed and executed the studies, analyzed the results and prepared the figures. BK executed the studies involving cDNA cloning and mutagenesis. PW designed the studies and prepared the manuscript.

\section{FUNDING}

This study was funded in part by grants from the NIDDK to PW. 


\section{REFERENCES}

Ballester, Y., Benson, D. W., Wong, B., Law, I. H., Mathews, K. D., Vanoye, C. G., et al. (2006). Trafficking-competent and trafficking-defective KCNJ2 mutations in Andersen syndrome. Hum. Mutat. 27:388.

Bendahhou, S., Donaldson, M. R., Plaster, N. M., Tristani-Firouzi, M., Fu, Y. H., and Ptacek, L. J. (2003). Defective potassium channel Kir2.1 trafficking underlies Andersen-Tawil syndrome. J. Biol. Chem. 278, 51779-51785. doi: 10.1074/jbc.M310278200

Brown, C., Schindelhaim, C. H., and Pfeffer, S. R. (2011). GCC185 plays independent roles in Golgi structure maintenance and AP-1-mediated vesicle tethering. J. Cell Biol. 194, 779-787. doi: 10.1083/jcb.201104019

Bundis, F., Neagoe, I., Schwappach, B., and Steinmeyer, K. (2006). Involvement of Golgin-160 in cell surface transport of renal ROMK channel: co-expression of Golgin-160 increases ROMK currents. Cell. Physiol. Biochem. 17, 1-12. doi: 10.1159/000091454

Chen, Y., Gershlick, D. C., Park, S. Y., and Bonifacino, J. S. (2017). Segregation in the Golgi complex precedes export of endolysosomal proteins in distinct transport carriers. J. Cell Biol. 216, 4141-4151. doi: 10.1083/jcb.201707172

Cowan, D. A., Gay, D., Bieler, B. M., Zhao, H., Yoshino, A., Davis, J. G., et al. (2002). Characterization of mouse tGolgin-1 (golgin-245/trans-golgi p230/256 $\mathrm{kD}$ golgin) and its upregulation during oligodendrocyte development. DNA Cell Biol. 21, 505-517. doi: 10.1089/104454902320219068

Derby, M. C., Lieu, Z. Z., Brown, D., Stow, J. L., Goud, B., and Gleeson, P. A. (2007). The trans-Golgi network golgin, GCC185, is required for endosometo-Golgi transport and maintenance of Golgi structure. Traffic 8, 758-773. doi: 10.1111/j.1600-0854.2007.00563.x

Derby, M. C., van Vliet, C., Brown, D., Luke, M. R., Lu, L., Hong, W., et al. (2004). Mammalian GRIP domain proteins differ in their membrane binding properties and are recruited to distinct domains of the TGN. J. Cell Sci. 117(Pt 24), 5865-5874. doi: $10.1242 /$ jcs. 01497

Gillingham, A. K., and Munro, S. (2016). Finding the Golgi: Golgin coiled-coil proteins show the way. Trends Cell Biol. 26, 399-408. doi: 10.1016/j.tcb.2016. 02.005

Han, H., Rosenhouse-Dantsker, A., Gnanasambandam, R., Epshtein, Y., Chen, Z., Sachs, F., et al. (2014). Silencing of Kir2 channels by caveolin-1: cross-talk with cholesterol. J. Physiol. 592, 4025-4038. doi: 10.1113/jphysiol.2014.273177

Hase, K., Nakatsu, F., Ohmae, M., Sugihara, K., Shioda, N., Takahashi, D., et al. (2013). AP-1B-mediated protein sorting regulates polarity and proliferation of intestinal epithelial cells in mice. Gastroenterology 145, 625-635. doi: 10.1053/j. gastro.2013.05.013

Leonoudakis, D., Conti, L. R., Anderson, S., Radeke, C. M., McGuire, L. M., Adams, M. E., et al. (2004a). Protein trafficking and anchoring complexes revealed by proteomic analysis of inward rectifier potassium channel (Kir2.x)-associated proteins. J. Biol. Chem. 279, 22331-22346. doi: 10.1074/jbc.M400285200

Leonoudakis, D., Conti, L. R., Radeke, C. M., McGuire, L. M., and Vandenberg, C. A. (2004b). A multiprotein trafficking complex composed of SAP97, CASK, Veli, and Mint1 is associated with inward rectifier Kir2 potassium channels. J. Biol. Chem. 279, 19051-19063. doi: 10.1074/jbc.M400284200

Li, X., Ortega, B., Kim, B., and Welling, P. A. (2016). A common signal patch drives AP-1 dependent Golgi export of inwardly rectifying potassium channels. J. Biol. Chem. 291, 14963-14972. doi: 10.1074/jbc.M116.729822

Lieu, Z. Z., Lock, J. G., Hammond, L. A., La Gruta, N. L., Stow, J. L., and Gleeson, P. A. (2008). A trans-Golgi network golgin is required for the regulated secretion of TNF in activated macrophages in vivo. Proc. Natl. Acad. Sci. U.S.A. 105, 3351-3356. doi: 10.1073/pnas.0800137105

Lock, J. G., Hammond, L. A., Houghton, F., Gleeson, P. A., and Stow, J. L. (2005). E-cadherin transport from the trans-Golgi network in tubulovesicular carriers is selectively regulated by golgin-97. Traffic 6, 1142-1156. doi: 10.1111/j.16000854.2005.00349.x

Lu, L., and Hong, W. (2003). Interaction of Arl1-GTP with GRIP domains recruits autoantigens Golgin-97 and Golgin-245/p230 onto the Golgi. Mol. Biol. Cell 14, 3767-3781. doi: 10.1091/mbc.e03-01-0864

Lu, L., Tai, G., and Hong, W. (2004). Autoantigen Golgin-97, an effector of Arl1 GTPase, participates in traffic from the endosome to the trans-Golgi network. Mol. Biol. Cell 15, 4426-4443. doi: 10.1091/mbc.e03-12-0872

Ma, D., Taneja, T. K., Hagen, B. M., Kim, B. Y., Ortega, B., Lederer, W. J., et al. (2011). Golgi export of the Kir2.1 channel is driven by a trafficking signal located within its tertiary structure. Cell 145, 1102-1115. doi: 10.1016/j.cell. 2011.06.007
Ma, D., Tang, X. D., Rogers, T. B., and Welling, P. A. (2007). An andersenTawil syndrome mutation in Kir2.1 (V302M) alters the G-loop cytoplasmic K+ conduction pathway. J. Biol. Chem. 282, 5781-5789. doi: 10.1074/jbc. M608776200

Ma, D., Zerangue, N., Lin, Y. F., Collins, A., Yu, M., Jan, Y. N., et al. (2001). Role of ER export signals in controlling surface potassium channel numbers. Science 291, 316-339. doi: 10.1126/science.291.5502.316

Munro, S. (2011). The golgin coiled-coil proteins of the Golgi apparatus. Cold Spring Harb. Perspect. Biol. 3:a005256. doi: 10.1101/cshperspect.a005256

Newton-Cheh, C., Johnson, T., Gateva, V., Tobin, M. D., Bochud, M., Coin, L., et al. (2009). Genome-wide association study identifies eight loci associated with blood pressure. Nat. Genet. 41, 666-676. doi: 10.1038/ng.361

Panic, B., Perisic, O., Veprintsev, D. B., Williams, R. L., and Munro, S. (2003). Structural basis for Arl1-dependent targeting of homodimeric GRIP domains to the Golgi apparatus. Mol. Cell 12, 863-874. doi: 10.1016/S1097-2765(03)003563

Patterson, G. H., Hirschberg, K., Polishchuk, R. S., Gerlich, D., Phair, R. D., and Lippincott-Schwartz, J. (2008). Transport through the Golgi apparatus by rapid partitioning within a two-phase membrane system. Cell 133, 1055-1067. doi: 10.1016/j.cell.2008.04.044

Plaster, N. M., Tawil, R., Tristani-Firouzi, M., Canun, S., Bendahhou, S., Tsunoda, A., et al. (2001). Mutations in Kir2.1 cause the developmental and episodic electrical phenotypes of Andersen's syndrome. Cell 105, 511-519. doi: 10.1016/S0092-8674(01)00342-7

Rubi, L., Koenig, X., Kubista, H., Todt, H., and Hilber, K. (2017). Decreased inward rectifier potassium current IK1 in dystrophin-deficient ventricular cardiomyocytes. Channels 11, 101-108. doi: 10.1080/19336950.2016.1228498

Shin, H. W., Kobayashi, H., Kitamura, M., Waguri, S., Suganuma, T., Uchiyama, Y., et al. (2005). Roles of ARFRP1 (ADP-ribosylation factor-related protein 1) in post-Golgi membrane trafficking. J. Cell Sci. 118(Pt 17), 4039-4048. doi: $10.1242 /$ jcs.02524

Shin, J. J. H., Gillingham, A. K., Begum, F., Chadwick, J., and Munro, S. (2017). TBC1D23 is a bridging factor for endosomal vesicle capture by golgins at the trans-Golgi. Nat. Cell Biol. 19, 1424-1432. doi: 10.1038/ncb3627

Vaidyanathan, R., Van Ert, H., Haq, K. T., Morotti, S., Esch, S., McCune, E. C., et al. (2018). Inward rectifier potassium channels (Kir2.x) and caveolin-3 domainspecific interaction: implications for purkinje cell-dependent ventricular arrhythmias. Circ. Arrhythm. Electrophysiol. 11:e005800. doi: 10.1161/CIRCEP. 117.005800

Vaidyanathan, R., Vega, A. L., Song, C., Zhou, Q., Tan, B. H., Berger, S., et al. (2013). The interaction of caveolin 3 protein with the potassium inward rectifier channel Kir2.1: physiology and pathology related to long qt syndrome 9 (LQT9). J. Biol. Chem. 288, 17472-17480. doi: 10.1074/jbc.M112.43\{\break\} 5370

Ward, T. H., Polishchuk, R. S., Caplan, S., Hirschberg, K., and LippincottSchwartz, J. (2001). Maintenance of Golgi structure and function depends on the integrity of ER export. J. Cell Biol. 155, 557-570. doi: 10.1083/jcb.200107045

Witkos, T. M., and Lowe, M. (2015). The golgin family of coiled-coil tethering proteins. Front Cell Dev. Biol. 3:86. doi: 10.3389/fcell.2015.00086

Wong, M., Gillingham, A. K., and Munro, S. (2017). The golgin coiled-coil proteins capture different types of transport carriers via distinct N-terminal motifs. BMC Biol. 15:3. doi: 10.1186/s12915-016-0345-3

Wong, M., and Munro, S. (2014). Membrane trafficking. The specificity of vesicle traffic to the Golgi is encoded in the golgin coiled-coil proteins. Science 346:1256898. doi: 10.1126/science. 1256898

Wu, M., Lu, L., Hong, W., and Song, H. (2004). Structural basis for recruitment of GRIP domain golgin-245 by small GTPase Arl1. Nat. Struct. Mol. Biol. 11, 86-94. doi: $10.1038 / \mathrm{nsmb} 714$

Conflict of Interest Statement: The authors declare that the research was conducted in the absence of any commercial or financial relationships that could be construed as a potential conflict of interest.

Copyright (c) 2018 Taneja, Ma, Kim and Welling. This is an open-access article distributed under the terms of the Creative Commons Attribution License (CC BY). The use, distribution or reproduction in other forums is permitted, provided the original author(s) and the copyright owner(s) are credited and that the original publication in this journal is cited, in accordance with accepted academic practice. No use, distribution or reproduction is permitted which does not comply with these terms. 


\section{OPEN ACCESS}

Edited by:

Hugues Abriel,

University of Bern, Switzerland

Reviewed by:

Marc Chanson,

Université de Genève, Switzerland

Flavien Charpentier

Institut national de la Santé et de la

Recherche Médicale, France

*Correspondence:

Robin M. Shaw

robin.shaw@cshs.org

${ }^{\dagger}$ These authors have contributed equally to this work

Specialty section:

This article was submitted to

Cardiac Electrophysiology,

a section of the journal

Frontiers in Physiology

Received: 14 August 2017

Accepted: 25 October 2017

Published: 07 November 2017

Citation:

Fu Y, Zhang S-S, Xiao S, Basheer WA Baum R, Epifantseva I, Hong T and

Shaw RM (2017) CX43 Isoform

GJA1-20k Promotes Microtubule

Dependent Mitochondrial Transport.

Front. Physiol. 8:905

doi: 10.3389/fphys.2017.00905

\section{Cx43 Isoform GJA1-20k Promotes Microtubule Dependent Mitochondrial Transport}

\author{
Ying Fu ${ }^{1 \dagger}$, Shan-Shan Zhang ${ }^{1 \dagger}$, Shaohua Xiao ${ }^{1 \dagger}$, Wassim A. Basheer ${ }^{1}$, Rachel Baum ${ }^{1}$, \\ Irina Epifantseva ${ }^{1}$, TingTing Hong ${ }^{1,2}$ and Robin M. Shaw ${ }^{1,2 *}$ \\ ${ }^{1}$ Cedars-Sinai Medical Center, Cedars-Sinai Heart Institute, Los Angeles, CA, United States, ${ }^{2}$ Department of Medicine, \\ University of California, Los Angeles, Los Angeles, CA, United States
}

Connexin 43 (Cx43, encoded by GJA1) is a cell-cell communication gap junction protein expressed in all organ systems. It was recently found that GJA1 mRNA undergoes alternative translation to generate N-terminal truncated isoforms, of which GJA1-20k is the most abundant. Here we report a surprising finding that, unlike full length GJA1-43k, GJA1-20k has a strong tropism for mitochondria. Exploring function, we found that GJA1-20k appears to be an organelle chaperone and that overexpression of GJA1-20k is sufficient to rescue mitochondrial localization to the cell periphery upon exposure to hydrogen peroxide, which effectively limits the network fragmentation that occurs with oxidative stress. By high-resolution fluorescent imaging and electron microscopy, we determined that GJA1-20k is enriched at the interface between mitochondria and microtubules, appearing to load organelles for transport. Mutagenesis experiments revealed that although the microtubule-binding domain (MTBD) in GJA1-20k is not necessary for protein localization to mitochondria, the MTBD is essential for GJA1-20k to facilitate mitochondrial transport and maintain mitochondrial localization at the periphery. These results reveal an unexpected role for the alternatively translated isoform of the Cx43 gap junction protein, GJA1-20k, which is to facilitate microtubule-based mitochondrial transport and to maintain mitochondrial network integrity during cellular stress.

\section{Keywords: gap junction protein, Cx43, alternative translation, mitochondria, microtubule, oxidative stress}

\section{INTRODUCTION}

Connexin 43 (Cx43) is the most widely expressed of the 21 human connexins, occurring in all organ systems and is best recognized as a cell-cell communication protein (Beyer et al., 1987). Alternations of $\mathrm{Cx} 43$ expression and function are associated with numerous diseases including cardiac arrhythmias (Luke and Saffitz, 1991; Smith et al., 1991; Beardslee et al., 1998), cancer (Solan et al., 2012), ischemic injury (Beardslee et al., 2000), connective tissue disease (Paznekas et al., 2003), and heart failure (Akar et al., 2007; Basheer and Shaw, 2016). The mechanistic relationship between a cell-cell coupling protein and most non-arrhythmic diseases is not well understood.

Human Cx43 is encoded by the GJA1 gene in which the entire coding sequence is within the second exon (Fishman et al., 1991). Thus, GJA1 cannot produce different protein isoforms via alternative splicing. It was recently found that ribosomal translation initiating at internal AUG start codons within the mRNA coding sequence, commonly known as alternative translation, generates multiple endogenous carboxyl-terminal (C-terminal) segments of $\mathrm{Cx} 43$ protein. These products 
of alternative translation are N-terminal truncations of the full length $\mathrm{Cx} 43$ protein. Alternative translation of GJA1 occurs widely in cell lines (Smyth and Shaw, 2013; SalatCanela et al., 2014), primary cells (Salat-Canela et al., 2014; Ul-Hussain et al., 2014), and human heart (Smyth and Shaw, 2013). Mammalian target of rapamycin (mTOR) and MAP kinase-interacting serine/threonine-protein kinases $1 / 2$ (Mnk1/2) signaling pathways (Smyth and Shaw, 2013; SalatCanela et al., 2014) have been found to regulate alternative translation and inhibition of either mTOR or Mnk1/2 increases expression of the truncated isoforms (Smyth and Shaw, 2013; Salat-Canela et al., 2014). Pathway dependence implies alternative translation of GJA1 can be turned on or off, depending on metabolic condition. Hypoxic stress is another condition that induces endogenous expression of the smaller isoforms (Ul-Hussain et al., 2014).

The role of the smaller alternatively translated isoforms of GJA1 is largely unknown. Of the isoforms, GJA1-20k is commonly the most highly expressed (Smyth and Shaw, 2013; Salat-Canela et al., 2014; Ul-Hussain et al., 2014). We have previously reported that GJA1-20k occurs in endoplasmic reticulum and aids full length $\mathrm{Cx} 43$ trafficking to cell-cell borders (Smyth and Shaw, 2013; Basheer et al., 2017), indicating that GJA1-20k can act as a chaperone in forward trafficking.

In this study, we report the surprising finding that in additional to full length $\mathrm{Cx} 43$ trafficking, GJA1-20k also targets to mitochondria. Furthermore, upon $\mathrm{H}_{2} \mathrm{O}_{2}$-induced stress, GJA1-20k but not full-length $\mathrm{Cx} 43$ is sufficient to preserve localization of mitochondria at the cell periphery. Using electron microscopy, we identified GJA1-20k at the mitochondria and the interface between microtubules and mitochondria, appearing to load mitochondria for transport. Mutagenesis experiments reveal that the previously identified tubulin-binding domain in GJA1-20k (Saidi Brikci-Nigassa et al., 2012) is not required for its mitochondrial localization but is essential for rescue of mitochondrial network integrity upon $\mathrm{H}_{2} \mathrm{O}_{2}$ treatment. In addition, under control conditions, GJA1-20k promotes microtubule-based mitochondrial transport, which is lost when the tubulin-interacting residues are removed. Taken together, these findings introduce the alternatively translated GJA1-20k isoform of the traditional $\mathrm{Cx} 43$ gap junction protein as a regulator of microtubule-based mitochondrial transport, which protects the organelle network during stress.

\section{MATERIALS AND METHODS}

\section{Molecular Biology}

Human GJA1 cDNAs (Open Biosystems) encoding full-length $\mathrm{Cx} 43$ and small isoforms were first cloned into pDONR/221 to generate Gateway entry clones (Thermo Fisher Scientific) as previously described. Destination vectors (pDEST) encoding

Abbreviations: mRNA, messenger RNA; C-terminal, carboxyl-terminal; ER, endoplasmic reticulum; PDI, protein disulfide-isomerase; TMRM, indicator tetramethylrhodamine methyl ester; Tom20, translocase of outer membrane 20; TEM, transmission electron microscopy; NMR, nuclear magnetic resonance; MTBD, microtubule-binding domain; $\mathrm{H}_{2} \mathrm{O}_{2}$, hydrogen peroxide; Noc, nocodazole; DMSO, dimethyl sulfoxide.
C-terminal GFP-, mCherry-, and HA-tagged proteins were subsequently made for mammalian cell expression. All constructs are driven by the cytomegalovirus (CMV) promoter, and contain internal methionine start sites mutagenized to leucine to ensure single isoform expression. Mutagenesis was carried out with the Quick Change Lightning Mutagenesis Kit (Agilent) according to manufacturer's instructions. Mutagenesis primers used to remove all six tubulin-interacting residues (Saidi Brikci-Nigassa et al., 2012) in GJA1-20k-del6 are: 5' AAG GGC GTT AAG GAT AAG GGA AAG AGC GAC CCT AGT GGT GCG CTG AGC 3', and 5' GCT CAG CGC ACC ACT AGG GTC GCT CTT TCC CTT ATC CTT AAC GCC CTT 3'. The mito-BFP plasmid was a gift from Dr. Gia Voeltz (Addgene plasmid \# 49151).

\section{Cell Lines and Primary Cell Isolation}

$\mathrm{HeLa}, \mathrm{HaCaT}$, and HEK293T cell lines (ATCC) were maintained at $37^{\circ} \mathrm{C}$ in a humidified atmosphere of $5 \% \mathrm{CO}_{2}$ in fully supplemented media containing DMEM with $10 \%$ fetal bovine serum (FBS), nonessential amino acids, sodium pyruvate (Thermo Fisher Scientific), and Mycozap-CL (Lonza). Primary cardiac fibroblasts were isolated from neonatal mouse hearts as described (Zhang et al., 2014). Fibroblasts adhering to the dish during the pre-plating step were enriched for 1 week in DMEM:F12 supplemented with 3.5\% FBS and 1x Mycozap-PR (Lonza). Primary glial cells were isolated from neonatal mouse brains as previously described (He et al., 2007; Habas et al., 2013).

\section{Biochemistry}

Co-immunoprecipitation was carried out using HeLa cells expressing HA-tagged GJA1-20k. Cytoskeletal-protein interactions were stabilized by the addition of phalloidin (25 $\mathrm{MM}$, Sigma-Aldrich) during cell lysis in 0.5\% NP40 buffer (in $\mathrm{mM}, 150 \mathrm{KCl}, 20 \mathrm{HEPES}, 2 \mathrm{MgCl}_{2}, 2 \mathrm{~K}_{2} \mathrm{HPO}_{4}, 1 \mathrm{DTT}, 1 \mathrm{NaF}$, $0.1 \mathrm{Na}_{3} \mathrm{VO}_{4}, 0.5 \% \mathrm{NP} 40, \mathrm{pH} 7.4$ with halt protease inhibitor). Cells were rotated for $30 \mathrm{~min}$ and spun down at $10,000 \times \mathrm{g}$ for $20 \mathrm{~min}$ at $4^{\circ} \mathrm{C}$ to remove insoluble debris. Following protein normalization, cell lysates were precleared using Dynabeads protein $\mathrm{G}$ (Thermo Fisher Scientific) for $30 \mathrm{~min}$ with rotation at $4{ }^{\circ} \mathrm{C}$. Beads were discarded, and $2 \mathrm{mg}$ of precleared lysate was used for each reaction. Immunoprecipitation was undertaken using $5 \mu \mathrm{g}$ of either mouse anti-HA (4C12, Abcam), or mouse anti-GST (B-14, Santa-Cruz Biotechnology) as negative isotype control at $4^{\circ} \mathrm{C}$ for $4 \mathrm{~h}$ with rotation. Dynabeads protein $\mathrm{G}(20$ $\mu \mathrm{l}$ ) was added to each reaction, and the tubes were rotated for an additional $45 \mathrm{~min}$ at room temperature. Protein complexes were washed 3 times with lysis buffer using a Dynamag-2 magnet. Proteins were then eluted with $30 \mu \mathrm{l} 2 \mathrm{X}$ NuPAGE sample buffer containing $100 \mathrm{mM} \mathrm{DTT}$, incubated at $37^{\circ}$ for $20 \mathrm{~min}$, and subjected to SDS-PAGE electrophoresis and Western blotting. Membranes were imaged using the ChemiDoc MP detection system (Bio-Rad). The experiments were repeated three times.

\section{Mitochondrial Fractionation}

Mitochondria fractionation of $\mathrm{HeLa}$ cells transfected with HA-tagged GJA1-43k or GJA1-20k, was performed as previously described (Singh et al., 2012). Cells were manually homogenized 
in isolation buffer A with BSA (mM): 230 mannitol, 70 sucrose, 10 HEPES, 2 EDTA pH 7.2 with $\mathrm{KOH}$, and $1 \mathrm{mg} / \mathrm{mL}$ fatty acid free BSA using a Potter Elvehjem homogenizer (Sigma-Aldrich). Homogenates were centrifuged at $1,300 \times \mathrm{g}$ for $3 \mathrm{~min}$ at $4^{\circ} \mathrm{C}$. The resulting supernatants were collected and centrifuged at 10,000 $\times \mathrm{g}$ for $10 \mathrm{~min}$ at $4^{\circ} \mathrm{C}$. The supernatant fraction (F0) was saved for Western blotting. Pellets containing crude mitochondria were overlaid on $30 \%(\mathrm{v} / \mathrm{v})$ Percoll (Sigma-Aldrich) in buffer B (mM): 250 sucrose, 10 HEPES-Na, 1 EDTA-Na 2, pH 7.4. Samples were centrifuged (Optima MAX-XP, Beckman Coulter) in a fixed angle rotor at $50,000 \times \mathrm{g}$ at $4^{\circ} \mathrm{C}$ for $45 \mathrm{~min}$. After ultracentrifugation, three fractions were collected and labeled as F1, F2, and F3 from cell samples. Fractions were pelleted at 12,000 $\times \mathrm{g}$ for $5 \mathrm{~min}$ at $4^{\circ} \mathrm{C}$ for Western blotting. Three independent experiments were conducted and the representative blots were shown.

\section{Confocal Fixed and Live-Cell Imaging}

Images were acquired using a Nikon Eclipse Ti imaging system with a $\times 100 / 1.49$ Apo TIRF or a x20/0.75 Plan Apo objective, a spinning disk confocal unit (Yokogowa CSU-X1) with 486, 561, and 647-nm diode-pumped solid state lasers, and an ORCA-Flash 4.0 Hamamatsu camera (C11440), controlled by NIS Elements software. Live cell imaging was carried out in transiently transfected HeLa cells as previously described (Zhang et al., 2014). Glass-bottomed dishes were coated with human fibronectin $(10 \mu \mathrm{g} / \mathrm{ml}$, Corning) and $0.1 \%$ gelatin (SigmaAldrich). Cells were grown on these dishes at $37^{\circ} \mathrm{C}$ in a humidified atmosphere of $5 \% \mathrm{CO}_{2}$ in fully supplemented media. Cells were cotransfected with fluorescently tagged GJA1 isoforms and mito-BFP using Lipofectamine 2000 according to manufacture's instructions (Thermo Fisher Scientific). At 16$24 \mathrm{~h}$ post transfection, cells were immersed in imaging solution containing HBSS supplemented with 10\% FBS, and 1x Mycozap$\mathrm{CL}$. Images were acquired at $37^{\circ} \mathrm{C}$ using our Nikon Eclipse $\mathrm{T} i$ imaging system described above. Active mitochondria were labeled by loading cells for $30 \mathrm{~min}$ with imaging solution containing 2.5 $\mu \mathrm{M}$ TMRM (Thermo Fisher Scientific). Pearson's coefficient was calculated using the Image JACoP plugin (Bolte and Cordelières, 2006). Three independent experiments were conducted and 5-10 cells were imaged from each experiment.

\section{$\mathrm{H}_{2} \mathrm{O}_{2}$ Treatment and Mitochondrial Analysis}

HeLa cells were plated on coated glass-bottom dishes and transfected with the following plasmids: GST-GFP, GJA1-43kGFP, and GJA1-20k-GFP. At $24 \mathrm{~h}$ post transfection, samples were treated with $300 \mu \mathrm{M} \mathrm{H}_{2} \mathrm{O}_{2}$ (Sigma-Aldrich) or PBS in fully supplemented medium for $4 \mathrm{~h}$. Cells were fixed in $4 \%$ PFA (Electron Microscopy Services) in PBS for $20 \mathrm{~min}$ at RT. Immunolabeling: rabbit anti-Tom20 (1:100, Santa Cruz Biotechnology) and chicken anti-GFP (1:500, Abcam). Alexa Fluors (Thermo Fisher Scientific) were used for secondary antibody detection for $1 \mathrm{~h}$ at RT. ProLong Gold Antifade containing DAPI was used to mount samples. Using ImageJ $(\mathrm{NIH})$, the peripheral/central fluorescence ratio was determined by dividing peripheral Tom 20 signal by that of the perinuclear and Golgi regions. First, each image is background-subtracted using a rolling ball radius of 50 pixels. Thresholding for the inner region of interest (ROI) encompassing the nucleus was set based on $1 / 6$ of the maximal Tom 20 intensity of the entire cell. Signal from the nuclear ROI was removed from the cell. The middle ROI (perinuclear/Golgi) boundary was set by expanding the inner ROI by 4 micrometers. Finally, signal density from the remaining outer ROI (periphery) is divided by the sum of that of the inner and middle ROIs to obtain the ratio (Figure S10). Percentages of cells with connected mitochondria were determined by scoring blinded datasets of immunolabeled Tom 20 signal from at least 4 experimental replicates.

\section{Electron Microscopy}

HeLa cells were transfected with GST-GFP or GJA1-20kGFP plasmids as described above. Cells were fixed in $2 \%$ glutaraldehyde in PBS at RT for $10 \mathrm{~min}$, scraped, and pelleted by centrifugation at $4,200 \times \mathrm{g}$ followed by $16,000 \times \mathrm{g}$. Pellets were fixed for 2 additional hours, and then post fixed with $1 \%$ osmium tetroxide followed by incubation with $3 \%$ uranyl acetate. Samples were dehydrated in ethanol, treated with propylene oxide, embedded in Spurr resin (Electron Microscopy Services), and sectioned using an ultramicrotome (UCT, Leica). Sections were then mounted on EM grids and stained with uranyl acetate and lead citrate. Images were acquired using the JEM1200-EX, JEOL microscope equipped with a digital camera (BioScan 600W, Gatan). For immunogold labeling, cells were fixed in $4 \%$ formaldehyde and $0.1 \%$ glutaraldehyde in PBS at RT for $10 \mathrm{~min}$, scraped, and pelleted as described above. Cells were fixed overnight at $4^{\circ} \mathrm{C}$ in $4 \%$ formaldehyde and $0.1 \%$ glutaraldehyde in PBS and thereafter mixed with $1.5 \%$ low melting temperature agarose. Small pieces of agarose with embedded cells were incubated overnight in $1.85 \mathrm{M}$ sucrose $/ 20 \%$ PVP-10/50 mM Hepes $\mathrm{pH}$ 7.4. Each piece was mounted on an aluminum pin and snap frozen in liquid nitrogen. Ultrathin sections were prepared using a cryo-ultramicrotome (UC6, Leica) with an F6 cryo-attachment and a Diatome cryoimmuno $\left(35^{\circ}\right)$ diamond knife. The sections were incubated with rabbit anti-GFP primary antibody (1:200; Abcam) at $4^{\circ} \mathrm{C}$ overnight. The sections were then incubated with secondary antibody conjugated with $10 \mathrm{~nm}$ gold particles (1:20; Ted Pella) and imaged as described above. Electron microscopy work was done by the Electron Imaging Center at California NanoSystems Institute, University of California Los Angeles.

\section{Tracking of Mitochondrial Movement}

Live cell imaging was performed $24 \mathrm{~h}$ post transfection of GST-GFP, GJA1-20k-GFP, or GJA1-20k-del6-GFP together with mito-BFP. Fresh imaging solution, containing either $25 \mu \mathrm{M}$ nocodazole (to disrupt microtubules) or $0.08 \%$ DMSO, was added to cells for $45 \mathrm{~min}$ prior to image acquisition. MitoBFP signal was tracked every $5 \mathrm{~s}$ for $5 \mathrm{~min}$. To determine mitochondrial velocity and displacement, the MTrackJ plugin (Meijering et al., 2012) for ImageJ (NIH) was used to track individual mitochondrion moving toward the cell tip within a 60 $\times 60 \mu \mathrm{m}^{2}$ ROI. Four separate experiments were performed. 


\section{Statistical Analysis}

All quantitative data were expressed as mean \pm SEM and analyzed using Prism 6 software (GraphPad). For comparison between two groups, unpaired two-tail Student's $t$-test was performed. For comparison among three and more groups, oneway ANOVA followed by either Tukey's or Bonferroni's posthoc test was performed. For comparison between groups with or without $\mathrm{H}_{2} \mathrm{O}_{2}$ treatment, two-way ANOVA followed by Tukey's post-hoc test was performed. A $P$ value of less than 0.05 was deemed statistically significant. For tracking data, histograms of mean velocities of each condition were used for nonlinear Gaussian fitting. Single Gaussian fitting generated the following coefficients of determination $\left(\mathrm{R}^{2}\right)$ to assess the goodness of fit: 0.93 (GST control), 0.95 (GST treated with nocodazole), 0.78 (GJA1-20k), and 0.85 (GJA1-20k-del6). Based on these values, data for GJA1-20k and GJA1-20k-del6 were fitted with the sum of two Gaussian distributions to yield $R^{2}$-values of 0.91 and 0.97 , respectively.

\section{RESULTS}

\section{GJA1-20k Is Localized Outside of the ER}

In addition to the full-length $\mathrm{Cx} 43$ protein, endogenous GJA120k (see cartoon in Figure S1A) is highly expressed in primary cardiomyocytes and astrocytes, as well as many cell lines including cancer models (Smyth and Shaw, 2013; SalatCanela et al., 2014; Ul-Hussain et al., 2014). We previously reported that GJA1-20k primarily localizes to the cytoplasm in reticular structures that correspond to ER/Golgi suggesting a role for GJA1-20k in the $\mathrm{Cx} 43$ vesicular transport pathway (Smyth and Shaw, 2013). In detailed confocal imaging of immunofluorescence of HeLa cells labeled with exogenous GJA120k-GFP, we also found GJA1-20k positive signal throughout the cell (Figure S1B, arrows). As seen in Figure S1C, there is localization of GJA1-20k-GFP (green) with the ER marker protein disulfide-isomerase (PDI, red) (Pearson's coefficient: $r$ $=0.722$ ). However, the more intense clusters do not appear to share ER localization. The larger GJA1-20k clusters either overlap with ER (arrowhead) or exist in shapes independent of ER (arrow). These results prompted us to determine the identity of the structures associated with GJA1-20k.

\section{GJA1-20k Delineates the Mitochondrial Network}

It is recognized that the ER is closely associated with mitochondrial network, participating in dynamic mitochondrial regulation (Friedman et al., 2011). Additionally, accumulating evidence has supported that full length $\mathrm{Cx} 43$ is associated with mitochondria (Boengler et al., 2005; Srisakuldee et al., 2014; Gadicherla et al., 2017). Therefore, we decided to examine the association of GJA1-20k with mitochondria. As seen in Figure 1A, while full-length Cx43 (upper panel) (GJA1-43k, with internal start sites mutated to produce only the full-length protein) only partially localizes with the mitochondrial marker mito-BFP (arrows), GJA1-20k strongly co-localizes with mito-BFP (middle panel) as well as with actively respiring mitochondria marked by the membrane potential indicator tetramethylrhodamine methyl ester (TMRM) (bottom panel). GJA1-20k localization is indistinguishable from that of the two mitochondrial markers and appears to function as a mitochondrial marker itself. To address the concern that a GFP tag may interfere with cellular localization of GJA1 isoforms, we took advantage of the previously characterized cervical carcinoma cell line, C33A, that expresses endogenous GJA1-20k (Salat-Canela et al., 2014). Using anti- C-terminal and N-terminal antibodies for $\mathrm{Cx} 43$, we can distinguish localization patterns between GJA1-43k (anti- $\mathrm{N}$ and $\mathrm{C}$ terminal $\mathrm{Cx} 43$ antibody positive) and smaller GJA1 isoforms (anti-C terminal Cx43 antibody positive only). As seem in Figure S2, it is primarily the anti C-terminal antibody which outlines mitochondria, indicating that alternatively translated GJA1-20k are preferentially localized to mitochondria, consistent with observation of exogenously expressed GFP-tagged protein. Furthermore, as seen in the same figure, localization of endogenous protein to mitochondria occurs in the peripheral cortex of the cell rather than in more central locations. The imaging data in Figure S2 confirm that even endogenous alternatively translated GJA1-20k preferentially localizes to mitochondria.

We then performed biochemical fractionation to confirm mitochondrial enrichment of GJA1-20k in transfected cells. As seen in Figure 1B, translocase of outer membrane 20 (Tom20) marks mitochondrial fraction and is substantially enriched in fractions F2 and F3. This is concurrent with a corresponding decrease in plasma membrane markers including $\mathrm{Na}^{+} / \mathrm{K}^{+}$ATPase and N-cadherin. In addition to full length GJA1-43k, GJA1-20k protein is highly enriched in mitochondrial fractions F2 and F3, which supports the mitochondrial localization of GJA1-20k observed in immunofluorescence experiments (Figure 1A). These data indicate that in HeLa cells transfected GJA1-20k has a strong tropism to mitochondria and delineates the entire mitochondrial network.

Since both imaging and biochemical data support enrichment of GJA1-20k in mitochondria, we next sought to confirm that these findings are not restricted to HeLa cells. We obtained human keratinocytes (HaCaT), HEK293 cells, isolated primary neonatal mouse glial cells and cardiac fibroblasts. As seen in Figure 1C, mitochondrial expression of exogenous GJA1-20k is detected in all three types of cells. We have yet to identify cells in which GJA1-20k does not strongly localize to the mitochondrial network.

\section{GJA1-20k Localizes to the Interface of Mitochondria and Microtubules}

We have previously reported that GJA1-20k can organize the cytoskeleton trafficking pathways of Cx43 (Smyth and Shaw, 2013; Basheer et al., 2017), which occurs along microtubules (Giepmans et al., 2001; Lauf et al., 2002; Shaw et al., 2007). Microtubule-dependent transport has also been reported for organelles such as mitochondria (Chan, 2006; Wang and Schwarz, 2009; Tanaka et al., 2011). We are interested in the possibility of interaction between GJA1-20k and the 

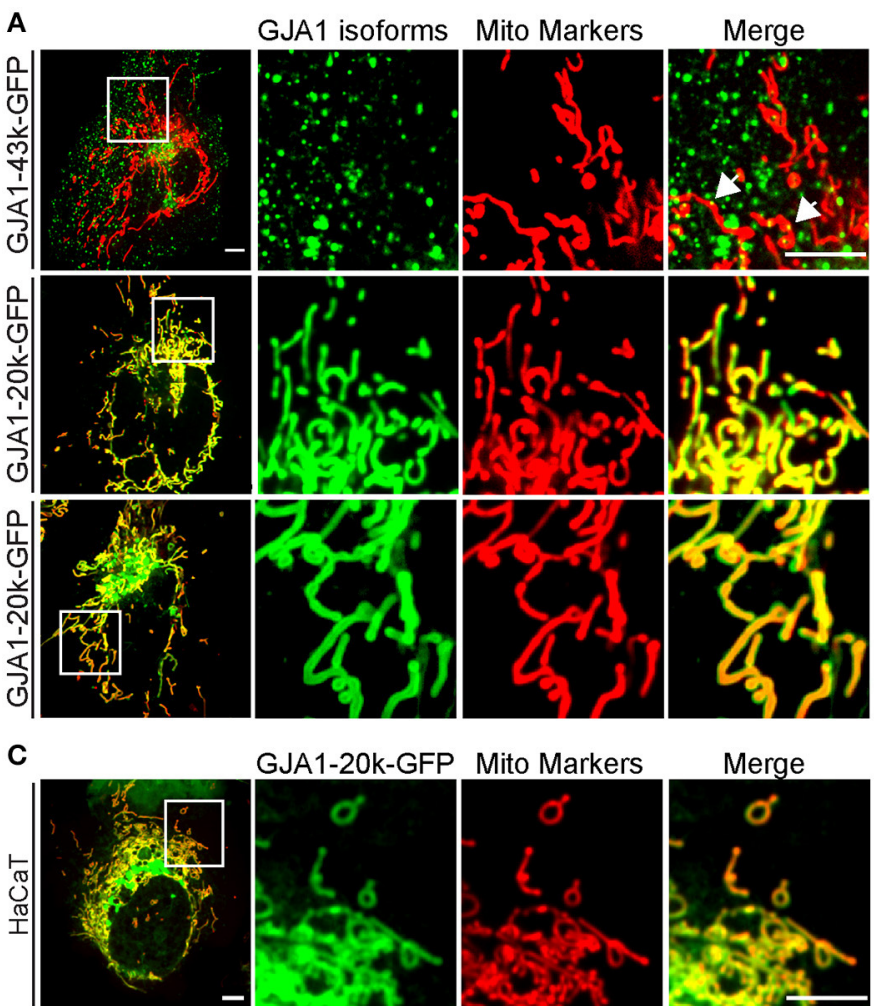

GJA1-20k-GFP Mito Markers
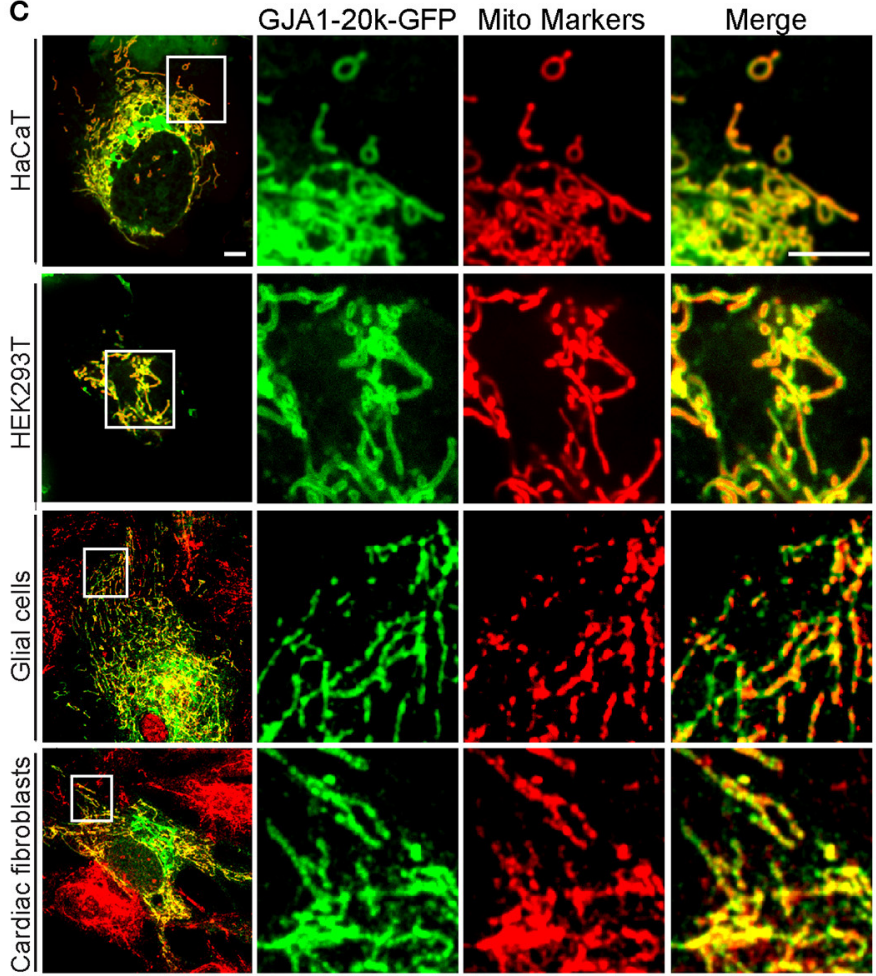

B
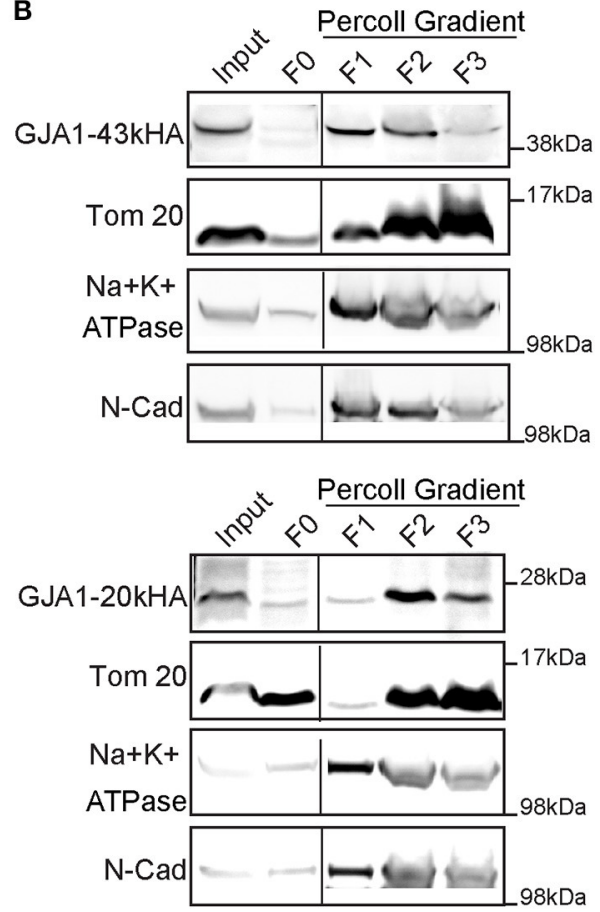

FIGURE 1 | GJA1-20k delineates the mitochondrial network. (A) Imaging of live HeLa cells expressing GFP-tagged GJA1-43k or GJA1-20k (green) and mitochondrial markers (red). GJA1-43k associates with mitochondria as small puncta (arrows). GJA1-20k colocalizes with mito-BFP (middle panel) and TMRM (bottom panel). Scale bar $=5 \mu \mathrm{m}$. (B) Relative enrichment of HA-tagged isoforms in total cell lysate (input), the cytosol supernatant (F0), and membrane fractions of crude mitochondrial pellet (F1-F3). Mitochondria (Tom20). Plasma membrane (Na+ $\mathrm{K}^{+}$ATPase, N-cadherin). Full blots were in Figures S7, S8. (C) Live cell imaging of HaCat and HEK293T cells cotransfected with mito-BFP and GJA1-20k-GFP. Immunofluorescence of GFP and Tom20 in primary glial cells and cardiac fibroblasts transfected with GJA1-20k-GFP. Scale bar $=5 \mu \mathrm{m}$.

microtubule network in respect to mitochondrial transport. As seen in Figure 2A, we found positive co-immunoprecipitation between HA-tagged GJA1-20k and alpha-tubulin, indicating interaction between GJA1-20k and the microtubule highway. Next, using live-cell imaging, we identified that movements of mitochondria containing GJA1-20k signal, when recorded over $45 \mathrm{~s}$, follow trajectories defined by microtubules (Figures 2B,C and Supplemental Video 1), indicating that microtubules might function as guides for GJA1-20k associated mitochondrial movement. 


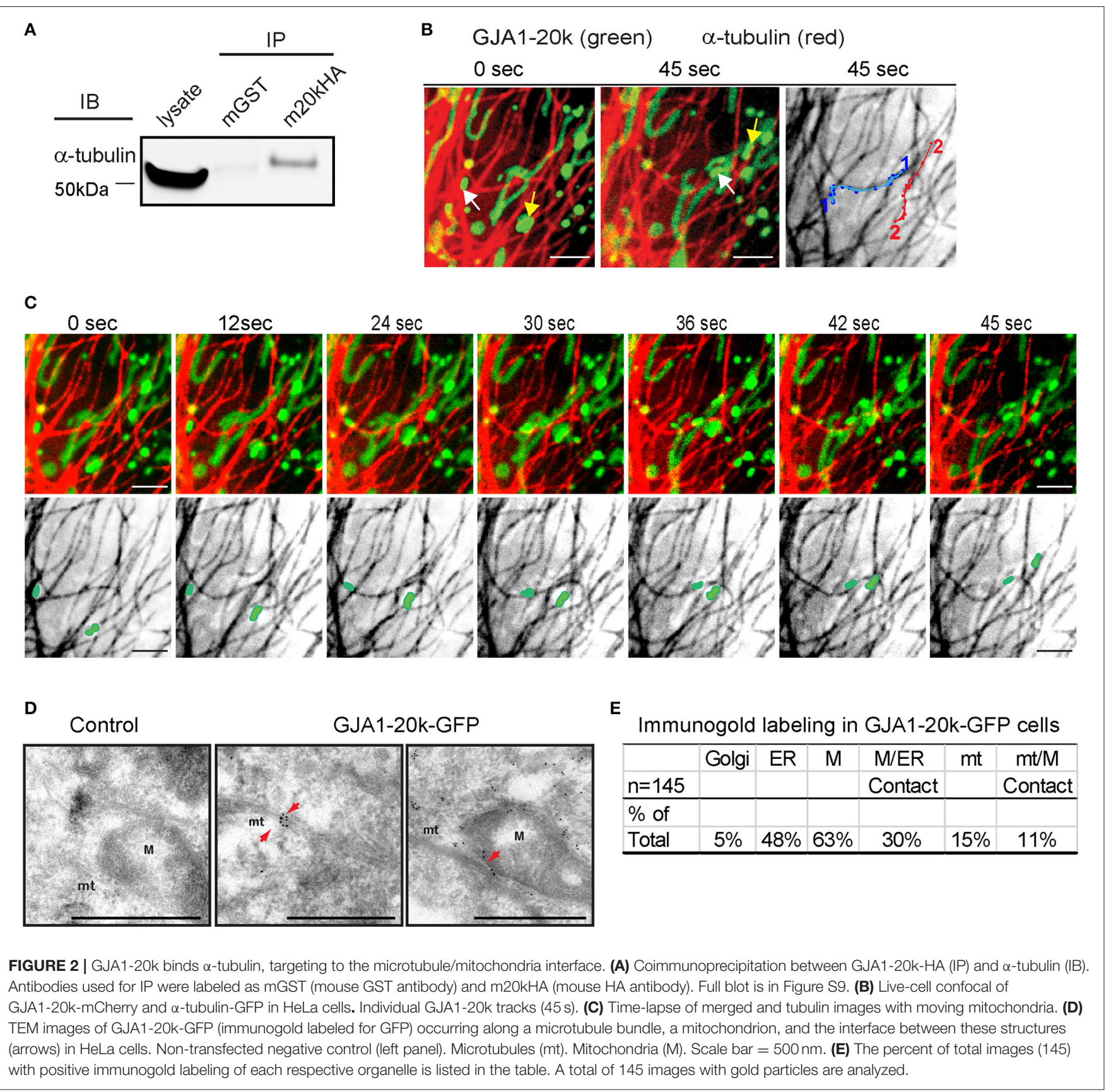

If GJA1-20k facilitates mitochondrial interaction with microtubules, then its localization is expected to be enriched at points of interaction. The confocal live cell imaging clearly demonstrates that mitochondria follow microtubule tracks. However, live cell confocal imaging cannot provide sufficient detail on spatial localization of GJA1-20k GFP due to the resolution of confocal imaging, especially when projecting signals of the three-dimensional organelle to two-dimensional images. Therefore, we used transmission electron microscopy (TEM) together with immunogold labeling of exogenous GJA1-20k to explore in high resolution the spatial relationship among GJA1-20k, mitochondria, and microtubules. Consistent with the confocal imaging results, mitochondria in GJA120k-expressing cells are closely associated with microtubules, stretching along them (Figure 2D, and Figure S3). Moreover, immunogold labeling further confirmed that GJA1-20k targets to mitochondria. More than $60 \%$ of total immunogold positive images contain gold particle-labeled GJA1-20k in mitochondria (Figure 2E), which is further enriched at mitochondrial membrane. Not surprisingly, cellular organelles such as ER and Golgi were also identified by immunogold labeling in GJA1-20k transfected cells. Although only 15\% (22) of 
all 145 images contain gold particle-labeled GJA1-20k at microtubules, the majority $(16 / 22,73 \%)$ of them are associated with mitochondria at the microtubule interface, which is within 0.1 micron of microtubules (Figures 2D,E). It appears that GJA1-20k helps to load the mitochondrion along the microtubule for transport. Together, the data in Figure 2 provide biochemical, live-cell imaging, and TEM evidence in support of a role for GJA1-20k in microtubule-based mitochondrial transport.

\section{GJA1-20k Mediates Microtubule-Based Mitochondrial Transport}

GJA1-20k, beginning with amino acid 213, contains a portion of the fourth transmembrane domain of $\mathrm{Cx} 43$, and the entire cytoplasmic C-terminal tail (Figure S1A). Like its full-length counterpart, this 170 amino acid isoform includes the microtubule-binding domain (MTBD), which occurs at amino acids 234-259 of Cx43 (Giepmans et al., 2001; Saidi Brikci-Nigassa et al., 2012) (Figure S3). Six residues $\left({ }^{239} \mathrm{RV}^{240}\right.$ and $\left.{ }^{247} \mathrm{YHAT}^{250}\right)$ in MTBD have been found critical for microtubule/Cx43 interaction (Saidi Brikci-Nigassa et al., 2012).

Based on the association between GJA1-20k with mitochondria (Figures 1, 2) and microtubules (Figure 2), we tested whether GJA1-20k mediates microtubule-based mitochondrial transport. We generated a mutant lacking the six residues essential for microtubule interaction (GJA1-20k-del6) (Figure 3A; Figure S11). GJA1-20k and mutated GJA1-20k-del6 were overexpressed in $\mathrm{HeLa}$ cells. Interestingly, as seen in Figure 3B, GJA1-20k-del6 retains a mitochondrial localization which is indistinguishable from wildtype GJA1-20k, suggesting that the MTBD is not necessary for GJA1-20k localization to mitochondria.

We next examined how the mutation of MTBD affects dynamics of mitochondrial transport in transfected cells. Mitochondrial movements were assessed by tracking individual mitochondrion over a 5-min period. Representative tracks are presented in Figure 3C, with original movies in Supplemental Videos S2-S5. Mitochondria were tracked in the presence of GJA1-20k, GJA1-20k-del6, or the microtubule disruptor nocodazole (noc). Quantitative analysis (Figures 3D,E) revealed that nocodazole significantly reduces average mitochondrial transport speed and net displacement relative to DMSO treated control cells. In contrast, GJA1-20k increases average mitochondrial speed, while average mitochondrial speed and displacement in GJA1-20k-del6 transfected cells were not significantly different from control. Frequency distribution analyses of individual average mitochondrial speeds (per 5 min windows) were fit with single Gaussian curves (single Gaussian unless $R^{2}$ fit was less than 0.9 and then double Gaussian curves were used to fit the data, Figure 3F). The original histograms on which the curve fits are based have been removed for clarity in Figure 3F. The interested reader is referred to Figure S4 for the original data. The primary peaks of GST (black), GJA1-20k (blue), and GJA1$20 \mathrm{k}$-del6 (red) curves were similar at an average speed of

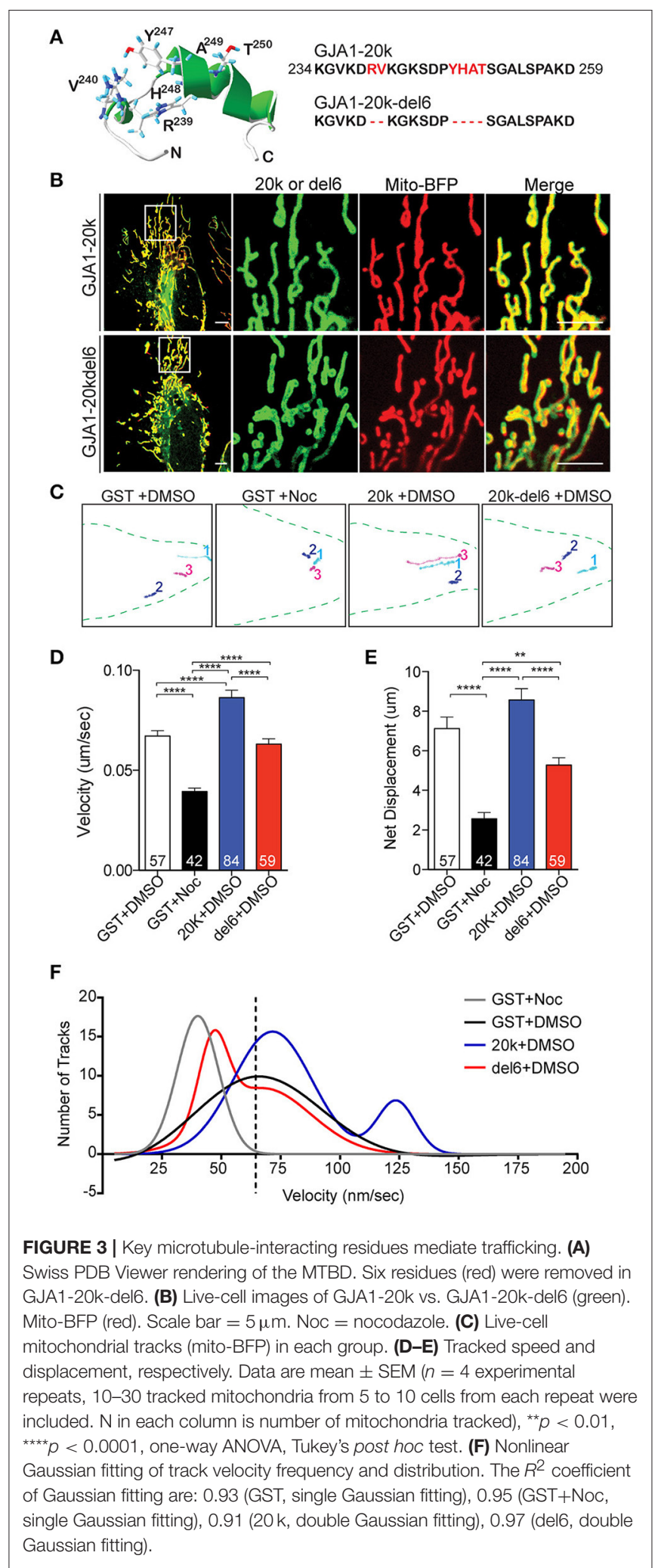

$\sim 65 \mathrm{~nm} / \mathrm{s}$. Nocodazole shifted the GST curve to the left (gray), indicating a loss of fast mitochondrial movement on microtubules, whereas a secondary curve to the right 
(movement at higher speeds) occurred only with GJA1-20k cells (blue) and the area under the curve indicates about $24 \%$ population of mitochondria are traveling at the higher speed. These data indicate that in cells with exogenous GJA1-20k containing an intact MTBD, a subpopulation of mitochondria travels at twice the median speed, which is consistent with kinesin-based transport (Wang and Schwarz, 2009; Tanaka et al., 2011). In contrast, the secondary peak of GJA1-20kdel6 cells is shifted to the left (lower speeds, red), closer to the nocodazole peak, indicating loss of mitochondrial transport on microtubules. This is further supported by reduced tubulin interaction with GJA1-20k-del6 (Figure S11). Thus, we conclude that exogenous GJA1-20k increases the instances of mitochondria utilizing microtubule-based transport. The rapid outward-directed movement supports the role of GJA1-20k in increasing microtubule-based transport of mitochondria to the cell periphery.

\section{GJA1-20k Preserves Mitochondrial Distribution during Stress}

Since our results indicate that GJA1-20k mediates mitochondrial movement along microtubules (Figures 2, 3), we next asked whether GJA1-20k can safeguard a distributed mitochondrial network during cellular stress. Mitochondrial morphology in fixed cells, as determined by Tom 20 immunofluorescence, was observed in HeLa cells subjected to PBS or $300 \mu \mathrm{M}$ $\mathrm{H}_{2} \mathrm{O}_{2}$ for $4 \mathrm{~h}$. Confocal imaging of cells expressing GFPtagged GST, GJA1-43k, or GJA1-20k revealed a distributed mitochondrial network in all groups treated with PBS (Figure 4A, left panels and Figure S5). Upon $\mathrm{H}_{2} \mathrm{O}_{2}$ treatment however, mitochondria became centralized and fragmented in cells expressing GST and GJA1-43k, indicating a damaged mitochondrial network. Interestingly, the majority of GJA120k transfected cells retained well distributed network and elongated mitochondrial morphology (Figure 4A, right panels). We quantified mitochondrial localization as a ratio of peripheral to central distribution and observed that GJA120k significantly rescued mitochondrial peripheralization during $\mathrm{H}_{2} \mathrm{O}_{2}$ stress (Figure 4B). We then quantified elongated mitochondria and found that GJA1-20k rescued mitochondrial morphology as well, when cells were treated with $\mathrm{H}_{2} \mathrm{O}_{2}$ (Figure 4C). These data indicate that introduction of GJA1-20k maintains peripheral mitochondria, limiting organelle network collapse when subjected to metabolic stress. It is possible that GJA1-20k could confer a protective and pro-survival effect through its regulation of mitochondrial distribution and morphology.

In Figure 3 we introduced the GJA1-20k-del6 mutant which lacks the key residues in the MTBD of GJA1-20k, and observed persistent mitochondrial localization of GJA1-20kdel6 but impaired microtubule transport (Figures 3B,F). We tested whether GJA1-20k-del6 could rescue mitochondrial localization and morphology when cells are subjected to $\mathrm{H}_{2} \mathrm{O}_{2}$ stress. The results, in Figures $\mathbf{4 A}, \mathbf{D}, \mathbf{E}$ are negative. Apparently without the microtubule binding capacity, GJA1-20k-del6 loses the capability of GJA1-20k to rescue mitochondrial network integrity during stress, indicating the importance of microtubule based transport for mitochondrial response to oxidative stress.

\section{DISCUSSION}

The present study identified that GJA1-20k, produced via alternative translation from the same mRNA encoding gap junction protein $\mathrm{Cx} 43$, preferentially localizes to mitochondria and mitochondria/microtubule interfaces. We find that GJA1-20k facilitates microtubule-dependent trafficking of mitochondria to cell periphery, thereby preserving distributed mitochondrial network and preventing mitochondrial fragmentation induced by oxidative stress (depicted in the cartoon in Figure 5). This work reveals a novel function of GJA1-20k in regulating mitochondrial distribution in response to cellular stress.

\section{Alternative Translation of Cx43 and Its Functional Significance}

It is commonly accepted that, in eukaryotic cells, mature mRNA molecules encode and correspond to single protein products. In recent years, accumulating evidence has suggested that alternative translation start sites are highly conserved in the mammalian genome and that proteome diversity produced via alternative translation may be more important than previously thought (Kochetov, 2008; Bazykin and Kochetov, 2011; de Klerk and 't Hoen, 2015). Cx43 is the first mammalian ion channel identified to undergo alternative translation (Smyth and Shaw, 2013; Salat-Canela et al., 2014; Ul-Hussain et al., 2014). Up to six alternatively translated $\mathrm{Cx} 43$ isoforms are produced from GJA1 mRNA in the heart (Smyth and Shaw, 2013), all of which are Nterminal truncated and contain either the entire or distal portion of the C-terminal tail. The loss of one or more transmembrane domains of full length $\mathrm{Cx} 43$ gives rise to different protein solubility which can result in different cellular distribution, biophysical properties and their functions. In addition to its role as a chaperone to facilitate full-length GJA1-43k protein trafficking to the cell-cell border (Smyth and Shaw, 2013; Basheer et al., 2017), we now report that by interacting with microtubules GJA1-20k also aids trafficking and distribution of mitochondrial organelles (Figures 2, 3), resulting in cellular protection from stress (Figure 4). With the microtubule binding domain located at proximal C-terminus, it is likely that the $\mathrm{N}$-terminal partial fourth transmembrane domain of GJA1-20k can interact with mitochondrial membrane lipids and/or other mitochondrial adaptor proteins to mediate microtubule dependent interaction and transport of mitochondria.

Alternative translation is a highly regulated process. In this study, we took advantage of HeLa cell lines with little endogenous expression of $\mathrm{Cx} 43$ which provides a clear background to study function of alternatively translated smaller isoforms. However, it is known that cellular stress may act as a trigger for alternative translation to generate isoforms that increase survival. For instance, the protein level of GJA1-20k in mouse primary astrocytes nearly doubled following exposure to intermittent hypoxia for $120 \mathrm{~min}$ (Ul-Hussain et al., 2014). Similarly, signaling 
A
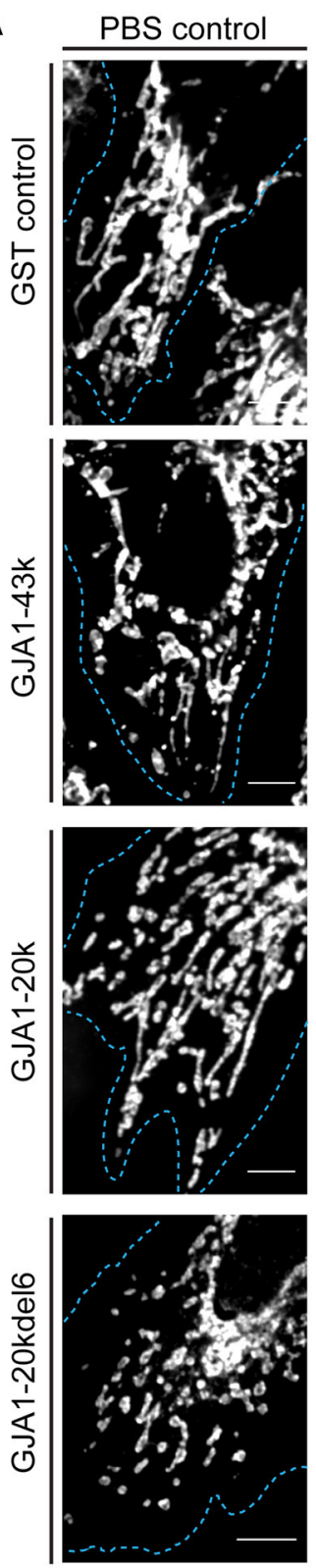
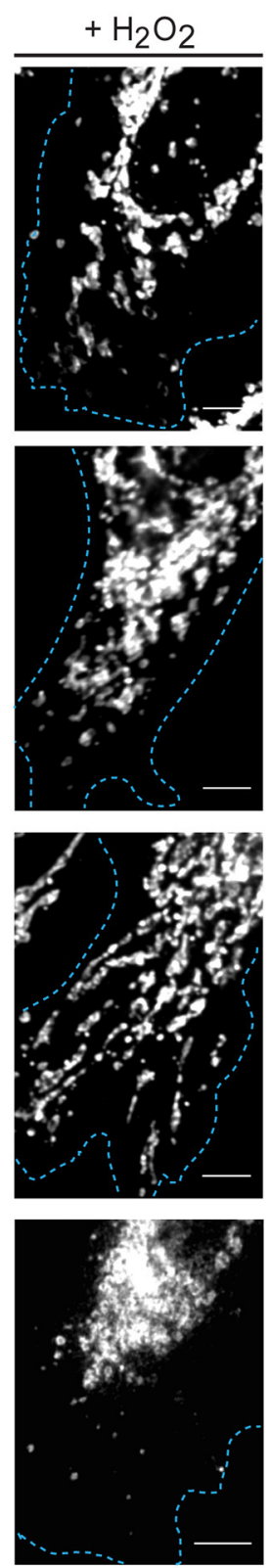

B

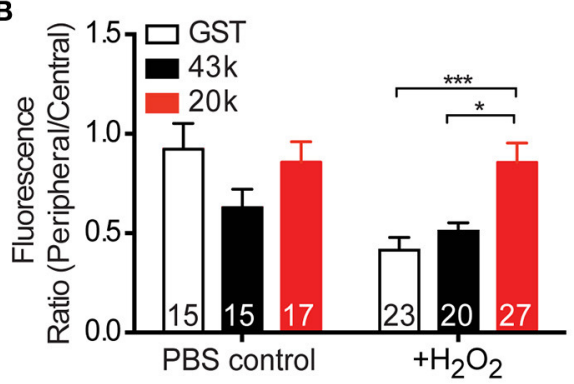

C

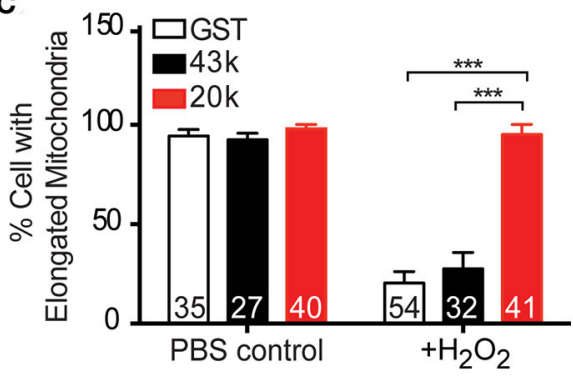

D

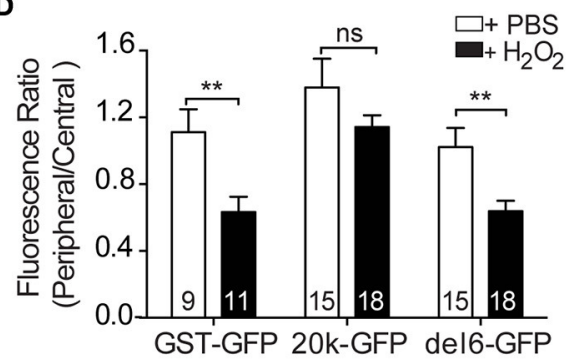

$\mathbf{E}$

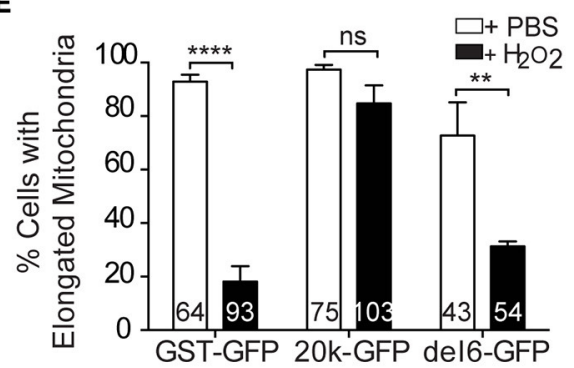

FIGURE 4 | GJA1-20k limits mitochondrial fragmentation upon oxidative stress. (A) Mitochondria morphology and distribution (Tom20) in HeLa cells expressing GFP-tagged GST, GJA1-43k, or GJA1-20k, or GJA1-20kdel6 treated with PBS or $300 \mu \mathrm{M} \mathrm{H}_{2} \mathrm{O}_{2}$. Cell borders (blue). Scale bar $=5 \mu \mathrm{m}$. See also Figure S6. (B) Periphery versus cell center Tom20 fluorescence intensity and (C) percentage of cells containing elongated mitochondria comparing GFP-tagged GST, GJA1-43k and GJA1-20k. (D) Peripheral vs. central mitochondria (Tom20) (See Figure S10) and (E) percentage of cells with elongated mitochondria comparing GFP-tagged GST, 20k, 20k-del6 in PBS or $\mathrm{H}_{2} \mathrm{O}_{2}$. All data are mean $\pm \mathrm{SEM}\left(n=4\right.$ repeats), ${ }^{\star} p<0.05,{ }^{\star \star} p<0.01,{ }^{\star \star \star} p<0.001,{ }^{\star \star \star \star} p<0.0001$, two-way ANOVA, Tukey's post-hoc-test.

pathways involved in survival, such as mTOR and Mnk1/2 have been linked to upregulation of GJA1-20k by between 2- and 50fold (Smyth and Shaw, 2013; Salat-Canela et al., 2014). Therefore, our study, though in a heterologous expression system, provides a glimpse of functional impact of GJA1-20k. Given the dynamic regulation of alternative translation, understanding the function of smaller isoforms of $\mathrm{Cx} 43$ provides a rare opportunity to identify novel protein targets required for cell survival.

\section{Microtubule-Based Mitochondrial Transport and Distribution}

Mitochondria form an extensively regulated and highly dynamic organelle network that is responsible for energy production, calcium homeostasis, cell signaling, cell growth and survival (Frederick and Shaw, 2007). Highly regulated intracellular movement of mitochondria and their appropriate distribution are crucial for the function and integrity of the overall network 


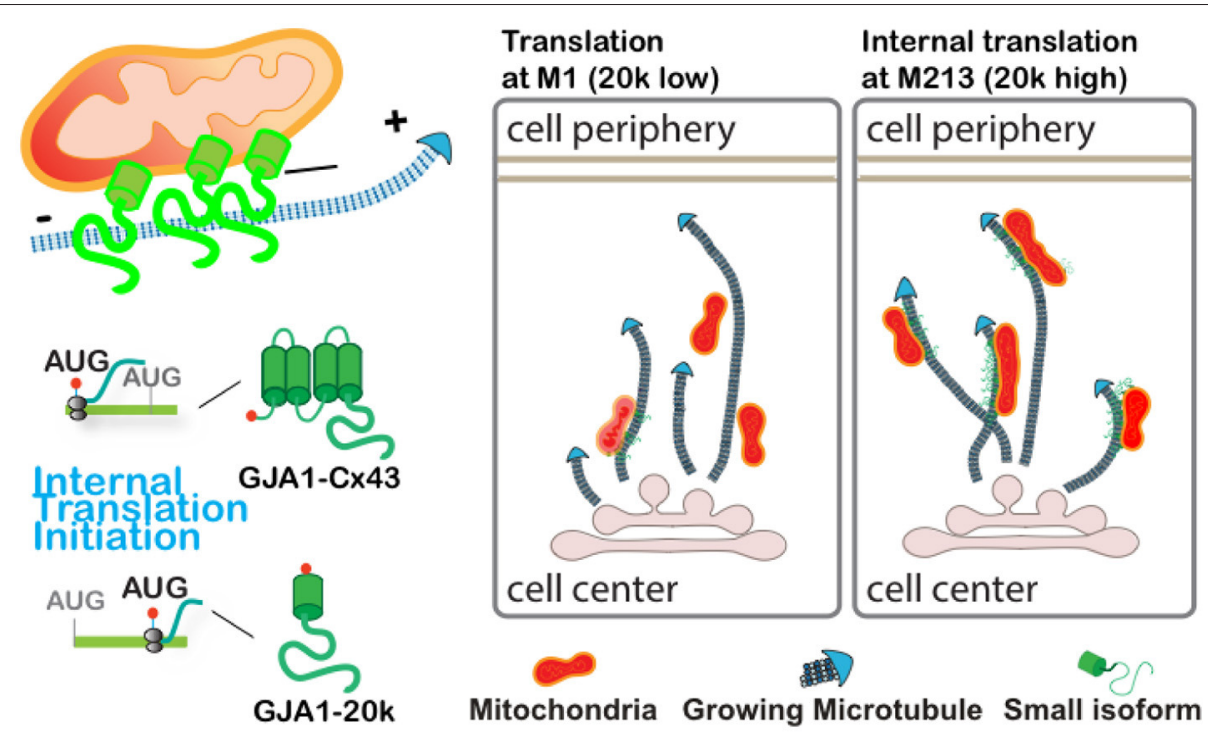

FIGURE 5 | Graphical illustration demonstrates that GJA1-20k localizes to mitochondria and facilitates microtubule-dependent mitochondrial transport to cell periphery and limits mitochondrial fragmentation upon oxidative stress.

(Chan, 2006). Spatial mobility is one of the primary means by which the mitochondria can alter their function to adapt to environmental changes and cellular stresses.

In multicellular eukaryotes, mitochondria move along microtubule tracks by attaching to motors such as kinesin for anterograde transport and dynein for retrograde transport (Hollenbeck and Saxton, 2005; Russo et al., 2009). Impaired mitochondrial movement and the resulting aberrant distribution are detrimental for the cell function, which is particularly manifest in highly polarized cells (Frederick and Shaw, 2007; Saotome et al., 2008). Here we find that, even in HeLa cells, pharmaceutical disruption of microtubules dramatically reduces mitochondrial transport (Figure 3), confirming the role of microtubules in mitochondrial movement. The alternatively translated small isoform of Cx43, GJA1-20k, when expressed exogenously, facilitates mitochondrial trafficking along microtubules. Our finding demonstrates that GJA1-20k not only regulates microtubule dependent vesicular protein cargo trafficking (Smyth and Shaw, 2013; Basheer et al., 2017), but also microtubule dependent organelle transport (Figures 3, 4). A mutant of GJA1-20k (GJA1-20k-del6) which lacks ability to bind microtubules still reaches mitochondrial membrane, suggesting microtubule transport is not needed for mitochondrial affinity and possibly GJA1-20k-del6 may localize to mitochondria at earlier stages of mitogenesis. However GJA1-20k-del6 fails to rescue mitochondrial mobility and to maintain mitochondrial network distribution in presence of $\mathrm{H}_{2} \mathrm{O}_{2}$ (Figure 4). Through its interaction with microtubules, GJA1-20k may act as an adaptor protein to facilitate loading of mitochondria onto microtubule trafficking highways for movement and distribution within the cell. In future studies, it will be important to address whether GJA1-20k also interacts with known microtubulebased motor/adaptor transport complex proteins (Chan, 2006;
Wang and Schwarz, 2009; Tanaka et al., 2011) which regulate mitochondrial trafficking velocity and directionality.

Of note and in additional to spatial mobility, mitochondria engage in repeating cycles of fusion and fission to intermix membrane lipids and matrix contents to ensure organelle network health and function (Ong et al., 2010, 2013; Huang et al., 2013). Maintenance of an intact network of elongated mitochondria protects against mitophagy and cell death through evasion of autophagosome engulfment (Gomes et al., 2011; Rambold et al., 2011). To buffer against damage and dysfunction, impaired mitochondria undergo fission and are distributed throughout the remaining healthy network (Nakada et al., 2001; Ono et al., 2001). In all cells, there exists a dynamic equilibrium between mitochondrial fission and fusion. Both fission and fusion are carried out by a distinct group of proteins, including Drp1, FIS1, OPA1, and mitofusin $1 / 2$. It is possible that, through interaction with one or more of these proteins, GJA1-20k tips the balance between fission and fusion in favor of elongated morphology of mitochondria.

\section{CONCLUSIONS}

We have identified that GJA1-20k enriches at mitochondria and facilitates microtubule-based mitochondrial transport which preserves organelle network integrity upon oxidative stress. GJA1-20k, a protein that was only recently recognized to exist by alternative translation (Smyth and Shaw, 2013; Salat-Canela et al., 2014; Ul-Hussain et al., 2014), provides a means by which otherwise traditional $\mathrm{Cx} 43$ gap junction protein can have a highly diverse repertoire of non-canonical roles. It is possible that the GJA1-20k peptide could be developed into a therapeutic to prevent mitochondrial fragmentation in situations of cellular stress. 


\section{AUTHOR CONTRIBUTIONS}

YF, S-SZ, and SX contribute equally to the experimental design, acquisition, interpretation of data and drafting the manuscript. $\mathrm{WB}, \mathrm{RB}$, and IE contribute to experimental design, data acquisition and drafting the manuscript. TH and RS contributed to all aspects of this work. All authors agree to be accountable for accuracy and integrity of the work.

\section{FUNDING}

This work was supported by National Institute of Health grants HL094414 and HL138577 (RS), HL133286 (TH), T32 HL116273 (S-SZ), and by the American Heart Association (RS, TH, and YF).

\section{REFERENCES}

Akar, F. G., Nass, R. D., Hahn, S., Cingolani, E., Shah, M., Hesketh, G. G., et al. (2007). Dynamic changes in conduction velocity and gap junction properties during development of pacing-induced heart failure. Am. J. Physiol. Heart Circ. Physiol. 293, H1223-H1230. doi: 10.1152/ajpheart.00079.2007

Basheer, W. A., Xiao, S., Epifantseva, I., Fu, Y., Kleber, A. G., Hong, T., et al. (2017). GJA1-20k arranges actin to guide $\mathrm{Cx} 43$ delivery to cardiac intercalated discs. Circ. Res. 121, 1069-1080. doi: 10.1161/CIRCRESAHA.117.311955

Basheer, W., and Shaw, R. (2016). The "tail" of Connexin43: an unexpected journey from alternative translation to trafficking. Biochim. Biophys. Acta 1863, 1848-1856. doi: 10.1016/j.bbamcr.2015.10.015

Bazykin, G. A., and Kochetov, A. V. (2011). Alternative translation start sites are conserved in eukaryotic genomes. Nucleic Acids Res. 39, 567-577. doi: $10.1093 /$ nar/gkq806

Beardslee, M. A., Laing, J. G., Beyer, E. C., and Saffitz, J. E. (1998). Rapid turnover of connexin43 in the adult rat heart. Circ. Res. 83, 629-635. doi: 10.1161/01.RES.83.6.629

Beardslee, M. A., Lerner, D. L., Tadros, P. N., Laing, J. G., Beyer, E. C., Yamada, K. A., et al. (2000). Dephosphorylation and intracellular redistribution of ventricular connexin 43 during electrical uncoupling induced by ischemia. Circ. Res. 87, 656-662. doi: 10.1161/01.RES.87.8.656

Beyer, E. C., Paul, D. L., and Goodenough, D. A. (1987). Connexin43: a protein from rat heart homologous to a gap junction protein from liver. J. Cell Biol. 105, 2621-2629. doi: 10.1083/jcb.105.6.2621

Boengler, K., Dodoni, G., Rodriguez-Sinovas, A., Cabestrero, A., Ruiz-Meana, M., Gres, P., et al. (2005). Connexin 43 in cardiomyocyte mitochondria and its increase by ischemic preconditioning. Cardiovasc. Res. 67, 234-244. doi: 10.1016/j.cardiores.2005.04.014

Bolte, S., and Cordelières, F. P. (2006). A guided tour into subcellular colocalization analysis in light microscopy. J. Microsc. 224, 213-232. doi: 10.1111/j.1365-2818.2006.01706.x

Chan, D. C. (2006). Mitochondria: dynamic organelles in disease, aging, and development. Cell 125, 1241-1252. doi: 10.1016/j.cell.2006.06.010

de Klerk, E., and 't Hoen, P.A. (2015). Alternative mRNA transcription, processing, and translation: insights from RNA sequencing. Trends Genet. 31, 128-139. doi: 10.1016/j.tig.2015.01.001

Fishman, G. I., Eddy, R. L., Shows, T. B., Rosenthal, L., and Leinwand, L. A. (1991). The human connexin gene family of gap junction proteins: distinct chromosomal locations but similar structures. Genomics 10, 250-256. doi: 10.1016/0888-7543(91)90507-B

Frederick, R. L., and Shaw, J. M. (2007). Moving mitochondria: establishing distribution of an essential organelle. Traffic 8, 1668-1675. doi: 10.1111/j.1600-0854.2007.00644.x

Friedman, J. R., Lackner, L. L., West, M., Dibenedetto, J. R., Nunnari, J., and Voeltz, G. K. (2011). ER tubules mark sites of mitochondrial division. Science 334, 358-362. doi: 10.1126/science. 1207385

\section{ACKNOWLEDGMENTS}

We thank L.Y. Jan and M. Petkovic for critical review of the manuscript and helpful discussions; S. Ryazantsev at the Electron Imaging Center at California NanoSystems Institute of UCLA for his expertise in electron microscopy; as well as T. Hitzeman, R. Naami and E. Naami for technical assistance. All constructs generated in this study are available at the Addgene plasmid repository.

\section{SUPPLEMENTARY MATERIAL}

The Supplementary Material for this article can be found online at: https://www.frontiersin.org/articles/10.3389/fphys. 2017.00905/full\#supplementary-material

Gadicherla, A. K., Wang, N., Bulic, M., Agullo-Pascual, E., Lissoni, A., De Smet, M., et al. (2017). Mitochondrial Cx43 hemichannels contribute to mitochondrial calcium entry and cell death in the heart. Basic Res. Cardiol. 112:27. doi: 10.1007/s00395-017-0618-1

Giepmans, B. N., Verlaan, I., Hengeveld, T., Janssen, H., Calafat, J., Falk, M. M., et al. (2001). Gap junction protein connexin-43 interacts directly with microtubules. Curr. Biol. 11, 1364-1368. doi: 10.1016/S0960-9822(01)00424-9

Gomes, L. C., Di Benedetto, G., and Scorrano, L. (2011). During autophagy mitochondria elongate, are spared from degradation and sustain cell viability. Nat. Cell Biol. 13, 589-598. doi: 10.1038/ncb2220

Habas, A., Hahn, J., Wang, X., and Margeta, M. (2013). Neuronal activity regulates astrocytic Nrf2 signaling. Proc. Natl. Acad. Sci. U.S.A. 110, 18291-18296. doi: $10.1073 /$ pnas. 1208764110

He, Y., Dupree, J., Wang, J., Sandoval, J., Li, J., Liu, H., et al. (2007). The transcription factor Yin Yang 1 is essential for oligodendrocyte progenitor differentiation. Neuron 55, 217-230. doi: 10.1016/j.neuron.2007.06.029

Hollenbeck, P. J., and Saxton, W. M. (2005). The axonal transport of mitochondria. J. Cell Sci. 118, 5411-5419. doi: 10.1242/jcs.02745

Huang, X., Sun, L., Ji, S., Zhao, T., Zhang, W., Xu, J., et al. (2013). Kissing and nanotunneling mediate intermitochondrial communication in the heart. Proc. Natl. Acad. Sci. U.S.A. 110, 2846-2851. doi: 10.1073/pnas. 1300741110

Kochetov, A. V. (2008). Alternative translation start sites and hidden coding potential of eukaryotic mRNAs. Bioessays 30, 683-691. doi: 10.1002/bies.20771

Lauf, U., Giepmans, B. N., Lopez, P., Braconnot, S., Chen, S. C., and Falk, M. M. (2002). Dynamic trafficking and delivery of connexons to the plasma membrane and accretion to gap junctions in living cells. Proc. Natl. Acad. Sci. U.S.A. 99, 10446-10451. doi: 10.1073/pnas.162055899

Luke, R. A., and Saffitz, J. E. (1991). Remodeling of ventricular conduction pathways in healed canine infarct border zones. J. Clin. Invest. 87, 1594-1602. doi: 10.1172/JCI115173

Meijering, E., Dzyubachyk, O., and Smal, I. (2012). Methods for cell and particle tracking. Meth. Enzymol. 504, 183-200. doi: 10.1016/B978-0-12-391857-4.00009-4

Nakada, K., Inoue, K., Ono, T., Isobe, K., Ogura, A., Goto, Y. I., et al. (2001). Intermitochondrial complementation: mitochondria-specific system preventing mice from expression of disease phenotypes by mutant mtDNA. Nat. Med. 7, 934-940. doi: 10.1038/90976

Ong, S. B., Hall, A. R., and Hausenloy, D. J. (2013). Mitochondrial dynamics in cardiovascular health and disease. Antioxid. Redox Signal. 19, 400-414. doi: 10.1089/ars.2012.4777

Ong, S. B., Subrayan, S., Lim, S. Y., Yellon, D. M., Davidson, S. M., and Hausenloy, D. J. (2010). Inhibiting mitochondrial fission protects the heart against ischemia/reperfusion injury. Circulation 121, 2012-2022. doi: 10.1161/CIRCULATIONAHA.109.906610

Ono, T., Isobe, K., Nakada, K., and Hayashi, J. I. (2001). Human cells are protected from mitochondrial dysfunction by complementation of DNA products in fused mitochondria. Nat. Genet. 28, 272-275. doi: 10.1038/90116 
Paznekas, W. A., Boyadjiev, S. A., Shapiro, R. E., Daniels, O., Wollnik, B., Keegan, C. E., et al. (2003). Connexin 43 (GJA1) mutations cause the pleiotropic phenotype of oculodentodigital dysplasia. Am. J. Hum. Genet. 72, 408-418. doi: $10.1086 / 346090$

Rambold, A. S., Kostelecky, B., and Lippincott-Schwartz, J. (2011). Together we are stronger: fusion protects mitochondria from autophagosomal degradation. Autophagy 7, 1568-1569. doi: 10.4161/auto.7.12. 17992

Russo, G. J., Louie, K., Wellington, A., Macleod, G. T., Hu, F., Panchumarthi, S., et al. (2009). Drosophila Miro is required for both anterograde and retrograde axonal mitochondrial transport. J. Neurosci. 29, 5443-5455. doi: 10.1523/JNEUROSCI.5417-08.2009

Saidi Brikci-Nigassa, A., Clement, M. J., Ha-Duong, T., Adjadj, E., Ziani, L., Pastre, D., et al. (2012). Phosphorylation controls the interaction of the connexin43 Cterminal domain with tubulin and microtubules. Biochemistry 51, 4331-4342. doi: 10.1021/bi201806j

Salat-Canela, C., Sesé, M., Peula, C., Ramón, Y., Cajal, S., and Aasen, T. (2014). Internal translation of the connexin 43 transcript. Cell Commun. Signal. 12:31. doi: 10.1186/1478-811X-12-31

Saotome, M., Safiulina, D., Szabadkai, G., Das, S., Fransson, A., Aspenstrom, P., et al. (2008). Bidirectional $\mathrm{Ca}^{2+}$-dependent control of mitochondrial dynamics by the Miro GTPase. Proc. Natl. Acad. Sci. U.S.A. 105, 20728-20733. doi: 10.1073/pnas.0808953105

Shaw, R. M., Fay, A. J., Puthenveedu, M. A., Von Zastrow, M., Jan, Y. N., and Jan, L. Y. (2007). Microtubule plus-end-tracking proteins target gap junctions directly from the cell interior to adherens junctions. Cell 128, 547-560. doi: 10.1016/j.cell.2006.12.037

Singh, A., Yadav, V., and Prasad, R. (2012). Comparative lipidomics in clinical isolates of Candida albicans reveal crosstalk between mitochondria, cell wall integrity and azole resistance. PLoS ONE 7:e39812. doi: 10.1371/journal.pone.0039812

Smith, J. H., Green, C. R., Peters, N. S., Rothery, S., and Severs, N. J. (1991). Altered patterns of gap junction distribution in ischemic heart disease. An immunohistochemical study of human myocardium using laser scanning confocal microscopy. Am. J. Pathol. 139, 801-821.
Smyth, J. W., and Shaw, R. M. (2013). Autoregulation of connexin43 gap junction formation by internally translated isoforms. Cell Rep. 5, 611-618. doi: 10.1016/j.celrep.2013.10.009

Solan, J. L., Hingorani, S. R., and Lampe, P. D. (2012). Changes in connexin 43 expression and localization during pancreatic cancer progression. J. Membr. Biol. 245, 255-262. doi: 10.1007/s00232-012-9446-2

Srisakuldee, W., Makazan, Z., Nickel, B. E., Zhang, F., Thliveris, J. A., Pasumarthi, K. B., et al. (2014). The FGF-2-triggered protection of cardiac subsarcolemmal mitochondria from calcium overload is mitochondrial connexin 43-dependent. Cardiovasc. Res. 103, 72-80. doi: 10.1093/cvr/cvu066

Tanaka, K., Sugiura, Y., Ichishita, R., Mihara, K., and Oka, T. (2011). KLP6: a newly identified kinesin that regulates the morphology and transport of mitochondria in neuronal cells. J. Cell Sci. 124, 2457-2465. doi: 10.1242/jcs.086470

Ul-Hussain, M., Olk, S., Schoenebeck, B., Wasielewski, B., Meier, C., Prochnow, N., et al. (2014). Internal Ribosomal Entry Site (IRES) activity generates endogenous carboxyl-terminal domains of $\mathrm{Cx} 43$ and is responsive to hypoxic conditions. J. Biol. Chem. 289, 20979-20990. doi: 10.1074/jbc.M113.540187

Wang, X., and Schwarz, T. L. (2009). The mechanism of $\mathrm{Ca}^{+}{ }^{+}$-dependent regulation of kinesin-mediated mitochondrial motility. Cell 136, 163-174. doi: 10.1016/j.cell.2008.11.046

Zhang, S. S., Hong, S., Kléber, A. G., Lee, L. P., and Shaw, R. M. (2014). A micropatterning approach for imaging dynamic $\mathrm{Cx} 43$ trafficking to cell-cell borders. FEBS Lett. 588, 1439-1445. doi: 10.1016/j.febslet.2014.01.002

Conflict of Interest Statement: The authors declare that the research was conducted in the absence of any commercial or financial relationships that could be construed as a potential conflict of interest.

Copyright (๔ 2017 Fu, Zhang, Xiao, Basheer, Baum, Epifantseva, Hong and Shaw. This is an open-access article distributed under the terms of the Creative Commons Attribution License (CC BY). The use, distribution or reproduction in other forums is permitted, provided the original author(s) or licensor are credited and that the original publication in this journal is cited, in accordance with accepted academic practice. No use, distribution or reproduction is permitted which does not comply with these terms. 


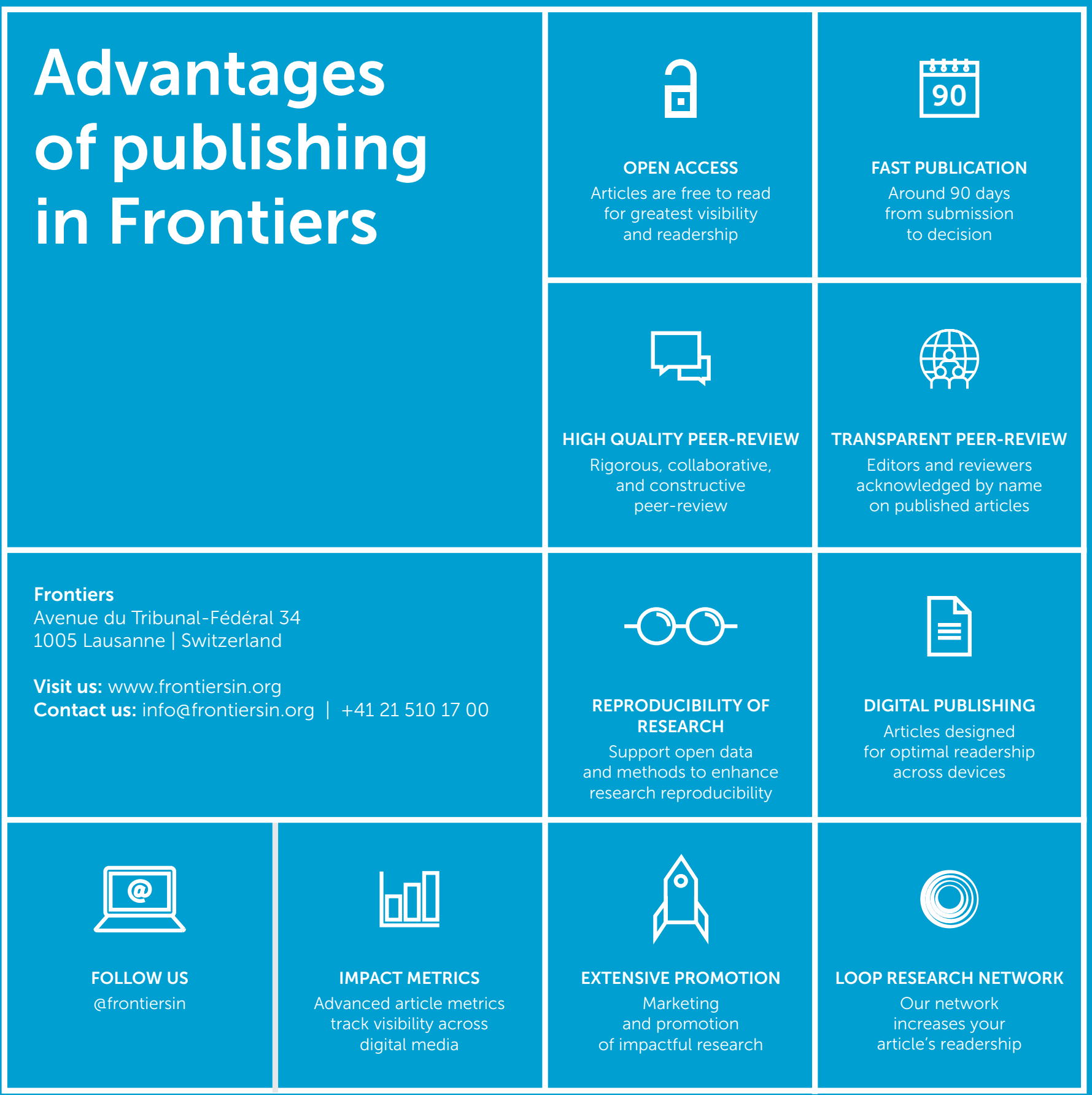

